\title{
ESTUDO DA RESISTÊNCIA E DA DEFORMABILIDADE DA ALVENARIA DE BLOCOS DE CONCRETO SUBMETIDA A ESFORÇOS DE COMPRESSÃO
}

\section{ANDREA ELIZABETH JUSTE}

Dissertação apresentada à Escola de Engenharia de São Carlos, da Universidade de São Paulo, como parte dos requisitos para a obtenção de título de Mestre em Engenharia de Estruturas.

ORIENTADOR: Prof. Dr. Márcio Roberto Silva Corrêa

São Carlos

2001 
Aos meus pais:

Philomena Antônia Botino Juste;

Olivio Juste;

À minha irmã Vera Regina Juste Rodado;

Pela educação, carinho e exemplo. Vocês fazem parte deste trabalho. 


\section{AGRADECIMENTOS}

A Deus, pela graça da existência e de nos possibilitar a realização de ações construtivas em nossas vidas.

Ao Prof. Dr. Márcio Roberto Silva Corrêa, meu orientador, pela orientação, dedicação, paciência e incentivo durante o desenvolvimento deste trabalho.

Ao Prof. Eloy Ferraz Machado Júnior, pela atenção dispensada e pelas importantes contribuições feitas ao trabalho.

A todos os funcionários do laboratório de Estruturas da EESC - USP, que auxiliaram no programa experimental.

À Coordenadoria de Aperfeiçoamento de Pessoal de Nível Superior - CAPES, pela bolsa concedida durante o programa de mestrado.

À Cimpor, especialmente ao engenheiro Fernando Cemin, pela doação das argamassas utilizadas no trabalho experimental.

À Tatu, especialmente ao engenheiro Rogério Durante, pela doação dos blocos utilizados no trabalho experimental.

Ao engenheiro Mario Collantes Candia, pelas dicas.

Ao Valentim e Ricardo, pelos ensinamentos e amizade.

À Suzana e Fabiana, pelo auxílio durante o desenvolvimento do trabalho.

Aos amigos que fiz durante o mestrado: Robson, Luciano, Fábio, Valério e Luís.

Às minhas grandes amigas Danielle, Deise, Paula e Patricia, pelo incentivo e apoio.

Às minhas sobrinhas Mariana e Carolina, por estarem ao meu lado. 


\section{SUMÁRIO}

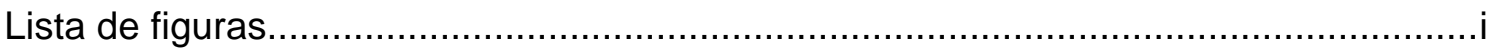

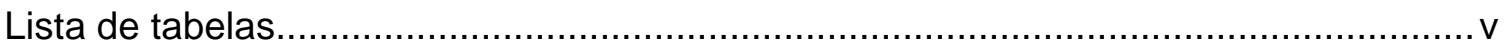

Lista de abreviaturas e siglas............................................................................... viii

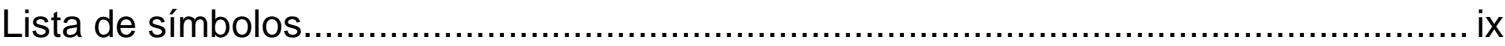

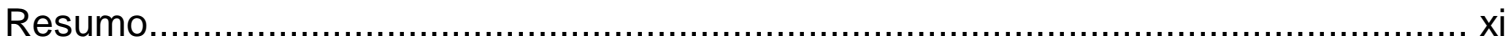

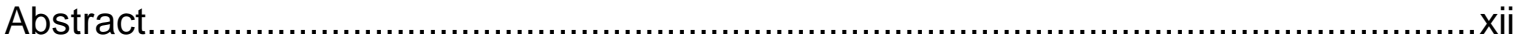

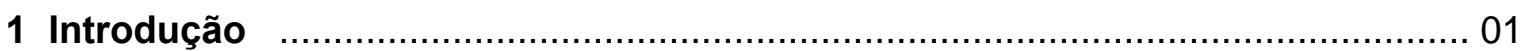

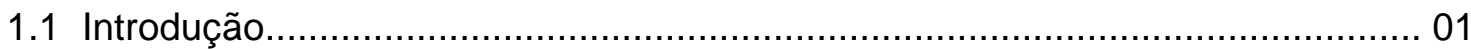

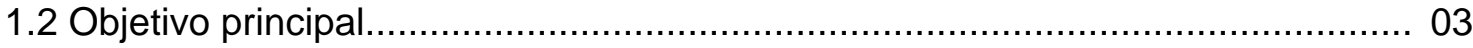

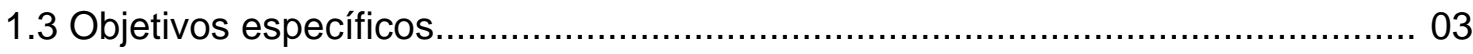

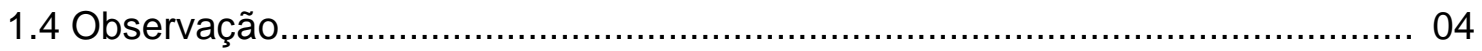

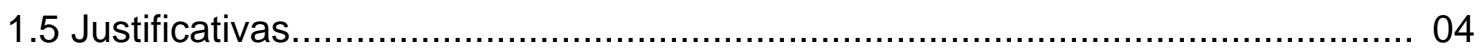

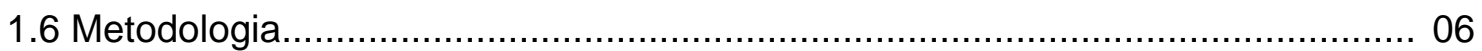

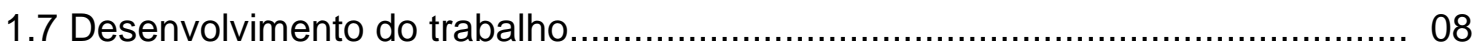

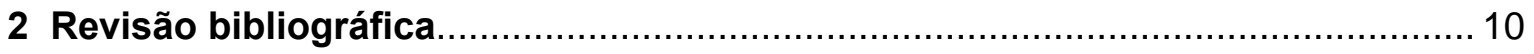

2.1 Características mecânicas dos componentes da alvenaria........................... 10

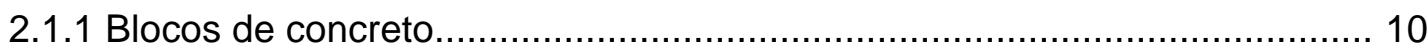

2.1.2 Argamassa de assentamento............................................................... 11

2.2 Fatores que influenciam as características mecânicas da alvenaria................... 13

2.2.1 Resistência dos blocos..................................................................... 13

2.2.2 Capacidade de absorver deformações............................................... 15

2.2.3 Resistência da argamassa.............................................................. 15 
2.2.4 Espessura da junta de argamassa....................................................... 17

2.2.5 Tipo de assentamento da argamassa................................................... 19

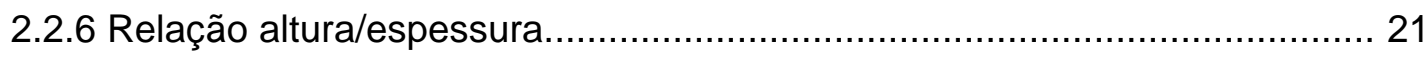

2.2.7 Aderência bloco-argamassa............................................................ 23

2.2.8 Retenção de água da argamassa...................................................... 24

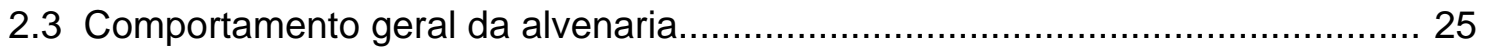

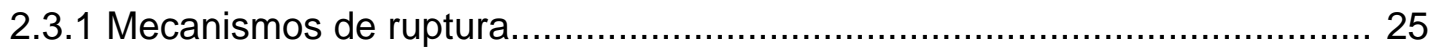

2.3.2 Previsão para tensão de ruptura na alvenaria......................................... 26

2.3.3 Determinação do módulo de elasticidade longitudinal............................... 33

2.3.4 Determinação das características mecânicas na direção paralela ao plano da face de assentamento do bloco ...................................................... 38

2.3.5 Curva tensão-deformação................................................................... 41

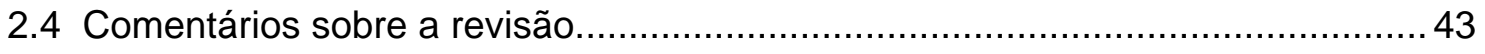

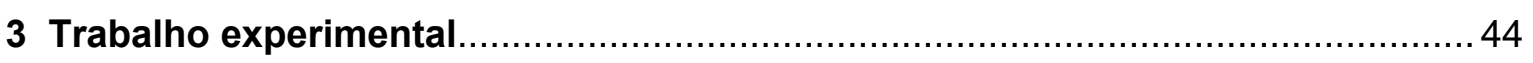

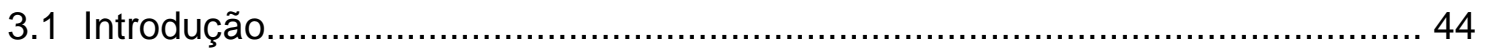

3.2 Caracterização dos materiais empregados nos ensaios.................................. 45

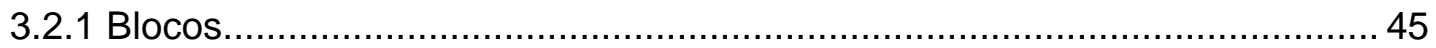

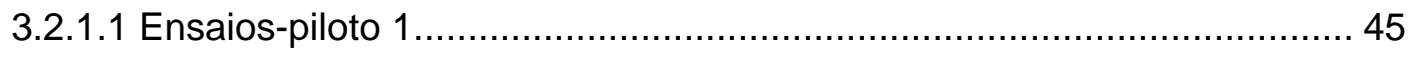

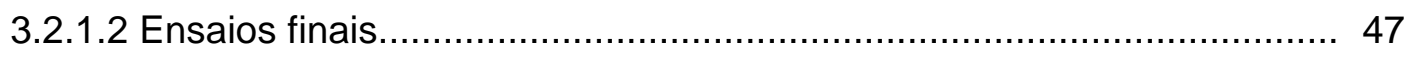

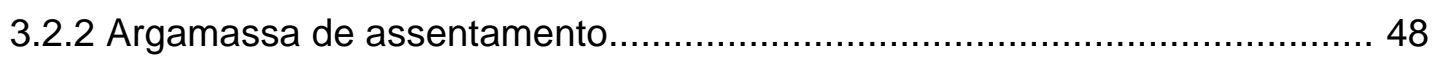

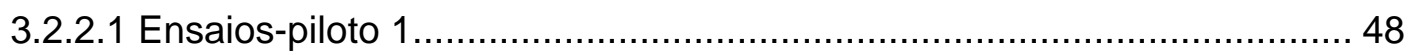

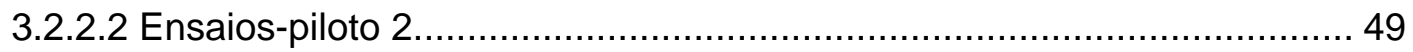

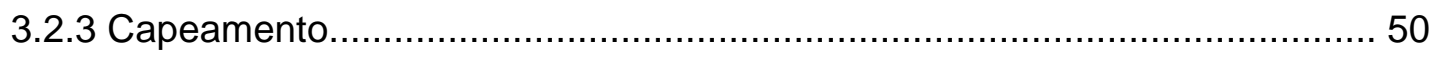

3.3 Execução dos ensaios de caracterização mecânica..................................... 51

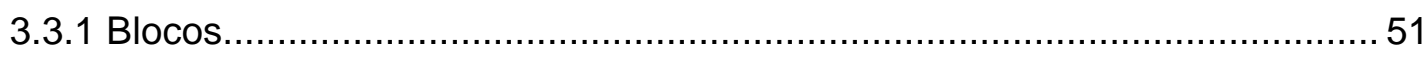

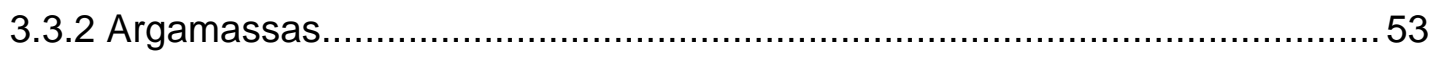

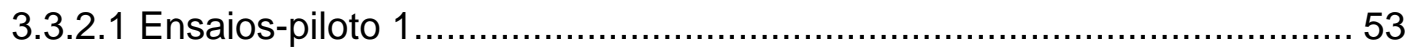




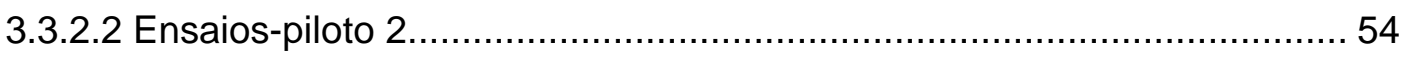

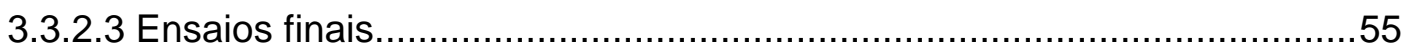

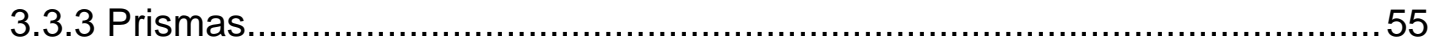

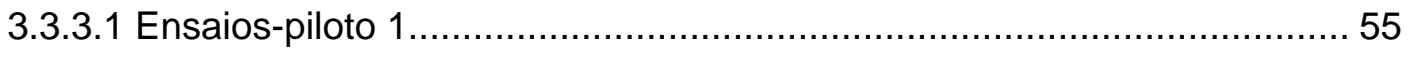

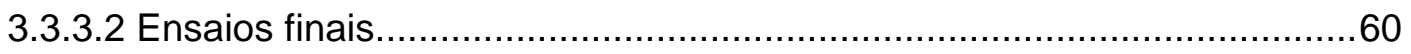

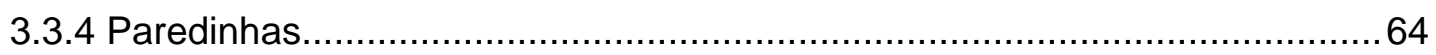

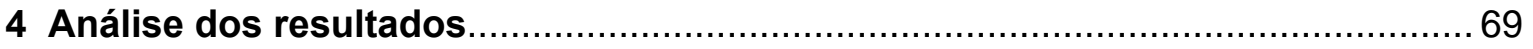

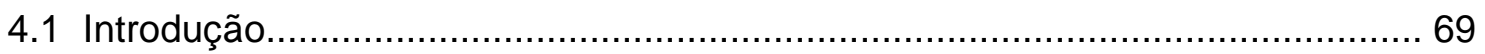

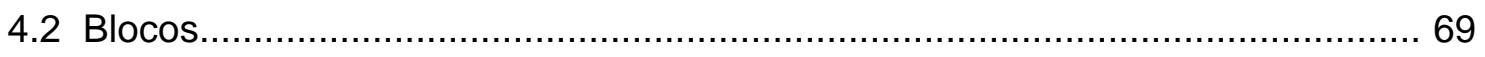

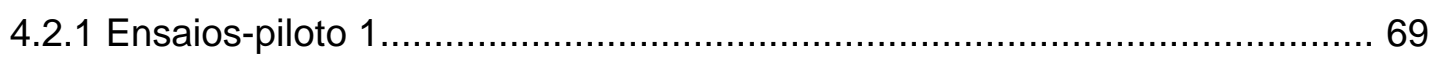

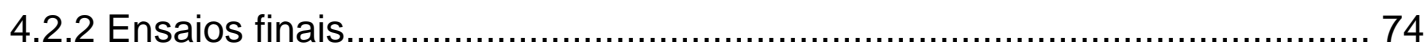

4.3 Argamassas. 77

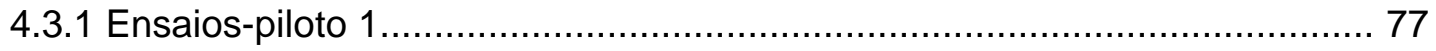

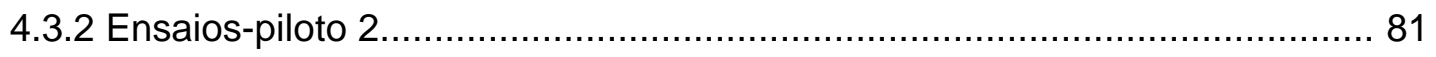

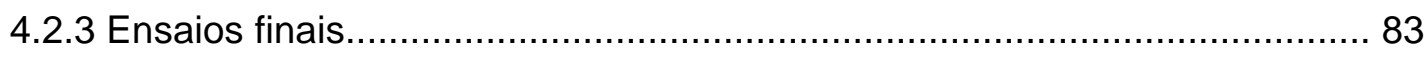

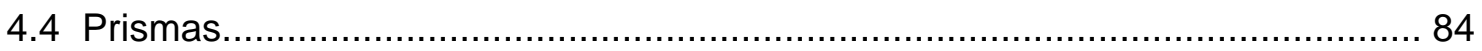

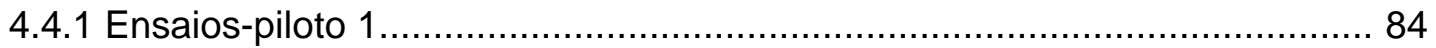

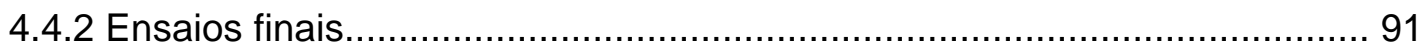

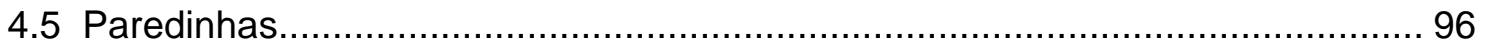

4.5.1 Resistência àcompressão......................................................... 96

4.5.2 Módulo de elasticidade ....................................................................... 99

4.5.3 Relação entre módulo de elasticidade e resistência àcompressão da

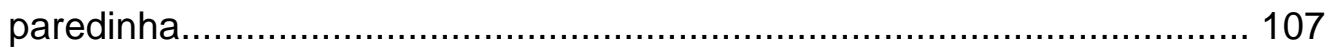

4.5.4 Relação entre resistência àcompressão do prisma e da paredinha........... 107

4.5.5 Coeficiente de Poisson................................................................ 107

4.5.6 Modo de ruptura das paredinhas................................................. 109 


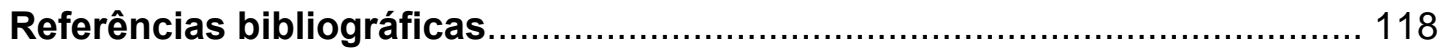

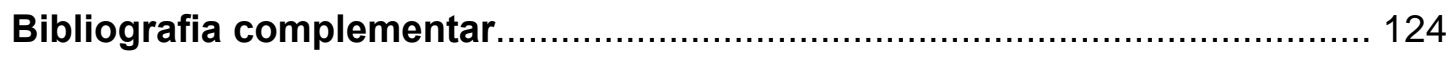

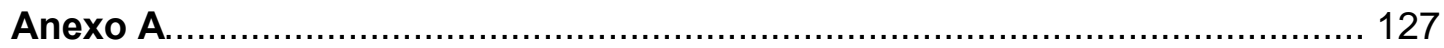

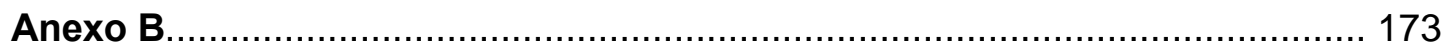


Figura 1.1 - Esquema dos corpos de prova utilizados nos ensaios finais (a) prisma; (b) paredinha........................................................... 08

Figura 2.1 - Gráfico módulo de elasticidade da argamassa x resistência à compressão da argamassa, SAHLIN (1.971)

Figura 2.2 - Relação entre a resistência de cálculo da alvenaria e a resistência á compressão dos materiais constituintes. BS 5628 (1992)......

Figura 2.3 - Influência da espessura da junta de argamassa nos módulos de elasticidade da alvenaria e da argamassa, em função do módulo de elasticidade do tijolo, SAHLIN (1971).

Figura 2.4 - Mecanismo de ruptura de Hilsdorf, MEDEIROS (1993).

Figura 2.5 - Influência do tipo de assentamento na resistência à compressão dos prismas não grauteados, ROMAGNA (2000)

Figura 2.6 - (a) Cargas atuantes em uma parede; (b) Tensões no tijolo e na junta de argamassa quando submetida à compressão axial, SABBATINI (1984).

Figura 2.7 - Ruptura do tipo cisalhamento cônico ("Conical shearcompression") em prismas de dois blocos, DRYSDALE et al (1994)

Figura 2.8 - Relação entre $f_{p} / f_{a}$ e $E_{a} / E_{b}$, MOHAMAD (1998).......................... 27

Figura 2.9 - Relação entre $f_{p} / f_{b t}$ e $E_{a} / E_{b}$, MOHAMAD (1998)............................ 28

Figura 2.10 - Curvas de ruptura para prismas de blocos não-grauteados, CHEEMA \& KLINGER (1986)

Figura 2.11 - Prismas utilizados nos ensaios de KHALAF (1997) - (a) Prismas de 3 blocos comprimidos normalmente à face de assentamento usual; (b) Prismas de 2 blocos comprimidos paralelamente à face de assentamento usual dos blocos (medidas em $\mathrm{mm}$ ).

Figura 2.12 - Modo de ruptura de prisma com carregamento paralelo ao plano de assentamento usual do bloco. DRYSDALE et al. (1994).............

Figura 2.13 - Relação entre resistências de prismas para carregamento paralelo e normal ao plano da face de assentamento usual do bloco. DRYSDALE et al. (1994)..... 
Figura 2.14 - Curvas obtidas nos ensaios de KNUTSSON \& NIELSEN (1995).... 42

Figura 3.1 - Geometria dos blocos de concreto............................................ 46

Figura 3.2 - Geometria dos blocos de concreto - Corte transversal................... 46

Figura 3.3 - Transdutor central para medições de deslocamento nos blocos e transdutores nas extremidades para medições de deslocamento nos prismas....................................................................... 52

Figura 3.4 - Posicionamento da instrumentação nos corpos de prova de argamassa (EP1) .............................................................. 54

Figura 3.5 - Dispositivo de fixação dos transdutores para corpos de prova com

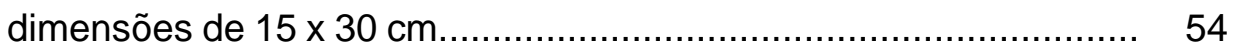

Figura 3.6 - Prismas de 3 blocos (EP1)..................................................... 57

Figura 3.7 - (a) Prisma com assentamento total; (b) Prisma com assentamento

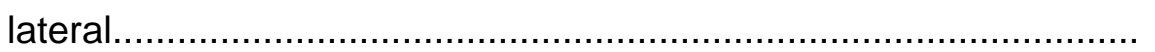

Figura 3.8 - (a) Vista frontal (b) Vista oposta. Transdutores 1,2,3 e 4: medições de deslocamentos no prisma; Transdutores 5 e 6 - medições de

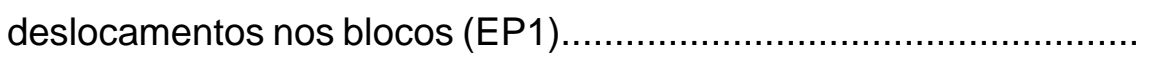

Figura 3.9 - (a) Vista frontal (b) Vista oposta. Transdutores 1, 2, 3 e 4: medições de deslocamentos no prisma; Transdutores 5 e 6 medições de deslocamentos nos blocos (EF).

Figura 3.10 - (a) Vista frontal (b) Vista oposta. Transdutores 1,2,3 e 4 medições de deslocamentos verticais na parede; Transdutores $5 \mathrm{e}$ 6 - medições de deslocamentos horizontais na parede (EF).

Figura 3.11 - (a) Vista frontal (b) Vista oposta. Transdutores 1,2,3 e 4: medições de deslocamentos verticais na parede; Transdutores 5 e 6 medições de deslocamentos horizontais na parede $(\mathrm{EF})$................ 66

Figura 3.12 - Transporte de paredinha para ensaio na posição horizontal............ 67

Figura 3.13 - Posicionamento da paredinha ensaiada na direção x na máquina de ensaio.

Figura 4.1 - Exemplo de um gráfico tensão-deformação para o bloco de 4,5 $\mathrm{MPa}$ (EP1)

Figura 4.2 - Exemplo da curva ajustada para os valores médios de tensãodeformação para o bloco de 4,5 MPa (EP1). 
Figura 4.3 - Exemplo de um gráfico tensão-deformação para o bloco de 4,5 $\mathrm{MPa}(\mathrm{EF})$.

Figura 4.4 - Exemplo da curva ajustada para os valores médios de tensãodeformação para o bloco de 4,5 MPa (EF).

Figura 4.5 - Exemplo de diagrama tensão-deformação típico para argamassa do tipo P com a leitura por extensômetros e transdutores (EP1).....

Figura 4.6 - Comparação das curvas tensão-deformação para as medições feitas com extensômetros (EP1)

Figura 4.7 - Comparação das curvas tensão-deformação para as medições feitas com transdutores (EP1)

Figura 4.8 - Exemplo de um gráfico tensão-deformação para o prisma com argamassa do tipo $\mathrm{P}$ (EP1)

Figura 4.9 - Gráfico de resistência do bloco x resistência do prisma (EP1)........ 90

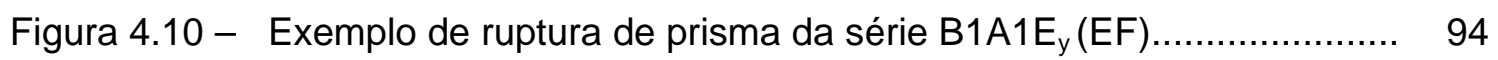

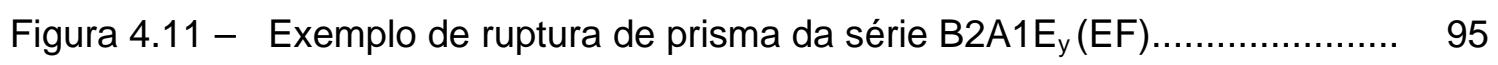

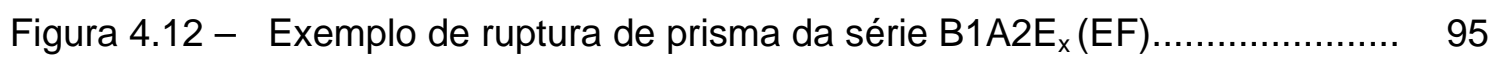

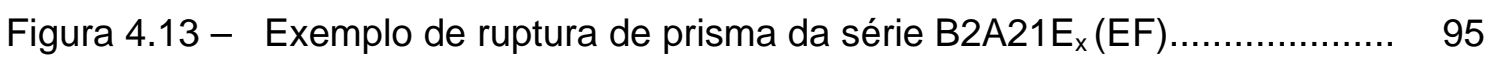

Figura 4.14- Gráfico de eficiência x resistência à compressão da paredinha (EF).

Figura 4.15 - Gráfico de resistência à compressão da paredinha ensaiada em $Y$ $x$ resistência à compressão da paredinha ensaiada em $X(E F)$........

Figura 4.16 - Exemplo de um gráfico tensão-deformação para a paredinha com carregamento na direção $X(E F)$.

Figura 4.17 - Exemplo da curva ajustada para os valores médios de tensãodeformação para a paredinha carregamento na direção X (EF)....... 100

Figura 4.18 - Exemplo de um gráfico tensão-deformação para a paredinha com carregamento na direção $\mathrm{Y}(\mathrm{EF})$.

Figura 4.19 - Exemplo da curva ajustada para os valores médios de tensãodeformação para a paredinha carregamento na direção $Y(E F)$....... 101

Figura 4.20 - Gráfico de módulo de elasticidade da paredinha ensaiada em Y X módulo de elasticidade da paredinha ensaiada em X (EF)............. 104 
Figura 4.21 - Comparação das curvas tensão-deformação para as medições feitas com transdutores nas paredinhas (EF).

Figura 4.22 - Gráfico Módulo de elasticidade x Resistência à compressão da paredinha (EF).

Figura 4.23 - Gráfico $E_{\mathrm{pa}} / \mathrm{f}_{\mathrm{pa}} \times$ Resistência à compressão da paredinha (EF)....... 106

Figura 4.24 - Exemplo da curva tensão $x$ deformação transversal para a paredinha com carregamento na direção X (EF) ........................... 108

Figura 4.25 - Exemplo da curva ajustada para os valores médios de tensãodeformação transversal para a paredinha com carregamento na direção X (EF) 108

Figura 4.26 - Detalhe da fissuração ao longo dos septos laterais para a paredinha com carregamento na direção X (EF). 109

Figura 4.27 - Detalhe da fissuração das paredes com carregamento na direção $X$ (a) descolamento das fiadas dos blocos; (b) fissuração nos septos longitudinais (EF). 
Tabela 2.1 - Traços de argamassa especificados pela BS 5628 (1992)............

Tabela 2.2 - Resistência à compressão característica da alvenaria de blocos vazados, com relação altura/menor dimensão horizontal entre 2 e 4, BS 5628 - part 1(1992)

Tabela 2.3 - Relação entre a resistência à compressão dos prismas prevista pela obtida experimentalmente por diversos autores, MOHAMAD (1.998)

Tabela 2.4 - Comparação entre as resistências à compressão de prismas obtidas em ensaios e as calculadas CHEEMA \& KLINGER (1986).

Tabela 2.5 - Eficiências de prismas, paredinhas e paredes em blocos de concreto, obtidas por ALY \& SABBATINI (1994).

Tabela 2.6 - Módulo de elasticidade para alvenaria de blocos de concreto....... 37

Tabela 3.1 - Tolerância de dimensões dos blocos de concreto........................ 45

Tabela 3.2 - Denominação dos blocos de concreto (EP1) .............................. 46

Tabela 3.3 - Dimensões nominais e quantidades dos blocos de concreto (EF). 47

Tabela 3.4 - Valores médios de massa unitária do bloco, áreas líquida e bruta dos blocos de concreto (EF) ................................................. 47

Tabela 3.5 - Denominação das argamassas de assentamento (EP1)............. 48

Tabela 3.6 - Denominação das argamassas de assentamento (EP2).............. 50

Tabela 3.7 - Características das argamassas de assentamento, FONTE

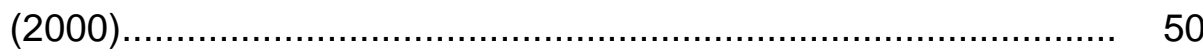

Tabela 3.8 - Denominação dos prismas (EP1) .......................................... 58

Tabela 3.9 - Valores médios de umidade e temperatura durante a moldagem

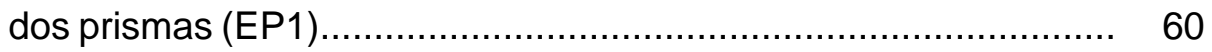

Tabela 3.10 - Denominação dos prismas para as paredinhas ensaiadas na direção $Y(E F)$.

Tabela 3.11 - Denominação dos prismas para as paredinhas ensaiadas na direção X (EF).

Tabela 3.12 - Valores médios de umidade e temperatura durante a moldagem dos prismas (EF).

Tabela 3.13 - Denominação das paredinhas (EF). 65 
Tabela 4.1 - Valores médios de resistência àcompressão dos blocos (EP1)... 70

Tabela 4.2 - Valores característicos de resistência à compressão dos blocos (EP1) ...................................................................... 70

Tabela 4.3 - Valores de resistência àcompressão dos blocos (EP1)............... 70

Tabela 4.4 - Módulo de elasticidade do bloco de 4,5 MPa (EP1).................... 72

Tabela 4.5 - Módulo de elasticidade do bloco de $10 \mathrm{MPa}($ EP1)...................... 73

Tabela 4.6 - Valores das relações entre módulo de elasticidade e resistência

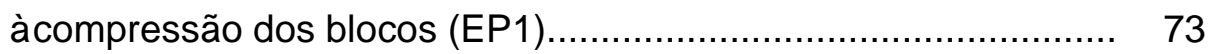

Tabela 4.7 - Valores médios de resistência àcompressão dos blocos (EF)..... 74

Tabela 4.8 - Valores característicos de resistência à compressão dos blocos

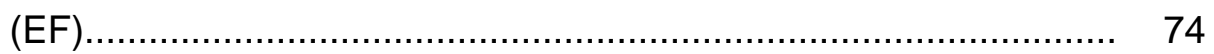

Tabela 4.9 - Módulo de elasticidade do bloco de 4,5 MPa (EF)....................... 76

Tabela 4.10 - Módulo de elasticidade do bloco de 12 MPa (EF)........................ 76

Tabela 4.11 - Valores das relações entre módulo de elasticidade e resistência

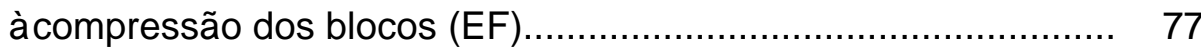

Tabela 4.12 - Resistência à compressão dos corpos de prova de argamassa

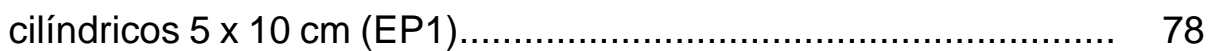

Tabela 4.13 - Módulo de elasticidade das argamassas industrializadas (EP1)... 78

Tabela 4.14 - Relação entre módulo de elasticidade e resistência à compressão das argamassas (EP1) ................................... 81

Tabela 4.15 - Resistência àcompressão das argamassas (EP2)..................... 82

Tabela 4.16 - Módulo de elasticidade das argamassas (EP2)........................... 82

Tabela 4.17 - Relação entre módulo de elasticidade e resistência à compressão das argamassas (EP2) ........................................

Tabela 4.18 - Resistência à compressão das argamassas para cada série de

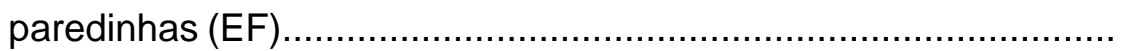

Tabela 4.19 - Resistência à compressão média dos corpos de prova de argamassa (EF) ........................................................... 84

Tabela 4.20 - Resistência àcompressão dos prismas (EP1)........................... 85

Tabela 4.21 - Módulo de elasticidade dos prismas da série Q (EP1)............... 88

Tabela 4.22 - Relação entre módulo de elasticidade e resistência à compressão dos prismas $($ EP1) ............................................ 8 
Tabela 4.23 - Relação entre resistência àcompressão do prisma e dos blocos

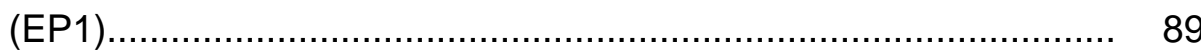

Tabela 4.24 - Resistência àcompressão dos prismas (EF) .......................... 91

Tabela 4.25 - Módulo de elasticidade dos prismas (EF) .................................... 92

Tabela 4.26 - Relação entre módulo de elasticidade e resistência à

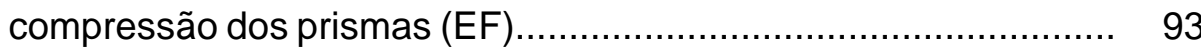

Tabela 4.27 - Relação entre resistência àcompressão do prisma e dos blocos

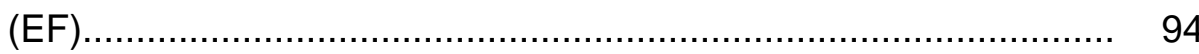

Tabela 4.28 - Resistência àcompressão das paredinhas (EF) .......................... 96

Tabela 4.29 - Relação entre resistência à compressão da paredinha e dos

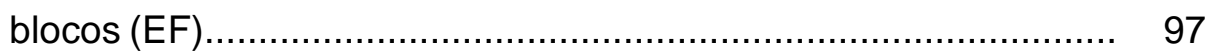

Tabela 4.30 - Módulo de elasticidade das paredinhas (EF)......................... 102

Tabela 4.31 - Comparação do módulo de elasticidade entre a expressão proposta por SHALIN (1971) e as obtidas pelo ensaio (EF)......... 103

Tabela 4.32 - Relação entre módulo de elasticidade e resistência à compressão das paredinhas (EF) ........................................... 106

Tabela 4.33 - Relação entre a resistência à compressão dos prismas e das

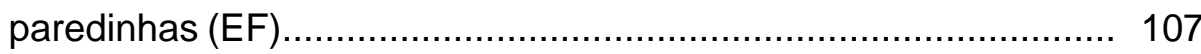




$\begin{array}{ll}\text { A }_{b} & \text { Área bruta } \\ A_{l} & \text { Área líquida } \\ \text { AL } & \text { Argamassamento lateral } \\ \text { AT } & \text { Argamassamento total } \\ \text { A1 } & \text { Argamassa com traço 1:0,5:4,5 } \\ \text { A2 } & \text { Argamassa com traço 1:1:6 } \\ \text { ABCl } & \text { Associação Brasileira de Construção Industrializada } \\ \text { ABNT } & \text { Associação Brasileira de Normas Técnicas } \\ \text { ACl } & \text { American Concrete Institute } \\ \text { ASTM } & \text { American Society For Testing and Materials } \\ \text { CP } & \text { Corpo de prova } \\ \text { CV } & \text { Coeficiente de variação } \\ \text { BS } & \text { British Standards Institution } \\ \text { B1 } & \text { Bloco de concreto com resistência àcompressão nominal de 4,5 MPa } \\ \text { B2 } & \text { Bloco de concreto com resistência àcompressão nominal de 12 MPa } \\ \text { EPUSP } & \text { Escola Politécnica da Universidade de São Paulo } \\ \text { EESC } & \text { Escola de Engenharia de São Carlos } \\ \text { EF } & \text { Ensaios finais } \\ \text { EP1 } & \text { Ensaios-piloto 1 } \\ \text { EP2 } & \text { Ensaios-piloto 2 } \\ \text { NBR } & \text { Norma Brasileira } \\ \text { P } & \text { Argamassa industrializada do tipo F51 } \\ \text { Q } & \text { Argamassa industrializada do tipo F07 } \\ \text { R } & \text { Argamassa industrializada do tipo F11 } \\ \text { SET } & \text { Departamento de Engenharia de Estruturas } \\ \text { UFSC } & \text { Universidade Federal de Santa Catarina } \\ \text { UFSM } & \text { Universidade Federal de Santa Maria } \\ \text { USP } & \text { Universidade de São Paulo } \\ \end{array}$


a/c Fator água/cimento

$\mathrm{cm}$ Centímetros

$\mathrm{cm}^{2} \quad$ Centímetros quadrados

Ealv Módulo de elasticidade da alvenaria

$E_{a} \quad$ Módulo de elasticidade da argamassa

$E_{a m} \quad$ Módulo de elasticidade médio da argamassa

$\mathrm{E}_{\mathrm{b}} \quad$ Módulo de elasticidade do bloco

$\mathrm{E}_{\mathrm{bm}} \quad$ Módulo de elasticidade médio do bloco

$E_{p} \quad$ Módulo de elasticidade do prisma

$\mathrm{E}_{\mathrm{pa}} \quad$ Módulo de elasticidade da paredinha

$E_{\text {pam }}$ Módulo de elasticidade médio da paredinha

$\mathrm{E}_{\mathrm{pm}} \quad$ Módulo de elasticidade médio do prisma

$F_{\text {rup }} \quad$ Força de ruptura àcompressão

$f_{a} \quad$ Resistência àcompressão da argamassa

$\mathrm{f}_{\mathrm{am}}$ Resistência àcompressão média da argamassa

$\mathrm{f}_{\mathrm{b}} \quad$ Resistência àcompressão do bloco

$f_{b k}$ Resistência característica àcompressão do bloco

$f_{b k, e s t}$ Resistência característica àcompressão estimada do bloco

$\mathrm{f}_{\mathrm{bm}} \quad$ Resistência média àcompressão do bloco

$\mathrm{f}_{\mathrm{cm}}(\mathrm{t})$ Resistência àcompressão média a t dias

$\mathrm{f}_{\mathrm{c} 28}(\mathrm{t})$ Resistência àcompressão média aos 28 dias

$f_{b t}$ Resistência àtração do bloco

$f_{p} \quad$ Resistência àcompressão do prisma

$\mathrm{f}_{\mathrm{pm}} \quad$ Resistência àcompressão média do prisma

$\mathrm{f}_{\mathrm{pa}} \quad$ Resistência àcompressão da paredinha

$f_{\text {pam }}$ Resistência àcompressão média da paredinha

$\mathrm{h} / \mathrm{t}$ Relação altura/espessura

i Argamassa de traço $1: 0$ a $1 / 4: 3$

ii Argamassa de traço $1: 1 / 24$ a $41 / 2$

iii Argamassa de traço $1: 1: 5$ a 6

iv Argamassa de traço $1: 2: 8$ a 9 


\begin{tabular}{ll}
\hline $\mathrm{kg}$ & Kilograma \\
$\mathrm{kN}$ & Kilo Newton \\
$\mathrm{m}$ & Metro \\
$\mathrm{m}^{3}$ & Metro cúbico \\
$\mathrm{min}$ & Minuto \\
$\mathrm{MPa}$ & Mega Pascal \\
$\mathrm{S}_{\mathrm{d}}$ & Desvio padrão \\
$\mathrm{t}$ & Número de dias \\
$\gamma_{\mathrm{b}}$ & Massa unitária do bloco \\
$v_{\mathrm{a}}$ & Coeficiente de Poisson da alvenaria \\
$v_{\mathrm{xy}}$ & Coeficiente de Poisson da alvenaria para carregamento na direção $\mathrm{X}$ \\
$v_{\mathrm{yx}}$ & Coeficiente de Poisson da alvenaria para carregamento na direção $\mathrm{Y}$ \\
$\varepsilon_{\mathrm{x}}$ & $\quad$ Deformação na direção $\mathrm{X}$ \\
$\varepsilon_{\mathrm{y}}$ & $\quad$ Deformação na direção $\mathrm{Y}$
\end{tabular}


JUSTE, A. E. (2001). Estudo da resistência e da deformabilidade da alvenaria de blocos de concreto submetida a esforços de compressão. São Carlos, 2001. 229p. Dissertação (Mestrado) - Escola de Engenharia de São Carlos, Universidade de São Paulo.

O estudo da resistência à compressão e da deformabilidade de paredes de alvenaria de blocos de concreto é de fundamental importância para a caracterização desse material e o desenvolvimento de análises de estruturas compostas por esse tipo de painel. Este trabalho trata desse tema, objetivando prever com maior acuidade os principais parâmetros de deformação e de resistência de paredes de alvenaria de blocos de concreto, a saber: resistência à compressão e módulo de elasticidade longitudinal nas direções paralela e perpendicular àjunta de assentamento.

Foi desenvolvido um trabalho experimental para estimar a influência da resistência dos blocos, da resistência da argamassa e da direção de aplicação de forças no comportamento mecânico da alvenaria de blocos de concreto não-grauteada, quando submetida a esforços de compressão. Para tanto, realizaram-se ensaios de laboratório em blocos, argamassas, prismas de três blocos e paredinhas com dimensões de $80 \mathrm{~cm} \times 80 \mathrm{~cm}$.

Por inferência estatística não foram obtidas correlações aceitáveis entre as variáveis estudadas. Porém, obtiveram-se tendências de comportamento dos corpos de prova estudados, confirmando a influência das características da argamassa e do bloco no comportamento estrutural da alvenaria quando submetida a esforços de compressão.

Palavras-chave: Alvenaria estrutural, análise experimental, blocos de concreto, curvas tensão-deformação, módulo de elasticidade, resistência à compressão. 
JUSTE, A. E. (2001). Study of strength and curved stress/strain relationship of blockwork masonry walls under compression. São Carlos, 2001. 229p. 229p. Dissertação (Mestrado) - Escola de Engenharia de São Carlos, Universidade de São Paulo.

The study of strength and the curved stress/strain relationship of blockwork masonry walls is basic for the material characterization and the development of structural analysis of blockwork walls. This work deals with that subject, aiming at the evaluation of the main elastic parameters and the strength of concrete blockwork walls: the compressive strength and modulus of elasticity for masonry in two orthogonal directions, parallel and perpendicular to bed joints.

An experimental program was developed to evaluate the influence of the strength of blocks and mortar, and the load application direction on the mechanical behavior of ungrouted concrete block masonry under compression. A series of laboratory tests was carried out with blocks, mortar, prisms of three blocks and wallets $(80 \mathrm{~cm} \times 80 \mathrm{~cm})$.

It was impossible to obtain acceptable correlations of the defined variables, usin statistical inference. However, tendencies of the specimens behavior were obtained, confirming the influence of mortar and block properties on the structural behavior of concrete blockwork walls under compression.

Keywords: Blockwork masonry, compressive strenght, compression tests, concrete blocks, modulus of elasticity, stress-strain curves. 


\section{INTRODUÇÃO}

\subsection{Introdução}

Desde a Antigüidade a alvenaria tem sido utilizada largamente pelo ser humano em suas habitações, monumentos e templos religiosos, AMRHEIN (1978). Como exemplos famosos podem ser citados: a pirâmide de Quéops, em que foram utilizados mais de dois milhões de blocos de pedra, o farol de Alexandria, com altura próxima a $190 \mathrm{~m}$ e as grandes catedrais góticas, construídas na Idade Média, com vãos expressivos e arquitetura belíssima, realizadas com a utilização de arcos e abóbadas.

Apesar do uso intenso da alvenaria, apenas no início do presente século, por volta de 1920, passou-se a estudá-la com base em princípios científicos e experimentação laboratorial, DICKEY (1994). Esta postura possibilitou o desenvolvimento de teorias racionais que fundamentam a arte de se projetar a alvenaria estrutural. A partir daí, edifícios cujas paredes tinham espessuras enormes, como, por exemplo, o Monadnock Building construído em Chicago no final do século XIX, com aproximadamente $1,80 \mathrm{~m}$ de espessura nas paredes do térreo, cederam lugar a edifícios com paredes mais esbeltas e, portanto, muito mais econômicos.

Entretanto, com a utilização do concreto armado e do aço estrutural, que possibilitaram a construção de edifícios com peças de reduzidas dimensões, a utilização da alvenaria dirigiu-se, prioritariamente, às edificações de pequeno porte. 
Mas, na década de 50, a utilização da alvenaria ganhou novo impulso, após a realização de uma série de experimentações na Europa. Em 1951, dimensionou-se e construiu-se na Suíça um edifício de 13 pavimentos em alvenaria não-armada, com paredes internas de $15 \mathrm{~cm}$ de espessura e externas com $37,5 \mathrm{~cm}, \mathrm{ABCl}$ (1990). Muitos outros edifícios foram construídos na Inglaterra, Alemanha e Suíça, e também nos Estados Unidos, país no qual a alvenaria estrutural passou a ser empregada mesmo em zonas sujeitas a abalos sísmicos, sendo neste caso utilizada a alvenaria armada.

No Brasil, após a sua implantação em 1966, quando em São Paulo foram construídos alguns prédios de quatro pavimentos em blocos vazados de concreto, o desenvolvimento da alvenaria estrutural de blocos se deu de maneira lenta. Isso ocorreu não obstante suas vantagens econômicas, especialmente associadas ao fato de se utilizarem as paredes não apenas como elementos de vedação, mas também como elementos portantes.

Por muitos anos a alvenaria estrutural foi pouco utilizada no Brasil devido a muitos fatores tais como: preconceito, maior domínio da tecnologia do concreto armado por parte de construtores e projetistas e pouca divulgação do assunto nas universidades durante o processo de formação dos engenheiros. Muitos projetistas são leigos no que diz respeito a este sistema construtivo e acabam, assim, optando pelo concreto armado. Isto é também influenciado pelo reduzido número de publicações sobre o assunto em português, pois a maior parte da bibliografia é estrangeira e voltada para as peculiaridades do país de origem.

Nos últimos cinco anos essa situação tem se alterado de forma significativa. O interesse por esse sistema estrutural cresceu de forma notável, especialmente pelas condições nitidamente favoráveis que se obtêm em termos de economia. $E$, no momento, a demanda por tecnologias que possam garantir a execução de obras econômicas e seguras é realmente muito grande.

Nesse aspecto, um ponto de grande importância a ser mais bem estudado é exatamente a deformabilidade de painéis de alvenaria de blocos, especialmente levando-se em consideração as características dos materiais empregados no Brasil e as peculiaridades nacionais dos sistemas construtivos utilizados na confecção desses painéis. Devido à carência dessas informações, o projetista de estruturas é, em geral, obrigado a lançar mão da intuição ou adaptar tabelas presentes em Normas Técnicas Internacionais, produzidas para materiais e condições construtivas diferentes dos utilizados no Brasil. 


\subsection{Objetivo Principal}

Este trabalho teve como objetivo principal caracterizar o comportamento da alvenaria de blocos de concreto não-grauteada, no que diz respeito aos aspectos relacionados à resistência e à deformabilidade dos seus elementos constituintes e do conjunto bloco-argamassa, quando submetida a esforços de compressão. Para tanto, realizou-se um programa experimental em que se procurou estudar as características de deformação e de resistência de blocos, argamassas, prismas e paredinhas.

\subsection{Objetivos Específicos}

Os objetivos específicos deste trabalho podem ser resumidos nos itens a seguir:

- Realizar pesquisa de trabalhos publicados que contenham procedimentos e análises experimentais no que diz respeito à deformabilidade e resistência de paredes, paredinhas e prismas de blocos de concreto, quando submetidos a esforços de compressão;

- Determinar, através de análise experimental, os parâmetros elásticos e de resistência em prismas e paredinhas mencionados no item anterior;

- Analisar a influência da resistência dos blocos e da argamassa, forma de preenchimento da argamassa para assentamento dos blocos e direção de aplicação da compressão na deformabilidade e na resistência dos corpos de provas estudados, comparando-se os resultados obtidos com os da bibliografia consultada;

- Tentar obter correlações confiáveis entre blocos, prismas e paredinhas, de modo que os mesmos possam ser utilizados para estimar as características mecânicas de paredes. 


\subsection{Observação}

Uma observação deve ser feita em relação ao uso dos termos: parâmetros elásticos e módulo de elasticidade, utilizados neste trabalho. Durante a realização da pesquisa bibliográfica, verificou-se que a maioria dos artigos publicados e normas estrangeiras utiliza o termo módulo de elasticidade ao se referir à "inclinação da reta entre dois pontos específicos quaisquer da curva tensãodeformação abaixo do limite elástico" (ASTM E111-82, 1988). Porém, na realidade, ocorre uma ultrapassagem em relação a este limite elástico para os valores normalmente utilizados. Dessa forma, o termo módulo de deformação, utilizado pela NBR 8522 (1984) e por alguns pesquisadores, tais como GOMES (1983) e FRANCO (1987), talvez seja uma definição mais representativa da realidade.

Como poderá ser visto nos capítulos 2 e 3 deste trabalho, a existência de poucos trabalhos e a falta de uma norma brasileira voltada à alvenaria estrutural que trate do tema fez com que a determinação do módulo fosse realizada baseada nos limites de tensões proposto pelo ACI 530-92 (1995). Dessa forma, optou-se por utilizar o termo módulo de elasticidade.

\subsection{Justificativas}

Uma das áreas da engenharia civil que tem apresentado maior potencial de crescimento é, sem sombra de dúvida, a execução de edifícios em alvenaria estrutural de blocos. Isso se deve principalmente à economia obtida por esse processo construtivo em relação ao concreto convencional. Por propiciar uma maior racionalidade na execução da obra, reduz-se o consumo e o desperdício dos materiais, aumentando-se, por outro lado, a eficiência da utilização da mão de obra. Além disso, o sistema construtivo também apresenta nítidas vantagens quanto aos revestimentos a serem utilizados, normalmente muito reduzidos em relação aos obtidos em estruturas convencionais de concreto, aumentando-se ainda mais a economia conseguida.

Dessa forma, as edificações tornam-se mais baratas para o comprador final, tornando-se também mais viáveis para o consumidor, especialmente em relação às classes média e baixa. Assim, fica evidente o grande benefício social que pode 
advir do desenvolvimento desse processo construtivo, principalmente num país que tem um grande déficit habitacional a eliminar.

Entretanto, deve-se considerar que, conforme foi mencionado em item anterior, o projeto de edifícios de alvenaria estrutural necessita ainda de grandes avanços tecnológicos para se aproximar do desenvolvimento que se observa para as estruturas convencionais em concreto armado. A própria normalização nacional, cujos principais documentos da Associação Brasileira de Normas Técnicas (ABNT) estão relacionados na bibliografia, é pobre e um grande esforço precisa ser feito nessa direção para que se possa projetar e executar edifícios baratos e seguros. Especificamente no assunto deste projeto de pesquisa, pode-se citar um exemplo claro de carência de informações. A ABNT apenas apresenta uma norma para cálculo de alvenaria de blocos de concreto, a NBR 10.837 (1989), não havendo norma específica para blocos cerâmicos. Na citada norma os valores dos módulos de elasticidade longitudinal e transversal são adaptados do ACl 530-92 (1995), confundindo área bruta e área liquida de bloco. É necessário, pois, implementar pesquisas voltadas para a realidade brasileira, sem o que se tornará praticamente impossível desenvolver de forma satisfatória os procedimentos normativos nessa área.

É importante ressaltar que, quanto às pesquisas mencionadas, uma dificuldade adicional deve ser considerada: na Europa e nos Estados Unidos, nossos tradicionais "fornecedores" de pesquisas em engenharia civil, os sistemas construtivos adotados são ligeiramente diferentes do ideal para o Brasil. Na Europa praticamente só se constrói com tijolos cerâmicos e nos Estados Unidos, devido à ocorrência de sismos, predomina amplamente a alvenaria armada de blocos vazados de concreto. Já no caso brasileiro, o sistema economicamente mais viável é a alvenaria não-armada de blocos vazados, sejam eles cerâmicos ou de concreto.

Assim sendo, é imprescindível e urgente que haja realmente uma concentração de esforços na direção de se implementar um conjunto de pesquisas que possa permitir o desenvolvimento de tecnologias adequadas à elaboração de edifícios de alvenaria estrutural cada vez mais econômicos e seguros. Exatamente por se encaixar nesse objetivo geral é que se justifica a importância da elaboração do presente trabalho. Pretende-se que ele seja uma contribuição nesse esforço de elucidação de detalhes significativos sobre esse processo construtivo de grande viabilidade econômica e interesse social. 


\subsection{Metodologia}

Inicialmente dedicou-se especial atenção à coleta de procedimentos e resultados confiáveis obtidos em ensaios de paredes, paredinhas, prismas e blocos, que já tenham sido realizados, especialmente para materiais utilizados no Brasil. Dentre os centros que foram consultados, responsáveis por grande quantidade de trabalhos na área em estudo, pode-se destacar a Escola Politécnica da USP (EPUSP), a Universidade Federal de Santa Catarina (UFSC) e a Universidade Federal de Santa Maria (UFSM), no Rio Grande do Sul.

Após a análise destas publicações, foi programada uma série de ensaios no Laboratório do Departamento de Engenharia de Estruturas.

De acordo com o planejamento feito, foram ensaiados os componentes bloco e argamassa e os elementos com eles executados: prismas e paredinhas.

A divisão do trabalho experimental consistiu em duas partes: ensaios-piloto utilizando apenas prismas e ensaios finais utilizando prismas e paredinhas. Os ensaios-piloto em prismas de três blocos foram realizados para determinar os parâmetros que deveriam ser considerados nos posteriores ensaios com paredinhas.

Assim, definiu-se para os ensaios-piloto em prismas, a análise das seguintes variáveis:

a) Resistência à compressão dos blocos

Consideração das resistências de 4,5 MPa e 10,0 MPa para blocos de concreto, por serem representativos da utilização prática no Brasil.

b) Argamassa

Utilização de dois tipos de argamassa industrializada da empresa CIMPOR, a F07 e a F51. A escolha dessas argamassas baseou-se na distinção em relação ao módulo de elasticidade e à resistência à compressão relatada em boletins técnicos fornecidos pelo fabricante.

Obs.: Foi realizado, paralelamente ao estudo em prismas, um estudo para a determinação da resistência e do módulo de elasticidade de um terceiro tipo de argamassa - a F11, através de ensaios utilizando-se apenas corpos de prova 
cilíndricos com dimensões de $5 \mathrm{~cm} \times 10 \mathrm{~cm}$, considerando-se a eventualidade de sua utilização, o que não ocorreu.

c) Cordões de argamassa

Moldagem dos prismas em duas situações: preenchimento de todos os septos dos blocos (assentamento total) e preenchimento apenas dos septos longitudinais dos blocos (assentamento lateral).

Como será visto no capítulo 4 , o quesito argamassa foi prejudicado em função de problemas nos ensaios-piloto de prismas com a argamassa industrializada. Optou-se, então, pelo uso de argamassas comuns, com traços usualmente empregados na alvenaria, especificados pela BS 5628 (1992). Foi também descartada a variável relacionada ao tipo de assentamento da argamassa, devido a restrições de tempo, ocupação e espaço no laboratório do SET/EESC/USP. Cabe ressaltar que essa decisão foi tomada com o objetivo de reduzir o programa experimental, não tendo a pretensão de julgá-la sem importância no comportamento da alvenaria comprimida.

Definiu-se que os ensaios finais deveriam contemplar os seguintes requisitos:

a) Resistência à compressão dos blocos

Consideração dos blocos de concreto com resistências de 4,5 MPa e 12,0 MPa. A alteração da resistência dos blocos de $10 \mathrm{MPa}$ para os de $12 \mathrm{MPa}$ deve-se a um engano ocorrido na entrega dos blocos. Pelo fato da análise dos corpos de prova necessitar da distinção de resistência à compressão e módulo de elasticidade, julgou-se que esta mudança não afetaria o objetivo dos estudos. Dessa forma, manteve-se a modificação da resistência do bloco.

b) Argamassa

Utilização de dois traços alternativos de argamassa recomendados pela BS 5628 (1978), usualmente empregados na alvenaria:

Cimento:Cal:Areia (em volume)

Tipo (ii) - 1:0,5:4,5

Tipo (iii) - 1:1:6 
Cordões de argamassa

Moldagem dos prismas e paredinhas feita apenas com o assentamento total dos blocos.

c) Direção de aplicação de carregamento

Consideração de duas situações de aplicação de carregamento: paralelo e perpendicular à junta de assentamento dos blocos.

Quanto aos corpos de prova, foram utilizados prismas de três blocos e paredinhas com dimensões modulares de $80 \mathrm{~cm} \times 80 \mathrm{~cm}$, conforme indica a figura 1.1 .

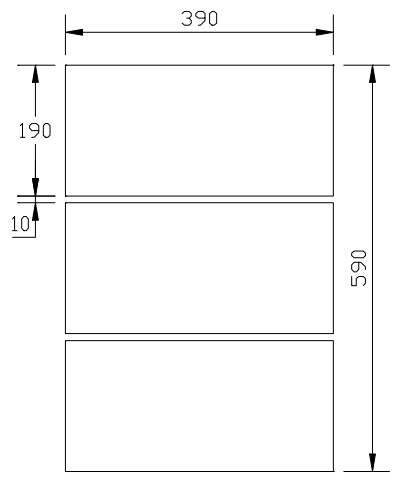

(a)

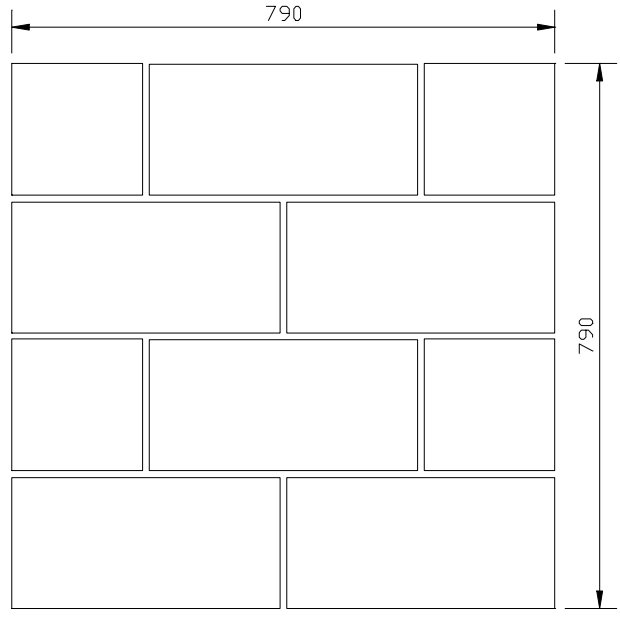

(b)

Figura 1.1 - Esquema dos corpos de prova utilizados nos ensaios finais - (a) Prisma (b) Paredinha (medidas em $\mathrm{mm}$ ).

\subsection{Desenvolvimento do trabalho}

O capítulo 1 deste trabalho contempla a apresentação e as propostas deste trabalho, procurando justificar a sua realização.

No capítulo 2 é apresentada a revisão bibliográfica, abordando as características mecânicas dos componentes que compõem a alvenaria - bloco e 
argamassa. Além disso, descreve-se o comportamento geral da alvenaria quando submetida a esforços de compressão.

O capítulo 3 detalha o trabalho experimental, procurando caracterizar os materiais e os procedimentos empregados.

No capítulo 4 são apresentados e discutidos os resultados obtidos nos ensaios realizados em paredinhas, primas, blocos e argamassas.

O capítulo 5 é dedicado às conclusões obtidas com a realização do trabalho experimental. São apresentadas algumas sugestões para futuros trabalhos que possam dar continuidade ao estudo aqui desenvolvido. 


\section{REVISÃO BIBLIOGRÁFICA}

\subsection{Características mecânicas dos componentes da alvenaria}

\subsubsection{Blocos de Concreto}

Para a determinação dos módulos de elasticidade secante dos blocos, vários autores sugerem expressões que relacionam sua resistência à compressão.

ROMAGNA (2000) e MOHAMAD (1998) utilizaram em seus trabalhos a expressão proposta pelo ACl - Building Code 318 (1990) para calcular o módulo de elasticidade secante do bloco, a partir do módulo secante do concreto com faixa de valores de massa específica entre 1442 e $2483 \mathrm{~kg} / \mathrm{m}^{3}$ :

$$
E_{b}=0,0428 \cdot \sqrt{f_{b}} \cdot \gamma_{b}^{1,5}
$$

onde

$\mathrm{f}_{\mathrm{b}}$ é a resistência à compressão do bloco $(\mathrm{MPa})$;

$\gamma_{b}$ é a massa unitária do bloco em $\mathrm{kg} / \mathrm{m}^{3}$.

Cabe ressaltar que a expressão 2.1 utilizada pelos autores citados acima refere-se a uma estimativa originalmente usada para determinar o módulo de elasticidade do concreto e não da alvenaria. 
O CEB-FIP Mode Code (1990) (Comité Euro-International du Béton) estima o valor do módulo de elasticidade do concreto em

$$
E_{b}=2,5.10^{4}\left(\frac{f_{b}}{10}\right)^{1 / 3}
$$

onde

$\mathrm{f}_{\mathrm{b}}$ é a resistência média à compressão aos 28 dias (MPa);

DRYSDALE et al. (1994) afirma que o módulo de elasticidade do bloco pode variar na faixa de 500 a 1000 vezes a resistência à compressão da unidade. SAHLIN (1971) indica que este mesmo valor pode variar entre 500 a 1500.

Em ensaios de diferentes tipos de blocos de concreto, realizados por RICHART et al. ${ }^{1}$ apud SAHLIN (1971), foi encontrada uma relação entre o módulo de elasticidade do bloco e sua resistência estimada aproximadamente por

$$
E_{b}=1000 f_{b}
$$

\subsubsection{Argamassa de assentamento}

Os ensaios desenvolvidos por GLANVILLE \& BARNETT (1934) e HILDSDORF (1965), apresentados por SAHLIN (1971), tiveram como objetivo relacionar os valores de resistência da argamassa com o módulo de elasticidade (tangente na origem) obtido experimentalmente. Estas relações são mostradas na figura 2.1.

Neste gráfico também são apresentadas as curvas obtidas a partir das expressões propostas para relacionar o módulo de elasticidade da argamassa com sua resistência à compressão, descritas a seguir. Note que a expressão 2.5 é igual à expressão 2.1 já apresentada e refere-se ao módulo de elasticidade do concreto.

$$
\begin{aligned}
& E_{a}=1000 f_{a} \\
& E_{a}=0,0428 \cdot \gamma_{a}^{1,5} \sqrt{f_{a}} \\
& \text { onde }
\end{aligned}
$$

$\gamma_{\mathrm{a}}$ é o massa unitária do concreto em $\mathrm{kg} / \mathrm{m}^{3}$.

1 RICHART, MOORMAN AND WOODWORTH Strength and Stability of Concrete Masonry Walls. Bulletin no 251, Engineering Experiment Station, University of Illinois, Urbana, Illinois, 1932. 
As equações foram obtidas a partir das curvas tensão-deformação ajustadas aos dados experimentais, para concretos com resistência entre 150 a 450 kg/cm².

Segundo os autores, a expressão 2.4 é uma aproximação válida para a maioria das argamassas. Porém, os mesmos recomendam a utilização da expressão 2.4 para argamassas de baixa resistência e a expressão 2.5 para argamassas de alta resistência, sem, entretanto, limitar valores que caracterizem estes dois tipos de argamassa.

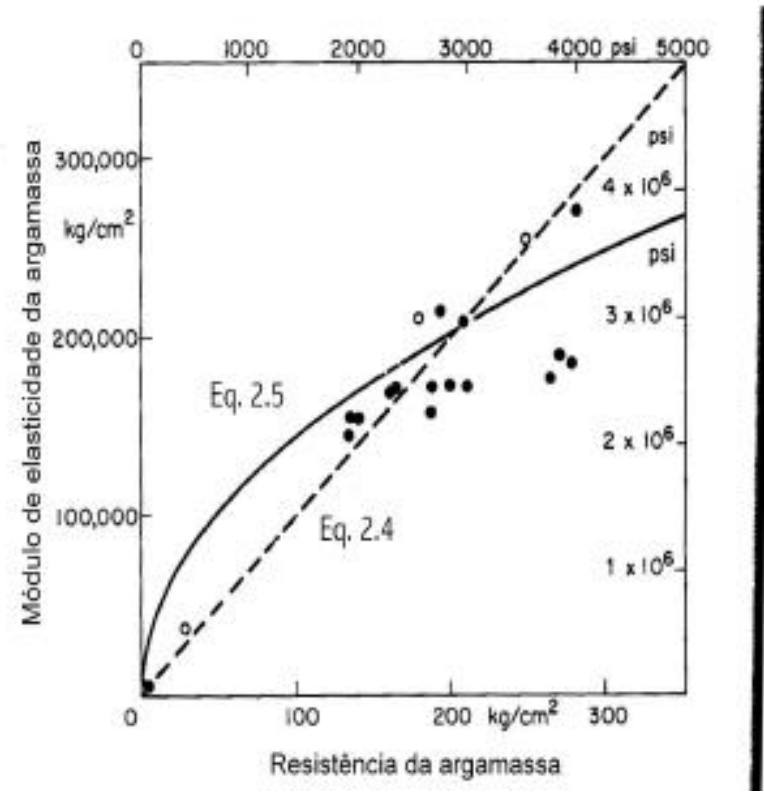

Figura 2.1 - Gráfico módulo de elasticidade da argamassa x resistência à compressão da argamassa, SAHLIN (1971).

CHEEMA \& KLINGER (1986), a partir dos estudos feitos por HILSDORF (1972) e MAHER \& DARWIN (1982), utilizaram em seu trabalho a expressão 2.6, que relaciona o módulo de elasticidade tangente inicial da argamassa em função da resistência da mesma. Através da idealização do comportamento da curva tensãodeformação utilizando esta relação, os autores estimaram o módulo secante da argamassa, dado pela expressão 2.7 .

$$
\begin{aligned}
& E_{a t}=1000 \cdot f_{a} \\
& E_{a s}=500 \cdot f_{a}
\end{aligned}
$$

onde

$E_{a t}$ é o módulo tangente inicial da argamassa;

$\mathrm{E}_{\mathrm{as}}$ é o módulo secante da argamassa;

$\mathrm{f}_{\mathrm{a}}$ é a resistência à compressão da argamassa. 
A tabela 2.1 transcreve as prescrições da norma britânica BS 5628: Part 1 (1992), no que diz respeito às classes de argamassas de assentamento a serem usadas na alvenaria estrutural, com seus respectivos traços e resistências à compressão esperadas aos 28 dias.

Tabela 2.1 - Traços de argamassa especificados pela BS 5628: Part 1 (1992).

\begin{tabular}{||c|c|c|c||}
\hline \multirow{2}{*}{$\begin{array}{c}\text { Tipo de } \\
\text { Argamassa }\end{array}$} & $\begin{array}{c}\text { Traço da argamassa } \\
\text { (em volume) }\end{array}$ & \multicolumn{2}{|c|}{$\begin{array}{c}\text { Resistência média à compressão aos } 28 \text { dias } \\
\text { (MPa) }\end{array}$} \\
\cline { 2 - 4 } & Cimento:cal: areia & Ensaios em laboratório & Ensaios em obra \\
\hline (i) & $1: 0 \mathrm{a}^{1 / 4: 3}$ & 16,0 & 11,0 \\
\hline (ii) & $1: 1 / 2: 4 \mathrm{a} 4 \frac{1}{1} 2$ & 6,5 & 4,5 \\
\hline (iii) & $1: 1: 5 \mathrm{a} 6$ & 3,6 & 2,5 \\
\hline (iv) & $1: 2: 8 \mathrm{a} 9$ & 1,5 & 1,0 \\
\hline
\end{tabular}

\subsection{Fatores que influenciam as características mecânicas da alvenaria}

A resistência e o módulo de elasticidade da alvenaria são afetados pelas características mecânicas dos seus materiais constituintes: bloco, argamassa e graute. O presente trabalho se restringirá ao estudo da alvenaria de blocos de concreto não-grauteados.

\subsubsection{Resistência dos blocos}

A resistência das unidades é o principal fator condicionante da resistência da alvenaria. Porém, cabe ressaltar que o aumento de resistência dos blocos não resulta em incrementos proporcionais de resistência da alvenaria. Dessa forma, o fator de eficiência da alvenaria, ou seja, a razão entre a resistência da alvenaria e a resistência dos blocos, diminui com o acréscimo da resistência da unidade. MEDEIROS (1993) indica que, no Brasil, este fator varia entre 25 e $70 \%$ para a alvenaria de blocos de concreto. 
HENDRY (1981) afirma que a resistência da alvenaria é aproximadamente proporcional à raiz quadrada da resistência do bloco. Segundo SAHLIN (1971), o fator de eficiência da alvenaria $\left(f_{a l} / f_{b}\right)$ varia entre 25 a $50 \%$.

A BS 5628 - Part 1 (1992) estabelece as relações entre as resistências de cálculo da alvenaria e a resistência do bloco e da argamassa. As curvas são apresentadas na figura 2.2.

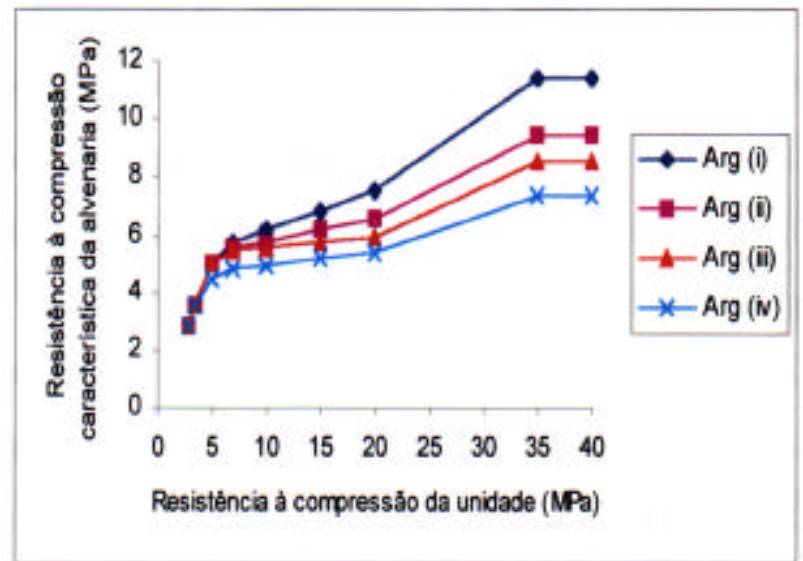

Figura 2.2 - Relação entre a resistência de cálculo da alvenaria e a resistência à compressão dos materiais constituintes, BS 5628 (1992).

DRYSDALE et al. (1994) apontam que tanto a resistência à compressão quanto a resistência à tração dos blocos tenham papel significativo na resistência da alvenaria. Segundo os autores, ensaios com grupos de blocos de mesma resistência apresentaram dispersões significativas quando era utilizado 0 assentamento lateral dos blocos, indicando a possibilidade da ruptura estar relacionada com as diferenças de resistência à tração dos blocos.

No estudo em blocos cerâmicos realizado por MENDES (1998), pode-se notar uma significativa influência da resistência da argamassa na resistência do prisma quando utilizados blocos de alta resistência. Nesse trabalho, obteve-se um aumento de eficiência do prisma de cerca de 60\%, ao passar da argamassa do tipo (iii) para argamassa do tipo (i), especificada pela BS 5628 part 1 (1992). 


\subsubsection{Capacidade de absorver deformações}

Segundo SABBATINI (1984), a argamassa deve possuir módulo de elasticidade adequado de forma a acomodar as deformações provenientes de movimentos da estrutura e intrínsecas, ou seja, aquelas provocadas por retração na secagem e de origem térmica, sem que ocorra o aparecimento de fissuras.

As argamassas mistas têm maior ductilidade. Materiais como a cal, incorporados nas argamassas, diminuem a rigidez das mesmas e permitem a acomodação das movimentações intrínsecas à alvenaria. Esta capacidade de se deformar ajuda na distribuição de esforços e na vedação, pois a argamassa pode absorver uma parte destes esforços e dissipá-los através de microfissuras não prejudiciais à estanqueidade e à resistência da parede. Este fato não acontece em argamassas muito rígidas, ou seja, com alto módulo de elasticidade, pois dissipam os esforços atuantes mediante macrofissuras, provocando infiltrações e perda de aderência (SOLÓRZANO, 1994).

FRANCO cita trabalhos do BUILDING RESEARCH STATION² em que afirmam que "raramente a fissuração da alvenaria é resultado de cargas aplicadas diretamente na estrutura, e sim de movimentos diferenciais entre várias partes da mesma, que podem ser causados por recalque da fundação ou por movimentos térmicos e de retração. Dessa forma, uma argamassa desnecessariamente forte possibilita a concentração dos efeitos de qualquer deformação diferencial em um pequeno número de fissuras com grandes aberturas. Já uma argamassa fraca acomoda-se com pequenos movimentos e qualquer fissura tende a distribuir-se por fissuras capilares nas juntas, que são imperceptíveis".

\subsubsection{Resistência da argamassa}

A escolha de uma argamassa adequada para uma determinada alvenaria estrutural dependerá do bloco utilizado e de sua resistência à compressão. Porém, conforme afirmam diversos pesquisadores, tais como SABBATINI (1984) e ANDREWS (1950), a resistência da parede de alvenaria constituída com blocos

2 BUILING RESEARCH STATION Strength and stability of walls. London, HMSO. Builing Research Station Digest no 75 (first series). Garston, 1955. 
usuais não é muito afetada pela resistência da argamassa. Isto se deve ao fato da argamassa estar submetida a um estado uniaxial de tensões nos ensaios à compressão em cilindros ou cubos, diferentemente do estado triaxial a que fica submetida na alvenaria. Assim, um grande aumento de resistência da argamassa no primeiro caso corresponde a um pequeno acréscimo no segundo, diminuindo também sua deformabilidade. Dessa forma, SOLÓRZANO (1994) propõe que a resistência da argamassa não seja usada como parâmetro representativo no controle da resistência da parede, mas sim para controle da produção da argamassa.

Segundo citações feitas por TANGO (1981), a argamassa utilizada na alvenaria estrutural deve apresentar uma resistência adequada, de modo a garantir a durabilidade e a impermeabilidade da parede, além de contribuir com sua estabilidade. Porém, o autor também ressalta que o controle da resistência à compressão da argamassa feita em moldes cilíndricos trata-se de um parâmetro de qualidade, já que a resistência à compressão não é a mesma desenvolvida na parede, devido às diferenças nas condições de adensamento e cura, ao estado de tensão a que fica submetida a argamassa e a fatores circunstanciais, tais como a absorção de água pelo bloco.

Dos estudos desenvolvidos por GOMES (1983), concluiu-se que paredes submetidas à compressão simples não precisam ser moldadas com argamassa de resistência superior à resistência dos blocos, com o objetivo de evitar uma argamassa muito rígida que comprometa o comportamento das paredes.

DRYSDALE et al. (1994) realizaram alguns ensaios com prismas de blocos cerâmicos, onde concluíram que a correlação existente entre menores resistências à compressão de argamassa e menores resistências à compressão de prismas é mais evidente em situações onde são utilizadas resistências de unidades elevadas.

A afirmação feita por DRYSDALE et al. (1994) pode ser comprovada através da tabela 2.2, transcrita da BS 5628: part 1 (1992), que apresenta valores estimados para a resistência característica à compressão da alvenaria, a partir da resistência do bloco e da argamassa utilizada. Através desta tabela é possível verificar o aumento da influência da resistência da argamassa na resistência da alvenaria conforme se aumenta a resistência da unidade. 
Tabela 2.2 - Resistência à compressão característica da alvenaria de blocos vazados, com relação altura/menor dimensão horizontal entre 2 e 4, BS 5628 Part 1 (1992).

\begin{tabular}{|c|c|c|c|c|}
\hline \hline \multirow{2}{*}{$\begin{array}{c}\text { Resistência do } \\
\text { bloco (MPa) }\end{array}$} & \multicolumn{4}{|c|}{ Tipo de argamassa (MPa) } \\
\cline { 2 - 5 } & (i) & (ii) & (iii) & (iv) \\
\hline 5 & 5,0 & 5,0 & 5,0 & 4,4 \\
\hline 10 & 6,1 & 5,7 & 5,5 & 4,9 \\
\hline 20 & 7,5 & 6,5 & 5,9 & 5,3 \\
\hline 35 & 11,4 & 9,4 & 8,5 & 7,3 \\
\hline
\end{tabular}

Os resultados dos ensaios de prismas feitos por MOHAMAD (1998) mostraram que o aumento da resistência do prisma não é proporcional ao aumento da resistência da argamassa. Segundo o autor, a variação da resistência do prisma com a resistência do bloco é mais evidente quando utilizada argamassa mais fraca, fato que deve ocorrer devido ao tipo de tensões surgidas no prisma quando submetido a cargas de ruptura.

MENDES (1998) afirma que o uso de argamassa mais rígida e resistente aumenta a parcela de carga absorvida pela alvenaria de blocos cerâmicos, devido ao aumento do módulo de elasticidade do conjunto bloco/argamassa. Porém, cabe ressaltar que este aumento de resistência pode prejudicar a capacidade de absorver deformações da argamassa, comprometendo o comportamento da alvenaria.

\subsubsection{Espessura da junta de argamassa}

Devido ao fato dos blocos de concreto terem propriedades similares às da argamassa, DRYSDALE et al. (1994) indicam que a influência da espessura da junta de argamassa na resistência à compressão de prismas é mais significativa na alvenaria de blocos cerâmicos do que na de blocos de concreto. No caso de paredes grauteadas, este efeito é ainda menor, devido ao graute contribuir com o conjunto.

HAMID \& DRYSDALE (1979) observaram uma diminuição de 16\% na resistência de prismas de blocos de concreto não-grauteados e de apenas 3\% para 
prismas grauteados, com o aumento da espessura da junta de argamassa de 10 para $19 \mathrm{~mm}$.

O gráfico 2.3 apresentado por SAHLIN (1971), mostra a influência da espessura da junta de argamassa na relação dos módulos de elasticidade da alvenaria $\left(E_{m}\right)$ e da argamassa $\left(E_{j}\right)$ em função do módulo de elasticidade do tijolo $\left(E_{b}\right)$. Neste gráfico, pode ser observado que aumentando em $50 \%$ o módulo de elasticidade da argamassa em função do módulo do tijolo, a relação entre $E_{N} / E_{b}$ não sofre grandes variações para diferentes relações de junta e tijolo. Porém, para relações baixas entre $E_{j} / E_{b}$, os valores de $E_{n} / E_{b}$ alteram-se significativamente para diferentes relações entre espessura da junta/altura do tijolo $\left(T_{j} / T_{b}\right)$. Com esse estudo, pode-se prever que, para alvenaria que tenha o módulo de elasticidade da argamassa bem maior que o módulo de elasticidade do tijolo, a razão entre o módulo de elasticidade da alvenaria e o módulo de elasticidade do bloco não seja expressivamente afetado pela espessura da junta de argamassa.

O mesmo autor também indica uma diminuição de 15\% na resistência da alvenaria para cada aumento de $0,3 \mathrm{~cm}$ na espessura da junta.

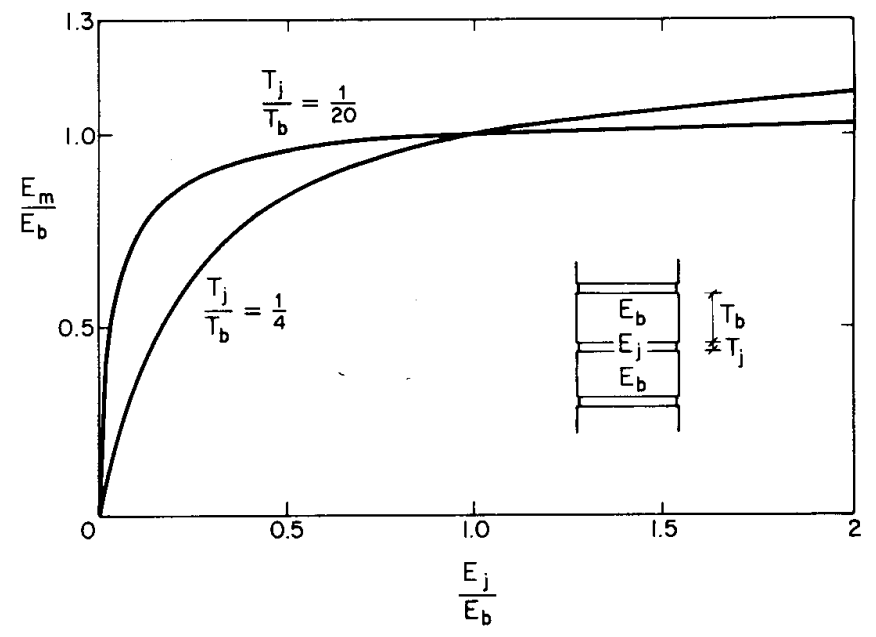

Figura 2.3 - Influência da espessura da junta de argamassa nos módulos de elasticidade da alvenaria e da argamassa, em função do módulo de elasticidade do tijolo, SAHLIN (1971).

De acordo com SABBATINI (1984), o aumento da espessura das juntas provoca uma deformação maior na argamassa, aumentando o diferencial de 
deformação em relação ao bloco. Este diferencial pode ser o responsável pelo acréscimo de tensões no bloco, diminuindo a resistência da alvenaria.

Através dos resultados obtidos pelos ensaios realizados por MOHAMAD (1998), foi possível mostrar um aumento de $32 \%$ na resistência do prisma ao diminuir a espessura da junta de argamassa de $1,0 \mathrm{~cm}$ para $0,7 \mathrm{~cm}$. Porém, o autor salienta que juntas com espessura inferior a $1,0 \mathrm{~cm}$ não têm capacidade de acomodar as fissurações na alvenaria.

\subsubsection{Tipo de assentamento da argamassa}

O tipo de assentamento é um fator importante no que diz respeito ao comportamento da alvenaria estrutural.

MEDEIROS (1993) cita a Teoria de Hilsdorf para explicar a ruptura típica de paredes de alvenaria carregada verticalmente, executadas com blocos assentados com preenchimento lateral das juntas horizontais, que ocorre através da propagação de fissuras verticais na região superior da espessura das paredes. Segundo esta teoria, também conhecida como Mecanismo de Fratura por Tração Transversal, a ruptura é causada pela diferença de rigidez entre a argamassa e o bloco. Com esta diferença, quando a parede está submetida à compressão, a deformação da argamassa confinada lateralmente gera tensões transversais nos blocos, ocorrendo a ruptura citada.

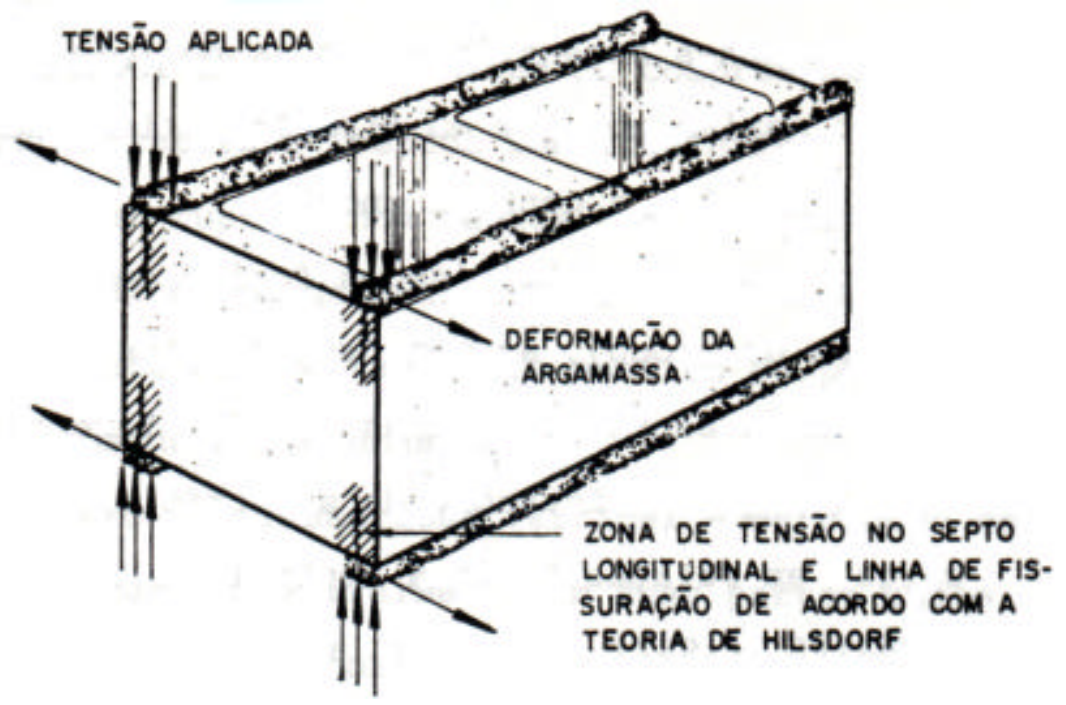

Figura 2.4 - Mecanismo de ruptura de Hilsdorf, MEDEIROS (1993). 
Segundo HILDSDORF (1964), a ruptura da alvenaria com esse tipo de assentamento ocorre com a fissuração dos septos longitudinais dos blocos submetidos à compressão, conforme mostra a figura 2.4.

No entanto, estudos realizados por SHRIVE ${ }^{3}$ apud MEDEIROS (1993) revelam que a ruptura da alvenaria com preenchimento de argamassa somente lateralmente ocorre nos septos tansversais dos blocos. Essa contradição à teoria desenvolvida por HILSDORF baseia-se em ensaios e modelagens utilizando o método de elementos finitos. Algumas das conclusões obtidas pelo autor estão transcritas a seguir:

"- As tensões aplicadas nas faces laterais de assentamento dos blocos espalham-se pelos septos transversais da unidade;

- Os blocos, ao serem solicitados por tensões de compressão aplicadas nos septos longitudinais, devem sofrer ruptura nos septos transversais no momento de aplicação da carga máxima de compressão axial;

- Na ruptura por fissuração vertical, os blocos rompem em partes praticamente simétricas, ocorrendo normalmente de baixo para cima, em cada bloco individualmente."

Através da aplicação do método dos elementos finitos SHRIVE (1982) observou que:

- As modificações nos módulos de elasticidade da argamassa de assentamento e do próprio bloco não alteraram as tensões nos septos dos blocos;

- As tensões de tração mais elevadas têm origem nos septos longitudinais de menor espessura;

- Os septos transversais dos blocos são mais solicitados pelas tensões de tração do que os septos longitudinais, devido à sua maior rigidez;

- O efeito de ruptura sugerido por HILDORF (1964) ocorre em menor intensidade e é superado pelo mecanismo "face-shell", que provoca tração nos septos.

3 SHRIVE, N.G. (1982). The failure mechanism of faceshell bedded (ungrouted and unreinforced) masonry. International Journal of Masonry Construction. London, v.2, n. 3, p. 115-28. 
Segundo DRYSDALE et al. (1994), para os prismas executados com preenchimento completo de argamassa, o aumento da carga de ruptura é menor que o proporcional aumento na área argamassada. Assim, com base na área efetiva, pode-se dizer que a resistência de prismas com argamassa apenas na face longitudinal é maior se comparada aos prismas com argamassamento total das juntas horizontais.

Nos ensaios realizados por ROMAGNA (2000) a resistência à compressão dos prismas com assentamento total e lateral não apresentou diferenças significativas. A figura 2.5 apresenta o gráfico das curvas obtidas da resistência do prisma em função da resistência do bloco para os diferentes tipos de prismas ensaiados.

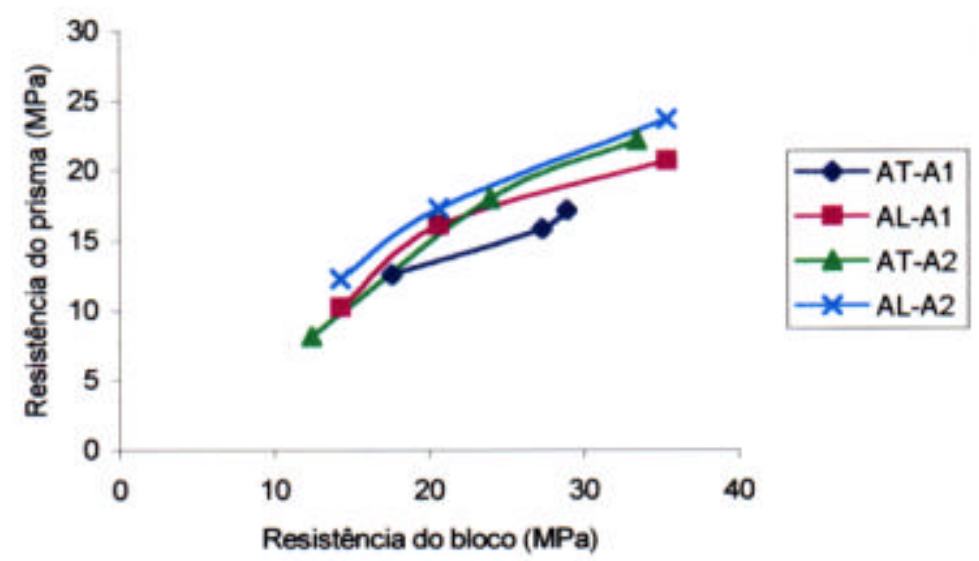

Figura 2.5 - Influência do tipo de assentamento na resistência à compressão dos prismas não grauteados, ROMAGNA (2000)

Notas: A denominação AT corresponde ao prisma com assentamento total e AL ao prisma com assentamento lateral.

A argamassa A1 corresponde ao traço 1:1:6 e a $\mathbb{R}$ ao traço 1:0,5:4,5 (traço (iii) e (ii), respectivamente, especificado pela BS 5628 part 1 (1.992)).

\subsubsection{Relação altura/espessura}

Dos ensaios realizados por DRYSDALE \& HAMID (1.979) concluiu-se que os prismas de dois blocos de altura não representam adequadamente 0 comportamento da alvenaria, superestimando a resistência da alvenaria, devido ao efeito de confinamento dos pratos da prensa. Os autores sugerem a utilização de 
prismas de, no mínimo, três blocos de altura, para que apresentem um modo de ruptura similar ao que acontece na alvenaria.

O uso de prismas com altura de dois blocos é um limite prático para o controle de qualidade e leva em consideração o transporte e os limites de altura dos equipamentos utilizados para os ensaios. Para ensaios de pesquisa, recomenda-se utilizar prismas com relação altura/espessura e número de juntas suficientes para reproduzir o modo de ruptura da parede.

Pelos estudos em prismas grauteados de blocos de concreto, realizados por COLVILLE \& WOLDE-TINSAE ${ }^{4}$ apud ROMAGNA (2000), os prismas moldados utilizando-se de 3 a 5 blocos representam de maneira bem mais significativa 0 comportamento da alvenaria quando comparados aos prismas de 2 blocos de altura.

Os autores sugerem estimativas de resistência à compressão da alvenaria de acordo com a resistência do prisma, dadas segundo as seguintes expressões:

$$
\begin{aligned}
& f_{a l v}=0,66 \cdot f_{p 2} \\
& f_{a l v}=0,90 \cdot f_{p 3}
\end{aligned}
$$

onde

$\mathrm{f}_{\mathrm{alv}}$ é a resistência à compressão da alvenaria;

$f_{p 2}$ é a resistência à compressão do prisma grauteado de 2 blocos;

$f_{p 3}$ é a resistência à compressão do prisma grauteado de 3 blocos;

\subsubsection{Aderência bloco-argamassa}

SABBATINI (1984) conceitua resistência de aderência como sendo a capacidade da interface unidade-argamassa em absorver esforços normais e tangenciais (tensões de cisalhamento e de tração) gerados na mesma, sem romper-se. Desta resistência dependem a monolicidade e a resistência da alvenaria

4 COLVILLE, J. \& WOLD-TINSAE, A. M. (1990). Compressive strength of hollow concrete masonry. In: $5^{\text {th }}$ North American Masonry Conference. June. University of Illinois at Urban-Champaign. P. 663672. 
quando submetida a esforços provocados por deformações volumétricas, carregamentos excêntricos e esforços ortogonais à parede.

O mesmo autor utiliza o termo capacidade de aderência da argamassa para determinar a capacidade necessária para que a interface bloco-argamassa apresente uma determinada resistência de aderência. Segundo o autor, uma possível avaliação dessa capacidade só seria possível realizando-se ensaios específicos que envolvessem o conjunto bloco-argamassa. Dessa forma, torna-se sem sentido a quantificação isolada desta capacidade na argamassa, já que ela não é uma característica intrínseca.

Segundo ROSELLO5 apud SOLÓRZANO (1994), pode-se dizer que existem os estágios de aderência da argamassa fresca e endurecida. O primeiro está relacionado com as propriedades reológicas da pasta de cimento e cal. Nesse caso, o aumento do teor de aglomerantes provoca uma diminuição da tensão superficial. A segunda situação corresponde à argamassa endurecida e sua avaliação depende das características das unidades utilizadas.

SOLÓRZANO (1994) afirma que a resistência de aderência é influenciada pelas características das unidades utilizadas, tais como absorção inicial, porosidade e rugosidade superficial; características da argamassa de assentamento, tais como trabalhabilidade, retenção de água, porosidade, granulometria da areia, e pelas condições de execução e cura da alvenaria.

O mesmo autor cita ainda que a absorção inicial do bloco é uma das características mais importantes e está relacionada com a capacidade da unidade em absorver uma certa quantidade de água imediatamente após o contato com a argamassa. A medição desta capacidade normalmente é feita em função do IRA ("Initial Rate of Absorption"), ou seja, da massa de água absorvida pela unidade quando a superfície do mesmo entra em contato com uma camada de água de aproximadamente $3 \mathrm{~mm}$ de altura, durante 1 minuto. Este fator depende da porosidade do bloco e do seu teor de umidade.

"A aderência bloco-argamassa está ligada ao gradiente de umidade que varia da zona superior da argamassa até a superfície de contato, na qual a perda

5 ROSELlO, M. T. (1976) Morteros de cemento para albañileria. ITECC (Instituto Eduardo Torroja de la Construcción y del Concreto). Boletín no 337. Madrid 
de água pode ser intensa de tal forma que a argamassa fique impedida de seguir liberando água, cortando-se a sucção que é fundamental para a aderência.

A diminuição ou perda de aderência pode estar ligada a perda rápida e excessiva de água da argamassa para os blocos de alto poder de absorção. Este fenômeno faz com que a argamassa não disponha de água suficiente para a hidratação do cimento. Assim, deve-se usar argamassas com capacidade de retenção de água compatível com o índice de absorção inicial (IRA) das unidades." (CANDIA, 1994).

SOLORZANO (1994) considera que a escolha de uma argamassa adequada para alvenaria estrutural está ligada com a capacidade de dissipação dos esforços atuantes da mesma, sem que ocorra fissuração prejudicial à alvenaria. Para tanto, é necessário que seja feito um estudo adequado da sua composição e dosagem, bem como da capacidade de aderência entre bloco e argamassa.

\subsubsection{Retenção de água da argamassa}

Uma das características principais da argamassa é possuir a capacidade de reter adequadamente a água que possui em excesso quando em contato com o bloco de alta sucção. A incorreta retenção de água pode gerar um comprometimento na aderência bloco-argamassa e uma diminuição na capacidade de absorver deformações na argamassa, pelo fato da mesma tornar-se mais rígida com a perda de água, aumentando seu módulo de elasticidade. Além disso, a resistência da argamassa pode diminuir, pois a perda de água prejudica a hidratação do cimento e a carbonatação da cal. No bloco, a absorção excessiva de água pode ocasionar uma expansão do bloco, aumentando o potencial de retração na secagem (SABBATINI, 1984). 


\subsection{Comportamento geral da alvenaria}

\subsubsection{Mecanismos de ruptura}

Segundo HILSDORF ${ }^{6}$ apud SABBATINI (1984), pode-se dizer que a alvenaria é constituída por materiais (argamassa e bloco) com diferentes características mecânicas, onde a resistência à compressão uniaxial da argamassa e o módulo de elasticidade da argamassa são geralmente menores que os do bloco. Porém, a aderência e o atrito entre os materiais constituintes impedem que a deformação lateral da argamassa seja maior que a dos blocos, criando um estado de tensão de compressão triaxial na argamassa e tração axial lateral nos blocos (ver figura 2.6). Com isso, a alvenaria pode ser submetida a esforços maiores que os suportados pela argamassa em estado uniaxial. A ruptura da alvenaria ocorre quando sucessivas e localizadas rupturas causam instabilidade do conjunto.

Ensaios à compressão de blocos tendem a produzir uma ruptura do tipo cisalhamento cônico ("Conical shear-compression"), como mostra a figura 2.7, apresentada por DRYSDALE et al (1994). Esta configuração de ruptura pode ser explicada pelos efeitos causados pela baixa relação altura/espessura $(\mathrm{h} / \mathrm{t})$ do corpo de prova, estando ligada ao confinamento lateral junto ao topo e à base do corpo de prova, o que gera um aumento na resistência à compressão aparente e altera a configuração de ruptura. Para que este efeito seja minimizado, o autor recomenda a utilização de "brush plattens", ou seja, escovas que permitem a deformabilidade horizontal dos corpos de prova.

Para alvenaria de blocos de concreto a ruptura normalmente ocorre devido à ruptura por tração do bloco em tensões de compressão relativamente baixas e a tração lateral é a tensão dominante no estado biaxial.

6 HILSDORF, H.K. (1969).Investigation into the Failure Mechanism of Brick Masonry Loaded in Axial Compression. Houston, Gulf. Londres. 


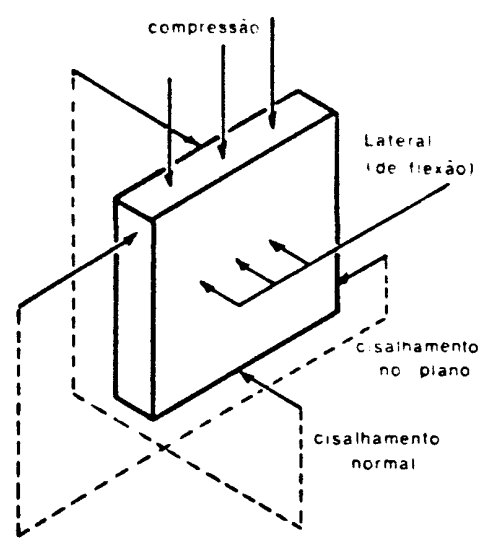

(a)
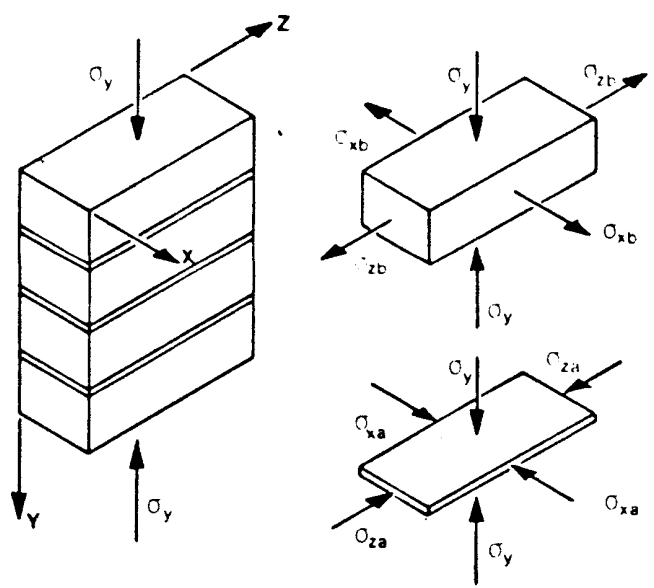

(b)

Figura 2.6 - (a) Cargas atuantes em uma parede; (b) Tensões no tijolo e na junta de argamassa quando submetida àcompressão axial, SABBATINI (1984).

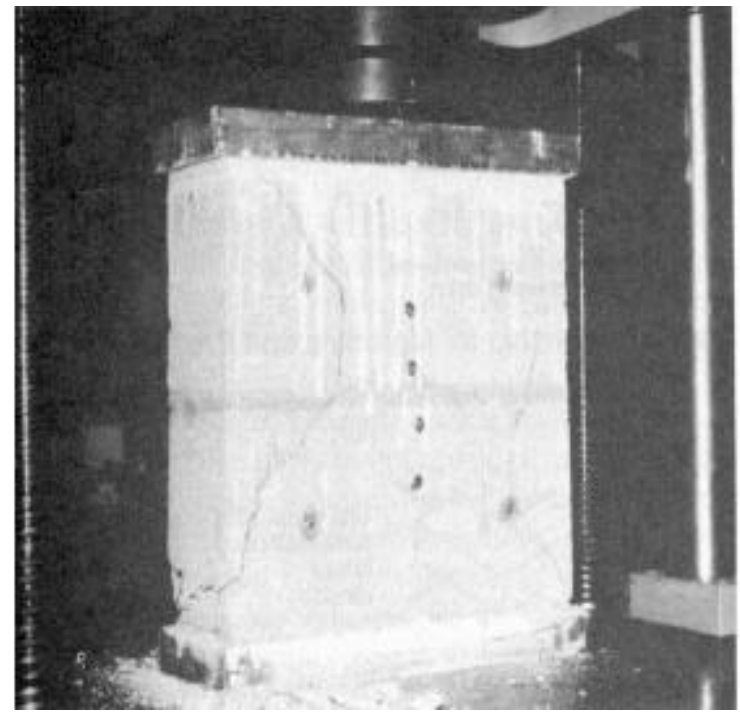

Figura 2.7 - Ruptura do tipo cisalhamento cônico ("Conical shearcompression") em prismas de dois blocos, DRYSDALE et al (1994).

\subsubsection{Previsão para tensão de ruptura na alvenaria}

Com o objetivo de desenvolver uma teoria que previsse a resistência da alvenaria baseada nos módulos de elasticidade do bloco e argamassa, resistência à 
compressão dos prismas e argamassa e a resistência à tração dos blocos, MOHAMAD (1998) realizou alguns ensaios de prismas utilizando diferentes resistências de blocos e de argamassa.

A partir dos resultados obtidos experimentalmente, MOHAMAD (1998) utilizou dois gráficos: o primeiro relacionando a razão entre a resistência à compressão do prisma e a resistência da argamassa $\left(\mathfrak{f}_{\beta} / f_{a}\right)$ com a razão entre os módulos de elasticidade da argamassa e do bloco $\left(E_{d} / E_{b}\right)$ (ver figura 2.8) e, o segundo, $E_{d} / E_{b}$ com a razão entre a resistência à compressão do prisma e a resistência à tração do bloco $\left(\mathrm{f}_{\mathrm{p}} / \mathrm{f}_{\mathrm{bt}}\right)$ (ver figura 2.9). Dessa forma, obtiveram-se as equações 2.10 e 2.11, apresentando a resistência última do prisma de acordo com o tipo de ruptura, na argamassa ou por tração do bloco, respectivamente. Estas equações são mostradas a seguir.

$$
\begin{aligned}
& f_{p}=f_{a} \cdot 0,5794 \cdot\left(\frac{E_{a}}{E_{b}}\right)^{-1,1093} \\
& f_{p}=f_{b t}\left(5,45\left(\frac{E_{a}}{E_{b}}\right)^{2}+3,64\left(\frac{E_{a}}{E_{b}}\right)+10,22\right)
\end{aligned}
$$

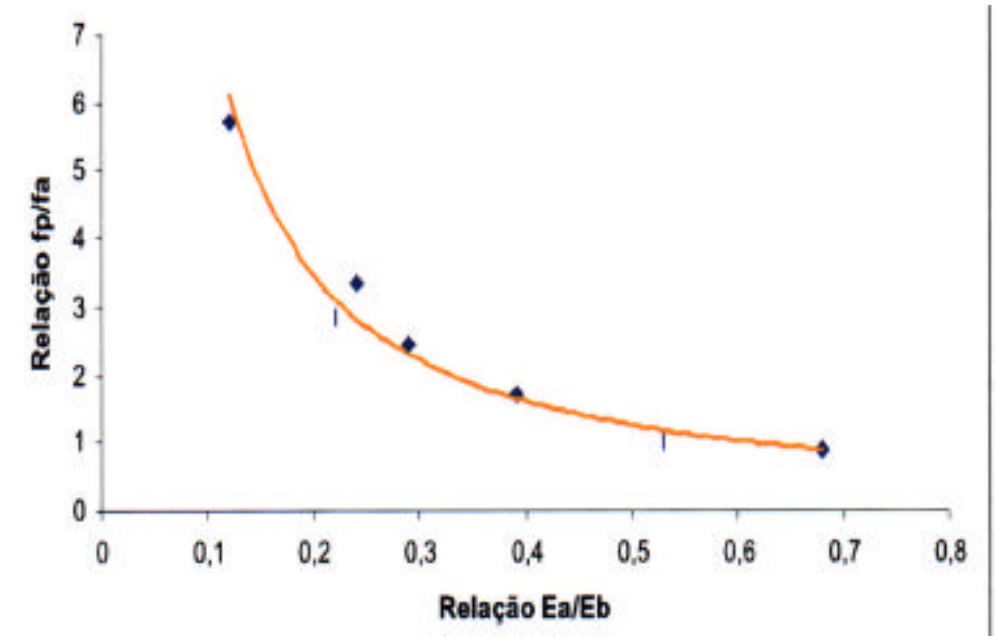

Figura 2.8 - Relação entre $f_{p} / f_{a}$ e $E_{a} / E_{b}$, MOHAMAD (1998). 


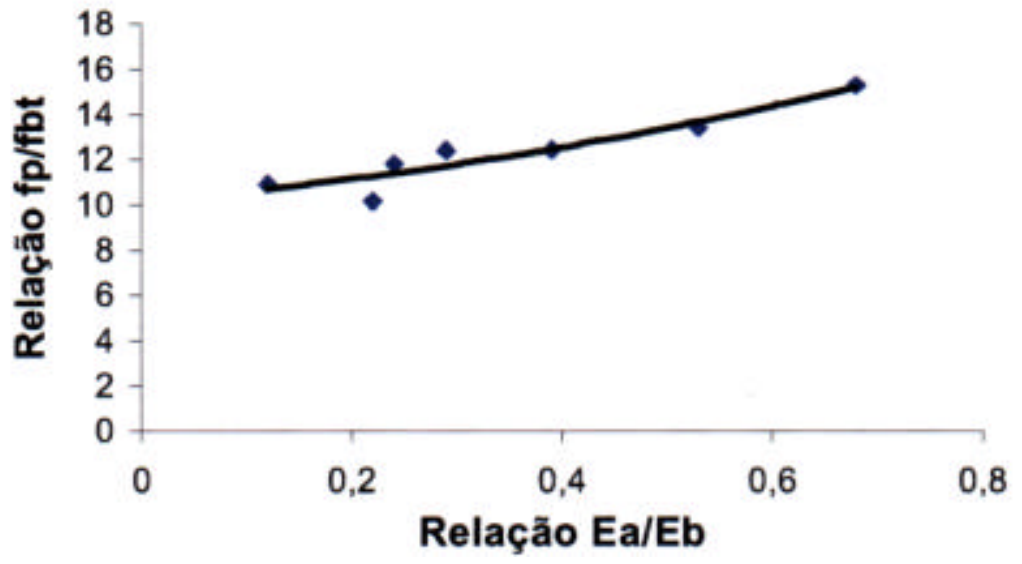

Figura 2.9 - Relação entre $f_{p} / f_{b t}$ e $E_{a} / E_{b}$, MOHAMAD (1998).

Com as equações apresentadas acima, o autor comparou os resultados experimentais obtidos por diversos autores com os valores propostos teoricamente. A partir daí, estabeleceu a forma de ruptura dos prismas. Esta comparação pode ser vista na tabela 2.3 .

Tabela 2.3 - Relação entre a resistência à compressão dos prismas prevista pela obtida experimentalmente por diversos autores, MOHAMAD (1998).

\begin{tabular}{|c|c|c|c|c|c|c|c|c|}
\hline & \multirow[t]{2}{*}{$\mathrm{E}_{\mathrm{a}} / \mathrm{E}_{\mathrm{b}}$} & \multirow[t]{2}{*}{$f_{a}$} & \multirow[t]{2}{*}{$f_{b t}$} & \multicolumn{2}{|c|}{$f_{\text {pprevista }}$} & \multirow{2}{*}{$\begin{array}{l}f_{\text {pobtica }} \\
\text { experim. }\end{array}$} & \multirow{2}{*}{$\begin{array}{l}f_{\text {pprevistd }} \\
\text { fpexperimen }\end{array}$} & \multirow[t]{2}{*}{ Tipo de ruptura } \\
\hline & & & & Eq. (2.10) & Eq. (2.11) & & & \\
\hline \multirow{3}{*}{$\begin{array}{c}\text { KHALAF \& } \\
\text { FAIRBAIN } \\
(1992)\end{array}$} & 0,29 & 9,2 & \multirow{3}{*}{1,5} & 21,04 & 17,6 & 17,8 & 0,99 & Tração no bloco \\
\hline & 0,54 & 15,4 & & 17,70 & 20,66 & 17,4 & 1,02 & $\mathrm{Na}$ argamassa \\
\hline & 0,74 & 26,5 & & 21,44 & 23,85 & 21,4 & 1,00 & $\mathrm{Na}$ argamassa \\
\hline \multirow{3}{*}{$\begin{array}{c}\text { HAMID \& } \\
\text { DRYSDALE } \\
(1979)\end{array}$} & 0,21 & 5,7 & \multirow{3}{*}{1,37} & 18,65 & 15,2 & 15,4 & 1,00 & Tração no bloco \\
\hline & 0,56 & 14,7 & & 16,2 & 13,13 & 16,4 & 0,99 & $\mathrm{Na}$ argamassa \\
\hline & 0,70 & 18,2 & & 15,7 & 21,15 & 16,3 & 0,96 & $\mathrm{Na}$ argamassa \\
\hline \multirow{2}{*}{$\begin{array}{c}\text { CHEEMA \& } \\
\text { KLNGER } \\
(1986)\end{array}$} & & & & & & & & \\
\hline & 0,48 & 14,9 & 1,56 & 19,48 & 20,63 & 19,26 & 1,01 & $\mathrm{Na}$ argamassa \\
\hline \multirow{2}{*}{$\begin{array}{c}\text { HEGEMEIR } \\
(1978)\end{array}$} & 03,7 & 22,8 & 2,25 & 39,7 & 27,7 & 31,7 & 0,87 & Tração no bloco \\
\hline & 0,47 & 22,8 & 1,87 & 30,5 & 25,5 & 24,6 & 0,96 & Tracão no bloco \\
\hline
\end{tabular}

Notas: Resistência dos prismas obtida na área líquida.

Resistência à tração dos blocos calculadas através da equação $f_{b t}=0,41 \sqrt{f_{b}}$. 
Através da tabela 2.3 o autor sugere a validade do método proposto para determinação do tipo de ruptura ocorrida, a partir da comparação dos resultados obtidos experimentalmente por diversos autores e os calculados utilizando as expressões 2.10 e 211. Dessa forma, pode-se perceber que os valores experimentais aproximaram-se muito dos valores obtidos ao utilizar uma das duas expressões apresentadas. Isto possibilitou ao autor sugerir os tipos de ruptura ocorridos durante estes ensaios, por tração no bloco ou por esmagamento da argamassa.

O estudo proposto por CHEEMA \& KLINGER (1986) teve como objetivo apresentar modelos que resultassem em relações simplificadas para prever a resistência à compressão e o tipo de ruptura em prismas de blocos de concreto. Para tanto, os autores desenvolveram um modelo em elementos finitos e uma série de ensaios em prismas grauteados e não-grauteados e seus materiais constituintes (argamassa, bloco e graute), sendo estes ensaios usados para definir o modelo analítico desenvolvido.

Os autores basearam seus estudos nos seguintes modos de ruptura para prismas não-grauteados:

- Ruptura por tração no bloco, onde a máxima tensão de tração principal no bloco é maior que a resistência à tração do bloco;

- Ruptura por esmagamento no bloco, onde a tensão de compressão principal é maior que a resistência à compressão do bloco;

- Ruptura por esmagamento da argamassa, onde a tensão de compressão axial na argamassa é maior que a resistência da argamassa confinada.

A partir destes modos de ruptura foram desenvolvidas várias expressões, utilizando as características dos materiais utilizados, que procuravam prever a tensão de compressão necessária para a ocorrência de cada tipo de ruptura, em função da relação entre o módulo de elasticidade da argamassa e do bloco.

Dessa forma, no caso de ruptura por tração no bloco, a expressão proposta é dada por:

$f_{t b}=(1 / \varsigma) f_{h b 1}$

onde

$\mathrm{f}_{\mathrm{tb}}$ é a tensão de tração transversal principal no bloco;

$f_{h b 1}$ é a tensão de compressão aplicada no prisma quando a ruptura é dada pela tração no bloco; 
$\zeta$ é o coeficiente de influência que pode ser obtido a partir da figura 2.10.

No caso da ruptura ocorrer quando a tensão de compressão nominal no bloco alcançar a resistência à compressão uniaxial no bloco, a expressão utilizada é a 2.13 , dada a seguir.

$$
f_{h b}=\varsigma \cdot f_{t b}, \text { mas }<f_{b}
$$

onde

$f_{h b}$ é a tensão de compressão aplicada no bloco;

$\mathrm{f}_{\mathrm{b}}$ é a resistência à compressão uniaxial no bloco;

A ruptura pode ainda ocorrer por esmagamento da argamassa. Neste caso, a expressão usada baseia-se no concreto confinado hidrostaticamente:

$f_{m}^{*}=f_{m}+4,1 . f_{l m}$

onde

$\mathrm{f}_{\mathrm{m}}{ }^{*}$ é a resistência à compressão da argama ssa confinada;

$f_{m}$ é a resistência à compressão uniaxial da argamassa;

$f_{I m}$ a tensão de confinamento transversal.

$$
f_{l m}=f_{t m i} . f_{h m}
$$

onde

$\mathrm{f}_{\mathrm{hm}}$ é a tensão de compressão máxima no prisma quando a ruptura é dada pelo esmagamento da junta;

$f_{\text {tmi }}$ é o coeficiente de influência.

$$
\begin{aligned}
& f_{h m}=f_{m}{ }^{*}=f_{m}+4,1 \cdot\left(f_{l m i} \cdot f_{h m}\right) \\
& f_{h m}=f_{m} /\left(1-4,1 f_{t m i}\right)
\end{aligned}
$$

Assim, a expressão que caracteriza este tipo de ruptura é dada por

$$
\begin{aligned}
& f_{h m}=\gamma \cdot f_{m} \\
& \gamma=1 /\left(1-4,1 \cdot f_{t m i}\right) \\
& \text { onde }
\end{aligned}
$$$$
\text { r pode ser obtido através da figura 2.10. }
$$ 


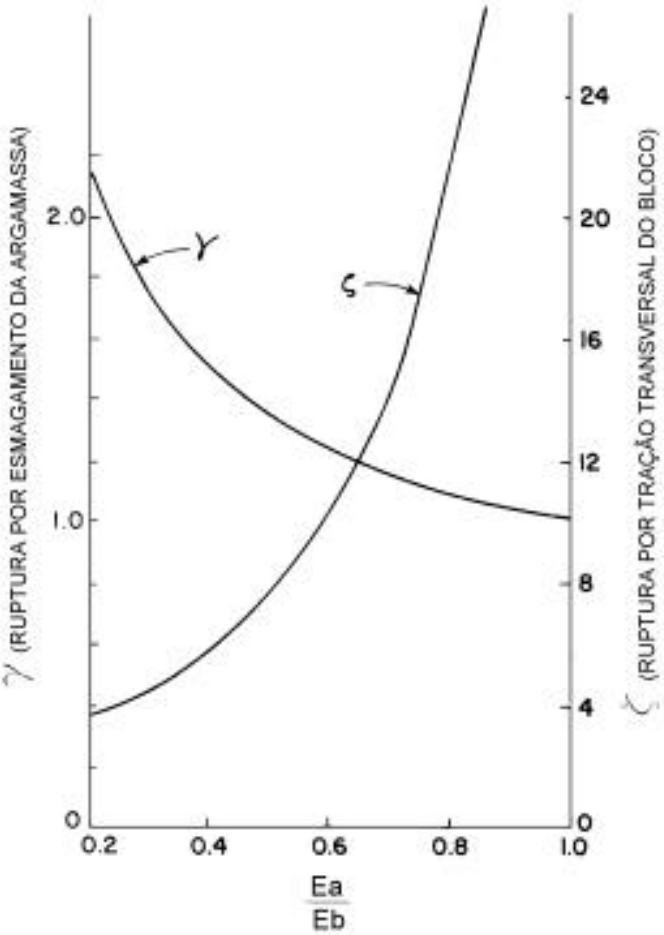

Figura 2.10 - Curvas de ruptura para prismas de blocos não-grauteados, CHEEMA \& KLINGER (1986).

Os autores apresentam a tabela 2.4, onde compararam os valores experimentais obtidos por alguns pesquisadores e os calculados utilizando as expressões propostas, alcançando resultados bastante favoráveis.

Tabela 2.4 - Comparação entre as resistências à compressão de prismas obtidas em ensaios e as calculadas CHEEM A \& KLINGER (1986).

\begin{tabular}{|c|c|c|c|c|c|c|}
\hline \multicolumn{2}{|c|}{ Ensaios } & \multirow{2}{*}{$\begin{array}{c}\begin{array}{c}\text { Resistência } \\
\text { do bloco } \\
(\mathrm{MPa})\end{array} \\
35,16\end{array}$} & \multirow{2}{*}{$\begin{array}{c}\text { Resistência } \\
\text { da argamassa } \\
(\mathrm{MPa})\end{array}$} & \multirow{2}{*}{$\begin{array}{c}\begin{array}{c}\text { Observada } \\
\text { (MPa) }\end{array} \\
25,33\end{array}$} & \multirow{2}{*}{$\begin{array}{c}\text { Prevista } \\
\text { (MPa) } \\
25,05\end{array}$} & \multirow{2}{*}{$\begin{array}{c}\frac{\text { Observada }}{\text { Prevista }} \\
1,02\end{array}$} \\
\hline & I & & & & & \\
\hline Hegemeier & II & 51,06 & 22,77 & 31,81 & 26,87 & 1,18 \\
\hline \multirow{3}{*}{ Hamid } & I & 19,66 & 14,70 & 16,42 & 17,04 & 0,96 \\
\hline & II & 19,66 & 18,22 & 16,28 & 19,66 & 0,83 \\
\hline & III & 19,66 & 5,73 & 15,39 & 6,90 & 2,23 \\
\hline
\end{tabular}


De uma maneira simplificada, CHEEMA \& KLINGER (1986) concluíram que, para uma dada relação entre os módulos de elasticidade da argamassa e do bloco, a ruptura ocorre preferencialmente por tração no bloco ou por esmagamento da argamassa. Assim, tem-se:

$\mathrm{E}_{\mathrm{a}} / \mathrm{E}_{\mathrm{b}} \geq 0,66 \Rightarrow$ ruptura por esmagamento da argamassa;

$\mathrm{E}_{\mathrm{a}} / \mathrm{E}_{\mathrm{b}}<0,66 \Rightarrow$ ruptura por tração no bloco.

O EUROCODE 6 (1995) estabelece uma equação para determinar a resistência à compressão característica da alvenaria, dada pela expressão 2.20.

$f_{k}=k \cdot f_{b}^{0,75} \cdot f_{a}^{0,25}$

onde

k é um coeficiente;

$\mathrm{f}_{\mathrm{a}}$ é a resistência à compressão média da argamassa;

$\mathrm{f}_{\mathrm{b}}$ é a resistência à compressão média do bloco.

$k=0,4 . \varphi$

para $\mathrm{f}_{\mathrm{b}}>15 \mathrm{~N} / \mathrm{mm}^{2} \Rightarrow \varphi=\left(15 / f_{b}\right)^{0,33} \quad 1,5$

para $\mathrm{f}_{\mathrm{b}} \quad 15 \mathrm{~N} / \mathrm{mm}^{2} \Rightarrow \varphi=1$

Através da equação 2.20 pode-se verificar que a contribuição da argamassa é menos significativa que a contribuição do bloco na resistência da alvenaria.

Tabela 2.5- Eficiências de prismas, paredinhas e paredes em blocos de concreto, obtidas por ALY \& SABBATINI (1994).

\begin{tabular}{||c|c|c|c|c||}
\hline $\begin{array}{c}\text { Resistência da } \\
\text { Argamassa (MPa) }\end{array}$ & $\begin{array}{c}\text { Eficiência do } \\
\text { Bloco }\end{array}$ & $\begin{array}{c}\text { Eficiência do } \\
\text { Prisma }\end{array}$ & $\begin{array}{c}\text { Eficiência da } \\
\text { Paredinha }\end{array}$ & $\begin{array}{c}\text { Eficiência da } \\
\text { Parede }\end{array}$ \\
\hline 7,9 & 1 & 0,81 & 0,67 & 0,65 \\
\hline 10,6 & 1 & 0,88 & 0,71 & 0,60 \\
\hline 13,2 & 1 & 0,74 & 0,49 & 0,62 \\
\hline
\end{tabular}

ALY \& SABBATINI (1994) realizaram ensaios à compressão em corpos de prova de pequenas dimensões - blocos, prismas, paredinhas - e em paredes em escala natural de blocos de concreto. Nestes ensaios, procurou-se obter valores de 
resistência à compressão, as características elásticas dos materiais, bem como as correlações entre as resistências mecânicas dos diversos tipos de corpos de prova estudados. As eficiências alcançadas para os prismas, paredinhas e paredes estão transcritas na tabela 2.5 .

\subsubsection{Determinação do módulo de elasticidade longitudinal}

SHALIN (1971) propôs uma equação para o cálculo do módulo de elasticidade da alvenaria, baseada nos módulos de elasticidade dos materiais que a constituem: o bloco e a argamassa. Segundo o autor, ensaios constataram que as juntas verticais não afetavam o módulo de elasticidade longitudinal da alvenaria, quando esta estava submetida a esforços na direção perpendicular à junta de assentamento. Dessa forma, considerando significativas somente as deformações perpendiculares às juntas horizontais e assumindo que os materiais obedecem à Lei de Hooke, foi realizada uma associação de molas a partir da compatibilização das deformações dos materiais. Assim, obteve-se:

$$
\begin{aligned}
& \Delta \ell_{t}=\Delta \ell_{a}+\Delta \ell_{b} \\
& \delta=\frac{\mathrm{h}_{\mathrm{b}}}{\mathrm{h}_{\mathrm{b}}+\mathrm{h}_{\mathrm{a}}} \\
& \mathrm{E}_{\mathrm{m}}=\frac{1}{\frac{1-\delta}{\mathrm{E}_{\mathrm{a}}}+\frac{\delta}{\mathrm{E}_{\mathrm{b}}}}
\end{aligned}
$$

onde

$\mathrm{D} \ell_{\mathrm{t}} \quad$ é a deformação total da alvenaria

$\mathrm{D} \ell_{\mathrm{a}} \quad$ é a deformação total da argamassa

$D l_{b} \quad$ é a deformação total do bloco

$h_{a} \quad$ é a espessura da argamassa

$h_{b} \quad$ é a altura do bloco

$E_{m} \quad$ é o módulo de elasticidade da alvenaria

$E_{a} \quad$ é o módulo de elasticidade da argamassa

$\mathrm{E}_{\mathrm{b}} \quad$ é o módulo de elasticidade do bloco 
FRANCO (1987) ressalta que os valores dos módulos de elasticidade dos materiais devem ser obtidos em condições de solicitações iguais a que os mesmos estarão submetidos nas paredes, ou seja, a argamassa sob estado triaxial de compressão e o bloco sob um estado biaxial de compressão-tração.

Além disso, FRANCO (1987) afirma que a argamassa tem grande influência no módulo de elasticidade da parede. A correlação exposta pode sugerir que a influência da argamassa é pequena, mas levando em consideração que o módulo de elasticidade da argamassa $\left(E_{a}\right)$ é bem menor se comparado com o módulo do bloco $\left(E_{b}\right)$, a parcela correspondente à argamassa pode ter um papel importante no módulo da alvenaria.

GOMES (1983) propõe que a expressão 2.24 seja utilizada com algumas modificações, de modo que o nível de tensão em que se determinam os módulos de elasticidade da argamassa $\left(E_{a}\right)$ e do bloco $\left(E_{b}\right)$ representem de modo mais realista as condições da alvenaria. Dessa forma, atenção especial deve ser tomada em relação ao módulo da argamassa $\left(\mathrm{E}_{\mathrm{a}}\right)$, já que a mesma se encontra submetida à compressão triaxial quando presente na alvenaria, o que não ocorre quando o ensaio é realizado com corpos de provas individuais de argamassa. Para tanto, o autor sugeriu que a correção do módulo de elasticidade da argamassa $\left(E_{a}\right)$ seja feita utilizando a seguinte expressão:

$$
\frac{E_{a, a}}{E_{a}}=\left(1-\frac{2 . v_{a}{ }^{2}}{1-v_{a}}\right)^{-1}
$$

onde

$\mathrm{E}_{\mathrm{a}, \mathrm{a}}$ é o módulo de elasticidade aparente da argamassa de assentamento quando confinada;

$E_{a}$ é o módulo de elasticidade da argamassa de assentamento quando comprimida uniaxialmente;

$v_{a}$ é o coeficiente de Poisson da alvenaria.

KNUTSSON \& NIELSEN (1995) apresentaram um método padronizado para a determinação do módulo de elasticidade da alvenaria denominado NORDTEST ${ }^{7}$. Este método baseia-se na aproximação de uma reta secante entre a origem e um

7 NORDTEST method NT Buid - Determination of the strength and the modulus of elasticity for masonry in compression (under publication). 
ponto correspondente a $0,4 \mathrm{f}_{\mathrm{c}}$, por uma outra secante entre os pontos de $5 \%$ e $35 \%$ da curva tensão $x$ deformação.

O método de ensaio para determinação desta curva consiste em submeter os corpos de prova a carregamentos com controle de deformação ou força, até aproximadamente $75 \%$ da resistência à compressão estimada. Posteriormente, a amostra deve ser carregada até alcançar a ruptura dentro de um período de tempo de $(15 \pm 3)$ minutos. Os autores sugerem que este intervalo de tempo é suficiente para assegurar que as deformações de fluência sejam aproximadamente guais em peças fracas e fortes. Segundo eles, a utilização de uma razão fixa de carregamento influencia o resultado de resistência, já que nos ensaios, peças fracas atingem o esmagamento através de deformações totais relativamente pequenas quando comparadas com peças fortes, devido às deformações de fluência serem bem menores nas primeiras.

Os resultados dos ensaios são utilizados para determinar o módulo de elasticidade secante para alvenaria através da seguinte equação:

$$
E_{m a}=E_{05-35}=\frac{0,35 f_{c}-0,05 f_{c}}{\varepsilon_{0-35}-\varepsilon_{0-05}}
$$

onde

$E_{m a}$ é a inclinação da secante entre as tensões $\sigma_{0,05}=0,05 f_{c}$ e $\sigma_{0,35}=0,35 f_{c}$;

$\varepsilon_{0,05}$ é a deformação correspondente a tensão $\sigma_{0,05}$;

$\varepsilon_{0,35}$ é a deformação correspondente a tensão $\sigma_{0,35}$.

$\mathrm{f}_{\mathrm{c}}$ é a resistência à compressão da alvenaria.

Os resultados obtidos são muito próximos do módulo secante obtido a partir da origem ao ponto de $0,4 \mathrm{f}_{\mathrm{c}}$ da curva tensão $\mathrm{x}$ deformação, com a vantagem de terem os primeiros $5 \%$ do carregamento desprezados. Com isto, minimizam-se os efeitos causados pela falta de precisão nas medições correspondente ao início do ensaio, período este em que ocorre a acomodação dos corpos de prova.

A norma NBR 8522 "Concreto - Determinação do Módulo de Deformação Estática e Diagrama Tensão-Deformação" determina o plano de carregamento a ser efetuado para a avaliação do módulo de elasticidade, de acordo com o tipo de carregamento a que a estrutura estará submetida. Para a determinação do módulo 
de elasticidade secante, utiliza-se o plano de carregamento do tipo III e, a partir do diagrama tensão-deformação, obtémse a inclinação da reta secante que corta o diagrama nos pontos correspondentes à tensão de $0,5 \mathrm{MPa}$ e à tensão considerada para o cálculo do módulo secante. Assim, calcula-se o módulo segundo a seguinte expressão:

$$
E_{\mathrm{sec}, n}=\frac{\sigma_{\mathrm{sup}}-\sigma_{\mathrm{inf}}}{\varepsilon_{n}-\varepsilon_{0}}
$$

onde

$\mathrm{E}_{\mathrm{sec}, \mathrm{n}}$ é o módulo de elasticidade secante;

$\sigma_{\mathrm{n}}$ é a tensão considerada para o cálculo do módulo secante;

$\varepsilon_{\mathrm{n}}$ é a deformação específica correspondente a tensão $\sigma_{n}$;

$\varepsilon_{0}$ é a deformação específica correspondente a tensão $\sigma_{0}$;

$\mathrm{n}=0,1 \ldots 0,7$ ou 0,8

É usual em pesquisas e normas técnicas relacionar o módulo de elasticidade da alvenaria com sua resistência última à compressão. Essas expressões são normalmente utilizadas para estimar o valor do módulo de elasticidade pelos projetistas de estruturas de alvenaria.

A BS 5628 (1992) sugere a utilização da expressão 2.28 para determinação do módulo de elasticidade da alvenaria de blocos cerâmicos, sílico-calcáreos e de concretos, incluindo a alvenaria grauteada.

$$
E_{m}=900 \cdot f_{k}
$$

onde $\mathrm{f}_{\mathrm{k}}$ é a resistência à compressão característica da alvenaria

É comum adotar-se o módulo de elasticidade $\left(E_{m}\right)$ como sendo igual a 1000. $f_{k}$. Porém, pesquisas mais recentes têm mostrado que este valor é superestimado para a maioria das alvenarias. Dessa forma, têm-se adotado valores da ordem de $750 . f_{k}$, acreditando que esta seja uma melhor estimativa, (DRYSDALE et al. (1994)).

O ACl 530-92/ASCE 5-92 apresenta uma tabela, transcrita neste trabalho pela tabela 2.6, em que estabelece os valores dos módulos de elasticidade para alvenaria de blocos concreto, a partir da resistência à compressão obtida na área 
líquida. A referida norma também propõe a determinação do módulo de elasticidade secante da alvenaria, entre os valores correspondentes a 5\% e 33\% da resistência à compressão, a partir do método de ensaio de prisma proposto pelo $\mathrm{ACl}$ 530.1/ASCE 6 e pela ASTM E 111.

Tabela 2.6 - Módulo de elasticidade para alvenaria de blocos de concreto.

\begin{tabular}{||c|c|c||}
\hline \multirow{2}{*}{$\begin{array}{c}\text { Resistência à } \\
\text { compressão da } \\
\text { unidade }(A) \text { em MPa }\end{array}$} & Argamassa do tipo N & Argamassa do tipo M ou S \\
\cline { 2 - 3 } & & 24150 \\
\hline 41,40 ou maior & - & 22080 \\
\hline 34,50 & 19320 & 20010 \\
\hline 27,60 & 17940 & 17250 \\
20,70 & 15870 & 16560 \\
\hline 17,25 & 15180 & 15180 \\
\hline 13,80 & 12420 & 11040 \\
\hline 10,35 & 10350 & \\
\hline
\end{tabular}

PLOWMAN ${ }^{8}$ apud FRANCO (1987) apresentou duas expressões (2.29 e 2.30) baseadas em trabalhos experimentais, onde procurava correlacionar 0 módulo de elasticidade da alvenaria com sua resistência à compressão e com a resistência à compressão dos blocos.

$$
\begin{aligned}
& E_{a l v}=\left(f_{a l v}-0,6894\right) .100\left(\mathrm{~N} / \mathrm{mm}^{2}\right) \\
& E_{a l v}=\left(f_{b}-20,6841\right) .200\left(\mathrm{~N} / \mathrm{mm}^{2}\right)
\end{aligned}
$$

onde

$\mathrm{E}_{\mathrm{alv}}$ é o módulo de elasticidade da alvenaria;

$\mathrm{f}_{\mathrm{alv}}$ é a resistência à compressão da alvenaria;

$f_{b}$ é a resistência à compressão dos blocos.

8 PLOWMAN, J.M. (1965). The modulus of elasticity of brickwork. Proceedings of the British Ceramic Society $n^{\circ} 4$. 


\subsubsection{Determinação das características mecânicas na direção paralela ao plano da face de assentamento do bloco}

Os códigos e normas atuais não citam recomendações referentes a ensaios que representem situações onde a alvenaria esteja sujeita a ações externas numa direção paralela a face de assentamento usual dos blocos, ou seja, paralela à junta horizontal. Entretanto, a análise deste tipo de solicitação pode ser de extrema importância, principalmente se esta situação for mais desfavorável quando comparada a alvenaria submetida à compressão no plano perpendicular à face de assentamento.

KHALAF (1997) desenvolveu um programa de pesquisa em que procurou verificar a influência do graute e da argamassa na resistência dos prismas quando submetidos à compressão em duas direções ortogonais: perpendicular e paralela à face de assentamento usual dos blocos (ver figura 2.11). Para tanto, foram ensaiados 57 prismas de blocos de concreto grauteados e não-grauteados, utilizando 3 tipos de argamassa e 3 resistências de graute.

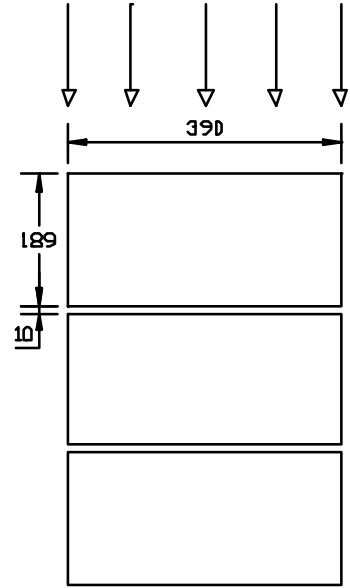

(a)

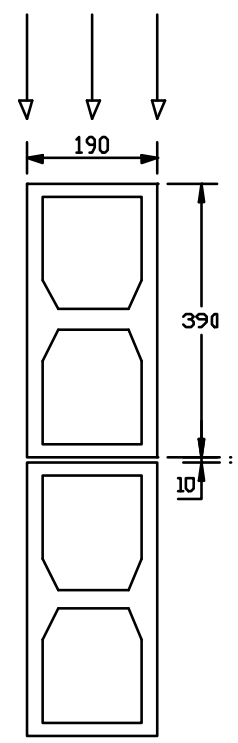

(b)

Figura 2.11 - Prismas utilizados nos ensaios de KHALAF (1997) - (a) Prismas de 3 blocos comprimidos normalmente à face de assentamento usual; (b) Prismas de 2 blocos comprimidos paralelamente à face de assentamento usual dos blocos (medidas em $\mathrm{mm}$ ). 
Segundo os resultados obtidos, o autor apresentou as seguintes conclusões:

- A resistência da alvenaria quando submetida à compressão perpendicular à face de assentamento usual pode ser obtida através ob ensaio de prismas de três blocos com junta a prumo;

- Quando a construção estiver sujeita a compressão paralela à face de assentamento usual, a resistência da alvenaria pode ser obtida através de ensaio utilizando-se prismas de dois blocos com assentamento de topo (vide fig. 2.11(b)), ou seja, com as juntas de argamassa entre as extremidades verticais;

- O efeito da resistência das argamassas foi menos significativo no caso de prismas comprimidos paralelamente à face de assentamento, devido à pequena relação espessura da junta de argamassa/altura do bloco no caso dos prismas comprimidos paralelamente se comparados aos comprimidos perpendicularmente à face de assentamento usual;

- Blocos grauteados comprimidos paralelamente apresentaram uma redução de resistência na faixa de $16 \%$ a $42 \%$ se comparada aos blocos comprimidos perpendicularmente;

- A presença do graute aumentou significativamente a capacidade resistente da seção dos prismas quando comparados aos prismas não-grauteados, com aumentos de $61 \%$ e $73 \%$ para prismas comprimidos na direção perpendicular e paralela, respectivamente;

- Amostras de prismas comprimidos paralelamente usando graute de alta resistência tiveram o mesmo efeito de redução de resistência do prisma observada com graute de baixa resistência.

Entretanto, cabe ressaltar que o trabalho apresentado acima refere-se a ensaios em que são utilizados somente prismas, não havendo nenhuma comparação realizada com corpos de prova de maiores dimensões, ou seja, paredinhas ou paredes em escala real. Dessa forma, não fica muito claro quais os parâmetros usados pelo autor para recomendar 0 ensaio de prismas, principalmente no que se refere à determinação da resistência à compressão da alvenaria na direção paralela à face de assentamento usual dos blocos.

Durante a pesquisa bibliográfica realizada pela autora não foi encontrado nenhum trabalho que contivesse procedimentos teóricos ou laboratoriais em 
relação à determinação do módulo de elasticidade da alvenaria quando submetida à compressão na direção paralela à face de assentamento dos blocos.

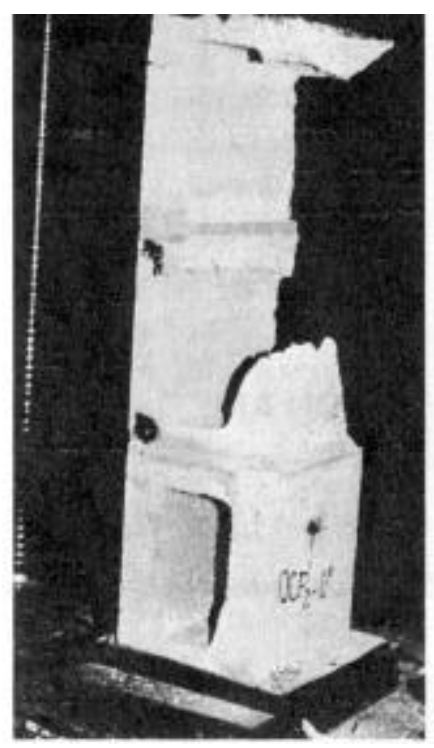

Figura 2.12 - Modo de ruptura de prisma com carregamento paralelo ao plano de assentamento usual do bloco, DRYSDALE et al. (1994).

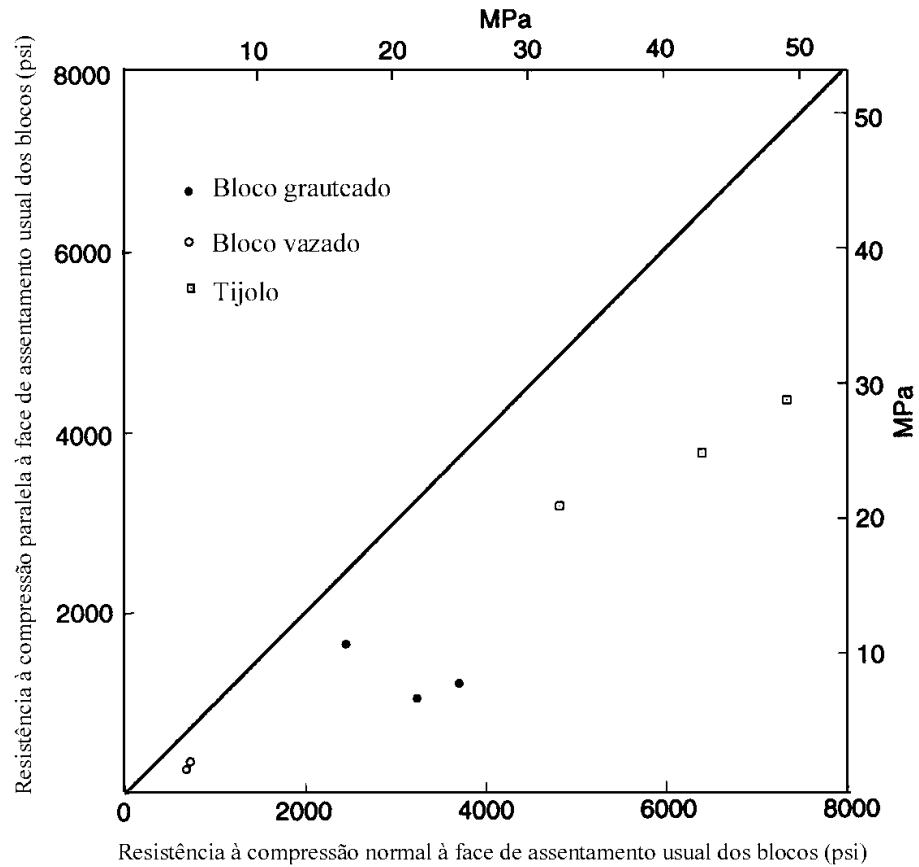

Figura 2.13 - Relação entre resistências de prismas para carregamento paralelo e normal ao plano da face de assentamento usual do bloco, DRYSDALE et al. (1994) 
DRYSDALE et al. (1994) apresentam os modos de ruptura típicos em prismas submetidos a carregamentos paralelos ao plano da face de assentamento do bloco mostrado aqui através da figura 2.12. Além disso, os autores também apresentam um gráfico com as relações típicas de resistência à compressão de prismas com carregamentos paralelo e normal à junta (figura 2.13).

\subsubsection{Curva tensão-deformação}

\section{Método desenvolvido por KNUTSSON \& NIELSEN (1.995) para obtenção da curva tensão-deformação}

A determinação da curva tensão-deformação a partir de resultados experimentais de ensaios à compressão foi proposta por KNUTSSON \& NIELSEN (1995), através da aplicação de um método baseado na aproximação do diagrama tensão x deformação por uma parábola ou por uma curva logarítmica.

Segundo os autores, a curva logarítmica foi obtida nos estudos desenvolvidos por RITTER (1899), através da variação do módulo tangente com os níveis de tensões, obtendo-se a seguinte expressão:

$$
\sigma=f_{c}\left(1-e^{-K_{r} \varepsilon}\right)
$$

onde

$K_{r}=\frac{E_{0, r i t}}{f_{c}}$ é a constante de Ritter para o material (Expressão utilizada inicialmente por Ritter para concretos, com $K_{r}=1000$ );

$\mathrm{E}_{0, \text { rit }}$ é o módulo tangente na origem para a curva de Ritter;

$\mathrm{f}_{\mathrm{c}}$ é a resistência à compressão da alvenaria;

A outra aproximação considera uma equação do segundo grau com dois graus de liberdade, através da origem e com uma tangente horizontal $\sigma=\mathrm{f}_{\mathrm{c}}$. Dessa forma, utilizando os parâmetros de módulo tangente inicial $E_{0, p a r}$ e a resistência f, tem-se a expressão da parábola dada por

$$
\sigma=E_{0, p a r} \varepsilon\left(1-\frac{E_{0, p a r}}{4 f_{c}} \varepsilon\right)
$$

onde 
$\mathrm{E}_{0, \mathrm{par}}$ é o módulo tangente na origem para a parábola.

Os parâmetros $E_{0, \text { rit }}$ e $E_{0, p a r}$ podem ser obtidos através de expressões teóricas que relacionam estes valores com os módulos de elasticidade secante de $5 \%$ a 35\%, obtida pelo método padrão já descrito anteriormente (equação 2.26).

KNUTSSON \& NIELSEN (1.995) realizaram ensaios com seis tipos de tijolos cerâmicos, obtendo uma boa aproximação dos resultados com a curva de Ritter e a parábola. A figura 2.14 mostra as curvas obtidas através dos ensaios, curva de Ritter, parábola e a reta secante definida pela ligação entre os pontos correspondentes às tensões de $5 \%$ e $35 \%$ da tensão de ruptura, na qual sua inclinação define o valor do módulo de elasticidade da alvenaria $\left(E_{\mathrm{ma}}\right)$, obtido através da expressão 2.26 .

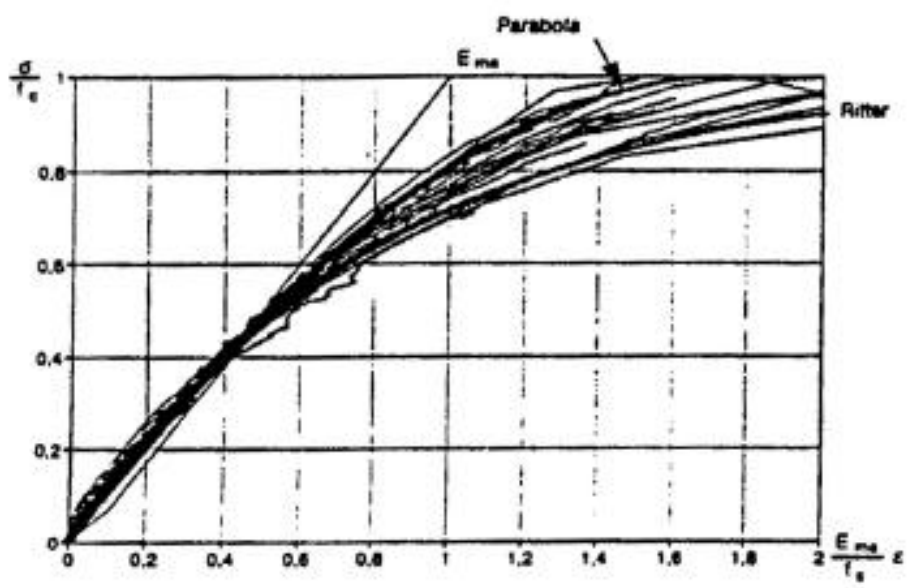

Figura 2.14 - Curvas obtidas nos ensaios de KNUTSSON \& NIELSEN (1995).

Com estes resultados observou-se que, para níveis de tensões moderados, pode-se utilizar diretamente 0 valor de $E_{\text {na }}$ obtido através do método normalizado. $O$ módulo secante $E_{m a}$ pode ser usado diretamente para cargas de serviço. As curvas de Ritter e a parábola também tiveram uma boa aproximação com os resultados experimentais, porém, para valores de tensões altos, a curva de Ritter conduz a valores mais conservadores de módulo de elasticidade se comparado com a parábola.

Para o Estado Limite Último, KNUTSSON \& NIELSEN (1.995) sugerem a utilização do módulo de elasticidade secante igual a $0,5 \cdot E_{0, \text { rit }}=0,625 \cdot E_{m a}$ combinado com uma tensão máxima de $1,25 . f_{c}$. 
DRYSDALE et al. (1994) realizaram alguns ensaios em alvenarias de blocos cerâmicos e de concreto, onde observaram um comportamento não-linear na curva tensão x deformação para valores de tensões acima de $50 \%$ da carga de ruptura, principalmente para alvenaria de blocos de concreto. Além disso, os ensaios também mostraram a ocorrência de uma ruptura frágil das paredes ao alcançarem a tensão de ruptura.

\subsection{Comentários sobre a revisão}

A revisão bibliográfica possibilitou concluir a existência de uma grande deficiência de trabalhos relacionados à deformabilidade de paredes de alvenaria estrutural em blocos de concreto. Os artigos internacionais voltam o assunto principalmente para a alvenaria grauteada, além do fato dos materiais serem diferentes dos empregados no Brasil. Desta forma, torna-se impraticável fazer comparações com os resultados obtidos pelos pesquisadores estrangeiros.

No Brasil, o número de trabalhos relacionados a este assunto é ainda mais reduzido, sendo a maioria dos artigos voltados para a alvenaria de blocos cerâmicos. Os únicos trabalhos que continham resultados experimentais para blocos de concreto foram os de ROMAGNA (2000) e ALY \& SABBATINI (1994).

Com relação à determinação do módulo de elasticidade longitudinal da alvenaria, o único artigo encontrado que sugere um método específico é o publicado por KNUTSSON \& NIELSEN (1995).

Também houve grande dificuldade em definir os procedimentos de ensaios para a determinação do módulo de elasticidade, já que as normas brasileiras e estrangeiras não são voltadas especificamente para alvenaria estrutural. Isso dificultou a determinação do número de corpos de prova, velocidade e procedimento de ensaio. 


\section{TRABALHO EXPERIMENTAL}

\subsection{Introdução}

Neste capítulo será apresentada a fase experimental deste trabalho, caracterizando detalhadamente os materiais, equipamentos e procedimentos utilizados durante os ensaios executados no Laboratório de Estruturas da Escola de Engenharia de São Carlos (EESC), da Universidade de São Paulo (USP).

Serão descritos aqui os ensaios de prismas e paredinhas de blocos de concreto submetidos a esforços de compressão axial, com o objetivo de obter dados necessários para a determinação das características elásticas e de resistência dos materiais utilizados e do conjunto bloco-argamassa.

Primeiramente, optou-se por realizar uma série de ensaios-piloto visando investigar as seguintes variáveis: resistência do bloco, resistência da argamassa e forma de assentamento da mesma. A execução destes ensaios tinha como objetivo avaliar as variáveis, no que diz respeito à deformabilidade dos materiais e do conjunto bloco-argamassa, de modo que fossem escolhidas as de maior influência no módulo de elasticidade, para posterior análise em paredinhas, completando o trabalho experimental. Porém, como detalhado mais adiante no item 4.4, os ensaios foram prejudicados pela aderência entre o bloco e a argamassa utilizada. Dessa forma, a escolha das variáveis do ensaio final foi feita com o auxílio de pesquisa bibliográfica, além dos resultados obtidos nos ensaios-piloto. 


\subsection{Caracterização dos materiais empregados nos ensaios}

\subsubsection{Blocos}

\subsubsection{Ensaios-piloto 1}

Para a realização dos ensaios-piloto foram recebidos dois lotes, contendo cada um 60 blocos de concreto. Os blocos foram fornecidos pela empresa Tatu, localizada no município de Limeira - SP.

As dimensões nominais das unidades de $15 \mathrm{~cm}$ x $20 \mathrm{~cm}$ x $40 \mathrm{~cm}$ (largura $\times$ altura $x$ comprimento) atendem aos padrões definidos pela Norma Brasileira NBR 6163 (1994), bem como às condições de tolerância de dimensões. As tolerâncias máximas exigidas por norma são apresentadas na tabela 3.1.

A geometria destes blocos é mostrada nas figuras 3.1 e 3.2. Ambos os blocos possuíam as mesmas características geométricas, sendo diferenciados apenas por sua classe de resistência.

No que diz respeito às características visuais, que também podem ocasionar - comprometimento da capacidade portante da estrutura, as amostras apresentaram aspecto homogêneo e as arestas vivas estavam livres de trincas e imperfeições.

Tabela 3.1 - Tolerância de dimensões dos blocos de concreto.

\begin{tabular}{|c|c|}
\hline Dimensão & Tolerância (mm) \\
\hline Largura & \pm 2 \\
\hline Altura & \pm 3 \\
\hline Comprimento & \pm 3 \\
\hline
\end{tabular}

A área bruta nominal da face de assentamento é de $546 \mathrm{~cm}^{2}$ e a área líquida igual a $55 \%$ da área bruta, ou seja, $300 \mathrm{~cm}^{2}$, obtida através do método das medidas geométricas. A relação entre a área líquida e área bruta de 0,55 enquadra as unidades em estudo dentro da classificação de blocos vazados. Os valores das massas unitárias $\left(\gamma_{\mathrm{b}}\right)$, relativas ao volume aparente total, foram de $1378 \mathrm{~kg} / \mathrm{m}^{3}$ para o bloco de 4,5 MPa e $2356 \mathrm{~kg} / \mathrm{m}^{3}$ para o bloco de $10 \mathrm{MPa}$, sendo os mesmos estimados através do uso do método das medidas geométricas e pesagem dos corpos de prova. 


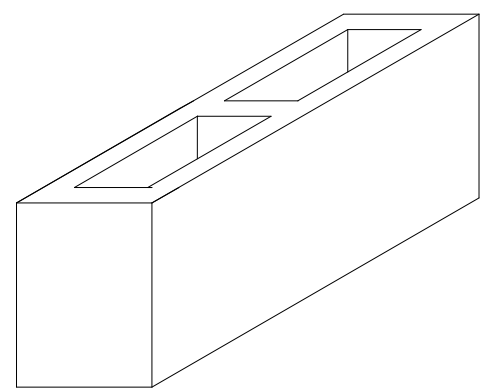

(a)

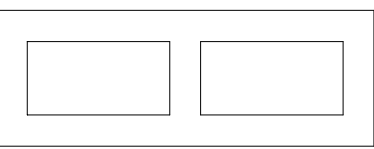

(b)

Figura 3.1 - Geometria dos blocos de concreto (a) perspectiva; (b) face de assentamento.
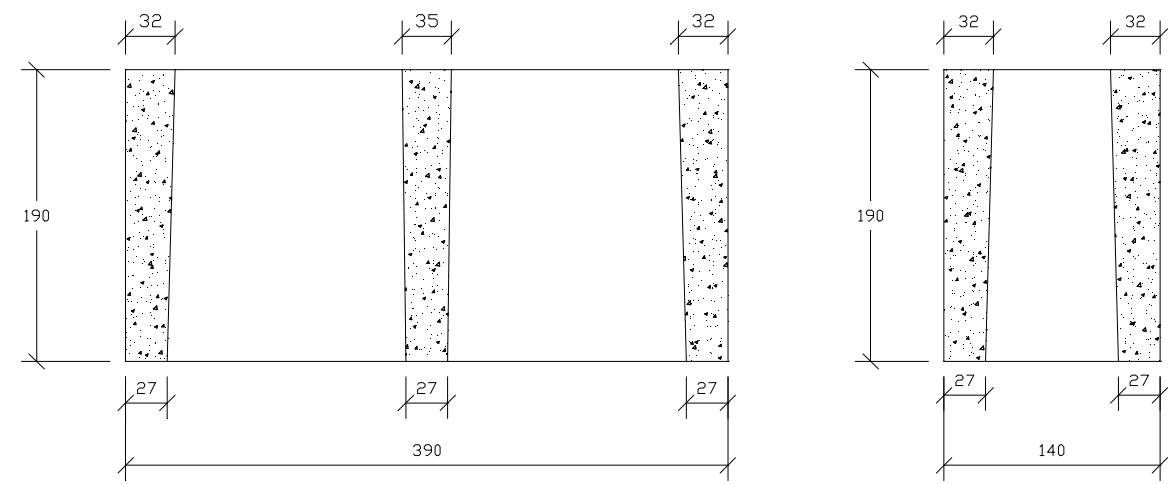

Figura 3.2 - Geometria dos blocos de concreto - Corte transversal (medidas em $\mathrm{mm}$ ).

As designações utilizadas para os blocos durante o ensaio-piloto e suas respectivas classes de resistência são dadas na tabela 3.2.

A utilização destes blocos com resistências à compressão bem distintas tem como objetivo determinar a influência da resistência dos blocos na resistência e no módulo de elasticidade dos prismas.

Tabela 3.2 - Denominação dos blocos de concreto (EP1).

\begin{tabular}{||c|c||}
\hline Denominação do bloco & Classe de resistência (MPa) \\
\hline 1 & 4,5 \\
\hline 2 & 10,0 \\
\hline
\end{tabular}




\subsubsection{Ensaios finais}

A empresa Tatu manteve-se como fornecedora dos blocos utilizados nos ensaios finais. A quantidade dos lotes recebidos e as dimensões nominais dos blocos são apresentadas na tabela 3.3.

Como citado no capítulo 1, a mudança na utilização dos blocos de $10 \mathrm{MPa}$ para os blocos de $12 \mathrm{MPa}$ foi resultado de um engano na entrega dos mesmos. Como essa alteração não afeta a proposta do estudo, mantiveram-se os blocos de $12 \mathrm{MPa}$.

Tabela 3.3 - Dimensões nominais e quantidades dos blocos de concreto (EF).

\begin{tabular}{|c|c|c|c|c||}
\hline \multirow{2}{*}{$\begin{array}{c}\text { Classe de } \\
\text { resistência }\end{array}$} & \multicolumn{3}{|c|}{ Dimensões nominais } & Quantidade \\
\cline { 2 - 5 } & Largura (cm) & Altura (cm) & Comprimento (cm) & recebida \\
\hline \multirow{2}{*}{4,5} & 15 & 20 & 40 & 180 \\
\cline { 2 - 5 } & 15 & 20 & 20 & 80 \\
\hline \multirow{2}{*}{12} & 15 & 20 & 40 & 180 \\
\cline { 2 - 5 } & 15 & 20 & 20 & 80 \\
\hline
\end{tabular}

Nestes ensaios, a determinação da área líquida dos blocos foi feita utilizando o método prescrito pela norma MB 3459 (1991). Os resultados obtidos são apresentados na tabela 3.4.

Tabela 3.4 - Valores médios de massa unitária do bloco, áreas líquida e bruta dos blocos de concreto (EF).

\begin{tabular}{|c|c|c|c|c|}
\hline Classe de resistência & $\mathbf{A}_{\mathbf{l}}\left(\mathbf{c m}^{\mathbf{2}}\right)$ & $\mathbf{A}_{\mathbf{b}}\left(\mathbf{c m}^{\mathbf{2}}\right)$ & $\mathbf{A}_{\boldsymbol{l}} / \mathbf{A}_{\mathbf{b}}$ & $\mathbf{w}_{\mathbf{b}} \mathbf{( \mathbf { k g } / \mathbf { m } ^ { \mathbf { 3 } } )}$ \\
\hline 4,5 & 290,3 & 547,3 & 0,53 & 1160 \\
\hline 12 & 290,5 & 549,1 & 0,53 & 1264 \\
\hline
\end{tabular}

Pode-se perceber que a relação área líquida/área bruta de ambos os blocos aproximou-se bastante do valor de 0,50 , normalmente adotado para o cálculo da alvenaria estrutural. 


\subsubsection{Argamassa de assentamento}

\subsubsection{Ensaio-piloto 1}

Para a execução do primeiro ensaio-piloto foram utilizados três tipos de argamassas de assentamento. Optou-se pelo uso de argamassas prontas da empresa Cimpor, pela sua facilidade de preparo e devido ao pequeno número de trabalhos que analisam o comportamento deste tipo de argamassa quando utilizada no assentamento de paredes de alvenaria estrutural de blocos de concreto.

A denominação das argamassas usada nos ensaios é dada pela tabela 3.3. As argamassas utilizadas atenderam a todas as especificações da Norma Brasileira NBR 13.281 (1995). As características apresentadas pelo fabricante, segundo a utilização de cada um dos tipos de argamassa usada no trabalho experimental, são descritas a seguir.

Massa Única F-07 - Recomendada para assentar alvenarias estruturais de bloco sílico-calcário e para revestir internamente alvenarias de blocos cerâmicos, concreto, sílico-calcário e concreto celular com espessura de revestimento de 1,0 $\mathrm{cm}$ até $1,5 \mathrm{~cm}$.

Massa Única F-11 - Recomendada para assentar e revestir internamente alvenarias de blocos de concreto celular, cerâmicos ou de concreto com espessura de revestimento de 0,5 até $1,5 \mathrm{~cm}$.

Massa Única F-51 - Recomendada para assentar e revestir alvenarias com espessura acima de $1,5 \mathrm{~cm}$.

Tabela 3.5 - Denominação das argamassas de assentamento (EP1).

\begin{tabular}{|c|c||}
\hline Denominação & Tipo de argamassa \\
\hline $\mathrm{P}$ & $\mathrm{F} 51$ \\
\hline $\mathrm{Q}$ & $\mathrm{F} 07$ \\
\hline $\mathrm{R}$ & $\mathrm{F} 11$ \\
\hline
\end{tabular}

Para a confecção dos prismas foram utilizadas as argamassas do tipo F07 e F51. O uso da argamassa do tipo F07 teve como objetivo analisar o seu comportamento quando utilizada no assentamento de alvenaria de blocos de concreto, apesar da mesma não ser indicada pelo fabricante para esta finalidade. As características de resistência e deformabilidade da argamassa do tipo F11 foram 
estudadas apenas através de ensaios de compressão uniaxial, utilizando corpos de prova cilíndricos com dimensões de $5 \mathrm{~cm} \times 10 \mathrm{~cm}$.

A preparação das argamassas $P$ e $Q$ foi realizada em uma argamassadeira mecânica de eixo horizontal, adicionando 7 litros de água para cada saco de argamassa de $40 \mathrm{~kg}$, até adquirir uma mistura homogênea, deixando em seguida o material descansar por 10 minutos antes de sua utilização, seguindo, assim, as recomendações do fabricante do produto. Como a argamassa foi utilizada num curto período de tempo, não foi necessária a realização do reamassamento do material. Dessa forma, garantiram-se as propriedades da argamassa sem afetar a sua trabalhabilidade.

A Norma Americana ASTM C 270 (1982) recomenda que a água utilizada no amassamento deve ser clara, potável e livre de substâncias que possam comprometer seu desempenho. Essa recomendação foi seguida, utilizando-se água potável da rede pública.

\subsubsection{Ensaio-Piloto 2}

Com a perda de alguns prismas no primeiro ensaio-piloto, conseqüência do destacamento da interface bloco-argamassa durante o transporte, e os resultados poucos satisfatórios obtidos na maioria dos ensaios dos prismas, devido a prováveis problemas de aderência entre o bloco e a argamassa industrializada, tornou-se necessário a execução de novos ensaios para a determinação dos traços das argamassas a serem utilizados nos ensaios finais das paredinhas. Para tanto, utilizou-se o estudo desenvolvido por FONTE (2000), no próprio laboratório de Estruturas da EESC-USP, durante o mesmo período do presente trabalho. Neste estudo, foram analisados alguns dos traços prescritos pela Norma Britânica BS 5628: Part 1 (1992). Dentre as argamassas analisadas, optou-se por escolher as de classe (ii) e (iii), cujos traços, em volume, são 1:0,5:4,5 (argamassa de média resistência) e 1:1:6 (argamassa de baixa resistência).

A análise das argamassas consistiu em determinar dois traços com módulos de elasticidade distintos, de modo a possibilitar analisar sua influência no comportamento das paredinhas.

A tabela 3.6 apresenta a denominação adotada para as argamassas e suas características são apresentadas na tabela 3.7. 
Tabela 3.6 - Denominação das argamassas de assentamento (EP2).

\begin{tabular}{|c|c|c|c|c||}
\hline Denominação & $\begin{array}{c}\text { Classificação } \\
\text { ASTM C-270 }\end{array}$ & $\begin{array}{c}\text { Classificação } \\
\text { BS-5628 }\end{array}$ & $\begin{array}{c}\text { Traço em } \\
\text { volume }\end{array}$ & $\begin{array}{c}\text { Traço em } \\
\text { massa }\end{array}$ \\
\hline A1 & Tipo S & Classe (ii) & $1: 0,5: 4,5$ & $1: 0,31: 5,80$ \\
\hline A2 & Tipo N & Classe (iii) & $1: 1: 6$ & $1: 0,61: 7,73$ \\
\hline
\end{tabular}

Tabela 3.7 - Características das argamassas de assentamento, FONTE (2000).

\begin{tabular}{|c|c|c|c|c|c||}
\hline \hline Traço & $\mathbf{a} / \mathbf{c}$ & IC(mm) & C.teórico $\left(\mathbf{k g} / \mathbf{m}^{\mathbf{3}}\right)$ & $\gamma_{\mathbf{a}}\left(\mathbf{k g} / \mathbf{m}^{\mathbf{3}}\right)$ & C. real $\left(\mathbf{k g} / \mathbf{m}^{\mathbf{3}}\right)$ \\
\hline A1 & 1,16 & 225 & 255 & 1983 & 240 \\
\hline A2 & 1,56 & 230 & 197 & 1980 & 182 \\
\hline \hline
\end{tabular}

onde:

a/c é a relação água/cimento;

IC é o índice de consistência, segundo a NBR 13276 (1995);

C. teórico corresponde ao consumo de cimento dado pela quantidade de massa de cimento por litro de argamassa, obtido através do traço da mesma;

C. real é o consumo de cimento dado pela quantidade de massa de cimento por litro de argamassa, obtido através das características da argamassa fresca;

$\gamma_{\mathrm{a}}$ é a massa específica da argamassa no estado fresco, segundo a NBR 13278 (1995).

\subsubsection{Capeamento}

Para os ensaios de blocos e prismas utilizou-se como material de capeamento placas utilizadas em forros de edificações, especificada como do tipo Forropacote da empresa Eucatex. A utilização deste tipo de capeamento é recomendada pela norma Britânica BS 5628 - part 1 (1978) e justificada pela dificuldade encontrada em realizar o capeamento com enxofre, comumente utilizado pelo laboratório onde foram realizados os ensaios, já que os corpos de prova possuíam um peso elevado, dificultando o seu transporte e manuseio.

Segundo informações do fabricante, estas placas são produzidas em fibra de madeira do tipo "soft" e possuem espessura de $12 \mathrm{~mm}$. Sendo constituída de um 
material bastante deformável, este tipo de capeamento permitiu, de modo eficiente, corrigir os efeitos das imperfeições do bloco e distribuir uniformemente o carregamento ao longo da área da seção atuante.

DRYSDALE et al. (1994) discute a utilização deste tipo de capeamento do tipo "soft", citando as vantagens de diminuição do tempo de preparo do corpo de prova para o ensaio, além de sugerir que sua utilização reduza os efeitos de confinamento da chapas da máquina de ensaio, apresentando resultados mais próximos dos que ocorrem na alvenaria.

Os corpos de prova cilíndricos de argamassa foram capeados com enxofre.

\subsection{Execução dos ensaios de caracterização mecânica}

\subsubsection{Blocos}

\section{Ensaios-Piloto 1 e Ensaios Finais}

A caracterização dos blocos, feita em termos de resistência média $\left(f_{b m}\right)$ e de resistência característica $\left(f_{b k}\right)$, seguiu as especificações da Norma Brasileira NBR 7186 (1994). Foram ensaiadas à compressão 6 amostras de cada classe de resistência. Para o ensaio utilizou-se a máquina de ensaio computadorizada da marca ELE, com capacidade de $2.000 \mathrm{kN}$. A velocidade para os ensaios-piloto 1 foi de $3,7 \mathrm{kN} / \mathrm{s}$, definida automaticamente pelo próprio equipamento. Nos ensaios finais utilizou-se a velocidade especificada pela NBR 7186 (1994), no valor de 2,73 kN/s $\left(0,5 \mathrm{~N} / \mathrm{cm}^{2} / \mathrm{s}\right)$. Foi utilizada uma placa de aço de espessura $2,4 \mathrm{~cm}$ entre o cilindro da prensa e o bloco, de modo a garantir a transferência uniforme do carregamento.

A determinação do módulo de elasticidade longitudinal dos blocos foi realizada simultaneamente com os ensaios de prismas. Para tanto, foram instalados transdutores de deslocamento com curso de $10 \mathrm{~mm}$ e base de $155 \mathrm{~mm}$ nos blocos centrais dos prismas (ver figura 3.3), repetindo esse posicionamento na face oposta do prisma. A opção por este tipo de medição pode ser explicada pela tentativa de eliminar a influência do efeito da restrição da base da prensa e do capeamento utilizado, já que ensaios anteriores realizados pelo laboratório, onde 
eram utilizadas unidades individuais, indicaram dificuldades na obtenção de resultados satisfatórios. Além disso, o posicionamento dos transdutores no prisma permitiu que o estudo das deformações do bloco fosse feito numa situação semelhante ao seu comportamento na alvenaria.

Durante o ensaio para a determinação do módulo de elasticidade longitudinal, utilizou-se a máquina universal de ensaios mecânicos, hidráulica, servo-controlada, com capacidade de $2.500 \mathrm{kN}$ (dinâmico), de altura útil de ensaio $4 \mathrm{~m}$, da marca INSTRON e o SYSTEM 5000 para a aquisição de dados dos instrumentos.

Apesar da Norma Brasileira NBR 8.522 (1984) indicar para a execução do ensaio de determinação do módulo de elasticidade o controle da velocidade de carregamento, optou-se pela utilização do controle de deslocamento, já que este último evita uma ruptura brusca do corpo de prova. Dessa forma, o controle de deslocamento possibilitou obter uma parte descendente da curva tensãodeformação, caracterizando o material de uma maneira completa.

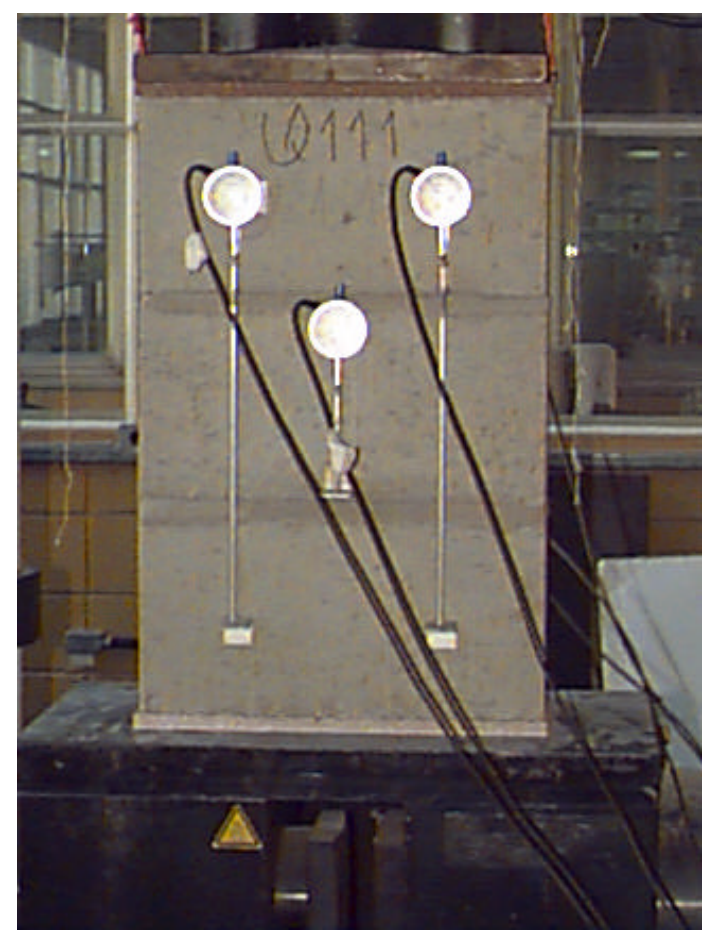

Figura 3.3 - Transdutor central para medições de deslocamento nos blocos e transdutores nas extremidades para medições de deslocamento nos prismas. 


\subsubsection{Argamassas}

\subsubsection{Ensaio-Piloto 1}

Para cada tipo de argamassa do primeiro ensaio-piloto, executaram-se em moldes metálicos 6 corpos de prova cilíndricos com dimensões de $5 \mathrm{~cm} \times 10 \mathrm{~cm}$ (diâmetro x altura), seguindo as recomendações da Norma Brasileira NBR 7215 (1982). Destes 6 corpos de prova, 3 foram ensaiados para obter a resistência à compressão uniaxial, conforme a NBR 13279 (1995), e 3 para a determinação do módulo de elasticidade longitudinal, conforme as especificações da NBR 8522 (1984) e da Norma Americana ASTM E111-82.

As medições de deformações dos corpos de prova de argamassa foram obtidas através do uso de dois tipos de instrumentação: extensômetros, com base de $10 \mathrm{~mm}$, e transdutores de deslocamentos, com curso de $10 \mathrm{~mm}$ (ver figura 3.4). Dois extensômetros com base de $10 \mathrm{~mm}$, colados longitudinalmente com massa plástica para a medição das deformações axiais, foram dispostos ao longo da geratriz do corpo de prova, igualmente espaçados no perímetro da seção transversal. A disposição dos dois transdutores foi a mesma dos extensômetros, sendo os encurtamentos tomados em relação aos pratos da prensa. Com o uso destes dois tipos de aparelhagem foi possível comparar os resultados obtidos pelos mesmos, de modo a escolher o mais adequado para a medição de deformações que iriam ser utilizados nos ensaios finais.

A velocidade do ensaio para a determinação da resistência à compressão foi de $0,5 \mathrm{kN} / \mathrm{s}$. Para o ensaio de determinação da curva tensão-deformação, adotou-se uma velocidade de $0,02 \mathrm{~mm} / \mathrm{s}$.

Tanto os ensaios de resistência à compressão quanto os de determinação do módulo de elasticidade longitudinal foram realizados na máquina de ensaios servo-hidráulica INSTRON e utilizou-se o SYSTEM 5000 para a aquisição de dados dos instrumentos. 


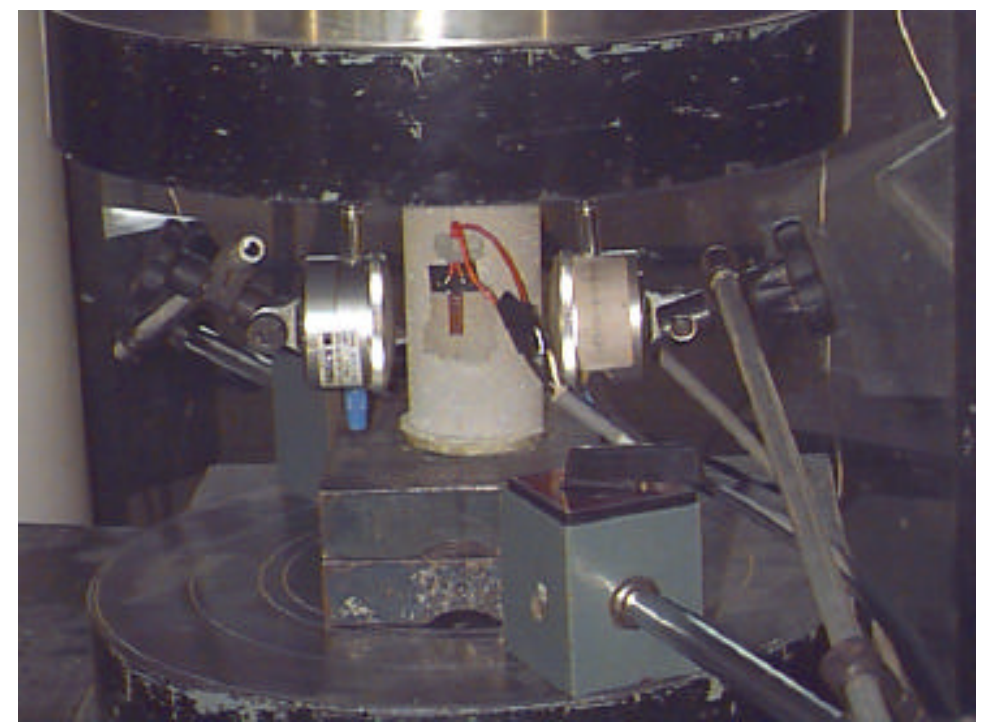

Figura 3.4 - Posicionamento da instrumentação nos corpos de prova de argamassa (EP1).

\subsubsection{Ensaio-Piloto 2}

Nos ensaios das argamassas do segundo ensaio-piloto foram empregados corpos de prova cilíndricos com dimensões de $15 \mathrm{~cm} \times 30 \mathrm{~cm}$. Este tipo de corpo de prova foi usado para que fosse possível utilizar o dispositivo mostrado na figura 3.5, para a fixação dos transdutores de deslocamentos, sem que os mesmos ficassem em contato com os pratos da prensa. Essa medida teve como objetivo reduzir o efeito do capeamento nos resultados das deformações.

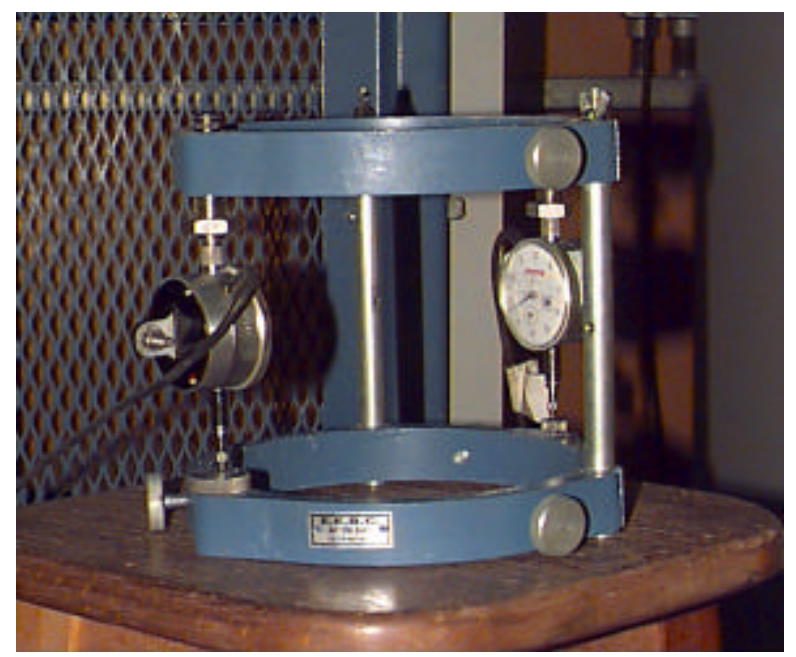

Figura 3.5 - Dispositivo de fixação dos transdutores para corpos de prova com dimensões de $15 \mathrm{~cm}$ x $30 \mathrm{~cm}$. 
A velocidade do ensaio foi de $0,05 \mathrm{~mm} / \mathrm{s}$ e as medidas de deformações foram feitas através do uso do sistema de aquisição de dados SYSTEM 4000.

\subsubsection{Ensaios Finais}

Para os ensaios finais foram moldados 4 corpos de prova cilíndricos de argamassa, com dimensões de $5 \mathrm{~cm} \times 10 \mathrm{~cm}$, para cada preparo de argamassa de moldagem de 3 paredinhas e 6 prismas.

Os corpos de prova foram ensaiados para determinar sua resistência à compressão, utilizando a máquina ELE com uma velocidade de 0,5 kN/s.

Não foi realizado nenhum ensaio de determinação do módulo de elasticidade para as argamassas utilizadas na moldagem das paredinhas, já que durante a realização do segundo ensaio-piloto essa determinação já havia sido feita utilizando os mesmos traços dos ensaios finais. Dessa forma, admitiu-se que a diferença entre aqueles ensaios e os ensaios finais não seria significativa a ponto de ser necessária a realização de novas determinações.

\subsubsection{Prismas}

\subsubsection{Ensaio-Piloto 1}

Os ensaios utilizando-se prismas foram escolhidos por serem de fácil execução e mais econômicos se comparados às paredes. Com isso, foi possível a moldagem de um número maior de corpos de prova, viabilizando o estudo da influência de um número maior de variáveis no comportamento da alvenaria. Além disso, a utilização de corpos de prova com dimensões reduzidas pode servir como um parâmetro de correlação entre os mesmos e a parede em dimensões reais.

Os prismas dos ensaios-piloto foram moldados utilizando três blocos assentados a prumo (ver figura 3.6), conforme especifica Norma Americana ASTM E 447 (1997). Dessa forma, foram obtidos corpos de prova com relação altura/espessura (h/t) no valor de 4,21, procurando assim, atender as 
especificações da norma citada acima, que estabelece valores de relações de altura/espessura para os corpos de prova entre 2 e 5 . Além disso, com o uso desta relação procurou-se minimizar os efeitos de confinamento das placas da prensa, representando de maneira coerente o modo de ruptura característico da alvenaria, conforme recomendações de DRYSDALE et al. (1994).

Outro fator importante que se deve levar em consideração para a realização do ensaio, é o fato da alvenaria não ser homogênea em todas as direções, o que pode levar a variações das deformações locais no decorrer da altura, comprimento e largura do corpo de prova. Dessa forma, torna-se necessário medir a deformação através de um comprimento suficiente para que se obtenha valores médios representativos do conjunto.

A execução dos prismas foi feita por um mesmo pedreiro e obedeceu as especificações da NBR 8.215 (1983).

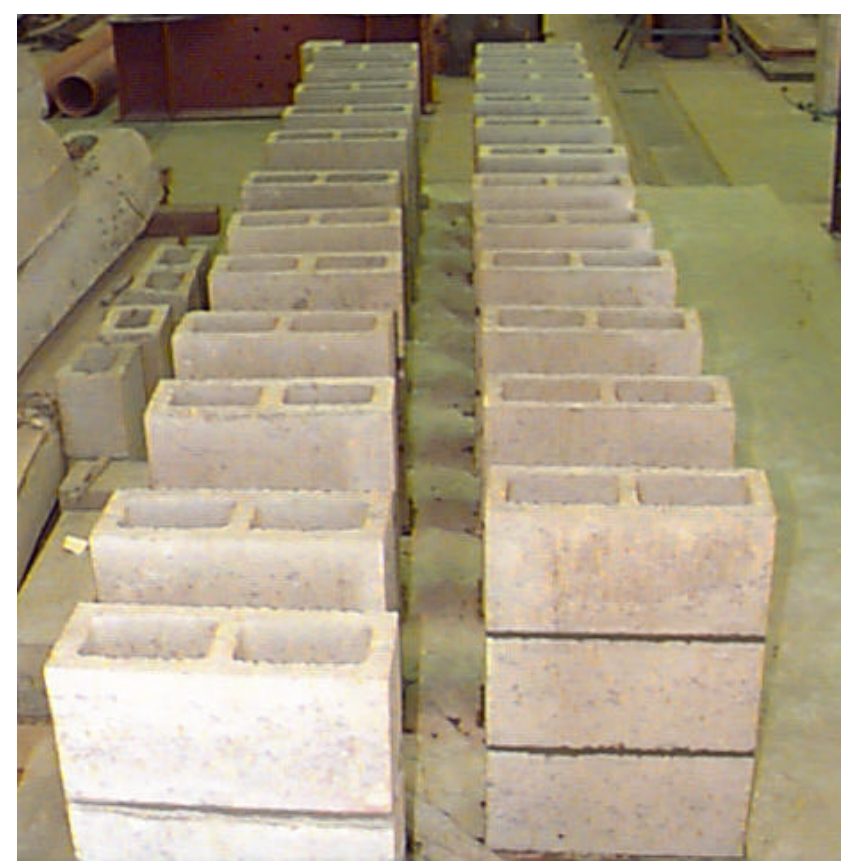

Figura 3.6 - Prismas de 3 blocos (EP1).

A moldagem dos prismas foi feita através de séries de 3 exemplares, sendo cada série diferenciada uma da outra pela variação de dois tipos de argamassa (mostrada na tabela 3.5), duas resistência de blocos (mostrada na tabela 3.2) e duas formas de assentamento. Dessa maneira, foram ensaiadas 8 séries de 3 prismas, totalizando 24 prismas. 
As formas de assentamento são o assentamento total e lateral dos blocos. 0 assentamento total consiste em preencher com argamassa toda a seção transversal do bloco (ver figura 3.7.a). Para o assentamento lateral o preenchimento é feito apenas nas faces longitudinais da seção transversal do bloco. (ver figura 3.7.b). A espessura das juntas de argamassa obedeceu o valor especificado pela NBR 8215 (1983) de $10 \pm 3 \mathrm{~mm}$.

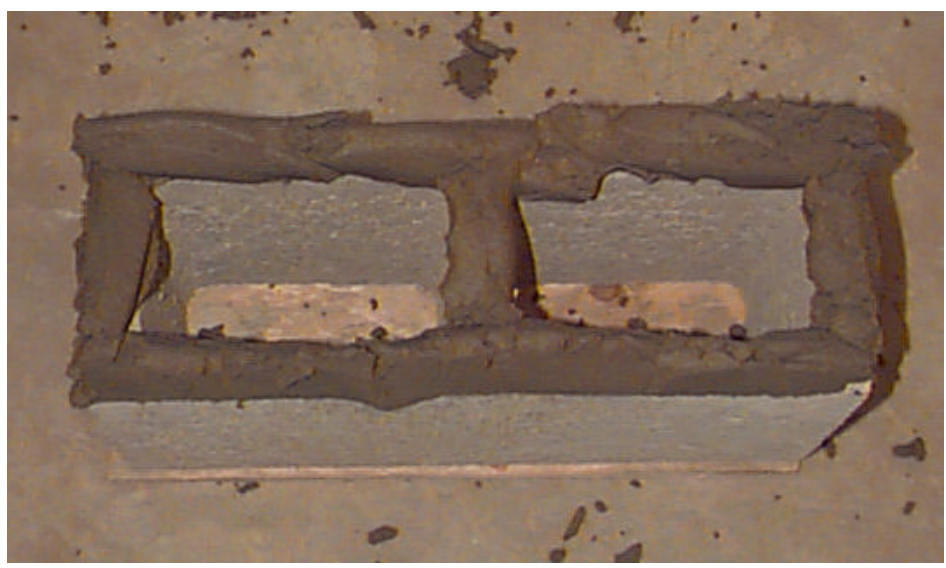

(a) Assentamento total

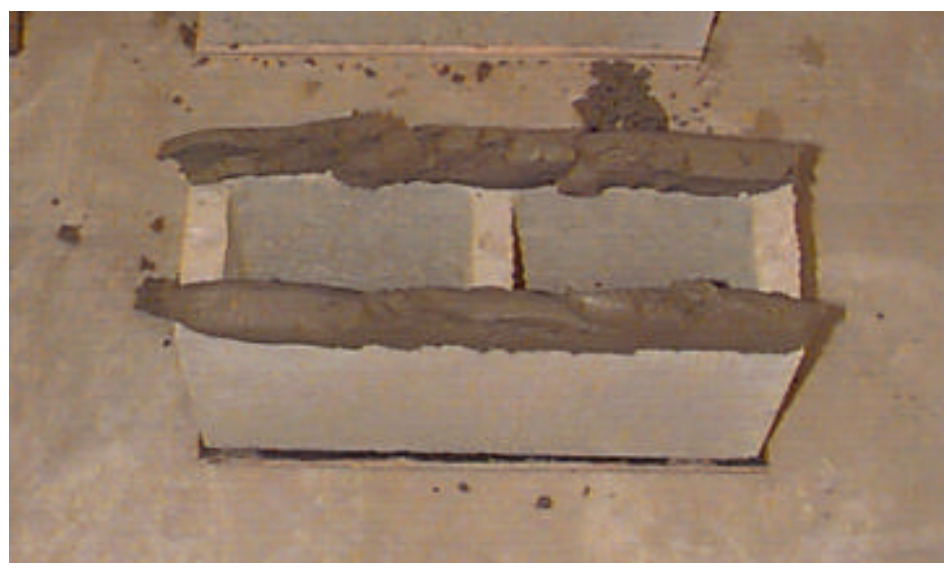

(b) Assentamento lateral

Figura 3.7 - (a) Prisma com assentamento total; (b) Prisma com assentamento lateral.

Para efeito de notação neste trabalho, a nomeação dos prismas, com finalidade de facilitar a identificação durante os ensaios, foi feita utilizando uma letra e três números. A letra indica o tipo de argamassa utilizada ( $P, Q$ ou $R)$. O primeiro número indica a classe de resistência do bloco utilizado (1 ou 2), o segundo a forma de assentamento da argamassa (1 ou 2) e o terceiro o número do exemplar da 
série (1, 2 ou 3). A tabela 3.8 apresenta um resumo das denominações feitas para os prismas.

As condições de temperatura e umidade durante a moldagem dos prismas são mostradas na tabela 3.9.

Tabela 3.8 - Denominação dos prismas (EP1).

\begin{tabular}{||c|c|c|c|c||}
\hline $\begin{array}{c}\text { Denominação } \\
\text { Do prisma }\end{array}$ & $\begin{array}{c}\text { Tipo de } \\
\text { Argamassa }\end{array}$ & $\begin{array}{c}\text { Resistência do } \\
\text { Bloco (MPa) }\end{array}$ & $\begin{array}{c}\text { Forma de } \\
\text { Assentamento }\end{array}$ & Exemplar \\
\hline P111 & F51 & 4,5 & Total & 1 \\
\hline P112 & F51 & 4,5 & Total & 2 \\
\hline P113 & F51 & 4,5 & Total & 3 \\
\hline P121 & F51 & 4,5 & Lateral & 1 \\
\hline P122 & F51 & 4,5 & Lateral & 2 \\
\hline P123 & F51 & 4,5 & Lateral & 3 \\
\hline P211 & F51 & 10 & Total & 1 \\
\hline P212 & F51 & 10 & Total & 2 \\
\hline P213 & F51 & 10 & Total & 3 \\
\hline P221 & F51 & 10 & Lateral & 1 \\
\hline P222 & F51 & 10 & Lateral & 2 \\
\hline P223 & F51 & 10 & Lateral & 3 \\
\hline Q111 & F07 & 4,5 & Total & 1 \\
\hline Q112 & F07 & 4,5 & Total & 2 \\
\hline Q113 & F07 & 4,5 & Total & 3 \\
\hline Q121 & F07 & 4,5 & Lateral & 1 \\
\hline Q122 & F07 & 4,5 & Lateral & 2 \\
\hline Q123 & F07 & 4,5 & Lateral & 3 \\
\hline Q211 & F07 & 10 & Total & 1 \\
\hline Q212 & F07 & 10 & Total & 2 \\
\hline Q213 & F07 & 10 & Total & 3 \\
\hline Q221 & F07 & 10 & Lateral & 1 \\
\hline Q222 & F07 & 10 & Lateral & 2 \\
\hline Q223 & F07 & 10 & Lateral & 3 \\
\hline & & & & \\
\hline & & 10 & & 1 \\
\hline
\end{tabular}

Os ensaios foram realizados no período entre 28 e 33 dias da moldagem dos prismas. 
Para a determinação do módulo de elasticidade longitudinal foram realizadas etapas de escorvamento, com o objetivo de acomodar e diminuir prováveis excentricidades do corpo de prova. Em seguida os corpos de prova foram submetidos a carregamentos até alcançarem a ruptura, obtendo-se assim também a resistência à compressão dos prismas. A velocidade de ensaio foi de $0,05 \mathrm{~mm} / \mathrm{s} \mathrm{e}$ os registros dos deslocamentos foram feitos a cada 1,5 segundos.

A aplicação do incremento de carga para acomodação dos corpos de prova foi feita em duas etapas, com valor igual a $10 \%$ da carga de ruptura prevista para 0 prisma. Assim, os corpos de prova foram submetidos à carga de escorvamento $e$ descarregados totalmente, sendo esta operação repetida novamente. A carga de ruptura foi prevista teoricamente, já que não foi possível realizar ensaios preliminares de determinação da resistência dos prismas.

Nos ensaios de prismas também se utilizou uma placa de aço entre o cilindro da prensa e o bloco, de mesma espessura daquela utilizada nos ensaios dos blocos, que além de garantir a transferência uniforme do carregamento, procurou diminuir os efeitos de flexão do prisma.

A figura 3.8 apresenta o esquema de posicionamento dos transdutores nos prismas para medições de deslocamentos no prisma e no bloco.

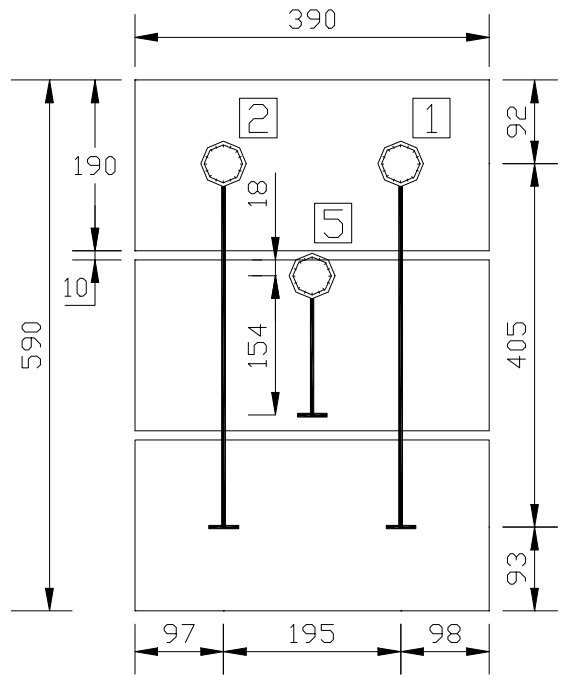

(a)

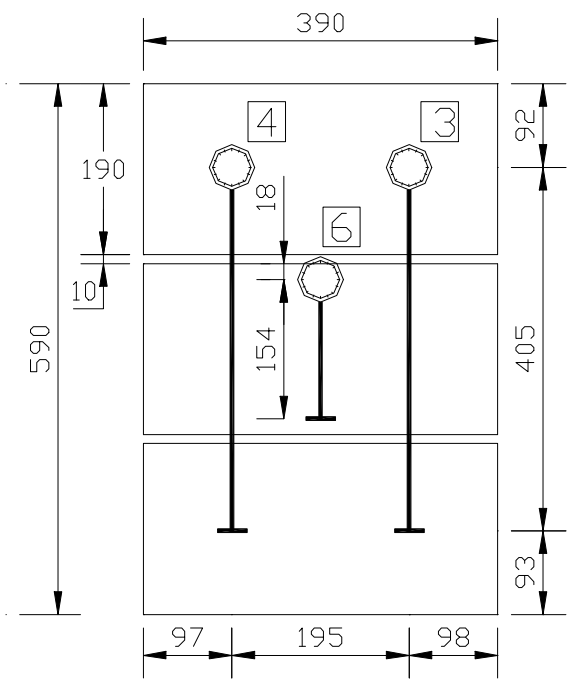

(b)

Figura 3.8 - (a) Vista frontal (b) Vista oposta. Transdutores 1,2,3 e 4: medições de deslocamentos no prisma; Transdutores 5 e 6 - medições de deslocamentos nos blocos (EP1) (medidas em mm). 
Tabela 3.9 - Valores médios de umidade e temperatura durante a moldagem dos prismas (EP1).

\begin{tabular}{|c|c|c||}
\hline Tipo de argamassa & Temperatura $\left({ }^{\circ} \mathbf{C}\right)$ & Umidade (\%) \\
\hline P & 20 & 50 \\
\hline Q & 29 & 45 \\
\hline R & 32 & 52 \\
\hline
\end{tabular}

\subsubsection{Ensaios Finais}

Nos ensaios finais foram moldados 2 prismas com três blocos assentados a prumo para cada paredinha. A execução dos prismas obedeceu as especificações da NBR 8.215 (1983). Através destes prismas pretendeu-se obter correlações de resistência entre os mesmos e as paredinhas.

A determinação do módulo de elasticidade dos blocos foi feita utilizando-se três prismas para cada classe de resistência de bloco. Os demais prismas foram ensaiados apenas para obter sua resistência à compressão.

A denominação dos prismas durante os ensaios foi feita de modo que fosse possível diferenciar as séries estudadas segundo a classe de resistência dos blocos, traço da argamassa e direção de aplicação do carregamento. Desta forma, as tabelas 3.10 e 3.11 apresentam a denominação dos prismas correspondentes às paredinhas ensaiadas com carregamento nas direções $\mathrm{Y}$ e $\mathrm{X}$, ou seja, carregadas nas direções perpendicular e normal à face de assentamento usual dos blocos, respectivamente. Porém, cabe ressaltar que os prismas correspondentes às paredinhas ensaiadas na direção $X$ foram moldados de maneira usual e ensaiados à compressão normal ao plano da face de assentamento dos prismas. Assim, os mesmos não foram moldados e ensaiados paralelamente ao plano da face de assentamento usual, como realizado por KHALAF (1997) e mostrado na figura 2.11.

Como proposta para futuros trabalhos, sugere-se a moldagem para estudo de resistência e deformabilidade em prismas ensaiados na direção $\mathrm{X}$, conforme propõe KHALAF (1997) (ver item 2.3.4). Porém, cabe ressaltar que a realização destes ensaios deve ser feita simultaneamente aos ensaios em paredinhas ou 
paredes, de modo a obter parâmetros de comparação entre os diferentes corpos de prova.

Tabela 3.10 - Denominação dos prismas para as paredinhas ensaiadas na direção $Y(E F)$.

\begin{tabular}{|c|c|c|c|c|}
\hline $\begin{array}{c}\text { Denominação } \\
\text { do prisma }\end{array}$ & $\begin{array}{l}\text { Resistência do } \\
\text { Bloco (MPa) } \\
\end{array}$ & $\begin{array}{c}\text { Traço da } \\
\text { Argamassa }\end{array}$ & $\begin{array}{c}\text { Direção de } \\
\text { aplicação do } \\
\text { carregamento }\end{array}$ & Exemplar \\
\hline PRB1A1EY1 & 4,5 & $1: 0,5: 4,5$ & $Y$ & 1 \\
\hline PRB1A1EY2 & 4,5 & $1: 0,5: 4,5$ & Y & 2 \\
\hline PRB1A1EY3 & 4,5 & $1: 0,5: 4,5$ & Y & 1 \\
\hline PRB1A1EY4 & 4,5 & $1: 0,5: 4,5$ & $Y$ & 2 \\
\hline PRB1A1EY5 & 4,5 & $1: 0,5: 4,5$ & Y & 1 \\
\hline PRB1A1EY6 & 4,5 & $1: 0,5: 4,5$ & Y & 2 \\
\hline PRB1A2EY1 & 4,5 & $1: 1: 6$ & Y & 1 \\
\hline PRB1A2EY2 & 4,5 & $1: 1: 6$ & Y & 2 \\
\hline PRB1A2EY3 & 4,5 & $1: 1: 6$ & Y & 1 \\
\hline PRB1A2EY4 & 4,5 & $1: 1: 6$ & Y & 2 \\
\hline PRB1A2EY5 & 4,5 & $1: 1: 6$ & $Y$ & 1 \\
\hline PRB1A2EY6 & 4,5 & $1: 1: 6$ & Y & 2 \\
\hline PRB2A1EY1 & 12 & $1: 0,5: 4,5$ & $Y$ & 1 \\
\hline PRB2A1EY2 & 12 & $1: 0,5: 4,5$ & Y & 2 \\
\hline PRB2A1EY3 & 12 & $1: 0,5: 4,5$ & $Y$ & 1 \\
\hline PRB2A1EY4 & 12 & $1: 0,5: 4,5$ & Y & 2 \\
\hline PRB2A1EY5 & 12 & $1: 0,5: 4,5$ & $Y$ & 1 \\
\hline PRB2A1EY6 & 12 & $1: 0,5: 4,5$ & Y & 2 \\
\hline PRB2A2EY1 & 12 & $1: 1: 6$ & $Y$ & 1 \\
\hline PRB2A2EY2 & 12 & $1: 1: 6$ & $\mathrm{Y}$ & 2 \\
\hline PRB2A2EY3 & 12 & $1: 1: 6$ & $\mathrm{Y}$ & 1 \\
\hline PRB2A2EY4 & 12 & $1: 1: 6$ & $\mathrm{Y}$ & 2 \\
\hline PRB2A2EY5 & 12 & $1: 1: 6$ & Y & 1 \\
\hline PRB2A2EY6 & 12 & $1: 1: 6$ & $Y$ & 2 \\
\hline
\end{tabular}


Tabela 3.11 - Denominação dos prismas para as paredinhas ensaiadas na direção X (EF).

\begin{tabular}{|c|c|c|c|c|}
\hline $\begin{array}{c}\text { Denominação } \\
\text { do prisma } \\
\end{array}$ & $\begin{array}{l}\text { Resistência do } \\
\text { Bloco (MPa) } \\
\end{array}$ & $\begin{array}{c}\text { Traço da } \\
\text { Argamassa }\end{array}$ & $\begin{array}{c}\text { Direção de } \\
\text { aplicação do } \\
\text { carregamento }\end{array}$ & Exemplar \\
\hline PRB1A1EX1 & 4,5 & $1: 0,5: 4,5$ & $\mathrm{X}$ & 1 \\
\hline PRB1A1EX2 & 4,5 & $1: 0,5: 4,5$ & $x$ & 2 \\
\hline PRB1A1EX3 & 4,5 & $1: 0,5: 4,5$ & $x$ & 1 \\
\hline PRB1A1EX4 & 4,5 & $1: 0,5: 4,5$ & $x$ & 2 \\
\hline PRB1A1EX5 & 4,5 & $1: 0,5: 4,5$ & $x$ & 1 \\
\hline PRB1A1EX6 & 4,5 & $1: 0,5: 4,5$ & $X$ & 2 \\
\hline PRB1A2EX1 & 4,5 & $1: 1: 6$ & $x$ & 1 \\
\hline PRB1A2EX2 & 4,5 & $1: 1: 6$ & $x$ & 2 \\
\hline PRB1A2EX3 & 4,5 & $1: 1: 6$ & $x$ & 1 \\
\hline PRB1A2EX4 & 4,5 & $1: 1: 6$ & $x$ & 2 \\
\hline PRB1A2EX5 & 4,5 & $1: 1: 6$ & $x$ & 1 \\
\hline PRB1A2EX6 & 4,5 & $1: 1: 6$ & $x$ & 2 \\
\hline PRB2A1EX1 & 12 & $1: 0,5: 4,5$ & $x$ & 1 \\
\hline PRB2A1EX2 & 12 & $1: 0,5: 4,5$ & $x$ & 2 \\
\hline PRB2A1EX3 & 12 & $1: 0,5: 4,5$ & $x$ & 1 \\
\hline PRB2A1EX4 & 12 & $1: 0,5: 4,5$ & $x$ & 2 \\
\hline PRB2A1EX5 & 12 & $1: 0,5: 4,5$ & $x$ & 1 \\
\hline PRB2A1EX6 & 12 & $1: 0,5: 4,5$ & $x$ & 2 \\
\hline PRB2A2EX1 & 12 & $1: 1: 6$ & $\mathrm{X}$ & 1 \\
\hline PRB2A2EX2 & 12 & $1: 1: 6$ & $x$ & 2 \\
\hline PRB2A2EX3 & 12 & $1: 1: 6$ & $x$ & 1 \\
\hline PRB2A2EX4 & 12 & $1: 1: 6$ & $x$ & 2 \\
\hline PRB2A2EX5 & 12 & $1: 1: 6$ & $x$ & 1 \\
\hline PRB2A2EX6 & 12 & $1: 1: 6$ & $\mathrm{X}$ & 2 \\
\hline
\end{tabular}

Para a realização dos ensaios de determinação de resistência à compressão e módulo de elasticidade dos prismas seguiram-se as mesmas especificações de moldagem, cura e ensaio das normas citadas para os ensaiospiloto 1. 
Os ensaios foram realizados no período entre 28 e 32 dias da moldagem dos prismas. A velocidade de ensaio foi de $0,02 \mathrm{~mm} / \mathrm{s}$ e os registros dos deslocamentos foram feitos a cada 1,0 segundo.

A instrumentação dos prismas foi feita conforme indica a figura 3.9. Os transdutores 1, 2, 3 e 4 foram utilizados para medir os deslocamentos relativos nos prismas e os transdutores 5 e 6 para medir os deslocamentos nos blocos.

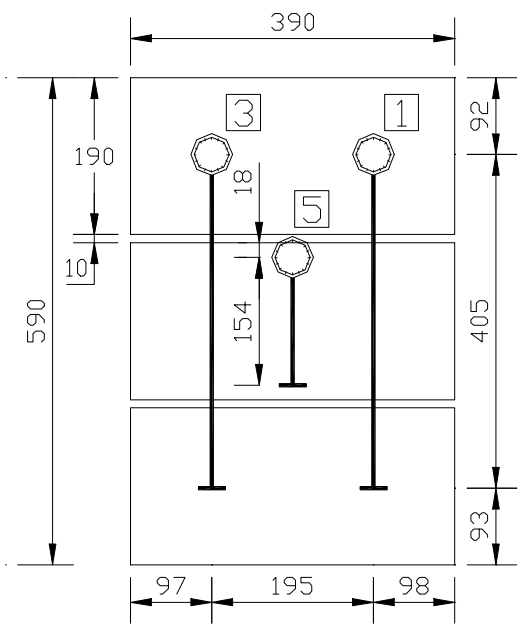

(a)

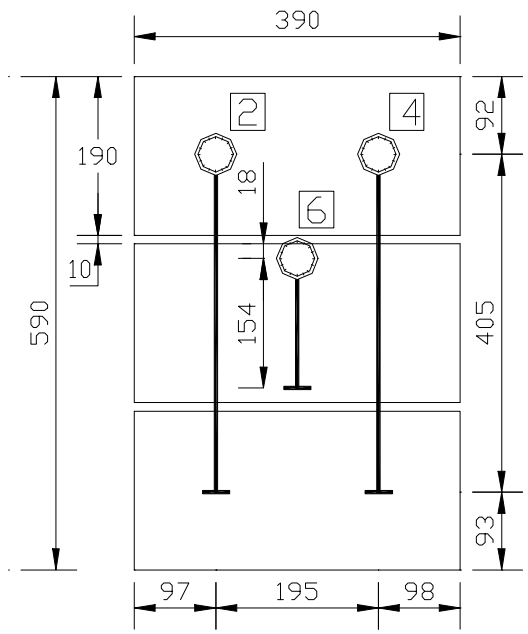

(b)

Figura 3.9 - (a) Vista frontal (b) Vista oposta. Transdutores 1, 2, 3 e 4: medições de deslocamentos no prisma; Transdutores 5 e 6 - medições de deslocamentos nos blocos (EF) (medidas em mm).

As condições de temperatura e umidade durante a moldagem dos prismas são mostradas na tabela 3.12.

Tabela 3.12 - Valores médios de umidade e temperatura durante a moldagem dos prismas (EF).

\begin{tabular}{|c|c|c||}
\hline Tipo de argamassa & Temperatura ( $\left.{ }^{\circ} \mathbf{C}\right)$ & Umidade (\%) \\
\hline A1 & 27 & 56 \\
\hline A2 & 28 & 51 \\
\hline
\end{tabular}




\subsubsection{Paredinhas}

Conforme citado, a escolha do uso de paredinhas nos ensaios para determinação da resistência e do módulo de elasticidade baseou-se na facilidade em relação ao custo e tempo de execução, pois possibilitou moldar um número grande de corpos de prova sem que houvesse a necessidade de disponibilizar grande espaço e tempo de ensaio no laboratório. Além disso, acredita-se que o uso deste tipo de corpo de prova apresente uma razoável correlação com ensaios de parede em escala natural e seja adaptável ao ensaio em canteiro.

Assim, optou-se por realizar ensaios em paredinhas de blocos de concreto com dimensões $80 \mathrm{~cm} \times 80 \mathrm{~cm}$. Para tanto, foram moldadas 24 paredinhas, onde variou-se a resistência do bloco, tipo de argamassa e direção de aplicação de carregamento, estando cada variação dividida em séries compostas por três exemplares, seguindo por analogia as recomendações da NBR 8522 (1984) para a determinação do módulo de elasticidade.

Dessa forma, os parâmetros analisados podem ser resumidos em:

- 2 resistências de bloco;

- 2 resistências de argamassa;

- 2 direções de aplicação de carregamento.

Totalizando 8 séries ensaiadas.

Conforme dito anteriormente, com o objetivo de realizar um controle de resistência, para cada paredinha foram moldados dois prismas de três blocos. E, para cada mistura de argamassa, calculada para ser suficiente na execução de três paredinhas e 6 prismas, foram moldados 4 corpos de prova.

A denominação utilizada para diferenciar as paredinhas é apresentada na tabela 3.13.

Os esquemas de instrumentação utilizados durante os ensaios para a paredinha ensaiada nas direções $x$ e y são mostrados na figura 3.10 e 3.11, respectivamente. 
Tabela 3.13 - Denominação das paredinhas (EF).

\begin{tabular}{|c|c|c|c|c|}
\hline Denominação & Resistência do & Traço da & $\begin{array}{c}\text { Direção de } \\
\text { aplicação do }\end{array}$ & Exemplar \\
\hline da paredinha & Bloco (MPa) & Argamassa & carregamento & \\
\hline PAB1A1EY1 & 4,5 & $1: 0,5: 4,5$ & $Y$ & 1 \\
\hline PAB1A1EY2 & 4,5 & $1: 0,5: 4,5$ & $Y$ & 2 \\
\hline PAB1A1EY3 & 4,5 & $1: 0,5: 4,5$ & Y & 3 \\
\hline PAB1A1EX1 & 4,5 & $1: 0,5: 4,5$ & $x$ & 1 \\
\hline PAB1A1EX2 & 4,5 & $1: 0,5: 4,5$ & $x$ & 2 \\
\hline PAB1A1EX3 & 4,5 & $1: 0,5: 4,5$ & $x$ & 3 \\
\hline PAB1A2EY1 & 4,5 & $1: 1: 6$ & Y & 1 \\
\hline PAB1A2EY2 & 4,5 & $1: 1: 6$ & $\mathrm{Y}$ & 2 \\
\hline PAB1A2EY3 & 4,5 & $1: 1: 6$ & $Y$ & 3 \\
\hline PAB1A2EX1 & 4,5 & $1: 1: 6$ & $x$ & 1 \\
\hline PAB1A2EX2 & 4,5 & $1: 1: 6$ & $x$ & 2 \\
\hline PAB1A2EX3 & 4,5 & $1: 1: 6$ & $x$ & 3 \\
\hline PAB2A1EY1 & 12 & $1: 0,5: 4,5$ & Y & 1 \\
\hline PAB2A1EY2 & 12 & $1: 0,5: 4,5$ & $\mathrm{Y}$ & 2 \\
\hline PAB2A1EY3 & 12 & $1: 0,5: 4,5$ & Y & 3 \\
\hline PAB2A1EX1 & 12 & $1: 0,5: 4,5$ & $x$ & 1 \\
\hline PAB2A1EX2 & 12 & $1: 0,5: 4,5$ & $x$ & 2 \\
\hline PAB2A1EX3 & 12 & $1: 0,5: 4,5$ & $x$ & 3 \\
\hline PAB2A2EY1 & 12 & $1: 1: 6$ & $\mathrm{Y}$ & 1 \\
\hline PAB2A2EY2 & 12 & $1: 1: 6$ & $\mathrm{Y}$ & 2 \\
\hline PAB2A2EY3 & 12 & $1: 1: 6$ & $Y$ & 3 \\
\hline PAB2A2EX1 & 12 & $1: 1: 6$ & $x$ & 1 \\
\hline PAB2A2EX2 & 12 & $1: 1: 6$ & $x$ & 2 \\
\hline PAB2A2EX3 & 12 & $1: 1: 6$ & $x$ & 3 \\
\hline
\end{tabular}

Os extensômetros 1, 2, 3 e 4 tiveram como objetivo medir os deslocamentos verticais dos blocos, de modo a possibilitar a obtenção do módulo de elasticidade longitudinal das paredinhas. Os extensômetros 5 e 6 foram utilizados para medir os deslocamentos horizontais nos blocos na região central da paredinha. Com isso, tinha-se como objetivo calcular o coeficiente de Poisson local nas paredes. 


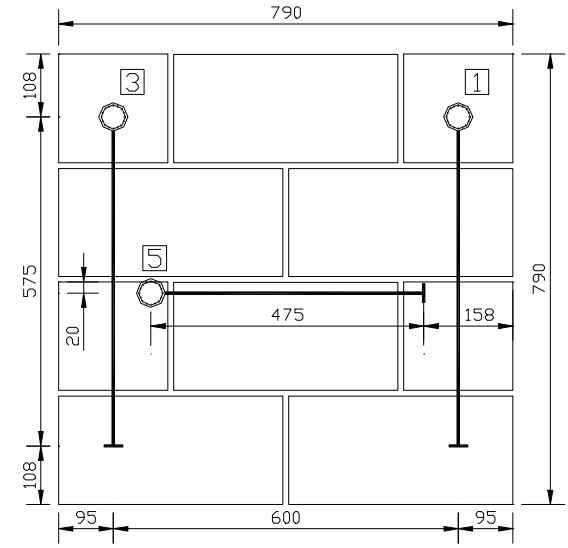

(a)

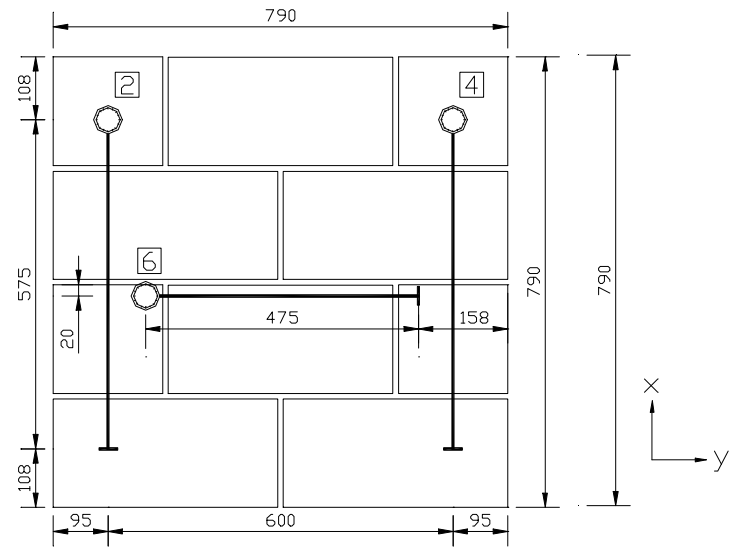

(b)

Figura 3.10 - (a) Vista frontal (b) Vista oposta. Transdutores 1,2,3 e 4 medições de deslocamentos verticais na parede; Transdutores 5 e 6 medições de deslocamentos horizontais na parede (EF) (medidas em mm).

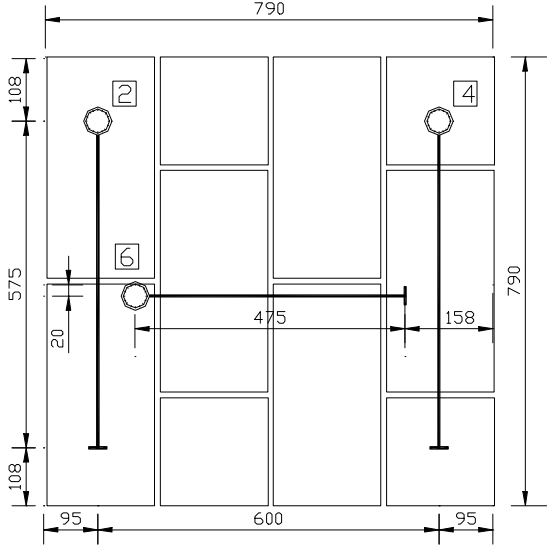

(a)

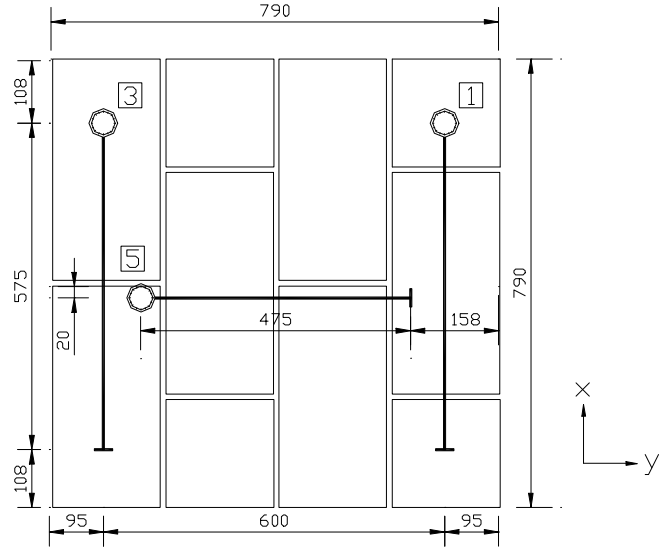

(b)

Figura 3.11 - (a) Vista frontal (b) Vista oposta. Transdutores 1,2,3 e 4: medições de deslocamentos verticais na parede; Transdutores 5 e 6 medições de deslocamentos horizontais na parede (EF) (medidas em mm).

Para o transporte das paredinhas até a máquina de ensaio foi necessário travar as mesmas para evitar a ruptura da aderência bloco/argamassa durante o manuseio. Para tanto, utilizaram-se fusos rosqueáveis de aço e duas chapas de madeira dispostas nas extremidades inferior e superior das paredinhas. A base de madeira foi feita com dimensões suficientes para permitir o encaixe da paleteira. 
As paredes que foram ensaiadas na direção paralela ao plano usual de assentamento dos blocos (direção X) não foram moldadas nesta posição. Com o uso deste método de construção, permitiu-se que as paredinhas fossem ensaiadas na condição real, ou seja, com as juntas horizontais preenchidas completamente. Assim, diminuiu-se a probabilidade destas juntas apresentarem vazios que pudessem comprometer os ensaios, já que, em estudos citados por KHALAF (1997), obtiveram-se reduções de resistência à compressão de até 35\% em prismas moldados horizontalmente quando comparados aos moldados verticalmente.

Com a opção por este tipo de moldagem, tornou-se necessário girar a parede em $90^{\circ}$ para a realização dos ensaios na direção X. Esta rotação foi feita com auxílio de uma ponte rolante que suspendeu a parede travada e, com o auxílio de dois funcionários do laboratório, as paredinhas foram apoiadas em bases que permitiram o transporte das mesmas até a posição de ensaio, através do uso de paleteira (ver figura 3.12).

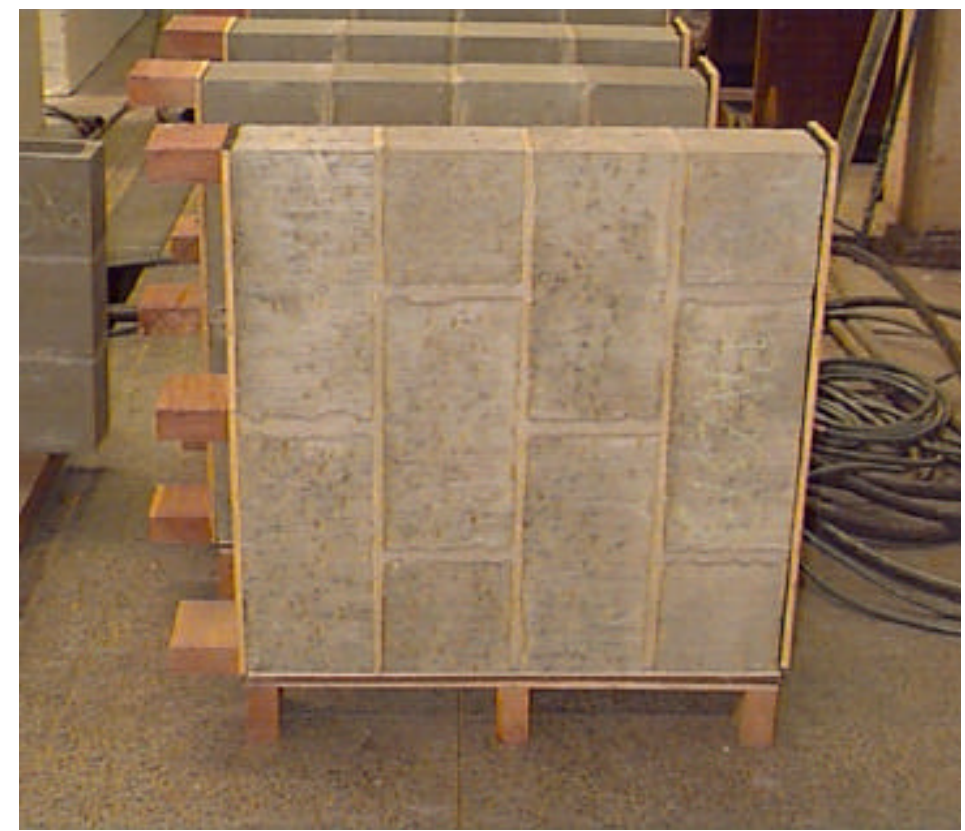

Figura 3.12 - Transporte de paredinha para ensaio na direção X.

No ensaio das paredinhas foi verificado primeiramente o prumo. Procurou-se aplicar o carregamento sem excentricidade e garantir a distribuição uniforme do mesmo através do uso de um perfil de aço no topo da parede. A figura 3.13 apresenta o posicionamento da paredinha na máquina de ensaio. 


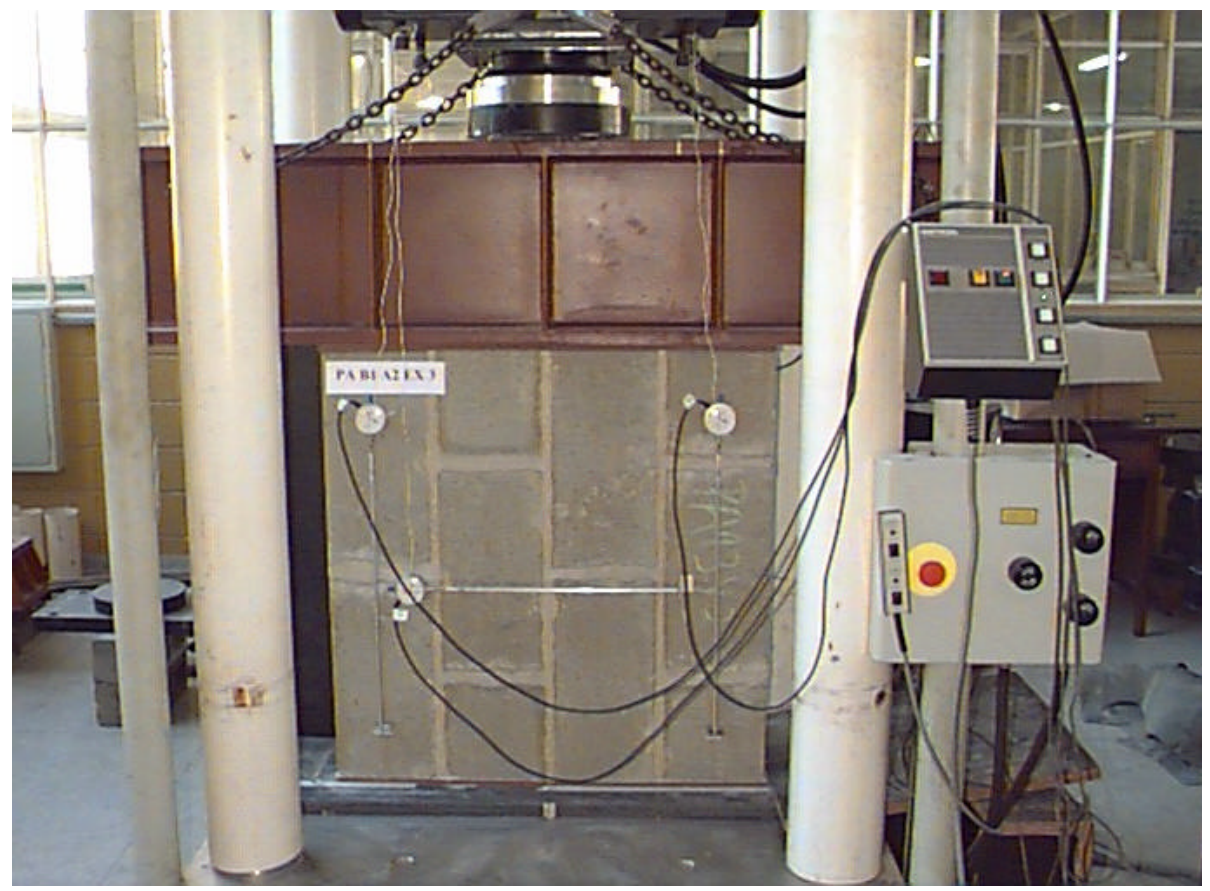

Figura 3.13 - Posicionamento da paredinha ensaiada na direção X na máquina de ensaio.

A realização dos ensaios das paredinhas seguiu basicamente os mesmos procedimentos utilizados durante os ensaios de determinação do módulo de elasticidade longitudinal dos prismas. Assim, foram executadas duas etapas de escorvamento, com valores iguais a $10 \%$ da carga de ruptura prevista, sendo esta prevista teoricamente. Em seguida, os corpos de prova foram submetidos a carregamentos até alcançarem a ruptura.

A velocidade adotada para o ensaio das paredinhas foi de $0,02 \mathrm{~mm} / \mathrm{s}$ e os registros de deslocamentos feitos a cada 1,0 segundo. 


\section{ANÁLISE DOS RESULTADOS}

\subsection{Introdução}

Neste capítulo são apresentados e discutidos os resultados obtidos através do programa experimental desenvolvido no presente trabalho. Dessa forma, procuraram-se analisar as características físicas e mecânicas dos corpos de prova utilizados durante a fase de ensaios-piloto e ensaios finais.

Esses dados possibilitaram realizar algumas comparações entre as diversas amostras em estudo, no que diz respeito às resistências àcompressão e ao módulo de elasticidade dos materiais utilizados. Além disso, os ensaios também tiveram como objetivo analisar a influência de cada material na resistência àcompressão e na deformabilidade da alvenaria de blocos de concreto.

\subsection{Blocos}

\subsubsection{Ensaios-Piloto 1}

No que diz respeito à caracterização física, ambos os blocos estudados apresentaram dimensões reais de 14 x 19 × $39 \mathrm{~cm}$ (largura x altura x comprimento), 
resultando numa área bruta de $546 \mathrm{~cm}^{2}$. Como já dito anteriormente, a área líquida calculada foi igual a $55 \%$ da área bruta, ou seja, igual a $300 \mathrm{~cm}^{2}$.

Os valores das resistências médias à compressão são apresentados na tabela 4.1 e os valores característicos estimados na tabela 4.2.

Tabela 4.1 - Valores médios de resistência à compressão dos blocos (EP1).

\begin{tabular}{|c|c|c|c|c|c|c|c|c|}
\hline \multirow{2}{*}{$\begin{array}{c}\text { Tipo } \\
\text { de } \\
\text { bloco } \\
\end{array}$} & \multirow{2}{*}{$\begin{array}{l}\text { Classe de } \\
\text { resistência } \\
(\mathrm{MPa})\end{array}$} & \multirow{2}{*}{$\begin{array}{c}\text { Idade dos } \\
\text { blocos } \\
\text { (dias) } \\
\end{array}$} & \multicolumn{3}{|c|}{$\begin{array}{l}\text { Área bruta } \\
\left(546 \mathrm{~cm}^{2}\right)\end{array}$} & \multicolumn{3}{|c|}{$\begin{array}{c}\text { Área líquida } \\
\left(300 \mathrm{~cm}^{2}\right)\end{array}$} \\
\hline & & & $\mathrm{f}_{\mathrm{bm}}(\mathrm{MPa})$ & $\mathrm{S}_{\mathrm{d}}(\mathrm{MPa})$ & CV (\%) & $\mathrm{f}_{\mathrm{bm}}(\mathrm{Mpa})$ & $\mathrm{S}_{\mathrm{d}}(\mathrm{MPa})$ & CV (\%) \\
\hline 1 & 4,5 & 114 & 9,43 & 0,86 & 9,12 & 17,15 & 1,56 & 9,10 \\
\hline 2 & 10,0 & 206 & 22,55 & 1,01 & 4,48 & 41,00 & 1,84 & 4,49 \\
\hline
\end{tabular}

Tabela 4.2 - Valores característicos de resistência à compressão dos blocos (EP1).

\begin{tabular}{||c|c|c|c|c|c|c|c||}
\hline \hline \multirow{2}{*}{$\begin{array}{c}\text { Tipo de } \\
\text { Bloco }\end{array}$} & \multirow{2}{*}{$\begin{array}{c}\text { Classe de } \\
\text { resistência (MPa) }\end{array}$} & \multicolumn{3}{|c|}{ Área bruta $\left(546 \mathrm{~cm}^{2}\right)$} & \multicolumn{3}{c||}{ Área líquida $\left(300 \mathrm{~cm}^{2}\right)$} \\
\cline { 3 - 8 } & $\mathrm{f}_{\mathrm{bk}, \text { est }}(\mathrm{MPa})$ & $\mathrm{S}_{\mathrm{d}}(\mathrm{MPa})$ & $\mathrm{CV}(\%)$ & $\mathrm{f}_{\mathrm{bk}, \text { est }}(\mathrm{MPa})$ & $\mathrm{S}_{\mathrm{d}}(\mathrm{MPa})$ & $\mathrm{CV}(\%)$ \\
\hline 1 & 4,5 & 8,37 & 0,86 & 10,27 & 15,22 & 1,56 & 10,25 \\
\hline 2 & 10,0 & 20,27 & 1,01 & 4,98 & 36,85 & 1,84 & 4,99 \\
\hline
\end{tabular}

A tabela 4.3 apresenta os valores de resistência à compressão dos lotes utilizados nos ensaios, fornecido pela empresa fabricante do bloco. Os resultados correspondem àidade de 7 dias.

Tabela 4.3 - Valores de resistência à compressão dos blocos (EP1).

\begin{tabular}{||c|c|c|c||}
\hline \multirow{2}{*}{$\begin{array}{c}\text { Tipo de } \\
\text { bloco }\end{array}$} & \multirow{2}{*}{$\begin{array}{c}\text { Classe de } \\
\text { resistência }(\mathrm{MPa})\end{array}$} & \multicolumn{2}{|c|}{ Resistência média aos 7 dias } \\
\cline { 3 - 4 } $\mathrm{f}_{\mathrm{bm}}{ }^{*}(\mathrm{Mpa})$ & $\mathrm{f}_{\mathrm{bk} . \text { est }}{ }^{*}(\mathrm{Mpa})$ \\
\hline 1 & 4,5 & 5,42 & 4,6 \\
\hline 2 & 10,0 & 12,07 & 10,3 \\
\hline
\end{tabular}

${ }^{*}$ Resistência do bloco na área bruta.

A resistência à compressão média dos blocos foi cerca de $10 \%$ maior do que sua resistência característica. Além disso, pode-se perceber que os valores de resistência média dos blocos excederam em mais de $100 \%$ a resistência nominal dos mesmos. 
Mesmo os valores sendo bem maiores que o esperado, os blocos foram utilizados pelo fato de que:

- O de menor resistência à compressão apresentou valor entre os limites esperados, ou seja, entre 4,5 MPa e $10 \mathrm{MPa}$;

- A razão das resistências àcompressão é parecida com a prevista:

Bloco $1-\frac{10}{4,5}=2,2$

Bloco $2-\frac{20,3}{8,4}=2,4$.

A determinação do módulo de elasticidade dos blocos foi feita a partir do gráfico tensão-deformação, utilizando-se a equação de uma parábola ajustada à curva obtida experimentalmente, com os valores médios entre os dois transdutores indutivos de deslocamento. Cabe ressaltar que esta curva foi determinada descartando-se o trecho de acomodação do corpo de prova e os pontos em que se percebeu grande distanciamento entre a parábola e os resultados dos ensaios, compreendendo níveis de carregamento superiores em torno de $50 \%$ da carga de ruptura. A figura 4.1 apresenta um gráfico com as curvas tensão-deformação típicas para o bloco, obtidas nos ensaios, e a figura 4.2 o gráfico com a curva ajustada aos valores médios de deformações. Os demais gráficos são apresentados no Anexo $A$ deste trabalho.

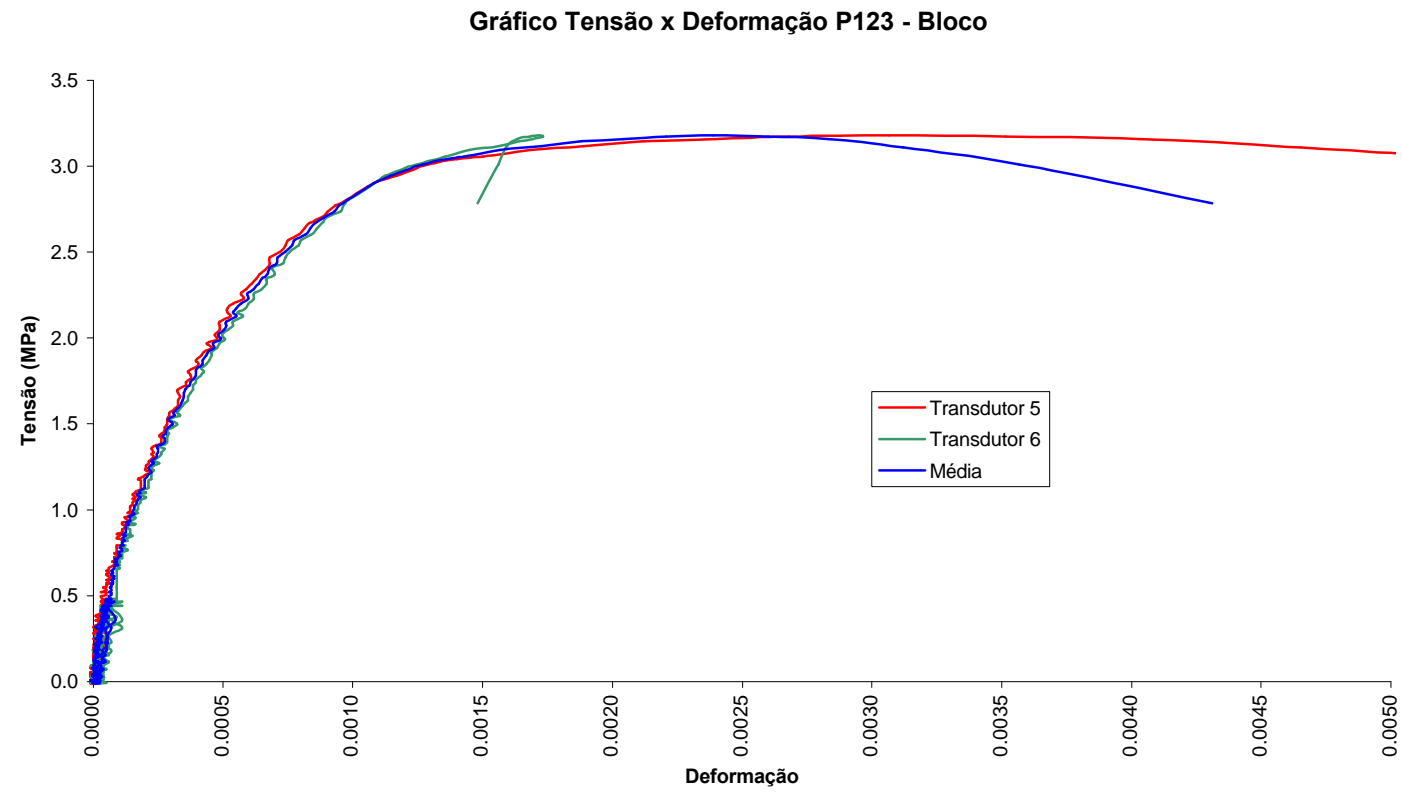

Figura 4.1 - Exemplo de um gráfico tensão-deformação para o bloco de 4,5 MPa (EP1). 
Segundo recomendação do ACI 530-92 (1995), o módulo de elasticidade longitudinal do bloco foi calculado a partir da inclinação de uma reta secante obtida no gráfico tensão-deformação, através da ligação entre os pontos correspondentes a $5 \%$ e $33 \%$ da tensão de ruptura do bloco durante o ensaio à compressão. Com isso, pretendeu-se minimizar as possíveis perturbações referentes ao início do ensaio. Os resultados alcançados para os blocos de 4,5 $\mathrm{MPa}$ e $10 \mathrm{MPa}$ são mostrados na tabela 4.4 e 4.5 , respectivamente.

Gráfico Tensão x Deformação P123 - Bloco

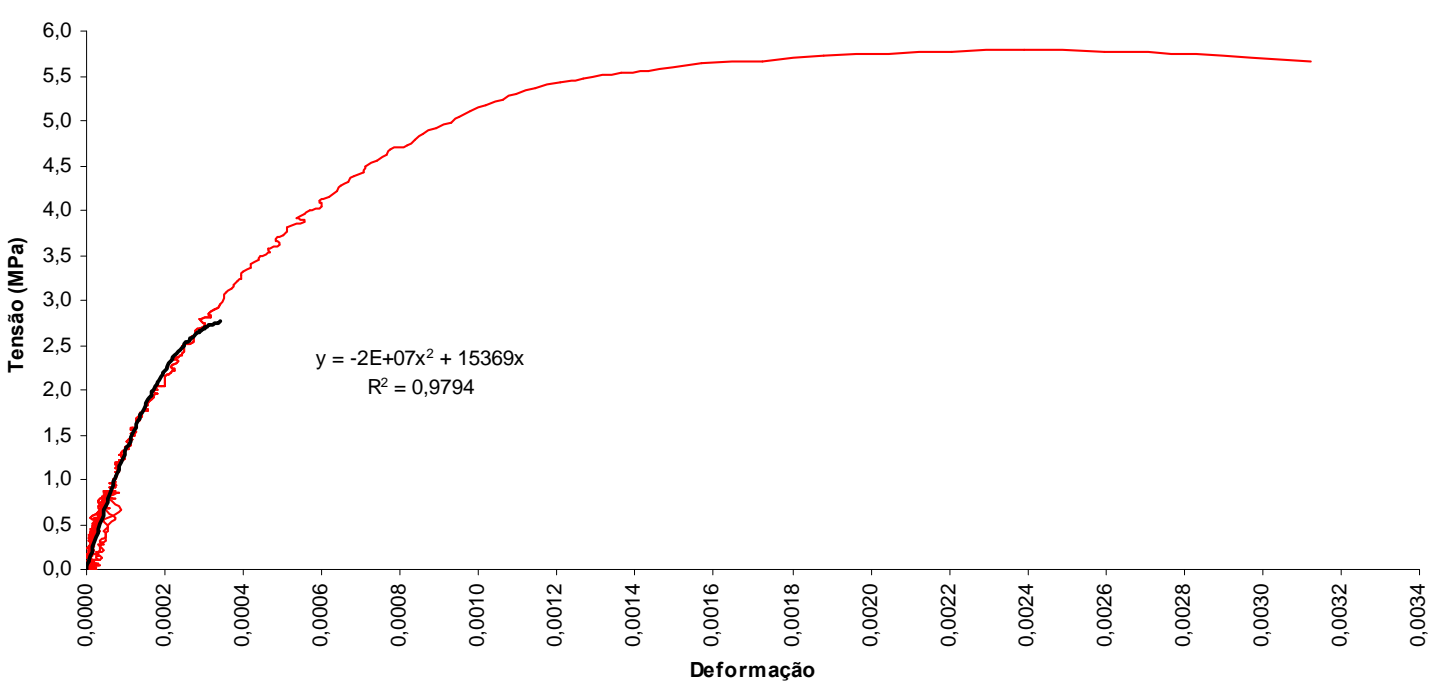

Figura 4.2 - Exemplo da curva ajustada para os valores médios de tensãodeformação para o bloco de 4,5 MPa (EP1).

Tabela 4.4- Módulo de elasticidade do bloco de 4,5 MPa (EP1).

\begin{tabular}{|c|c|}
\hline $\mathrm{CP}$ & Módulo de elasticidade $^{*}\left(\mathrm{E}_{\mathrm{b}}\right)(\mathrm{MPa})$ \\
\hline 1 & 15641 \\
2 & 18528 \\
3 & 16537 \\
\hline Média (MPa) & 16902 \\
Desvio Padrão (MPa) & 2818 \\
CV (\%) & 18,03 \\
\hline
\end{tabular}

* Resistência do bloco na área líquida. 
Tabela 4.5- Módulo de elasticidade do bloco de 10 MPa (EP1).

\begin{tabular}{|c|c|}
\hline $\mathrm{CP}$ & Módulo de elasticidade $^{*}\left(\mathrm{E}_{\mathrm{b}}\right)(\mathrm{MPa})$ \\
\hline 1 & 38212 \\
2 & 40930 \\
3 & 45031 \\
\hline Média (MPa) & 41391 \\
Desvio Padrão (MPa) & 3433 \\
CV (\%) & 8,29 \\
\hline
\end{tabular}

* Resistência do bloco na área líquida.

Na tabela 4.6 são apresentados os valores das relações entre o módulo de elasticidade e a resistência à compressão dos blocos. Segundo DRYSDALE et al. (1994), este valor para blocos de concreto pode variar entre 500 e 1000 . Dessa forma, verificaram-se que ambos os blocos atenderam as especificações do referido autor. Os valores também encontram-se na faixa entre 500 a 1500, proposta por SAHLIN (1971). Além disso, pode-se concluir que a rigidez dos blocos aumenta proporcionalmente ao aumento das resistências dos mesmos. Esta tabela também apresenta a mesma relação ao utilizar as expressões sugeridas pelo CEBFIP Mode Code (1990) e pelo ACI - Building Code 318 (1990) (expressão 2.1) para estimar o valor do módulo de elasticidade do concreto. Os valores obtidos através destas expressões mostraram grande distanciamento dos valores experimentais, exceto para a estimativa utilizando a expressão do CEB-FIP Mode Code (1990) para o bloco do tipo 2.

Tabela 4.6 - Valores das relações entre módulo de elasticidade e resistência à compressão dos blocos (EP1).

\begin{tabular}{|c|c|c|c|c|c|c|c|}
\hline \multirow[t]{2}{*}{$\begin{array}{l}\text { Tipo de } \\
\text { Bloco }\end{array}$} & \multicolumn{3}{|c|}{$\begin{array}{c}\text { Valores obtidos } \\
\text { nos ensaios }\end{array}$} & \multicolumn{2}{|c|}{$\begin{array}{c}E_{b m} \text { segundo ACl } \\
E_{b m}=0,0428 \cdot f_{b m}^{1 / 2} \cdot \gamma_{b}^{1,5}(* *)\end{array}$} & \multicolumn{2}{|c|}{$\begin{array}{l}E_{b m} \text { segundo CEB-FIP } \\
E_{b m}=2,5 \cdot 10^{4}\left(. f_{b m} / 10\right)^{1 / 3}\end{array}$} \\
\hline & $\mathrm{f}_{\mathrm{bm}}{ }^{*}(\mathrm{MPa})$ & $\mathrm{E}_{\mathrm{bm}}(\mathrm{MPa})$ & $E_{b m} / f_{b m}$ & $\mathrm{E}_{\mathrm{bm}}(\mathrm{Mpa})$ & $\mathrm{E}_{\mathrm{bm}} / \mathrm{f}_{\mathrm{bm}}$ & $\mathrm{E}_{\mathrm{bm}}(\mathrm{MPa})$ & $\mathrm{E}_{\mathrm{bm}} / \mathrm{f}_{\mathrm{bm}}$ \\
\hline 1 & 17,15 & 16902 & 986 & 9066 & 529 & 29922 & 1745 \\
\hline 2 & 41,00 & 41391 & 1010 & 31340 & 764 & 40013 & 976 \\
\hline
\end{tabular}

* Resistência do bloco na área líquida;

** Os valores de $\gamma_{\mathrm{b}}$ estão apresentados no item 3.2.1.1. 


\subsubsection{Ensaios Finais}

As dimensões reais dos blocos empregados nos ensaios finais foram de 14 x 19 x $39 \mathrm{~cm}$ (largura x altura x comprimento) para o bloco inteiro e $14 \times 19 \times 14 \mathrm{~cm}$ para o meio bloco, resultando numa área bruta de 546 e $392 \mathrm{~cm}^{2}$, respectivamente.

Para estes ensaios, a determinação da área líquida dos blocos foi feita seguindo as especificações da MB 3459 (1991) e alcançou o valor de 53\% da área bruta, tanto para o bloco de resistência à compressão nominal de 4,5 MPa quanto para o de 12,0 MPa.

Os valores das resistências médias à compressão são apresentados na tabela 4.7 e os valores característicos estimados na tabela 4.8 .

Tabela 4.7 - Valores médios de resistência àcompressão dos blocos (EF).

\begin{tabular}{|c|c|c|c|c|c|c|c|c|}
\hline \multirow{2}{*}{$\begin{array}{c}\text { Tipo } \\
\text { de } \\
\text { bloco } \\
\end{array}$} & \multirow{2}{*}{$\begin{array}{c}\text { Classe de } \\
\text { resistência } \\
(\mathrm{MPa})\end{array}$} & \multirow{2}{*}{$\begin{array}{c}\text { Idade dos } \\
\text { blocos } \\
\text { (dias) }\end{array}$} & \multicolumn{3}{|c|}{$\begin{array}{l}\text { Área bruta } \\
\left(546 \mathrm{~cm}^{2}\right)\end{array}$} & \multicolumn{3}{|c|}{$\begin{array}{c}\text { Área líquida } \\
\left(289 \mathrm{~cm}^{2}\right)\end{array}$} \\
\hline & & & $\mathrm{f}_{\mathrm{bm}}(\mathrm{MPa})$ & $\mathrm{S}_{\mathrm{d}}(\mathrm{MPa})$ & $\mathrm{CV}(\%)$ & $\mathrm{f}_{\mathrm{bm}}(\mathrm{Mpa})$ & $S_{d}(M p a)$ & CV (\%) \\
\hline B1 & 4,5 & 77 & 10,80 & 1,14 & 10,51 & 20,38 & 2,14 & 10,51 \\
\hline B2 & 12,0 & - & 22,92 & 1,32 & 5,75 & 41,00 & 2,49 & 5,75 \\
\hline
\end{tabular}

Tabela 4.8 - Valores característicos de resistência à compressão dos blocos

(EF).

\begin{tabular}{|c|c|c|c|c|c|c|c||}
\hline \multirow{2}{*}{$\begin{array}{c}\text { Tipo de } \\
\text { bloco }\end{array}$} & \multirow{2}{*}{$\begin{array}{c}\text { Classe de } \\
\text { resistência }(\mathrm{MPa})\end{array}$} & \multicolumn{3}{|c|}{ Área bruta $\left(546 \mathrm{~cm}^{2}\right)$} & \multicolumn{3}{c|}{ Área líquida $\left(289 \mathrm{~cm}^{2}\right)$} \\
\cline { 3 - 8 } & $\mathrm{f}_{\text {bkest }}(\mathrm{MPa})$ & $\mathrm{S}_{\mathrm{d}}(\mathrm{MPa})$ & $\mathrm{CV}(\%)$ & $\mathrm{f}_{\text {bk.est }}(\mathrm{MPa})$ & $\mathrm{S}_{\mathrm{d}}(\mathrm{MPa})$ & $\mathrm{CV}(\%)$ \\
\hline $\mathrm{B} 1$ & 4,5 & 8,84 & 1,14 & 12,90 & 16,68 & 2,14 & 12,83 \\
\hline B2 & 12,0 & 19,91 & 1,32 & 4,41 & 38,83 & 2,49 & 6,41 \\
\hline
\end{tabular}

Nestes ensaios, pode-se perceber aumentos na resistência à compressão média dos blocos de até $150 \%$ quando comparada aos valores nominais. Foram obtidos baixos coeficientes de variação para os valores de resistência alcançados, encontrando-se na faixa entre 5 e $11 \%$.

O módulo de elasticidade dos blocos foi obtido do mesmo modo dos ensaios-piloto 1, ou seja, a partir da equação de uma parábola ajustada à curva obtida experimentalmente no gráfico tensão-deformação. O ajuste desta curva foi feito até níveis de tensão da ordem de $60 \%$ do valor da carga de ruptura. Este valor 
foi estipulado por permitir o cálculo do módulo de elasticidade secante entre níveis de tensões entre 5 e $33 \%$ da carga de ruptura e apresentar ótimos coeficientes de ajustes para as parábolas obtidas.

Gráfico Tensão x Deformação PRB1A2E 2 - Bloco de 4,5 MPa

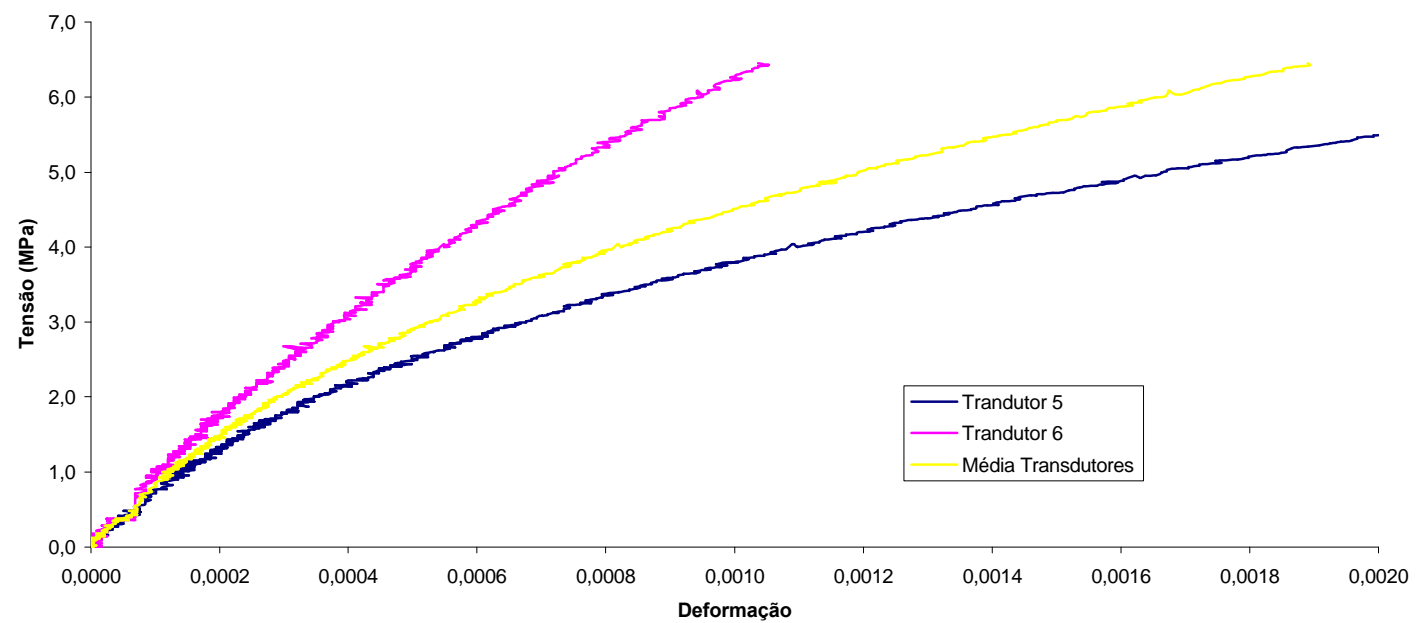

Figura 4.3 - Exemplo de um gráfico tensão-deformação para o bloco de 4,5 $\mathrm{MPa}(\mathrm{EF})$.

Gráfico Tensão x Deformação PRB1A2E 2 - Bloco de 4,5 MPa

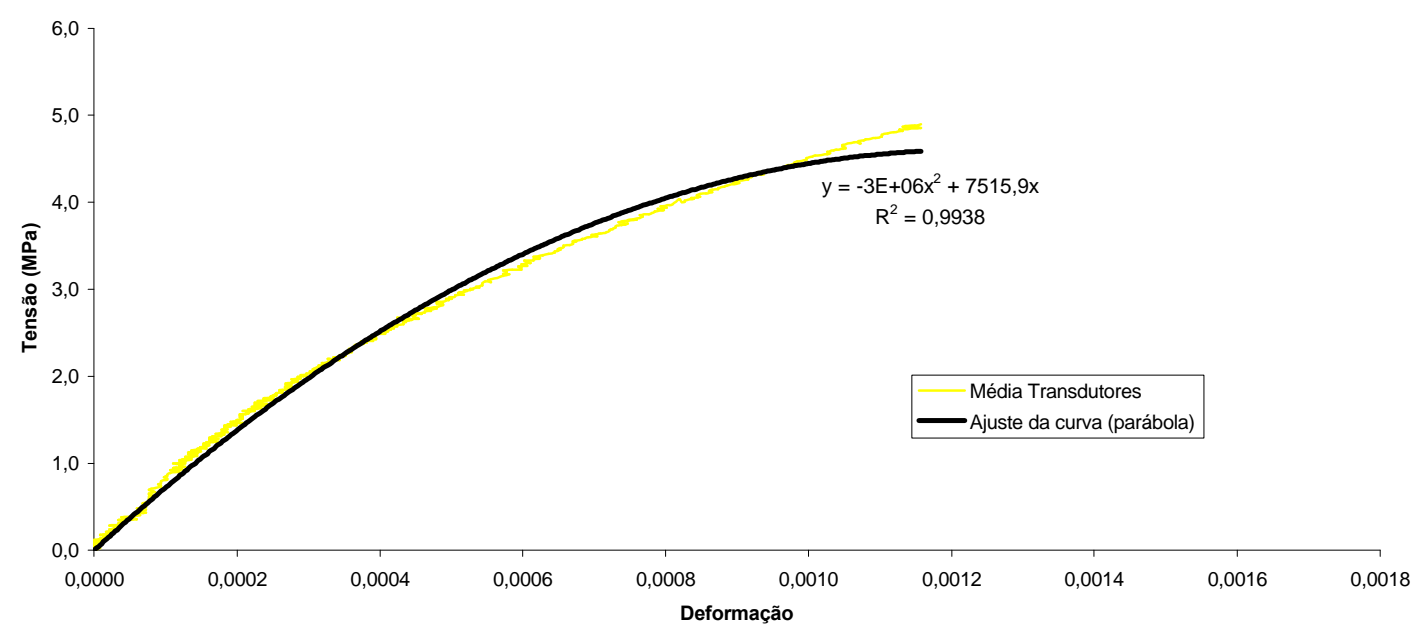

Figura 4.4 - Exemplo da curva ajustada para os valores médios de tensãodeformação para o bloco de 4,5 MPa (EF). 
A figura 4.3 apresenta um gráfico com as curvas tensão-deformação para o bloco e a figura 4.4 o gráfico com uma curva ajustada aos valores médios de deformações, estando os demais gráficos apresentados no Anexo B deste trabalho.

Porém, cabe ressaltar que, ao contrário dos ensaios-piloto, o módulo de elasticidade longitudinal foi calculado a partir da resistência à compressão em relação à área bruta dos corpos de prova. Admitiu-se esta convenção para que fosse possível fazer comparações coerentes entre blocos, prismas e paredinhas ensaiadas nas duas direções, sem a necessidade de determinação da área efetiva de cada corpo de prova.

Os valores dos módulos de elasticidade longitudinal dos blocos, obtidos a partir da inclinação da reta secante entre os pontos correspondentes a 5\% e 33\% da tensão de ruptura são apresentados na tabela 4.9 para os blocos de 4,5 MPa e na tabela 4.10 para os blocos de 12,0 MPa. Os valores obtidos que se distanciaram muito em relação aos demais foram descartados.

Tabela 4.9- Módulo de elasticidade do bloco de 4,5 MPa (EF).

\begin{tabular}{|c|c||}
\hline $\mathrm{CP}$ & Módulo de elasticidade $^{*}\left(\mathrm{E}_{\mathrm{b}}\right)(\mathrm{MPa})$ \\
\hline 1 & 6050 \\
2 & 6145 \\
3 & 6488 \\
\hline Média (MPa) & 6228 \\
Desvio Padrão (MPa) & 231 \\
CV (\%) & 3,70 \\
\hline
\end{tabular}

Tabela 4.10- Módulo de elasticidade do bloco de 12 MPa (EF).

\begin{tabular}{||c|c||}
\hline $\mathrm{CP}$ & Módulo de elasticidade $^{*}\left(\mathrm{E}_{\mathrm{b}}\right)(\mathrm{MPa})$ \\
\hline 1 & 7066 \\
2 & 8041 \\
3 & $15149^{* *}$ \\
\hline Média (MPa) & 7554 \\
Desvio Padrão (MPa) & 689 \\
CV (\%) & 9,12 \\
\hline
\end{tabular}

* Calculado com a área bruta;

** Resultado descartado por apresentar um desvio grande em relação aos outros valores. 
A tabela 4.11 apresenta as relações entre módulo de elasticidade e resistência à compressão dos blocos para os valores obtidos nos ensaios, ao utilizar a expressão sugerida pelo ACI - Building Code 318 (1990) (expressão 2.1) e a proposta pelo CEB-FIP Mode Code (1990), para estimar o valor do módulo de elasticidade do concreto (expressão 2.2). Verificou-se que, para os blocos de 4,5 $\mathrm{MPa}$, a relação $\mathrm{E}_{\mathrm{bm}} / \mathrm{f}_{\mathrm{bm}}$ obtida experimentalmente atendeu aos limites especificados por DRYSDALE et al. (1994), entre 500 e 1000, e SAHLIN (1971), entre 500 e1500. Porém, para os blocos de $12 \mathrm{MPa}$ este valor ficou abaixo do esperado.

Para estes ensaios, com os valores de $\gamma_{b}$ obtidos a partir dos ensaios de determinação de área líquida dos blocos, pode-se observar também que os valores calculados a partir da equação sugerida pelo CEB-FIP Mode Code (1990) ficaram bem distantes dos obtidos experimentalmente.

Tabela 4.11 - Valores das relações entre módulo de elasticidade e resistência à compressão dos blocos (EF).

\begin{tabular}{||c|c|c|c|c|c|c|c||}
\hline \multirow{2}{*}{$\begin{array}{c}\text { Tipo de } \\
\text { Bloco }\end{array}$} & \multicolumn{3}{|c|}{ Valores obtidos } & \multicolumn{2}{c|}{$E_{b m}$ segundo ACl } & \multicolumn{2}{c||}{$E_{b m}$ segundo CEB-FIP } \\
\cline { 2 - 9 } & $\mathrm{f}_{\mathrm{bm}}{ }^{*}(\mathrm{Mpa})$ & $\mathrm{E}_{\mathrm{bm}}(\mathrm{MPa})$ & $\mathrm{E}_{\mathrm{bm}} / \mathrm{f}_{\mathrm{bm}}$ & $\mathrm{E}_{\mathrm{bm}}(\mathrm{MPa})$ & $\mathrm{E}_{\mathrm{bm}} / \mathrm{f}_{\mathrm{bm}}$ & $\mathrm{E}_{\mathrm{bm}}(\mathrm{Mpa})$ & $\mathrm{E}_{\mathrm{bm}} / \mathrm{f}_{\mathrm{bm}}$ \\
\hline $\mathrm{B} 1$ & 10,80 & 6228 & 577 & 5557 & 515 & 25650 & 2375 \\
\hline B2 & 22,92 & 7554 & 330 & 9208 & 402 & 32962 & 1438 \\
\hline
\end{tabular}

* Resistência do bloco na área bruta.

\subsection{Argamassas}

\subsubsection{Ensaio-Piloto 1}

A tabela 4.12 apresenta as resistências à compressão dos corpos de prova cilíndricos de dimensões de $5 \times 10 \mathrm{~cm}$, referentes às argamassas industrializadas utilizadas nas séries do primeiro ensaio-piloto.

A determinação do módulo de elasticidade obedeceu aos mesmos procedimentos usados para os blocos de concreto. Um exemplo de gráfico com as curvas de tensão-deformação, obtidas através do uso de extensômetros e transdutores, é mostrado na figura 4.5, estando os demais presentes no Anexo $\mathrm{A}$ 
deste trabalho. Os valores obtidos pelas medições feitas através dos transdutores indutivos de deslocamentos e dos extensômetros estão apresentados na tabela 4.13.

Tabela 4.12 - Resistência à compressão dos corpos de prova de argamassa cilíndricos $5 \times 10 \mathrm{~cm}$ (EP1).

\begin{tabular}{|c|c|c|c|c|c||}
\hline \multirow{2}{*}{$\begin{array}{c}\text { Tipo de } \\
\text { argamassa }\end{array}$} & \multirow{2}{*}{$\begin{array}{c}\text { Resistência indicada } \\
\text { pelo fabricante (28 dias) }\end{array}$} & \multirow{2}{*}{$\begin{array}{c}F_{\text {rup,am }} \text { do } \\
\text { ensaio }(\mathrm{kN})\end{array}$} & \multicolumn{3}{|c|}{ Resistência à compressão (35 dias) } \\
\cline { 4 - 7 } & $\mathrm{f}_{\mathrm{am}}(\mathrm{MPa})$ & $\mathrm{S}_{\mathrm{d}}(\mathrm{MPa})$ & $\mathrm{CV}(\%)$ \\
\hline $\mathrm{P}$ & 6,0 & 10,3 & 5,2 & 0,28 & 5,4 \\
\hline $\mathrm{Q}$ & 4,2 & 11,1 & 5,7 & 0,48 & 8,4 \\
\hline $\mathrm{R}$ & 2,8 & 7,2 & 3,7 & 0,14 & 3,9 \\
\hline
\end{tabular}

Tabela 4.13- Módulo de elasticidade das argamassas industrializadas (EP1).

\begin{tabular}{|c|c|c|c|c|c|c||}
\hline \multirow{2}{*}{$\begin{array}{c}\text { Tipo de } \\
\text { argamassa }\end{array}$} & \multicolumn{3}{|c|}{$\begin{array}{c}\text { Módulo de elasticidade médio } \\
\text { Extensômetro }\end{array}$} & \multicolumn{3}{c||}{$\begin{array}{c}\text { Módulo de elasticidade médio } \\
\text { Transdutor }\end{array}$} \\
\cline { 2 - 7 } & $\mathrm{E}_{\mathrm{am}}(\mathrm{MPa})$ & $\mathrm{S}_{\mathrm{d}}(\mathrm{MPa})$ & $\mathrm{CV}(\%)$ & $\mathrm{E}_{\mathrm{am}}(\mathrm{MPa})$ & $\mathrm{S}_{\mathrm{d}}(\mathrm{MPa})$ & $\mathrm{CV}(\%)$ \\
\hline $\mathrm{P}$ & 7396 & 1244,35 & 16,82 & 5664 & 883,88 & 15,61 \\
\hline $\mathrm{Q}$ & 8879 & 671,75 & 7,57 & 9720 & 1000,98 & 10,30 \\
\hline $\mathrm{R}$ & 5903 & 444,43 & 7,53 & 8144 & 144,96 & 1,78 \\
\hline
\end{tabular}

Através dos resultados fornecidos pela tabela 4.13, percebeu-se que os coeficientes de variação, na sua maioria, foram menores para as medições feitas utilizando extensômetros. A exceção para a argamassa do tipo $\mathrm{P}$ deveu-se ao fato de ter sido desconsiderado o resultado que apresentou um desvio grande em relação à média. Caso contrário essa variação teria sido de $28 \%$, ou seja, bem superior à obtida com o uso do extensômetro. Assim, pode-se admitir a grande influência do capeamento na variação dos resultados ao se utilizar transdutores apoiados na base da prensa, concluindo que o uso de extensômetros para medições de deformações ainda é considerado o mais adequado. 
Gráfico Tensão x Deformação Argamassa P1

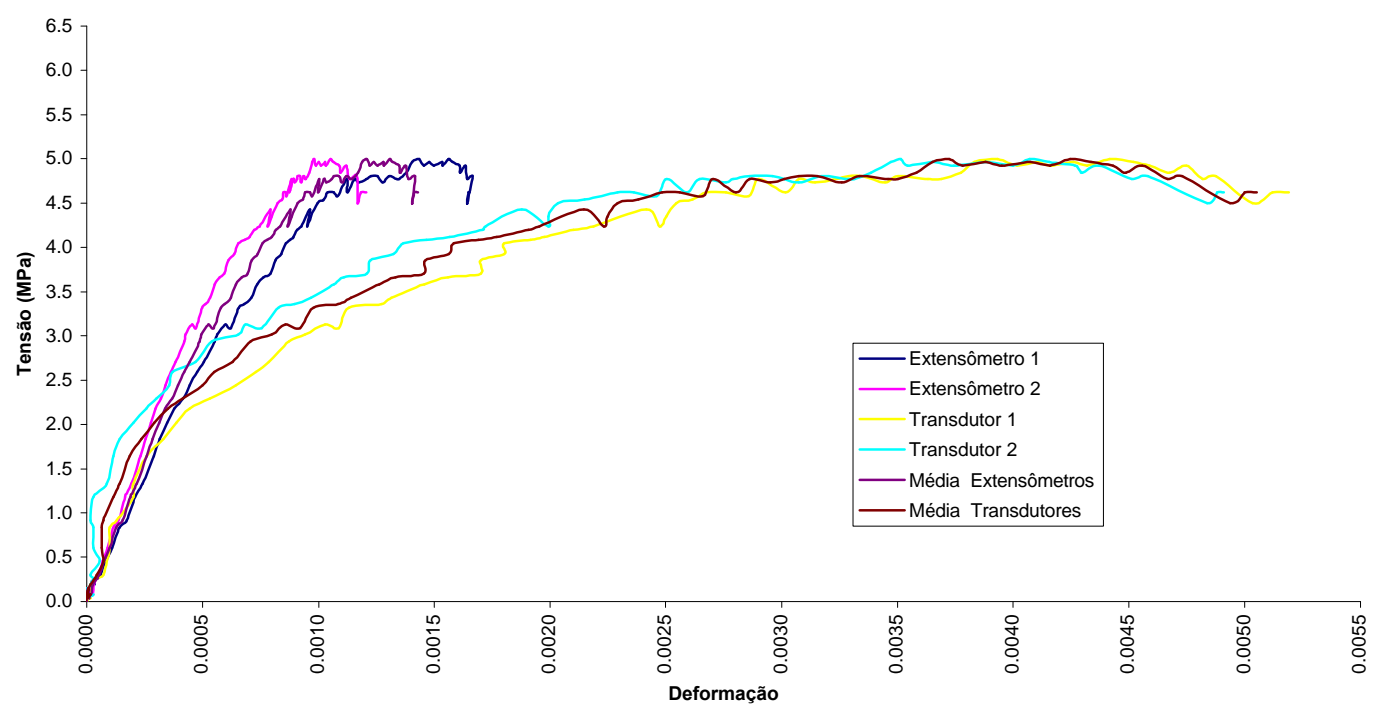

Figura 4.5 - Exemplo de diagrama tensão-deformação típico para argamassa do tipo P com a leitura por extensômetros e transdutores (EP1).

Foi realizado um estudo com a argamassa do tipo $\mathrm{R}$ para a determinação da curva tensão-deformação utilizando o método proposto por KNUTSSON \& NIELSEN (1995). Para tanto, traçou-se a curva logarítmica e a parábola a partir das expressões 2.30 e 2.31, respectivamente. Essas duas curvas foram comparadas com a parábola resultante da aproximação dos pontos obtidos no ensaio. A figura 4.6 apresenta a comparação das curvas para as medições feitas com os extensômetros e a figura 4.7 com transdutores.

A partir dos gráficos apresentados abaixo se pode observar que a curva de Ritter e a parábola produziram uma boa aproximação para os resultados do ensaio quando utilizados extensômetros. As mesmas curvas tiveram um certo distanciamento dos resultados obtidos experimentalmente ao utilizarem-se transdutores indutivos de deslocamento apoiados na base da prensa.

Cabe ressaltar que as curvas não foram ajustadas para a origem como procedimento realizado para os demais corpos de prova, devido a um descuido durante a realização do escorvamento, o que de certa forma pode ter prejudicado os resultados obtidos, devido àfalta de acomodação das deformações no início do ensaio. 
Gráfico Tensão x Deformação Argamassa R2 - Extensômetro

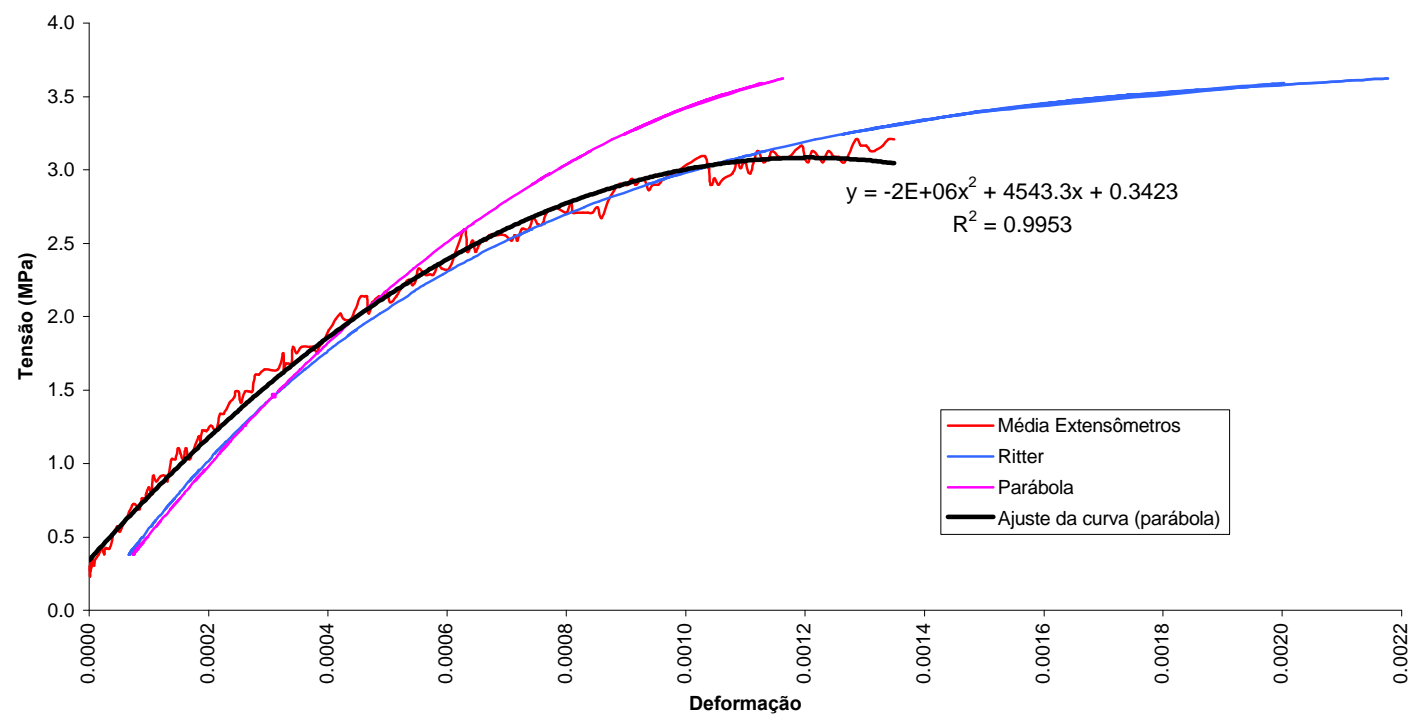

Figura 4.6 - Comparação das curvas tensão-deformação para as medições feitas com extensômetros (EP1).

Gráfico Tensão x Deformação Argamassa R2 - Transdutor

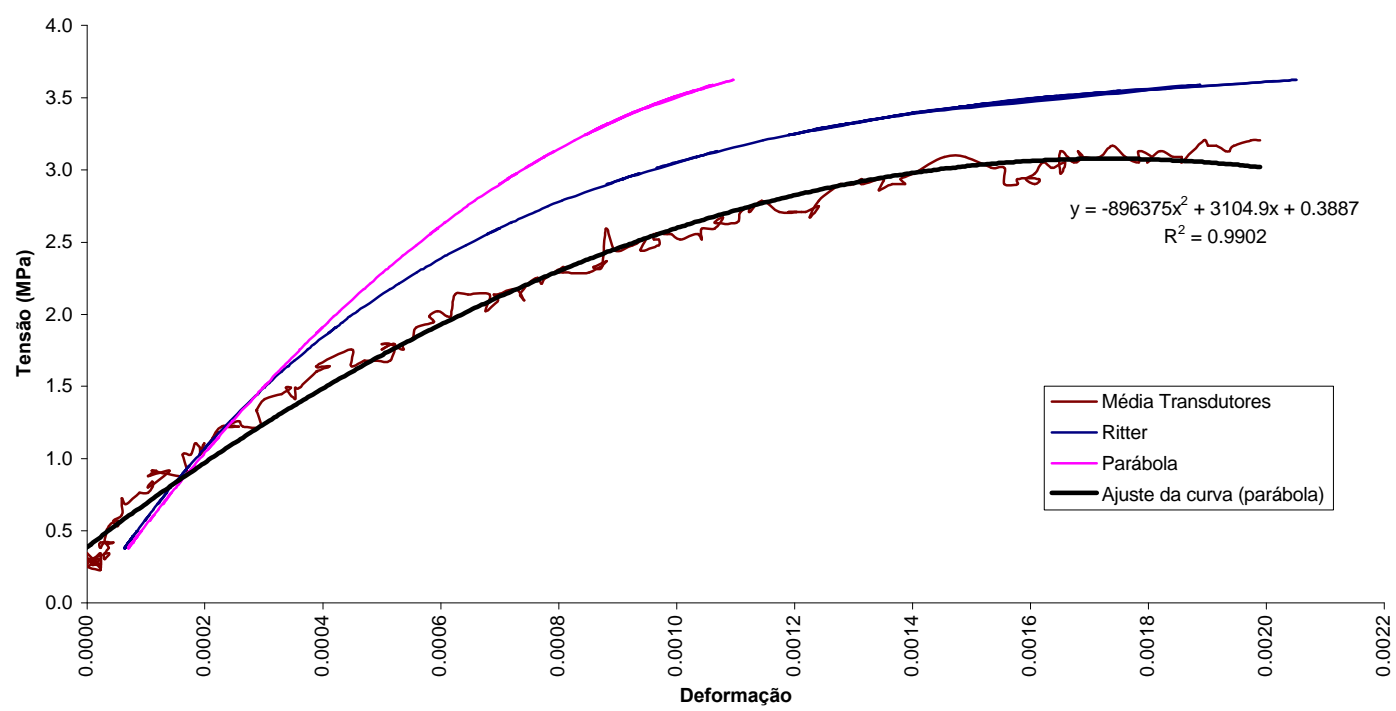

Figura 4.7 - Comparação das curvas tensão-deformação para as medições feitas com transdutores (EP1).

A tabela 4.14 apresenta a relação entre o módulo de elasticidade e a resistência àcompressão da argamassa, a partir dos valores obtidos através do uso 
de extensômetros e de transdutores. Esta mesma relação tem o valor proposto por HILDSDORF ${ }^{1}$ apud ALY (1992) de 1000.

Tabela 4.14- Relação entre módulo de elasticidade e resistência à compressão das argamassas (EP1).

\begin{tabular}{||c|c|c|c|c|c|c||}
\hline \multirow{2}{*}{$\begin{array}{c}\text { Tipo de } \\
\text { argamassa }\end{array}$} & \multicolumn{3}{|c|}{$\begin{array}{c}\text { Módulo de elasticidade médio } \\
\text { Extensômetro }\end{array}$} & \multicolumn{3}{c||}{ Módulo de elasticidade médio } \\
\cline { 2 - 7 } & $\mathrm{E}_{\mathrm{am}} / \mathrm{f}_{\mathrm{am}}$ & $\mathrm{S}_{\mathrm{d}}$ & $\mathrm{CV}(\%)$ & $\mathrm{E}_{\mathrm{am}} / \mathrm{f}_{\mathrm{am}}$ & $\mathrm{S}_{\mathrm{d}}$ & $\mathrm{CV}(\%)$ \\
\hline $\mathrm{P}$ & 1142 & 130,67 & 9,74 & 890 & 169,88 & 19,09 \\
\hline $\mathrm{Q}$ & 1530 & 95,00 & 6,20 & 1685 & 261,53 & 15,52 \\
\hline $\mathrm{R}$ & 1633 & 188,43 & 11,55 & 1699 & 873,98 & 51,44 \\
\hline
\end{tabular}

Observa-se que os valores obtidos para as relações $\mathrm{E}_{\mathrm{am}} / f_{a m}$ foram bem próximos em ambos os casos, porém o coeficiente de variação teve um valor muito superior quando utilizado o transdutor.

A NBR 8522 (1984) especifica um comprimento das bases de medidas de, no mínimo, três vezes a dimensão máxima do agregado ou $2 / 3$ do diâmetro do corpo de prova. Dessa forma, para os corpos de prova cilíndricos de argamassa, com dimensões de $5 \times 10 \mathrm{~cm}$, tem-se um extensômetro ideal de comprimento maior que 33 mm. Porém, ensaios realizados por MARTINELLI (1961), em corpos de prova de concreto, mostraram que as deformações não eram afetadas pelo comprimento do extensômetro elétrico. A mesma conclusão foi obtida em ensaios realizados pelo laboratório do SET, ao comparar extensômetros elétricos de $10 \mathrm{~mm}$ e $30 \mathrm{~mm}$. Assim, foram utilizados extensômetros elétricos com base de $10 \mathrm{~mm}$

\subsubsection{Ensaio-Piloto 2}

O segundo ensaio-piloto teve como objetivo determinar dois traços de argamassas, apresentando diferentes módulos de elasticidade, para posterior uso nos ensaios finais das paredinhas, de modo que se possa analisar a influência da

1 HILSDORF, H.K. (1969).Investigation into the Failure Mechanism of Brick Masonry Loaded in Axial Compression. Houston, Gulf. Londres. 
variabilidade das características mecânicas das mesmas no comportamento das paredinhas.

As tabelas 4.15 e 4.16 apresentam, respectivamente, as características de resistência àcompressão e de deformabilidade das argamassas estudadas.

As resistências à compressão alcançadas pelo ensaio das argamassas do tipo A1 e A2 tiveram variações de 15 e 35\%, respectivamente, em relação à estimativa feita para os 16 dias dos resultados de FONTE (2000), obtidos através da interpolação dos resultados aos 7 e 28 dias, a partir do gráfico de resistência à compressão x relação água/cimento apresentada pela autora. Porém, a necessidade da escolha de duas argamassas com módulos de elasticidade distintos foi atendida. Dessa forma, julgou-se plausível utilizar a dosagem desenvolvida pela autora citada.

Tabela 4.15- Resistência à compressão das argamassas (EP2).

\begin{tabular}{||c|c|c|c|c|c||}
\hline \multirow{2}{*}{$\begin{array}{c}\text { Tipo de } \\
\text { argamassa }\end{array}$} & \multirow{2}{*}{$\begin{array}{c}\text { Resistência à compressão } \\
\text { FONTE (28 dias) }\end{array}$} & \multirow{2}{*}{$\begin{array}{c}F_{\text {rup,am }} \text { do } \\
\text { ensaio }(\mathrm{kN})\end{array}$} & \multicolumn{3}{|c||}{ Resistência à compressão (16 dias) } \\
\cline { 4 - 7 } & $\mathrm{f}_{\mathrm{am}}(\mathrm{MPa})$ & $\mathrm{S}_{\mathrm{d}}(\mathrm{MPa})$ & $\mathrm{CV}(\%)$ \\
\hline $\mathrm{A} 1$ & 6,9 & 116 & 6,44 & 0,13 & 1,99 \\
\hline $\mathrm{A} 2$ & 4,1 & 74 & 4,20 & 0,07 & 1,64 \\
\hline
\end{tabular}

Tabela 4.16- Módulo de elasticidade das argamassas (EP2).

\begin{tabular}{|c|c|c|c||}
\hline \hline Tipo de argamassa & $\mathrm{E}_{\mathrm{am}}(\mathrm{MPa})$ & $\mathrm{S}_{\mathrm{d}}(\mathrm{MPa})$ & $\mathrm{CV}(\%)$ \\
\hline $\mathrm{A} 1$ & 9796 & 102,55 & 1,05 \\
\hline $\mathrm{A} 2$ & 7598 & 359,56 & 4,73 \\
\hline
\end{tabular}

É possível notar uma diminuição no valor de $E_{a m}$ a medida em que se diminui a quantidade de cimento nos traços da argamassa.

METHA \& MONTEIRO (1993) apresentam a expressão especificada pela ASTM (1991) para estimar a resistência à compressão do concreto quando submetidos a cura úmida e ao utilizar o cimento equivalente ao CP I:

$$
f_{c m}(t)=f_{c 28} \cdot\left[\frac{t}{(4-0,85 t)}\right]
$$

Onde:

t é o número de dias;

$\mathrm{f}_{\mathrm{cm}}(\mathrm{t})$ é a resistência àcompressão média a t dias;

$\mathrm{f}_{\mathrm{c} 28}(\mathrm{t})$ é a resistência àcompressão média aos 28 dias. 
Porém, vale salientar que esta expressão é usada para corpos de prova de concreto e para tipos de cimentos um pouco diferentes dos produzidos no Brasil.

A estimativa para a argamassa de resistência à compressão ao utilizar a expressão acima alcançou valores de 7,09 MPa e 4,62 MPa para as argamassas do tipo 1 e 2 , respectivamente.

Os diagramas de tensão-deformação para as argamassas e os ajustes das curvas realizados para determinar os módulos de elasticidade longitudinais podem ser encontrados no Anexo A.

Tabela 4.17- Relação entre módulo de elasticidade e resistência à compressão das argamassas (EP2).

\begin{tabular}{|c|c|c|c||}
\hline \hline Tipo de argamassa & $\mathrm{E}_{\mathrm{am}} / \mathrm{f}_{\mathrm{am}}(\mathrm{MPa})$ & $\mathrm{S}_{\mathrm{d}}(\mathrm{MPa})$ & $\mathrm{CV}(\%)$ \\
\hline $\mathrm{A} 1$ & 1517 & 17,62 & 1,16 \\
\hline $\mathrm{A} 2$ & 1809 & 74,03 & 4,09 \\
\hline Média & 1663 & 206,89 & 12,44 \\
\hline
\end{tabular}

Nota: Os módulos foram obtidos a partir do ajuste da curva tensão-deformação até $80 \%$ do valor da carga de ruptura.

As relações entre o módulo de elasticidade e a resistência àcompressão da argamassa, apresentadas na tabela 4.17, mostram que os coeficientes de variação foram bem menores que os obtidos nos ensaios-piloto 1. Porém, a média dos valores desta relação comprovou um certo distanciamento já indicado nos ensaiospiloto 1 , no que diz respeito ao valor igual a 1000, proposto por HILDSDORF (1992).

\subsubsection{Ensaios Finais}

Conforme já citado, os ensaios finais dos corpos de prova cilíndricos de argamassa, com dimensões de $5 \mathrm{~cm} \times 10 \mathrm{~cm}$, foram feitos com o objetivo de realizar o controle da resistência à compressão das mesmas, estando os valores médios obtidos para cada série de parede apresentados na tabela 4.18.

Já a tabela 4.19 indica os valores médios de cada tipo de argamassa para todos os corpos de prova ensaiados.

Ao comparar os resultados de resistência à compressão dos ensaios finais e os valores estimados para os 28 dias dos ensaios-piloto 2 , utilizando a expressão 
4.1, observou-se aumentos de 44,4\% para a argamassa do tipo 1 e 9,3\% para a argamassa do tipo 2.

Tabela 4.18- Resistência à compressão das argamassas para cada série de paredinhas (EF).

\begin{tabular}{||c|c|c|c|c|c||}
\hline \multirow{2}{*}{$\begin{array}{c}\text { Séries de paredes } \\
\text { correspondentes }\end{array}$} & \multirow{2}{*}{$\begin{array}{c}\text { idade } \\
\text { (dias) }\end{array}$} & $\begin{array}{c}\mathrm{F}_{\text {rup,am }} \text { do } \\
\text { Ensaio }(\mathrm{kN})\end{array}$ & \multicolumn{4}{|c|}{ Resistência média à compressão } \\
\cline { 5 - 7 } & $\mathrm{f}_{\mathrm{am}}(\mathrm{MPa})$ & $\mathrm{S}_{\mathrm{d}}(\mathrm{MPa})$ & $\mathrm{CV}(\%)$ \\
\hline PAB1A1E & 29 & 198 & 10,09 & 0,77 & 7,59 \\
\hline PAB2A1E $_{X}$ & 30 & 191 & 9,70 & 1,31 & 13,53 \\
\hline PAB1A1E $_{Y}$ & 35 & 203 & 10,32 & 0,27 & 2,64 \\
\hline PAB2A1E & 29 & 213 & 10,84 & 0,28 & 2,56 \\
\hline PAB1A2E & 31 & 106 & 5,41 & 0,25 & 4,59 \\
\hline PAB2A2E & 35 & 104 & 5,28 & 0,97 & 18,43 \\
\hline PAB1A2E & 34 & 88 & 4,49 & 1,40 & 31,25 \\
\hline PAB2A1E & 31 & 99 & 5,03 & 0,43 & 8,54 \\
\hline \hline
\end{tabular}

Tabela 4.19- Resistência à compressão média dos corpos de prova de argamassa (EF).

\begin{tabular}{||c|c|c|c||}
\hline \multirow{2}{*}{$\begin{array}{c}\text { Tipo de } \\
\text { Argamassa }\end{array}$} & \multicolumn{3}{|c||}{ Resistência média à compressão } \\
\cline { 2 - 4 } & $\mathrm{f}_{\mathrm{am}}(\mathrm{MPa})$ & $\mathrm{S}_{\mathrm{d}}(\mathrm{Mpa})$ & $\mathrm{CV}(\%)$ \\
\hline $\mathrm{A} 1$ & 10,24 & 0,82 & 8,00 \\
\hline $\mathrm{A} 2$ & 5,05 & 0,88 & 17,31 \\
\hline
\end{tabular}

\subsection{Prismas}

\subsubsection{Ensaios-Piloto 1}

A tabela 4.20 apresenta os valores obtidos nos ensaios das séries de prismas e os valores de carga de ruptura previstos teoricamente, baseados num valor médio de eficiência igual a 0,80 , obtido pelos ensaios realizados por ALY \& SABBATINI (1994), a diferença entre estes valores, em relação aos previstos 
teoricamente, além da sua resistência à compressão, obtida em função da área líquida dos blocos.

Tabela 4.20 - Resistência à compressão dos prismas (EP1).

\begin{tabular}{|c|c|c|c|c|c|c|}
\hline \multirow[t]{2}{*}{ Série } & \multirow{2}{*}{$\begin{array}{c}F_{\text {rup,prevista }} \\
(\mathrm{kN})\end{array}$} & \multirow{2}{*}{$\begin{array}{c}F_{\text {rup,ensaio }} \\
(\mathrm{kN})\end{array}$} & \multirow{2}{*}{$\begin{array}{c}\text { Diferença } \\
(\%)\end{array}$} & \multicolumn{3}{|c|}{ Resistência média à compressão } \\
\hline & & & & $\mathrm{f}_{\mathrm{pm}}{ }^{*}(\mathrm{MPa})$ & $\mathrm{S}_{\mathrm{d}}(\mathrm{MPa})$ & $\mathrm{CV}(\%)$ \\
\hline Q11 & 260 & 255 & $-1,9$ & 8,48 & 1,02 & 12,04 \\
\hline Q12 & 260 & 227 & $-12,7$ & 7,56 & 1,23 & 16,22 \\
\hline Q21 & 579 & 503 & $-13,1$ & 16,75 & 1,53 & 9,13 \\
\hline Q22 & 579 & 344 & $-40,6$ & 10,82 & 0,07 & 0,63 \\
\hline
\end{tabular}

* Resistência do prisma na área líquida.

A tabela acima mostra uma proximidade nos valores previstos teoricamente e os obtidos nos ensaios para os prismas de blocos de resistência àcompressão de 4,5 MPa. Porém, cabe ressaltar que estes valores teóricos referem-se aos blocos com suas resistências à compressão correspondentes aos valores característicos especificados pelo fabricante. Porém, notou-se que os mesmos representavam a resistência à compressão característica dos blocos aos 7 dias e não aos 28, como previsto. Com a realização do ensaio de resistência à compressão dos blocos, notou-se um ganho de resistência de 86 e 103\% para os blocos de 4,5 MPa e 10 $\mathrm{MPa}$, respectivamente. Dessa forma, deveriam ser obtidos valores bem superiores aos alcançados, o que resultou valores de eficiência extremamente baixos (ver tabela 4.23).

Como citado no capítulo 3 do presente trabalho, os ensaios de prismas à compressão foram feitos utilizando-se as argamassas dos tipos $\mathrm{P}$ e $\mathrm{Q}$. Os prismas com o tipo $\mathrm{P}$ apresentaram um esmagamento precoce da argamassa utilizada, ocorrendo o esboroamento da mesma com níveis de carregamento na faixa de 15 a $40 \%$ da carga de ruptura alcançada. Com isso, alguns corpos de prova chegaram ao final do ensaio com perda total da interface bloco-argamassa. Além disso, houve o descolamento de alguns blocos durante o transporte dos corpos de prova. Ambas as ocorrências indicaram que estes prismas tiveram problemas em relação à aderência bloco-argamassa quando usada a referida argamassa. 
Gráfico Tensão x Deformação P111 - Prisma

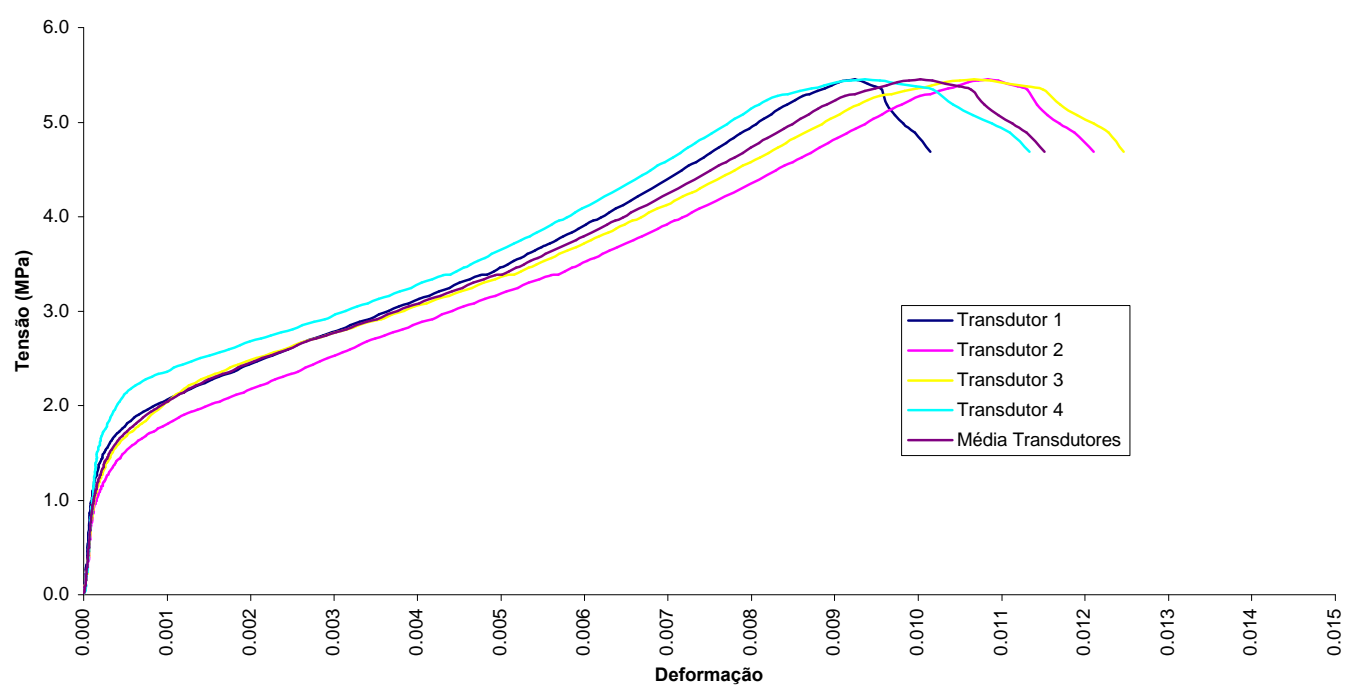

Figura 4.8 - Exemplo de um gráfico tensão-deformação para o prisma com argamassa do tipo $P$ (EP1).

A apresentação gráfica dos pontos obtidos no ensaio possibilitou a confirmação da alteração do comportamento do gráfico tensão-deformação ao utilizar a argamassa do tipo $\mathrm{P}$, como pode ser vista na figura 4.8. Isto comprometeu a determinação do módulo de elasticidade do prisma, já que a ruptura precoce levou os prismas a alcançarem módulos de elasticidade extremamente elevados. Assim, optou-se por não considerar os módulos de elasticidade dos ensaios com argamassa do tipo $P$, já que os mesmos resultaram em resultados insatisfatórios.

Verificou-se, também, um comprometimento na aderência da interface bloco-argamassa nos ensaios pilotos realizados com a argamassa industrializada do tipo $Q$, já que em vários dos prismas houve o descolamento dos blocos durante o transporte dos corpos de prova e algumas ocorrências de esboroamento em cargas muito baixas durante o ensaio. Porém, para este tipo de argamassa, o gráfico tensão-deformação apresentou um comportamento típico, sem a mudança brusca de inclinação da curva.

Segundo SOLÓRZANO (1994), a perda de aderência da interface blocoargamassa pode estar relacionada àcapacidade de retenção de água deste tipo de argamassa. Durante o assentamento da unidade de alvenaria, ocorre absorção de parte da água da argamassa e, de acordo com HOGBERG (1980), se esta absorção acontecer muito rapidamente, resulta em um vazio na interface unidadeargamassa, prejudicando a aderência do prisma. 
Ainda segundo SOLÓRZANO (1994), argamassas com alto módulo de deformação, ou seja, muito rígidas, não permitem a dissipação dos esforços sem que haja o comprometimento da estanqueidade e da perda de aderência da alvenaria.

ISBERNER ${ }^{2}$ apud SABATTINI (1984) listaram algumas dos prováveis fatores para a perda de aderência:

“- Qualidade da argamassa: capacidade de retenção de água, consistência e conteúdo de ar;

- Qualidade dos blocos: Sucção inicial (IRA), condições de superfície (partículas soltas, textura, etc.);

- Qualidade da mão-de-obra: tecnologia de assentamento e preenchimento completo da junta, intervalo de tempo entre o espalhamento e a colocação do bloco, intervalo entre a mistura e o uso da argamassa;

- Condições de cura."

No presente trabalho, verificou-se que o uso da argamassa industrializada não resultou numa boa combinação argamassa/tipo de bloco. Além disso, a argamassa $Q$ é recomendada pelo fabricante para assentar blocos sílico-calcáreos, o que pode explicar em parte a perda de aderência.

Outro motivo que poderia explicar o comprometimento dos valores obtidos nos ensaios é o uso de aditivos incorporadores de ar na argamassa que, segundo SOLÓRZANO (1994), apesar de diminuir a quantidade de água que deve ser colocada na argamassa, melhorar a trabalhabilidade da argamassa e beneficiar na retenção de água, diminui a resistência de aderência.

A BS 4721 limita o teor de ar incorporado para argamassa pronta industrializada em um teor mínimo de $7 \%$ e máximo de $18 \%$. As argamassas utilizadas do tipo P e Q apresentaram teores de 29 e 17\%, respectivamente. De fato, a argamassa do tipo $P$, que não atende aos limites estipulados por essa norma, foi a que mais apresentou comprometimento na resistência de aderência, resultando em valores de resistência à compressão e módulo de elasticidade poucos satisfatórios.

\footnotetext{
${ }^{2}$ ISBERNER, A. W. (1964). Masonry: A progress report. Portland Cement Association - PCA. Sokie. PCA.
} 
Tabela 4.21- Módulo de elasticidade dos prismas da série Q (EP1).

\begin{tabular}{||c|c|c|c||}
\hline Série & $\mathrm{E}_{\mathrm{pm}}(\mathrm{Mpa})$ & $\mathrm{S}_{\mathrm{d}}(\mathrm{MPa})$ & $\mathrm{CV}(\%)$ \\
\hline $\mathrm{Q} 11$ & 4756 & 64 & 1,35 \\
\hline $\mathrm{Q} 12$ & 7302 & 410 & 5,61 \\
\hline $\mathrm{Q} 21$ & 13738 & 543 & 3,95 \\
\hline $\mathrm{Q} 22$ & 12412 & 190 & 1,53 \\
\hline
\end{tabular}

* Resistência do prisma na área líquida.

A média dos prismas apresentou baixos coeficientes de variação. Vale lembrar que foram descartados os resultados que se distanciaram muito dos dois outros.

Notou-se que, conforme é aumentada a resistência àcompressão do bloco, a influência da forma de assentamento no módulo de elasticidade do prisma diminui. Assim, a diferença entre o módulo de elasticidade do prisma quando comparado o argamassamento total e o lateral para o bloco de 4,5 MPa foi de $54 \%$, sendo que para o bloco de $10 \mathrm{MPa}$ esta diferença foi de $11 \%$. Além disso, observou-se um aumento no módulo de elasticidade quando utilizado o argamassamento lateral para o bloco de 4,5 MPa e uma diminuição deste valor para blocos de $10 \mathrm{MPa}$ (ver tabela 4.21).

A influência da resistência à compressão da argamassa na resistência à compressão do prisma não pode ser analisada, já que os ensaios referentes ao segundo tipo de argamassa foram desconsiderados.

Tabela 4.22- Relação entre módulo de elasticidade e resistência à compressão dos prismas (EP1).

\begin{tabular}{||c|c|c|c||}
\hline Série de Prisma & $\mathrm{E}_{\mathrm{pm}} / \mathrm{f}_{\mathrm{pm}}$ & $\mathrm{S}_{\mathrm{d}}$ & $\mathrm{CV}(\%)$ \\
\hline $\mathrm{Q} 11$ & $525^{*}$ & 10,36 & 1,97 \\
\hline Q12 & 864 & 86,00 & 9,96 \\
\hline Q21 & 964 & 243,25 & 25,23 \\
\hline Q22 & 1145 & 26,32 & 2,30 \\
\hline Média & 991 & 116,45 & 11,75 \\
\hline
\end{tabular}

* Resultado descartado por apresentar um desvio grande em relação aos outros valores. 
A tabela 4.22 apresenta a relação entre o módulo de elasticidade e a resistência média à compressão dos prismas. Por estes valores, descartando o valor da série Q11, que se afastou bastante da média, a relação fica em torno de 1000 , próxima àobtida para os blocos.

\section{Influência da resistência à compressão do bloco na resistência à compressão do prisma}

A tabela 4.23 apresenta os valores de eficiência obtidos nos ensaios de prismas.

As relações entre $f_{p m}$ e $f_{b m}$ mostradas nesta tabela diferem bastante dos valores esperados nos ensaios. Para a previsão teórica da resistência à compressão dos prismas, utilizou-se a relação de 0,80 , assumida com no valor médio obtido nos ensaios em prismas de blocos de concreto realizados por ALY \& SABBATINI (1994).

OLIVEIRA (1997) alcançou em seus ensaios com prismas utilizando dois blocos de 4,5 MPa uma eficiência de 0,87.

Atribuíram-se os baixos valores de eficiência alcançados àbaixa aderência entre bloco e a argamassa.

Tabela 4.23- Relação entre resistência à compressão do prisma e dos blocos (EP1).

\begin{tabular}{||c|c|c|c|c|c||}
\hline \hline $\begin{array}{c}\text { Série de } \\
\text { Prisma }\end{array}$ & $\begin{array}{c}\mathrm{f}_{\mathrm{pm}}\left(\mathrm{A}_{\mathrm{l}}\right) \\
(\mathrm{Mpa})\end{array}$ & $\begin{array}{c}\mathrm{f}_{\mathrm{pm}}\left(\mathrm{A}_{\mathrm{b}}\right) \\
(\mathrm{MPa})\end{array}$ & $\begin{array}{c}\mathrm{f}_{\mathrm{bm}}\left(\mathrm{A}_{\mathrm{l}}\right) \\
(\mathrm{MPa})\end{array}$ & $\begin{array}{c}\mathrm{f}_{\mathrm{bm}}\left(\mathrm{A}_{\mathrm{b}}\right) \\
(\mathrm{MPa})\end{array}$ & $\begin{array}{c}\text { Eficiência } \\
\mathrm{f}_{\mathrm{pm}} / \mathrm{f}_{\mathrm{bm}}\end{array}$ \\
\hline $\mathrm{P} 11$ & 5,42 & 2,98 & 17,15 & 9,43 & 0,32 \\
\hline $\mathrm{P} 12$ & 4,61 & 2,54 & 17,15 & 9,43 & 0,27 \\
\hline P21 & 13,05 & 7,18 & 41,00 & 22,55 & 0,32 \\
\hline P22 & 12,83 & 7,06 & 41,00 & 22,55 & 0,31 \\
\hline $\mathrm{Q} 11$ & 8,48 & 4,67 & 17,15 & 9,43 & 0,49 \\
\hline $\mathrm{Q} 12$ & 7,56 & 4,16 & 17,15 & 9,43 & 0,44 \\
\hline Q21 & 15,09 & 8,30 & 41,00 & 22,55 & 0,37 \\
\hline Q22 & 11,47 & 6,31 & 41,00 & 22,55 & 0,28 \\
\hline
\end{tabular}


O gráfico 4.9 apresenta os resultados de resistência à compressão de prismas em função da resistência àcompressão dos blocos, obtidos para os corpos de prova utilizando argamassas do tipo $\mathrm{P}$ e $\mathrm{Q}$, com assentamento total e parcial.

Gráfico Resistência bloco x Resistência prisma

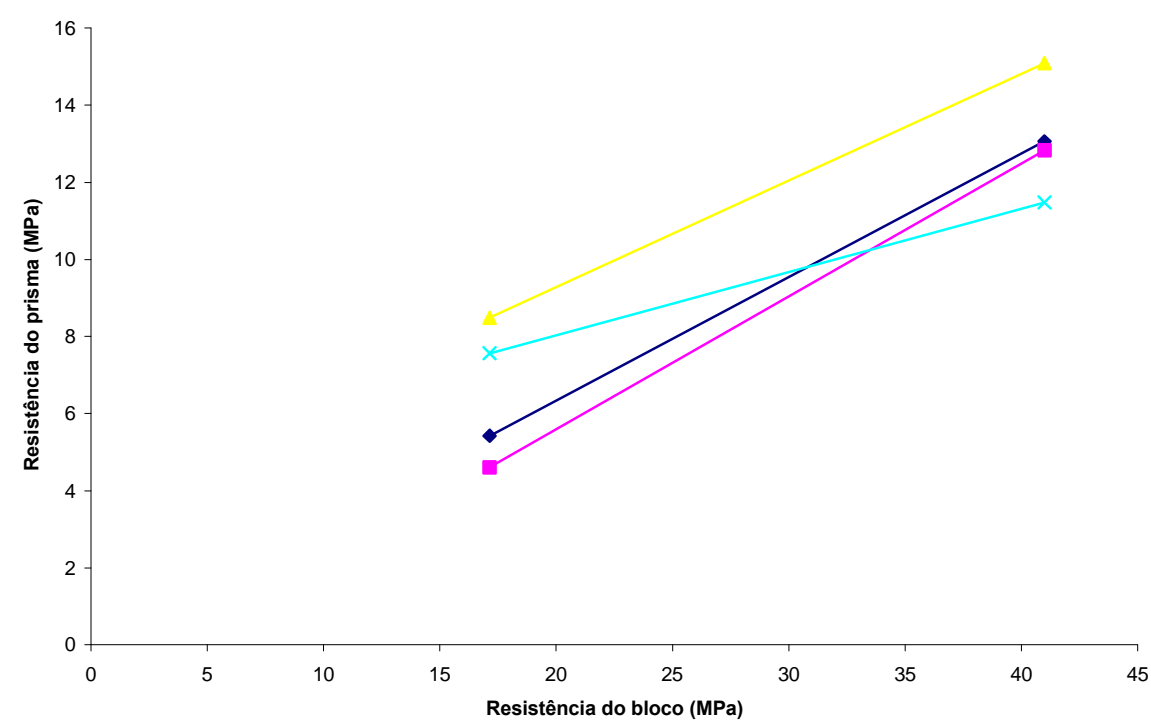

$\longrightarrow$ Argamassa $P$ total - Argamassa P parcia Argamassa Q total Argamassa Q parcial

Figura 4.9 - Gráfico de resistência à compressão do bloco x resistência à compressão do prisma (EP1).

O uso de argamassa de menor resistência à compressão resultou em resistências à compressão de prismas maiores para ambos os tipos de assentamento, com exceção da argamassa do tipo Q com assentamento parcial, que apresentou menor resistência à compressão de prisma quando utilizado o bloco de alta resistência à compressão. Porém, estes resultados podem ter sido afetados pelo comprometimento na aderência quando utilizada a argamassa do tipo $\mathrm{P}$, já que, como comprovado por diversos pesquisadores, tal como ROMAGNA (2000), não haveria de ter influência a resistência àcompressão da argamassa na resistência àcompressão do prisma para blocos de menor resistência.

As curvas correspondentes à argamassa do tipo $Q$ apresentaram-se bem próximas, indicando a pouca influência do tipo do assentamento na resistência à compressão de prisma. 


\section{Tipos de ruptura dos prismas}

O Anexo A deste trabalho ilustra o tipo de ruptura ocorrido em um exemplar de cada série de prisma ensaiada. Através das fotos mostradas pode-se notar a perda da junta horizontal de argamassa, principalmente para os prismas em que foram utilizadas as argamassas do tipo P. Com esta perda, fica clara a falta de aderência entre o bloco e a argamassa, diminuindo consideravelmente a resistência à compressão do prisma, provavelmente devido à interferência no fenômeno relacionado ao estado de triaxial de compressão, responsável por permitir que o prisma seja submetido a esforços superiores aos suportados pela argamassa. A argamassa apresentou microfissuração e degeneração generalizada, esboroando antes da ocorrência de fissuras nos blocos.

\subsubsection{Ensaios Finais}

Na tabela 4.24 são apresentados os valores de cargas de ruptura previstos teoricamente e os obtidos nas séries ensaiadas, a diferença entre estes valores, em relação aos previstos teoricamente, além de suas correspondentes resistências à compressão, calculada em relação àárea bruta dos blocos.

Para a previsão teórica da resistência àcompressão dos prismas, utilizou-se a relação de 0,80 , assumida com base no valor médio obtido nos ensaios em prismas de blocos de concreto realizados por ALY \& SABBATINI (1994).

Tabela 4.24 - Resistência à compressão dos prismas (EF).

\begin{tabular}{|c|c|c|c|c|c|c|}
\hline \multirow{2}{*}{$\begin{array}{c}\text { Série } \\
\text { correspondente }\end{array}$} & \multirow{2}{*}{$\begin{array}{c}F_{\text {rup,prevista }} \\
(\mathrm{kN}) \\
\end{array}$} & \multirow{2}{*}{$\begin{array}{c}F_{\text {rup,ensaio }} \\
(\mathrm{kN}) \\
\end{array}$} & \multirow{2}{*}{$\begin{array}{c}\text { Diferença } \\
(\%) \\
\end{array}$} & \multicolumn{3}{|c|}{ Resistência média à compressão } \\
\hline & & & & $\mathrm{f}_{\mathrm{pm}}(\mathrm{MPa})$ & $\mathrm{S}_{\mathrm{d}}(\mathrm{Mpa})$ & $\mathrm{CV}(\%)$ \\
\hline PRB1A1E $_{y}$ & 422 & 437 & 3,6 & 7,96 & 0,67 & 8,39 \\
\hline PRB1A1E $E_{x}$ & 422 & 377 & $-10,7$ & 6,89 & 0,89 & 12,01 \\
\hline PRB2A1E $E_{Y}$ & 1001 & 459 & $-54,2$ & 7,75 & 0,78 & 10,03 \\
\hline PRB2A1Ex & 1001 & 574 & $-42,7$ & 10,48 & 1,37 & 12,74 \\
\hline $\mathrm{PRB}_{1 \mathrm{~A} 2 \mathrm{E}_{Y}}$ & 422 & 433 & 2,6 & 7,93 & 0,85 & 10,77 \\
\hline PRB1A2E $E_{X}$ & 422 & 388 & $-8,1$ & 7,07 & 0,84 & 11,91 \\
\hline PRB2A2E $_{v}$ & 1001 & 507 & $-49,4$ & 9,22 & 1,23 & 13,38 \\
\hline PRB2A2E $_{x}$ & 1001 & 491 & $-51,0$ & 9,44 & 1,46 & 15,44 \\
\hline
\end{tabular}

* Resistência do prisma na área bruta. 
Os valores apresentados na tabela acima mostram as resistências médias à compressão dos 6 prismas de cada série de paredes (2 prismas para cada parede).

As séries moldadas com blocos do tipo 1 apresentaram variações de resistência à compressão desprezíveis ao variar os tipos de argamassa utilizados. Porém, pode-se perceber que os valores de resistência à compressão obtidos durante os ensaios finais distanciaram-se muito dos valores previstos teoricamente para os prismas que utilizaram o bloco do tipo 2. Esta ocorrência pode ter como motivo o uso de blocos de resistência àcompressão muito elevada se comparada à resistência à compressão da argamassa. Desta forma, o esmagamento da argamassa ocorreu muito precocemente, fato este observado durante os ensaios. Com isso, comprova-se a observação de DRYSDALE et al. (1994), a respeito do aumento da influência da resistência à compressão da argamassa na resistência à compressão da alvenaria conforme se aumenta a resistência da unidade.

Tabela 4.25- Módulo de elasticidade dos prismas (EF).

\begin{tabular}{||c|c|c|c|c||}
\hline \multirow{2}{*}{$\begin{array}{c}\text { Série } \\
\text { correspondente }\end{array}$} & \multirow{2}{*}{$\begin{array}{c}\mathrm{f}_{\mathrm{pm}} \\
(\mathrm{MPa})\end{array}$} & \multicolumn{3}{|c||}{ Módulo de Elasticidade } \\
\cline { 3 - 5 } & $\mathrm{E}_{\mathrm{pm}}(\mathrm{MPa})$ & $\mathrm{S}_{\mathrm{d}}(\mathrm{MPa})$ & $\mathrm{CV}(\%)$ \\
\hline PRB1A2E $_{\mathrm{y}}$ & 7,74 & 6183 & 501 & 8,10 \\
\hline PRB2A2E $_{\mathrm{y}}$ & 9,98 & 4870 & 487 & 10,00 \\
\hline
\end{tabular}

* Resistência do prisma na área bruta.

Para estes ensaios, os valores médios de módulos de elasticidade dos prismas também apresentaram baixos coeficientes de variação. Vale lembrar que foram descartados os resultados que se distanciaram muito dos demais.

A determinação do módulo de elasticidade foi realizada em apenas 3 prismas correspondentes a cada tipo de bloco estudado. Desta forma, procurou-se analisar os módulos de elasticidade das duas séries em que foram utilizadas duas resistências distintas de blocos, totalizando 6 prismas ensaiados.

Observaram-se que os prismas com resistência de blocos maiores tiveram seu módulo de elasticidade menor ao compará-los com os de menor resistência. Isto contradiz o que era esperado, partindo da hipótese de que resistências maiores tendem a produzir um conjunto mais rígido, ou seja, com módulo de elasticidade mais elevado. Com isso, os resultados indicaram uma maior deformabilidade ao utilizar o bloco de maior resistência. Isto pode ter ocorrido pelo fato de ter sido realizado o ensaio usando a argamassa do tipo 2 , que apresentou resistências de 
prismas bem inferiores à esperada quando combinada com o bloco do tipo 2, resultando numa ruptura por esmagamento da argamassa. Dessa forma, o módulo de elasticidade menor para esta série indica a deformabilidade da parede levando à ruptura por esmagamento da argamassa, enquanto a série PRB1A2Ey indica a deformabilidade da parede levando àruptura por tração do bloco.

Tabela 4.26 - Relação entre módulo de elasticidade e resistência à compressão dos prismas (EF).

\begin{tabular}{||c|c|c|c||}
\hline Série de prisma & $\mathrm{E}_{\mathrm{pm}} / \mathrm{f}_{\mathrm{pm}}$ & $\mathrm{S}_{\mathrm{d}}$ & $\mathrm{CV}(\%)$ \\
\hline B1A2E $_{\mathrm{y}}$ & 789 & 18,88 & 2,27 \\
\hline B2A2E $_{\mathrm{y}}$ & 489 & 57,89 & 11,84 \\
\hline
\end{tabular}

A relação entre módulo de elasticidade e resistência à compressão média dos prismas, mostrada através da tabela 4.26, mostra que, provavelmente, a baixa resistência à compressão da argamassa em relação ao bloco tenha afetado o comportamento do conjunto.

\section{Influência da resistência à compressão do bloco na resistência à compressão do prisma}

Os valores de eficiência obtidos nos ensaios de prismas são apresentados na tabela 4.27 .

As eficiências obtidas através dos ensaios de prismas aproximaram do valor 0,70 quando usados prismas com blocos do tipo B1 e 0,40 quando usados blocos do tipo B2. Com isso, pode-se comprovar que para o primeiro caso os valores estão 14\% abaixo da média obtida por ALY \& SABBATINI (1994). No segundo caso o valor cai muito, indicando inadequação da argamassa para o bloco usado.

O uso da argamassa de menor resistência àcompressão teve pouquíssima interferência nos valores de resistências à compressão dos prismas, no caso do bloco B1, concordando com a consideração feita por ROMAGNA (2000), que diz não haver influência da resistência à compressão da argamassa na resistência à compressão do prisma para blocos de menor resistência. 
Tabela 4.27- Relação entre resistência à compressão do prisma e dos blocos

(EF).

\begin{tabular}{||c|c|c|c||}
\hline $\begin{array}{c}\text { Série } \\
\text { correspondente }\end{array}$ & $\begin{array}{c}f_{\mathrm{pm}}\left(\mathrm{A}_{\mathrm{b}}\right) \\
(\mathrm{Mpa})\end{array}$ & $\begin{array}{c}f_{\mathrm{bm}}\left(\mathrm{A}_{\mathrm{b}}\right) \\
(\mathrm{MPa})\end{array}$ & $\begin{array}{c}\text { Eficiência } \\
f_{\mathrm{pm}} / \mathrm{f}_{\mathrm{bm}}\end{array}$ \\
\hline PRB1A1E $_{Y}$ & 7,96 & 10,80 & 0,74 \\
\hline PRB1A1E $_{\mathrm{x}}$ & 6,89 & 10,80 & 0,64 \\
\hline PRB2A1E $_{Y}$ & 7,75 & 22,92 & 0,34 \\
\hline PRB2A1E $_{x}$ & 10,48 & 22,92 & 0,46 \\
\hline PRB1A2E $_{Y}$ & 7,93 & 10,80 & 0,73 \\
\hline PRB1A2E $_{x}$ & 7,07 & 10,80 & 0,66 \\
\hline PRB2A2E $_{Y}$ & 9,22 & 22,92 & 0,40 \\
\hline PRB2A2E $_{x}$ & 9,44 & 22,92 & 0,41 \\
\hline
\end{tabular}

\section{Tipos de ruptura dos prismas}

As figuras 4.10 a 4.13 mostram as formas de rupturas observadas em alguns dos prismas ensaiados. Foi apresentado um exemplar correspondente a cada um dos tipos de séries ensaiadas.

A maioria dos prismas moldados com blocos do tipo 1 apresentou propagação de fissuras verticais ao longo dos septos laterais, com ruptura característica por tração na região próxima da junta de argamassa. Alguns dos prismas, entretanto, romperam de maneira frágil e brusca, sem a presença prévia de nenhuma fissura visível.

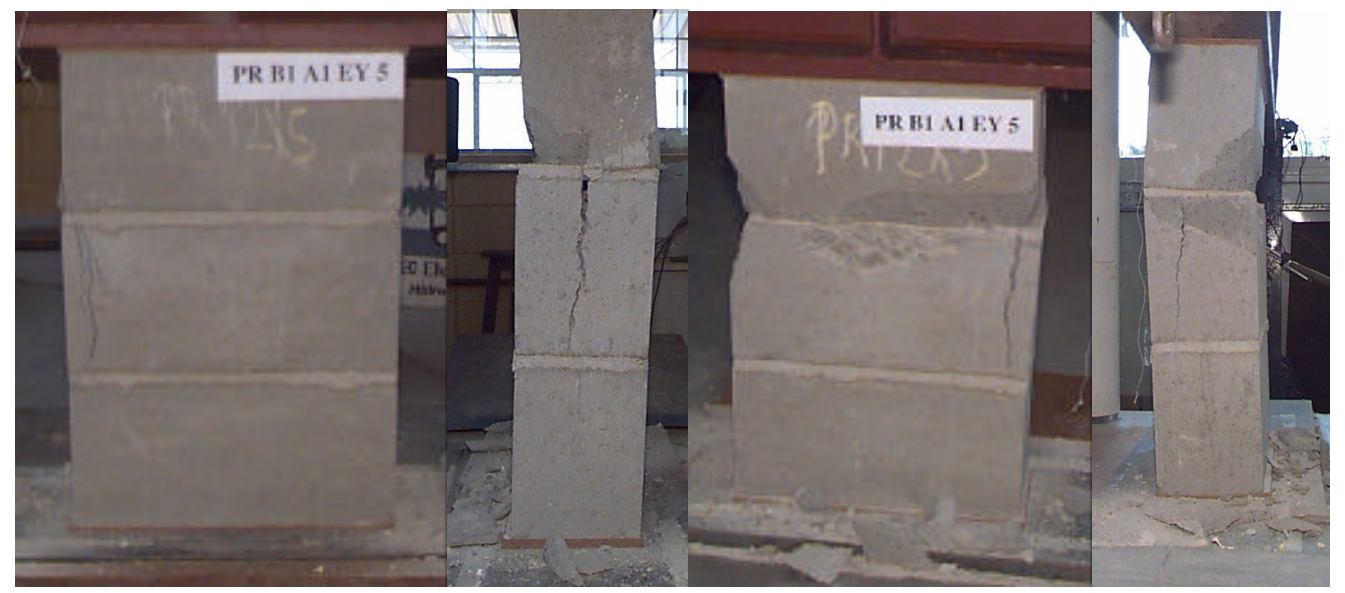

Figura 4.10 - Exemplo de ruptura de prisma da série $B 1 A 1 E_{y}(E F)$. 


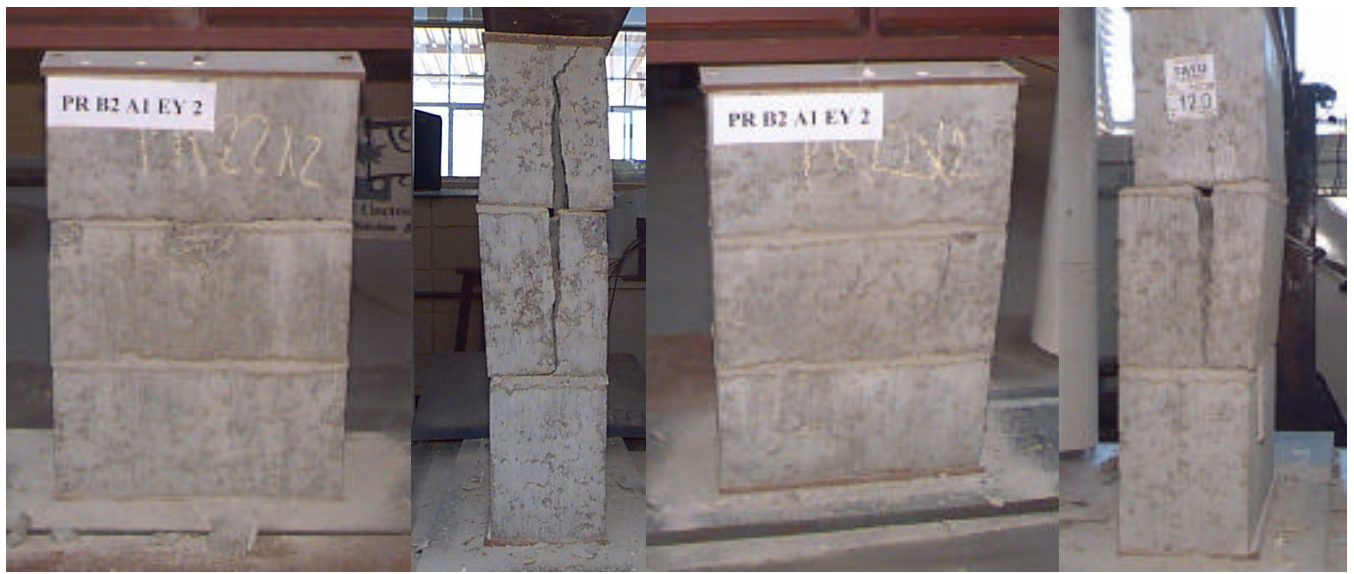

Figura 4.11 - Exemplo de ruptura de prisma da série $B_{2} A 1 E_{y}(E F)$.

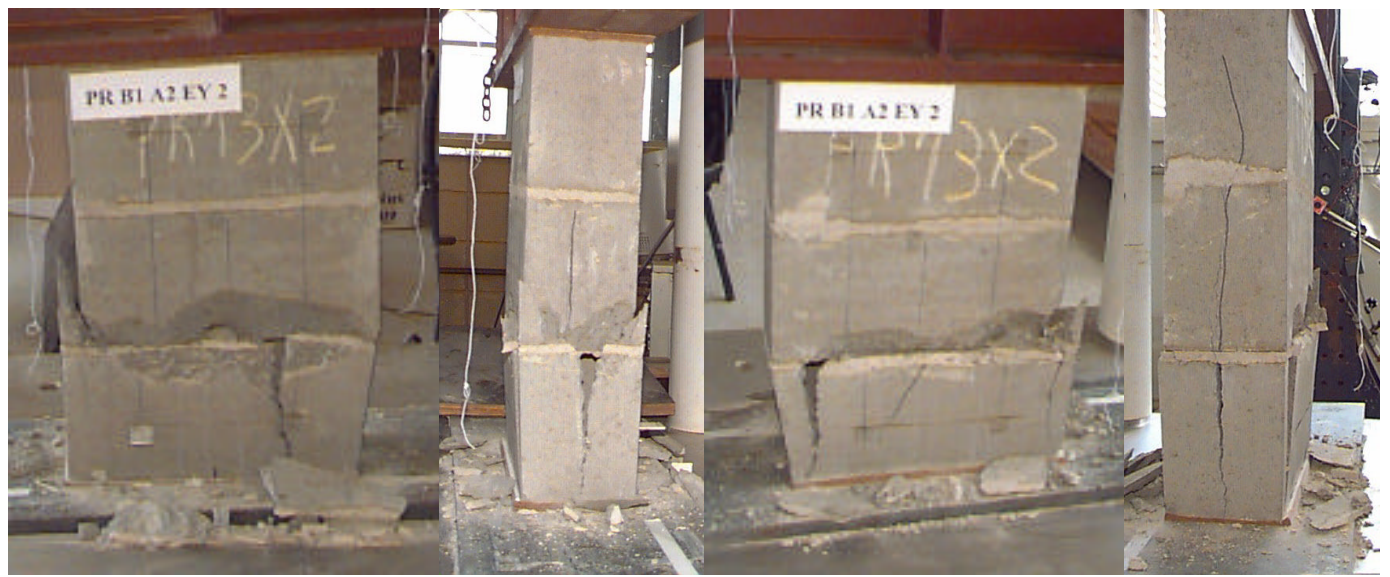

Figura 4.12 - Exemplo de ruptura de prisma da série $B 1 A 2 E_{x}(E F)$.

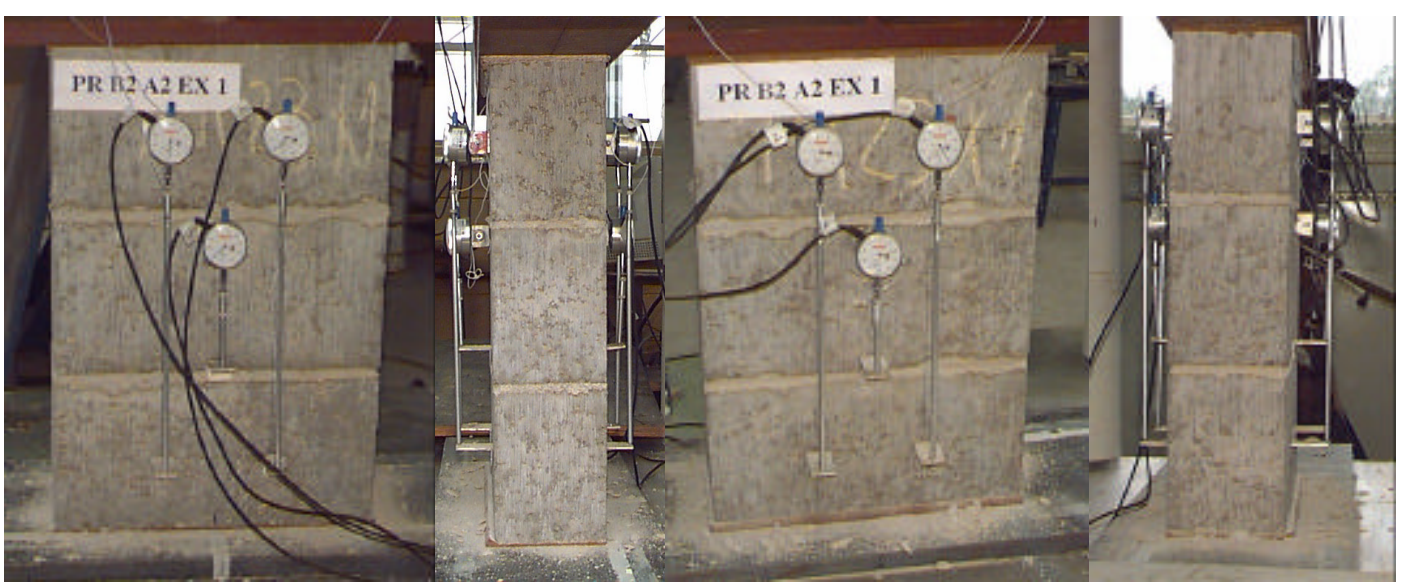

Figura 4.13 - Exemplo de ruptura de prisma da série $B_{2} A_{21 E_{x}}(E F)$.

Para as séries onde foram utilizados os blocos do tipo 2, verificou-se uma perda na capacidade de suporte da junta próximo ao valor da carga de ruptura. A 
figura 4.13 mostra que o prisma não apresentou fissuras visíveis, caracterizando a ruptura por esmagamento da argamassa, ocorrida na maioria dos ensaiados de prismas com este tipo de bloco.

\subsection{Paredinhas}

\subsubsection{Resistência àcompressão}

Os valores médios de força de compressão de ruptura prevista teoricamente e os alcançados nos ensaios, a diferença entre estes valores, em relação aos estimados, e a resistência média àcompressão obtida em função da área bruta das paredinhas podem ser encontrados na tabela 4.28.

Tabela 4.28 - Resistência à compressão das paredinhas (EF).

\begin{tabular}{|c|c|c|c|c|c|c|}
\hline \multirow{2}{*}{$\begin{array}{c}\text { Série } \\
\text { correspondente }\end{array}$} & \multirow{2}{*}{$\begin{array}{c}F_{\text {rup,prevista }} \\
(\mathrm{kN})\end{array}$} & \multirow{2}{*}{$\begin{array}{c}F_{\text {rup,ensaio }} \\
(\mathrm{kN})\end{array}$} & \multirow{2}{*}{$\begin{array}{c}\text { Diferença } \\
(\%) \\
\end{array}$} & \multicolumn{3}{|c|}{ Resistência média à compressão } \\
\hline & & & & $\mathrm{f}_{\mathrm{pam}}{ }^{*}(\mathrm{MPa})$ & $\mathrm{S}_{\mathrm{d}}(\mathrm{MPa})$ & CV $(\%)$ \\
\hline $\mathrm{PAB} 1 \mathrm{~A} 1 \mathrm{E}_{\mathrm{y}}$ & 669 & 550 & $-17,8$ & 4,97 & 0,35 & 7,12 \\
\hline PAB1A1E $E_{x}$ & 335 & 238 & $-29,0$ & 2,16 & 0,14 & 6,48 \\
\hline PAB2A1E $E_{Y}$ & 1420 & 978 & $-31,1$ & 8,84 & 0,96 & 10,89 \\
\hline $\mathrm{PAB} 2 \mathrm{~A} 1 \mathrm{E}_{\mathrm{X}}$ & 710 & 576 & $-18,9$ & 5,20 & 0,60 & 11,53 \\
\hline $\mathrm{PAB1A2E_{Y }}$ & 669 & 456 & $-31,8$ & 4,12 & 0,39 & 9,42 \\
\hline PAB1A2E ${ }_{X}$ & 335 & 222 & $-33,7$ & 2,01 & 0,06 & 2,99 \\
\hline PAB2A2E $_{y}$ & 1420 & $625^{\star *}$ & $-56,0$ & 5,65 & - & - \\
\hline PAB2A2E $_{x}$ & 710 & 427 & $-39,9$ & 3,38 & 0,35 & 10,45 \\
\hline
\end{tabular}

* Resistência do prisma na área bruta;

** Nesta série não foi possível obter valores médios devido à ruptura de duas paredinhas durante o transporte.

A previsão teórica da resistência à compressão das paredinhas ensaiadas com carregamento na direção $Y$ foi de $0,56 . f_{b m}\left(0,7 . f_{p m}\right)$, com base nos resultados médios de eficiência obtidos nos ensaios de ALY \& SABBATINI (1994). Para as paredinhas com carregamento na direção $X$, admitiu-se que esse valor cairia pela metade, ou seja, $0,28 . \mathrm{f}_{\mathrm{bm}}$. 
Cabe ressaltar que este valor corresponde apenas a uma estimativa, estando abaixo da encontrada por KHALAF \& FAIRBAIN (1992). Os referidos autores obtiveram uma razão média entre as resistências à compressão com carregamentos na direção paralela e normal à face de assentamento usual dos blocos de 0,82. Ao estabelecer uma relação linear entre os resultados da previsão teórica e utilizando o valor médio de 0,56. $\mathrm{f}_{\mathrm{bm}}$, obtido nos ensaios em paredinhas realizados por ALY \& SABBATINI (1994), o valor previsto para a eficiência das paredinhas ensaiadas paralelamente ao plano da junta de argamassa seria de 0,46. Porém, a expectativa em relação aos valores de resistência à compressão destas paredinhas foi de que seriam obtidos valores menores de eficiência, o que se confirmou nos ensaios.

$\mathrm{Na}$ série $\mathrm{PAB} 2 \mathrm{~A} 2 \mathrm{E}_{\mathrm{y}}$ não se pode obter resultados médios de resistência à compressão e deformabilidade, já que duas das três paredinhas romperam-se durante o transporte até o equipamento de ensaio. Desta forma, optou-se apenas por apresentar os valores experimentais correspondentes à única paredinha ensaiada, sem realizar nenhuma comparação com as outras séries, já que a confiabilidade do resultado obtido nesta série ficou comprometida.

Pode-se observar a existência de grandes diferenças entre as resistências à compressão previstas e as obtidas experimentalmente.

Tabela 4.29 - Relação entre resistência à compres são da paredinha e dos blocos (EF).

\begin{tabular}{||c|c|c|c||}
\hline $\begin{array}{c}\text { Série } \\
\text { correspondente }\end{array}$ & $\begin{array}{c}f_{\text {pam }}\left(A_{b}\right) \\
(\mathrm{MPa})\end{array}$ & $\begin{array}{c}\mathrm{f}_{\mathrm{bm}}\left(\mathrm{A}_{\mathrm{b}}\right) \\
(\mathrm{MPa})\end{array}$ & $\begin{array}{c}\text { Eficiência } \\
\mathrm{f}_{\mathrm{pam}} / \mathrm{f}_{\mathrm{bm}}\end{array}$ \\
\hline PAB1A1E & 4,97 & 10,80 & 0,46 \\
\hline PAB1A1E $_{\mathrm{y}}$ & 2,16 & 10,80 & 0,20 \\
\hline PAB2A1E & 8,84 & 22,92 & 0,39 \\
\hline PAB2A1E & 5,20 & 22,92 & 0,23 \\
\hline PAB1A2E & 4,12 & 10,80 & 0,38 \\
\hline PAB1A2E & 2,01 & 10,80 & 0,19 \\
\hline PAB2A2E & 5,65 & 22,92 & 0,25 \\
\hline PAB2A2E & 3,38 & 22,92 & 0,15 \\
\hline
\end{tabular}

A tabela 4.29 foi elaborada com o objetivo de verificar o fator de eficiência em paredinhas quando carregadas na direção $Y$ e $X$, alcançando valores próximos 
de 0,40 e 0,20 , respectivamente, contra 0,56 e 0,28 , utilizados para estimar as resistências àcompressão.

Ao comparar as paredinhas moldadas com blocos do tipo $1(4,5 \mathrm{MPa})$ ensaiadas na direção $Y$ e $X$, verificou-se diminuições de resistência de 17\% e 7\%, respectivamente, ao passar da argamassa do tipo 1 para a do tipo 2. Para as paredinhas de $12 \mathrm{MPa}$, esta diferença foi de $35 \%$ para as paredinhas ensaiadas na direção $X$.

A partir do gráfico mostrado na figura 4.14 é possível verificar que as paredinhas de blocos do tipo B1 alcançaram valores de eficiência superiores aos alcançados pelas que utilizaram o bloco do tipo B2. Dessa forma, comprova-se que as paredinhas moldadas com blocos do tipo B2 não tiveram sua resistência à compressão aumentada proporcionalmente ao aumento da resistência à compressão do bloco.

Gráfico Eficiência $x$ Resistência à compressão da paredinha

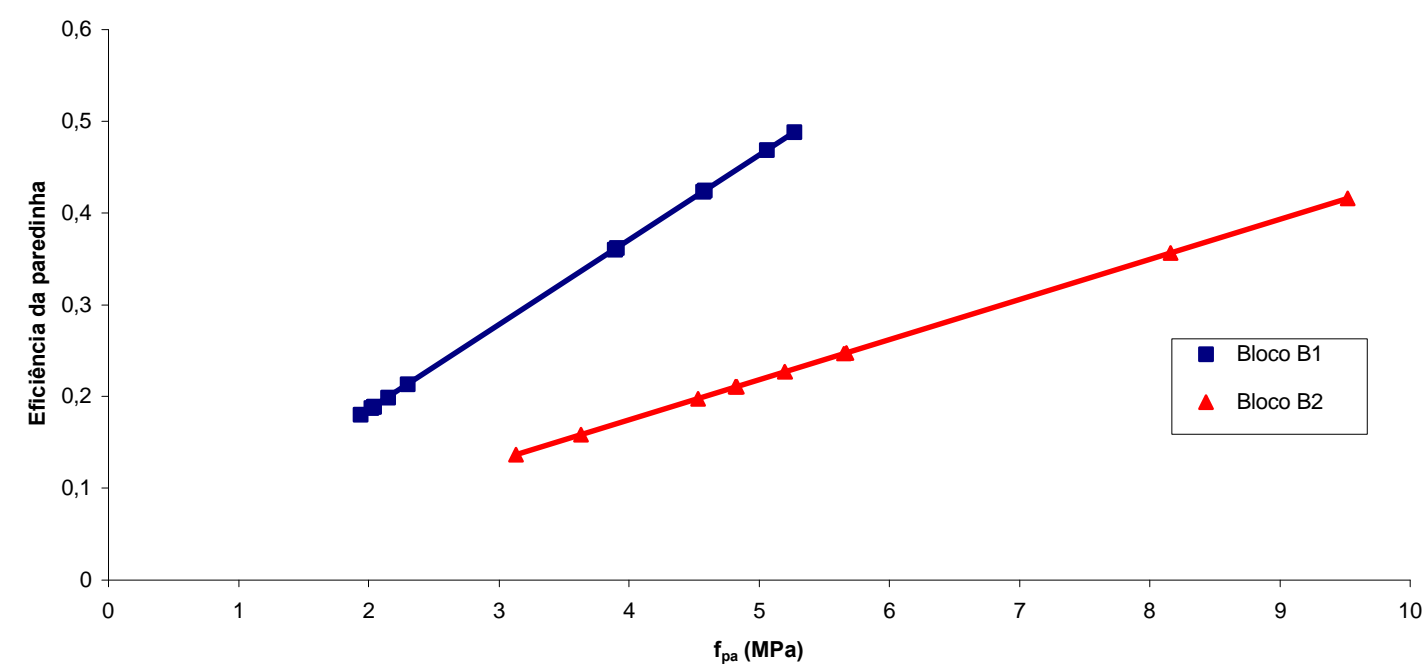

Figura 4.14 - Gráfico de eficiência x resistência à compressão da paredinha (EF).

A figura 4.15 apresenta um gráfico com a reta obtida a partir dos resultados de resistência à compressão das paredinhas ensaiada na direção $Y$ e suas correspondentes ensaiadas na direção $X$, mostrando uma certa tendência destas últimas resistirem a cerca de $50 \%$ dos esforços suportados pelas primeiras. 
Resistência à compressão da paredinha em $Y$ x Resistência à compressão da paredinha em $X$

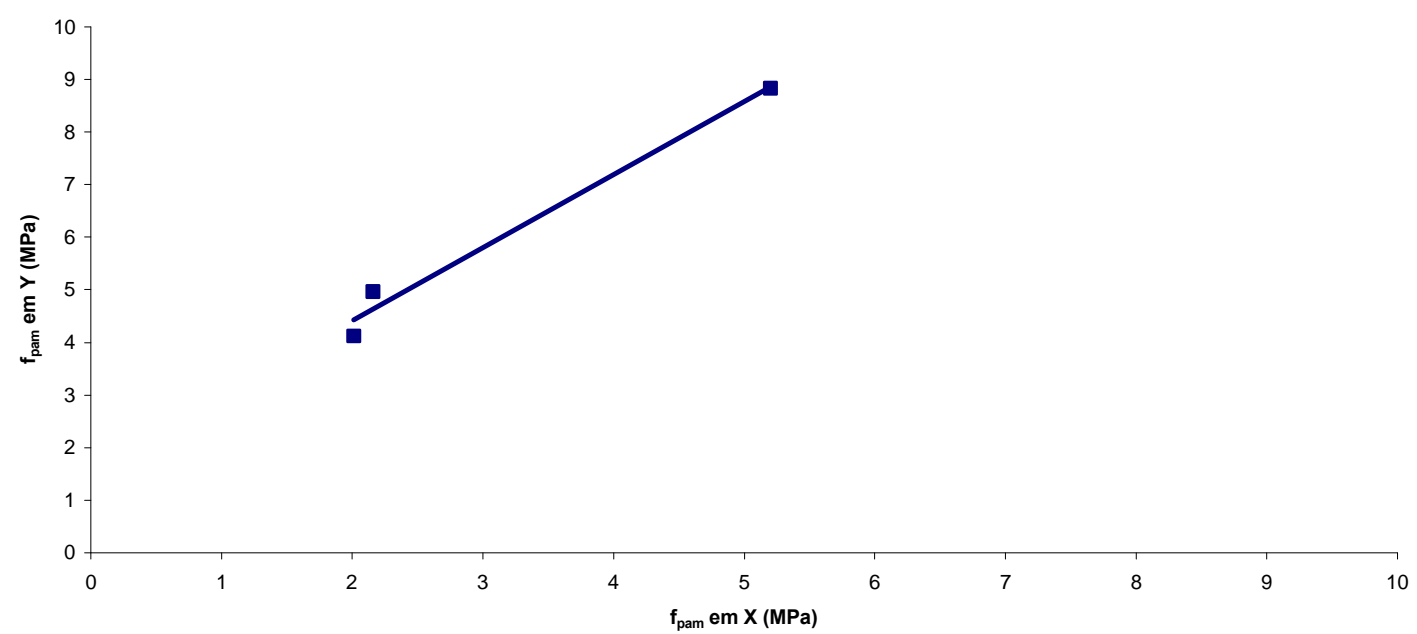

Figura 4.15 - Gráfico de resistência à compressão da paredinha ensaiada em $Y \mathbf{X}$ resistência à compressão da paredinha ensaiada em $X(E F)$.

\subsubsection{Módulo de elasticidade}

As figuras 4.16 e 4.18 mostram gráficos tensão-deformação típicos, obtidos nos ensaios das paredinhas nas direções $Y$ e $X$, respectivamente.

Gráfico Tensão x Deformação PAB1A1E 1 - Parede $\left(E_{x}\right)$

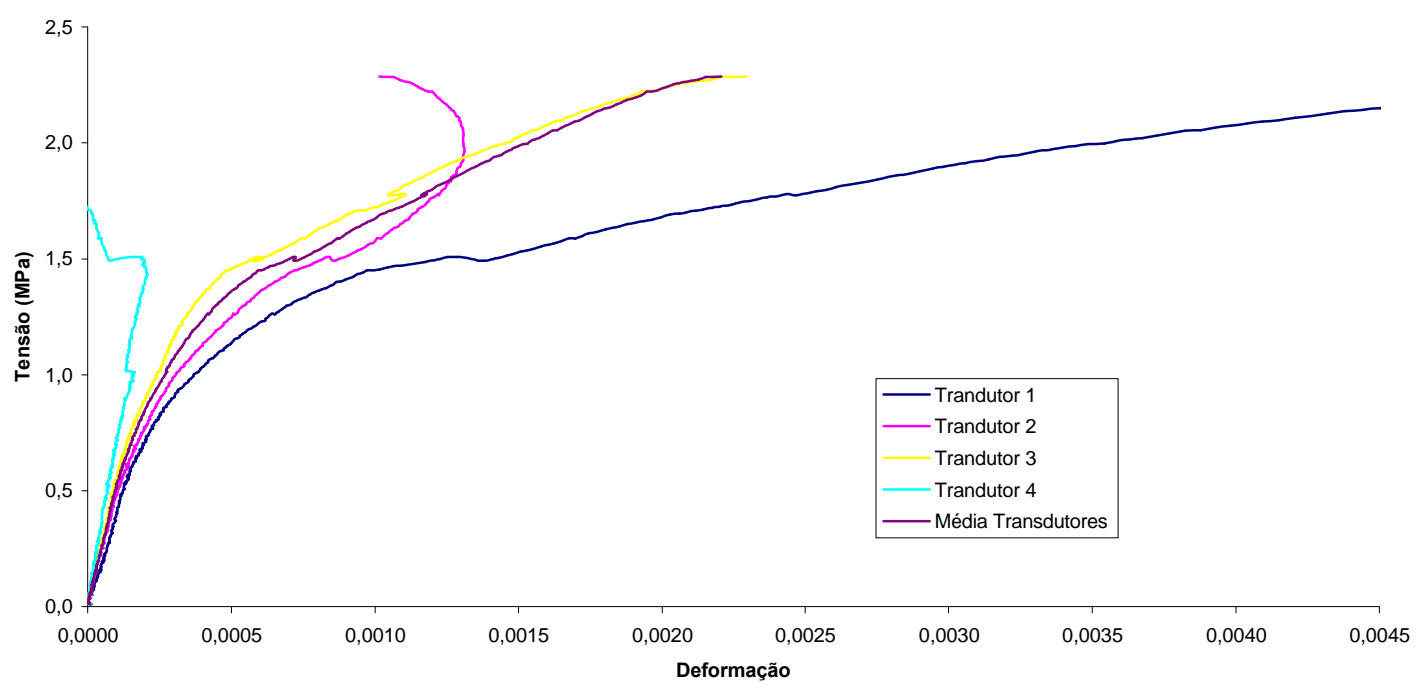

Figura 4.16 - Exemplo de um gráfico tensão-deformação para a paredinha com carregamento na direção X (EF). 
Gráfico Tensão x Deformação PAB1A1E 1 - Parede $\left(E_{x}\right)$

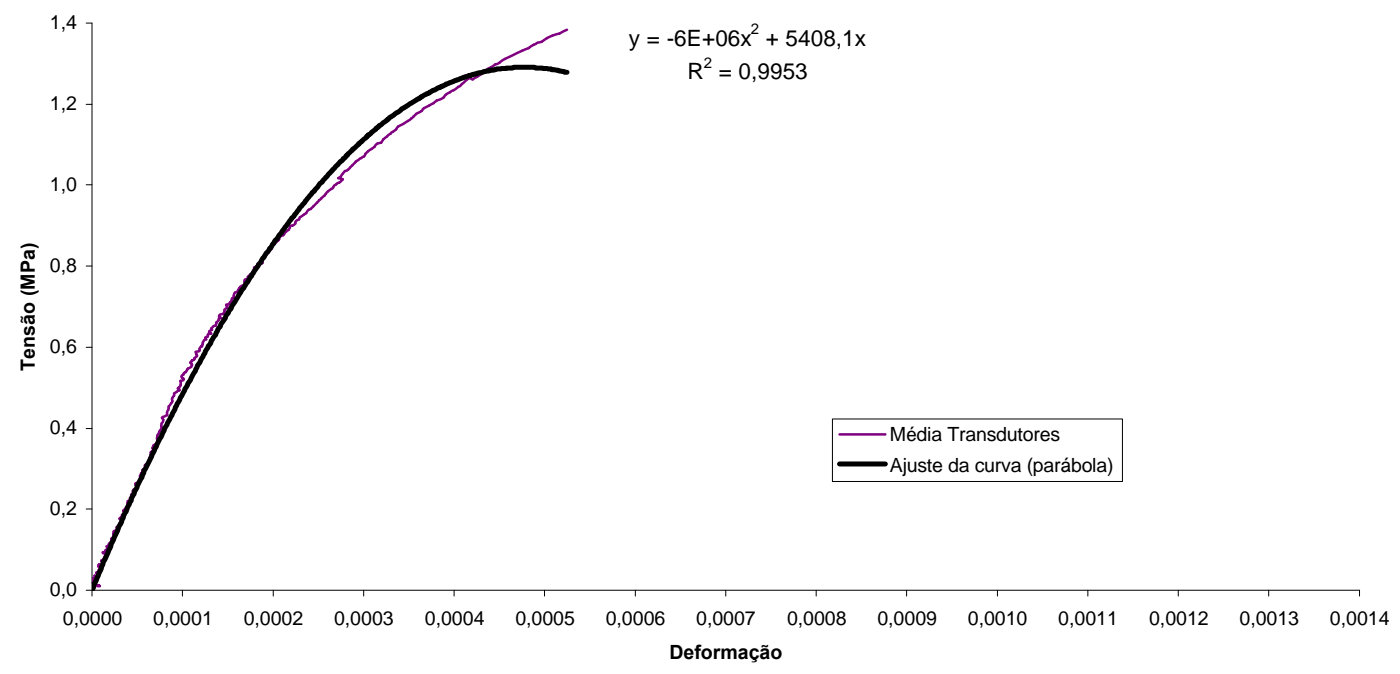

Figura 4.17 - Exemplo da curva ajustada para os valores médios de tensãodeformação para a paredinha carregamento na direção X (EF).

Gráfico Tensão x Deformação PAB1A1E 1 - Parede $\left(E_{y}\right)$

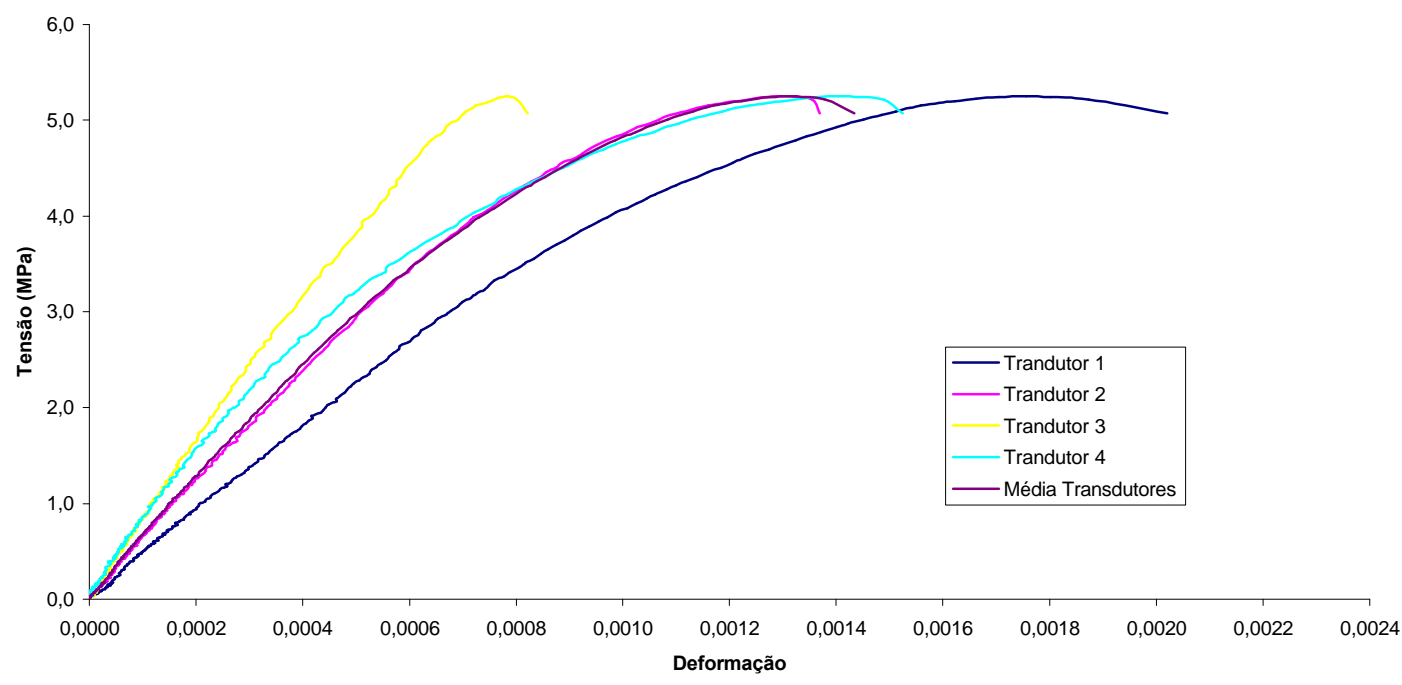

Figura 4.18 - Exemplo de um gráfico tensão-deformação para a paredinha com carregamento na direção $Y(E F)$. 
Gráfico Tensão x Deformação PAB1A1E 1 - Parede $\left(E_{y}\right)$

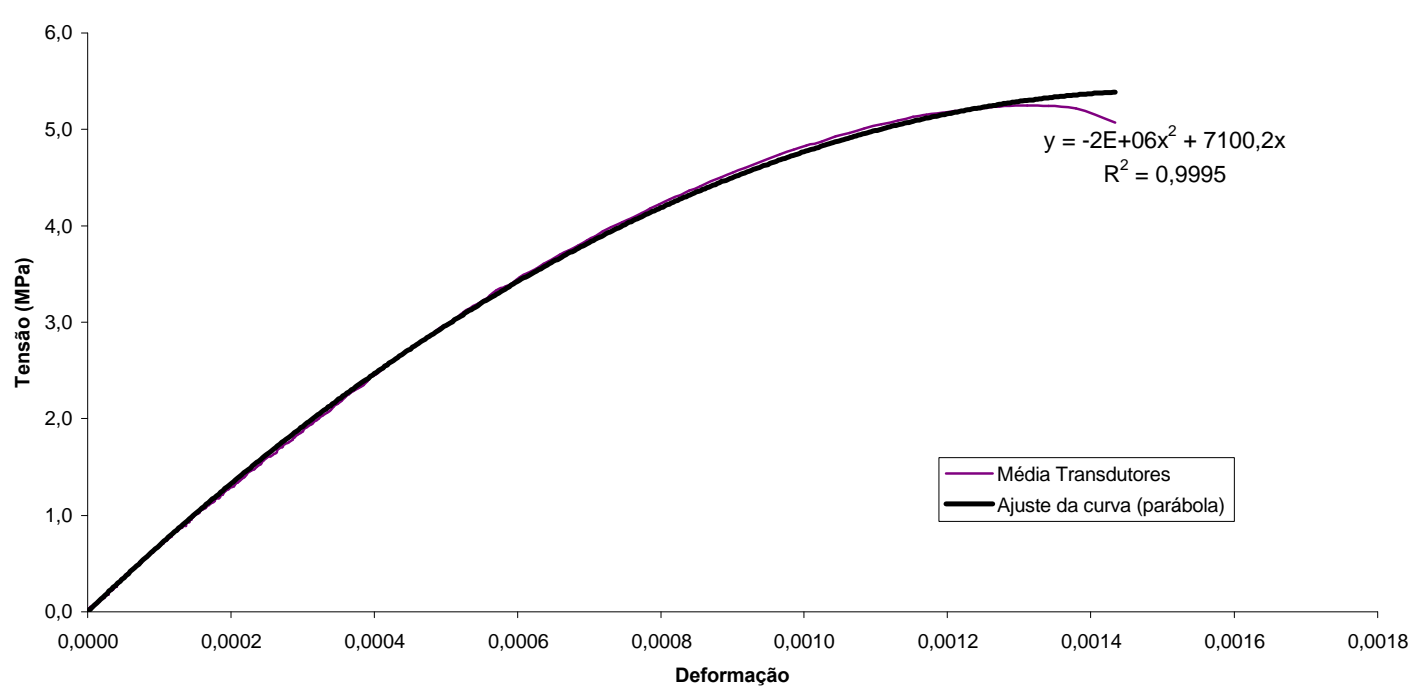

Figura 4.19 - Exemplo da curva ajustada para os valores médios de tensãodeformação para a paredinha carregamento na direção $Y$ (EF).

O módulo de elasticidade das paredinhas foi obtido da mesma maneira descrita para os demais ensaios, ou seja, através da inclinação da reta formada entre os pontos de 5 a 33\% da tensão de ruptura, a partir da equação de cada curva ajustada, obtida com os valores experimentais médios de tensão $\mathrm{x}$ deformação (ver figuras 4.17 e 4.19). Os demais gráficos encontram-se no Anexo B deste trabalho.

A tabela 4.30 mostra os valores de módulo de elasticidade médios ( $\left.E_{p a m}\right)$ para as paredinhas. Exceto para a série PAB2A2E $E_{x}$, concluiu-se que os coeficientes de variação dos resultados foram extremamente baixos, devido à grandeza das medições, já que se tratando de módulo de elasticidade, pequenas variações de medidas de deformações originam grandes variações do módulo de elasticidade obtido.

$\mathrm{O}$ alto coeficiente de variação da série $\mathrm{PAB} 2 \mathrm{~A} 2 \mathrm{E}_{\mathrm{x}}$ pode ser explicado pela imprecisão intrínseca às medidas realizadas e a grande variabilidade do módulo de elasticidade dentro do corpo de prova, já que com a realização da reamassamento da argamassa durante a moldagem, realizada para manter a trabalhabilidade da mesma, pode ter sido introduzida uma considerável variabilidade nas propriedades da junta de argamassa, sendo esta transferida para o corpo de prova. 
Tabela 4.30 - Módulo de elasticidade das paredinhas (EF).

\begin{tabular}{||c|c|c|c|c||}
\hline \multirow{2}{*}{$\begin{array}{c}\text { Séries de paredes } \\
\text { correspondentes }\end{array}$} & \multirow{2}{*}{$\begin{array}{c}\mathrm{f}_{\mathrm{pam}} \\
(\mathrm{Mpa})\end{array}$} & \multicolumn{3}{|c||}{ Módulo de Elasticidade * } \\
\cline { 3 - 6 } & $\mathrm{E}_{\mathrm{pam}}(\mathrm{Mpa})$ & $\mathrm{S}_{\mathrm{d}}(\mathrm{Mpa})$ & $\mathrm{CV}(\%)$ \\
\hline PAB1A1E $_{\mathrm{Y}}$ & 4,97 & 6383 & 160,62 & 2,52 \\
\hline PAB1A1E $_{\mathrm{X}}$ & 2,16 & 3060 & 40,72 & 1,33 \\
\hline PAB2A1E & 8,84 & 9128 & 1105,50 & 12,11 \\
\hline PAB2A1E & 5,20 & 8062 & 566,92 & 7,03 \\
\hline PAB1A2E & 4,12 & 6440 & 147,96 & 2,30 \\
\hline PAB1A2E & 2,01 & 3125 & 173,94 & 5,57 \\
\hline PAB2A2E & 3,86 & $8693^{\star *}$ & - & - \\
\hline PAB2A2E & 3,38 & 6966 & 2552,04 & 36,64 \\
\hline
\end{tabular}

* Resistência do prisma na área bruta

** Nesta série não foi possível obter valores médios devido a ruptura de duas paredinhas durante o transporte.

Analisando os resultados em paredinhas moldadas com blocos do tipo 1 é possível perceber que os módulos de elasticidade praticamente não sofreram aumentos significativos com a mudança do tipo de argamassa utilizada. Já nas paredinhas onde foram usados blocos do tipo B2, esta variação foi de $13 \%$. Isto pode comprovar o que já concluído por FRANCO (1987) em seu trabalho experimental, que a diferença entre os módulos de elasticidade se torna cada vez mais sensível com a alteração dos traços da argamassa, conforme maior o módulo de elasticidade da alvenaria.

Entretanto, ao comparar os módulos de elasticidade obtidos nas séries de paredinhas com argamassa do tipo 1, observou-se aumentos de 43 e 164\% nas direções de ensaio $\mathrm{Y}$ e $\mathrm{X}$, respectivamente, ao passar de blocos do tipo 1 para 0 tipo 2. Ao utilizar a argamassa do tipo 2, esse aumento foi de $123 \%$ para a parede ensaiada na direção $X$.

As séries em que foram utilizados blocos do tipo 1 com as argamassas tanto do tipo 1 quanto do tipo 2, sofreram redução média de 52\% ao passar a direção de ensaio de $\mathrm{X}$ para $\mathrm{Y}$. Já para a série em que se utilizou o bloco do tipo 2 e argamassa do tipo 1 esta redução foi de $12 \%$. 
Tabela 4.31 - Comparação do módulo de elasticidade entre a expressão proposta por SHALIN (1971) e os obtidas no ensaio (EF).

\begin{tabular}{|c|c|c|c|c||}
\hline $\begin{array}{c}\text { Séries de paredes } \\
\text { correspondentes }\end{array}$ & $\begin{array}{c}\mathrm{E}_{\mathrm{am}} \\
(\mathrm{MPa})\end{array}$ & $\begin{array}{c}\mathrm{E}_{\mathrm{bm}}{ }^{*} \\
(\mathrm{MPa})\end{array}$ & $\begin{array}{c}\mathrm{E}_{\mathrm{pam}} \text { (Eq. 2.24) } \\
(\mathrm{MPa})\end{array}$ & $\begin{array}{c}\mathrm{E}_{\mathrm{pam}}{ }^{*} \text { (Ensaio) } \\
(\mathrm{MPa})\end{array}$ \\
\hline PAB1A1E & 9796 & 6228 & 6380 & 6383 \\
\hline PAB2A1E $_{\mathrm{Y}}$ & 9796 & 7554 & 7778 & 9128 \\
\hline PAB1A2E $_{Y}$ & 7598 & 6228 & 6425 & 6440 \\
\hline PAB2A2E & 7598 & 7554 & 6425 & $8693^{* *}$ \\
\hline
\end{tabular}

* Resistência do bloco na área bruta

** Nesta série não foi possível obter valores médios devido a ruptura de duas paredinhas durante o transporte.

A partir dos valores de módulo de elasticidade médios da argamassa e do bloco calculadas a partir dos ensaios, montou-se a tabela 4.31 para que fosse possível comparar os resultados ao utilizar a equação proposta por SHALIN (1971) para estimar o módulo de elasticidade da alvenaria (equação 2.24) e os obtidos nos ensaios de paredinhas. Com isso, verificou-se grande proximidade dos resultados estimados com os experimentais para os blocos do tipo 1, havendo uma variação de $17 \%$ para a série de blocos do tipo 2.

Porém, cabe ressaltar que este pesquisador sugere adotar os módulos de elasticidade do bloco e da argamassa obtidos a partir de medidas de deformações feitas na própria alvenaria, o que não ocorreu no caso da argamassa, já que a mesma foi calculada a partir de ensaio de compressão axial. Além disso, o módulo de elasticidade da argamassa não foi recalculado para os ensaios finais, sendo usados os valores obtidos nos ensaios-piloto 2. Porém, nestes ensaios, verificou-se uma considerável diferença entre as resistências à compressão da argamassa, o que provavelmente causou significativas modificações no módulo de elasticidade. A proximidade dos valores experimentais em relação aos propostos por SHALIN (1971), ao utilizar o bloco 1, pode ser um indício da pouca influência da argamassa na alvenaria quando a ruptura da mesma ocorre por ruptura do bloco. No caso das séries em que utilizaram-se os blocos do tipo 2, essa diferença passou a ser significativa, já que a ruptura pelo esmagamento da argamassa pode ter afetado os resultados. 
Módulo de elasticidade da paredinha em Y x Módulo de elasticidade da paredinha em X

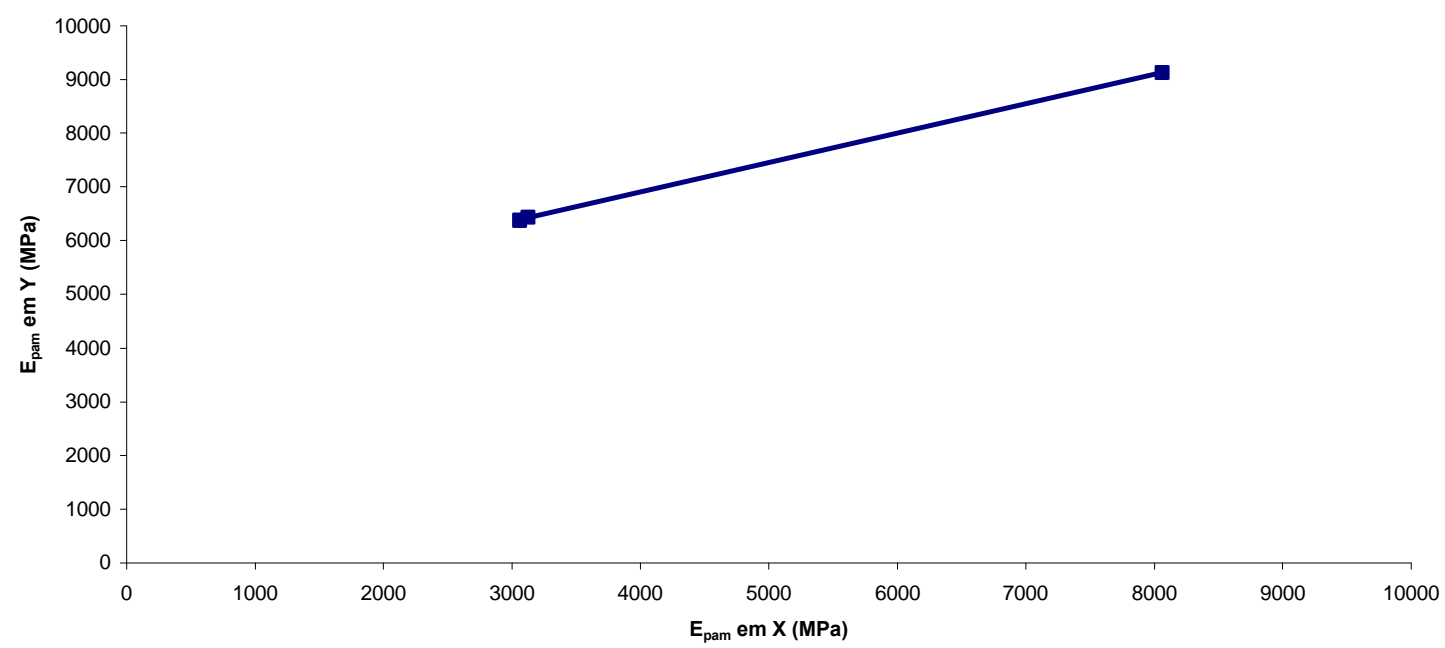

Figura 4.20 - Gráfico de módulo de elasticidade da paredinha ensaiada em Y x módulo de elasticidade da paredinha ensaiada em X (EF).

O gráfico 4.20 mostra a relação entre o módulo de elasticidade da paredinha ensaiada na direção $Y$ em função da sua correspondente ensaiada na direção $X$. Para as paredinhas com blocos do tipo 1 a relação entre $E_{p a m}$ em $X$ tende a $50 \%$ do valor de $E_{p a m}$ em $Y$.

Gráfico Tensão x Deformação PAB1A1E 2 - Parede $\left(E_{x}\right)$

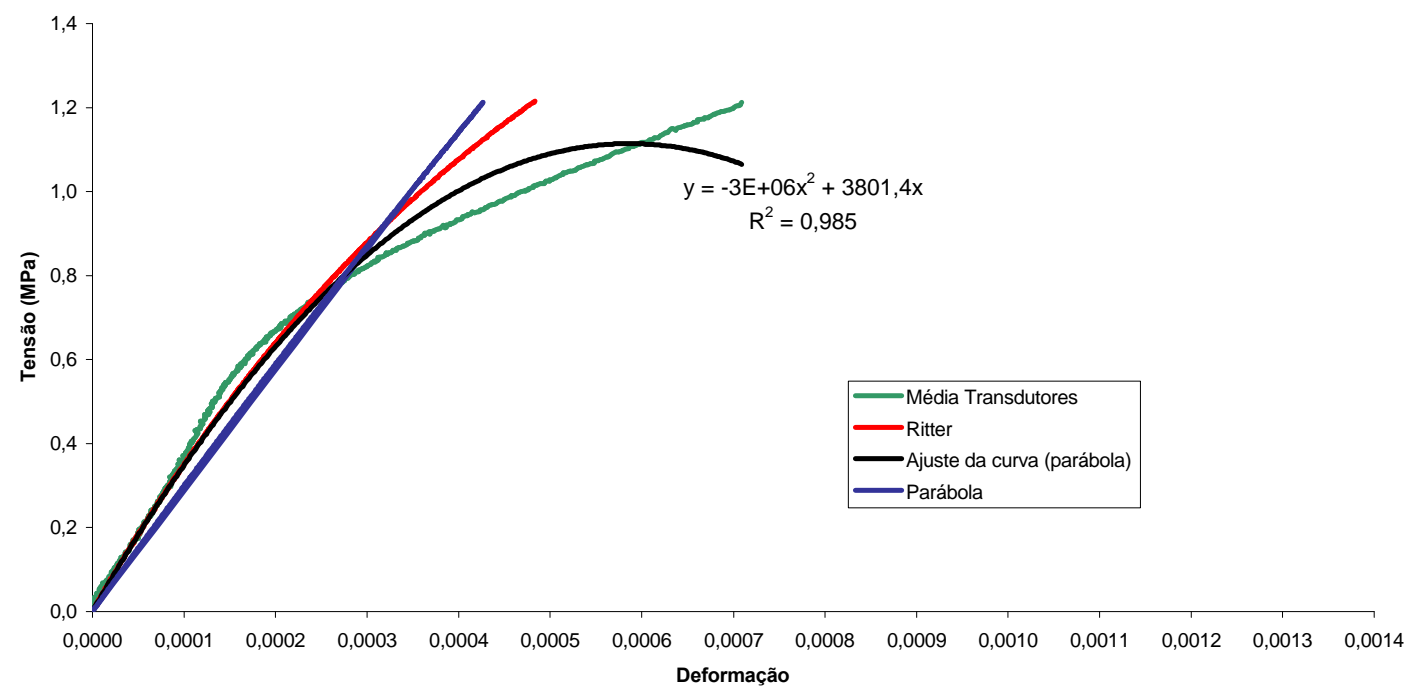

Figura 4.21 - Comparação das curvas tensão-deformação para as medições feitas com transdutores nas paredinhas (EF). 
Foi feito um exemplo utilizando as expressões propostas por KNUTSSON \& NIELSEN (1995) para verificar a aproximação das curvas propostas pelos autores com a curva ajustada aos resultados experimentais (ver fig. 4.21). As curvas, propostas pelos referidos autores, principalmente a parábola, aproximaram-se da parábola alcançada pelo ajuste da curva até a cerca de $50 \%$ do valor da tensão de ruptura.

Um ponto importante a esclarecer é o fato de que paredes com dimensões reais podem apresentar valores de módulo de elasticidade um pouco menores aos obtidos em ensaios em paredinhas. No trabalho desenvolvido por FRANCO (1987), os valores de módulo de elasticidade para paredes cerâmicas tiveram diminuição de cerca de $13 \%$.

\subsubsection{Relação entre módulo de elasticidade e resistência àcompressão da paredinha}

A figura 4.22 mostra um gráfico que relaciona o módulo de elasticidade da paredinha com a sua resistência à compressão, onde foram consideradas as paredinhas ensaiadas nas direções $X$ e $Y$ em conjunto. Esta opção foi adotada após verificar que a separação acarretaria pouca diferença em relação àmédia.

Gráfico de Módulo de Elasticidade x Resistência à compressão da paredinha

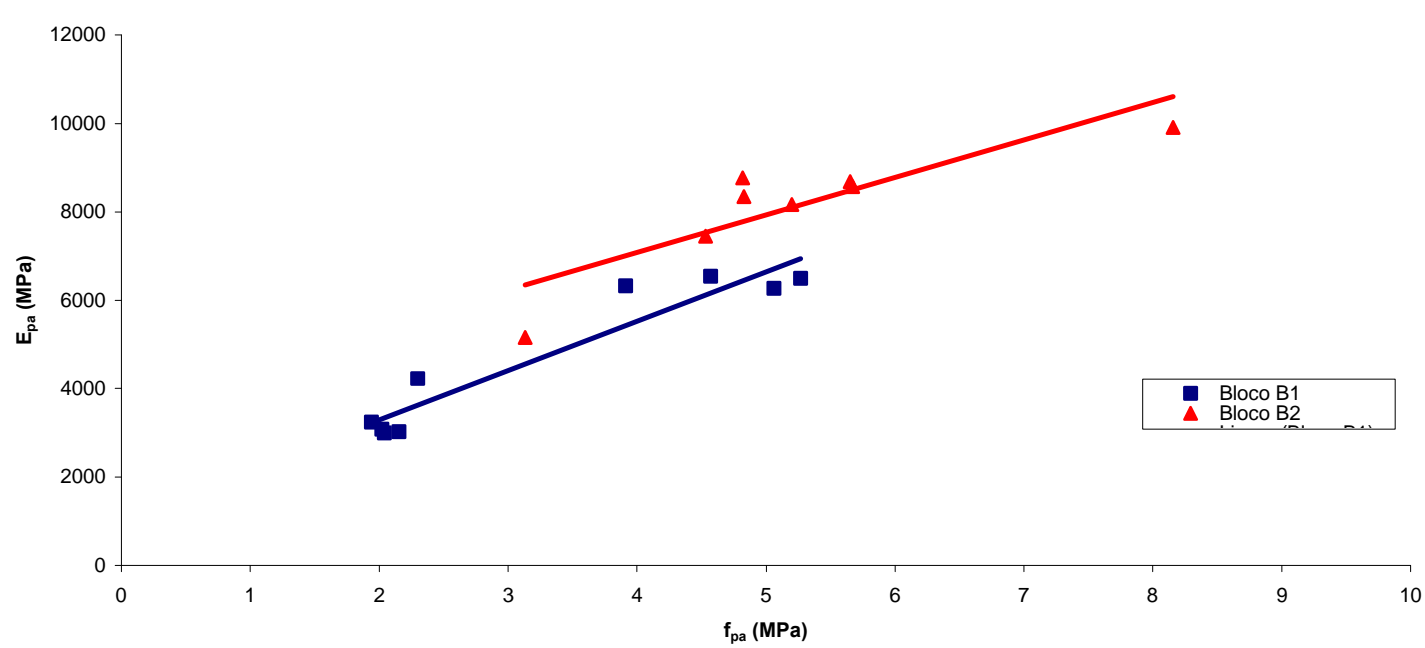

Figura 4.22 - Gráfico Módulo de elasticidade x Resistência à com pressão da paredinha (EF). 
Através deste gráfico é possível perceber que as paredinhas com blocos dos tipos 1 e 2 apresentaram a maioria dos seus valores de resistência à compressão próximos (na faixa entre 3,0 e $6,0 \mathrm{MPa}$ ), porém com um certo aumento na sua rigidez.

Na média, a razão entre o módulo de elasticidade da paredinha e sua resistência àcompressão alcançou o valor de 1500.

Tabela 4.32 - Relação entre módulo de elasticidade e resistência à compressão das paredinhas (EF).

\begin{tabular}{||c|c|c|c||}
\hline Série de Prisma & $\mathrm{E}_{\mathrm{pam}} / f_{\text {pam }}$ & $\mathrm{S}_{\mathrm{d}}$ & $\mathrm{CV}(\%)$ \\
\hline PAB1A1E $_{\mathrm{V}}$ & 1236 & 3,33 & 0,27 \\
\hline PAB1A1E $_{\mathrm{x}}$ & 1469 & 84,84 & 5,77 \\
\hline PAB2A1E & 1272 & 80,92 & 6,36 \\
\hline PAB2A1E & 1569 & 27,54 & 1,76 \\
\hline PAB1A2E & 1525 & 132,39 & 8,68 \\
\hline PAB1A2E & 1573 & 145,47 & 9,25 \\
\hline PAB2A2E & $1539^{*}$ & - & - \\
\hline PAB2A2E & 1735 & 119,11 & 6,87 \\
\hline Média & $\mathbf{1 5 0 1}$ & $\mathbf{3 5 2 , 8 5}$ & $\mathbf{2 3 , 5 1}$ \\
\hline \hline
\end{tabular}

${ }^{*}$ Resultado descartado

Gráfico de $\mathrm{E}_{\mathrm{pa}} / \mathrm{f}_{\mathrm{pa}} \times$ Resistência à compressão da paredinha

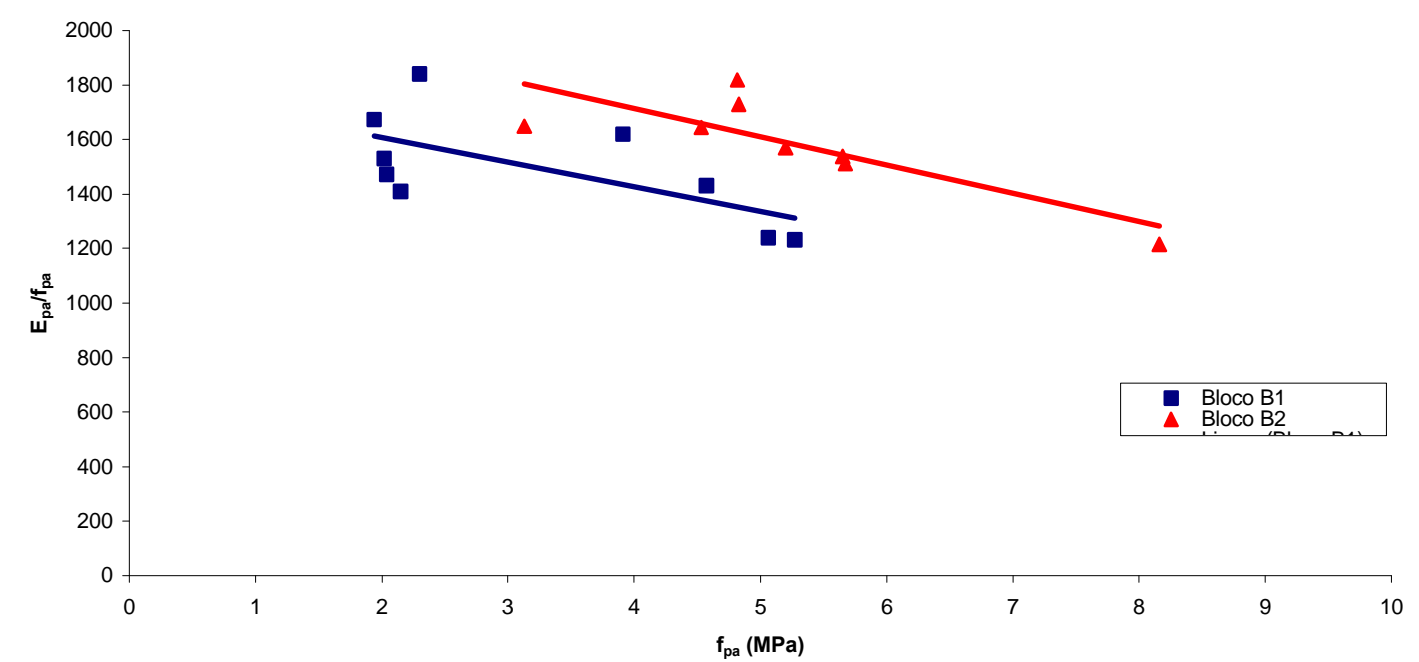

Figura 4.23 - Gráfico $\mathrm{E}_{\mathrm{pa}} / \mathrm{f}_{\mathrm{pa}} \times$ Resistência à compressão da paredinha (EF). 
A figura 4.23 apresenta um gráfico que relaciona a razão módulo de elasticidade/resistência à compressão da paredinha com a sua resistência à compressão. Através deste gráfico, pode-se perceber que as paredinhas com blocos do tipo 2 apresentaram relações entre $E_{p a} / f_{p a}$ maiores quando comparados às que utilizaram blocos do tipo 1 .

\subsubsection{Relação entre resistência àcompressão do prisma e da paredinha}

A figura 4.33 mostra os resultados das relações entre as resistências à compressão dos prismas e a resistência àcompressão das paredinhas.

Tabela 4.33 - Relação entre a resistências à compressão dos prismas e das paredinhas (EF).

\begin{tabular}{||c|c|c|c||}
\hline $\begin{array}{c}\text { Série } \\
\text { correspondente }\end{array}$ & $\begin{array}{c}\mathrm{f}_{\mathrm{prm}}\left(\mathrm{A}_{\mathrm{b}}\right) \\
(\mathrm{MPa})\end{array}$ & $\begin{array}{c}\mathrm{f}_{\mathrm{pam}}\left(\mathrm{A}_{\mathrm{b}}\right) \\
(\mathrm{MPa})\end{array}$ & $\mathrm{f}_{\mathrm{pam}} / \mathrm{f}_{\mathrm{prm}}$ \\
\hline PAB1A1E $_{Y}$ & 7,96 & 4,97 & 0,62 \\
\hline PAB1A1E $_{x}$ & 6,89 & 2,16 & 0,31 \\
\hline PAB2A1E & 7,75 & 8,84 & $1,14^{*}$ \\
\hline PAB2A1E & 10,48 & 5,20 & 0,50 \\
\hline PAB1A2E & 7,93 & 4,12 & 0,51 \\
\hline PAB1A2E $_{X}$ & 7,07 & 2,01 & 0,28 \\
\hline PAB2A2E $_{y}$ & 9,22 & 5,65 & 0,61 \\
\hline PAB2A2E $_{x}$ & 9,44 & 3,38 & 0,36 \\
\hline \hline
\end{tabular}

${ }^{*}$ Resultado descartado

A relação média das resistências entre prismas e paredinhas nas direções $X$ e $Y$ foi de 0,58 e 0,36 , respectivamente.

\subsubsection{Coeficiente de Poisson}

Notou-se uma grande dificuldade em calcular o coeficiente de Poisson a partir dos resultados obtidos experimentalmente. Esta dificuldade deveu-se ao fato da ocorrência de grandes oscilações nos resultados experimentais, principalmente sob baixas tensões, que pode ter tido como causa a grande variabilidade das medidas de ensaio aliada à variabilidade intrínseca do material. Além disso, a 
grandeza das medidas (pequenos valores de leitura) também dificultou sua obtenção, sendo desta forma bastante influenciada por imprecisões de medida ligadas ao ensaio. Um exemplo de gráfico pode ser visto na figura 4.24, estando os demais presentes no Anexo B deste trabalho.

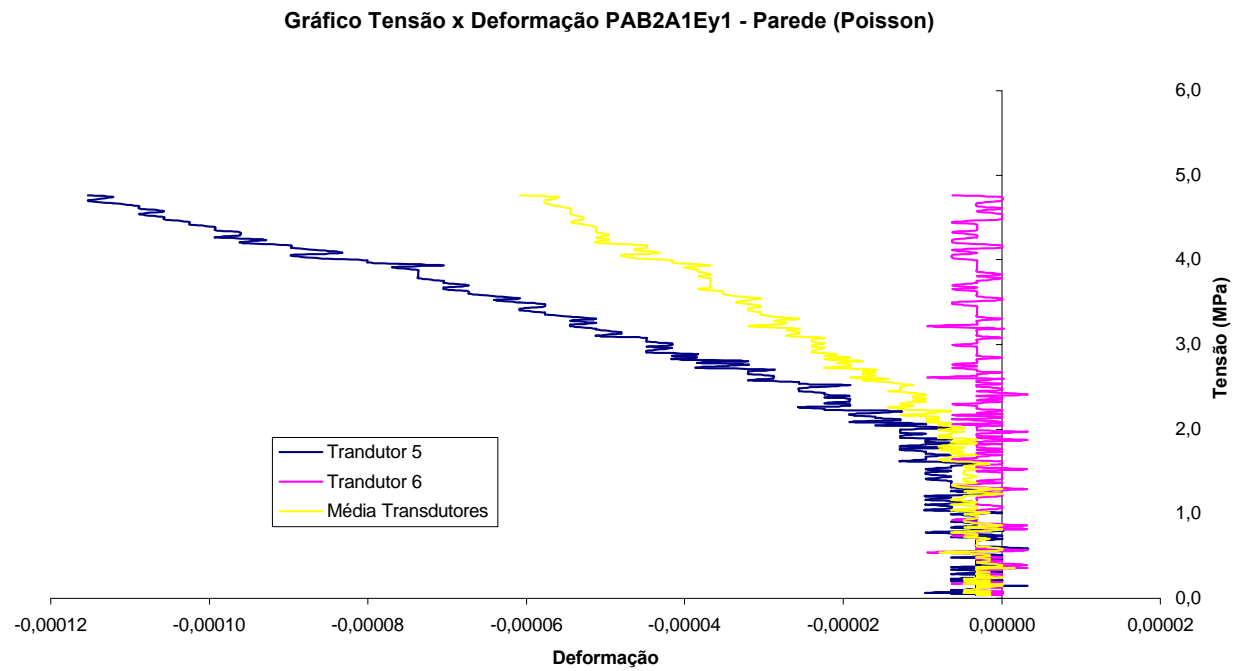

Figura 4.24 - Exemplo da curva tensão x deformação transversal para a paredinha com carregamento na direção X (EF).

Gráfico Tensão x Deformação PAB2A1Ey1 - Parede (Poisson)

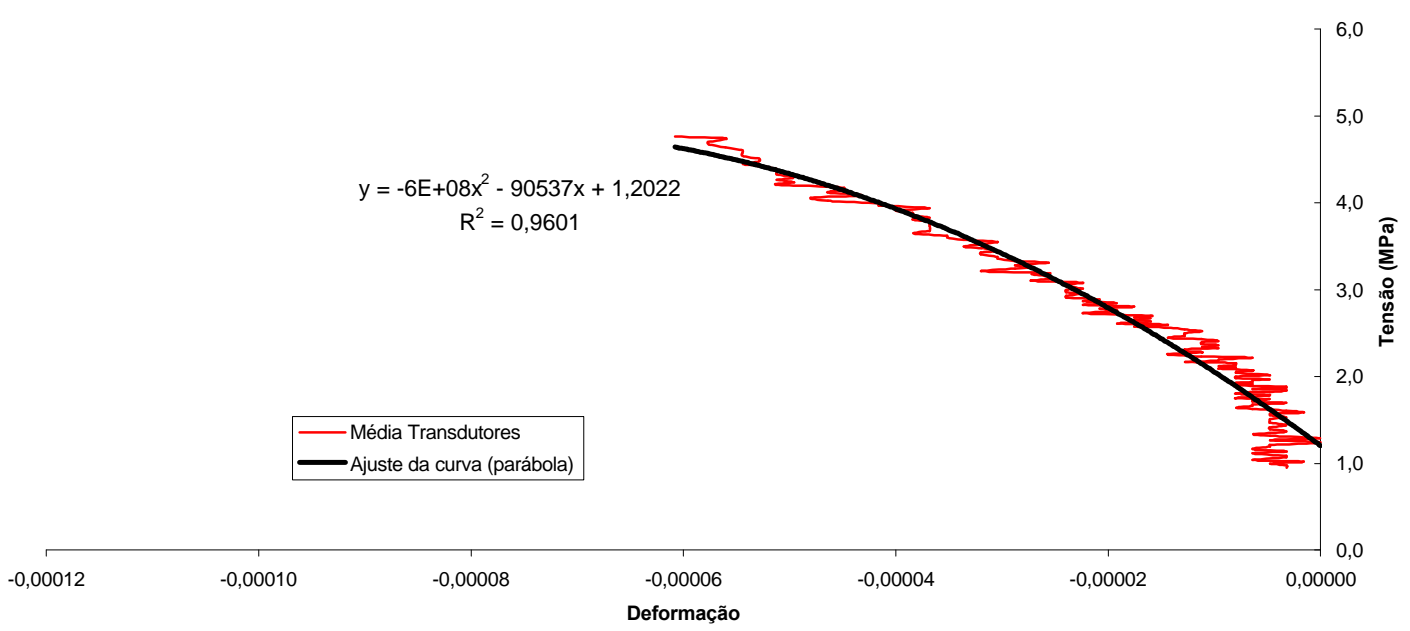

Figura 4.25- Exemplo da curva ajustada para os valores médios de tensãodeformação transversal para a paredinha com carregamento na direção $X$ (EF). 
Como causas da grande variabilidade nos resultados obtidos pode-se citar a variabilidade nas propriedades mecânicas dos materiais, principalmente da argamassa entre os pontos distintos do corpo de prova, bem como a possibilidade de existência de imperfeições em alguns destes pontos, devido ao mal preenchimento da junta, fissuras internas nos blocos e variações nas espessuras das juntas.

Para tentar amenizar essas diferenças e ajustar uma curva aceitável para os resultados obtidos, partiu-se da consideração da existência de uma relação linear entre tensão e deformação até cerca de $50 \%$ da tensão de ruptura. Com isso, foi ajustada uma curva aos dados experimentais de deformações transversais entre as tensões de 10 e $50 \%$ da tensão de ruptura, descartando, assim, os resultados referentes ao início do ensaio (ver exemplo na figura 4.25). Com as equações do $2^{\circ}$ grau, obtidas a partir dos gráficos tensão $x$ deformação nas duas direções ortogonais em que foram instrumentadas, calculou-se as respectivas deformações referentes aos pontos de 25, 35 e 45\% da tensão de ruptura. A partir destes valores calculou-se $v_{x y}$ e $v_{y x}$ para as paredinhas ensaiadas nas direções $Y$ e $X$, respectivamente.

Porém, observou-se que os pontos não eram homogêneos, o que comprometeu os resultados obtidos. As tabelas com os valores calculados a partir do método descrito acima estão apresentadas no Anexo B. Porém, não foi alcançada nenhuma média aceitável, devido àgrande variação dos resultados.

\subsubsection{Modo de ruptura das paredinhas}

De um modo geral, as paredinhas ensaiadas na direção $Y$ apresentaram propagação de fissuras verticais, predominantemente através das juntas verticais na região central das paredes, sendo algumas desviadas pelas faces dos blocos. Observou-se também a presença de fissuras verticais ao longo dos septos laterais das paredinhas. A ruptura ocorreu, na maioria das vezes, por tração transversal dos blocos.

Porém, para as paredinhas que utilizaram blocos do tipo 2, as fissurações descritas acima ocorreram de maneira bem menos pronunciada, prevalecendo a ruptura por esmagamento da argamassa.

As paredinhas ensaiadas na direção $X$ apresentaram fissuração dos septos transversais ao longo do comprimento da parede dos blocos, tanto no topo quanto na base das paredinhas, conforme mostra a figura 4.26. O início da fissuração 
visível deu-se normalmente em carregamentos com valores de cerca de $60 \%$ da carga de ruptura. Nesse momento ouviu-se um estalo que se repetiu mais tarde por cerca de duas ou três vezes, o que caracterizava a ruptura dos septos transversais dos blocos, provavelmente pela presença de concentração de tensões nessa região. Também observou-se a presença de fissuras nos septos longitudinais dos blocos próximos ao topo da paredinha (ver figura 4.27a). Na maioria das vezes a ruptura ocorreu posteriormente ao descolamento das fiadas dos blocos. (fig 4.27b).

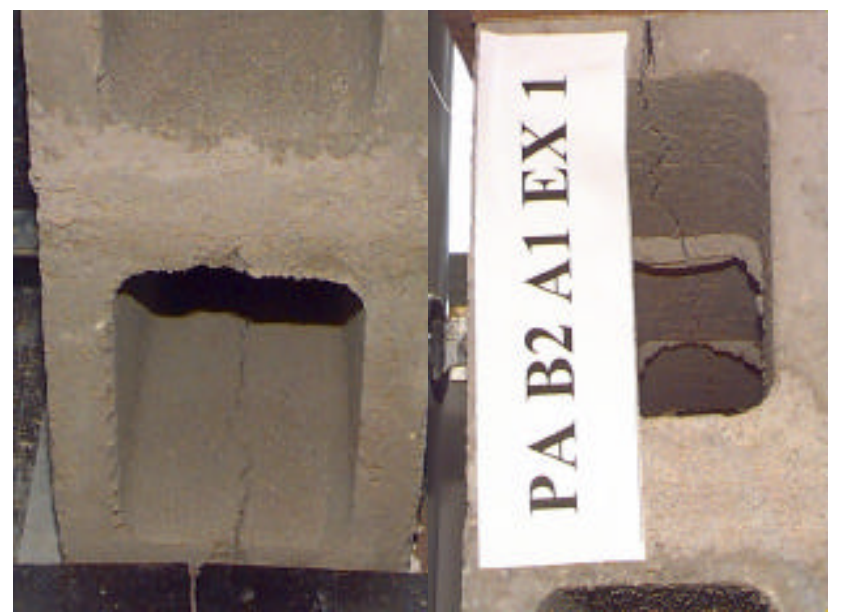

Figura 4.26 - Detalhe da fissuração ao longo dos septos laterais para a paredinha com carregamento na direção $X(E F)$.

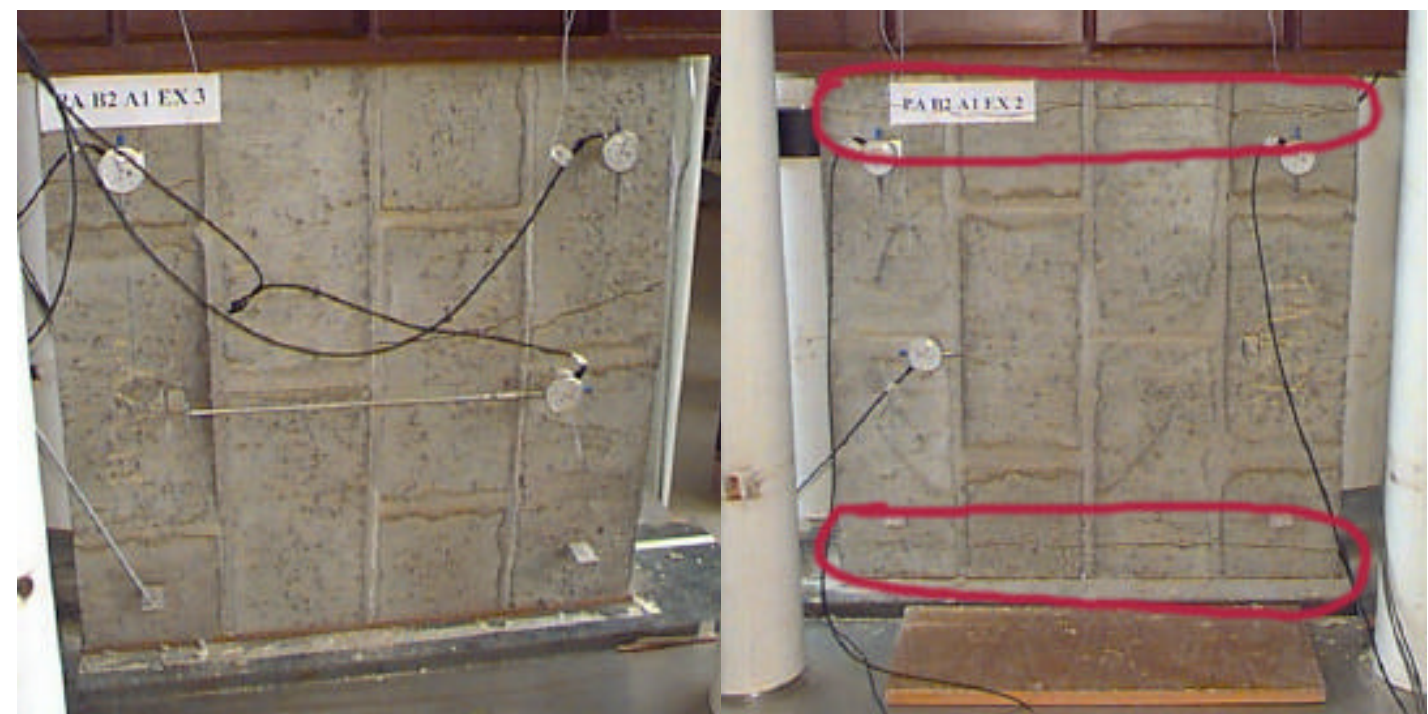

Figura 4.27 - Detalhe da fissuração das paredes com carregamento na direção $X$ (a) descolamento das fiadas dos blocos; (b) fissuração nos septos longitudinais (EF).

As fotos de um exemplar de cada série ensaiada podem ser vistas no Anexo B deste trabalho. 


\section{CONCLUSÕES E RECOMENDAÇÕES}

\section{Conclusões}

Este trabalho teve como objetivo estudar a alvenaria não armada de blocos de concreto, no que diz respeito æ̀ suas características mecânicas, de modo que fosse aprofundado o conhecimento tecnológico dos materiais e componentes utilizados no Brasil. Com este intuito, procurou-se analisar experimentalmente algumas das variáveis que podem afetar a deformabilidade e a resistência à compressão da alvenaria.

Basicamente, o trabalho experimental foi dividido em duas partes. A primeira consistiu em ensaiar prismas e componentes (bloco e argamassa), para que fossem definidas as variáveis que seriam avaliadas nos ensaios em paredinhas. Porém, com os problemas ocorridos no primeiro ensaio-piloto, em relação à aderência entre o bloco e a argamassa ao utilizar argamassa industrializada, não foi possível analisar a influência da resistência à compressão da argamassa na deformabilidade da alvenaria. Com isso, foi necessário manter a variação de duas resistências àcompressão de argamassa para os ensaios finais.

A utilização de duas resistências à compressão de blocos de concreto também foi adotada.

Como já citado no capítulo 1 deste trabalho, a análise das formas de assentamento de argamassa, em todos os septos e apenas nos septos laterais, foi descartada com o objetivo de reduzir o programa experimental sem, entretanto, 
julgar sua importância no comportamento da alvenaria comprimida. Dessa forma, acreditou-se que o programa experimental teria uma contribuição mais significativa no âmbito científico ao estudar a deformabilidade da alvenaria quando submetida a esforços na direção paralela e perpendicular àface de assentamento dos blocos, já que existe uma grande deficiência em trabalhos que abordem este assunto.

A segunda parte do trabalho experimental consistiu em ensaiar oito séries de paredinhas, variando-se duas resistências àcompressão de blocos de concreto, duas resistências à compressão de argamassa e duas direções ortogonais de aplicação de carregamentos.

Desta forma, com base na análise experimental e na revisão bibliográfica, pode-se chegar às seguintes conclusões:

A utilização das placas de fibra de madeira no capeamento dos corpos de prova mostrou-se bastante eficiente, pois permitiu o esmagamento da placa do capeamento, provocando o aparecimento de tensões laterais e o preenchimento dos vazios, acomodando as deformações iniciais. Entretanto, a comparação entre ensaios realizados com diferentes tipos de capeamento deve ser feita de maneira criteriosa, já que esta mudança pode alterar os valores de resistência e deformabilidade. SELF ${ }^{1}$ apud MEDEIROS (1993) estudou o uso deste tipo de placa de fibra de madeira e verificou que, além da menor restrição, o mesmo apresenta menor custo quando comparado aos convencionais normalmente especificados (enxofre, gesso e polzolana).

O fato de não haver nenhum método de ensaio padronizado que possa ser utilizado para determinar o módulo de elasticidade da alvenaria, faz com que os valores obtidos sejam afetados por diversos fatores, tais como: velocidade $\mathrm{e}$ intensidade de carregamento, dimensões dos corpos de prova. Dessa forma, a comparação direta dos resultados de deformabilidade em corpos de prova ensaiados por outros pesquisadores torna-se inviável, ressaltando a necessidade de uma norma brasileira específica sobre o assunto.

Não se pode dizer que foram obtidas correlações, no que diz respeito à deformabilidade e às resistências à compressão dos corpos de prova, pela insuficiência de números de corpos de prova ensaiados e o grande número de variáveis envolvidas. Porém, pode-se afirmar que foram verificadas algumas

\footnotetext{
${ }^{1}$ SELF, M W. (1975). Structural properties of load-bearing concrete masonry. In: Masonry: past and present. Philadelphia, American Society for Testing and Materils.
} 
importantes tendências de comportamento estruturais dos componentes e do conjunto envolvido neste estudo.

Os valores de ruptura estimados teoricamente foram superiores aos obtidos através dos ensaios realizados na maioria dos corpos de prova.

O ajuste da curva tensão-deformação através de uma parábola, até níveis de tensão na ordem de 60 a $70 \%$ da carga de ruptura, apresentou coeficientes de ajuste bastante satisfatórios para os valores obtidos experimentalmente.

As expressões propostas por KNUTSSON \& NIELSEN (1995), para verificar a proximidade das curvas propostas pelos mesmos com a curva ajustada aos resultados experimentais, tiveram boas aproximações das parábolas alcançadas pelo ajuste das curvas até a cerca de $50 \%$ do valor da tensão de ruptura.

Os blocos alcançaram aumentos de até $150 \%$ nos valores de resistência à compressão média se comparados às resistências nominais indicadas pelo fabricante, notando-se que, para os blocos estudados, os valores característicos determinantes das classes de resistência dos blocos foram obtidos a partir de ensaios realizados aos 7 dias.

Os baixos valores de coeficientes de variação obtidos durante os ensaios de determinação da resistência dos blocos de concreto, entre 4 e $11 \%$, permitiram concluir que os blocos utilizados neste trabalho apresentaram um controle de produção bastante satisfatório, onde provavelmente utilizaram-se medidas de uniformização de sua produção com o objetivo de melhorar a qualidade do produto final, tais como as sugeridas por MEDEIROS (1993):

“- Exigência e controle dos fornecimentos dos agregados, principalmente em relação àgranulometria, quantidade de impurezas e condições de umidade;

- Condições de dosagens adequadas, definidas principalmente pelo emprego de balanças de precisão e mecanismos de controle e correção da umidade da mistura;

- Condições de moldagem ajustadas através da sincronização dos eixos da mesa de vibração, emprego de aditivos plastificantes e controle dos tempos de alimentação, vibração e prensagem da vibro-prensa produtora de blocos;

- Controle sistemático das condições de cura;

- Nível do controle de qualidade de aceitação dos blocos produzidos." 
O método para determinação dos valores de módulo de elasticidade do bloco a partir do ensaio de prisma mostrou-se bastante eficiente, já que, na maioria dos casos, os valores de relação entre $\mathrm{E}_{\mathrm{bm}} / \mathrm{f}_{\mathrm{bm}}$ estavam dentro das faixas propostas pelos autores DRYSDALE et al. (1994) e SAHLIN (1971). Assim, acredita-se que a diminuição da influência da restrição lateral da base da máquina de ensaio, conseguida a partir da medida de deformações no bloco intermediário do prisma de três blocos, contribuiu de maneira significativa para a obtenção do módulo de elasticidade do bloco $\left(E_{b}\right)$.

Outra conclusão que pode ser obtida foi que a estimativa dos $E_{b m}$ feita através da utilização das expressões apresentadas pelo CEB-FIP Mode Code (1990) e pelo $\mathrm{ACl}$ - Building Code 318 (1990), para estimar o módulo de elasticidade do concreto, pode introduzir valores muito distantes dos reais. Dessa forma, é necessário que seja feito um estudo mais aprofundado para procurar obter expressões que representem o comportamento dos blocos utilizados na alvenaria estrutural de maneira mais realista.

O papel da absorção inicial do bloco é importante, pois além de ajudar na produção de aderência, ajuda absorvendo água em excesso da argamassa, diminuindo a relação $\mathrm{a} / \mathrm{c}$ e incrementando a resistência àcompressão. O excesso é prejudicial, pois produz o efeito contrário, roubando água necessária para que ocorra a hidratação. Esta situação foi notada quando utilizadas as argamassas industrializadas para moldagem dos prismas dos ensaios-piloto 1.

FRANCO (1987) afirma que o princípio para a escolha de uma determinada argamassa é que esta não contenha mais cimento que o necessário para dar a resistência adequada àalvenaria.

Para selecionar uma argamassa adequada não se deve preocupar somente com sua resistência à compressão. A resistência de aderência, uma boa trabalhabilidade e o índice de retenção de água são fatores de extrema importância.

O mesmo autor ainda cita alguns fatores que podem ser responsáveis pela diminuição da resistência da alvenaria, tais como a adição de cal, maior incorporação de areia e o reamassamento para devolver a trabalhabilidade.

A afirmação feita por diversos autores citados durante este trabalho sobre a resistência à compressão depender principalmente da resistência e característica do bloco utilizado e em bem menor proporção das características da argamassa confirmou-se neste trabalho experimental para blocos de baixa resistência à 
compressão. Assim, para esta situação deve-se escolher um tipo de argamassa com traço adequado, de modo a otimizar outras propriedades da argamassa, tais como trabalhabilidade e capacidade de absorver deformações. Porém, ao serem utilizados blocos de resistência à compressão elevada, deve ser tomado cuidado especial na escolha da argamassa, para que a mesma não interfira na resistência à compressão da alvenaria.

A utilização da argamassa industrializada na moldagem dos prismas não permitiu que os mesmos apresentassem o comportamento esperado durante os ensaios, provavelmente pelo comprometimento da resistência de aderência entre bloco e argamassa.

A resistência de aderência entre o bloco e a argamassa está ligada a variáveis interdependentes entre si, que estão definidas pelas características do bloco, da argamassa e da mão-de-obra. Assim, cabe analisar a influência de todas variáveis envolvidas de maneira conjunta. (SOLORZANO, 1994)

Autores citados por FRANCO (1987) afirmam que, na prática, a fissuração da alvenaria raramente ocorre devido æ̀ cargas diretamente aplicadas. Usualmente esta é resultado de movimentos diferenciais entre as várias partes da estrutura, causados por recalque da fundação ou por movimentos térmicos e de retração. Dessa forma, torna-se desejável a utilização de uma argamassa com grande capacidade de deformação, ou seja, com baixo módulo de elasticidade, de modo que seja possível acomodar pequenos movimentos da parede, aliviando as tensões na forma de fissuras capilares ou microfissuras, normalmente imperceptíveis ao olho humano, sem comprometer o desempenho estrutural da alvenaria.

Os requisitos de desempenho mais importantes atribuídos às juntas de argamassa observados no trabalho experimental desenvolvido e na pesquisa bibliográfica são: resistência de aderência, resistência à compressão (do conjunto bloco-argamassa) e o módulo de elasticidade do conjunto. Tal importância deve-se àinfluência que estes requisitos têm no desempenho da parede estrutural.

A diferença de resistências em paredinhas carregadas nas duas direções (paralela e perpendicular àjunta de assentamento) era esperada, já que as próprias unidades apresentam desigualdades geométricas em direções distintas. Dessa forma, se os blocos apresentam diferenças de resistência característica nas direções ortogonais, o mesmo deve ser esperado quando o conjunto blocoargamassa é analisado. 
As medidas do coeficiente de Poisson não foram consideradas confiáveis devido à grande dispersão dos valores obtidos, o que comprova a dificuldade de obtenção deste parâmetro.

Neste trabalho foram estudados alguns fatores que podem interferir na resistência e deformabilidade da alvenaria de blocos de concreto. Porém, outro fator de extrema importância na deformação da alvenaria é a fluência, caracterizada pelo aumento da deformação da parede com o tempo, sem o aumento da tensão aplicada. Dessa forma, o estudo desse parâmetro pode ser apontado como sugestão de continuidade do trabalho, para que seja estuda a influência do tempo nas deformações.

PLOWMAN $^{2}$ apud FRANCO (1987) cita alguns fatores que podem influenciar a fluência:

- Conteúdo de água presente na argamassa após absorção sofrida (índice de retenção de água - IRA?) pelo contato com os blocos;

- Tipo de areia utilizada;

- Nível de tensão;

- Conteúdo de umidade de ar.

LENCZNER $^{3}$, também citado por FRANCO (1987), acrescenta aos fatores acima citados, condições de cura e idade do carregamento. O mesmo autor afirma que a fluência cessa mais rapidamente se comparada ao concreto.

Como proposta para futuros trabalhos, sugere-se, além do estudo da fluência, a investigação da resistência e da deformabilidade em prismas ensaiados na direção X, conforme propõe KHALAF (1997) (ver item 2.3.4). Porém, a realização destes ensaios deve ser feita simultaneamente aos ensaios em paredinhas ou paredes, de modo a tentar obter parâmetros de comparação entre os diferentes corpos de prova.

\footnotetext{
2 PLOWMAN, J.M. (1965). The modulus of elasticity of brickwork. Proceedings of the British Ceramic Society $n^{\circ} \mathbf{4}$.

3 LENCZNER, J.M. (1965). Creep in brickwork. In: Proceedings of the Second International Brick Masonry Conference. Stoke-on Trent, The British Ceramic Research Association.
} 
Os resultados obtidos reforçam a idéia de que deve ser realizado um estudo mais aprofundado com os materiais utilizados no Brasil, com o objetivo de melhorar a segurança e a qualidade da alvenaria estrutural. 


\section{REFERÊNCIAS BIBLIOGRÁFICAS}

ALY, V.L.C.; SABBATINI, F.H. (1992). Determinação de correlações de resistência mecânica de paredes de alvenaria estrutural de blocos de concreto. In: Procedings of the 5 th International Seminar on Structural Masonry for Developing Countries. Florianópolis, SC.

AMERICAN CONCRETE INSTITUTE (1995). ACI 530-92 - Building code requirements for masonry structures. Detroid, Michigan.

AMERICAN SOCIETY FOR TESTING AND MATERIALS (1988). ASTM C $111-82$ - Standard test method for young's modulus, tangent modulus, and chord modulus. In: Annual Book of ASTM Standars. Philadelphia.

AMERICAN SOCIETY FOR TESTING AND MATERIALS (1991). ASTM C $150-$ Standard for Portland Cements. In: Annual Book of ASTM Standars. Philadelphia.

AMERICAN SOCIETY FOR TESTING AND MATERIALS (1982). ASTM C 270 - 82 - Standard specification for mortar for unit masonry. In: Annual Book of ASTM Standars. Philadelphia.

AMERICAN SOCIETY FOR TESTING AND MATERIALS (1997). ASTM C $447-97$ - Standard test method for compressive strength of laboratory constructed masonry prisms. In: Annual Book of ASTM Standars. Philadelphia. 
AMRHEIN, J. E. (1978). Reinforced Masonry Engineering Handbook. Masonry Institute of America.

ANDREWS, H. (1950). Mortar for brickwork, block construction and masonry. National Building Studies, Bulletin $\mathrm{n}^{\circ}$ 8. Building Research Station (BRS). London.

ASSOCIAÇÃO BRASILEIRA DA CONSTRUÇÃO INDUSTRIALIZADA (1990). Manual Técnico de Alvenaria. ABCI / Projeto.

ASSOCIAÇÃO BRASILEIRA DE NORMAS TÉCNICAS (1994). NBR 6.136 - Bloco vazado de concreto simples para alvenaria estrutural - Especificação. Rio de Janeiro.

ASSOCIAÇÃO BRASILEIRA DE NORMAS TÉCNICAS (1982). NBR 7.186 - Bloco vazado de concreto simples para alvenaria com função estrutural - Método de ensaio. Rio de Janeiro.

ASSOCIAÇÃO BRASILEIRA DE NORMAS TÉCNICAS (1982). NBR 7.215 - Ensaio de Cimento Portland - Método de ensaio. Rio de Janeiro.

ASSOCIAÇÃO BRASILEIRA DE NORMAS TÉCNICAS (1983). NBR 8.215 Prismas de blocos vazados de concreto simples para alvenaria estrutural Preparo e ensaio à compressão Rio de Janeiro.

ASSOCIAÇÃO BRASILEIRA DE NORMAS TÉCNICAS (1984). NBR 8522Concreto - Determinação do módulo de deformação estática e diagrama tensão-deformação. Rio de Janeiro.

ASSOCIAÇÃO BRASILEIRA DE NORMAS TÉCNICAS (1985). NBR 8.798 Execução e controle de obras em alvenaria estrutural de blocos vazados de concreto. Rio de Janeiro.

ASSOCIAÇÃO BRASILEIRA DE NORMAS TÉCNICAS (1985). NBR 10.837 Cálculo de alvenaria estrutural de blocos vazados de concreto. Rio de Janeiro. 
ASSOCIAÇÃO BRASILEIRA DE NORMAS TÉCNICAS (1989). NBR 13.279 Argamassa para assentamento e revestimento de paredes e tetos Determinação da resistência à compressão - Método de ensaio. Rio de Janeiro.

ASSOCIAÇÃO BRASILEIRA DE NORMAS TÉCNICAS (1995). NBR 13.281 Argamassa industrializada para assentamento e revestimento de paredes e tetos - Especificação. Rio de Janeiro.

BRITISH STANDARDS INSTITUTION (1978). BS 5628 - Code of practice for Structural use of masonry. Part 1. Unreinforced masonry. Londres, Inglaterra.

BRITISH STANDARDS INSTITUTION (1992). BS 5628 - Code of practice for Structural use of masonry. Part 1. Unreinforced masonry. Londres, Inglaterra.

CANDIA, M.C. (1994). Resistência de aderência ao cisalhamento da alvenaria estrutural não armada de blocos cerâmicos. São Paulo. Dissertação (Mestrado) - Escola Politécnica, Universidade de São Paulo.

CHEEMA, T.S.S. e KLINGNER, R.E. (1986). Compressive strength of concrete masonry prisms. In: American Concrete Institute Journal. January-February. p. 88-97.

COMITÉ EURO-INTERNATIONAL DU BETÓN (1990). CEB-FIP model code 1990. Bulletin d'Information.

DICKEY, W. L.; SCHNEIDER, R. R. (1994). Reinforced mansory design. Englewood Cliffs, Prentice Hall.

DRYSDALE, R.G.; HAMID, A.A. (1979). Behavior of concrete block masonry under axial compression. In: American Concrete Institute Journal. June. p. 707-721.

DRYSDALE, R.G.; HAMID, A.A.; BAKER, L.R. (1994). Masonry structures: behavior and design. Enhllewood Cliffs, New Jersey, Prentice Hall. 
FONTE, T.F. (2000). Influência da técnica de assentamento de blocos cerâmicos de parede de alvenaria estrutural, não armada, na resistência de aderência à flexão bloco-argamassa. São Carlos. Relatório final de Iniciação Científica Escola de Engenharia de São Carlos. PIBIC/CNPq/EESC/USP.

FRANCO, L.S. (1987). Desempenho estrutural do elemento parede de alvenaria empregado na alvenaria estrutural não armada, quando submetido a esforços de compressão. São Paulo. 136p. Dissertação (Mestrado)- Escola Politécnica, Universidade de São Paulo.

GLANVILLE \& BARNETT (1934). Mechanical properties of bricks and brickwork masonry. Department of Scientific and Industrial Research, Building Research, Special Repot №22. Building Research Station, Garston, Watford, Herts. Her Majesty's Stationery Office, London.

GOMES, N.S. (1983). A resistência das paredes de alvenaria. São Paulo. 190p. Dissertação (Mestrado)- Escola Politécnica, Universidade de São Paulo.

HENDRY, A.W. (1981). Structural Brickwork. Londres, The Macmillan Press Ltd.

HILSDORF, H.K. (1965). Untersuchungen über die Grrundlagen der Mauerwerksfestigkeit. Bericht Nr. 40, Materialprüfungsamt für das Bauwesen der Technischen Hochschule, München.

HILSDORF, H.K. (1972). Masonry materials and their physical properties. In Proceedings, ASCE-IABSE International Conference on Planning and design of Tall Buildings. American Society of Civil Engineers. New York. P 981-999.

HOGBERG, E. (1980) Mortar Bond. National Swedish Institute for Building Research. Stockholm.

ISBERNER, A. W. (1964). Masonry: A progress report. Portland Cement Association - PCA. Sokie. PCA.

KNUTSSON, H.H.; NIELSEN, J. (1995). On the modulus of elasticity for masonry. In: Journal of the British Masonry Society. Outubro. pg 57-61. 
KHALAF, F.M. (1997). Factors influencing compressive strength of concrete masonry prisms. In: Magazine of Concrete Research. June. Edinburg. pg. 95101.

MAHER, A.; DARWIN, D. (1982). Mortar constituent of concrete in comperssion. ACI Journal. March-April. p. 100-109.

MARTINELLI, D.A.O. (1961). Contribuição ao emprego de extensômetros elétricos de resistência no estudo de estruturas. São Carlos. Tese (Doutorado) - Escola de Engenharia de São Carlos, Universidade de São Paulo.

MEDEIROS, J.S. (1993). Alvenaria estrutural não armada de blocos de concreto: produção de componentes e parâmetros de projeto. São Paulo. 2 v. Dissertação (Mestrado)- Escola Politécnica, Universidade de São Paulo.

MENDES, R.J.K. (1998). Resistência à compressão de alvenarias de blocos cerâmicos estruturais. Florianópolis. 185 p. Dissertação (Mestrado) Universidade Federal de Santa Catarina.

METHA, P. K.; MONTEIRO, P.J. (1993). Concrete: Structures, properties and materials. 2 ed. Englewood Clifs. 548 p. Prentice Hall

MOHAMAD, G. (1998). Comportamento mecânico na ruptura de prismas de blocos de concreto. Florianópolis. 178 p. Dissertação (Mestrado) - Universidade Federal de Santa Catarina.

OLIVEIRA, F. (1997). Reabilitação de estruturas de alvenaria pela aplicação de revestimentos resistentes de argamassa armada. Relatório parcial de doutorado entregue à Fapesp. Escola de Engenharia de São Carlos, Universidade de São Paulo.

RITTER, W. (1899). Die Bauweise Hennebique Schweiz, Bauzeitung. 
ROMAGNA, R.H. (2000). Resistência à compressão de prismas de blocos de concreto grauteados e não grauteados. Florianópolis. 193 p. Dissertação (Mestrado). Universidade Federal de Santa Catarina.

SABBATINI, F.H. (1984). Processo construtivo de edifícios de alvenaria silicocalcaria. São Paulo. 298 p. Dissertação (Mestrado). Escola Politécnica, Universidade de São Paulo.

SAHLIN, S. (1971). Structural masony. Englewood Cliffs, Prentice Hall.

SOLORZANO, M.G.P. (1994). Características e desempenho de juntas de argamassa na alvenaria estrutural de blocos de concreto. São Paulo. 203 p. Dissertação (Mestrado). Escola Politécnica, Universidade de São Paulo.

TANGO, C.E.S. (1981). Ensaios de controle de alvenaria estrutural de blocos de concreto. Seminário sobre Inspeção de Concreto. Publicação I.11. Instituto Brasileiro de Concreto. 
ALY, V.L.C. (1991). Determinação da capacidade resistente do elemento parede de alvenaria armada de blocos de concreto, submetidos a esforços de compressão. São Paulo. 103 p. Dissertação (Mestrado). Escola Politécnica, Universidade de São Paulo.

AMERICAN SOCIETY FOR TESTING AND MATERIALS (1980). ASTM C $140-75$ - Sampling and testing concrete masonry units. In: Annual Book of ASTM Standars. Philadelphia.

AMERICAN SOCIETY FOR TESTING AND MATERIALS (1997). ASTM C 1314 97 - Standard test method for contructing end testing masonry prisms used to determine compliance with specified compressive strength of masonry. In: Annual Book of ASTM Standars. Philadelphia.

ASSOCIAÇÃO BRASILEIRA DE NORMAS TÉCNICAS (1991). MB 5.739 - Blocos vazados de concreto simples para alvenaria - Determinação da resistência à compressão - Método de ensaio. Rio de Janeiro.

ASSOCIAÇÃO BRASILEIRA DE NORMAS TÉCNICAS (1985). NBR 8.949 Paredes de alvenaria estrutural - Ensaio à compressão simples. Rio de Janeiro. 
ASSOCIAÇÃO BRASILEIRA DE NORMAS TÉCNICAS (1991). NBR 12.118 Blocos vazados de concreto simples para alvenaria - Determinação da absorção de água, do teor de umidade e da área líquida. Método de Ensaio. Rio de Janeiro.

CAMACHO, J.S. (1995). Contribuição ao estudo de modelos físicos reduzidos de alvenaria estrutural cerâmica. São Paulo. 157p. Tese de Doutorado - Escola Politécnica, Universidade de São Paulo.

CAPUZZO NETO, V. (2000). Estudo teórico e experimental da interação de paredes de alvenaria estrutural submetidas a ações verticais. São Carlos. 112 p. Dissertação (Mestrado) - Escola de Engenharia de São Carlos, Universidade de São Paulo.

CORRÊA, M.R.S.; RAMALHO, M.A.(1998b). Alvenaria estrutural. São Carlos, EESC-USP. (Notas de aula da disciplina: "SET-606 - Alvenaria estrutural").

EUROCODE 6 (1997). Design of masonry structures. Part 1-1: General rules for buildings. Rules for reinforced and unreinforced masonry. Madrid, Espanha.

GALLEGOS, H. (1989). Albañileria estructural. 2 ed. Lima, Fondo Editorial da Pontificia Universidad Católica del Peru.

GALLEGOS, H. (1993). Albañileria estructural: Diseño y calculo de muros. 2 ed. Lima, Fondo Editorial da Pontificia Universidad Católica del Peru.

HENDRY, A.W.; SINHA, B.P.; DAVIES, S.R. (1981). An introduction to load bearing brickwork desing. Chichester, England, Ellis Horwood Ltd.

MACHADO JR., E.F. ;TAKEYA, T ; VAREDA, L.V. (1999). Ensaios de compressão simples em paredes de alvenaria de blocos cerâmicos. Relatório técnico: Cerâmica Selecta. São Carlos.

MULLER, M.S.K. (1989). Estudo das correlações entre resistências à compressão de paredes e prismas de alvenaria estrutural cerâmica não armada 
submetidos a esforços de compressão axial. São Paulo. 269 p. Dissertação (Mestrado) - Escola Politécnica, Universidade de São Paulo.

SABBATINI, F.H.;(1984). Alvenaria Estrutural - Tecnologia, Processos Construtivos e Patologia. Apostila - Instituto de Pesquisas Tecnológicas (IPT), São Paulo.

TAKEYA, T. (1988). Introdução àanálise experimental de estruturas. Notas de aula. SET 5816 - Análise experimental de estruturas. São Carlos, Escola de Engenharia de São Carlos, Universidade de São Paulo. 
Gráfico Tensão x Deformação P112 - Bloco de 4,5 MPa

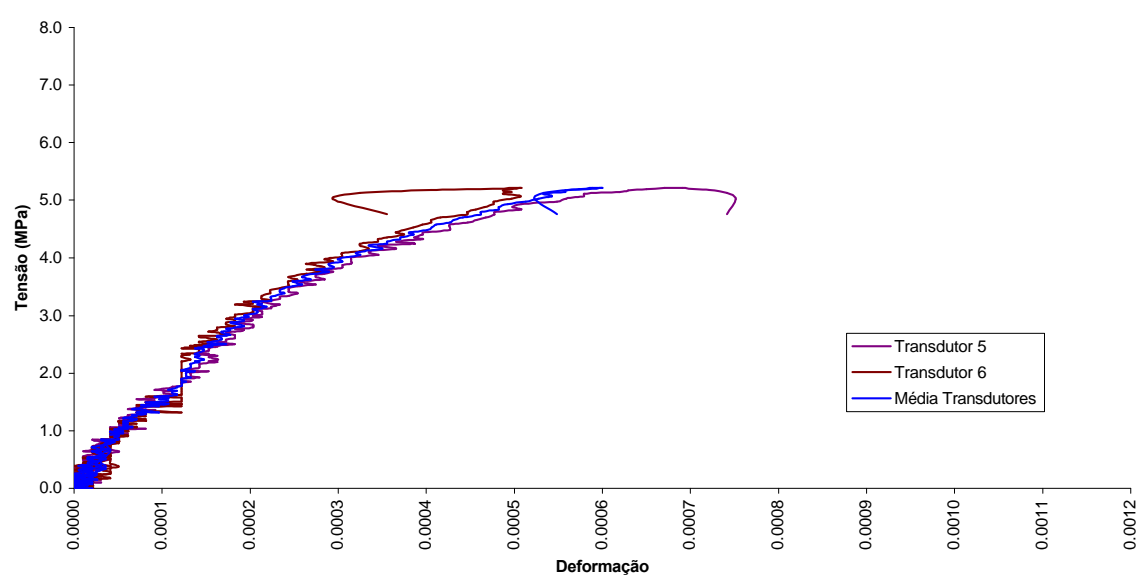

Gráfico Tensão x Deformação P113 - Bloco de 4,5 MPa

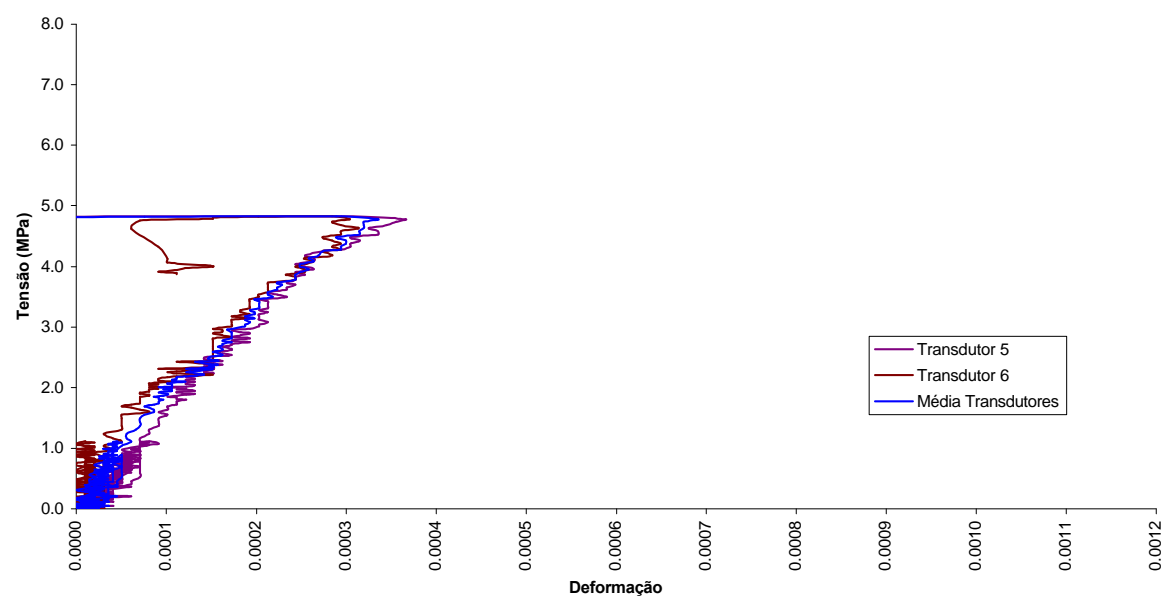

Gráfico Tensão x Deformação Q111 - Bloco de 4,5 MPa

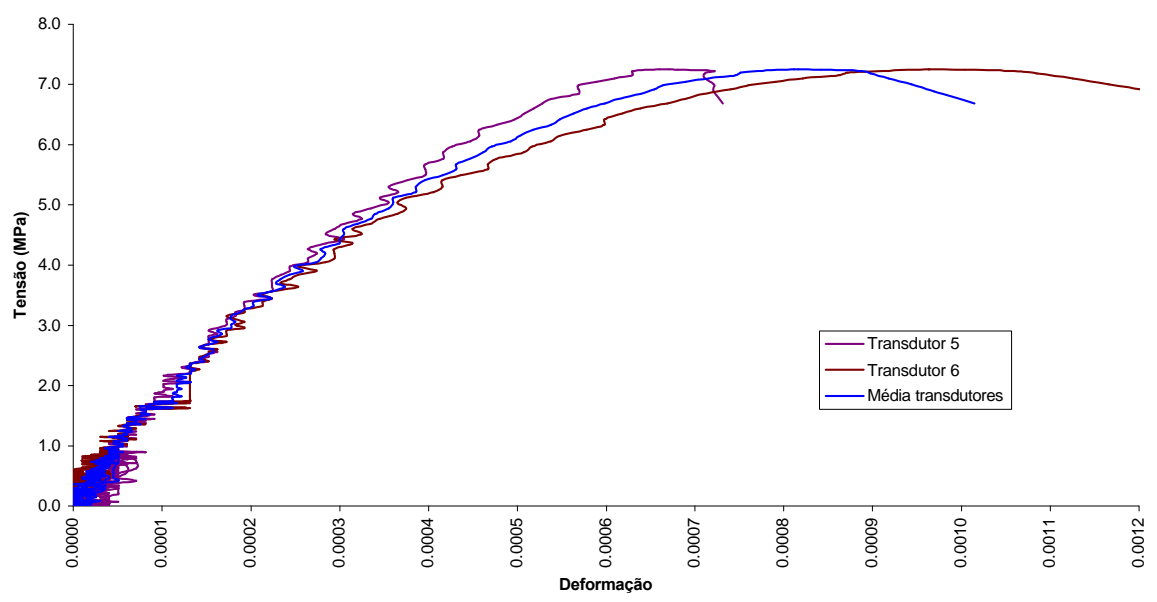



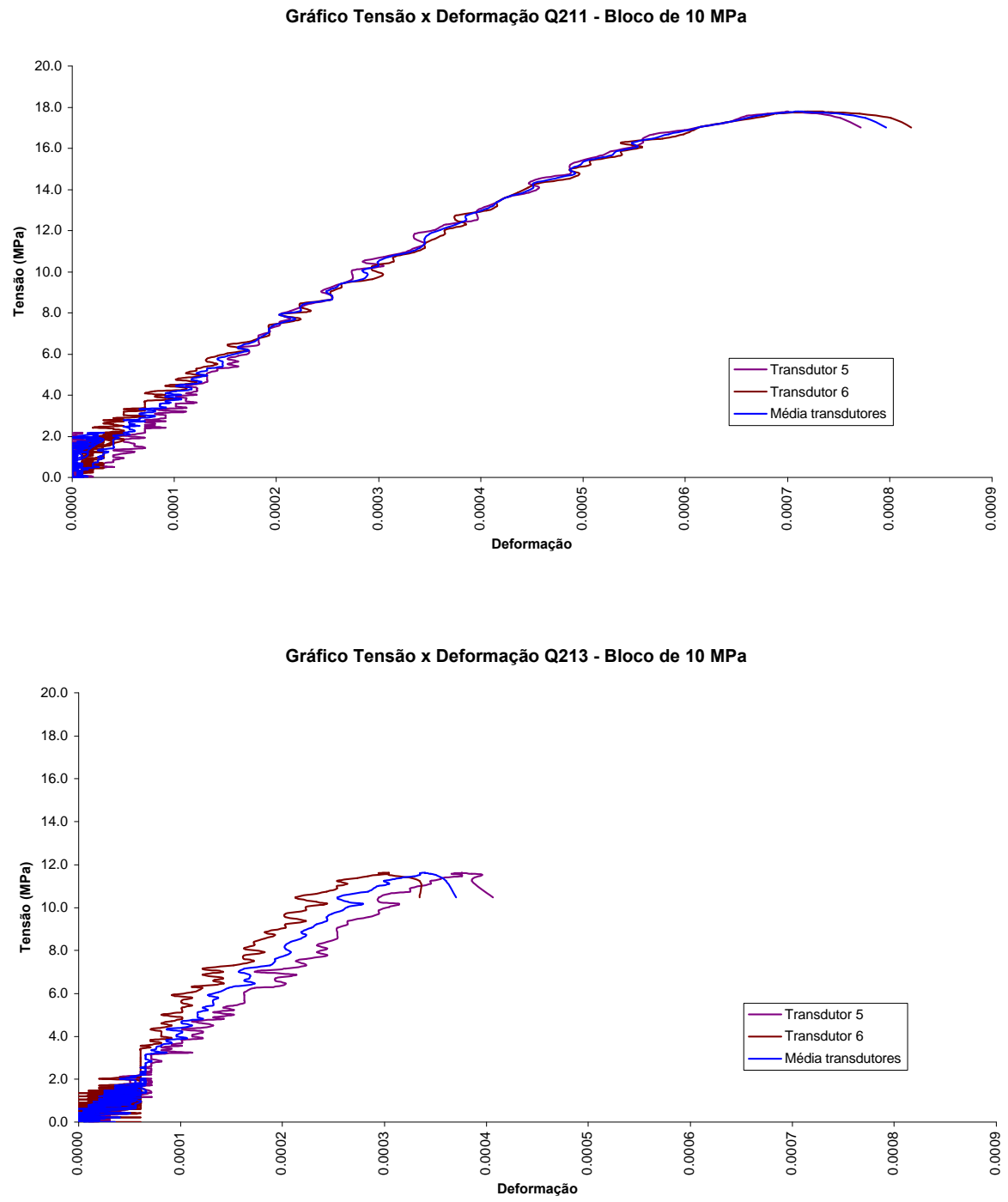

Gráfico Tensão x Deformação Q221 - Bloco de $10 \mathrm{MPa}$

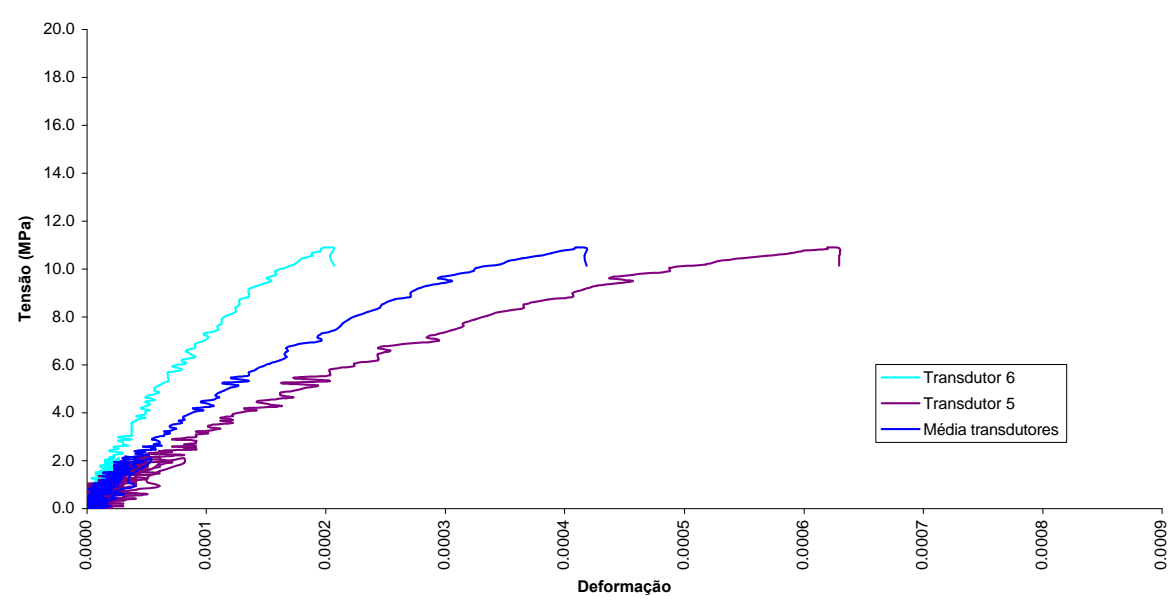




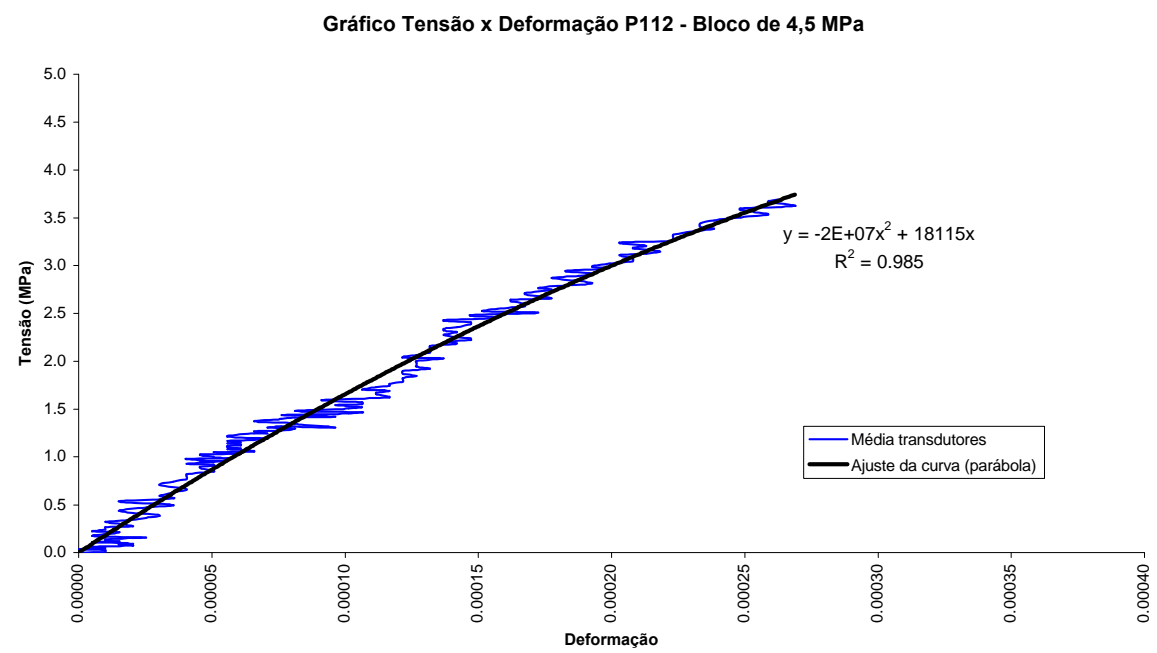

Gráfico Tensão x Deformação P113 - Bloco de 4,5 MPa

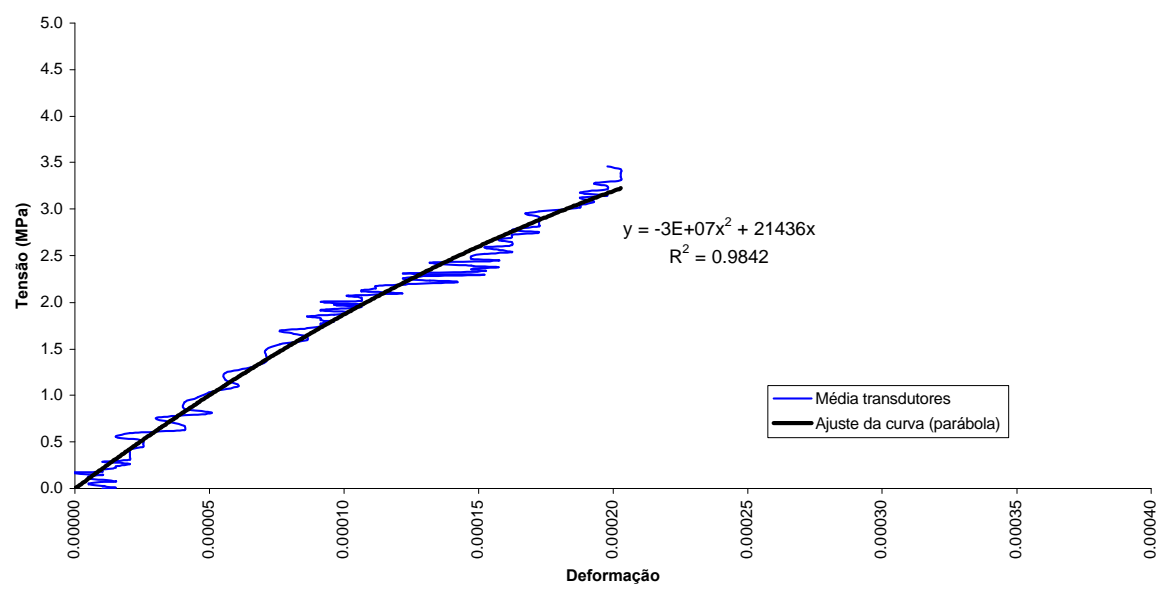

Gráfico Tensão x Deformação Q111 - Bloco de 4,5 MPa

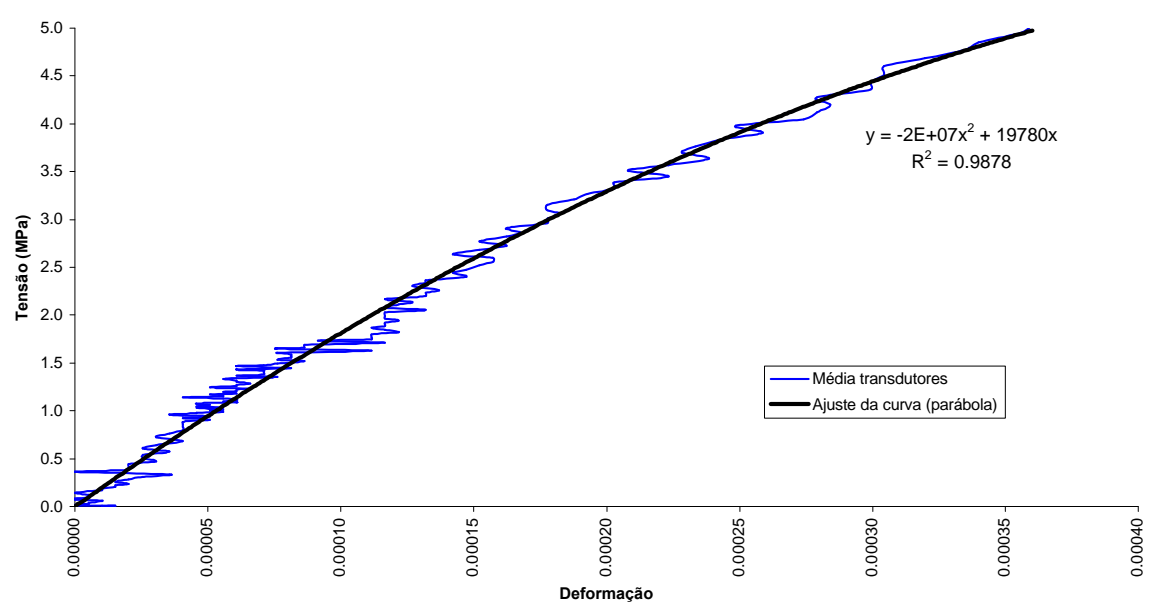




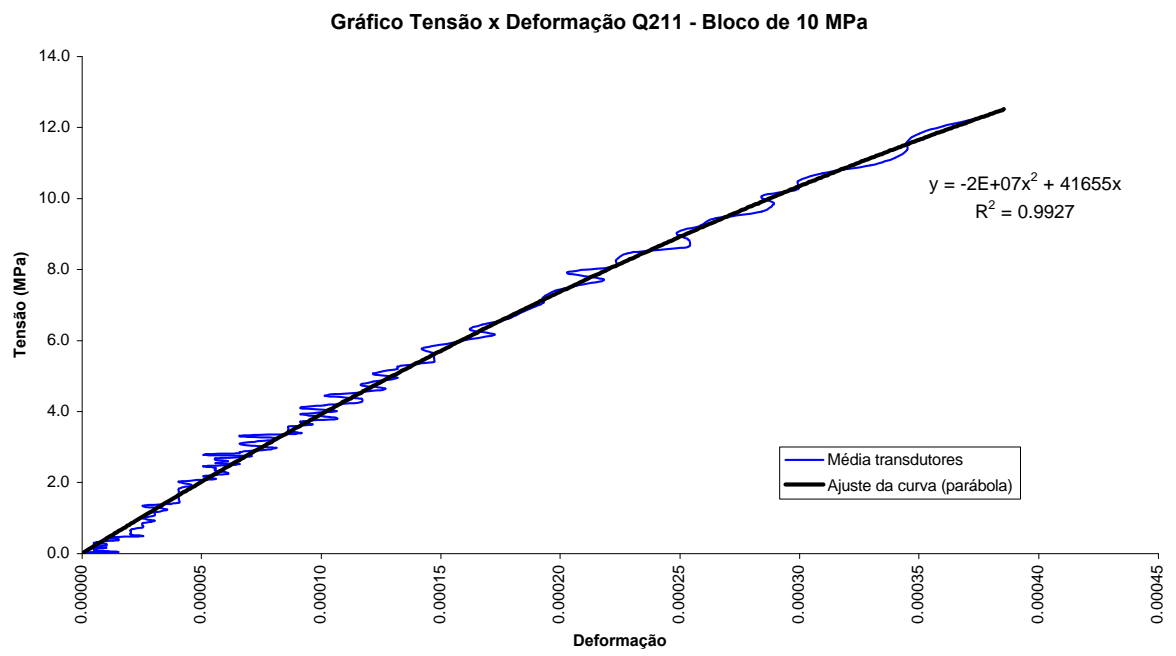

Gráfico Tensão x Deformação Q213 - Bloco de $10 \mathrm{MPa}$

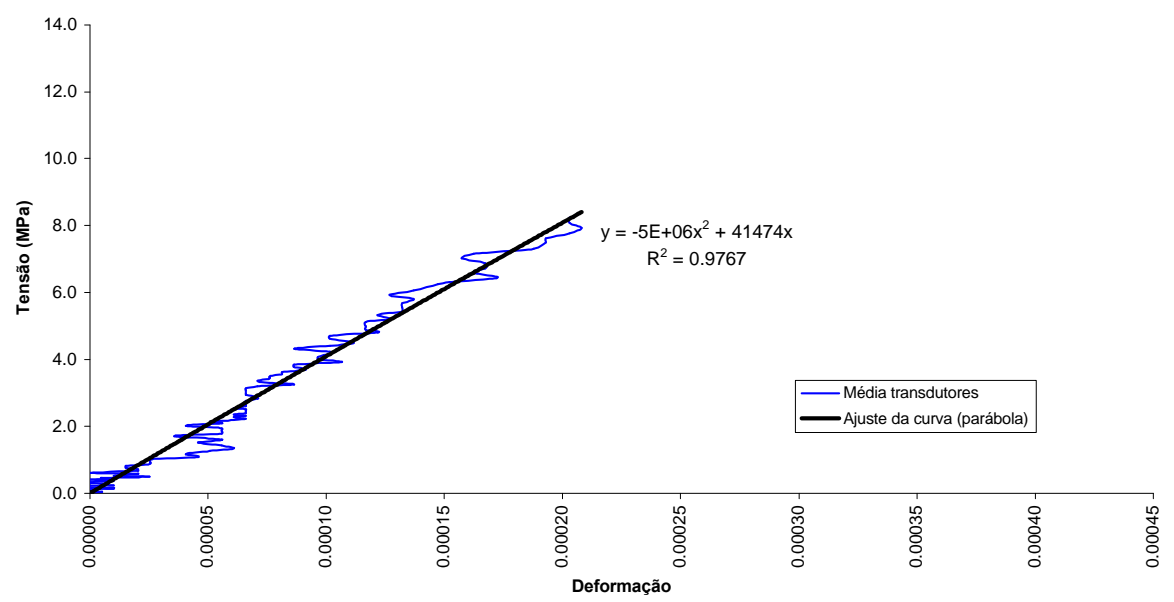

Gráfico Tensão x Deformação Q221 - Bloco de $10 \mathrm{MPa}$

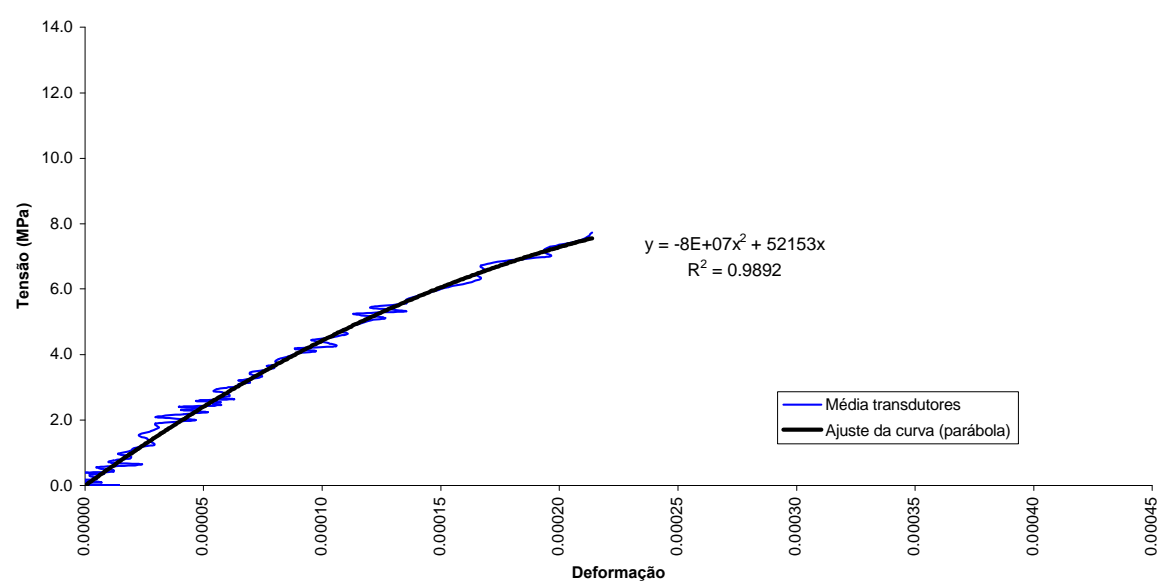


Gráfico Tensão x Deformação Argamassa P1

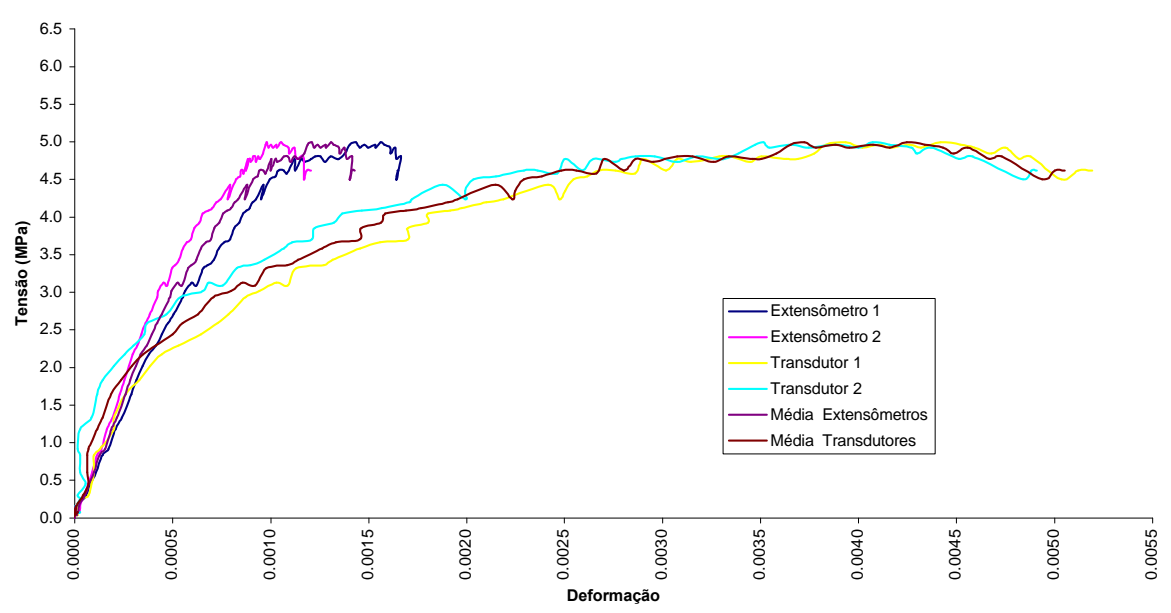

Gráfico Tensão x Deformação Argamassa P2

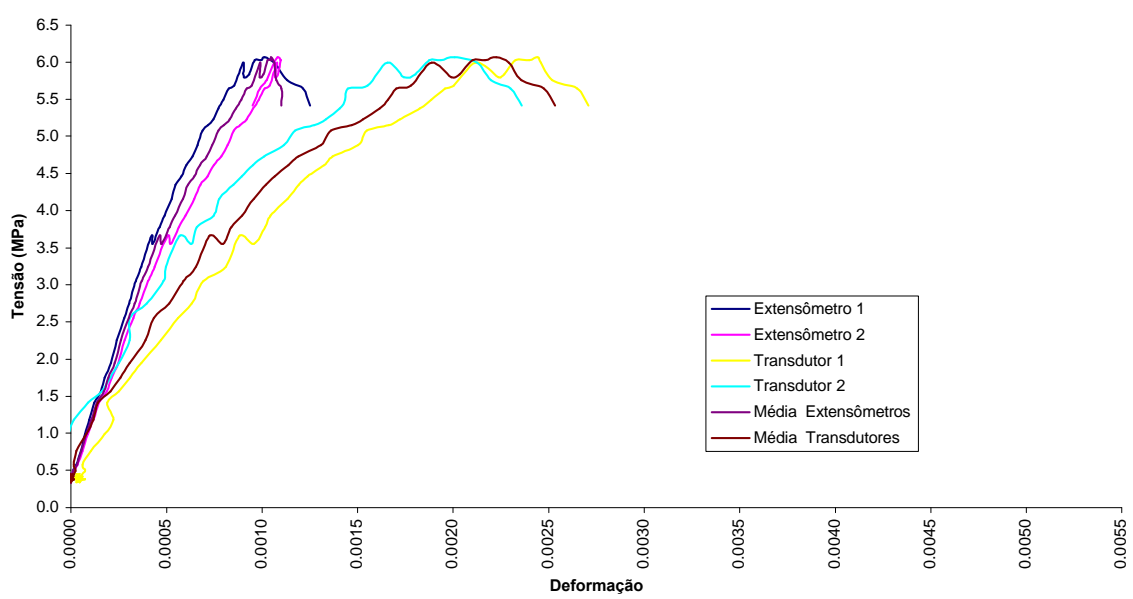

Gráfico Tensão x Deformação Argamassa P3

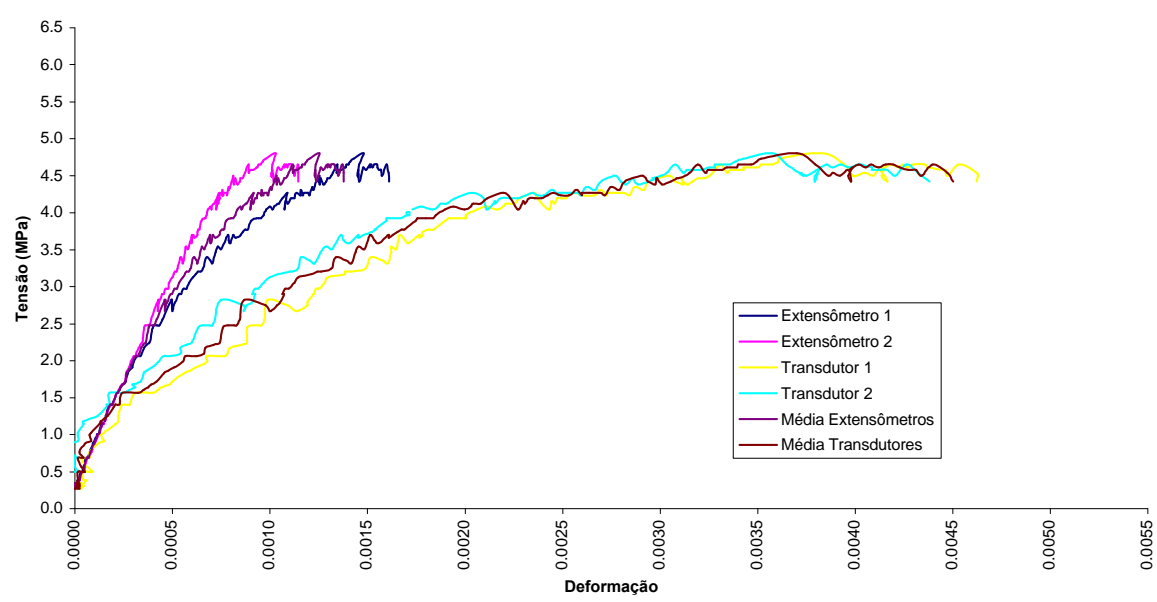


Gráfico Tensão x Deformação Argamassa Q1

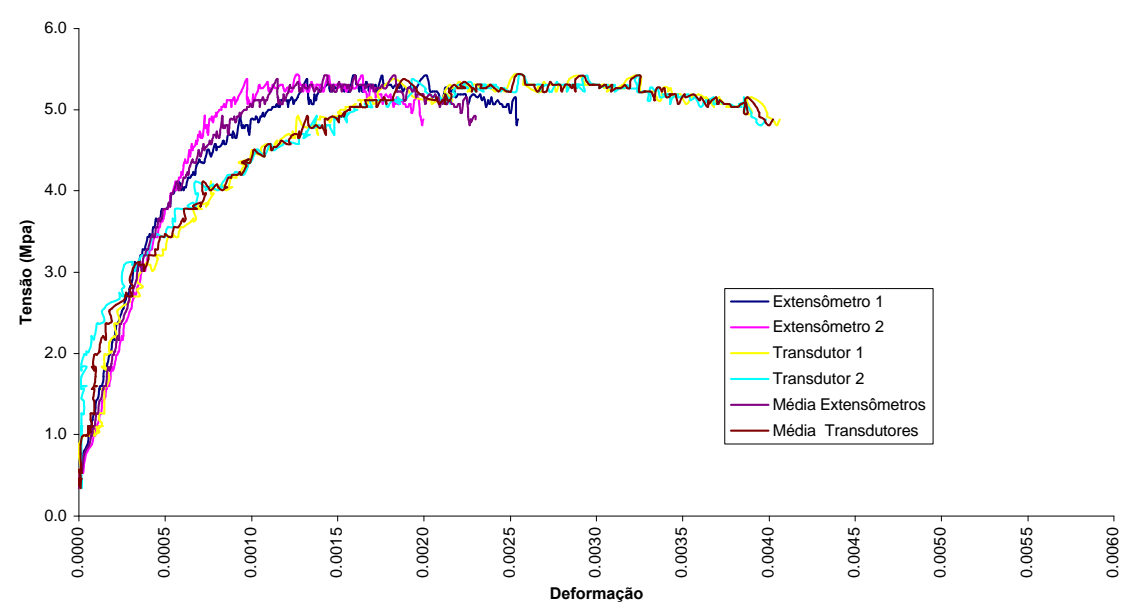

Gráfico Tensão x Deformação Argamassa Q2

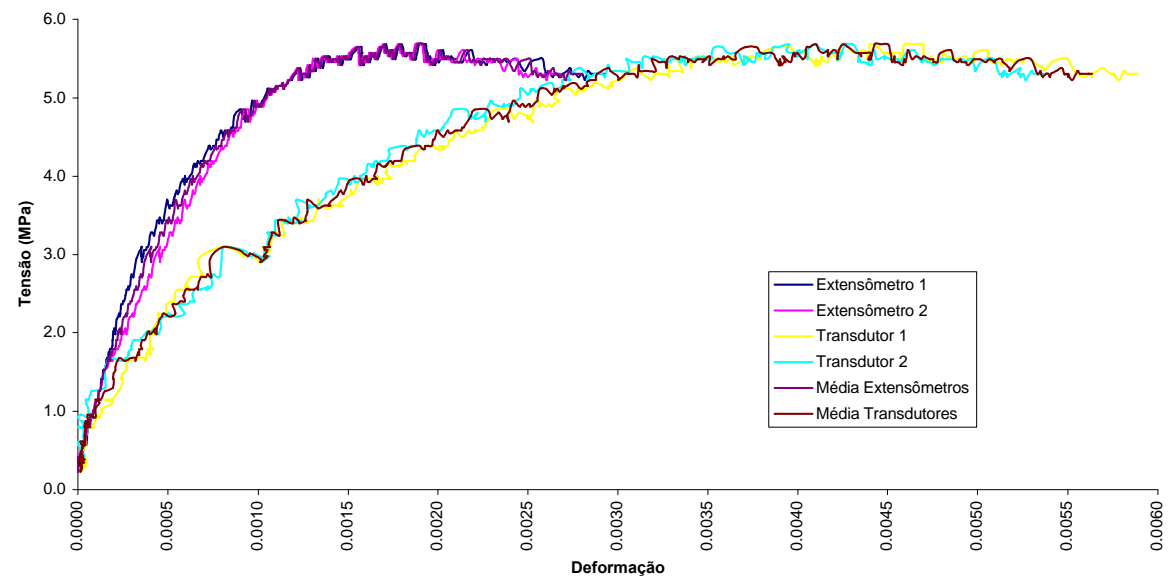

Gráfico Tensão x Deformação Argamassa Q3

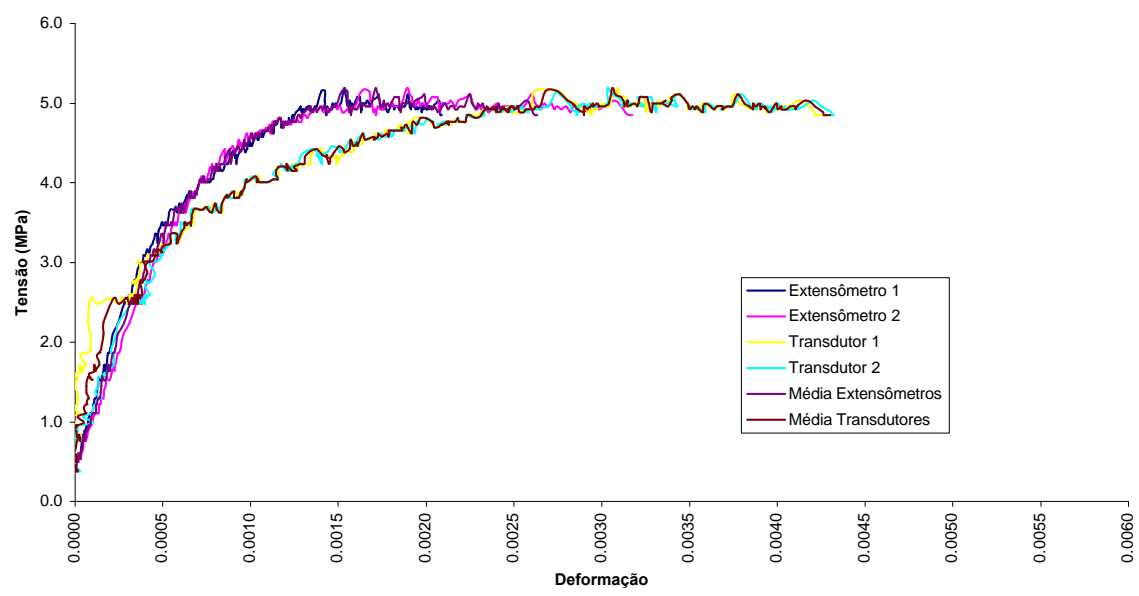



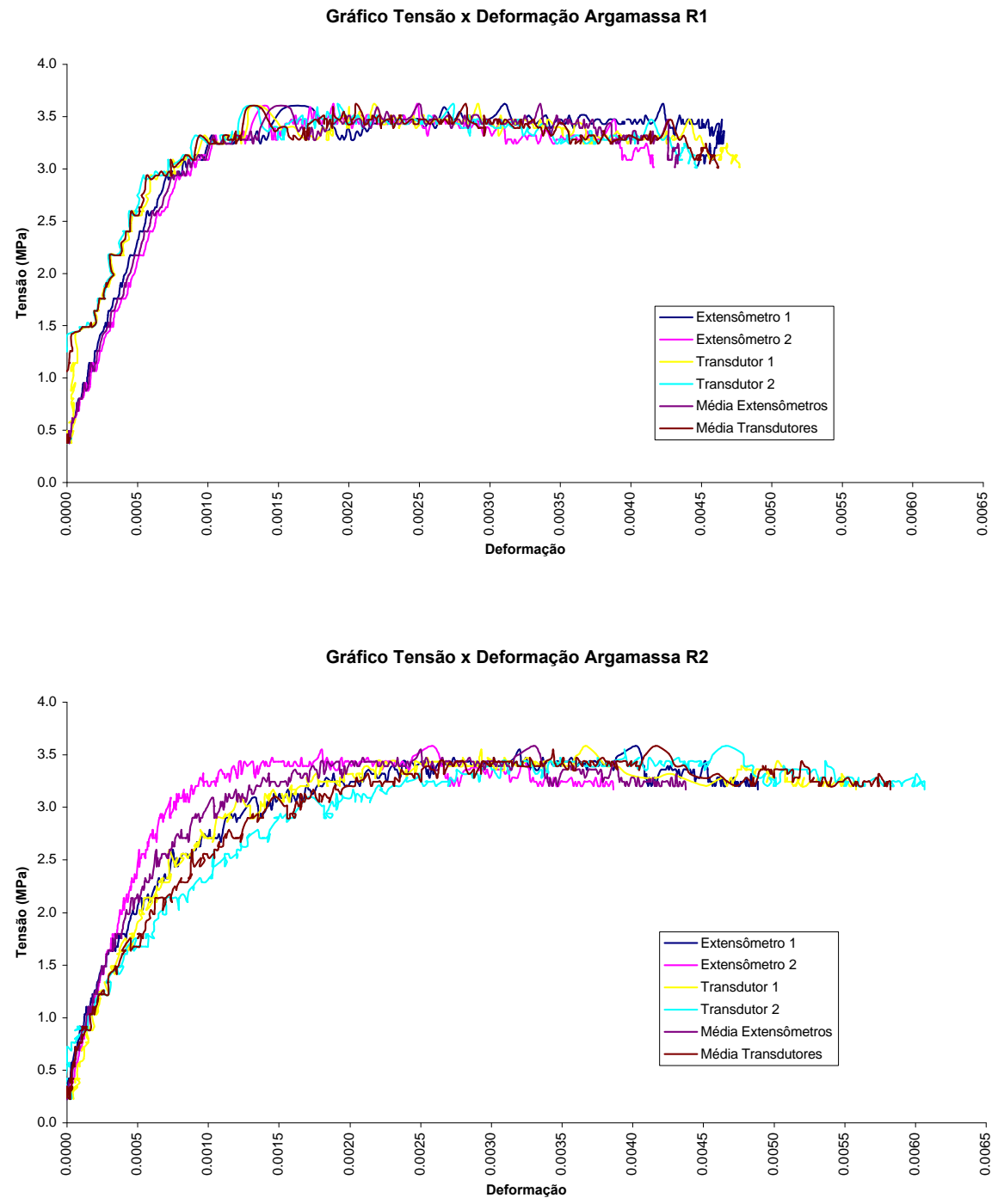

Gráfico Tensão x Deformação Argamassa R3

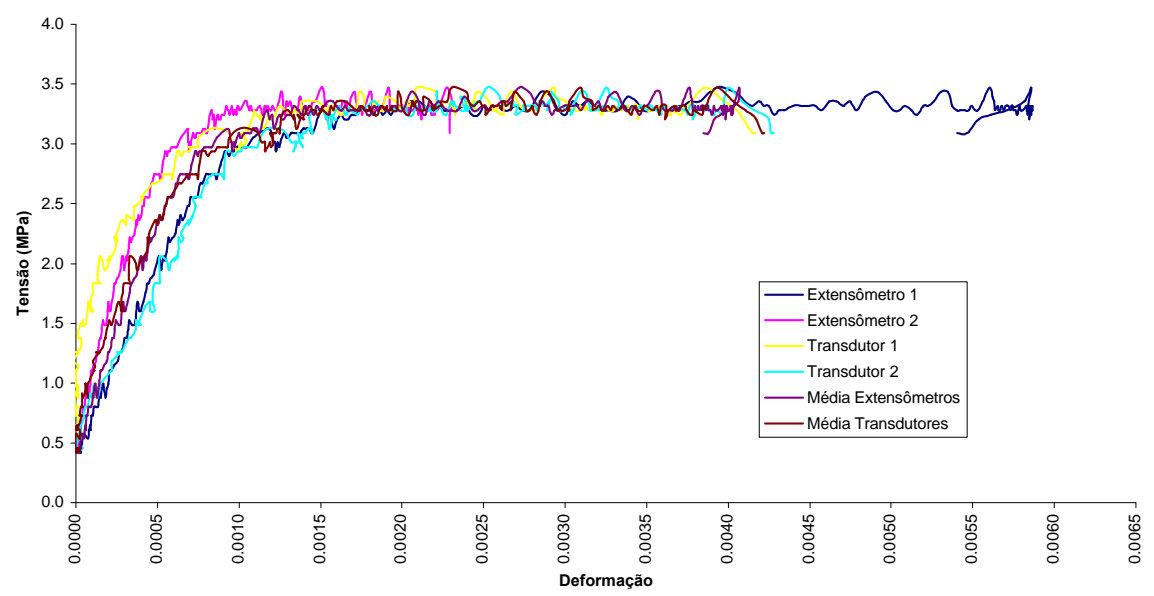


Gráfico Tensão x Deformação Argamassa P1 - Transdutor

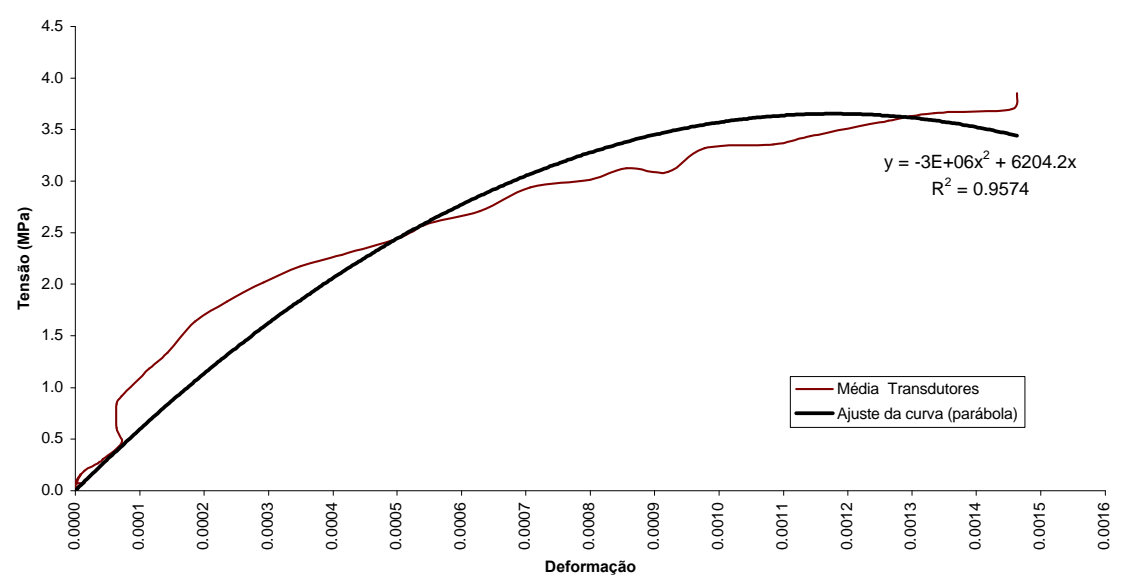

Gráfico Tensão x Deformação Argamassa P2 - Transdutor

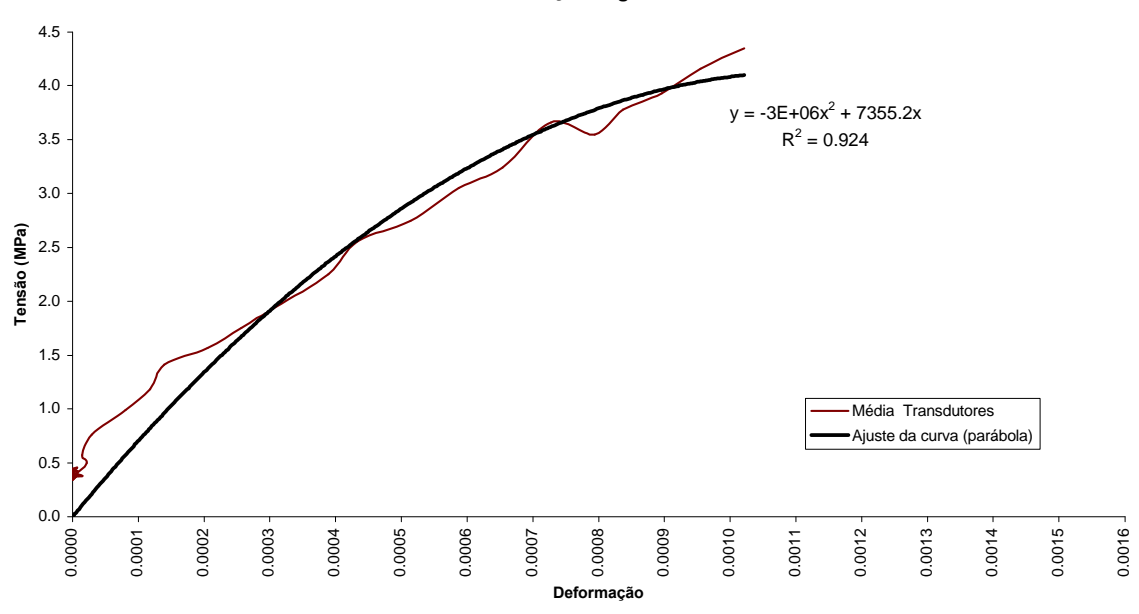

Gráfico Tensão x Deformação Argamassa P3 - Transdutor

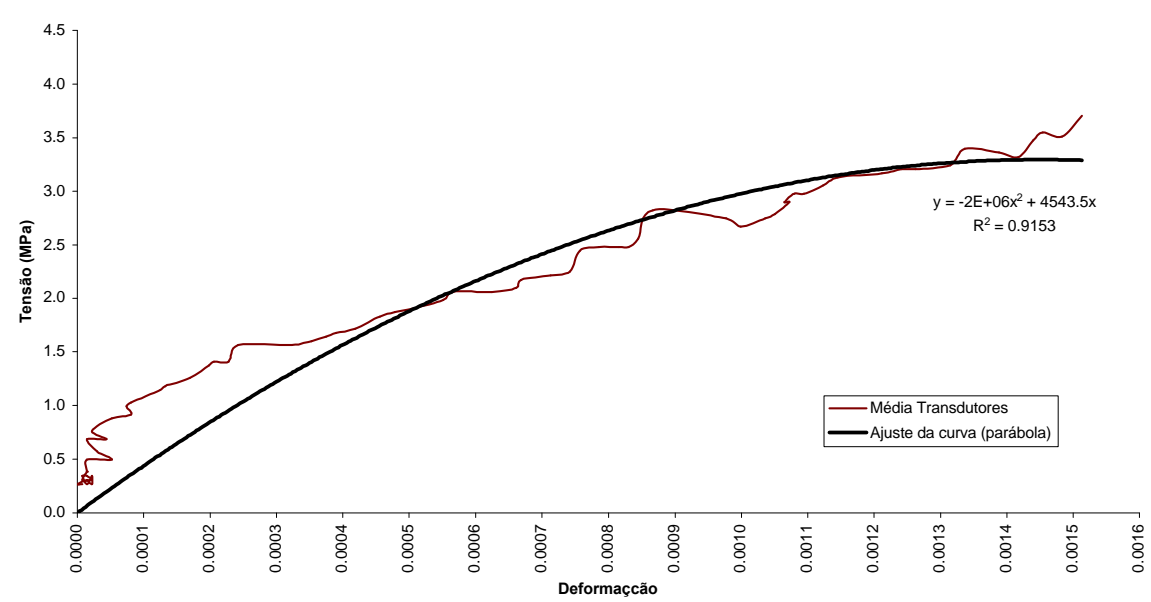



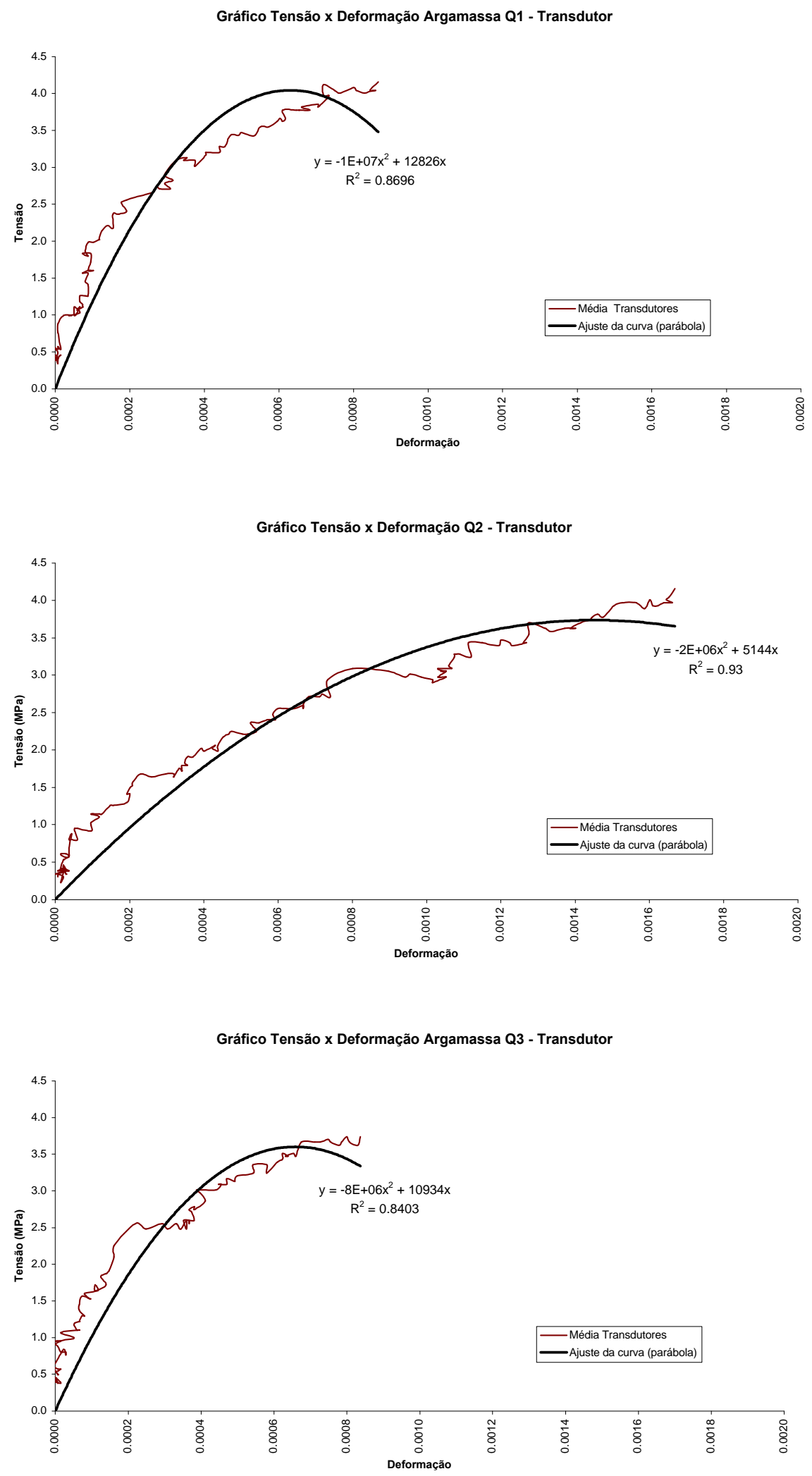

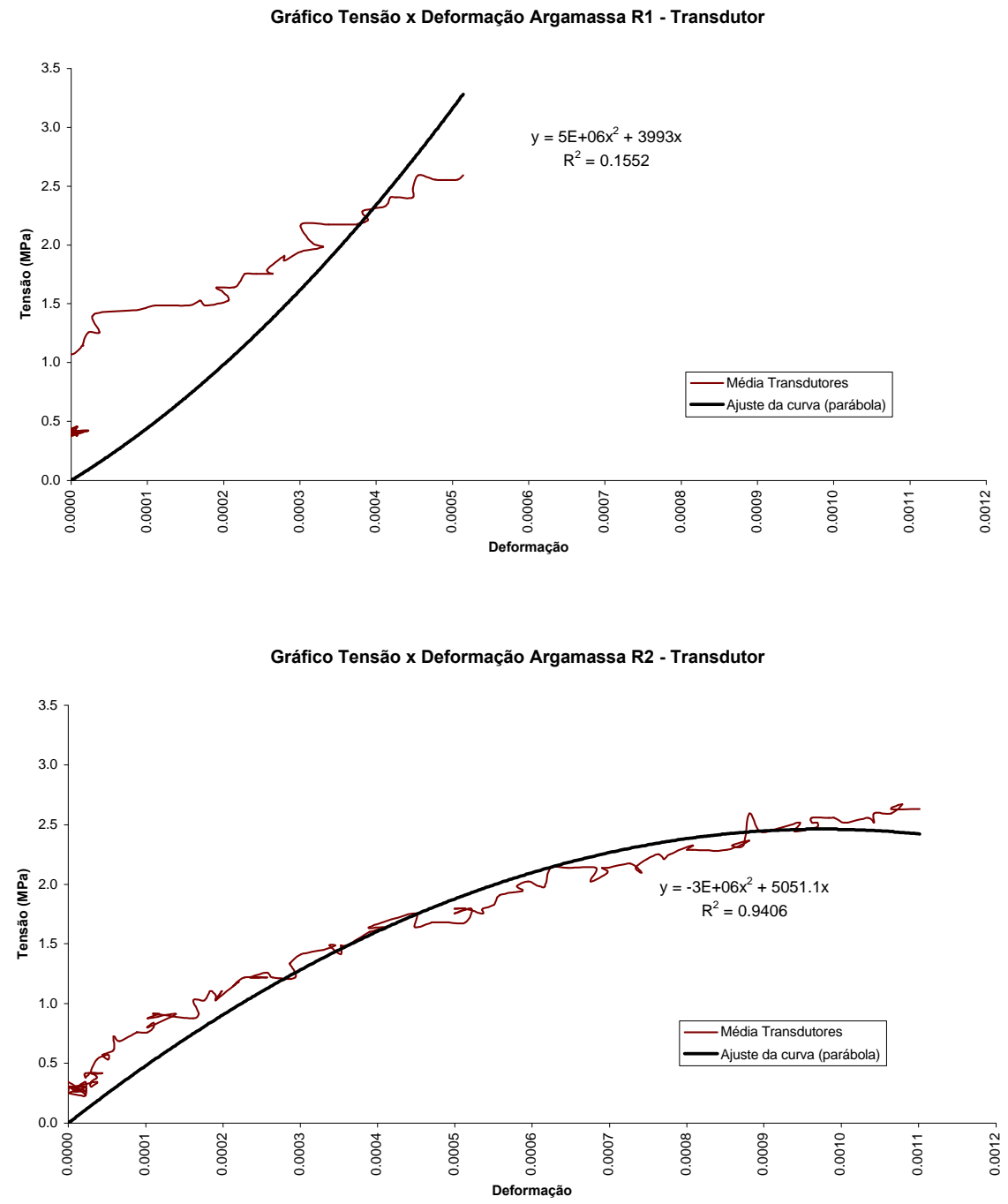

Gráfico Tensão x Deformação Argamassa R3 - Transdutor

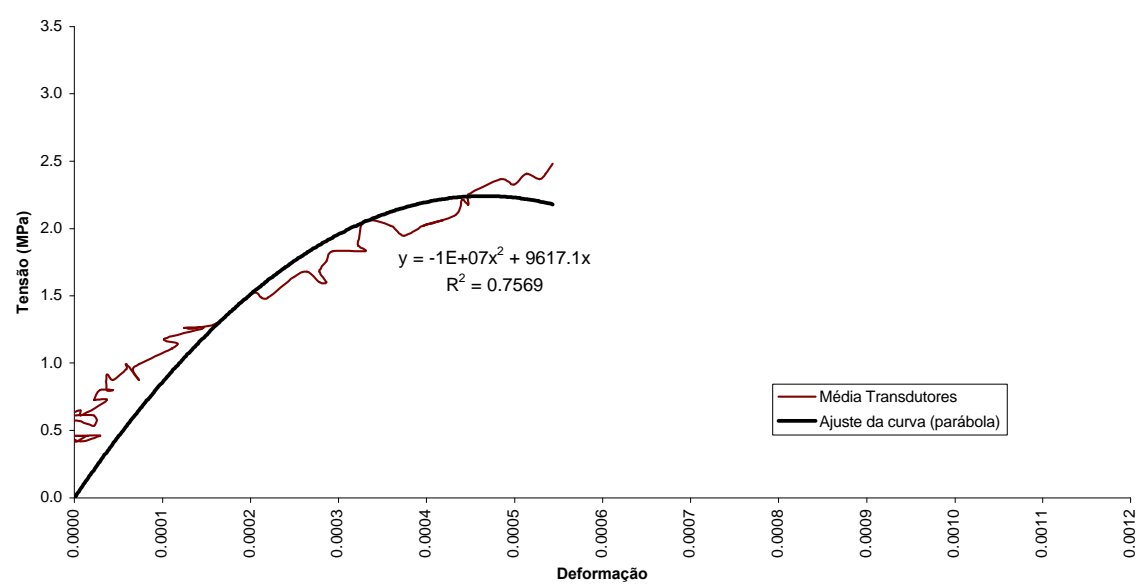


Gráfico Tensão x Deformação Argamassa P1 - Extensômetro

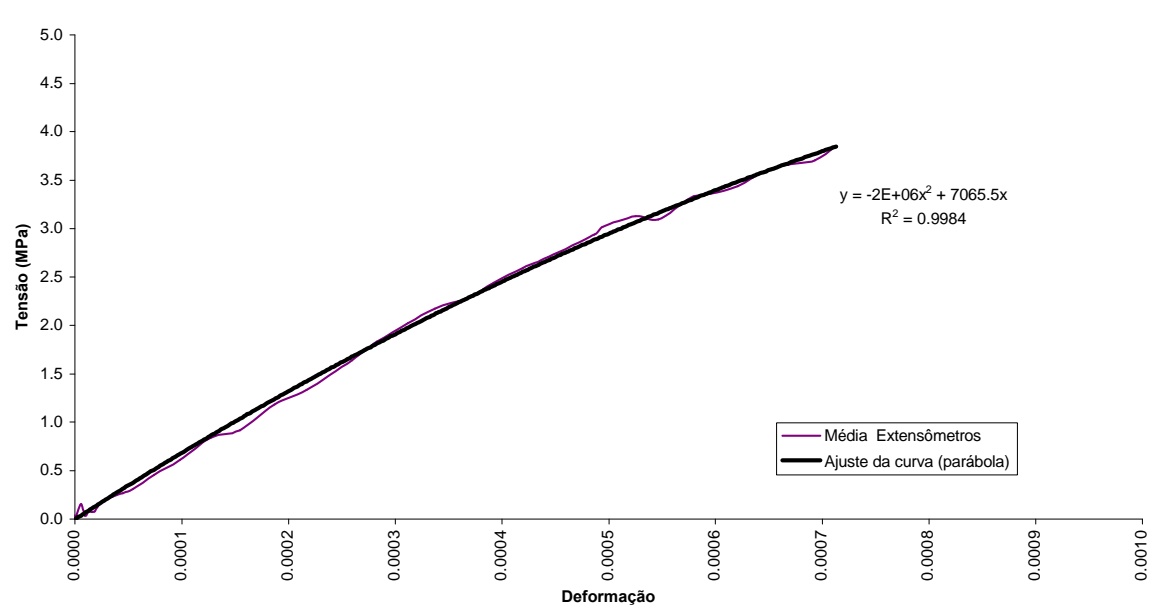

Gráfico Tensão x Deformação Argamassa P2 - Extensômetro

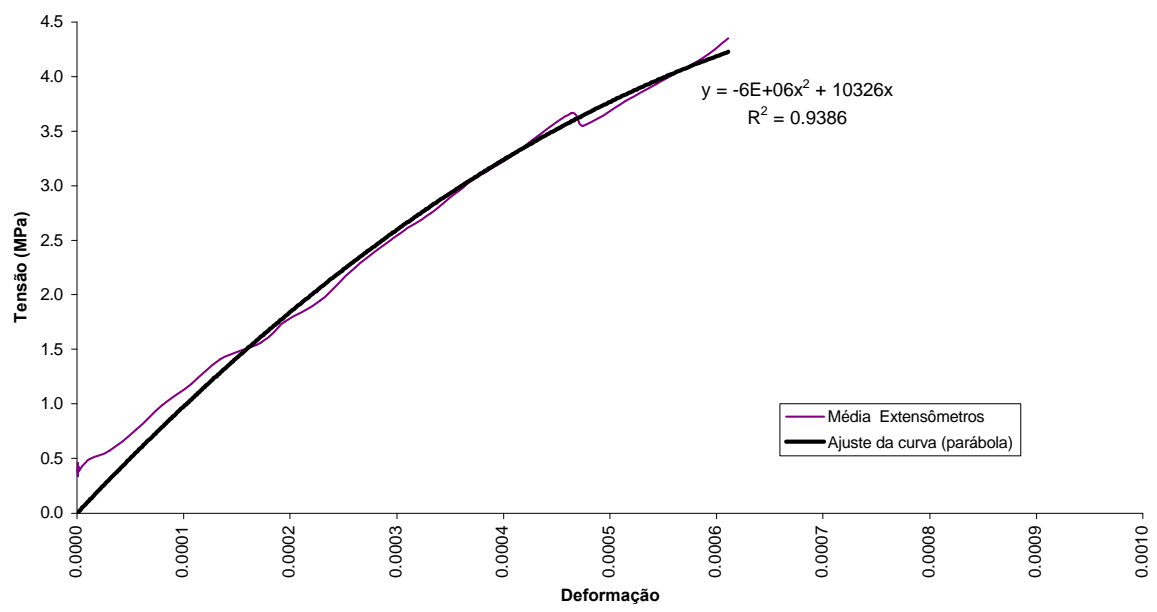

Gráfico Tensão x Deformação Argamassa P3 - Extensômetro

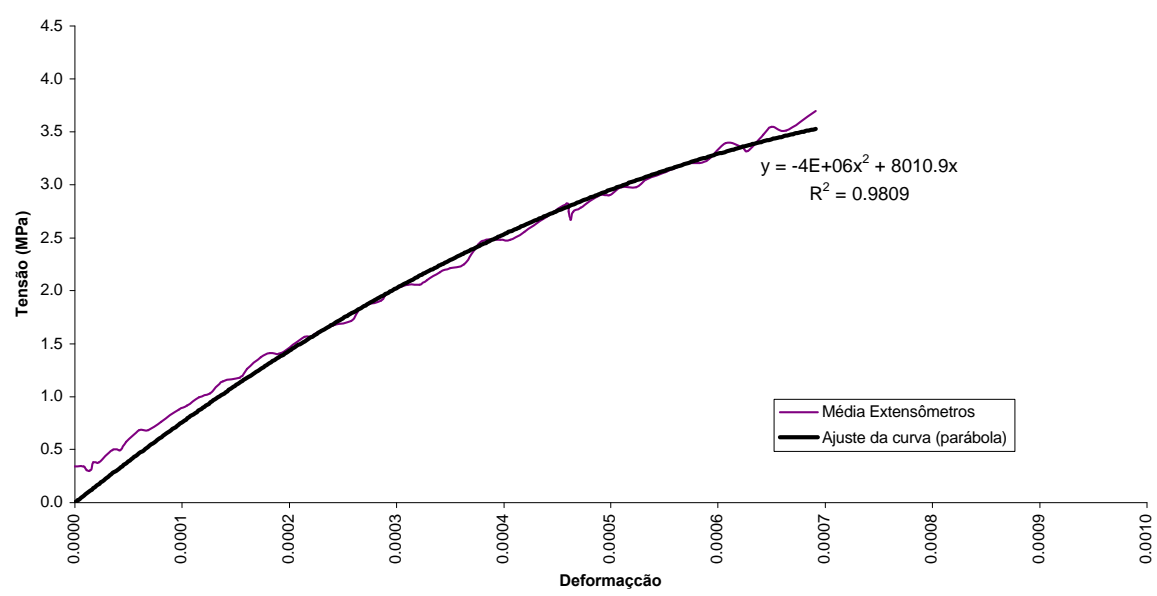



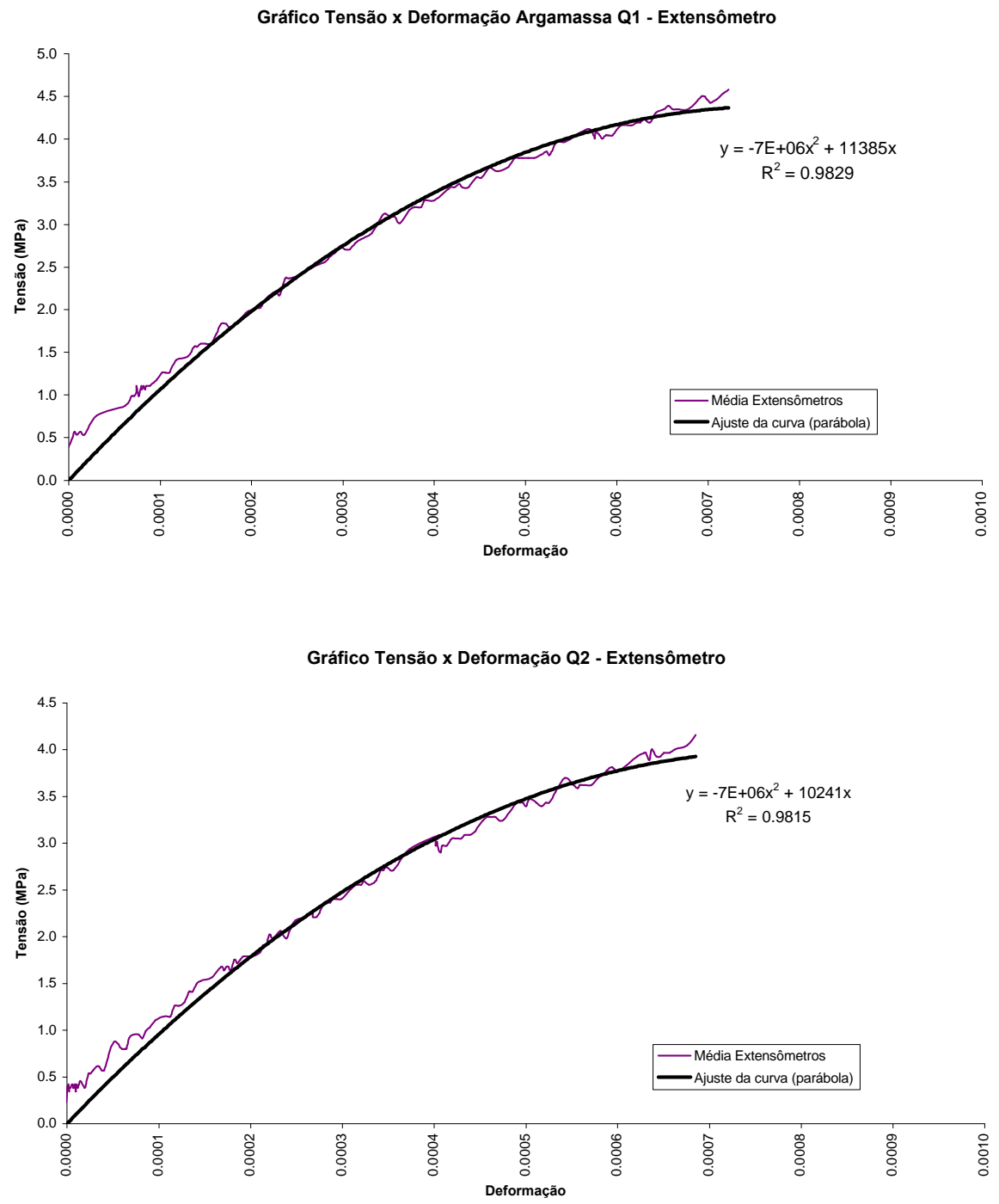

Gráfico Tensão x Deformação Argamassa Q3 - Extensômetro

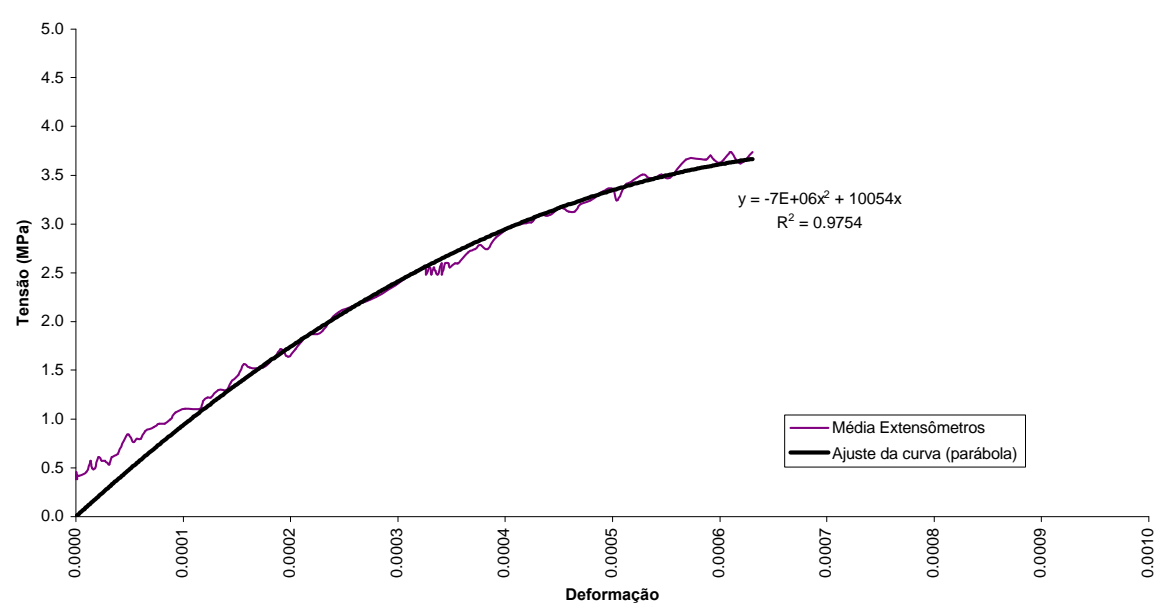


Gráfico Tensão x Deformação Argamassa R1 - Extensômetro

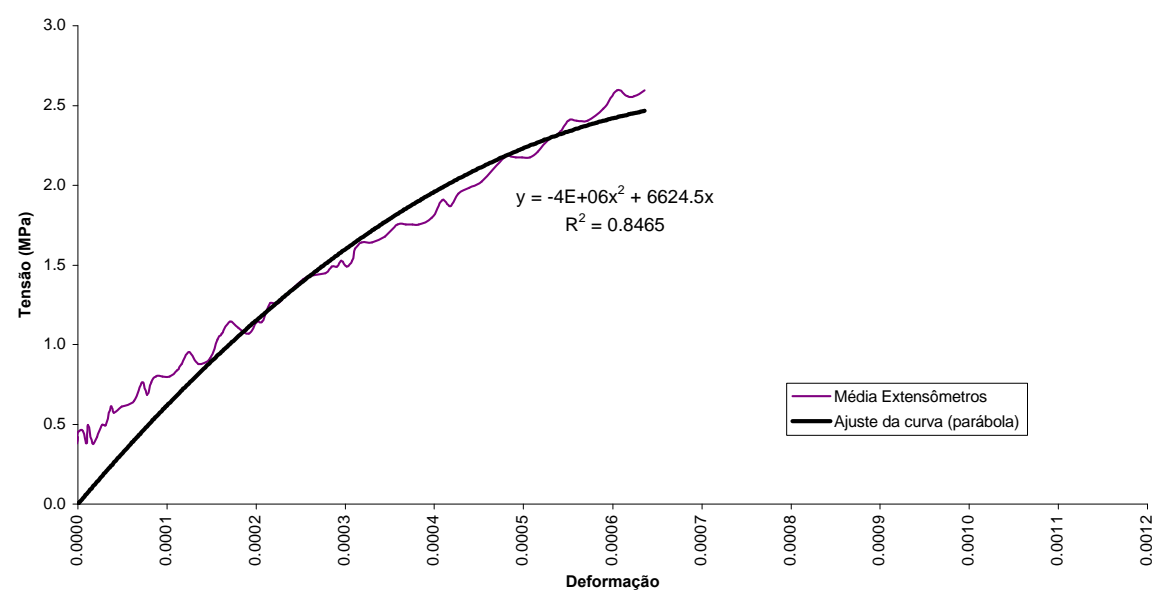

Gráfico Tensão x Deformação Argamassa R2 - Extensômetro

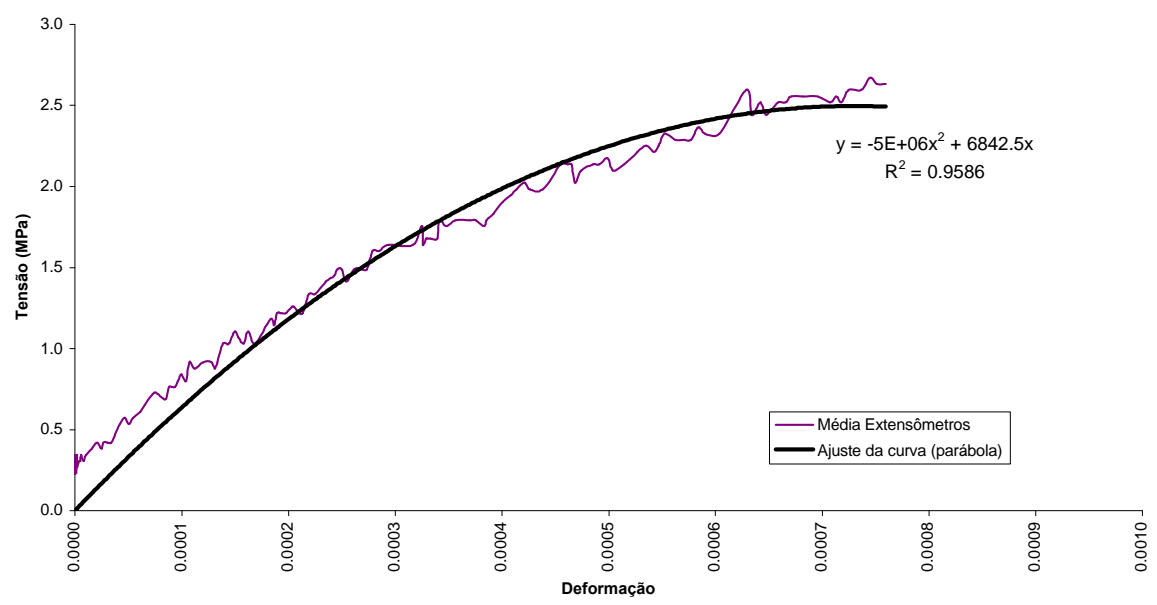

Gráfico Tensão x Deformação Argamassa R3 - Extensômetro

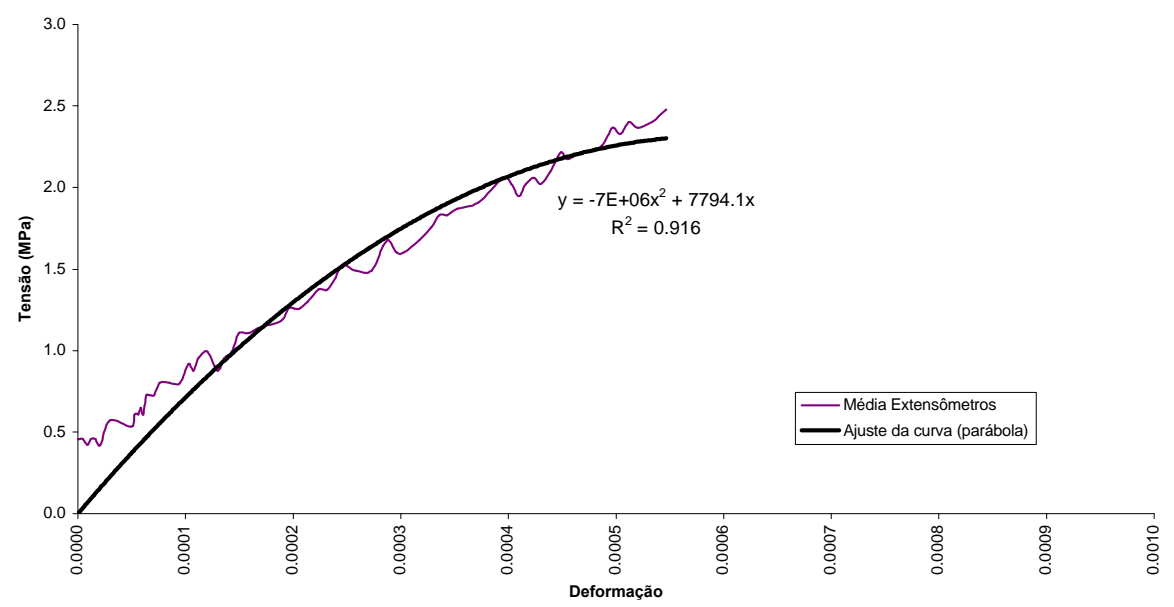




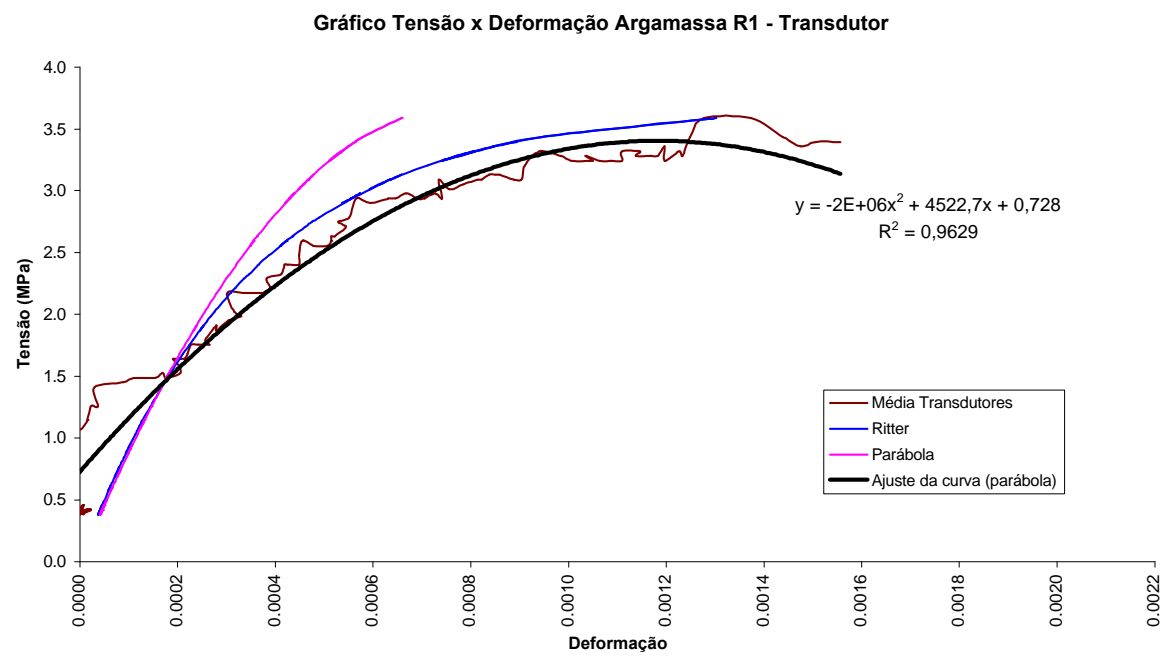

Gráfico Tensão x Deformação Argamassa R2 - Transdutor

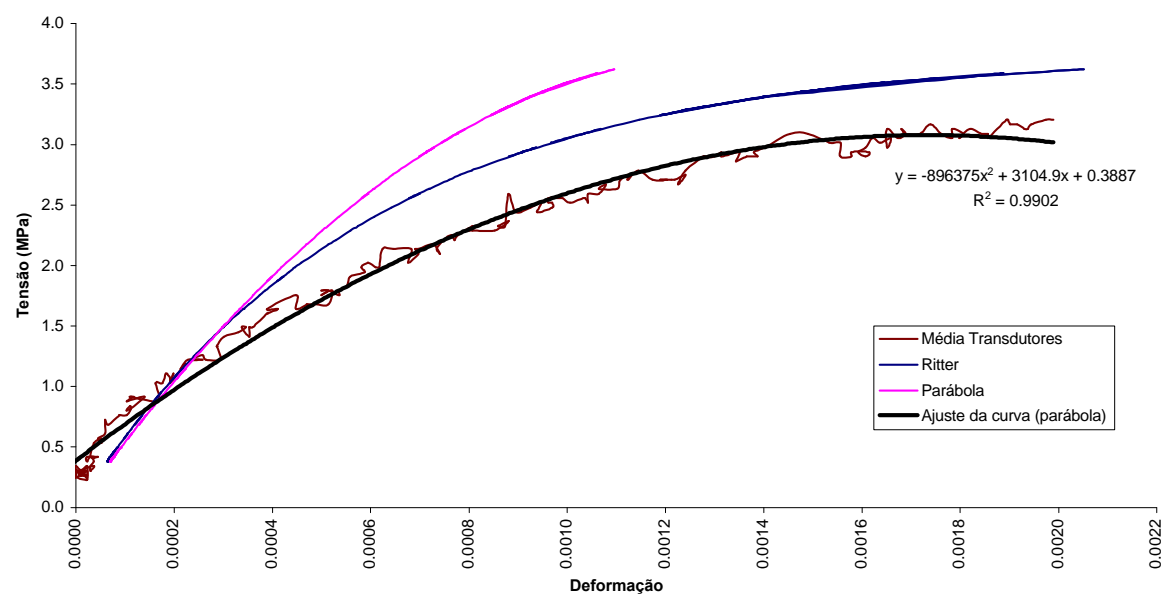

Gráfico Tensão x Deformação Argamassa R3 - Transdutor

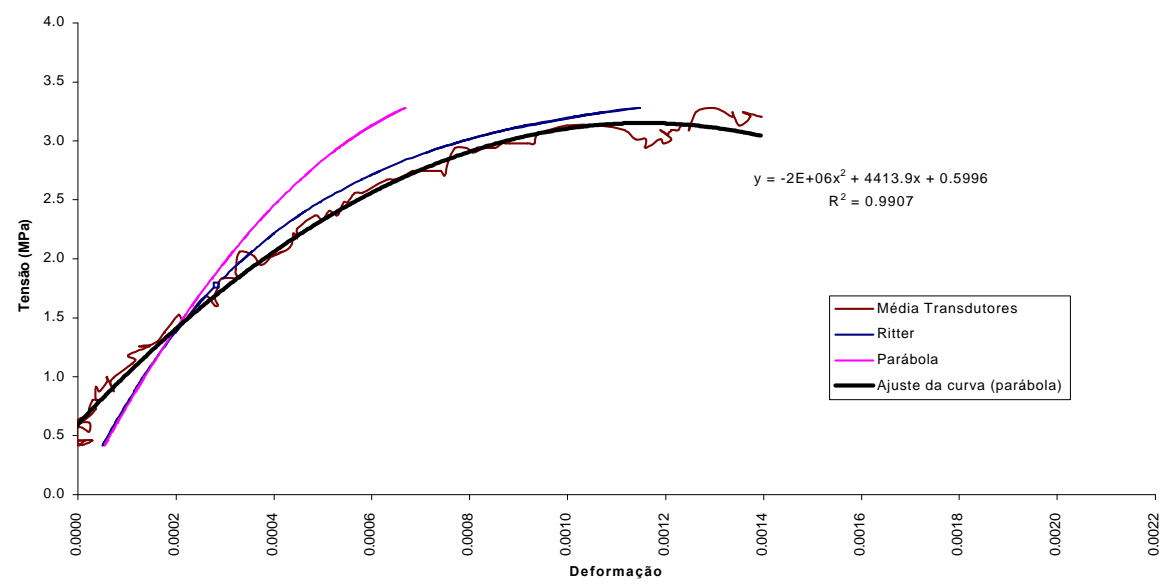


Gráfico Tensão x Deformação Argamassa R1 - Extensômetro

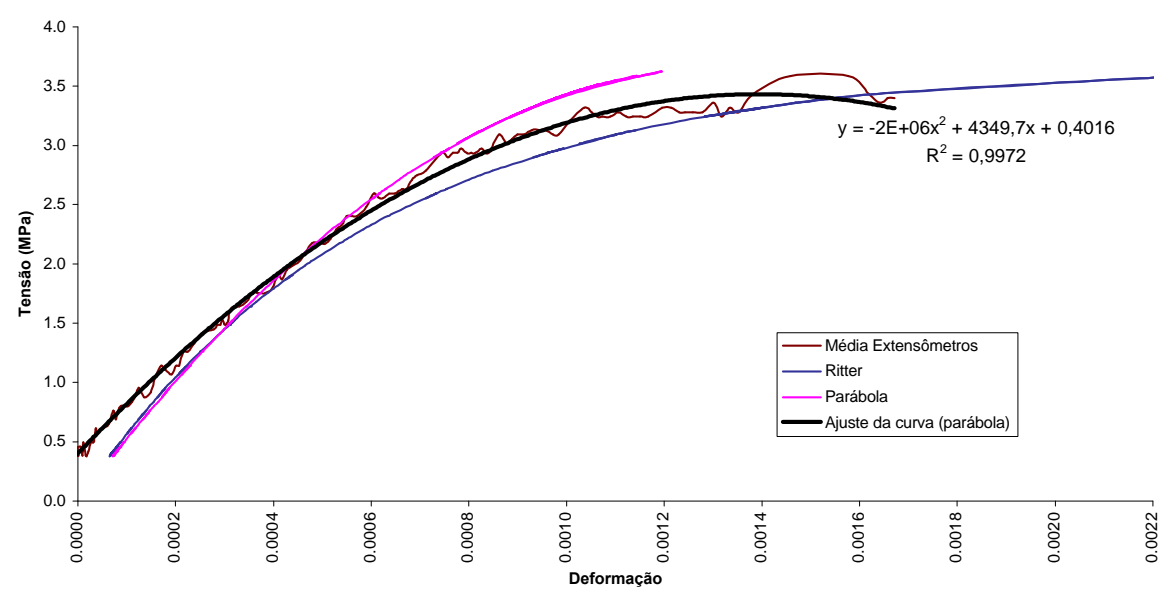

Gráfico Tensão x Deformação Argamassa R2 - Extensômetro

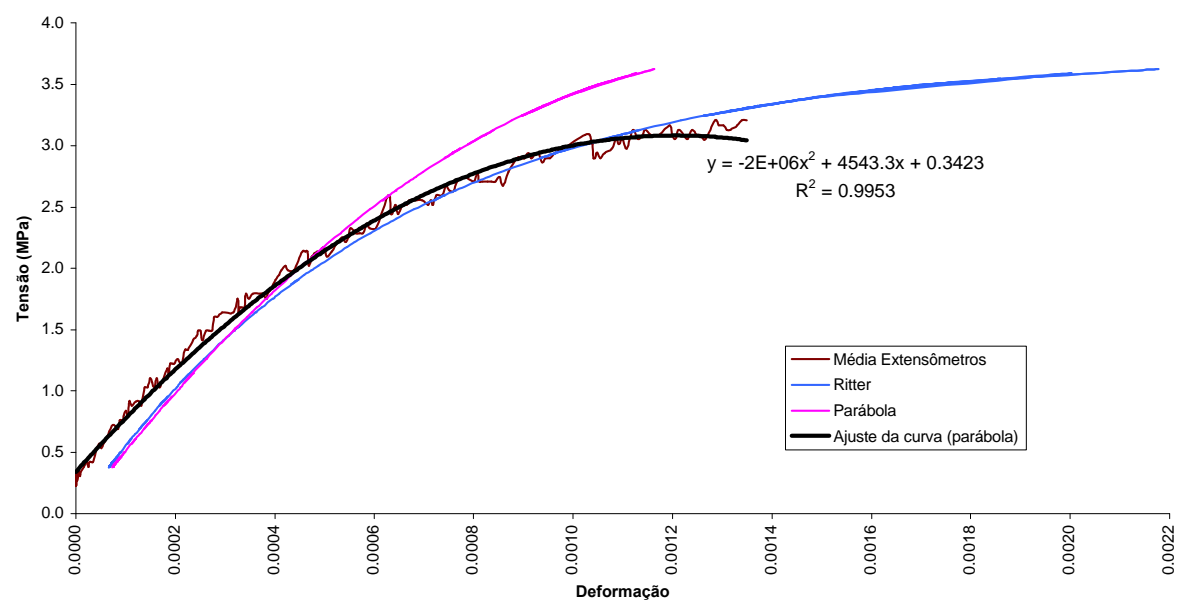

Gráfico Tensão x Deformação Argamassa R3 - Extensômetro

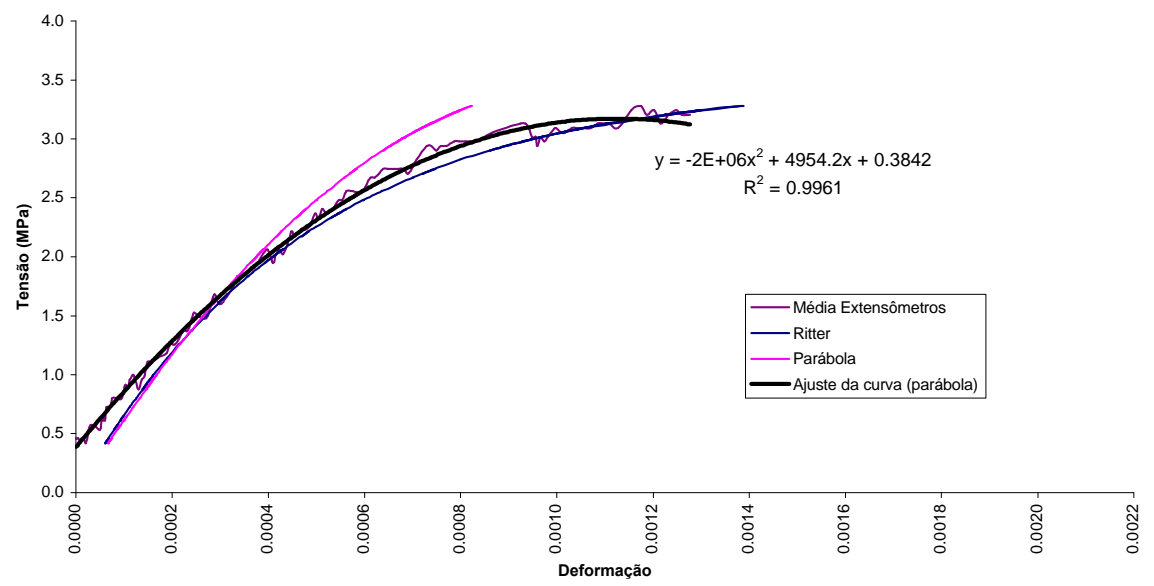


Gráfico Tensão x Deformação Argamassa Série A1 (CP n¹)

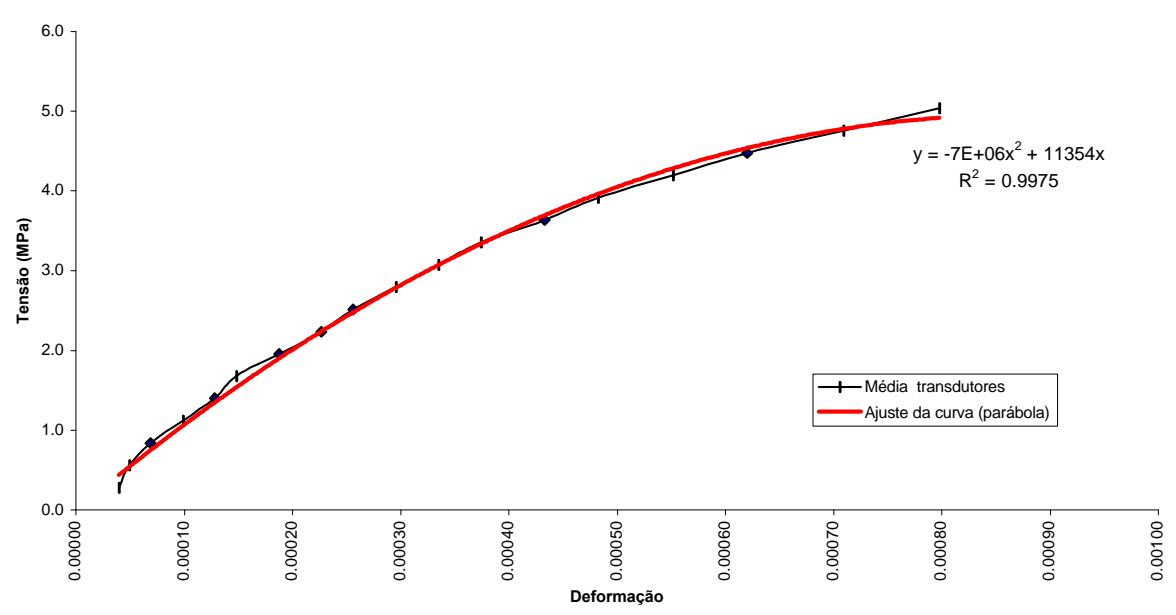

Gráfico Tensão x Deformação Argamassa Série A1 (CP n²)

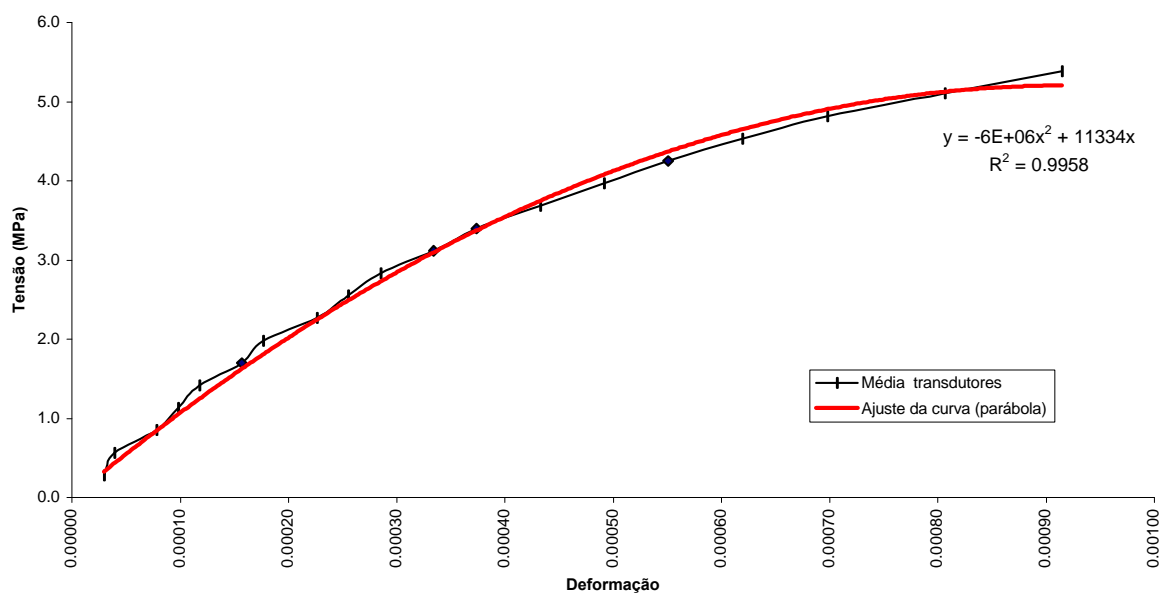

Gráfico Tensão x Deformação Argamassa Série A1 (CP n³)

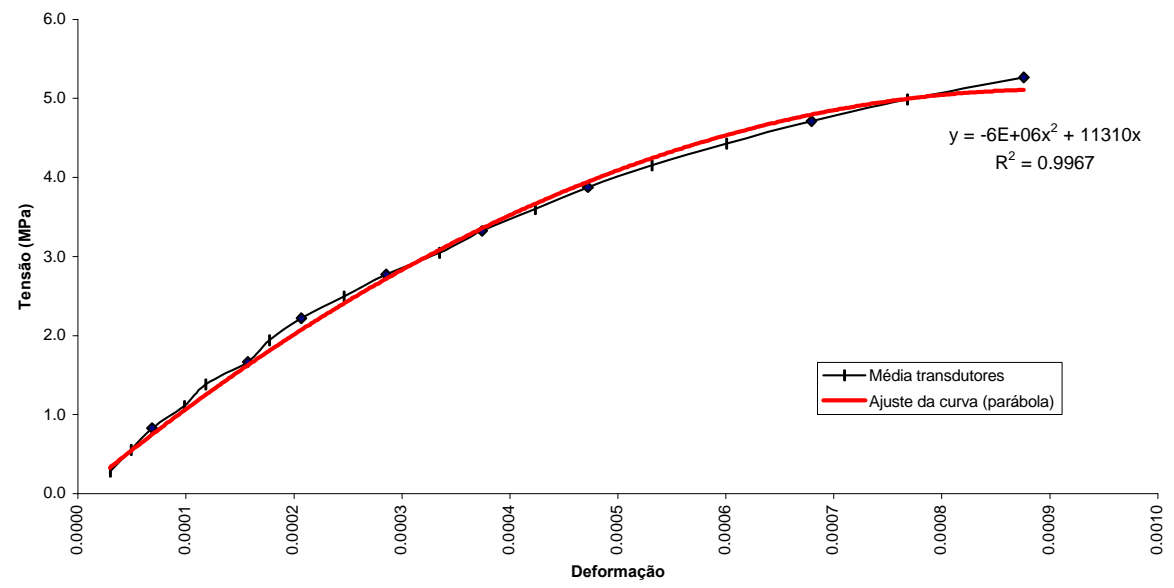




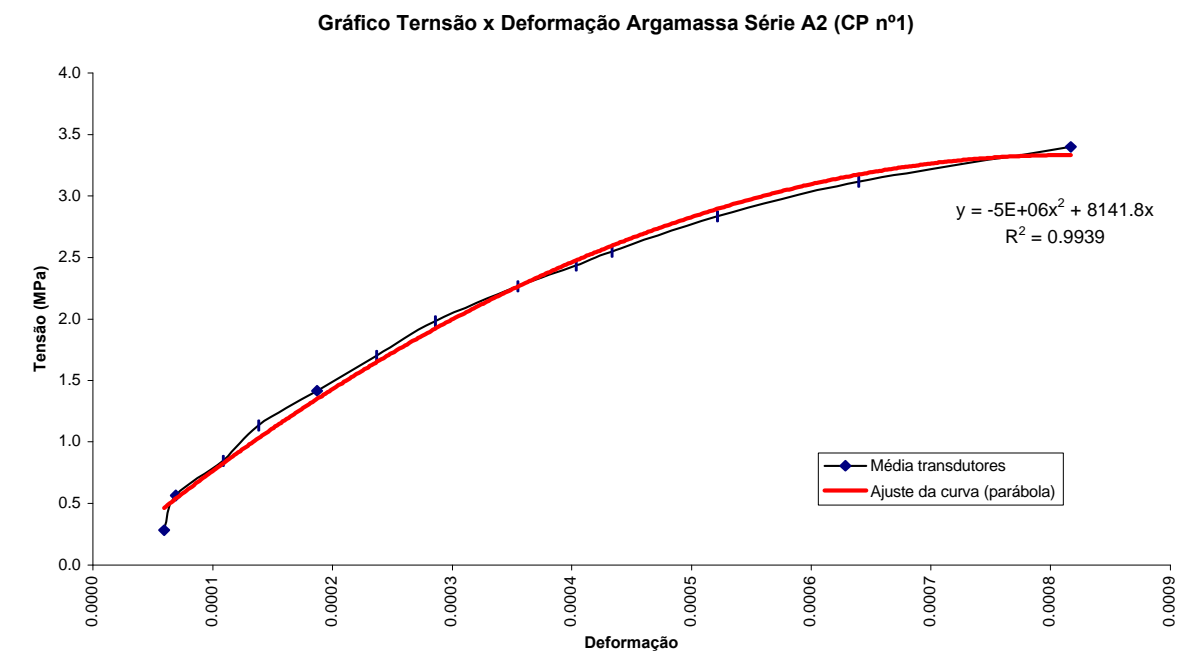

Gráfico Tensão x Deformação Argamassa Série A2 (CP n²)

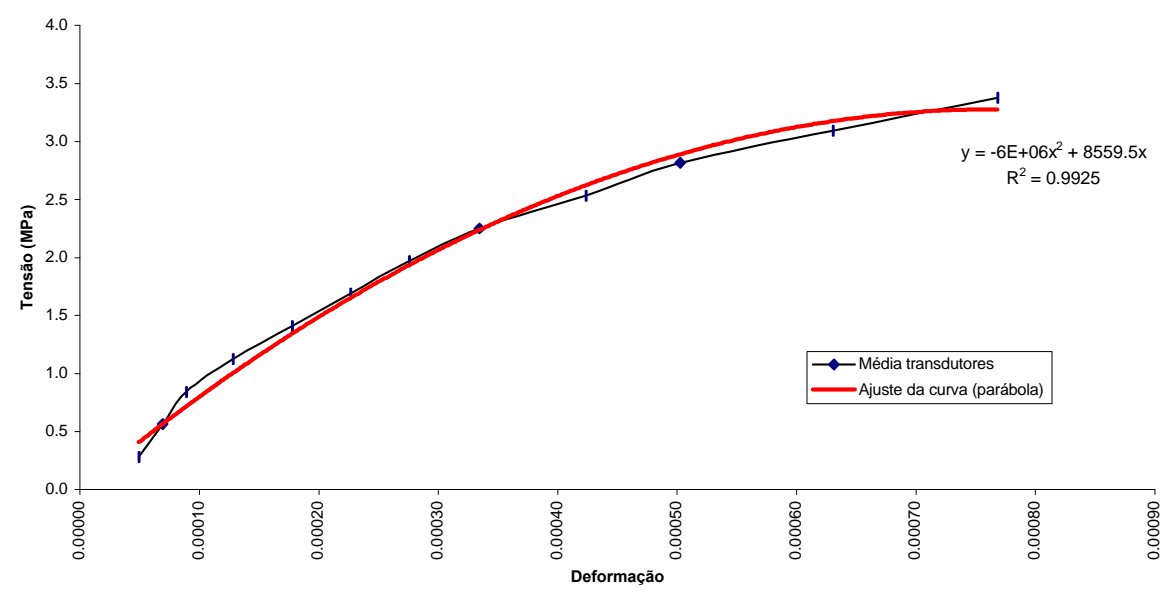

Gráfico Tensão x Deformação Argamassa Série A2 (CP n³)

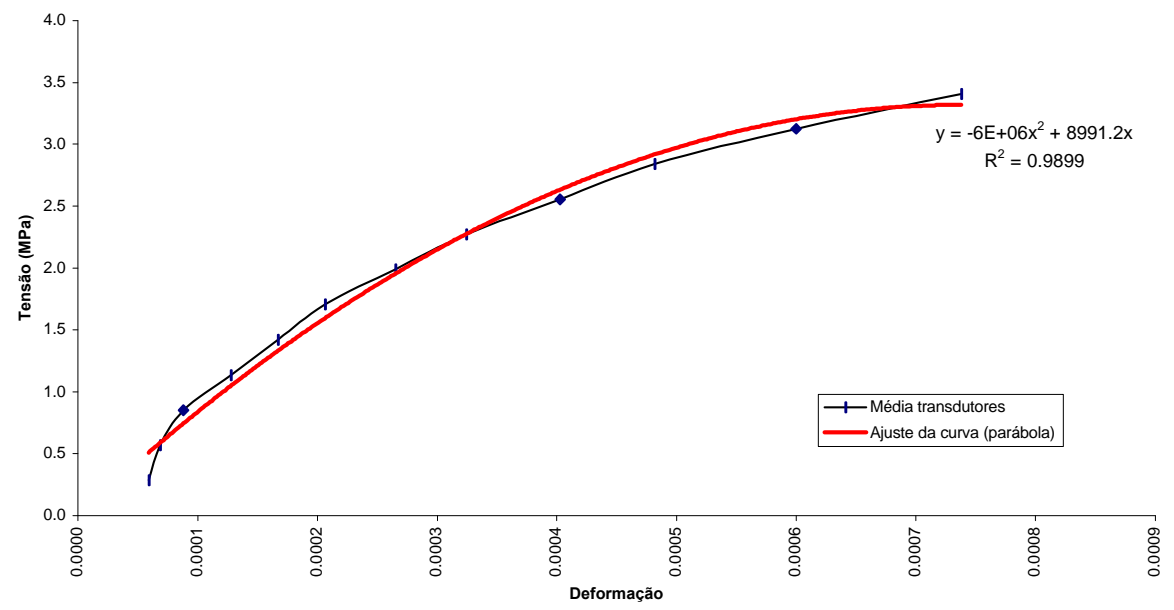


Gráfico Tensão x Deformação Argamassa Série A2 (CP nº)

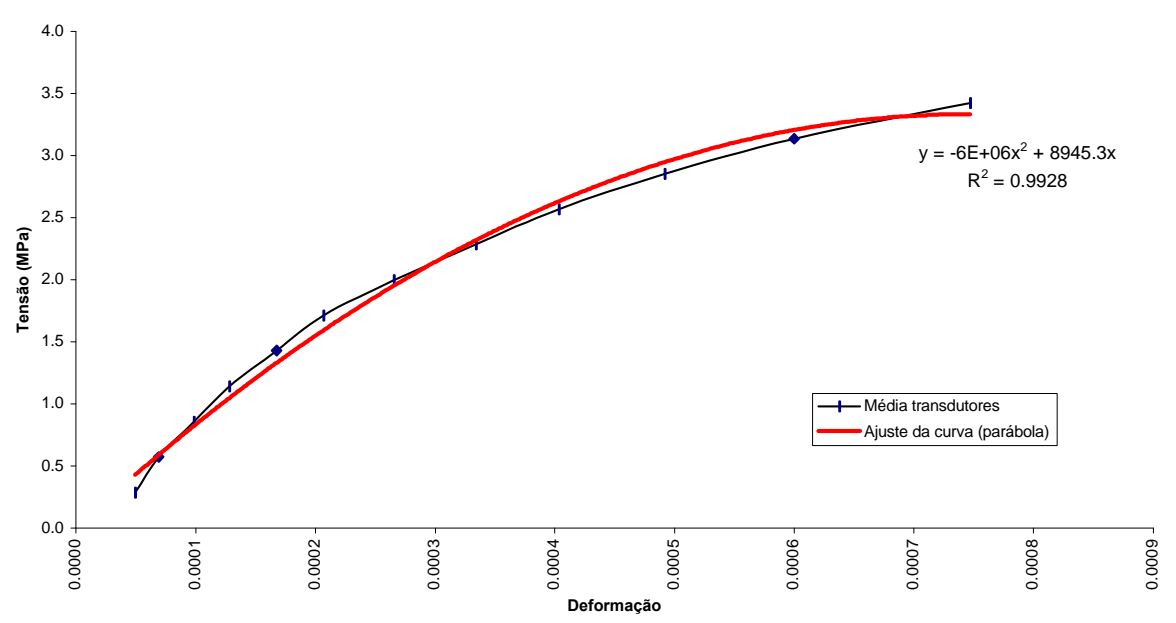


Gráfico Tensão x Deformação P111 - Prisma

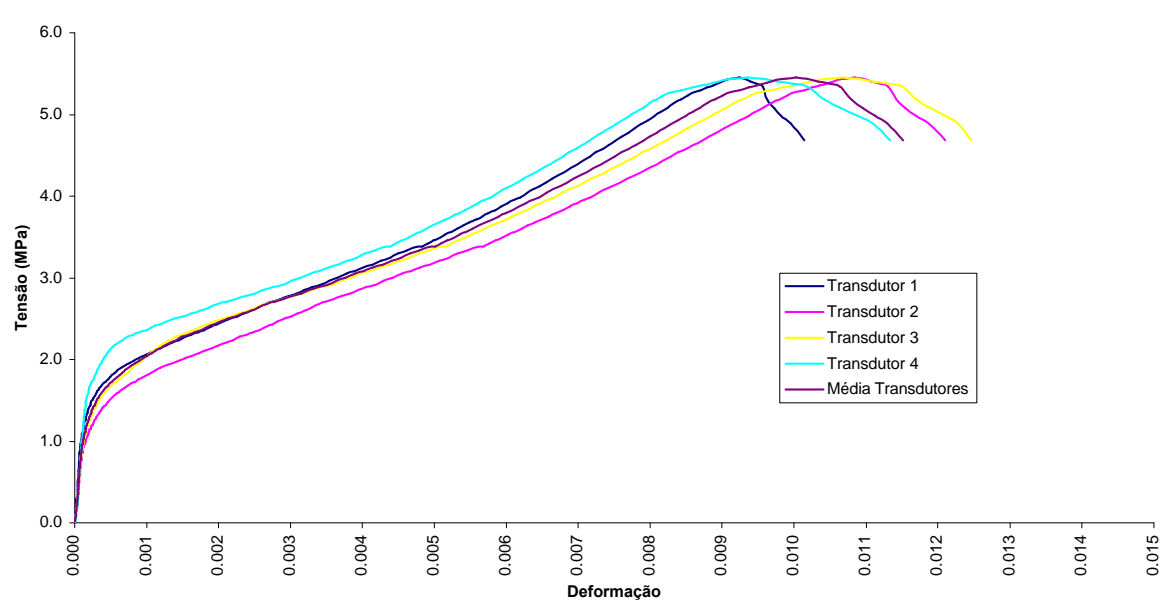

Gráfico Tensão x Deformação P112- Prisma

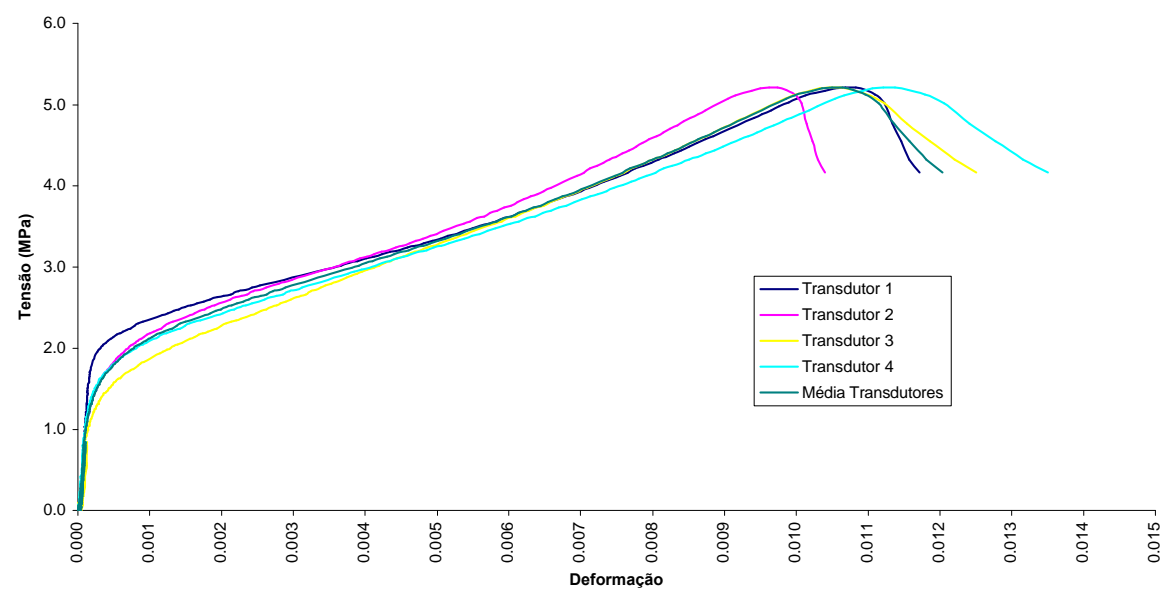

Gráfico Tensão x Deformação P113 - Prisma

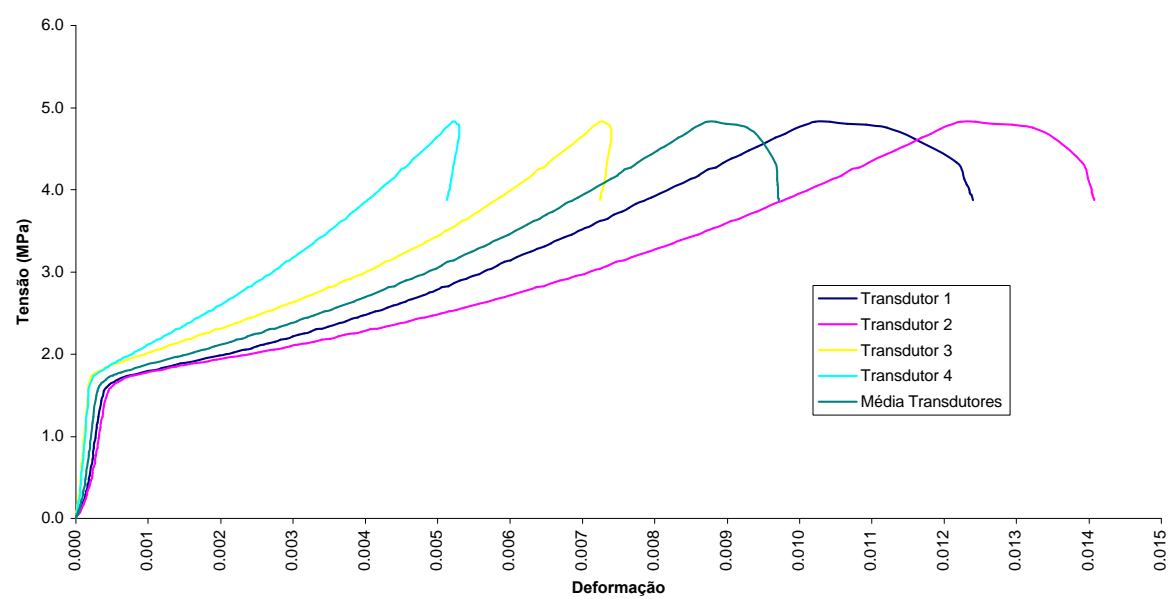




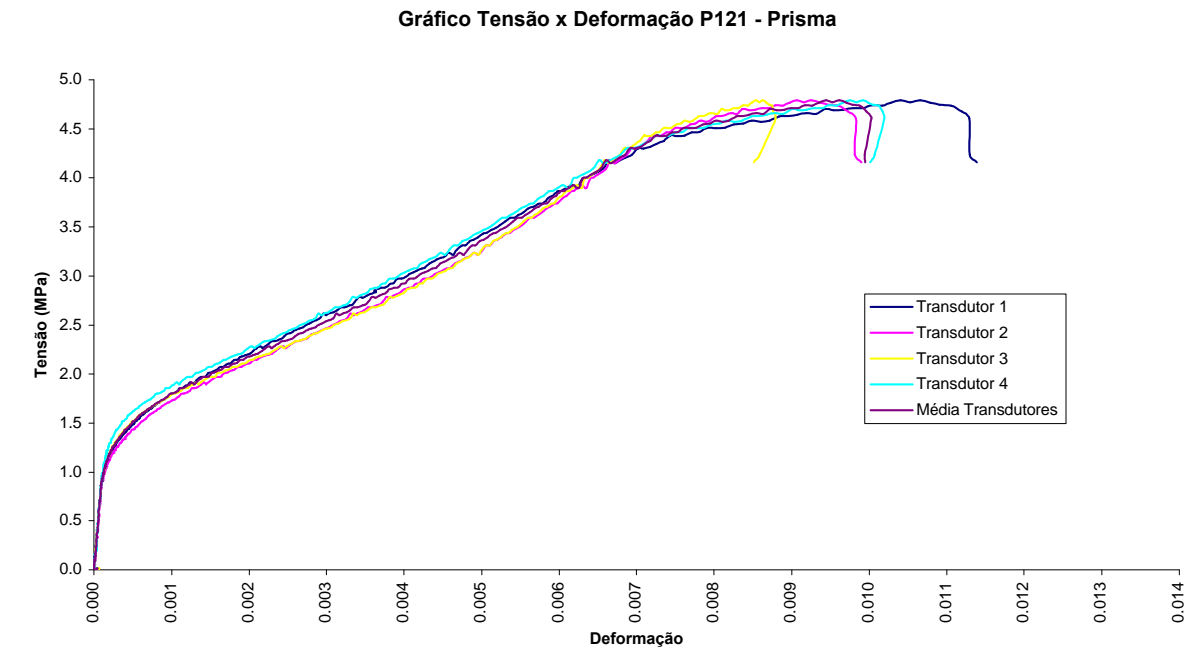

Gráfico Tensão x Deformação P122 - Prisma

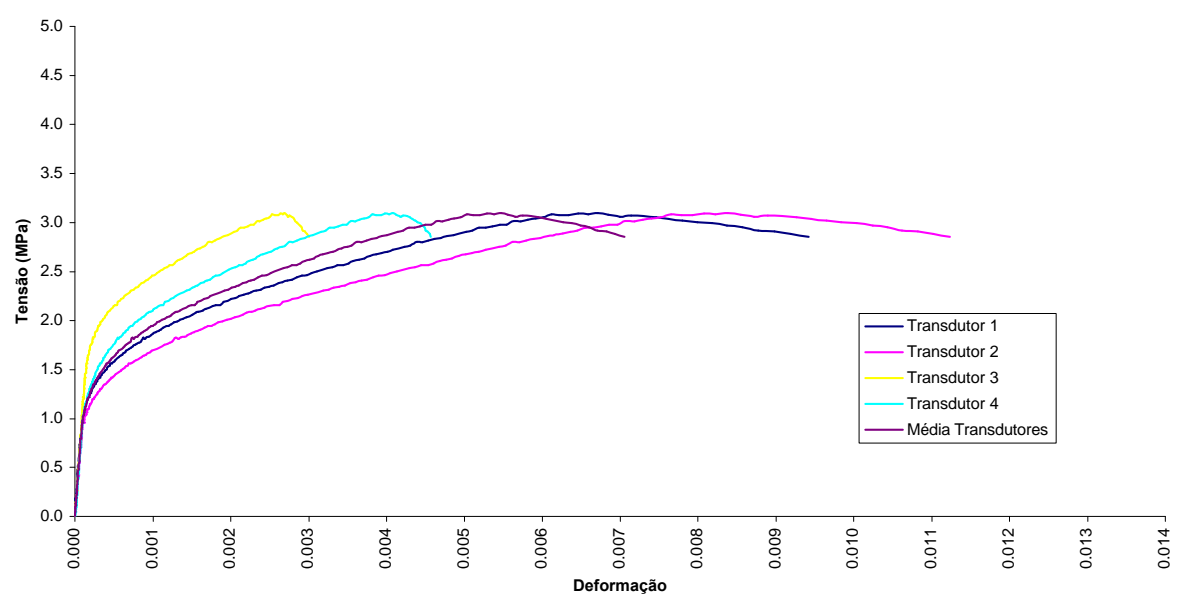

Gráfico Tensão x Deformação P123 - Prisma

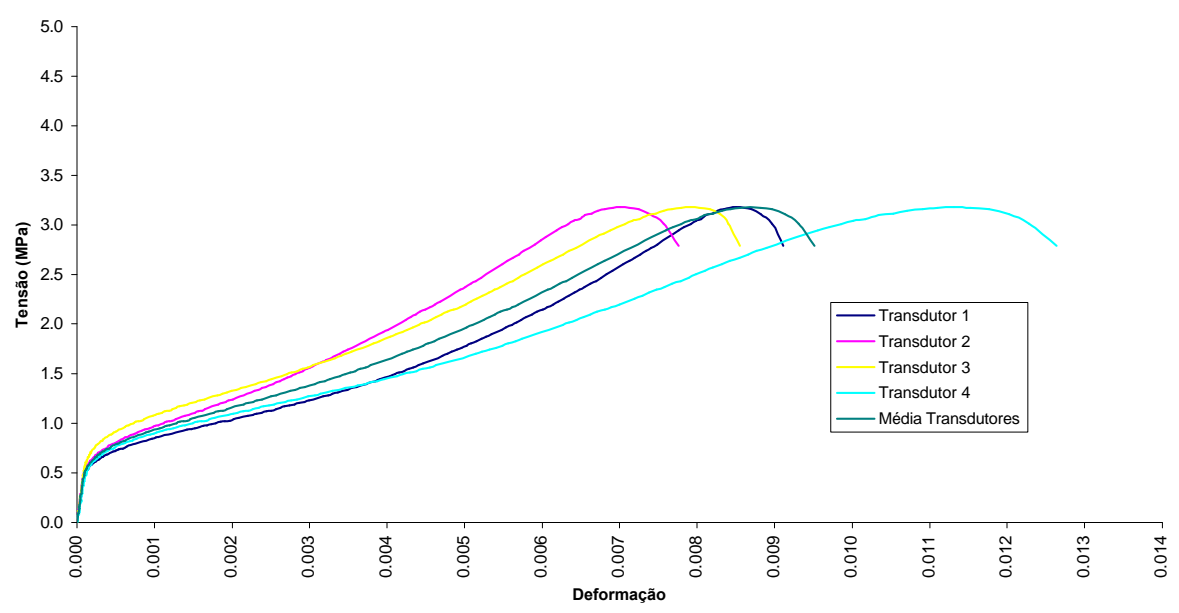




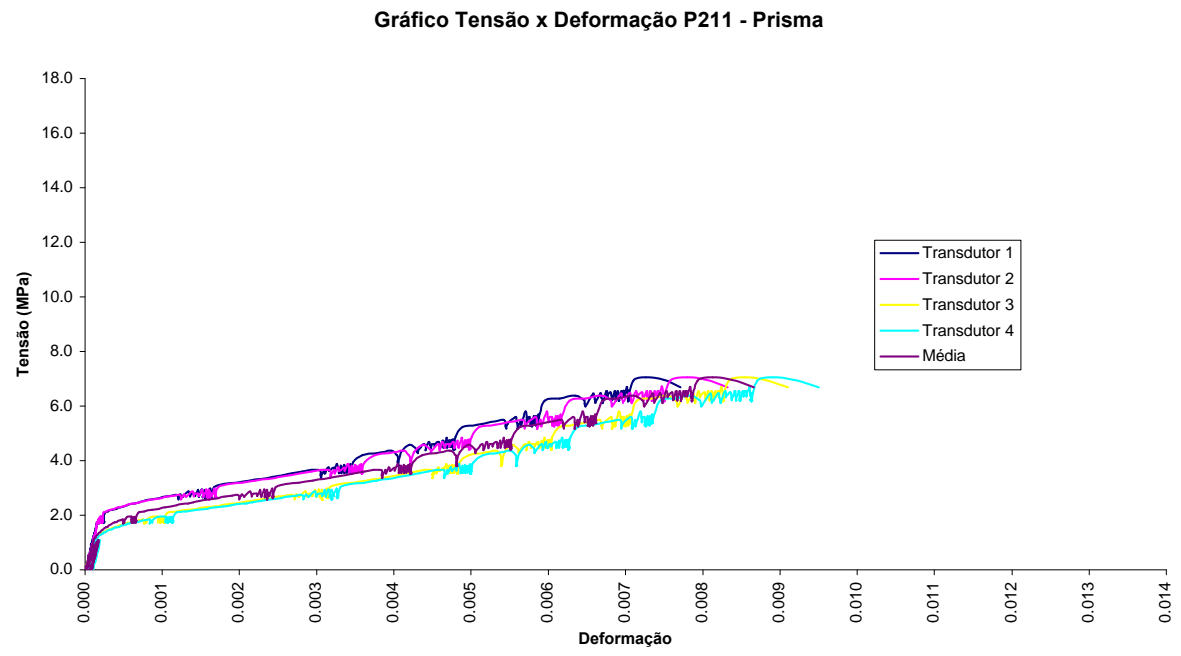

Gráfico Tensão x Deformação P212 - Prisma

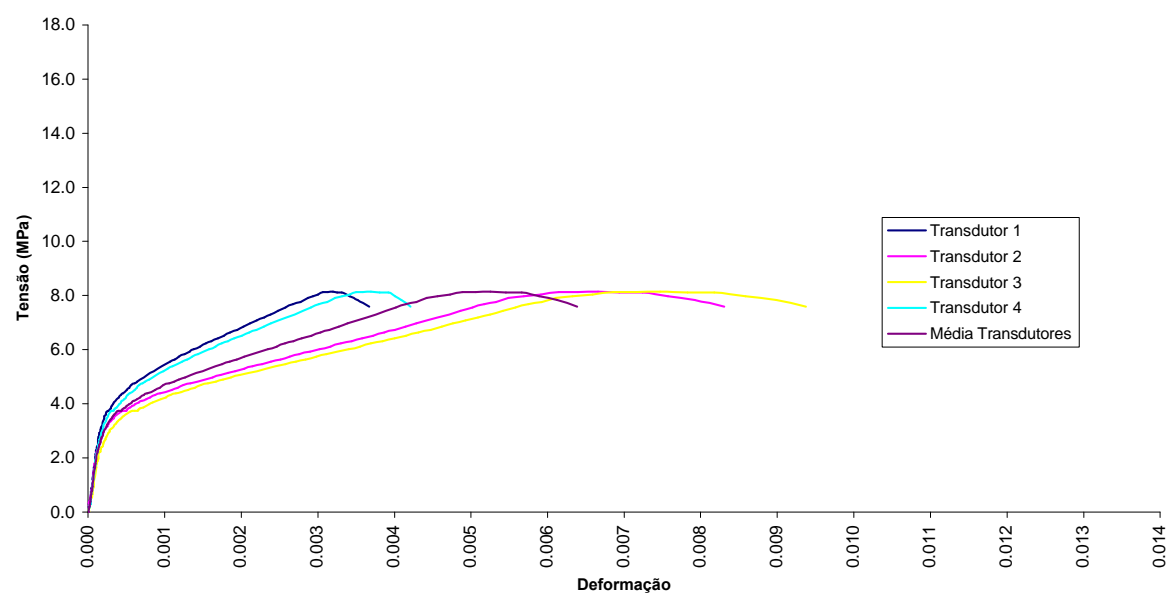

Gráfico Tensão x Deformação P213 - Prisma

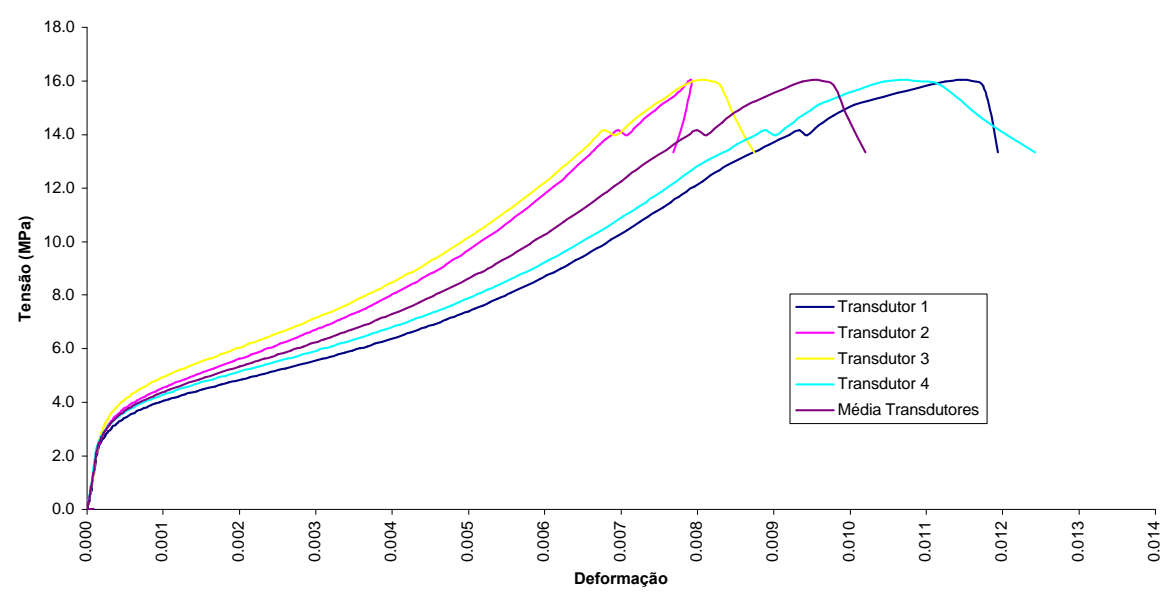


Gráfico Tensão x Deformação P221 - Prisma

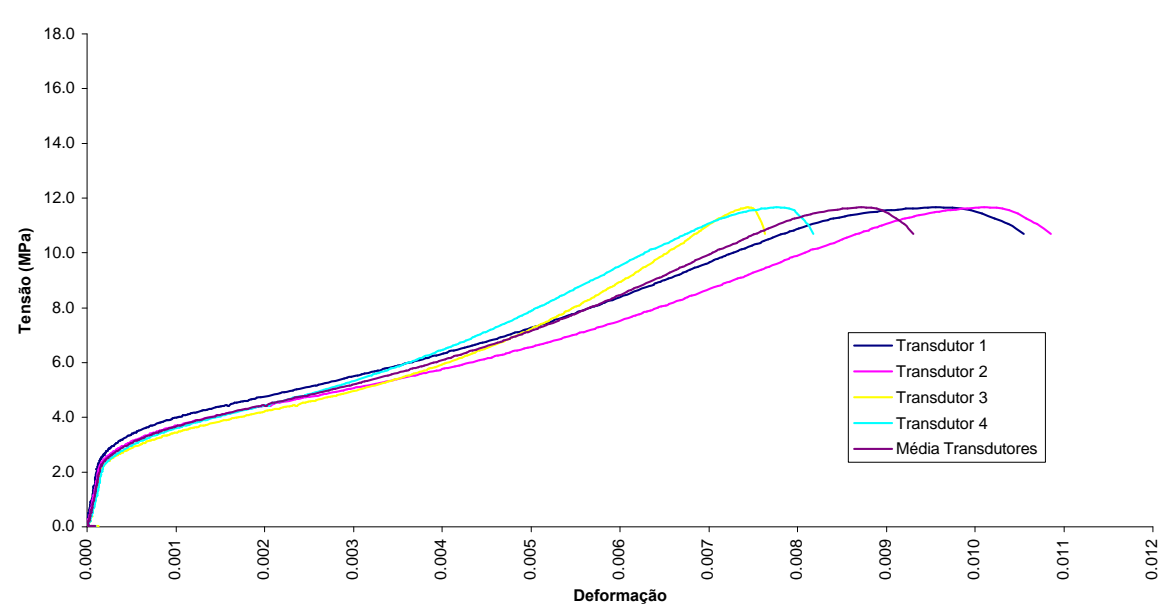

Gráfico Tensão x Deformação P222 - Prisma

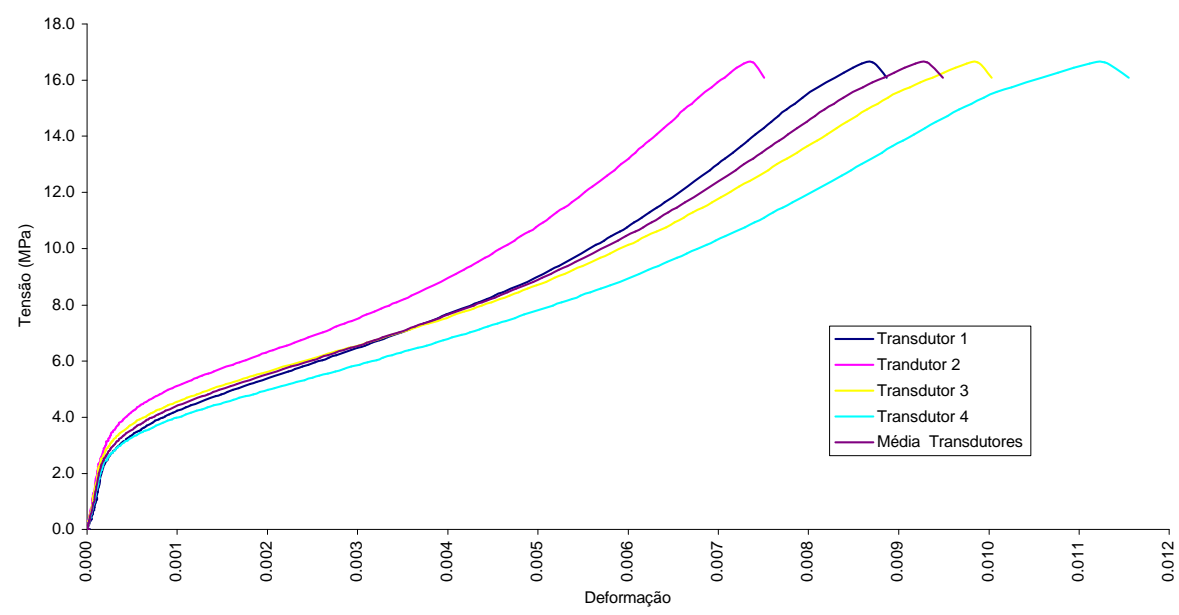

Gráfico Tensão x Deformação P223 - Prisma

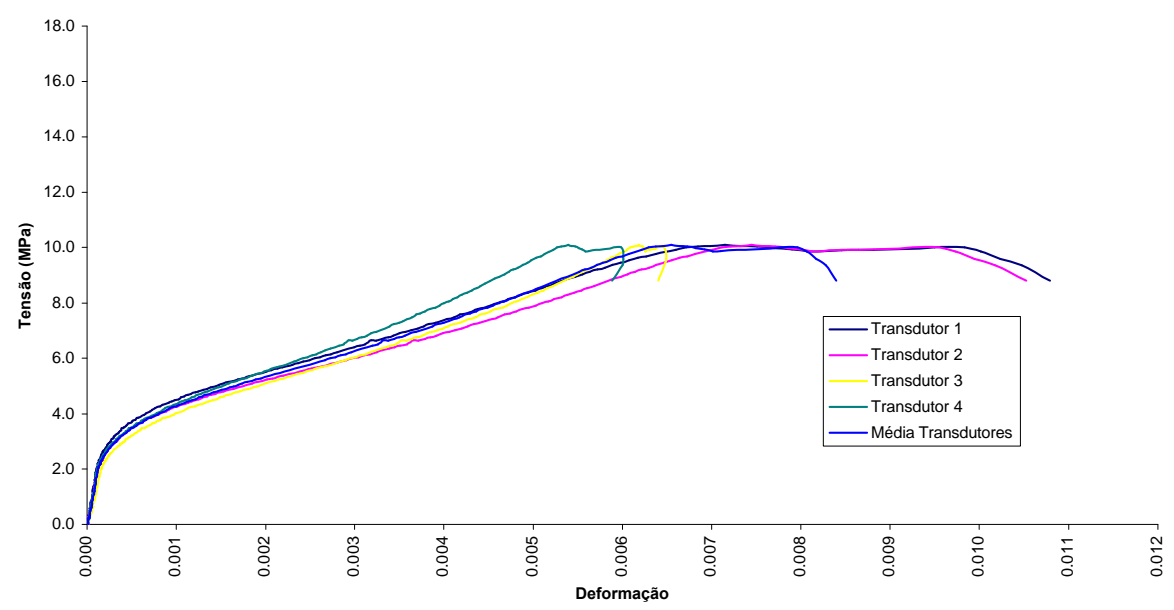


Gráfico Tensão x Deformação Q111 - Prisma

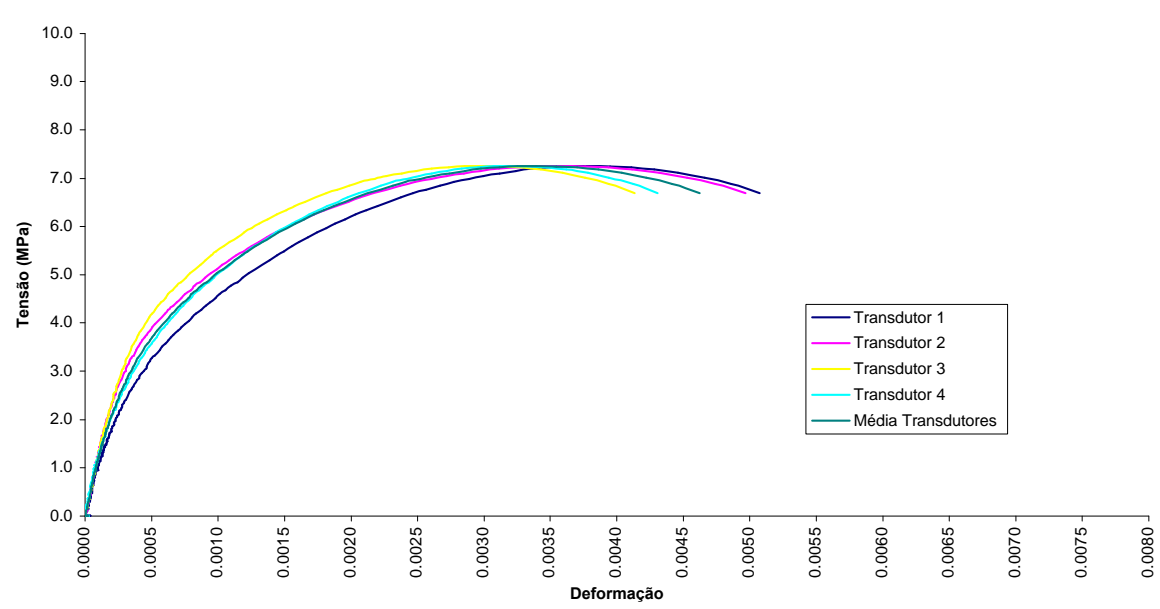

Gráfico Tensão x Deformação Q112 - Prisma

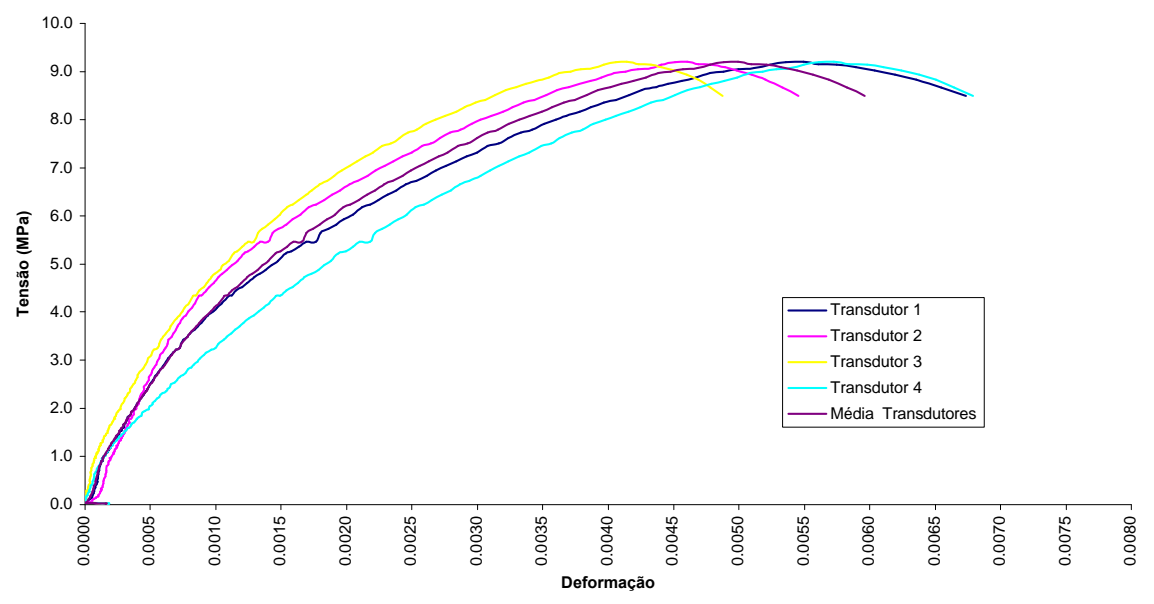

Gráfico Tensão x Deformação Q113 - Prisma

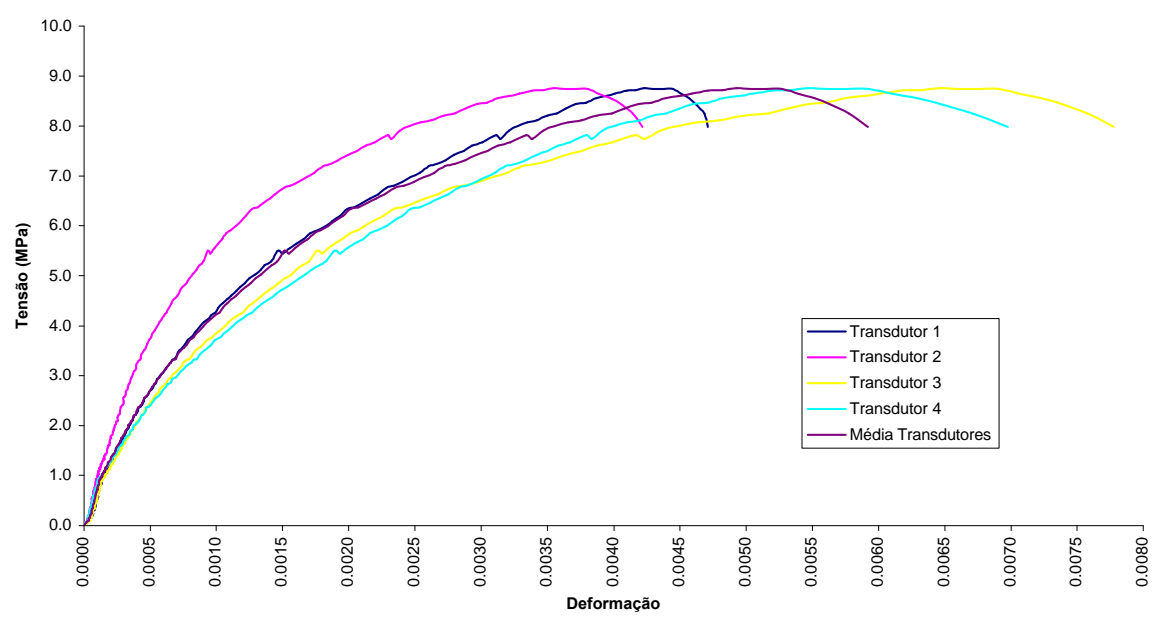


Gráfico Tensão x Deformação Q121 - Prisma

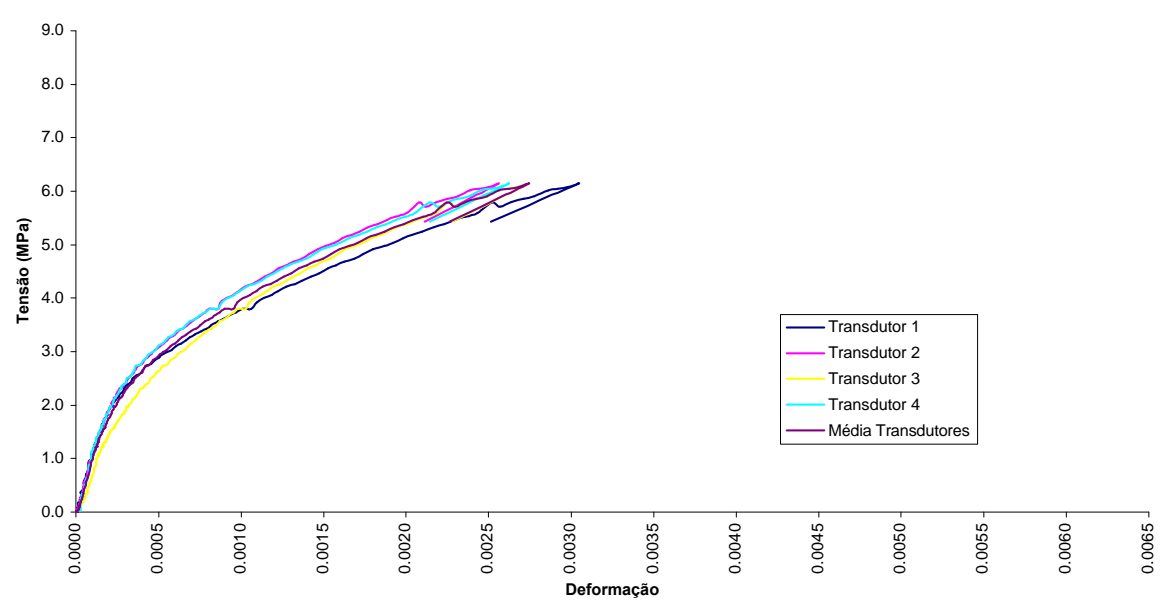

Gráfico Tensão x Deformação Q122 - Prisma

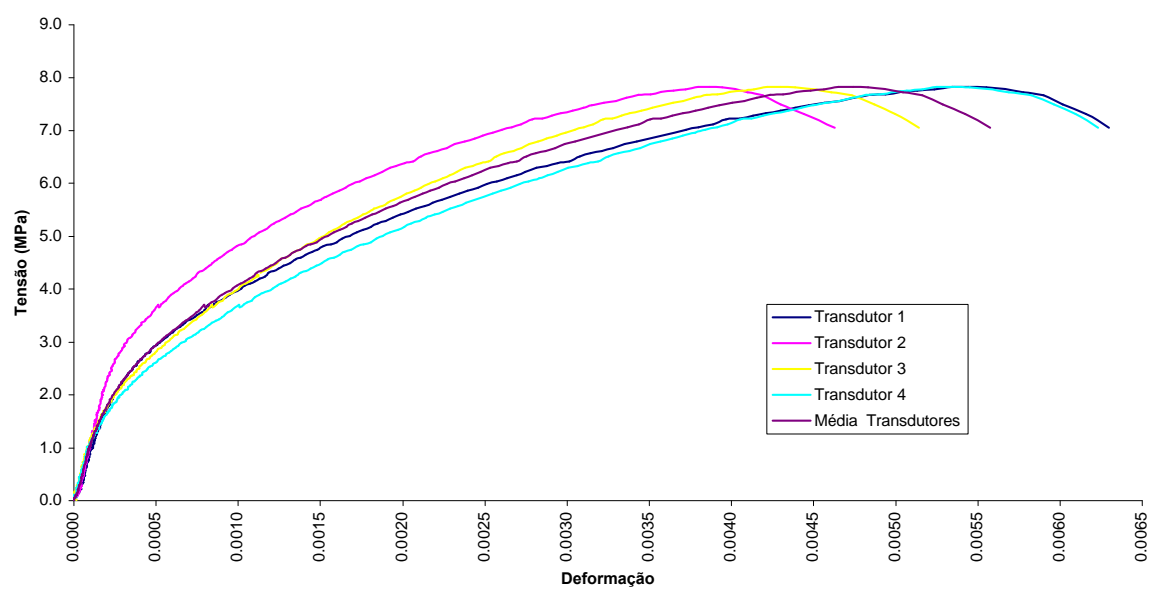

Gráfico Tensão x Deformação Q123 - Prisma

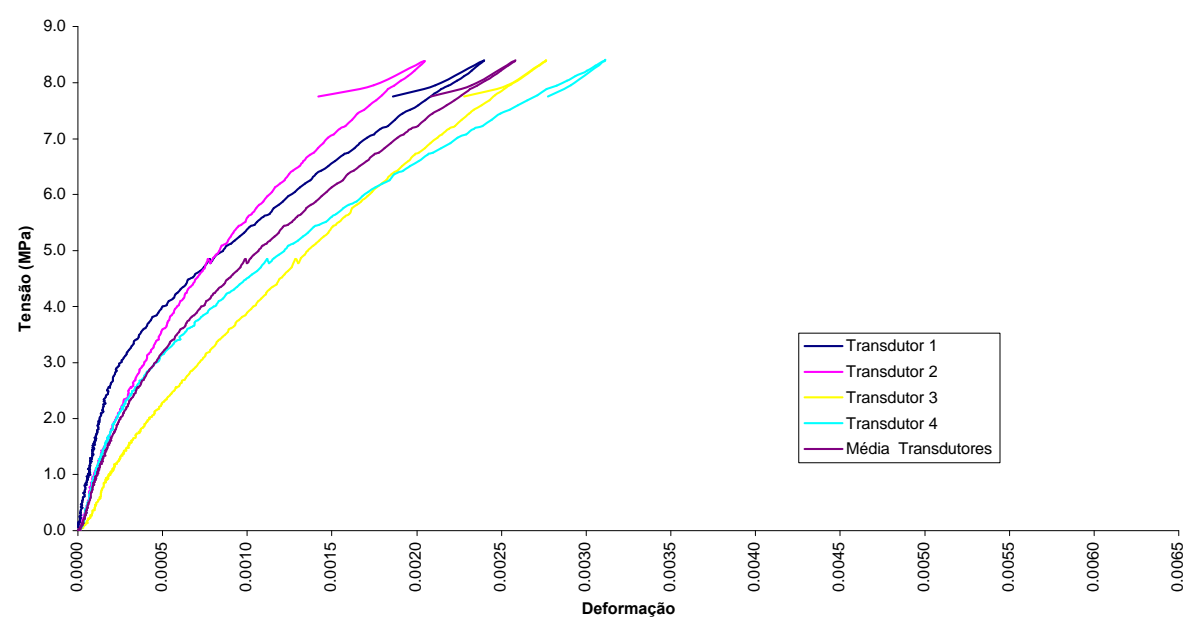


Gráfico Tensão x Deformação Q211 - Prisma

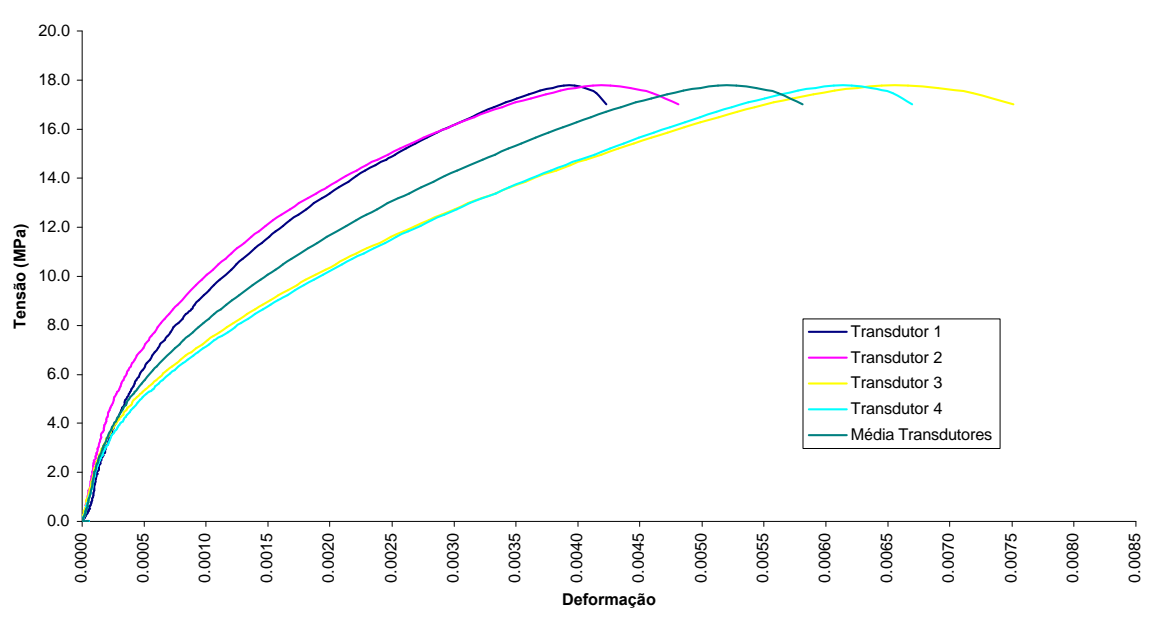

Gráfico Tensão x Deformação Q212 - Prisma

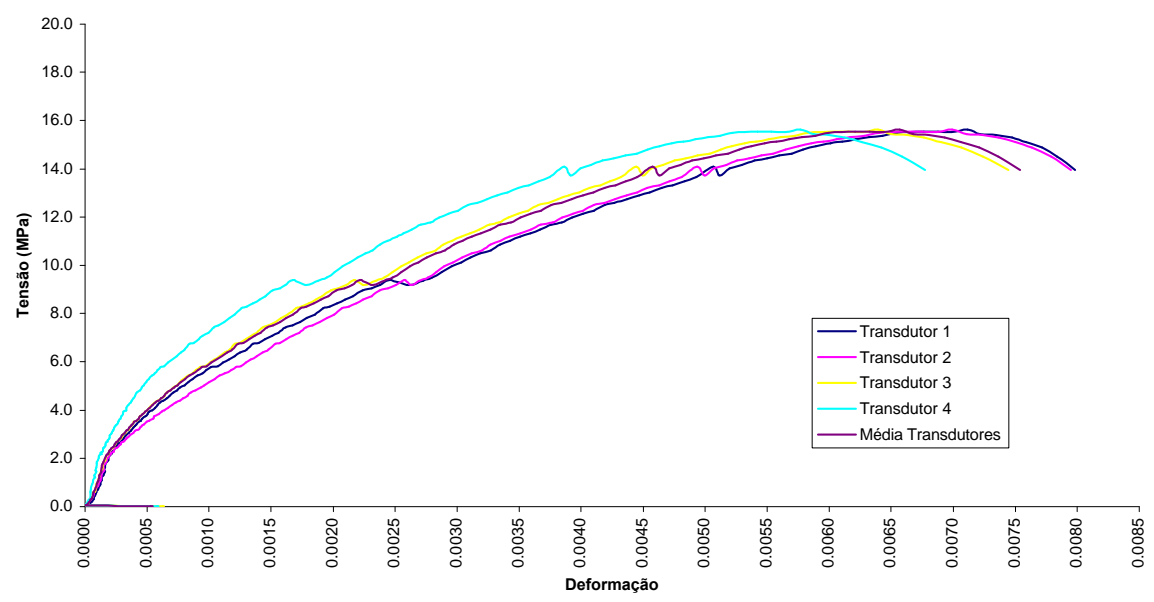

Gráfico Tensão x Deformação Q213 - Prisma

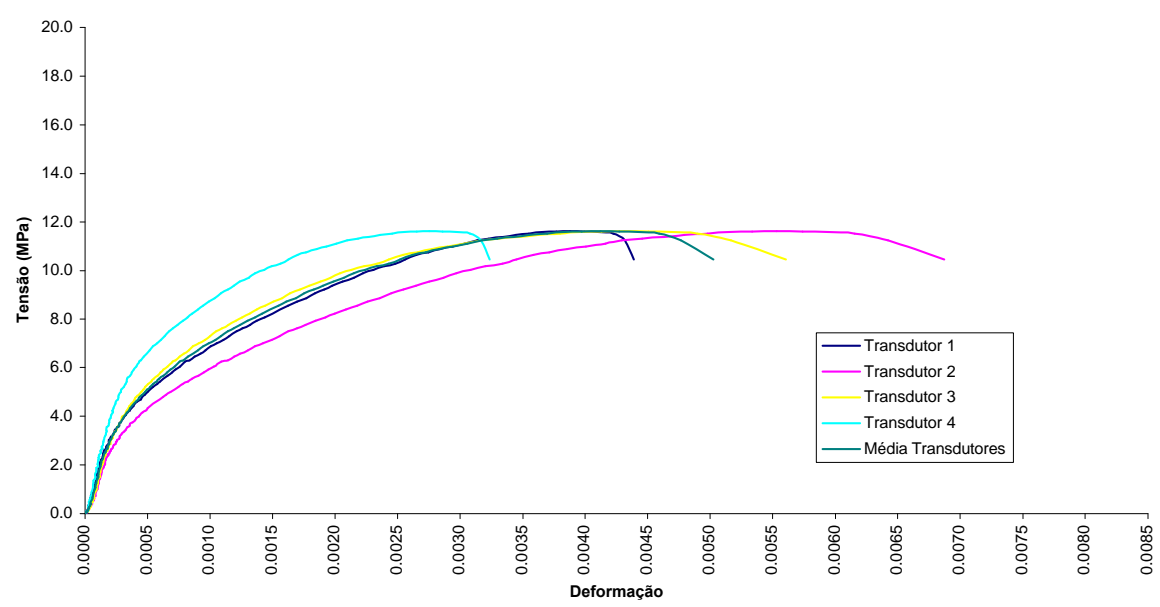



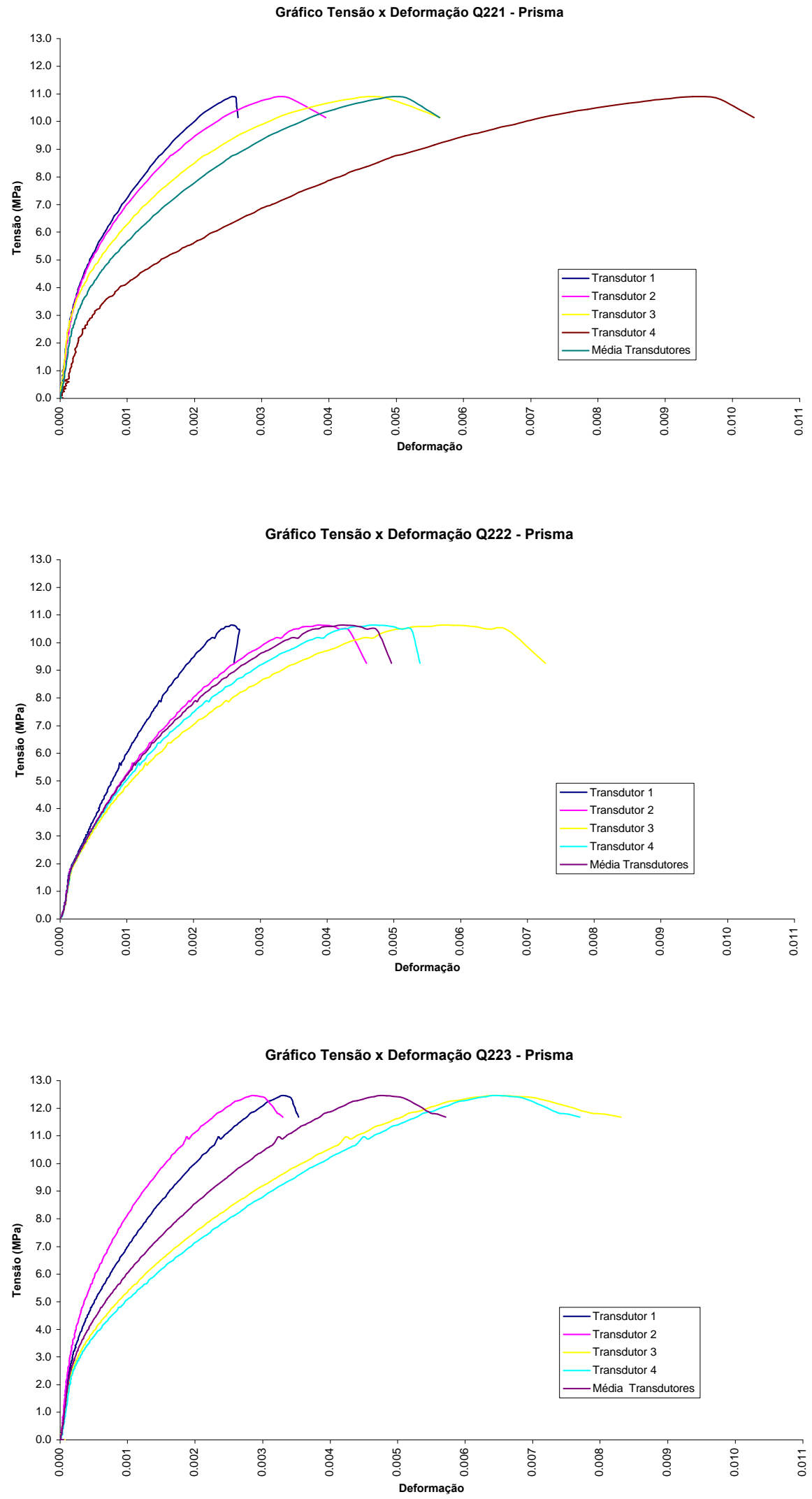

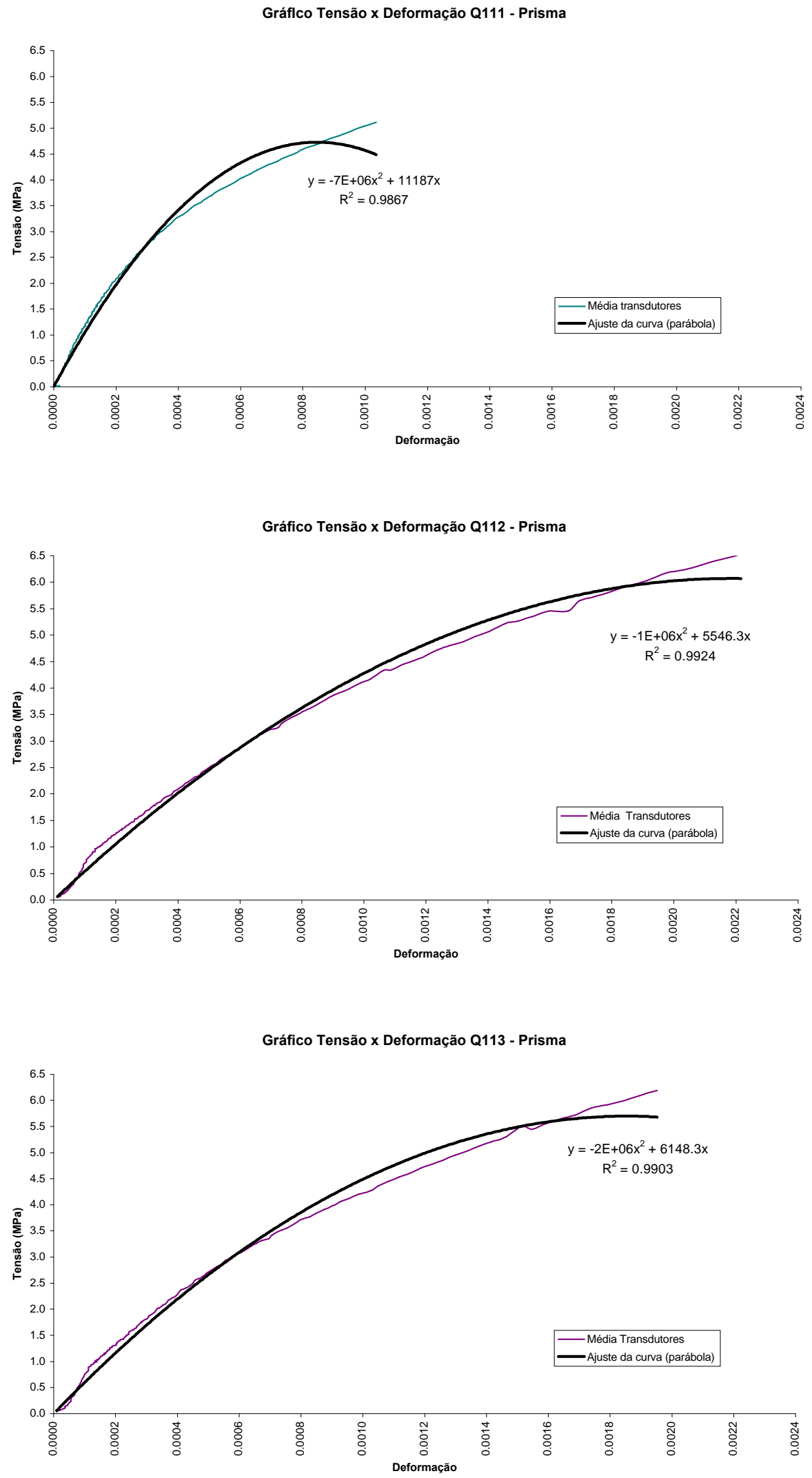

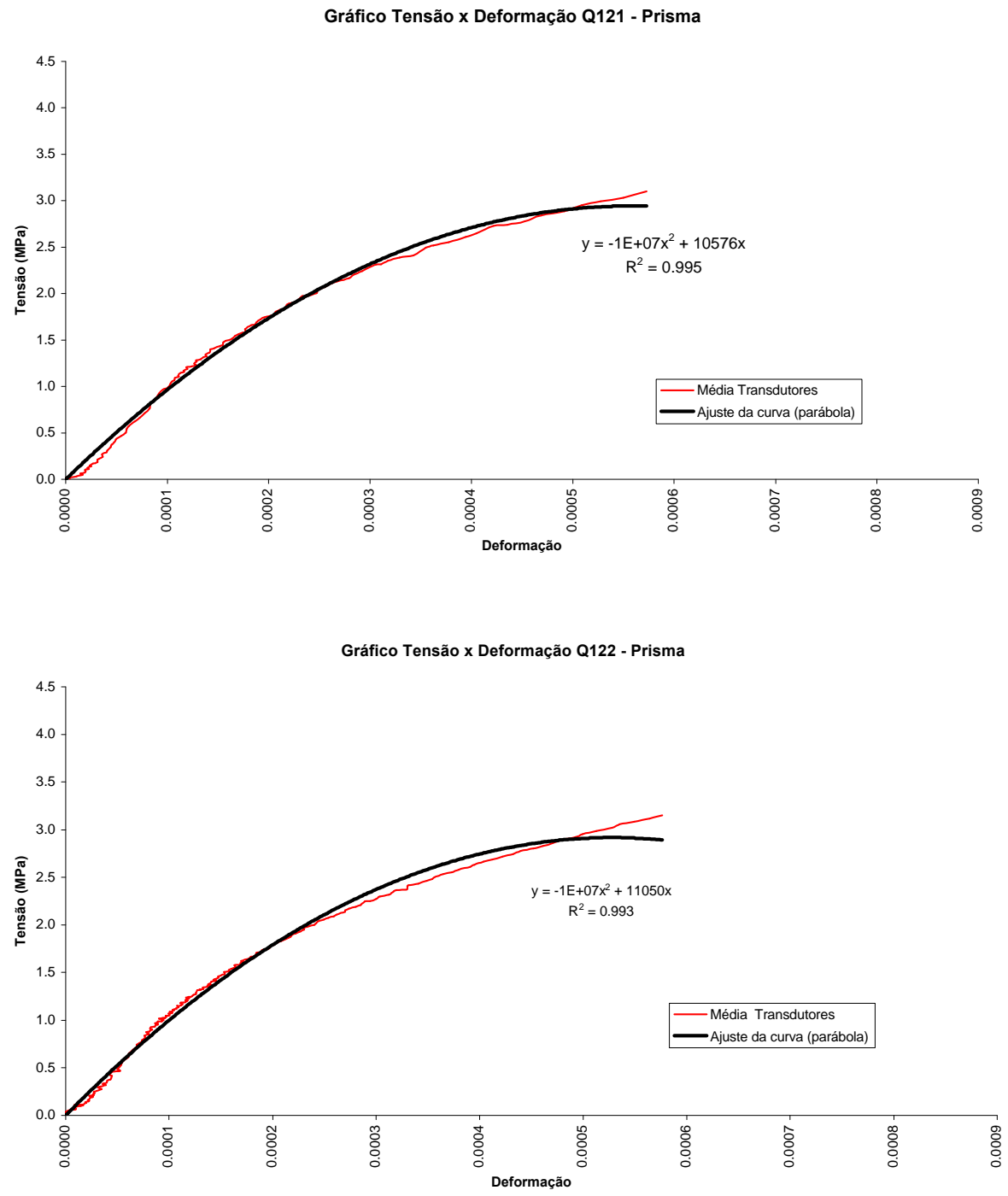

Gráfico Tensão x Deformação Q123 - Prisma

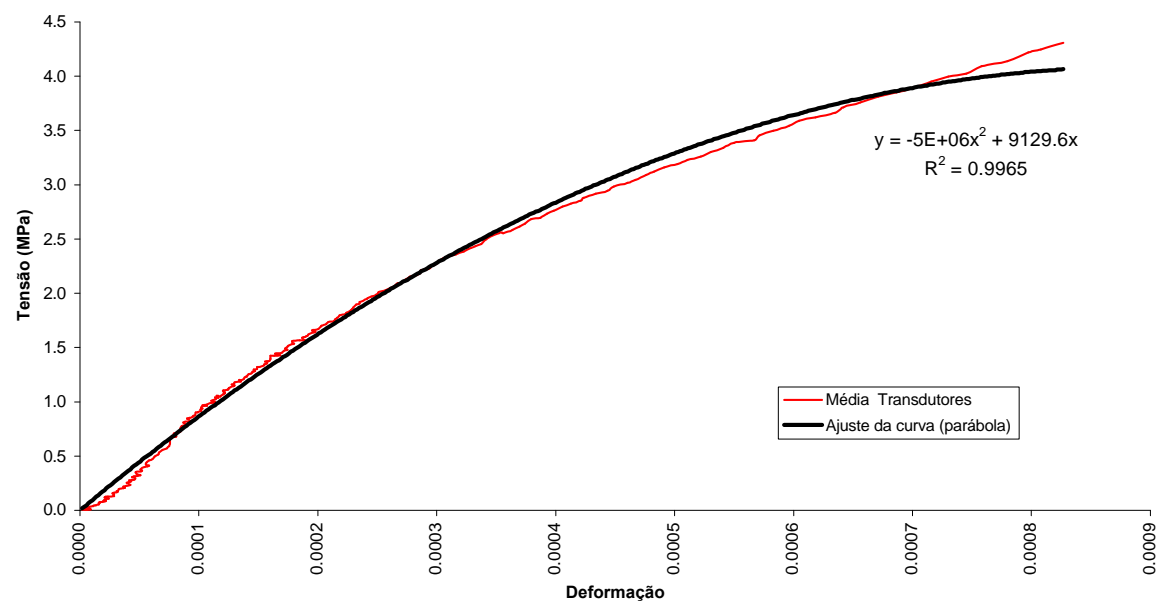




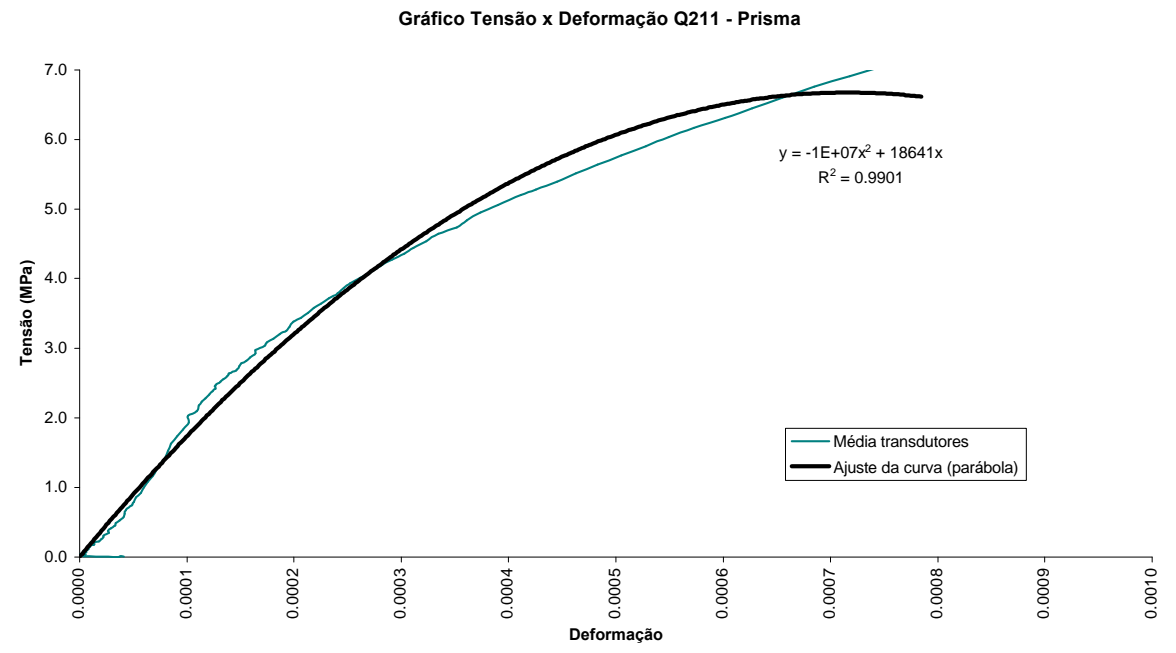

Gráfico Tensão x Deformação Q212 - Prisma

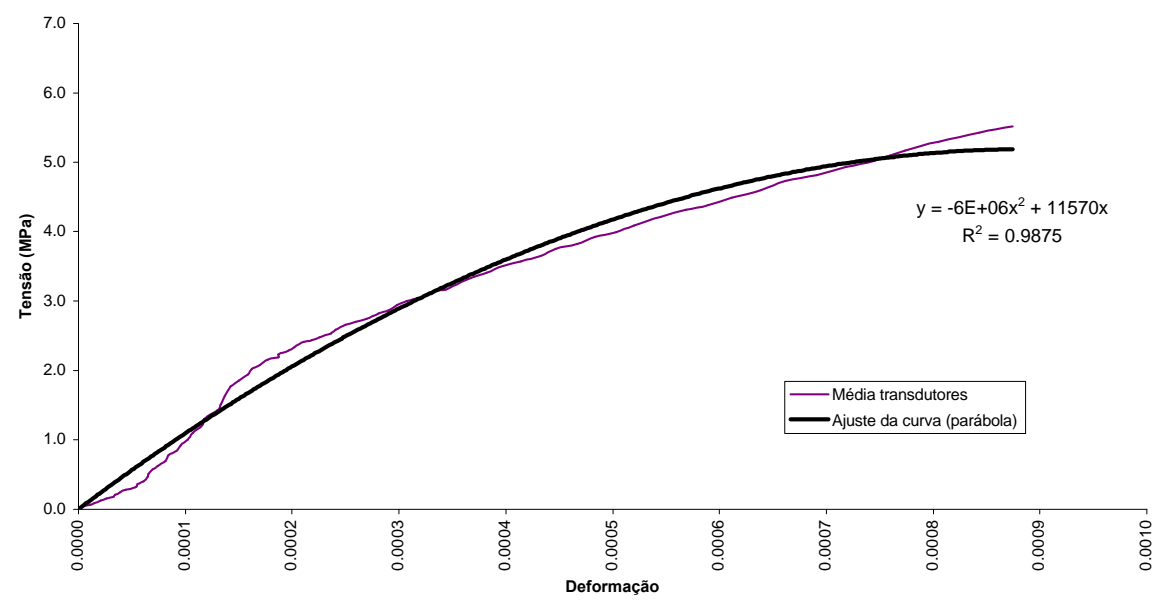

Gráfico Tensão x Deformação Q213 - Prisma

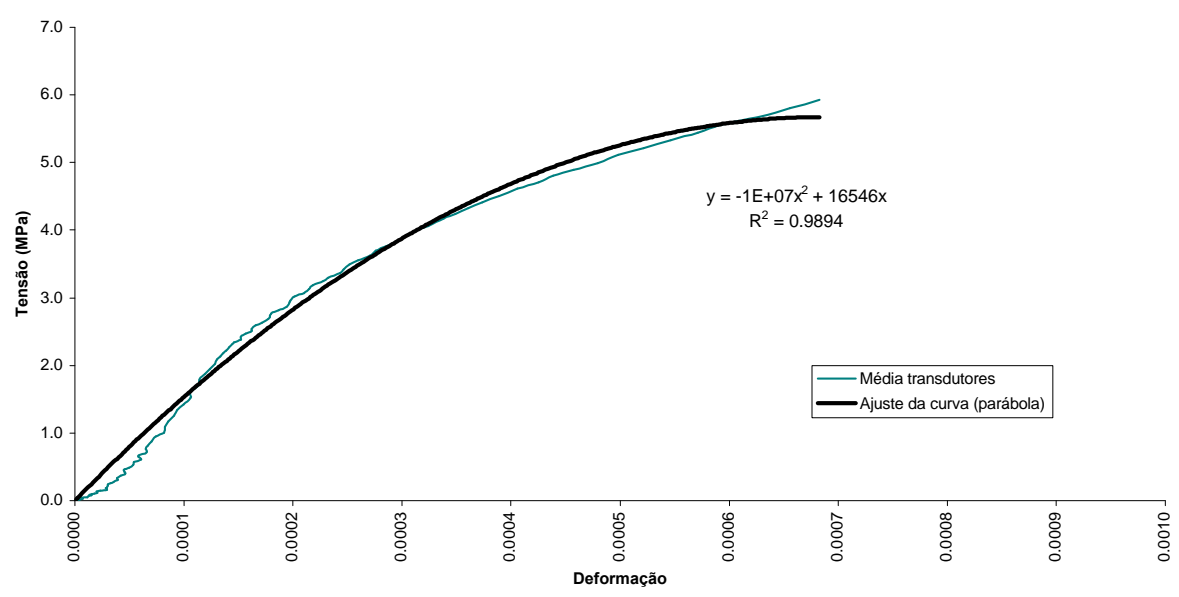



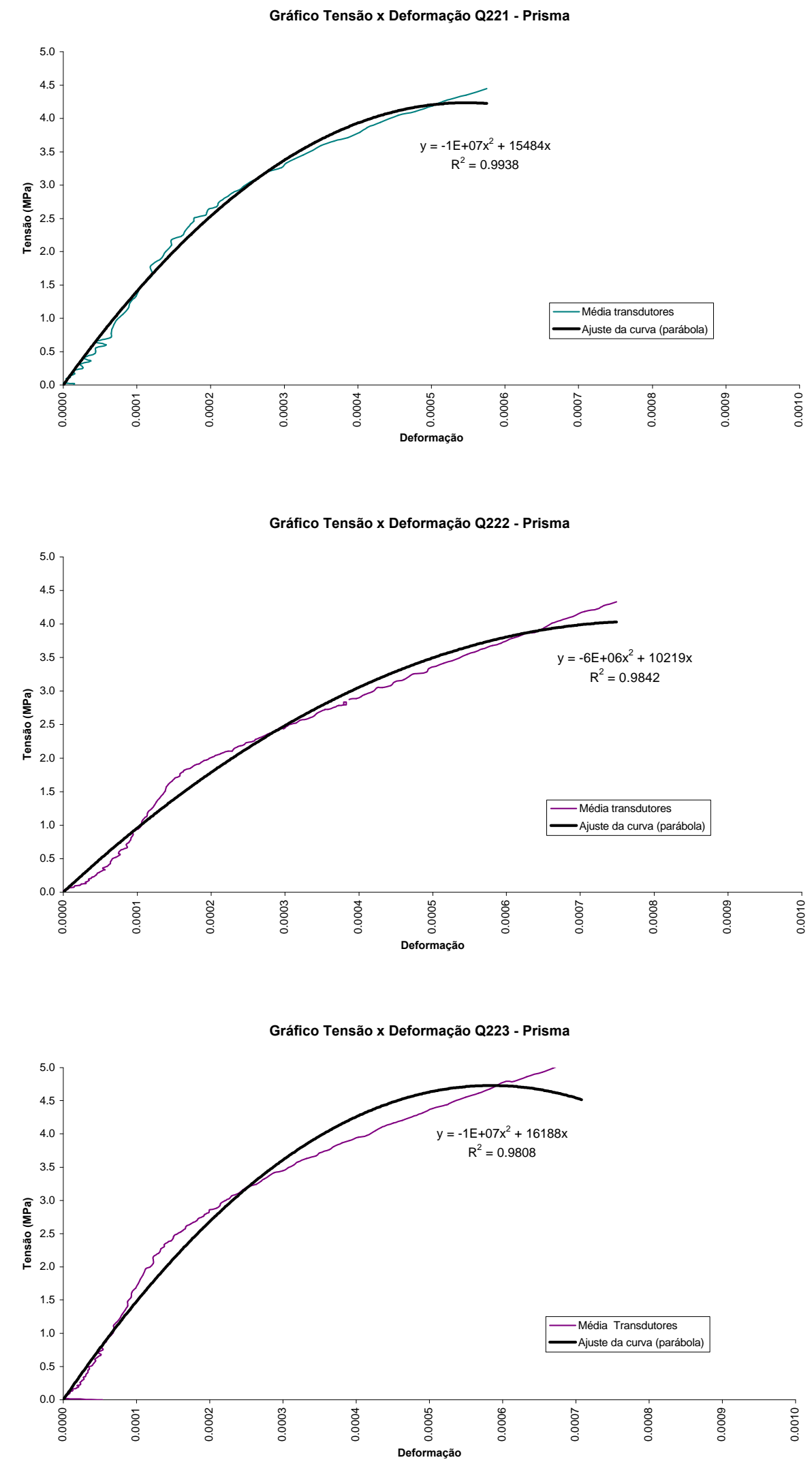
Tipo de ruptura da série P11 (F51, 4,5 MPa e AT)

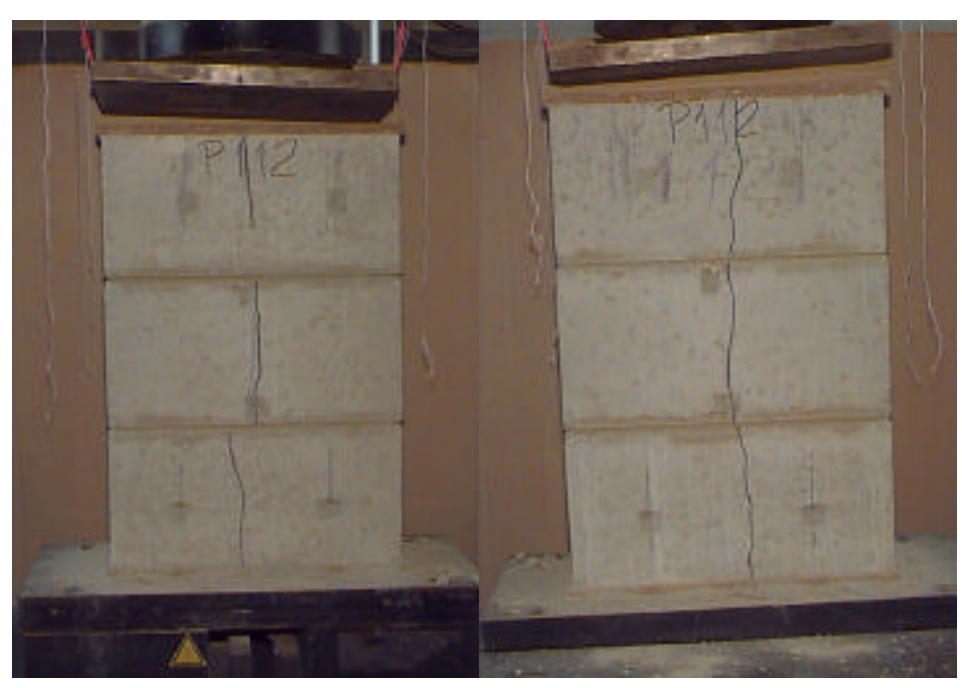

Tipo de ruptura da série P12 (F51, 4,5 MPa e AL)

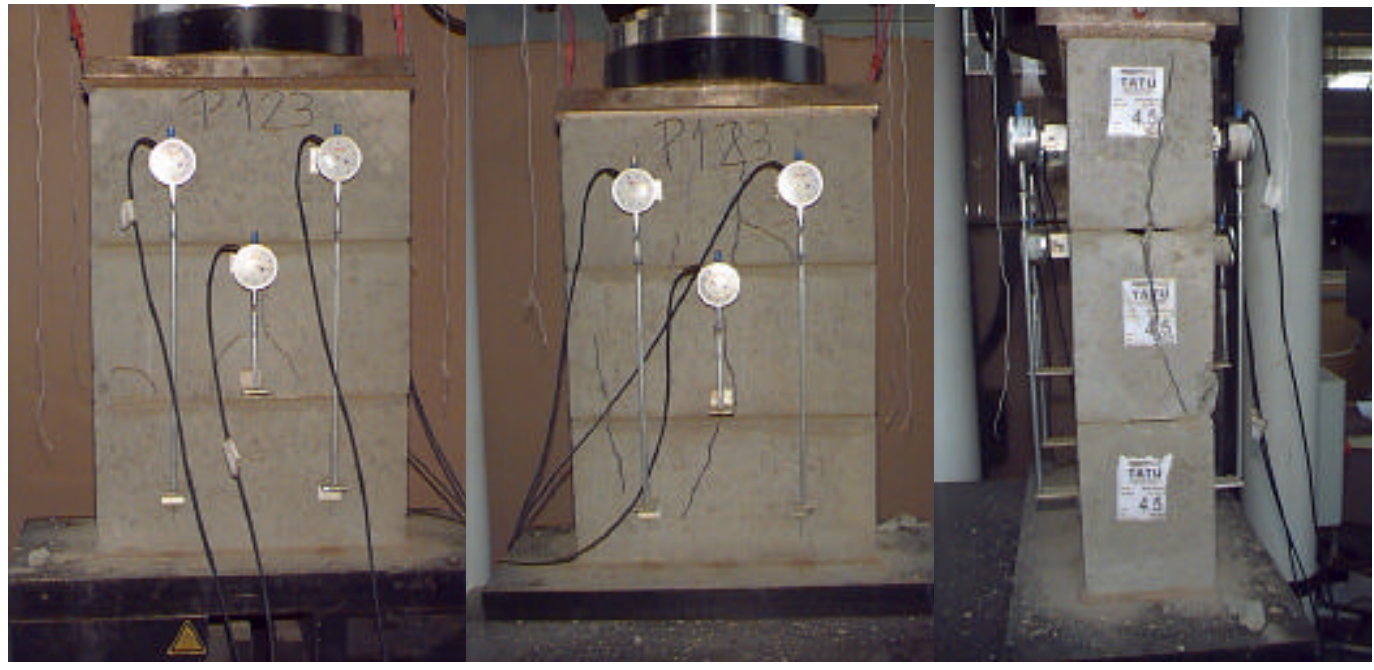


Tipo de ruptura da série P21 (F51, 10 MPa e AT)

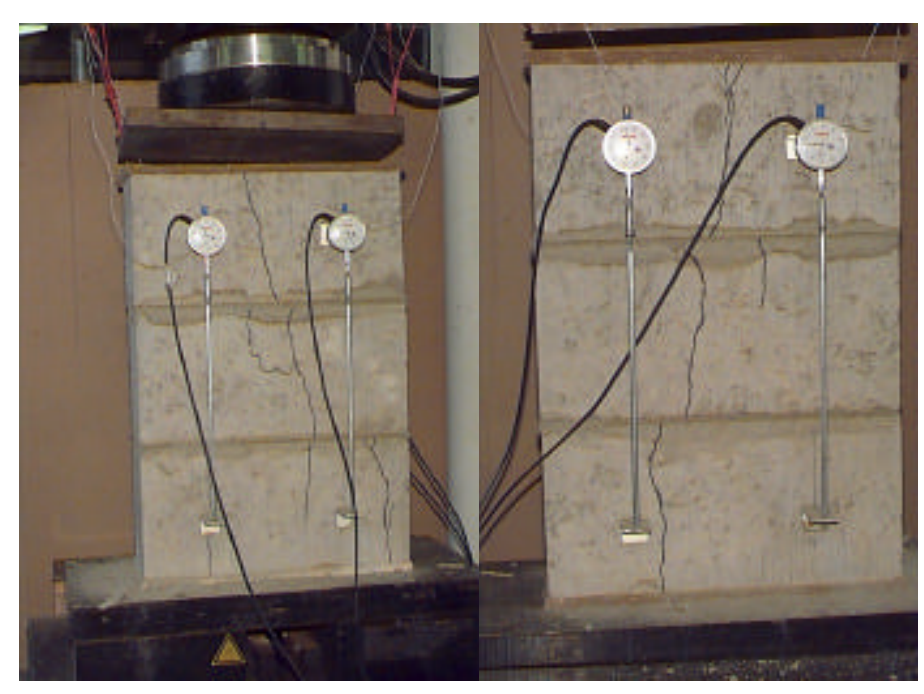

Tipo de ruptura da série P22 (F51, 10 MPa e AL)

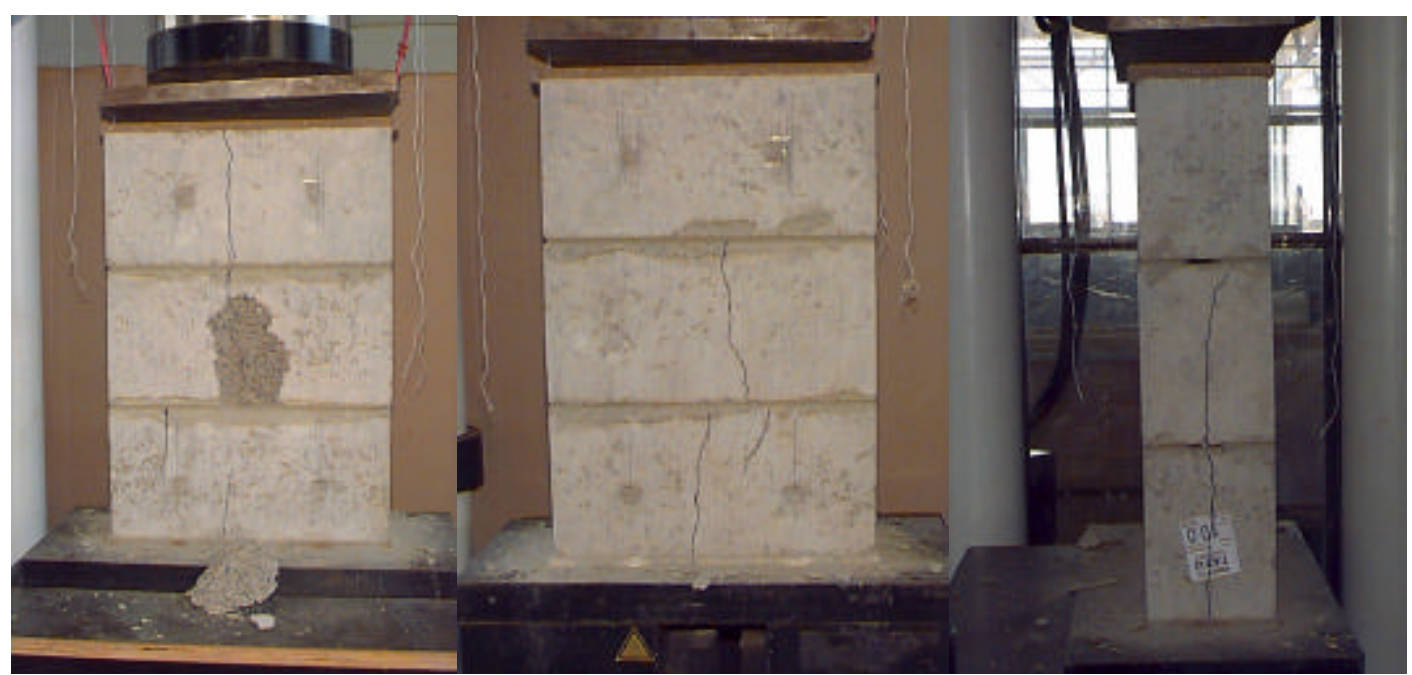


Tipo de ruptura da série Q11 (F07, 4,5 MPa e AL)

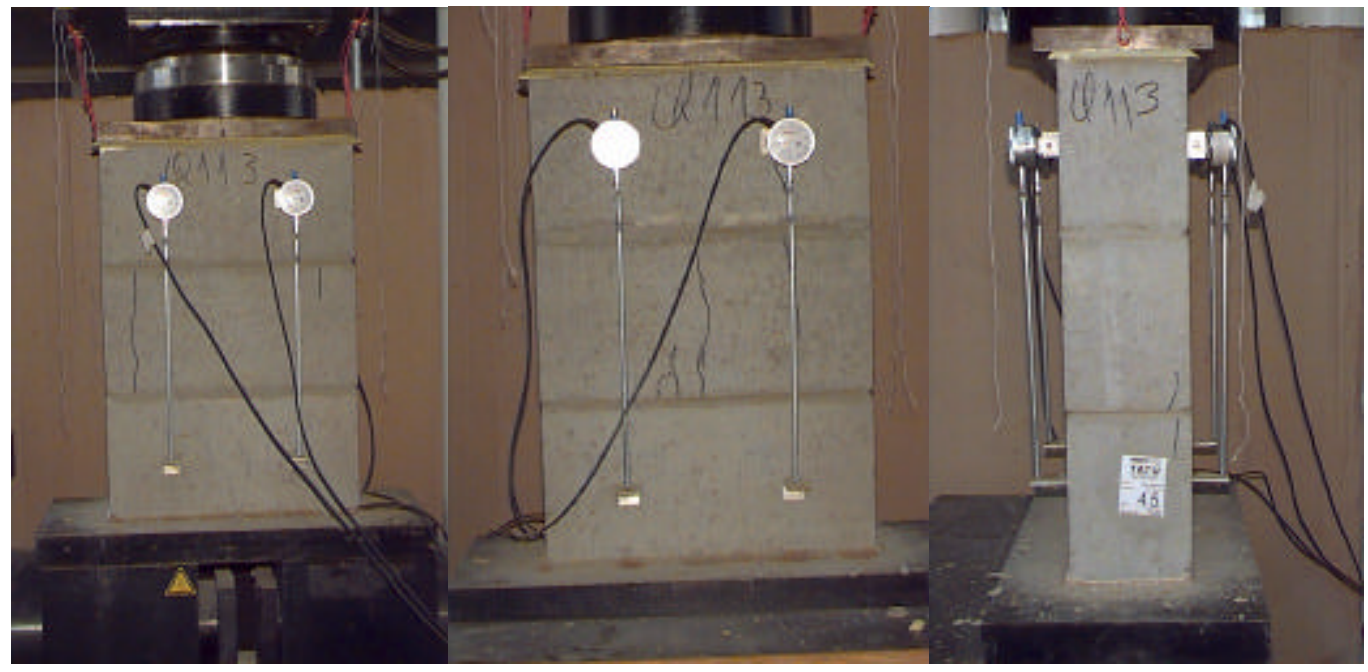

Tipo de ruptura da série Q12 (F07, 4,5 MPa e AL)

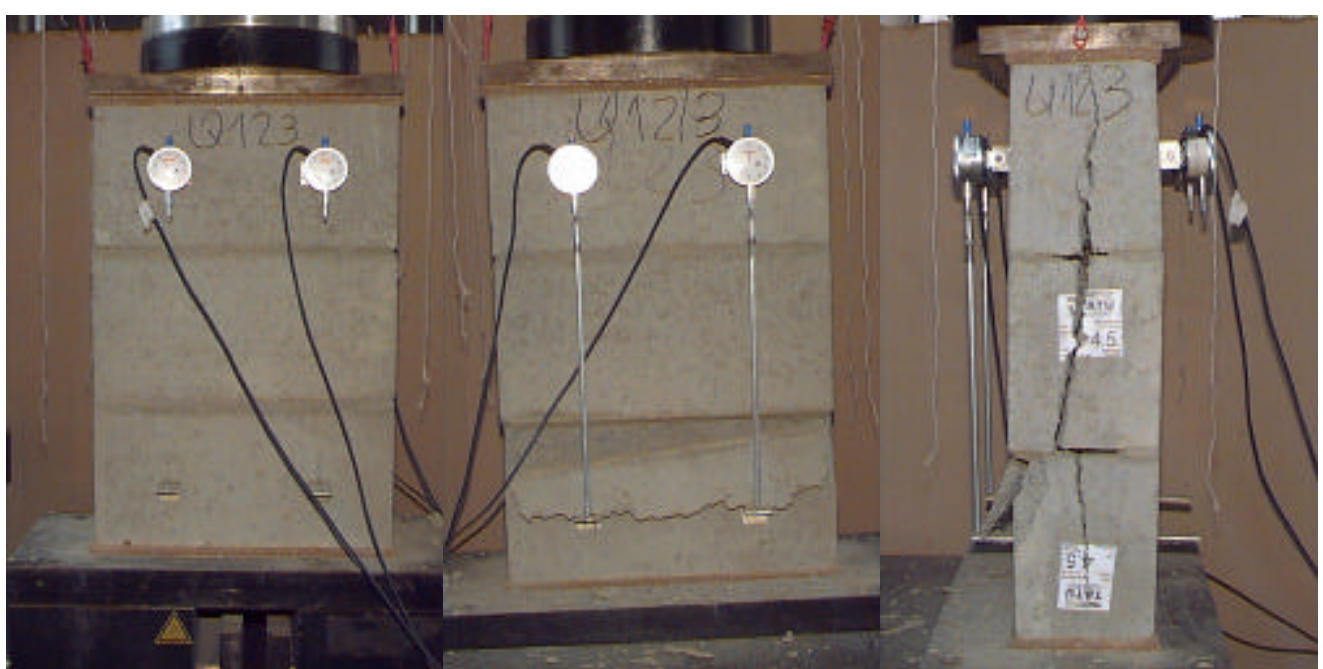


Tipo de ruptura da série Q21 (F07, 10 MPa e AT)

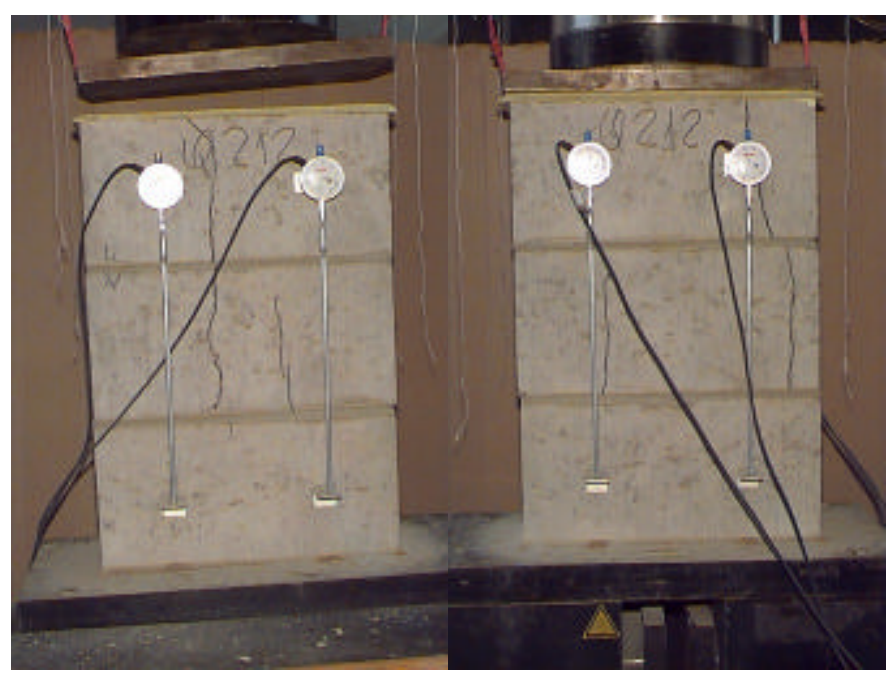

Tipo de ruptura da série Q22 (F07, $10 \mathrm{MPa}$ e AL)

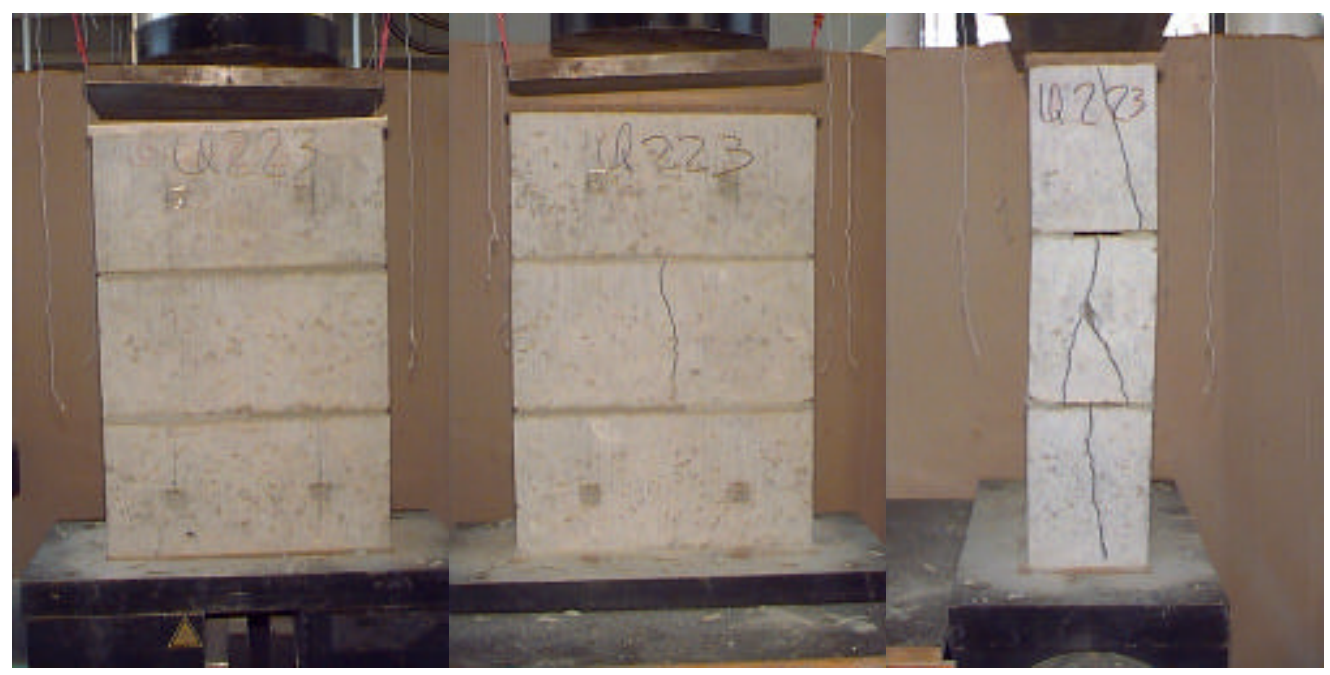




\begin{tabular}{|c|c|c|c|c|}
\hline $\begin{array}{l}\text { Classe de } \\
\text { resistência (MPa) }\end{array}$ & $\begin{array}{c}N^{\circ} \text { do } \\
\text { CP }\end{array}$ & $\begin{array}{l}\text { idade } \\
\text { (dias) } \\
\end{array}$ & $\begin{array}{c}F_{\text {rup }} \text { do } \\
\text { ensaio }(k N)\end{array}$ & $\begin{array}{c}\mathrm{f}_{\mathrm{b}}{ }^{*} \\
(\mathrm{MPa})\end{array}$ \\
\hline \multirow{6}{*}{4,5} & 1 & 114 & 474 & 8,68 \\
\hline & 2 & 114 & 571 & 10,45 \\
\hline & 3 & 114 & 491 & 8,99 \\
\hline & 4 & 114 & 504 & 9,22 \\
\hline & 5 & 114 & 576 & 10,56 \\
\hline & 6 & 114 & 474 & 8,68 \\
\hline \multicolumn{3}{|r|}{ Média } & 515 & 9,43 \\
\hline \multicolumn{3}{|r|}{$S_{d}(\mathrm{MPa})$} & 46,72 & 0,86 \\
\hline \multicolumn{3}{|r|}{ CV (\%) } & 9,07 & 9,10 \\
\hline
\end{tabular}

\begin{tabular}{|c|c|c|c|c|}
\hline $\begin{array}{c}\text { Classe de } \\
\text { resistência (MPa) }\end{array}$ & \begin{tabular}{|c|}
$N^{\circ}$ do \\
CP \\
\end{tabular} & $\begin{array}{l}\text { idade } \\
\text { (dias) }\end{array}$ & $\begin{array}{c}F_{\text {rup }} \text { do } \\
\text { ensaio }(k N)\end{array}$ & $\begin{array}{c}\mathrm{f}_{\mathrm{b}}{ }^{*} \\
(\mathrm{MPa})\end{array}$ \\
\hline \multirow{6}{*}{10,0} & 1 & 206 & 1266 & 23,19 \\
\hline & 2 & 206 & 1304 & 23,89 \\
\hline & 3 & 206 & 1246 & 22,83 \\
\hline & 4 & 206 & 1188 & 21,76 \\
\hline & 5 & 206 & 1150 & 21,07 \\
\hline & 6 & 206 & 1232 & 22,56 \\
\hline \multicolumn{3}{|r|}{ Média } & 1231 & 22,55 \\
\hline \multicolumn{3}{|r|}{$\mathrm{S}_{\mathrm{d}}(\mathrm{MPa})$} & 55,12 & 1,01 \\
\hline \multicolumn{3}{|r|}{ CV (\%) } & 4,48 & 4,48 \\
\hline
\end{tabular}

* Resistência em função da área líquida do bloco. 


\begin{tabular}{||c|c|c|c|c||}
\hline $\begin{array}{c}\text { Tipo de } \\
\text { argamassa }\end{array}$ & $\begin{array}{c}\mathbf{N}^{\circ} \text { do } \\
\text { CP }\end{array}$ & $\begin{array}{c}\text { idade } \\
\text { (dias) }\end{array}$ & $\begin{array}{c}\mathbf{F}_{\text {rup }} \text { do } \\
\text { ensaio (kN) }\end{array}$ & $\begin{array}{c}\mathbf{f}_{\mathbf{a}} \\
\text { (MPa) }\end{array}$ \\
\hline \multirow{2}{*}{ P } & 1 & 35 & 10,5 & 5,33 \\
\cline { 2 - 6 } & 2 & 35 & 9,6 & 4,87 \\
\cline { 2 - 6 } & 3 & 35 & 10,5 & 5,37 \\
\hline & Média & 10,2 & 5,19 \\
\hline & $\mathbf{S}_{\mathbf{d}}$ (MPa) & 0,55 & 0,28 \\
\hline & $\mathbf{C V}(\%)$ & 5,39 & 5,39 \\
\hline
\end{tabular}

\begin{tabular}{|c|c|c|c|c|}
\hline $\begin{array}{c}\text { Tipo de } \\
\text { Argamassa }\end{array}$ & \begin{tabular}{|c|}
$N^{\circ}$ do \\
CP \\
\end{tabular} & $\begin{array}{l}\text { idade } \\
\text { (dias) }\end{array}$ & $\begin{array}{c}F_{\text {rup }} \text { do } \\
\text { ensaio }(k N)\end{array}$ & $\begin{array}{c}f_{a} \\
(\mathrm{MPa})\end{array}$ \\
\hline \multirow{3}{*}{$Q$} & 1 & 35 & 12,1 & 6,15 \\
\hline & 2 & 35 & 11,1 & 5,63 \\
\hline & 3 & 35 & 10,2 & 5,20 \\
\hline \multicolumn{3}{|r|}{ Média } & 11,1 & 5,66 \\
\hline \multicolumn{3}{|r|}{$\mathrm{S}_{\mathrm{d}}(\mathrm{MPa})$} & 0,93 & 0,48 \\
\hline \multicolumn{3}{|r|}{ CV (\%) } & 8,39 & 8,39 \\
\hline
\end{tabular}

\begin{tabular}{||c|c|c|c|c||}
\hline $\begin{array}{c}\text { Tipo de } \\
\text { argamassa }\end{array}$ & $\begin{array}{c}\mathbf{N}^{\circ} \text { do } \\
\mathbf{C P}\end{array}$ & $\begin{array}{c}\text { idade } \\
\text { (dias) }\end{array}$ & $\begin{array}{c}\mathbf{F}_{\text {rup }} \text { do } \\
\text { ensaio }(\mathbf{k N})\end{array}$ & $\begin{array}{c}\mathbf{f}_{\mathbf{a}} \\
(\mathbf{M P a})\end{array}$ \\
\hline \multirow{3}{*}{$\mathrm{R}$} & 1 & 30 & 7,4 & 3,76 \\
\cline { 2 - 6 } & 2 & 30 & 7,4 & 3,75 \\
\cline { 2 - 6 } & 3 & 30 & 6,9 & 3,51 \\
\hline & $\mathbf{M e ́ d i a}$ & 721 & 3,67 \\
\hline & $\mathbf{S}_{\mathbf{d}}$ (MPa) & 0,28 & 0,14 \\
\hline & $\mathbf{C V}(\%)$ & 3,91 & 3,91 \\
\hline
\end{tabular}




\begin{tabular}{|c|c|c|c|c|}
\hline $\begin{array}{c}\text { Tipo de } \\
\text { argamassa }\end{array}$ & $\begin{array}{c}\mathrm{N}^{\circ} \text { do } \\
\mathrm{CP} \\
\end{array}$ & $\begin{array}{l}\text { idade } \\
\text { (dias) }\end{array}$ & $\begin{array}{c}F_{\text {rup }} \text { do } \\
\text { ensaio }(k N)\end{array}$ & $\begin{array}{c}\mathbf{f}_{\mathrm{a}} \\
(\mathrm{MPa})\end{array}$ \\
\hline \multirow{3}{*}{$\mathrm{A} 1$} & 1 & 16 & 113 & 6,32 \\
\hline & 2 & 16 & 116 & 6,55 \\
\hline & 3 & 16 & 118 & 6,53 \\
\hline \multicolumn{3}{|r|}{ Média } & 116 & 6,47 \\
\hline \multicolumn{3}{|r|}{$S_{d}(M P a)$} & 2,45 & 0,13 \\
\hline \multicolumn{3}{|r|}{ CV (\%) } & 2,12 & 1,99 \\
\hline
\end{tabular}

\begin{tabular}{|c|c|c|c|c|}
\hline $\begin{array}{c}\text { Tipo de } \\
\text { argamassa }\end{array}$ & $\begin{array}{c}N^{\circ} \text { do } \\
\text { CP } \\
\end{array}$ & $\begin{array}{l}\text { idade } \\
\text { (dias) }\end{array}$ & $\begin{array}{c}F_{\text {rup }} \text { do } \\
\text { ensaio }(k N) \\
\end{array}$ & $\begin{array}{c}\mathbf{f}_{\mathrm{a}} \\
(\mathrm{MPa})\end{array}$ \\
\hline \multirow{4}{*}{$\mathrm{A} 2$} & 1 & 16 & 73 & 4,14 \\
\hline & 2 & 16 & 74 & 4,15 \\
\hline & 3 & 16 & 75 & 4,27 \\
\hline & 4 & 16 & 74 & 4,25 \\
\hline \multicolumn{3}{|r|}{ Média } & 74 & 4,20 \\
\hline \multicolumn{3}{|r|}{$S_{d}(M P a)$} & 0,94 & 0,07 \\
\hline \multicolumn{3}{|r|}{ CV (\%) } & 1,27 & 1,64 \\
\hline
\end{tabular}




\begin{tabular}{||c|c|c|c|c||}
\hline $\begin{array}{c}\text { Série de prisma } \\
\text { correspondente }\end{array}$ & $\begin{array}{c}\mathbf{N}^{\circ} \text { do } \\
\mathbf{C P}\end{array}$ & $\begin{array}{c}\text { idade } \\
\text { (dias) }\end{array}$ & $\begin{array}{c}\mathbf{F}_{\text {rup }} \text { do } \\
\text { ensaio }(\mathbf{k N})\end{array}$ & $\begin{array}{c}\mathbf{f}_{\mathbf{p r}}{ }^{*} \\
\text { (MPa) }\end{array}$ \\
\hline \multirow{2}{*}{ P11 } & 1 & 32 & 184 & 6,15 \\
\cline { 2 - 6 } & 2 & 32 & 158 & 5,25 \\
\cline { 2 - 6 } & 3 & 32 & 147 & 4,87 \\
\hline & Média & 163 & 5,42 \\
\hline & $\mathbf{S}_{\mathbf{d}}$ (MPa) & 19,39 & 0,65 \\
\hline & $\mathbf{C V ~ ( \% )}$ & 11,90 & 12,04 \\
\hline
\end{tabular}

\begin{tabular}{||c|c|c|c|c||}
\hline $\begin{array}{c}\text { Série de prisma } \\
\text { correspondente }\end{array}$ & $\begin{array}{c}\mathbf{N}^{\circ} \text { do } \\
\mathbf{C P}\end{array}$ & $\begin{array}{c}\text { idade } \\
\text { (dias) }\end{array}$ & $\begin{array}{c}\mathbf{F}_{\text {rup }} \text { do } \\
\text { ensaio } \mathbf{( k N )}\end{array}$ & $\begin{array}{c}\mathbf{f}_{\mathbf{p r}}{ }^{*} \\
\text { (MPa) }\end{array}$ \\
\hline \multirow{2}{*}{ P12 } & 1 & 33 & 145 & 4,84 \\
\cline { 2 - 6 } & 2 & 33 & $84^{\star *}$ & $3,15^{* *}$ \\
\cline { 2 - 6 } & 3 & 32 & 176 & 5,85 \\
\hline & Média & 161 & 5,35 \\
\hline & $\mathbf{S}_{\mathbf{d}}$ (MPa) & 21,57 & 0,72 \\
\hline & $\mathbf{C V ~ ( \% )}$ & 13,43 & 13,47 \\
\hline
\end{tabular}

\begin{tabular}{|c|c|c|c|c|}
\hline $\begin{array}{l}\text { Série de prisma } \\
\text { correspondente }\end{array}$ & $\begin{array}{c}N^{\circ} \text { do } \\
\text { CP }\end{array}$ & $\begin{array}{l}\text { idade } \\
\text { (dias) }\end{array}$ & $\begin{array}{c}F_{\text {rup }} \text { do } \\
\text { ensaio }(k N)\end{array}$ & $\begin{array}{c}\mathbf{f}_{\mathrm{pr}}{ }^{*} \\
(\mathrm{MPa})\end{array}$ \\
\hline \multirow{3}{*}{ P21 } & 1 & 31 & 390 & 12,96 \\
\hline & 2 & 31 & 304 & 10,11 \\
\hline & 3 & 31 & 489 & 16,09 \\
\hline \multicolumn{3}{|r|}{ Média } & 392 & 13,05 \\
\hline \multicolumn{3}{|r|}{$S_{d}(\mathrm{MPa})$} & 89,93 & 2,99 \\
\hline \multicolumn{3}{|r|}{ CV (\%) } & 22,93 & 22,92 \\
\hline
\end{tabular}

* Resistência em função da área líquida

${ }^{* *}$ Resultado descartado por apresentar grande desvio em relação àmédia 


\begin{tabular}{||c|c|c|c|c||}
\hline $\begin{array}{c}\text { Série de prisma } \\
\text { correspondente }\end{array}$ & $\begin{array}{c}\mathbf{N}^{\circ} \text { do } \\
\mathbf{C P}\end{array}$ & $\begin{array}{c}\text { idade } \\
\text { (dias) }\end{array}$ & $\begin{array}{c}\mathbf{F}_{\text {rup }} \text { do } \\
\text { ensaio }(\mathbf{k N})\end{array}$ & $\begin{array}{c}\mathbf{f}_{\mathbf{p r}}{ }^{*} \\
\text { (MPa) }\end{array}$ \\
\hline \multirow{2}{*}{ P22 } & 1 & 33 & 350 & 11,65 \\
\cline { 2 - 6 } & 2 & 32 & $501^{* *}$ & $16,69^{* *}$ \\
\cline { 2 - 6 } & 3 & 32 & 305 & 10,15 \\
\hline & Média & 328 & 10,90 \\
\hline & $\mathbf{S}_{\mathbf{d}}$ (MPa) & 32,18 & 1,07 \\
\hline & $\mathbf{C V ~ ( \% )}$ & 9,82 & 9,79 \\
\hline
\end{tabular}

\begin{tabular}{||c|c|c|c|c||}
\hline $\begin{array}{c}\text { Série de prisma } \\
\text { correspondente }\end{array}$ & $\begin{array}{c}\mathbf{N}^{\circ} \text { do } \\
\mathbf{C P}\end{array}$ & $\begin{array}{c}\text { idade } \\
\text { (dias) }\end{array}$ & $\begin{array}{c}\mathbf{F}_{\text {rup }} \text { do } \\
\text { ensaio } \mathbf{( k N )}\end{array}$ & $\begin{array}{c}\mathbf{f}_{\mathbf{p r}}{ }^{*} \\
\text { (MPa) }\end{array}$ \\
\hline \multirow{2}{*}{ Q11 } & 1 & 32 & 220 & 7,33 \\
\cline { 2 - 6 } & 2 & 33 & 279 & 9,27 \\
\cline { 2 - 6 } & 3 & 33 & 266 & 10,02 \\
\hline & $\mathbf{M e ́ d i a}$ & 255 & 8,48 \\
\hline & $\mathbf{S}_{\mathbf{d}}$ (MPa) & 30,70 & 1,02 \\
\hline & $\mathbf{C V ~ ( \% )}$ & 12,07 & 12,07 \\
\hline
\end{tabular}

\begin{tabular}{|c|c|c|c|c|}
\hline $\begin{array}{l}\text { Série de prisma } \\
\text { correspondente }\end{array}$ & $\begin{array}{c}N^{\circ} \text { do } \\
\text { CP }\end{array}$ & $\begin{array}{l}\text { idade } \\
\text { (dias) }\end{array}$ & $\begin{array}{c}F_{\text {rup }} \text { do } \\
\text { ensaio }(k N)\end{array}$ & $\begin{array}{c}\mathbf{f}_{\mathrm{pr}}{ }^{*} \\
(\mathrm{MPa})\end{array}$ \\
\hline \multirow{3}{*}{ Q12 } & 1 & 33 & 186 & 6,20 \\
\hline & 2 & 33 & 237 & 7,87 \\
\hline & 3 & 33 & 258 & 8,60 \\
\hline \multicolumn{3}{|r|}{ Média } & 227 & 7,56 \\
\hline \multicolumn{3}{|r|}{$S_{d}(\mathrm{MPa})$} & 36,84 & 1,23 \\
\hline \multicolumn{3}{|r|}{ CV (\%) } & 16,22 & 16,28 \\
\hline
\end{tabular}

* Resistência em função da área líquida

${ }^{* *}$ Resultado descartado por apresentar grande desvio em relação àmédia 


\begin{tabular}{|c|c|c|c|c|}
\hline $\begin{array}{l}\text { Série de prisma } \\
\text { correspondente }\end{array}$ & \begin{tabular}{|c|}
$N^{\circ}$ do \\
CP \\
\end{tabular} & $\begin{array}{l}\text { idade } \\
\text { (dias) }\end{array}$ & $\begin{array}{c}F_{\text {rup }} \text { do } \\
\text { ensaio }(k N)\end{array}$ & $\begin{array}{c}\mathbf{f}_{\mathrm{pr}}^{*} \\
(\mathrm{MPa})\end{array}$ \\
\hline \multirow{3}{*}{ Q21 } & 1 & 32 & 536 & 17,84 \\
\hline & 2 & 33 & 471 & 15,67 \\
\hline & 3 & 33 & $353^{\star \star}$ & $11,76^{\star *}$ \\
\hline \multicolumn{3}{|r|}{ Média } & 255 & 16,75 \\
\hline \multicolumn{3}{|r|}{$S_{d}(M P a)$} & 30,70 & 1,53 \\
\hline \multicolumn{3}{|r|}{ CV (\%) } & 12,07 & 9,13 \\
\hline
\end{tabular}

\begin{tabular}{|c|c|c|c|c|}
\hline $\begin{array}{l}\text { Série de prisma } \\
\text { correspondente }\end{array}$ & \begin{tabular}{|c|}
$N^{\circ}$ do \\
CP \\
\end{tabular} & $\begin{array}{l}\text { idade } \\
\text { (dias) }\end{array}$ & $\begin{array}{c}F_{\text {rup }} \text { do } \\
\text { ensaio }(k N)\end{array}$ & $\begin{array}{c}\mathbf{f}_{\mathrm{pr}}{ }^{*} \\
(\mathrm{MPa})\end{array}$ \\
\hline \multirow{3}{*}{ Q22 } & 1 & 33 & 327 & 10,91 \\
\hline & 2 & 33 & 324 & 10,78 \\
\hline & 3 & 33 & 382 & 12,71 \\
\hline \multicolumn{3}{|r|}{ Média } & 344 & 11,47 \\
\hline \multicolumn{3}{|r|}{$\mathrm{S}_{\mathrm{d}}(\mathrm{MPa})$} & 32,46 & 1,08 \\
\hline \multicolumn{3}{|r|}{ CV (\%) } & 9,43 & 9,40 \\
\hline
\end{tabular}

* Resistência em função da área líquida

** Resultado descartado por apresentar grande desvio em relação àmédia 


\section{EXTENSÔMETRO}

\begin{tabular}{|c|c|c|c|c|}
\hline $\begin{array}{c}\text { Tipo de } \\
\text { argamassa }\end{array}$ & $\begin{array}{c}\text { Corpo de } \\
\text { prova }\end{array}$ & $\begin{array}{c}f_{a} \\
(\mathrm{MPa})\end{array}$ & $\begin{array}{c}\mathrm{E}_{\mathrm{a}} \\
(\mathrm{MPa})\end{array}$ & $E_{a} / f_{a}$ \\
\hline \multirow{3}{*}{$P$} & 1 & 5,39 & 6443 & 1195 \\
\hline & 2 & 5,01 & 6942 & 1386 \\
\hline & 3 & 6,09 & 8804 & 1446 \\
\hline \multicolumn{2}{|r|}{ Média (MPa) } & 5,50 & 7396 & 1342 \\
\hline \multicolumn{2}{|r|}{$\mathrm{S}_{\mathrm{d}}(\mathrm{MPa})$} & 0,55 & 1244,35 & 130,67 \\
\hline \multicolumn{2}{|r|}{ CV (\%) } & 9,97 & 16,82 & 9,74 \\
\hline
\end{tabular}

\begin{tabular}{|c|c|c|c|c|}
\hline $\begin{array}{c}\text { Tipo de } \\
\text { Argamassa }\end{array}$ & $\begin{array}{c}\text { Corpo de } \\
\text { prova }\end{array}$ & $\begin{array}{c}\mathbf{f}_{\mathrm{a}} \\
(\mathrm{MPa})\end{array}$ & $\begin{array}{c}\mathrm{E}_{\mathrm{a}} \\
(\mathrm{MPa})\end{array}$ & $E_{a} / f_{a}$ \\
\hline \multirow{3}{*}{ Q } & 1 & 6,49 & 9655 & 1488 \\
\hline & 2 & 5,80 & 8492 & 1464 \\
\hline & 3 & 5,18 & 8491 & 1639 \\
\hline \multicolumn{2}{|r|}{ Média (MPa) } & 5,82 & 8879 & 1530 \\
\hline \multicolumn{2}{|r|}{$\mathrm{S}_{\mathrm{d}}(\mathrm{MPa})$} & 0,66 & 671,75 & 95,00 \\
\hline \multicolumn{2}{|r|}{ CV (\%) } & 11,25 & 7,57 & 6,20 \\
\hline
\end{tabular}

\begin{tabular}{||c|c|c|c|c||}
\hline $\begin{array}{c}\text { Tipo de } \\
\text { argamassa }\end{array}$ & $\begin{array}{c}\text { Corpo de } \\
\text { prova }\end{array}$ & $\begin{array}{c}\mathbf{f}_{\mathbf{a}} \\
(\mathbf{M P a})\end{array}$ & $\begin{array}{c}\mathbf{E}_{\mathbf{a}} \\
(\mathbf{M P a})\end{array}$ & $\mathbf{E}_{\mathbf{a}} / \mathbf{f}_{\mathbf{a}}$ \\
\hline \multirow{2}{*}{$\mathrm{R}$} & 1 & 3,67 & 8246 & 1544 \\
\cline { 2 - 6 } & 2 & 3,74 & 4042 & 1505 \\
\cline { 2 - 6 } & 3 & 3,47 & 8041 & 1849 \\
\hline \multicolumn{2}{|c|}{ Média (MPa) } & 3,63 & 5903 & 1633 \\
\hline \multicolumn{2}{|c|}{$\mathbf{S}_{\mathrm{d}}$ (MPa) } & 0,14 & 444,43 & 188,48 \\
\hline \multicolumn{2}{|c|}{$\mathbf{C V}(\%)$} & 3,86 & 7,53 & 11,55 \\
\hline
\end{tabular}


TRANSDUTOR

\begin{tabular}{||c|c|c|c|c||}
\hline $\begin{array}{c}\text { Tipo de } \\
\text { Argamassa }\end{array}$ & $\begin{array}{c}\text { Corpo de } \\
\text { prova }\end{array}$ & $\begin{array}{c}\mathbf{f}_{\mathbf{a}} \\
(\mathbf{M P a})\end{array}$ & $\begin{array}{c}\mathbf{E}_{\mathrm{a}} \\
(\mathbf{M P a})\end{array}$ & $\mathbf{E}_{\mathrm{a}} / \mathbf{f}_{\mathrm{a}}$ \\
\hline \multirow{2}{*}{$\mathrm{P}$} & 1 & 5,39 & 5039 & 935 \\
\cline { 2 - 6 } & 2 & 5,01 & 3517 & $702^{*}$ \\
\cline { 2 - 6 } & 3 & 6,09 & 6289 & 1033 \\
\hline \multicolumn{2}{|c|}{ Média (MPa) } & 5,50 & 5664 & 890 \\
\hline \multicolumn{2}{|c|}{$\mathbf{S}_{\mathbf{d}}(\mathbf{M P a})$} & 0,55 & 883,88 & 169,88 \\
\hline \multicolumn{2}{|c|}{$\mathbf{C V}(\%)$} & 9,97 & 15,61 & 19,09 \\
\hline
\end{tabular}

\begin{tabular}{||c|c|c|c|c||}
\hline $\begin{array}{c}\text { Tipo de } \\
\text { Argamassa }\end{array}$ & $\begin{array}{c}\text { Corpo de } \\
\text { prova }\end{array}$ & $\begin{array}{c}\mathbf{f}_{\mathrm{a}} \\
(\mathbf{M P a})\end{array}$ & $\begin{array}{c}\mathbf{E}_{\mathrm{a}} \\
(\mathbf{M P a})\end{array}$ & $\mathbf{E}_{\mathrm{a}} / \mathbf{f}_{\mathrm{a}}$ \\
\hline \multirow{2}{*}{$\mathrm{Q}$} & 1 & 6,49 & 8996 & 1386 \\
\cline { 2 - 5 } & 2 & 5,80 & 10862 & 1873 \\
\cline { 2 - 6 } & 3 & 5,18 & 9301 & 1796 \\
\hline \multicolumn{2}{|c|}{ Média (MPa) } & 5,82 & 9720 & 1685 \\
\hline \multicolumn{2}{|c|}{$\mathbf{S}_{\mathbf{d}}$ (MPa) } & 0,66 & 1000,98 & 261,53 \\
\hline \multicolumn{2}{|c|}{$\mathbf{C V}(\%)$} & 11,25 & 10,30 & 15,52 \\
\hline
\end{tabular}

\begin{tabular}{|c|c|c|c|c|}
\hline $\begin{array}{c}\text { Tipo de } \\
\text { Argamassa }\end{array}$ & $\begin{array}{c}\text { Corpo de } \\
\text { prova }\end{array}$ & $\begin{array}{c}f_{a} \\
(\mathrm{MPa})\end{array}$ & $\begin{array}{c}\mathrm{E}_{\mathrm{a}} \\
(\mathrm{MPa})\end{array}$ & $E_{a} / f_{a}$ \\
\hline \multirow{3}{*}{$R$} & 1 & 3,67 & 8246 & 2247 \\
\hline & 2 & 3,74 & 4042 & $1081^{\text {** }}$ \\
\hline & 3 & 3,47 & 8041 & 2317 \\
\hline \multicolumn{2}{|c|}{ Média (MPa) } & 3,63 & 8144 & 2282 \\
\hline \multicolumn{2}{|c|}{$\mathrm{S}_{\mathrm{d}}(\mathrm{MPa})$} & 0,14 & 144,96 & 49,80 \\
\hline \multicolumn{2}{|c|}{ CV (\%) } & 3,86 & 1,78 & 2,18 \\
\hline
\end{tabular}

* Resultado descartado por apresentar um desvio grande em relação aos outros valores. 


\begin{tabular}{|c|c|c|c|c|}
\hline $\begin{array}{c}\text { Tipo de } \\
\text { argamassa }\end{array}$ & $\begin{array}{c}\text { Corpo de } \\
\text { prova }\end{array}$ & $\begin{array}{c}f_{a} \\
(\mathrm{MPa})\end{array}$ & $\begin{array}{c}\mathrm{E}_{\mathrm{a}} \\
(\mathrm{MPa})\end{array}$ & $E_{a} / f_{a}$ \\
\hline \multirow{3}{*}{$\mathrm{A} 1$} & 1 & 6,32 & 9678 & 1531 \\
\hline & 2 & 6,55 & 9866 & 1506 \\
\hline & 3 & 6,53 & 9843 & 1507 \\
\hline \multicolumn{2}{|r|}{ Média (MPa) } & 6,47 & 9796 & 1515 \\
\hline \multicolumn{2}{|r|}{$\mathrm{S}_{\mathrm{d}}(\mathrm{MPa})$} & 0,13 & 102,55 & 14,46 \\
\hline \multicolumn{2}{|r|}{ CV (\%) } & 1,99 & 1,05 & 0,95 \\
\hline
\end{tabular}

\begin{tabular}{||c|c|c|c|c||}
\hline $\begin{array}{c}\text { Tipo de } \\
\text { Argamassa }\end{array}$ & $\begin{array}{c}\text { Corpo de } \\
\text { prova }\end{array}$ & $\begin{array}{c}\mathbf{f}_{\mathbf{a}} \\
(\mathbf{M P a})\end{array}$ & $\begin{array}{c}\mathbf{E}_{\mathrm{a}} \\
(\mathbf{M P a})\end{array}$ & $\mathbf{E}_{\mathrm{a}} / \mathbf{f}_{\mathrm{a}}$ \\
\hline \multirow{3}{*}{ A2 } & 1 & 4,13 & 7062 & 1708 \\
\cline { 2 - 6 } & 2 & 4,15 & 7819 & 1886 \\
\cline { 2 - 6 } & 3 & 4,27 & 7779 & 1821 \\
\cline { 2 - 6 } & 4 & 4,24 & 7734 & 1822 \\
\hline & Média (MPa) & 4,20 & 7598 & 1809 \\
\hline & $\mathbf{S}_{\mathbf{d}}(\mathbf{M P a})$ & 0,07 & 359,56 & 74,07 \\
\hline
\end{tabular}




\begin{tabular}{|c|c|c|c|}
\hline $\begin{array}{c}\text { Prisma } \\
\text { correspondente }\end{array}$ & $\begin{array}{c}f_{\mathrm{pr}}^{*} \\
(\mathrm{MPa})\end{array}$ & $\begin{array}{c}\mathrm{E}_{\mathrm{pr}}{ }^{*} \\
(\mathrm{MPa})\end{array}$ & $\mathrm{E}_{\mathrm{pr}}^{*} / \mathrm{f}_{\mathrm{pr}}$ \\
\hline Q111 & 7,33 & $9148^{* *}$ & $1248^{\star *}$ \\
\hline Q112 & 9,27 & 4801 & 517 \\
\hline Q113 & 10,02 & 4710 & 532 \\
\hline Média (MPa) & 8,48 & 4756 & 525 \\
\hline $\mathrm{S}_{\mathrm{d}}(\mathrm{MPa})$ & 1,02 & 64,35 & 10,36 \\
\hline CV (\%) & 12,07 & 1,35 & 1,97 \\
\hline
\end{tabular}

\begin{tabular}{||c|c|c|c||}
\hline $\begin{array}{c}\text { Prisma } \\
\text { correspondente }\end{array}$ & $\begin{array}{c}\mathbf{f}_{\mathrm{pr}}{ }^{*} \\
(\mathrm{MPa})\end{array}$ & $\begin{array}{c}\mathbf{E}_{\mathrm{pr}}{ }^{*} \\
(\mathrm{MPa})\end{array}$ & $\mathbf{E}_{\mathrm{pr}}{ }^{*} / \mathbf{f}_{\mathrm{pr}}{ }^{*}$ \\
\hline Q121 & 6,20 & 7721 & $1244^{* *}$ \\
\hline Q122 & 7,87 & 57283 & 924 \\
\hline Q123 & 8,60 & 6902 & 803 \\
\hline Média (MPa) & 7,56 & 7302 & 864 \\
\hline $\mathbf{S}_{\mathrm{d}}(\mathrm{MPa})$ & 1,23 & 409,83 & 86,00 \\
\hline CV (\%) & 16,28 & 5,61 & 9,96 \\
\hline
\end{tabular}

\begin{tabular}{||c|c|c|c||}
\hline $\begin{array}{c}\text { Prisma } \\
\text { correspondente }\end{array}$ & $\begin{array}{c}\mathbf{f}_{\mathrm{pr}}{ }^{*} \\
\mathbf{M P a}\end{array}$ & $\begin{array}{c}\mathbf{E}_{\mathrm{pr}}{ }^{*} \\
\mathbf{( M P a}\end{array}$ & $\mathbf{E}_{\mathrm{pr}}{ }^{*} / \mathbf{f}_{\mathrm{pr}}{ }^{*}$ \\
\hline Q211 & 17,84 & 14122 & 792 \\
\hline Q212 & 15,67 & $6918^{* *}$ & $441^{* *}$ \\
\hline Q213 & $11,76^{\star *}$ & 13354 & 1136 \\
\hline Média (MPa) & 16,75 & 13354 & 964 \\
\hline $\mathbf{S}_{\mathbf{d}}$ (MPa) & 1,53 & 543,06 & 243,18 \\
\hline $\mathbf{C V}(\%)$ & 9,13 & 3,95 & 25,23 \\
\hline
\end{tabular}

* Resistência e módulo de elasticidade calculados em função da área líquida do prisma.

${ }^{* *}$ Resultado descartado por apresentar um desvio grande em relação aos outros valores. 


\begin{tabular}{||c|c|c|c||}
\hline $\begin{array}{c}\text { Prisma } \\
\text { correspondente }\end{array}$ & $\begin{array}{c}\mathbf{f}_{\mathrm{pr}}{ }^{*} \\
(\mathrm{MPa})\end{array}$ & $\begin{array}{c}\mathbf{E}_{\mathrm{pr}}{ }^{*} \\
(\mathbf{M P a})\end{array}$ & $\mathbf{E}_{\mathrm{pr}}{ }^{*} / \mathbf{f}_{\mathrm{pr}}{ }^{*}$ \\
\hline Q221 & 10,91 & 12277 & 1126 \\
\hline Q222 & 10,78 & $6965^{\star *}$ & $646^{* *}$ \\
\hline Q223 & 12,71 & 12546 & 1164 \\
\hline Média (MPa) & 11,47 & 12412 & 1145 \\
\hline $\mathbf{S}_{\mathbf{d}}(\mathbf{M P a})$ & 1,08 & 190,21 & 26,32 \\
\hline $\mathbf{C V}(\%)$ & 9,40 & 1,53 & 2,30 \\
\hline
\end{tabular}

* Resistência e módulo de elasticidade calculados em função da área líquida do prisma.

${ }^{* *}$ Resultado descartado por apresentar um desvio grande em relação aos outros valores. 
ANEXO B

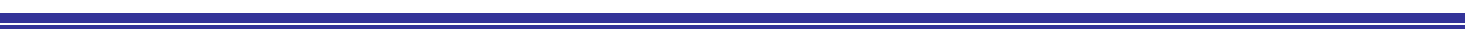


Gráfico Tensão x Deformação PRB1A2E 2 - Bloco de 4,5 MPa

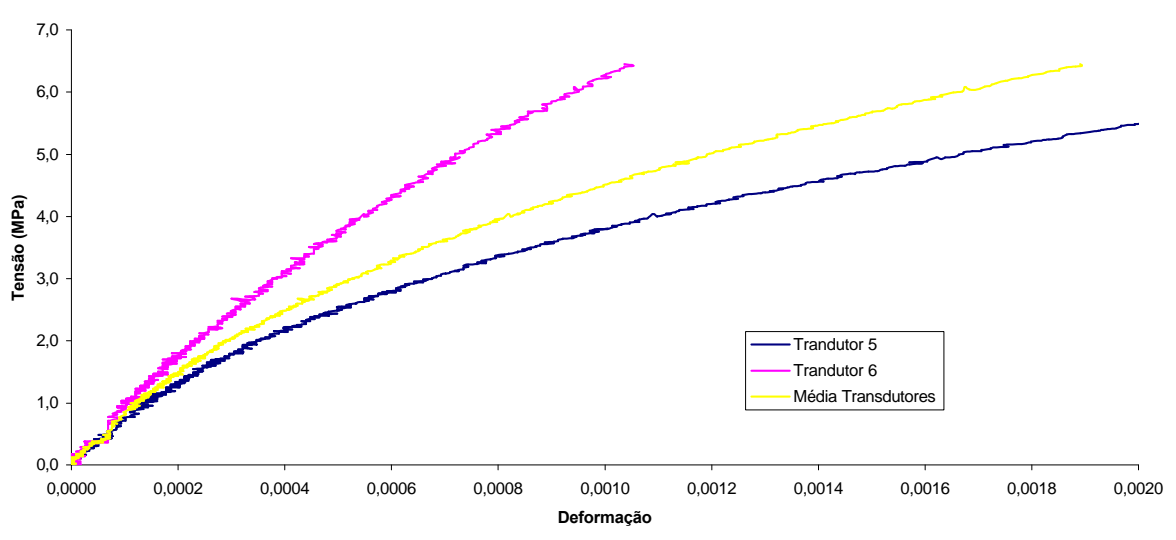

Gráfico Tensão x Deformação PRB1A2E 4 - Bloco de 4,5 MPa

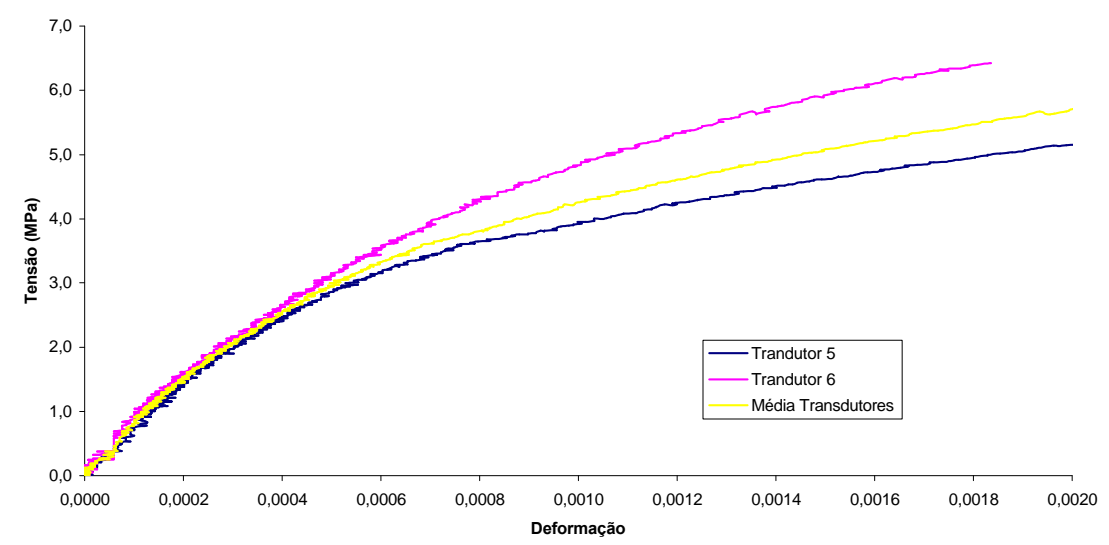

Gráfico Tensão x Deformação PRB1A2E 6 - Bloco de 4,5 MPa

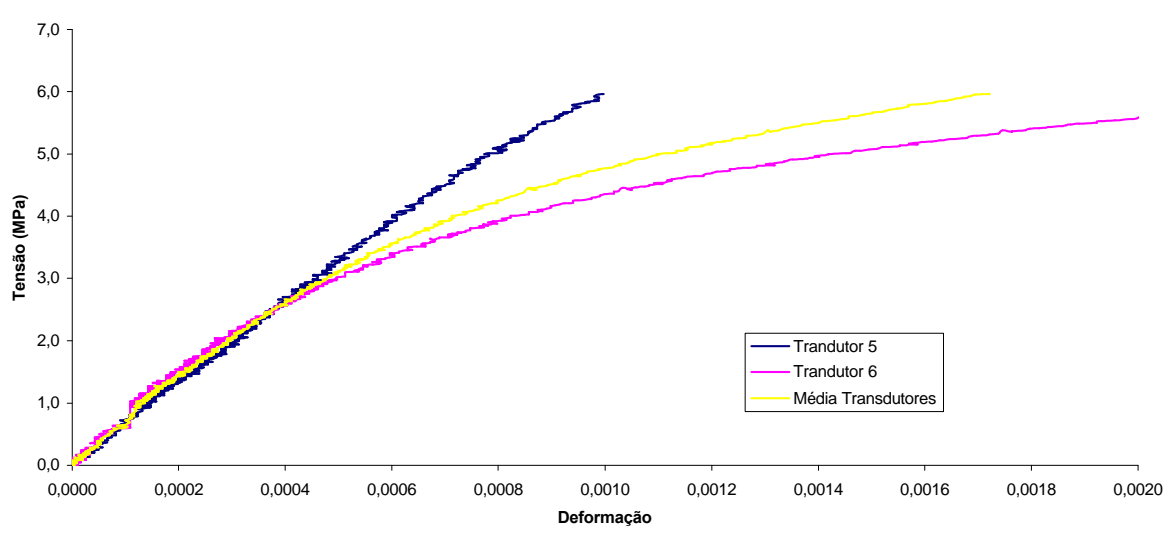


Gráfico Tensão x Deformação PRB2A2E 1 - Bloco de $12 \mathrm{MPa}$

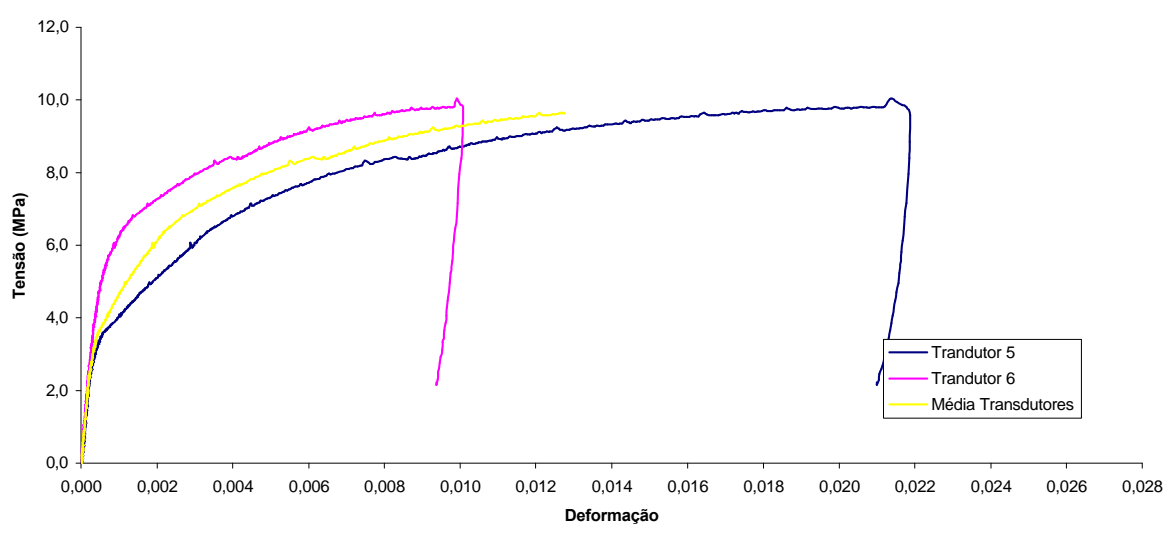

Gráfico Tensão x Deformação PRB2A2E 3 - Bloco de $12 \mathrm{MPa}$

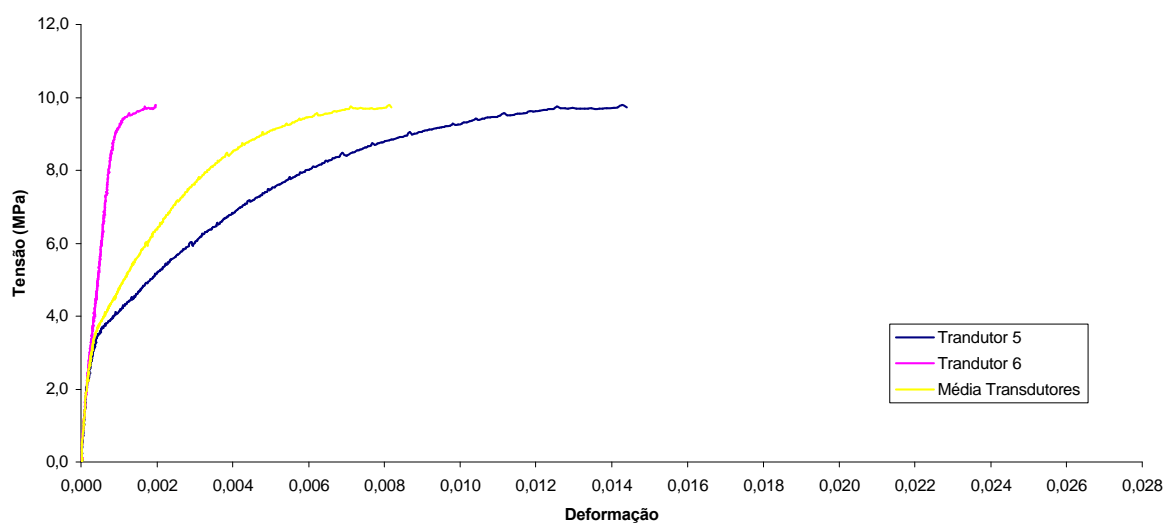

Gráfico Tensão x Deformação PRB2A2E 5 - Bloco de $12 \mathrm{MPa}$

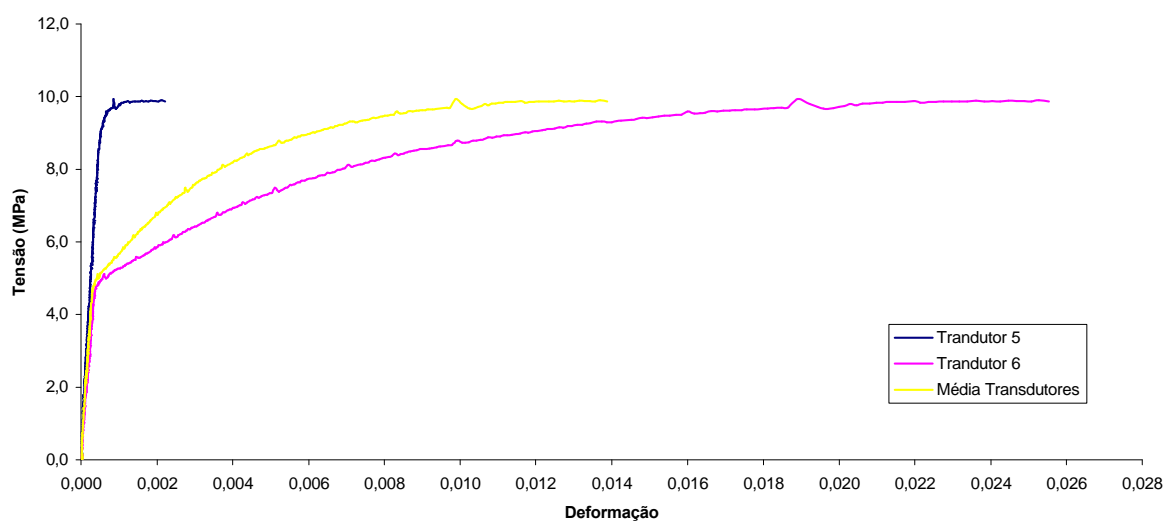


Gráfico Tensão x Deformação PRB1A2E 2 - Bloco de 4,5 MPa

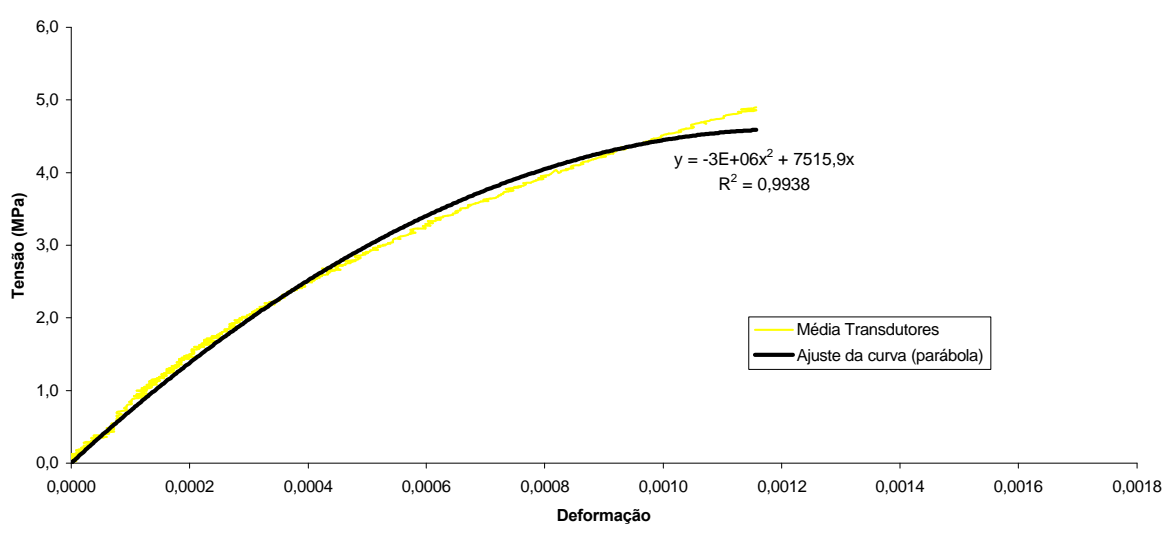

Gráfico Tensão x Deformação PRB1A2E 4 - Bloco de 4,5 MPa

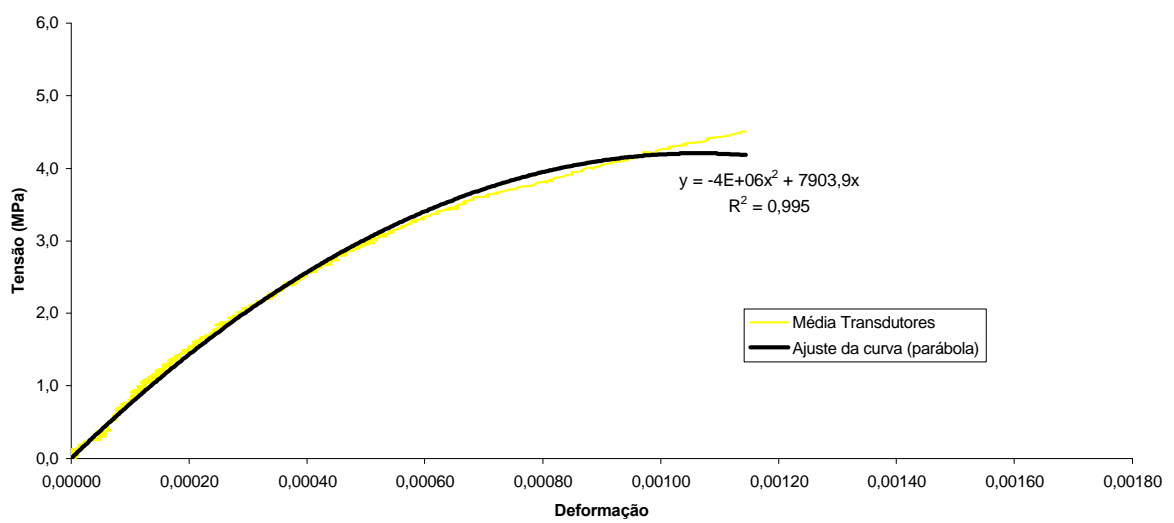

Gráfico Tensão x Deformação PRB1A2E 6 - Bloco de 4,5 MPa

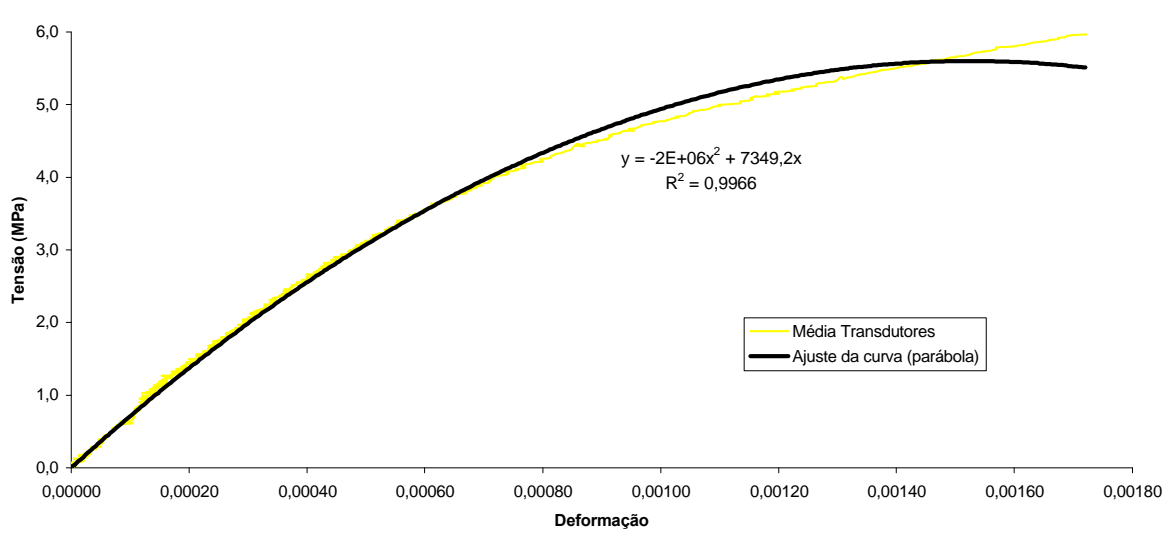


Gráfico Tensão x Deformação PRB2A2E 1 - Bloco de $12 \mathrm{MPa}$

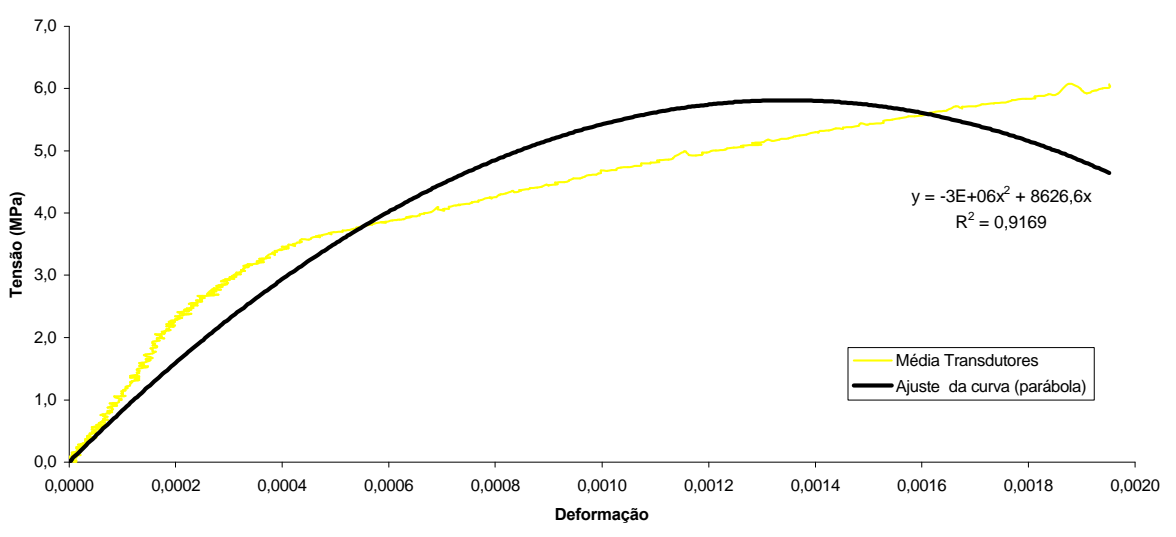

Gráfico Tensão x Deformação PRB2A2E 3- Bloco de $12 \mathrm{MPa}$

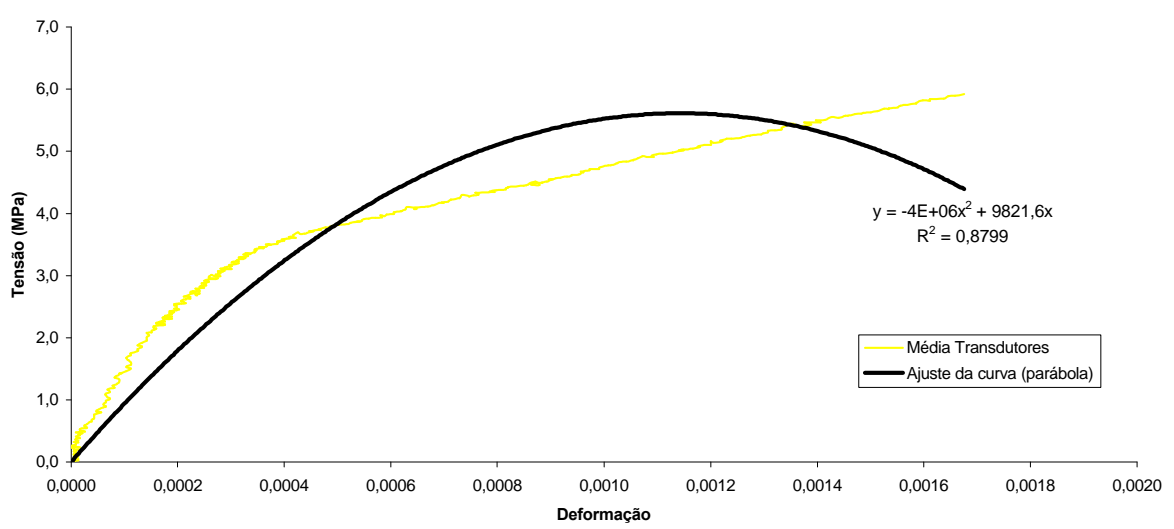

Gráfico Tensão x Deformação PRB2A2E 5 - Bloco de $12 \mathrm{MPa}$

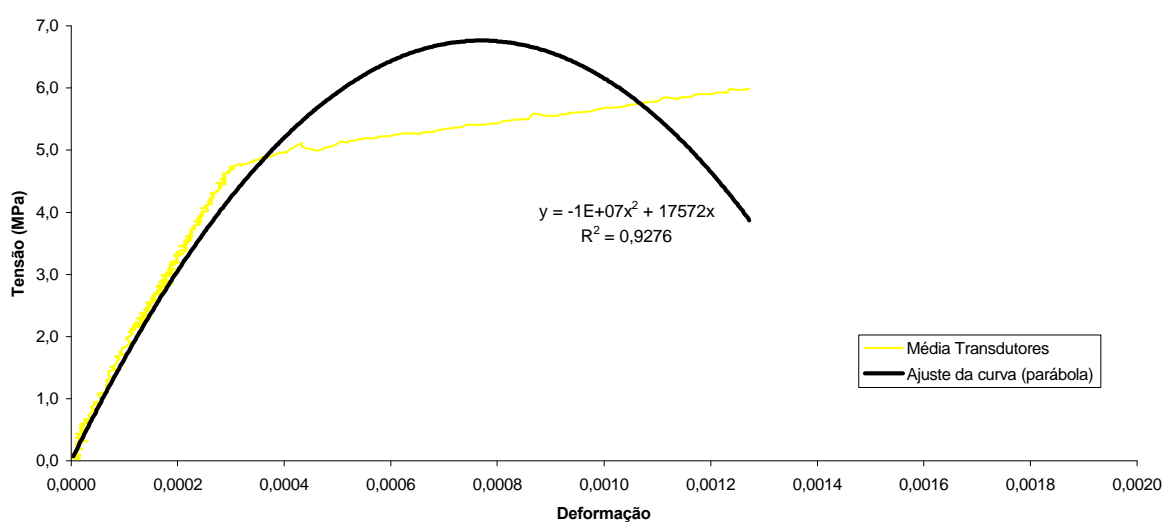


Gráfico Tensão x Deformação PRB1A2E 2 - Prisma

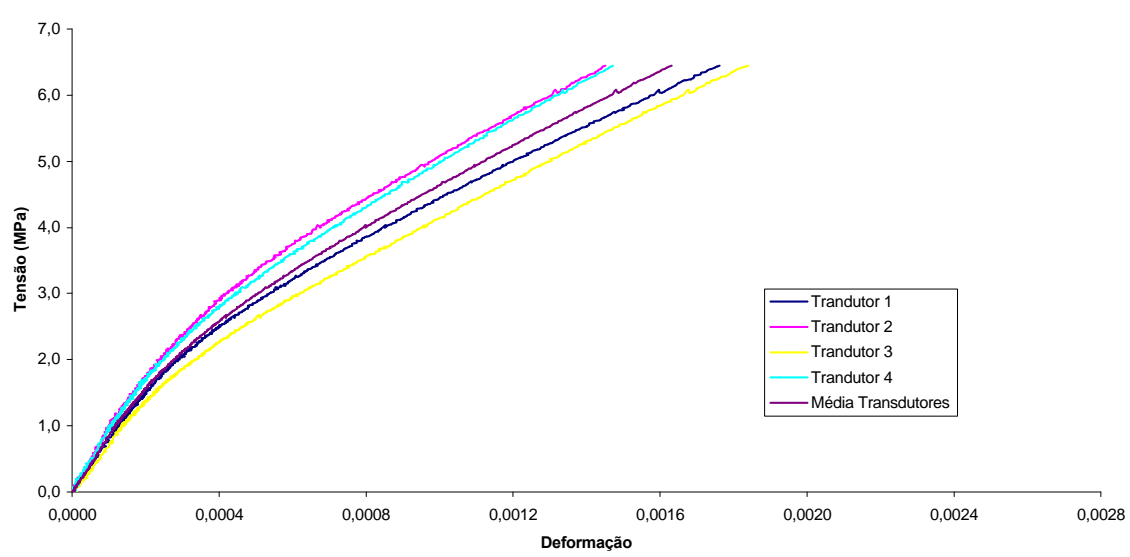

Gráfico Tensão x Deformação PRB1A2E 4 - Prisma

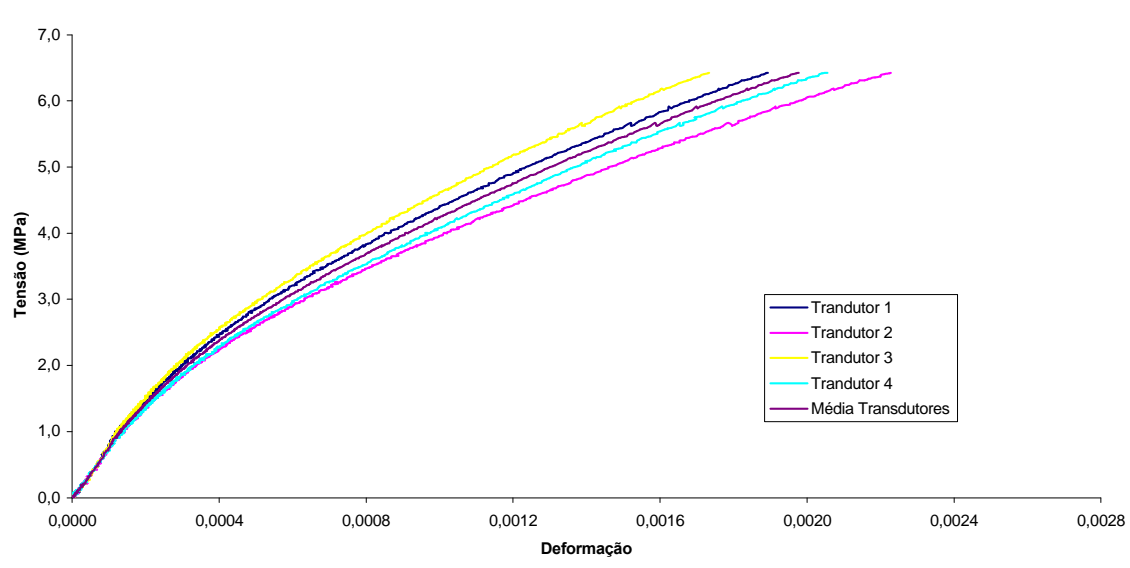

Gráfico Tensão x Deformação PRB1A2E 6 - Prisma

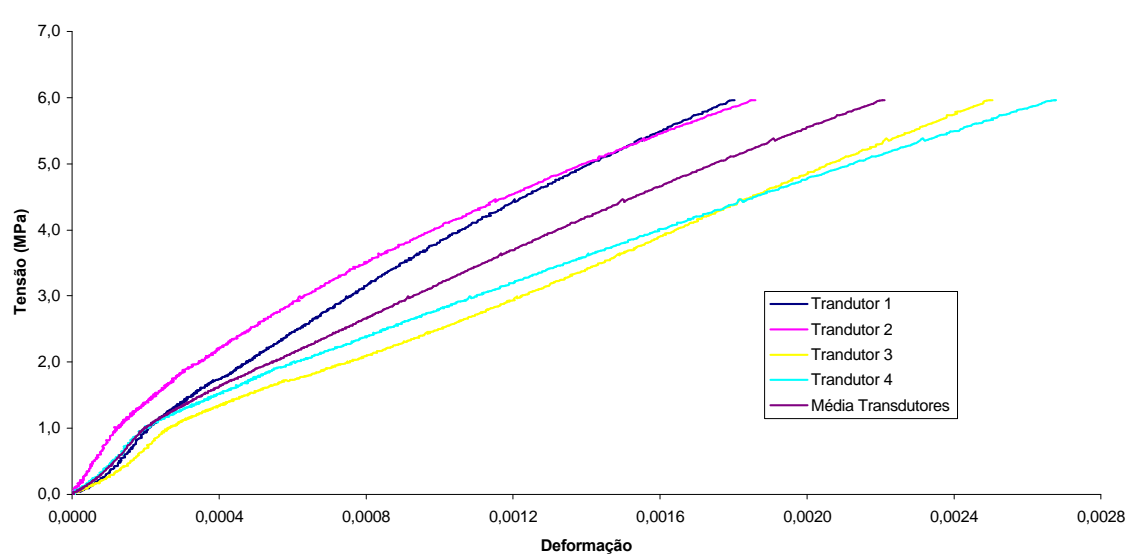


Gráfico Tensão x Deformação PRB2A2E 1 - Prisma

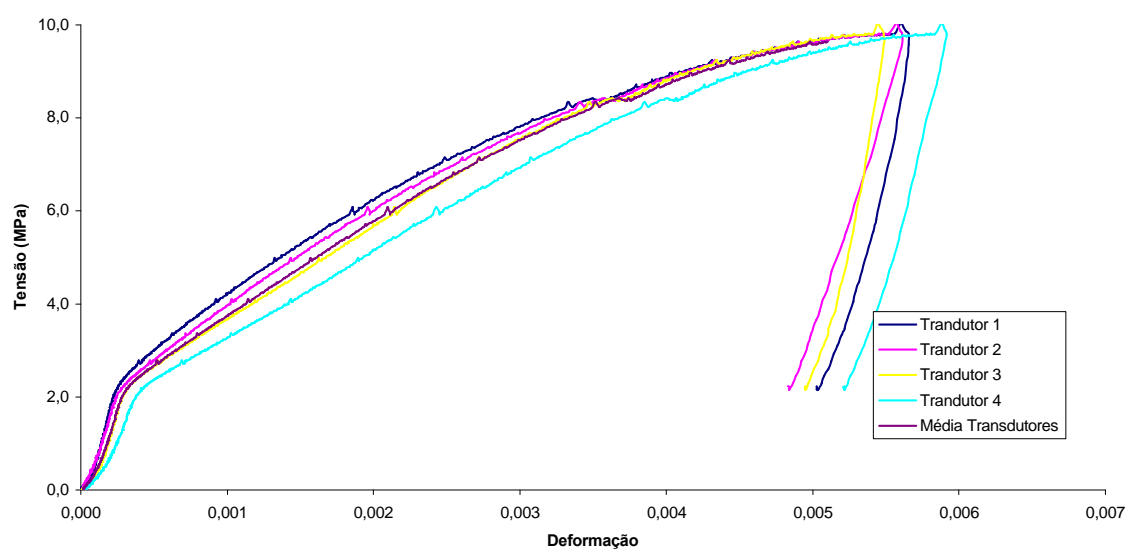

Gráfico Tensão x Deformação PRB2A2E 3 - Prisma

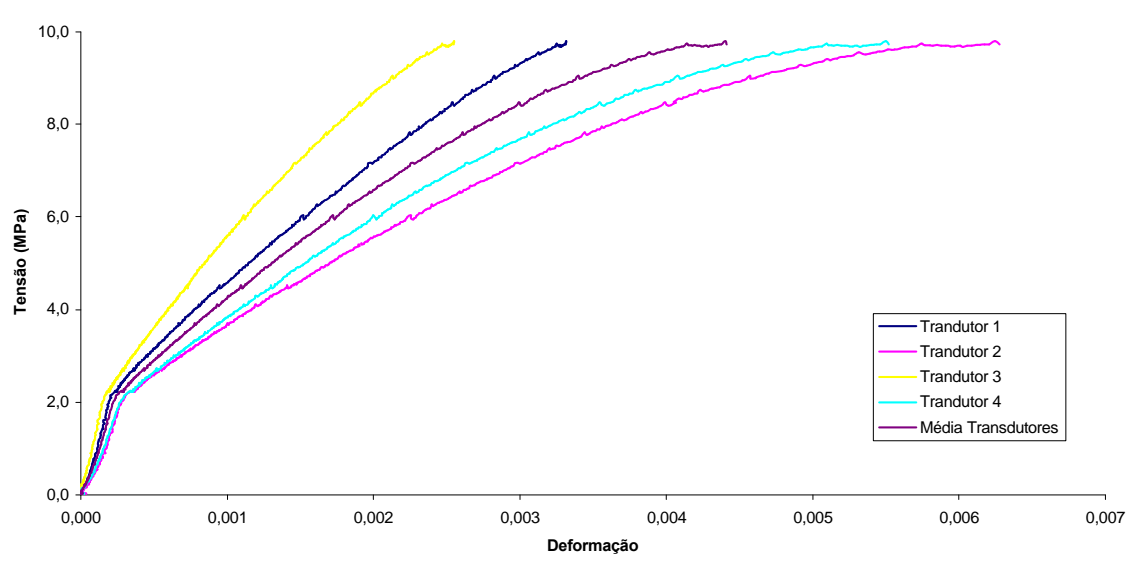

Gráfico Tensão x Deformação PRB2A2E 5 - Prisma

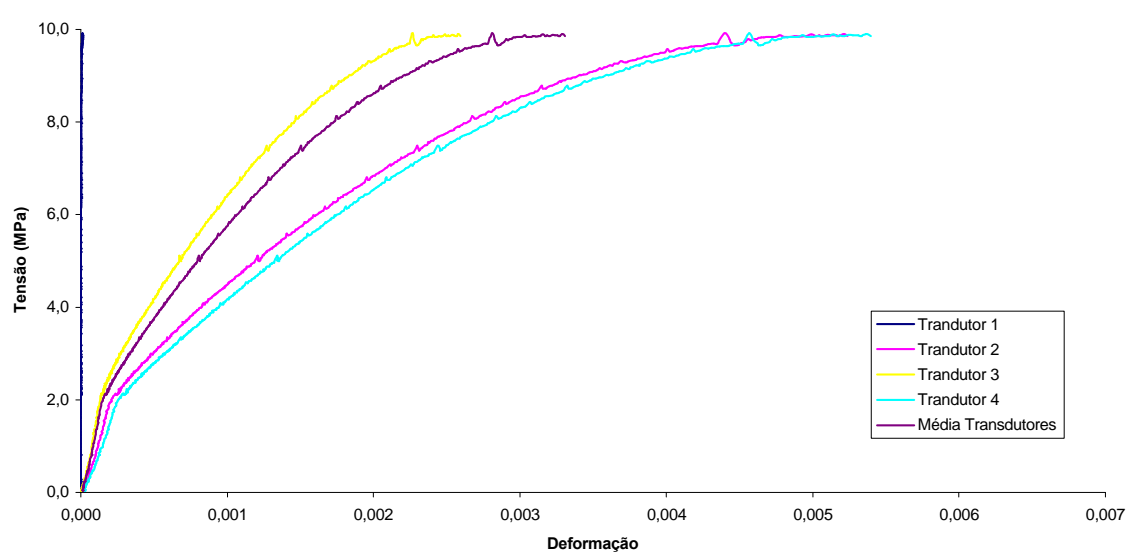




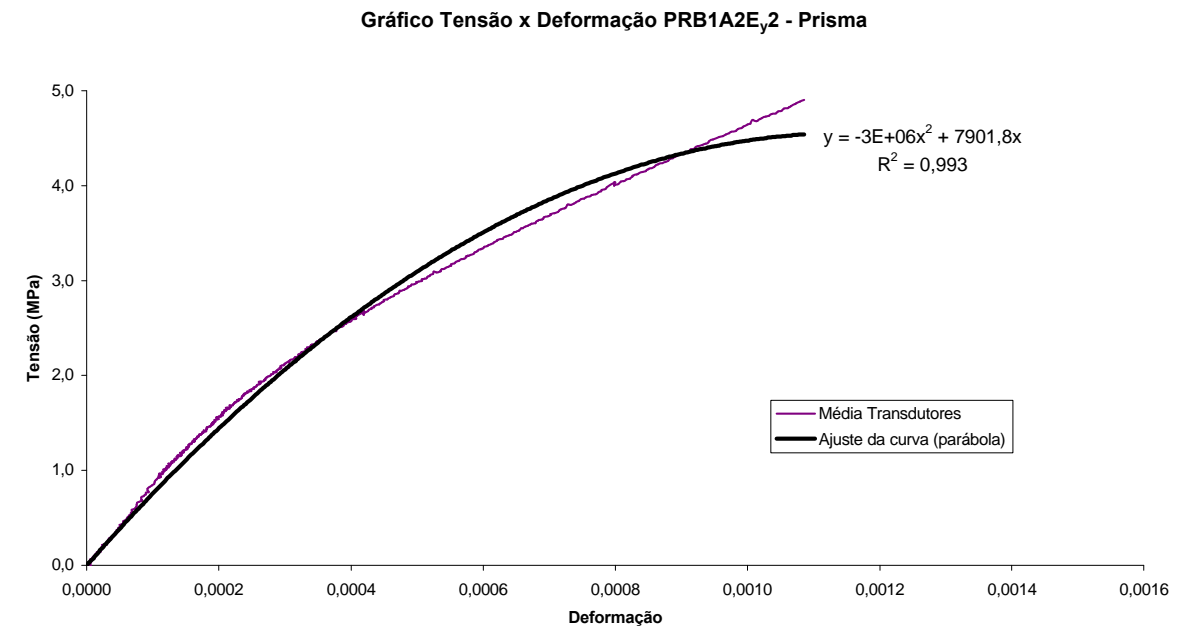

Gráfico Tensão x Deformação PRB1A2E 4 - Prisma

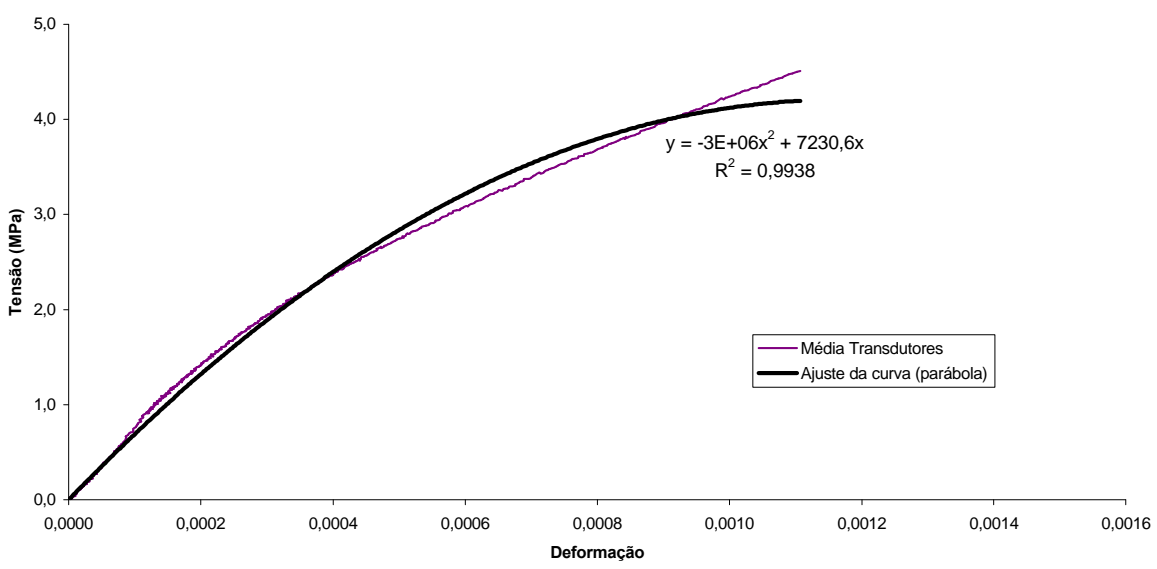

Gráfico Tensão x Deformação PRB1A2E 6 - Prisma

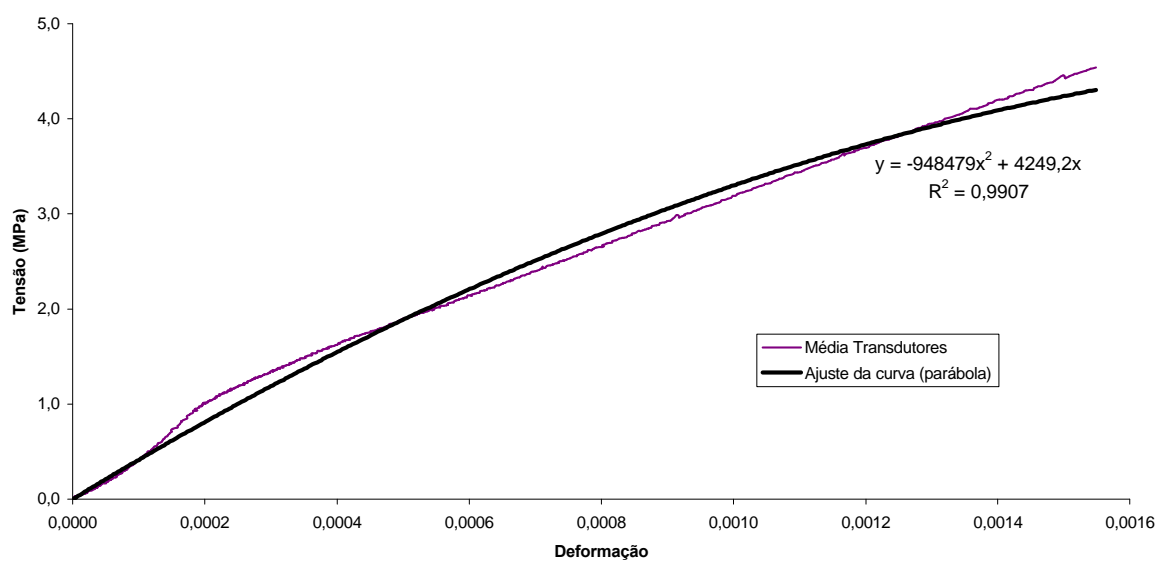


Gráfico Tensão x Deformação PRB2A2E 1 - Prisma

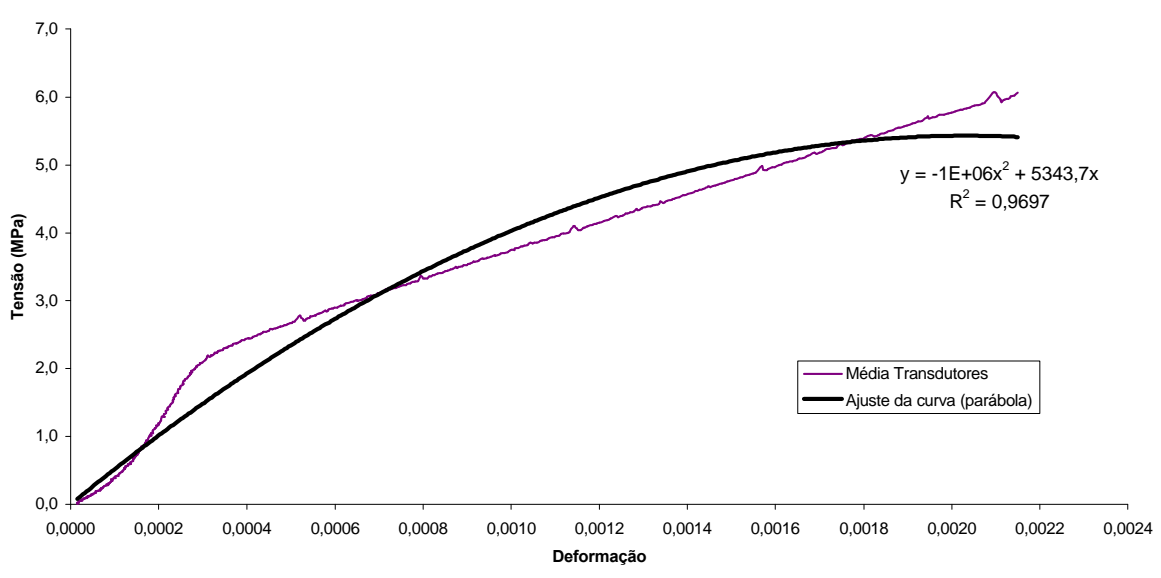

Gráfico Tensão x Deformação PRB2A2E 3 - Prisma

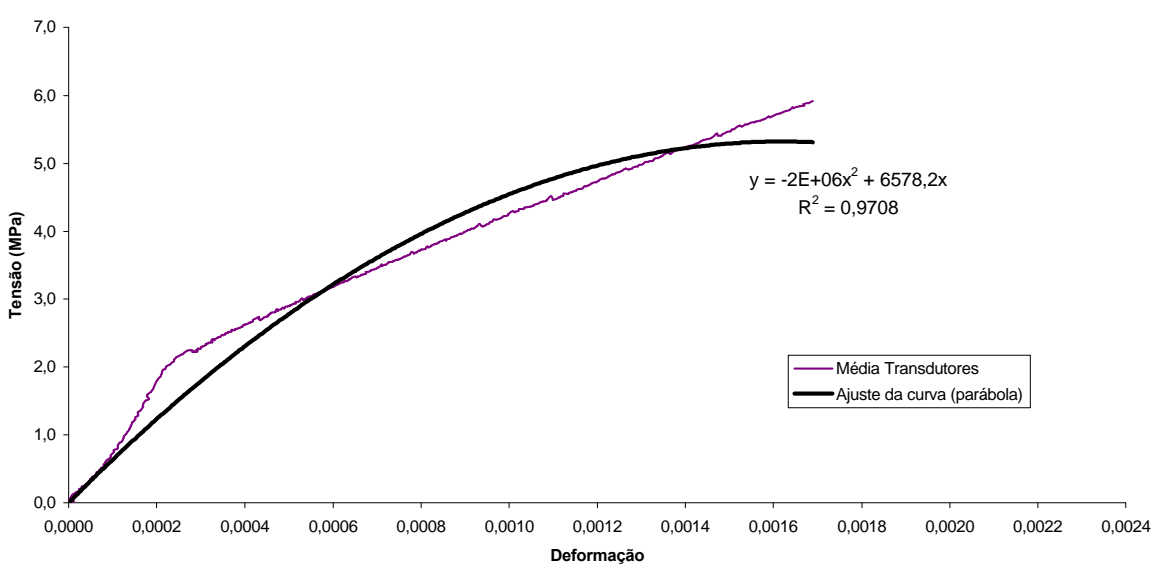

Gráfico Tensão x Deformação PRB2A2E 5 - Prisma

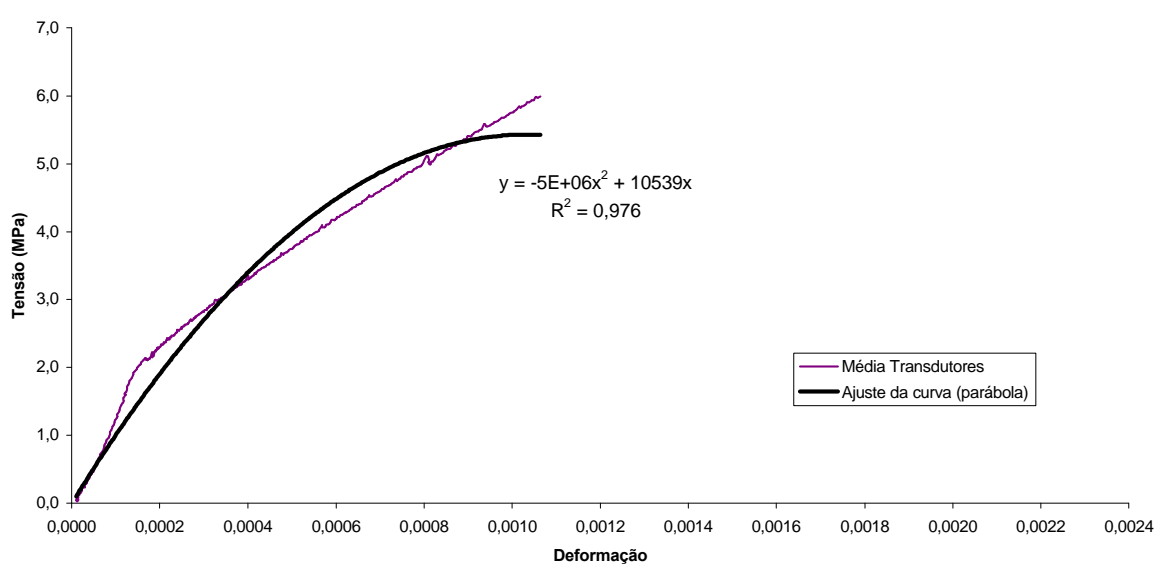


Gráfico Tensão x Deformação PAB1A1E 1 - Parede $\left(E_{y}\right)$

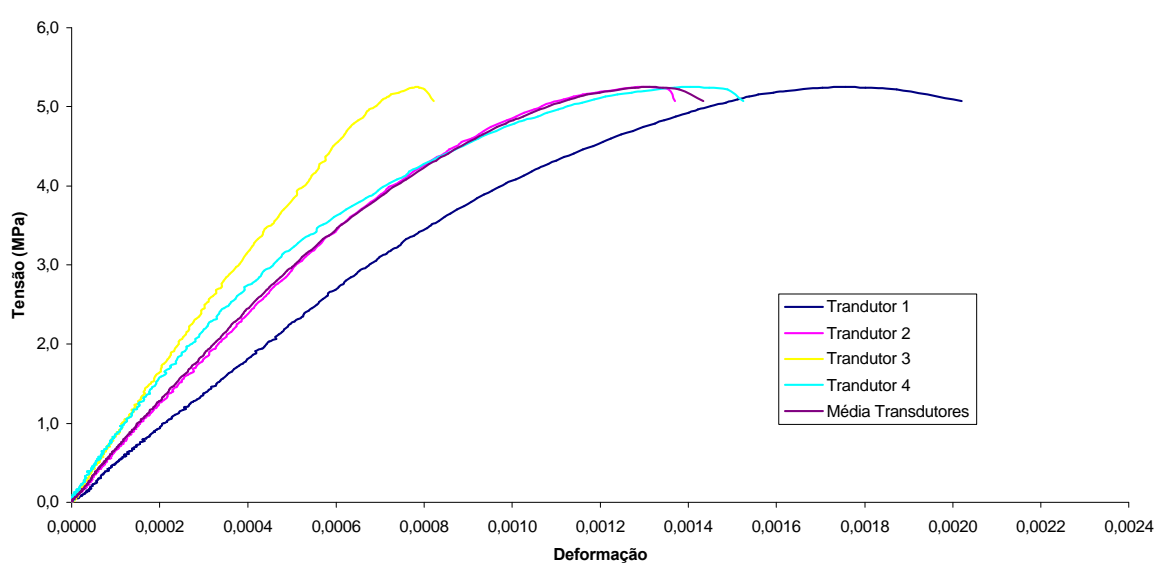

Gráfico Tensão x Deformação PAB1A1E 2 - Parede $\left(E_{y}\right)$

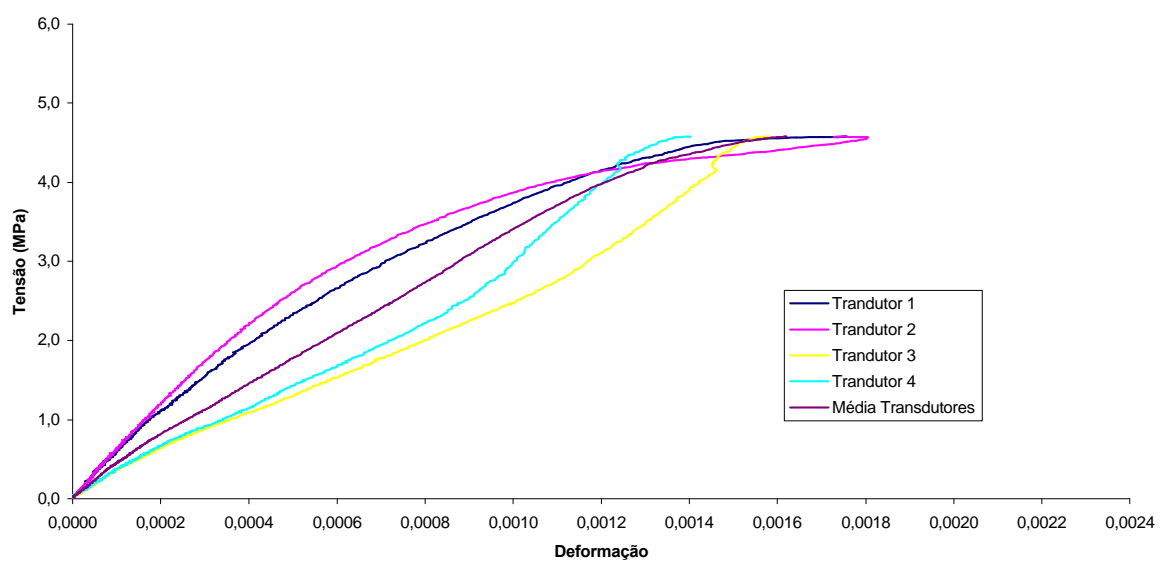

Gráfico Tensão x Deformação PAB1A1Ey3 - Parede (Ey)

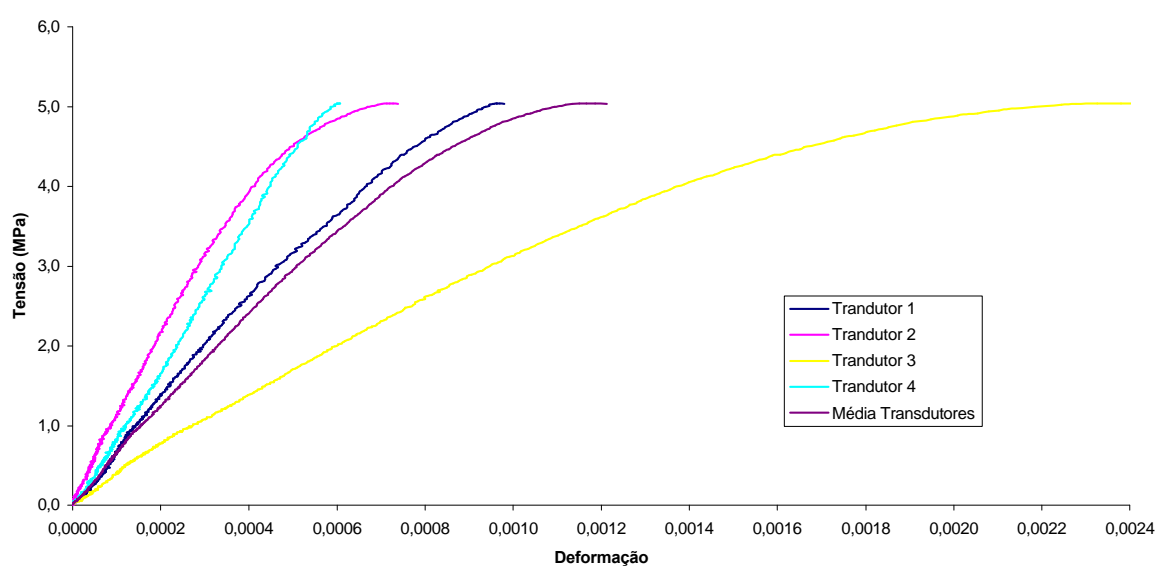


Gráfico Tensão x Deformação PAB1A2E 1 - Parede $\left(E_{y}\right)$

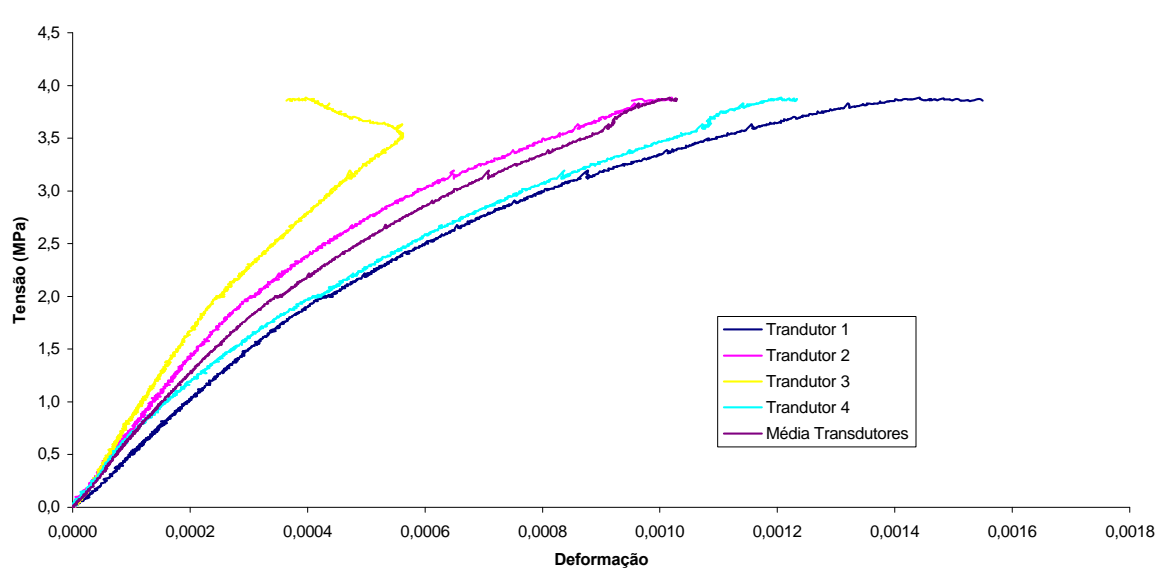

Gráfico Tensão x Deformação PAB1A2E 2 - Parede $\left(E_{y}\right)$

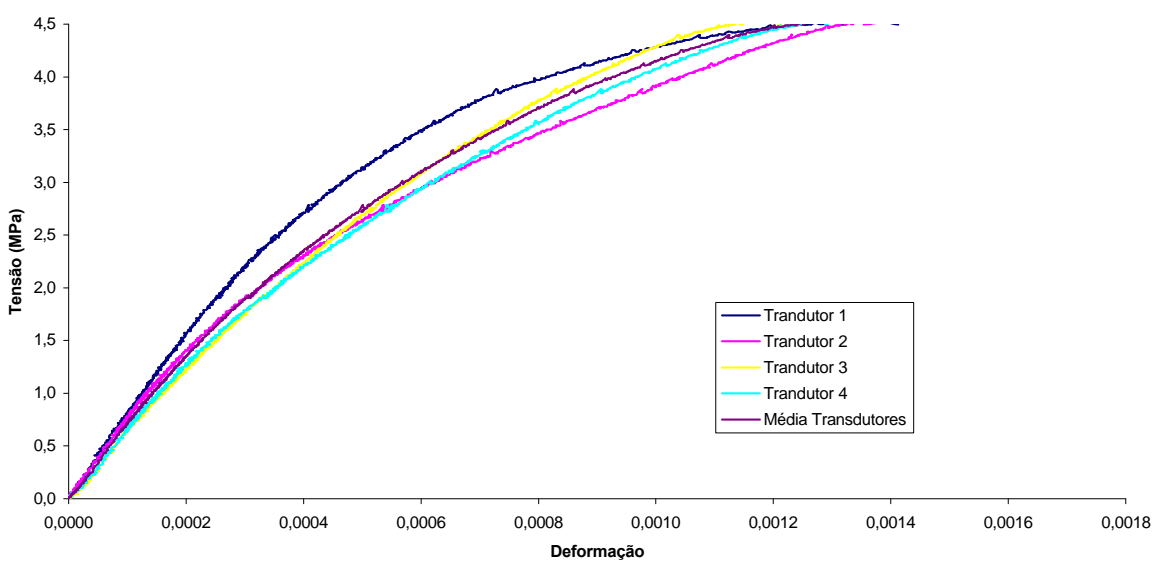

Gráfico Tensão x Deformação PAB1A2E 3 - Parede $\left(E_{y}\right)$

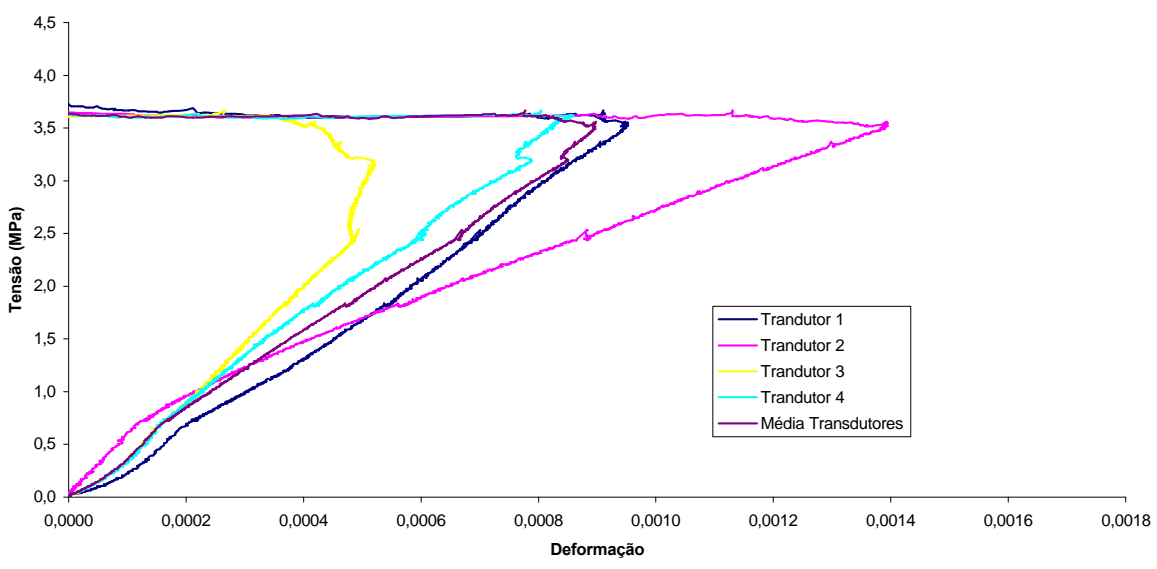




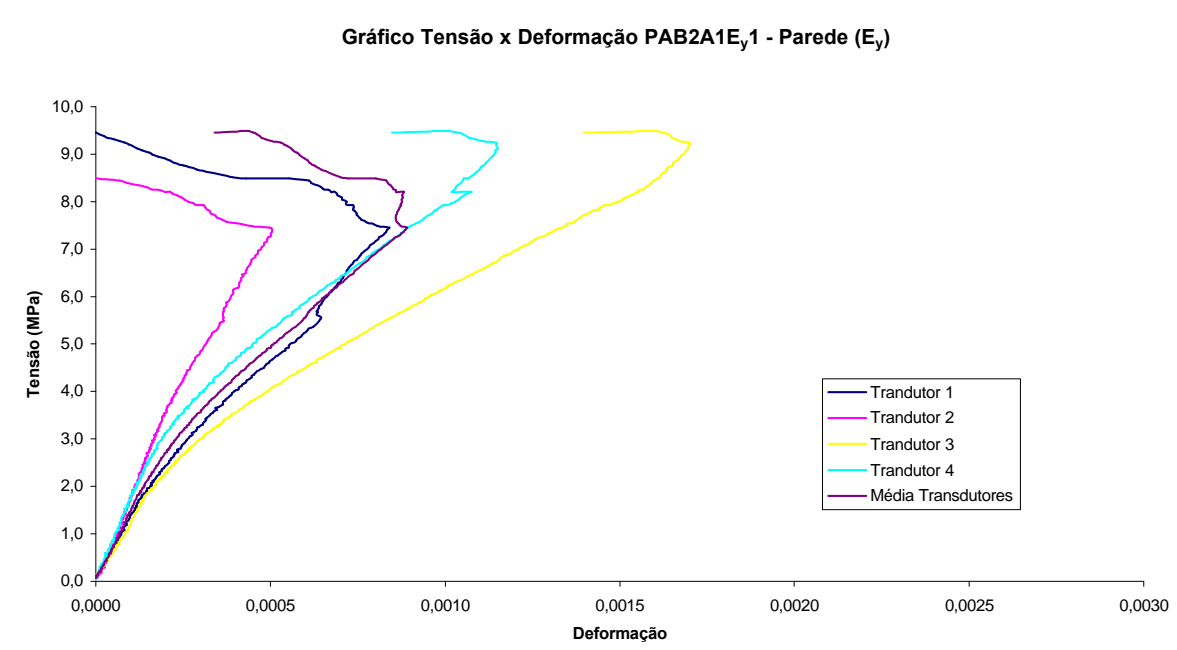

Gráfico Tensão x Deformação PAB1A2E 2 - Parede $\left(E_{y}\right)$

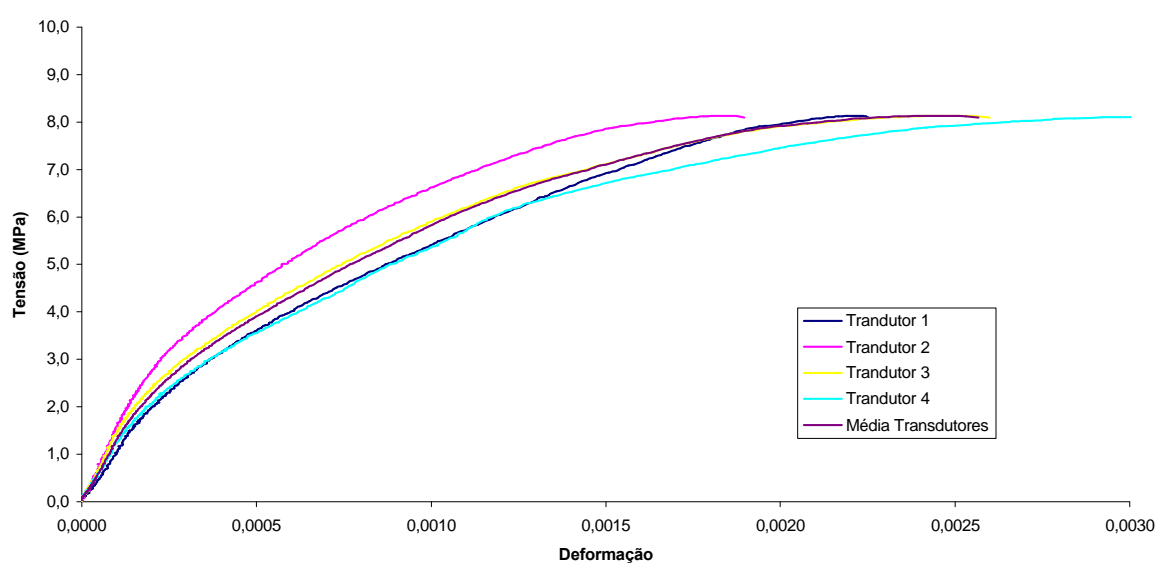

Gráfico Tensão x Deformação PAB2A1E 3 - Parede $\left(E_{y}\right)$

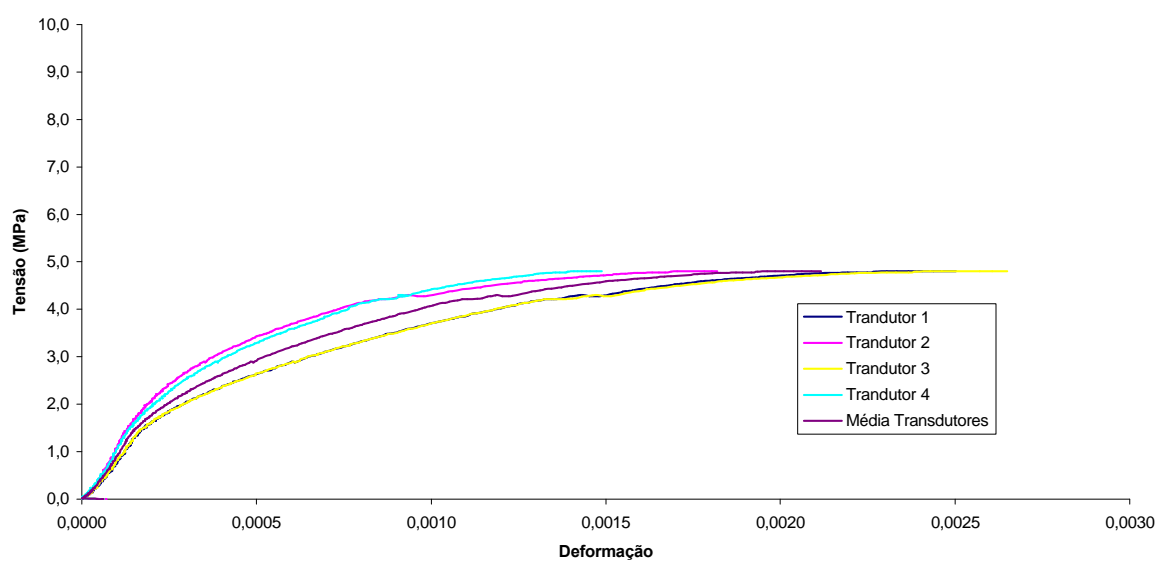


Gráfico Tensão x Deformação PAB2A2E 2 - Parede $\left(E_{y}\right)$

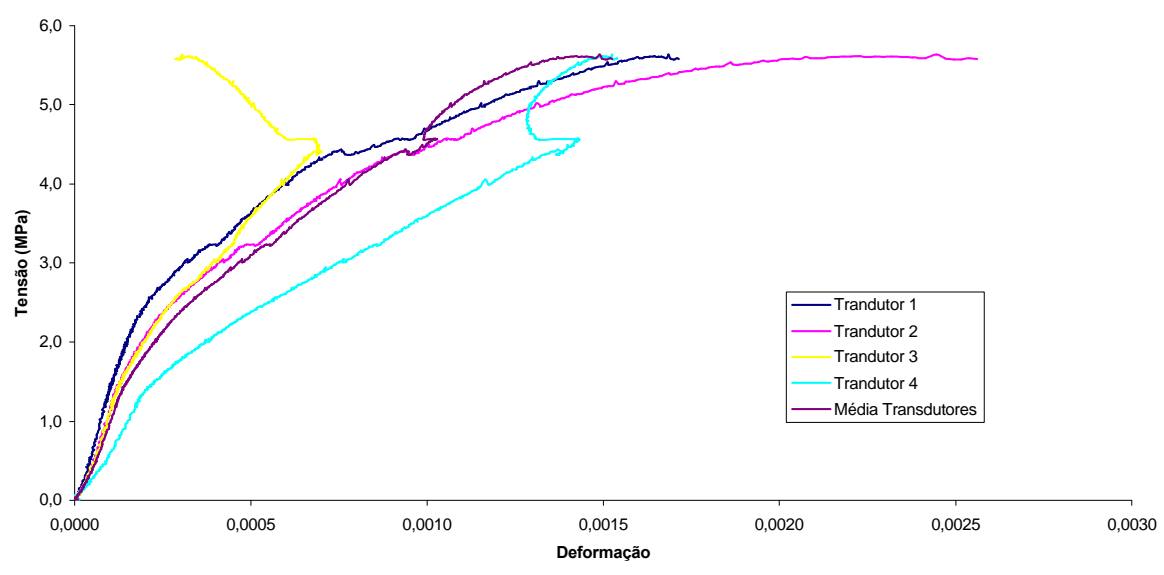


Gráfico Tensão x Deformação PAB1A1E 1 - Parede $\left(E_{x}\right)$

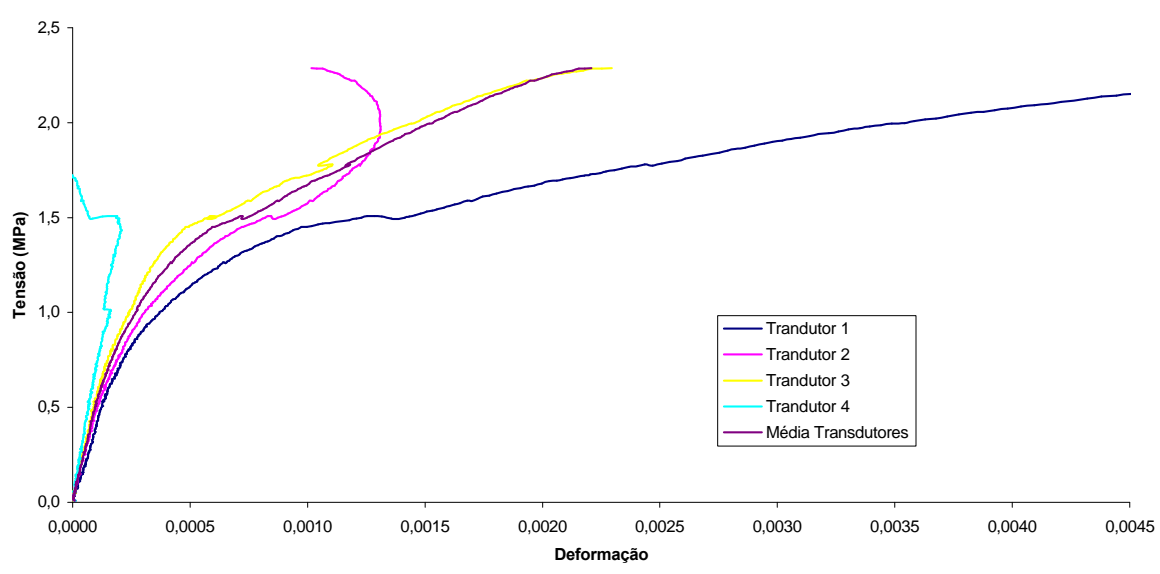

Gráfico Tensão x Deformação PAB1A1E 2 - Parede $\left(E_{x}\right)$

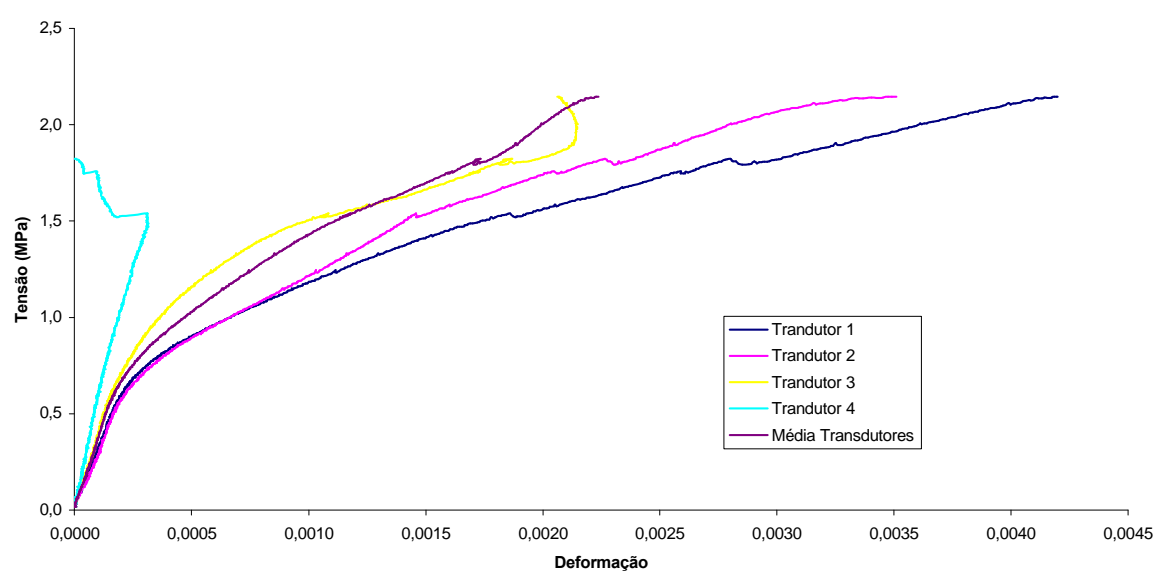

Gráfico Tensão x Deformação PAB1A1E 3 - Parede $\left(E_{x}\right)$

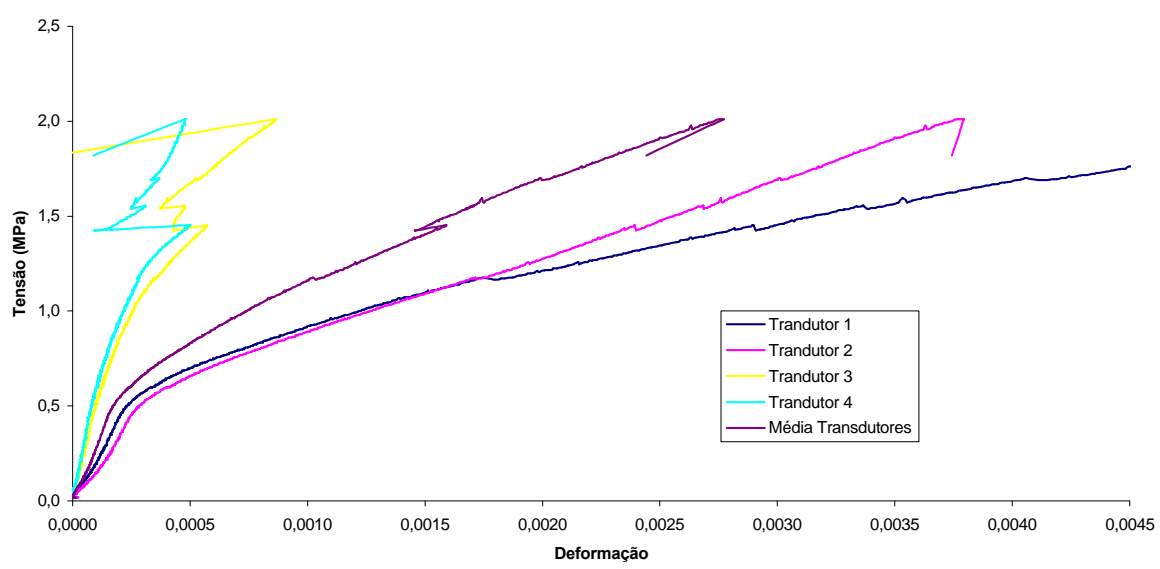


Gráfico Tensão x Deformação PAB1A2E 1 - Parede $\left(E_{x}\right)$

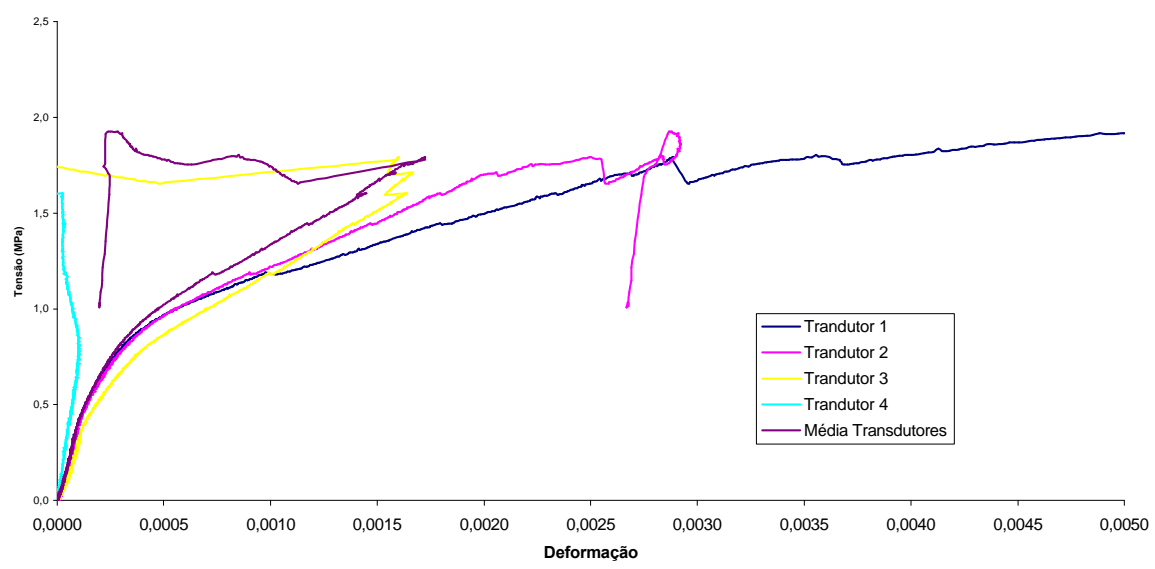

Gráfico Tensão x Deformação PAB1A2E 2 - Parede $\left(E_{x}\right)$

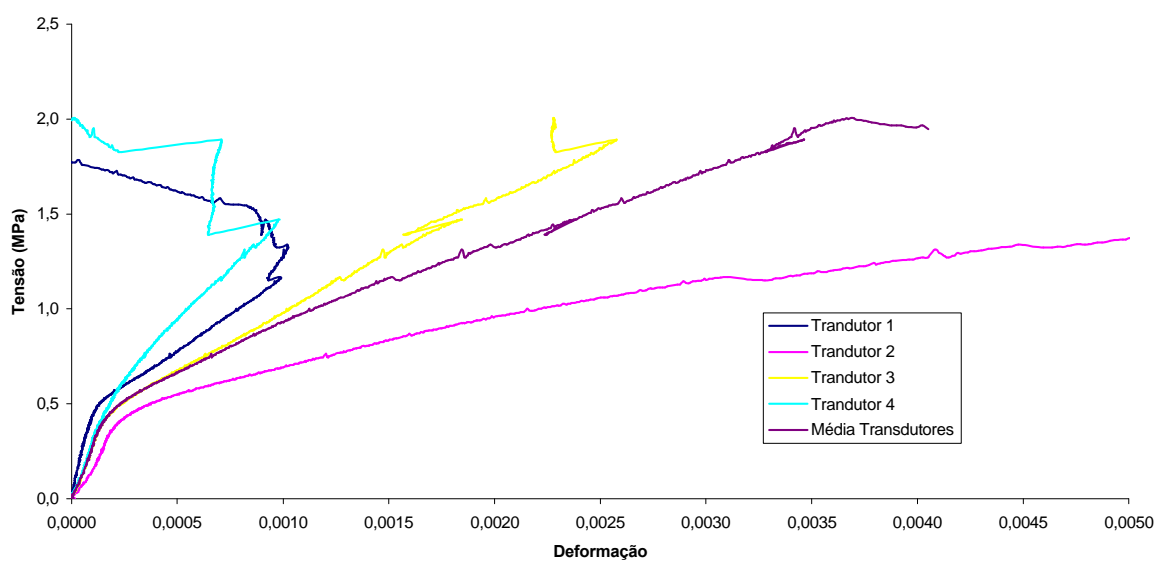

Gráfico Tensão x Deformação PAB1A2E 3 - Parede $\left(E_{x}\right)$

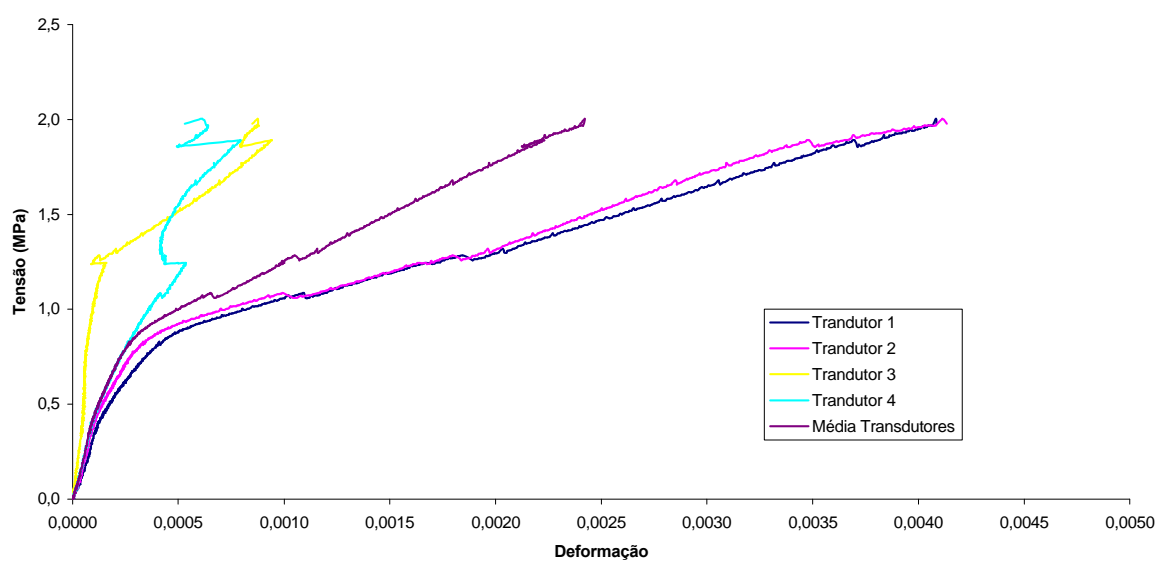


Gráfico Tensão x Deformação PAB2A1E 1 - Parede $\left(E_{x}\right)$

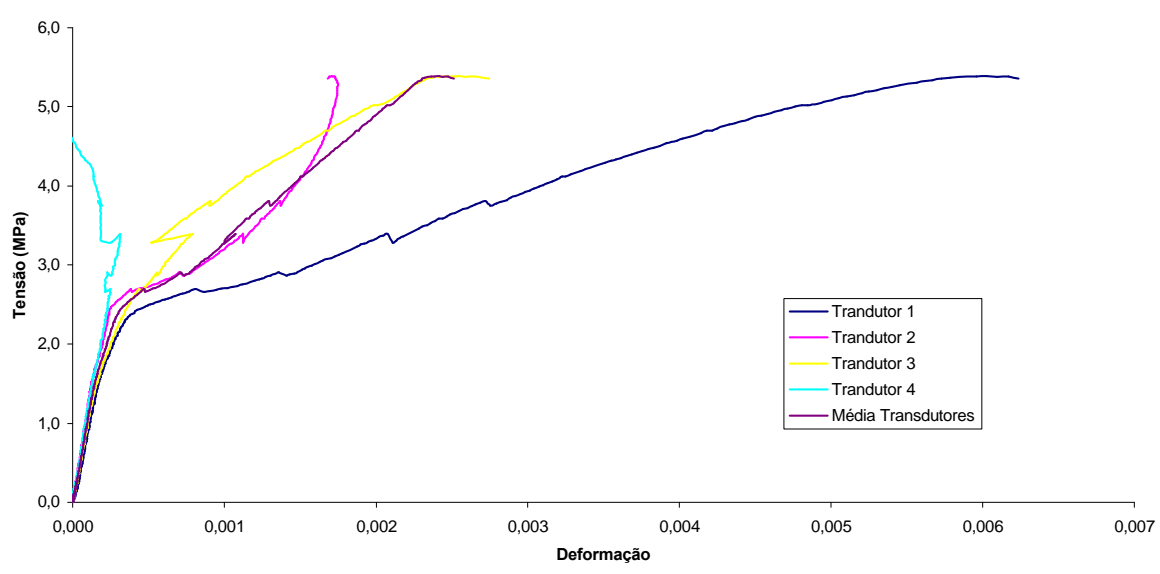

Gráfico Tensão x Deformação PAB2A1E 2 - Parede $\left(E_{x}\right)$

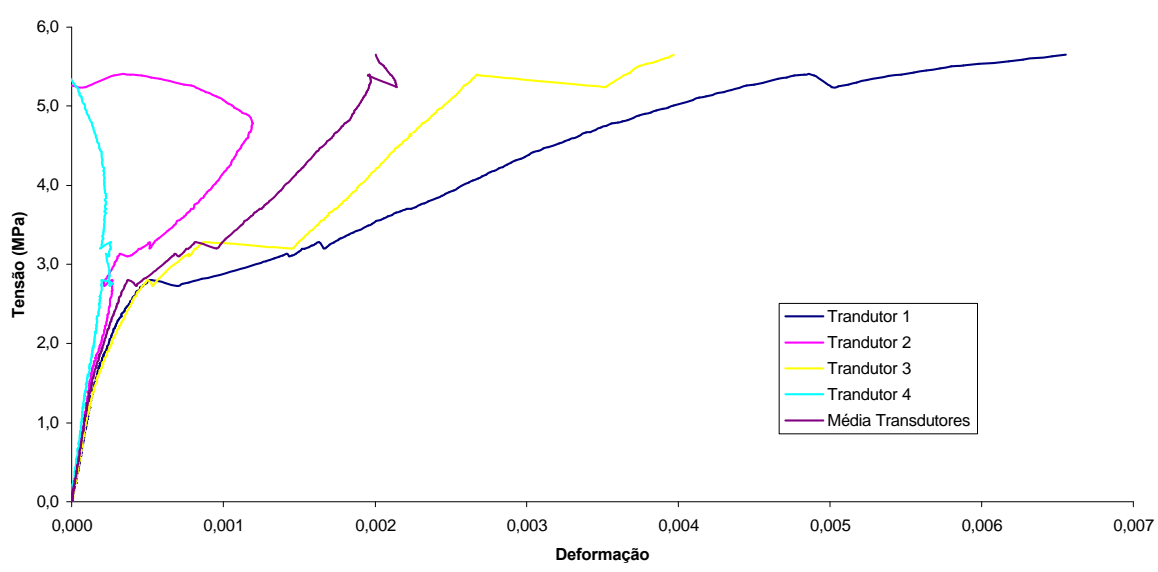

Gráfico Tensão x Deformação PAB2A1E 3 - Parede $\left(E_{x}\right)$

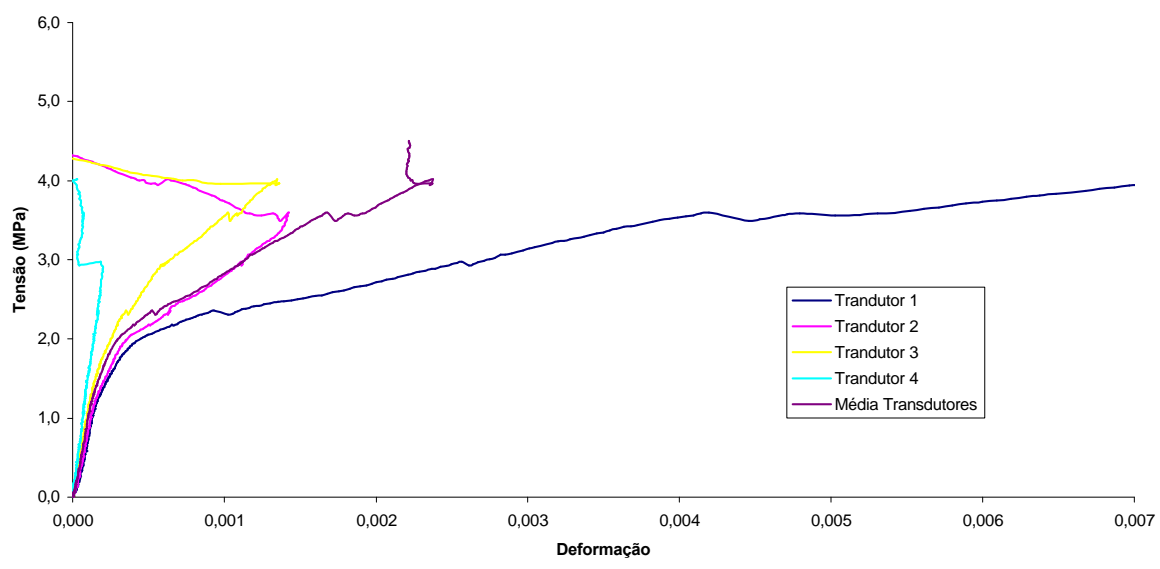


Gráfico Tensão x Deformação PAB2A2E 1 - Parede $\left(E_{x}\right)$

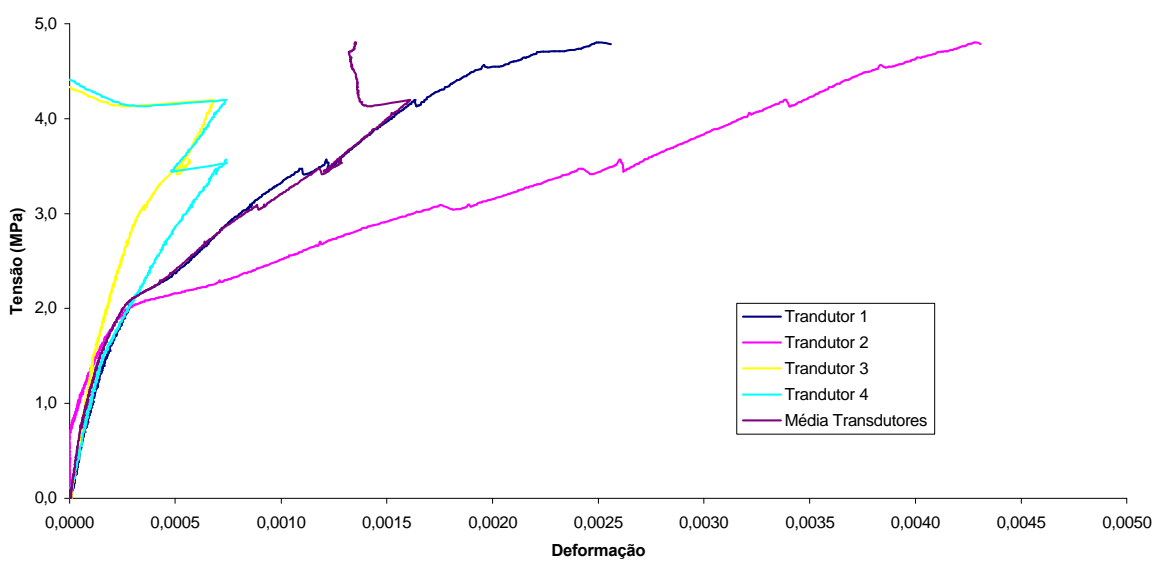

Gráfico Tensão x Deformação PAB2A2 $\mathrm{E}_{\mathrm{x}} 2$ - Parede $\left(\mathrm{E}_{\mathrm{x}}\right)$

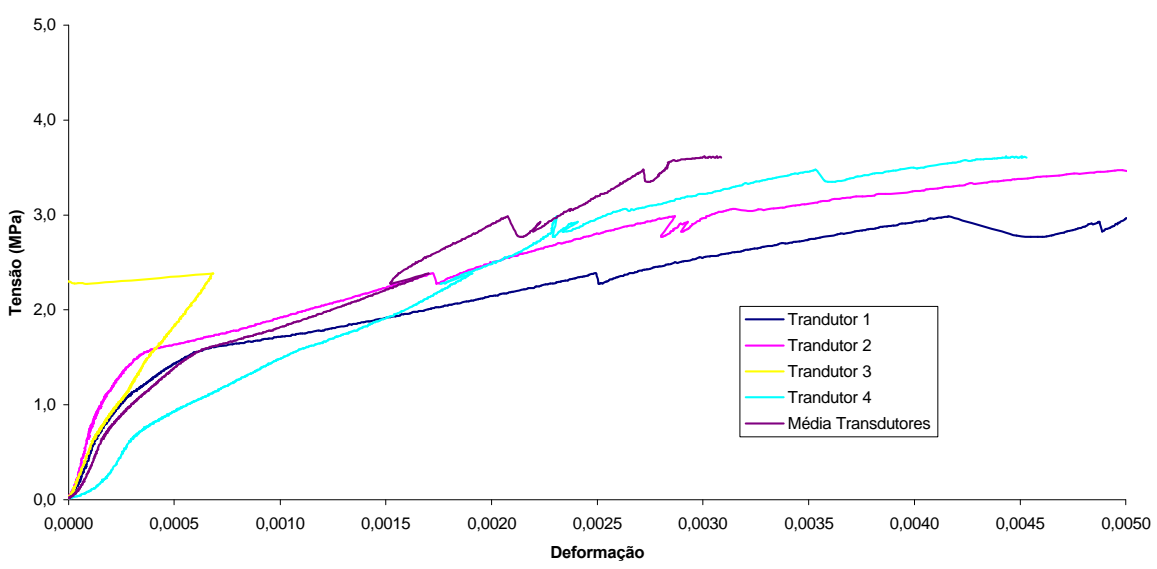

Gráfico Tensão x Deformação PAB2A2E 3 - Parede $\left(E_{x}\right)$

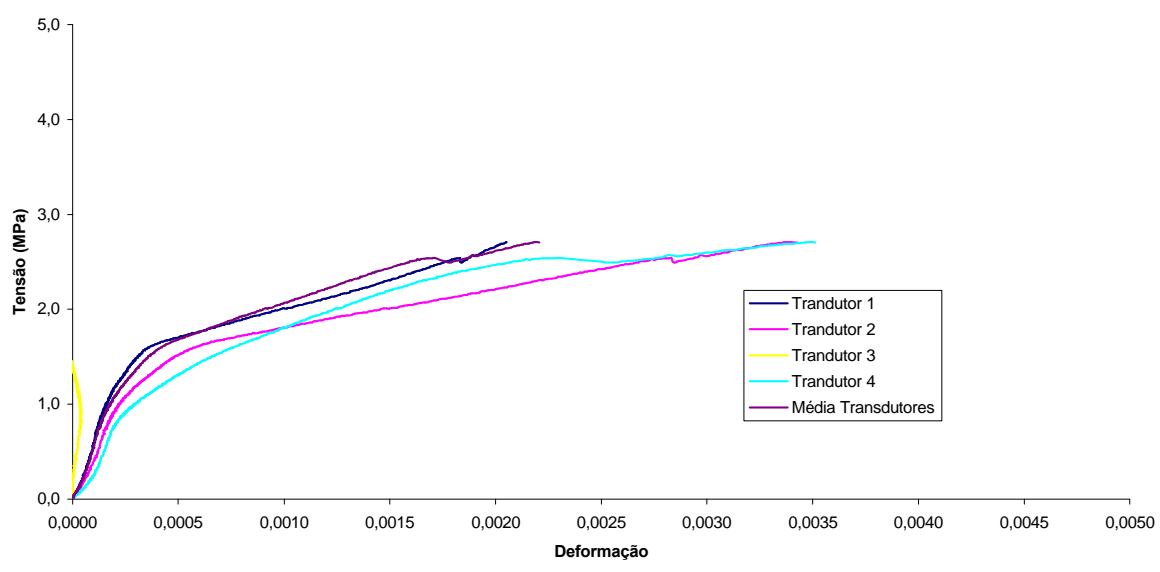




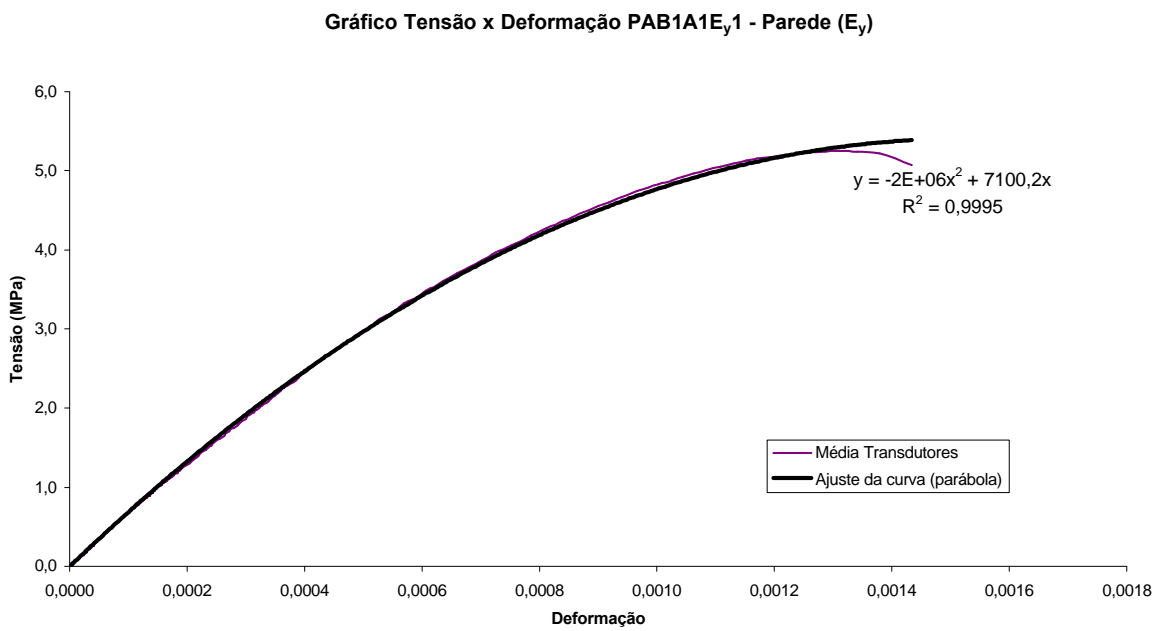

Gráfico Tensão x Deformação PAB1A1E 2 - Parede $\left(E_{y}\right)$

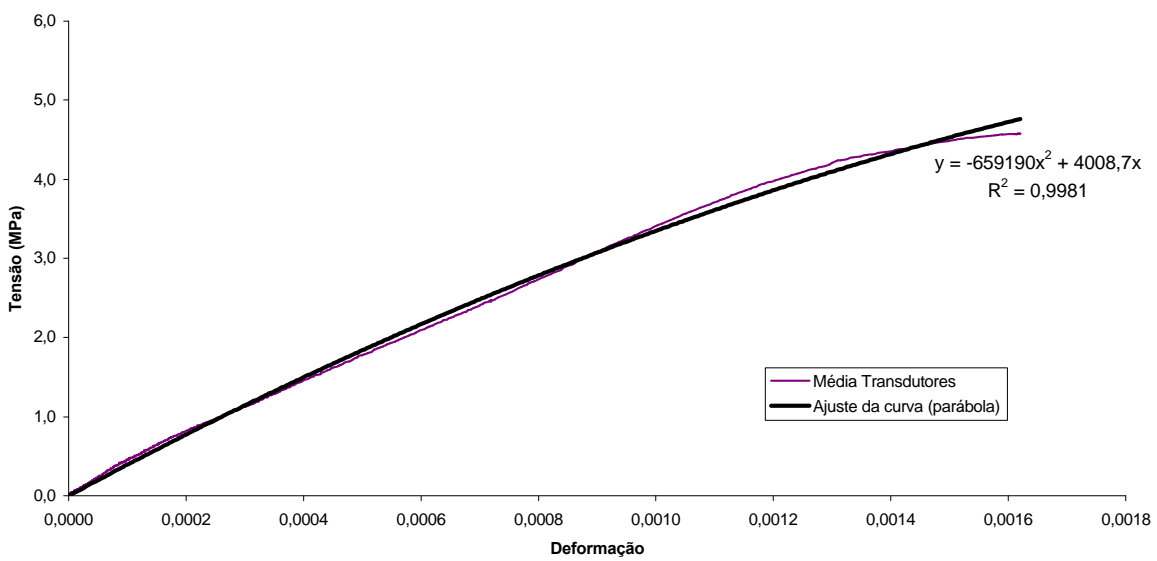

Gráfico Tensão x Deformação PAB1A1E 3 - Parede $\left(E_{\mathrm{y}}\right)$

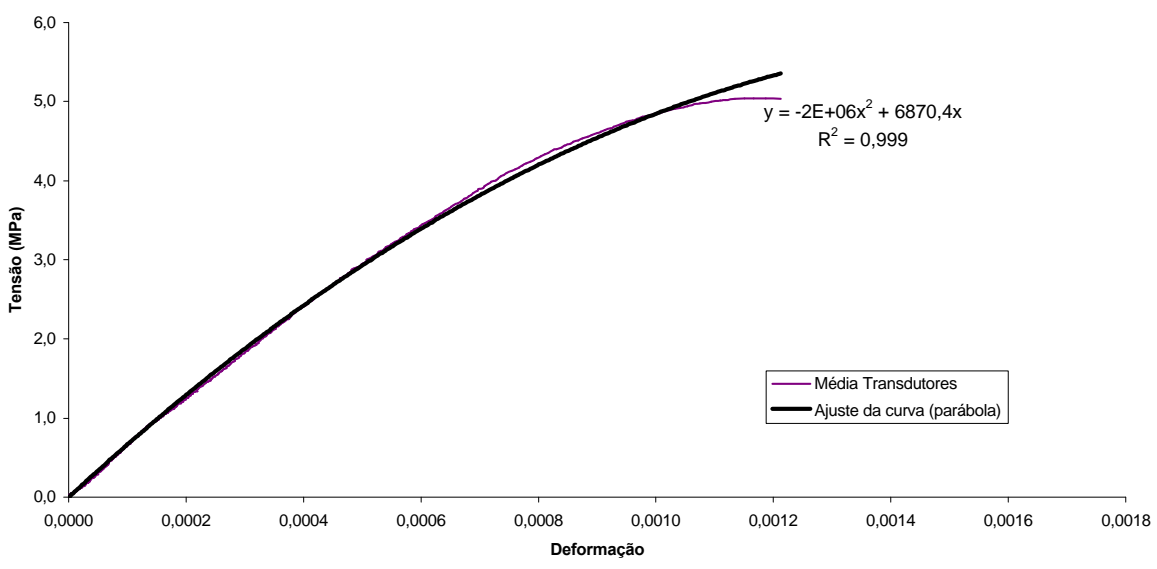




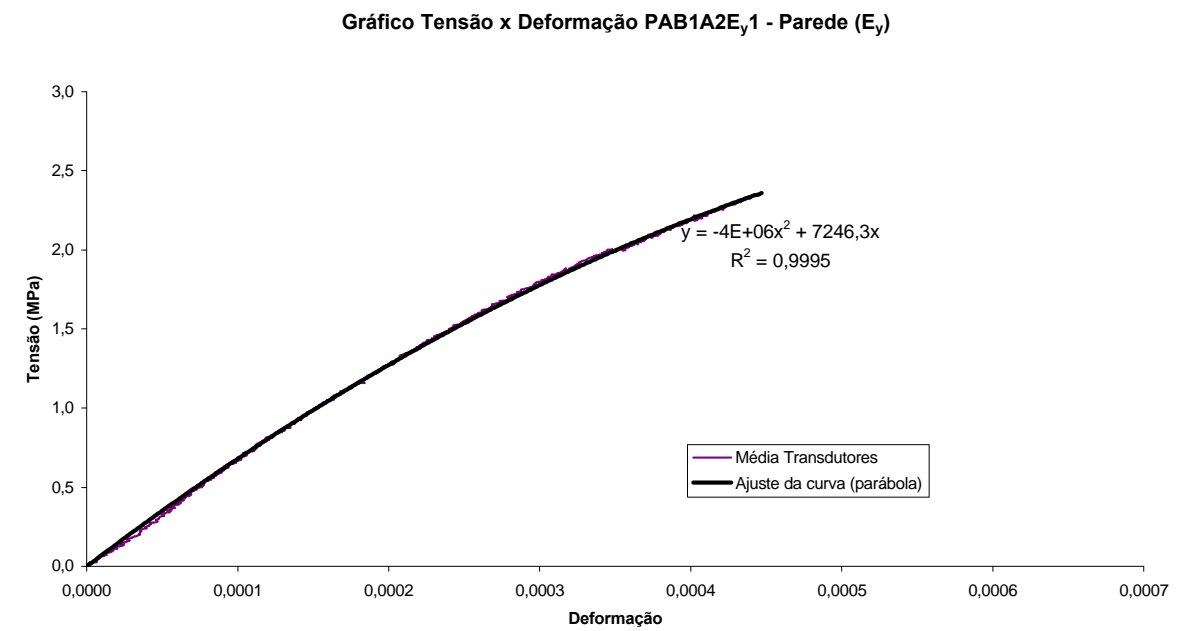

Gráfico Tensão x Deformação PAB1A2E 2 - Parede $\left(E_{y}\right)$

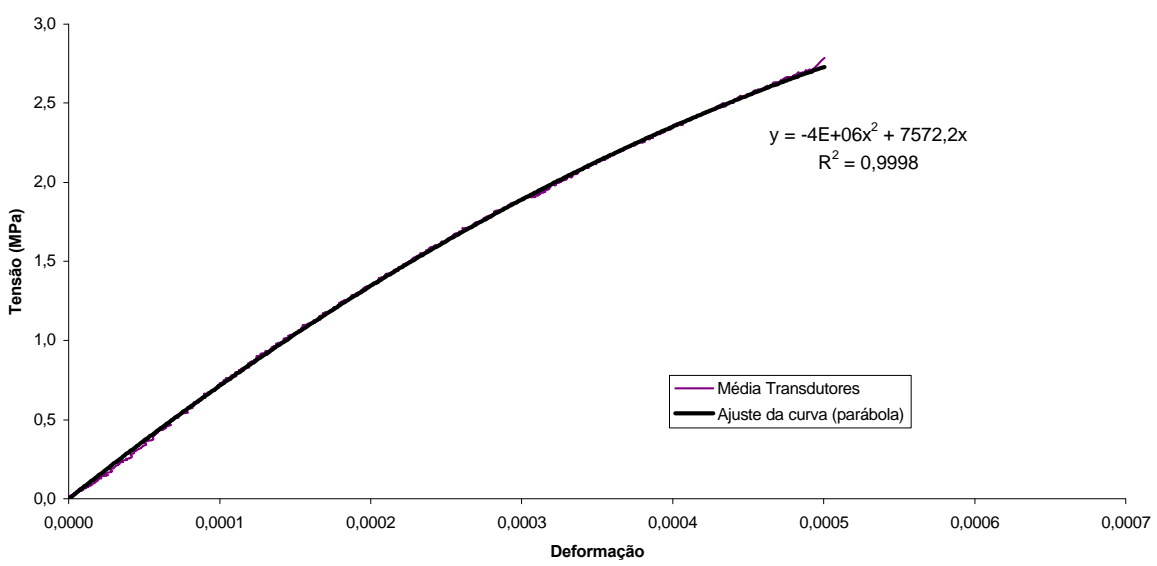

Gráfico Tensão x Deformação PAB1A2E 3 - Parede $\left(E_{y}\right)$

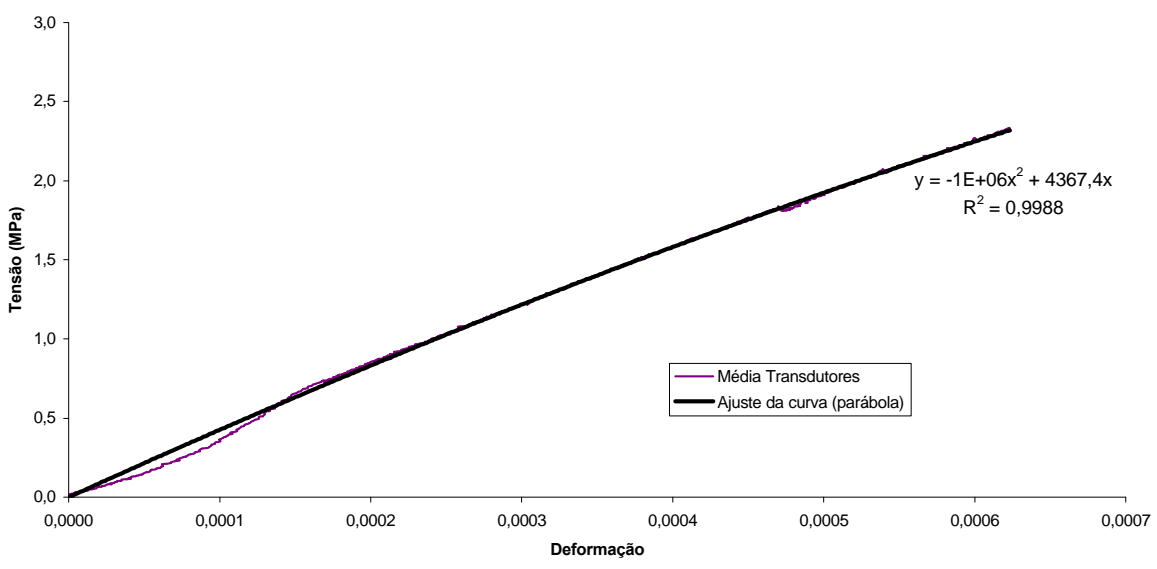




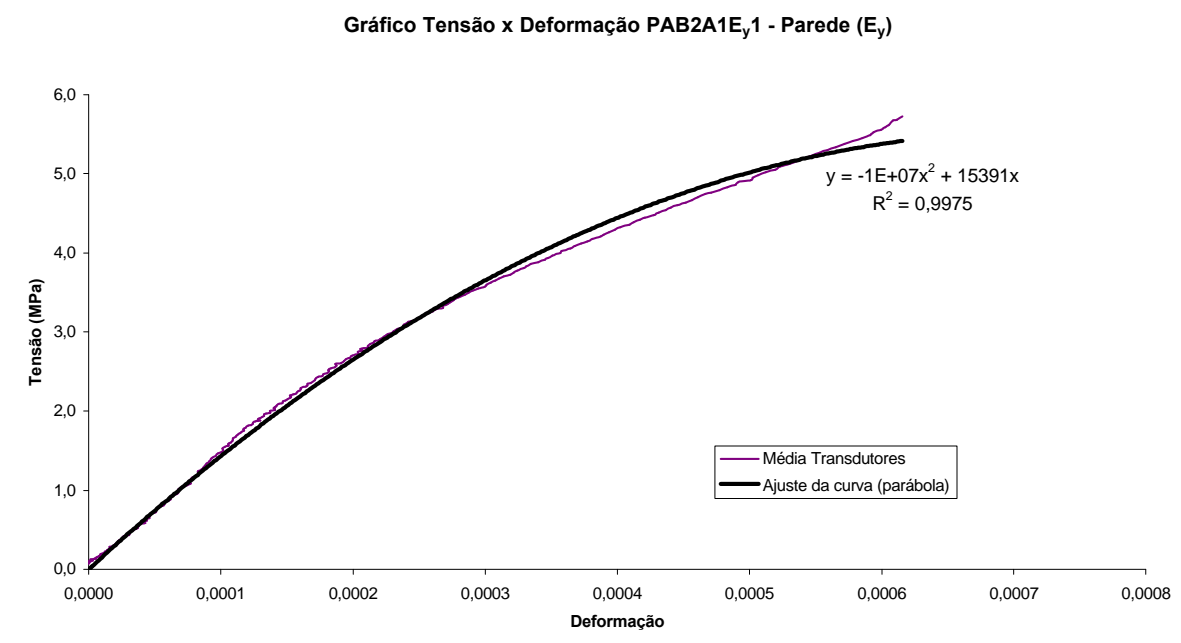

Gráfico Tensão x Deformação PAB1A2E 2 - Parede $\left(E_{y}\right)$

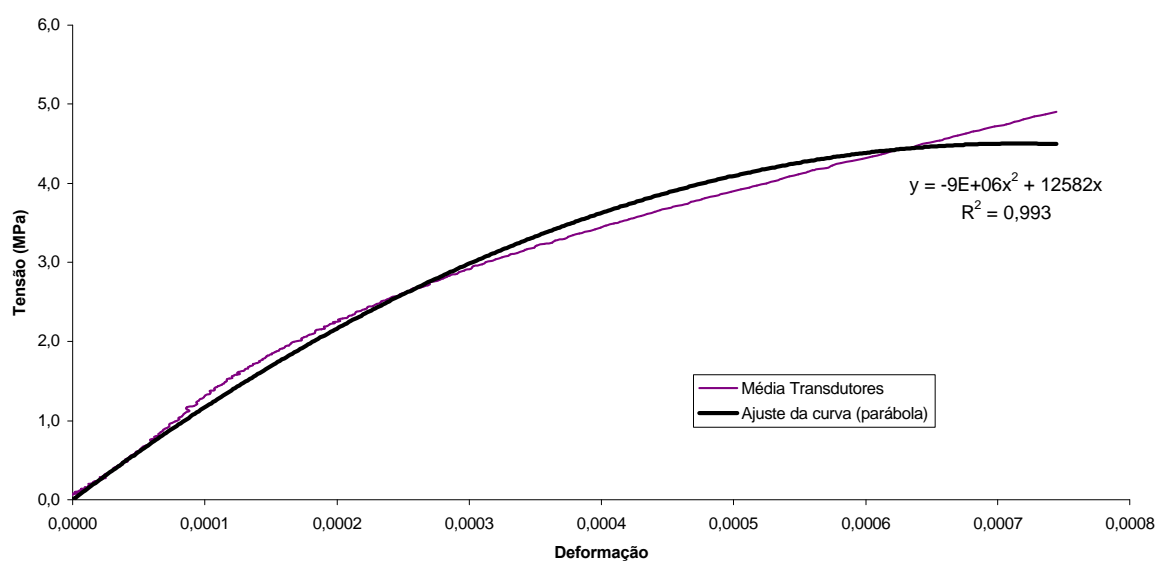

Gráfico Tensão x Deformação PAB2A1E 3 - Parede $\left(E_{y}\right)$

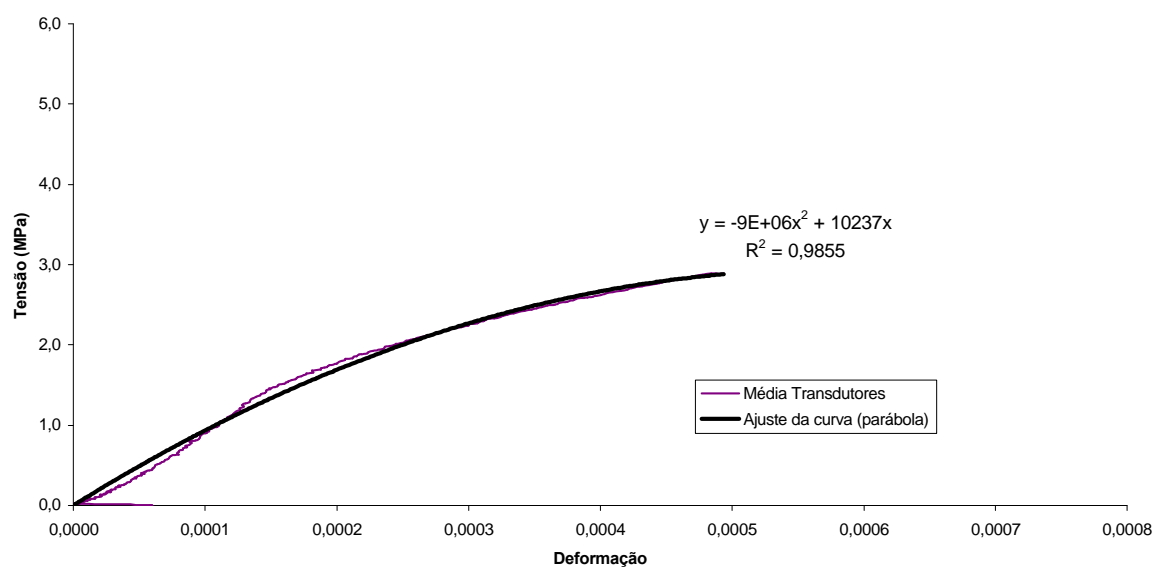


Gráfico Tensão x Deformação PAB2A2E 2 - Parede $\left(E_{y}\right)$

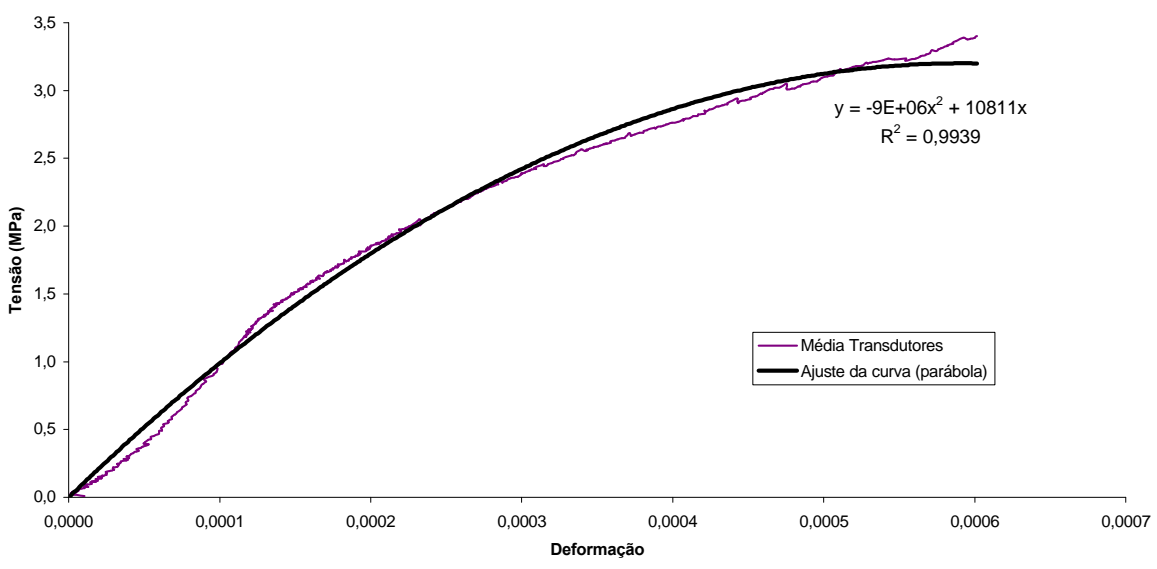


Gráfico Tensão x Deformação PAB1A1E 1 - Parede $\left(E_{x}\right)$

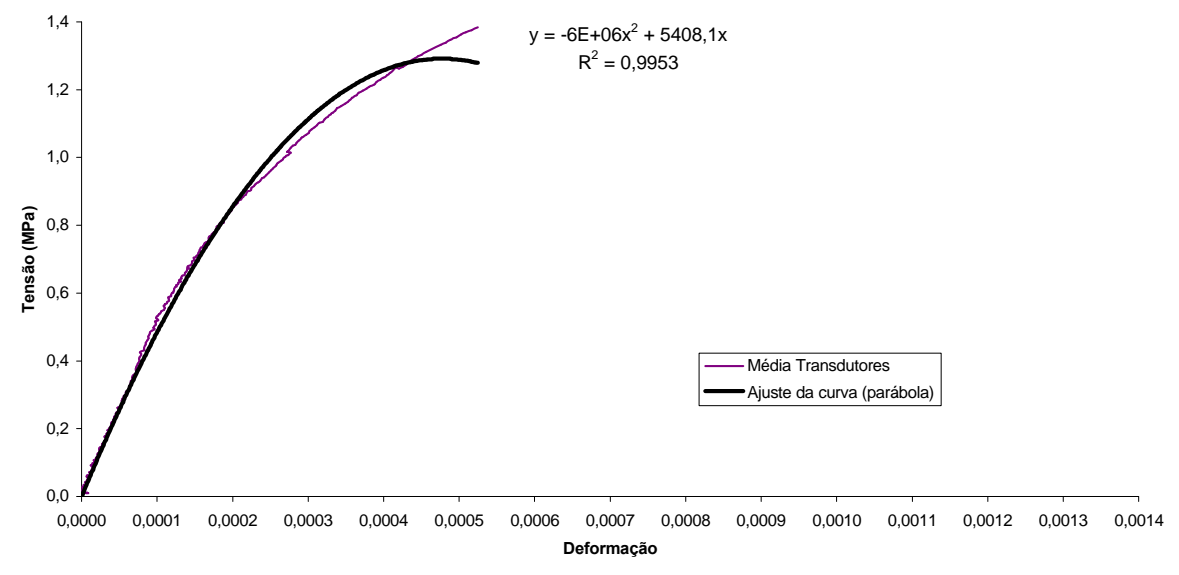

ç

Gráfico Tensão x Deformação PAB1A1E 2 - Parede $\left(E_{x}\right)$

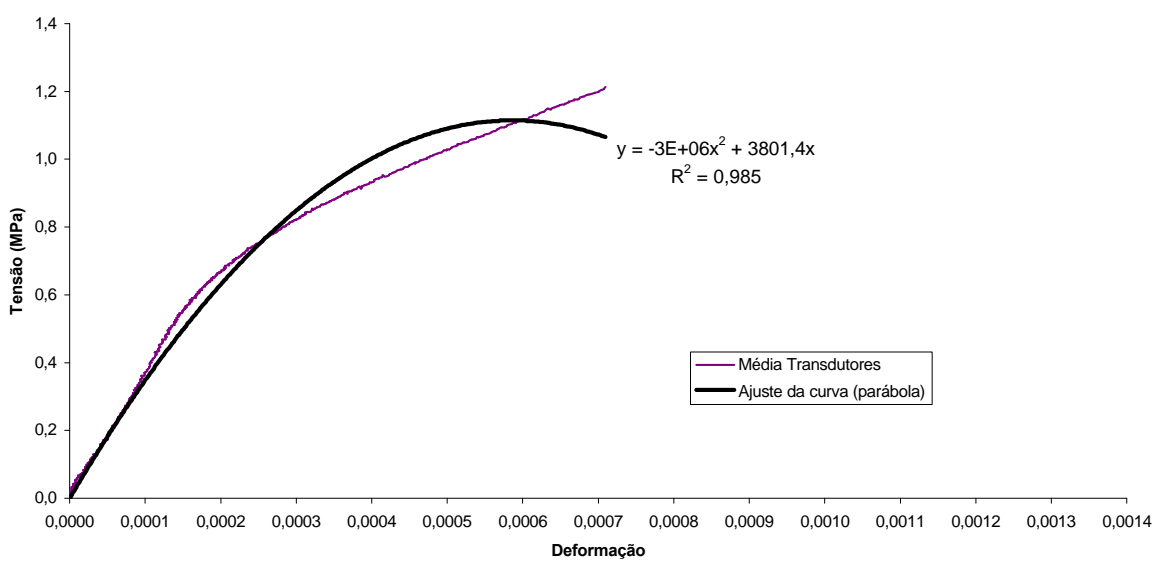

Gráfico Tensão x Deformação PAB1A1E 3 - Parede $\left(E_{x}\right)$

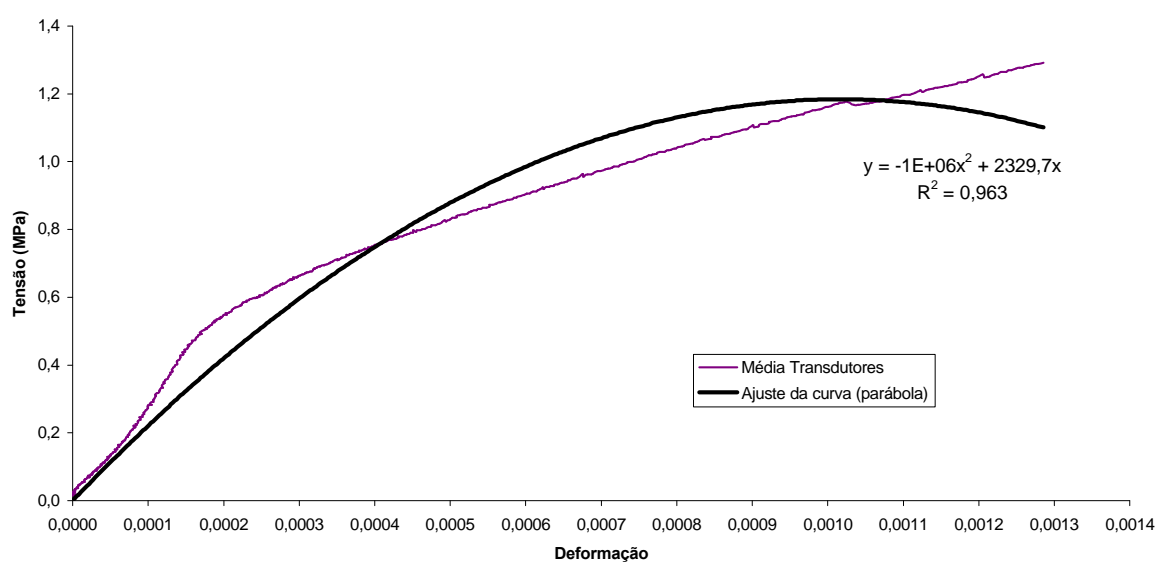


Gráfico Tensão x Deformação PAB1A2E 1 - Parede $\left(E_{x}\right)$

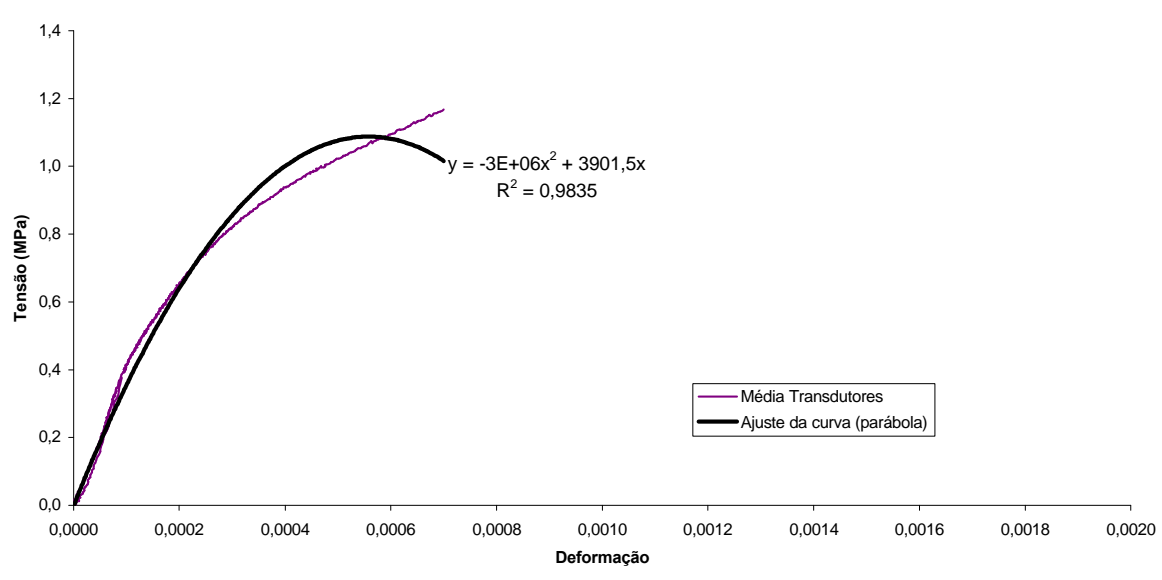

Gráfico Tensão x Deformação PAB1A2E 2 - Parede $\left(E_{x}\right)$

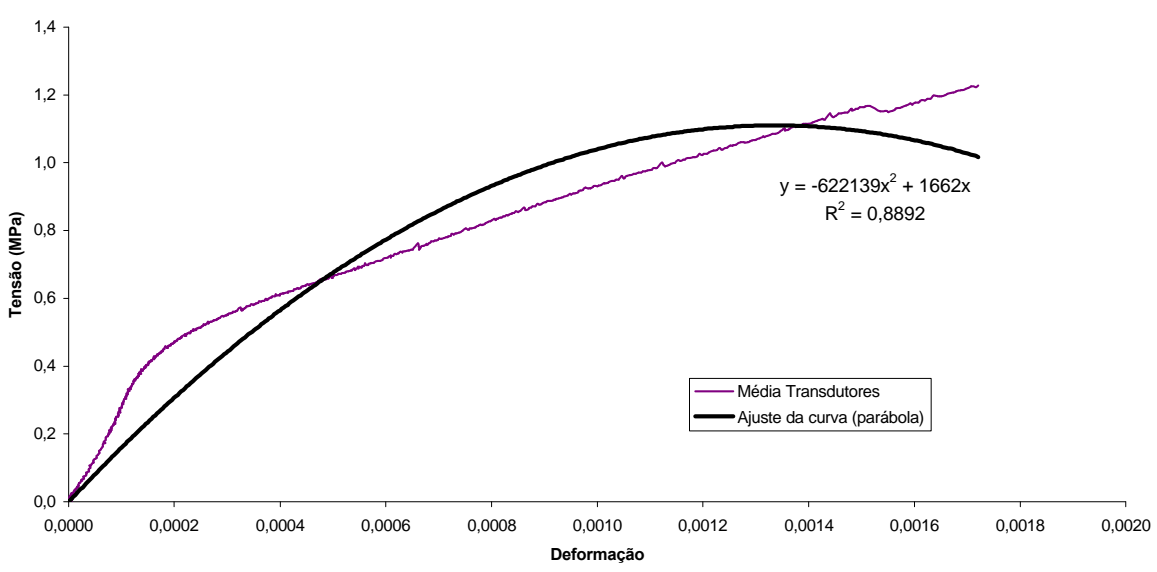

Gráfico Tensão x Deformação PAB1A2E 3 - Parede $\left(E_{x}\right)$

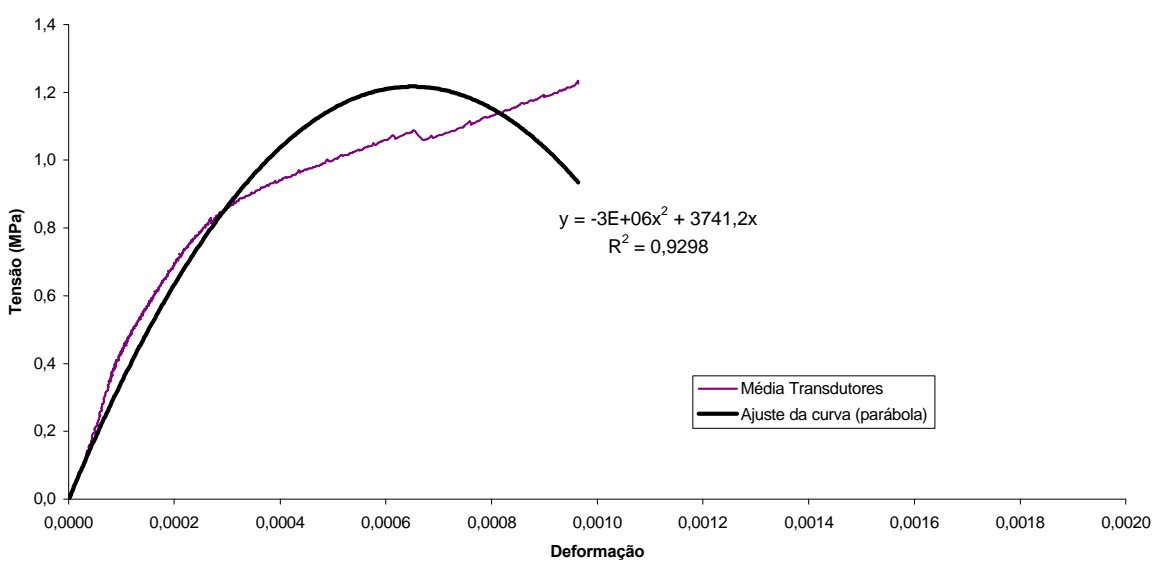


Gráfico Tensão x Deformação PAB2A1E 1 - Parede $\left(E_{x}\right)$

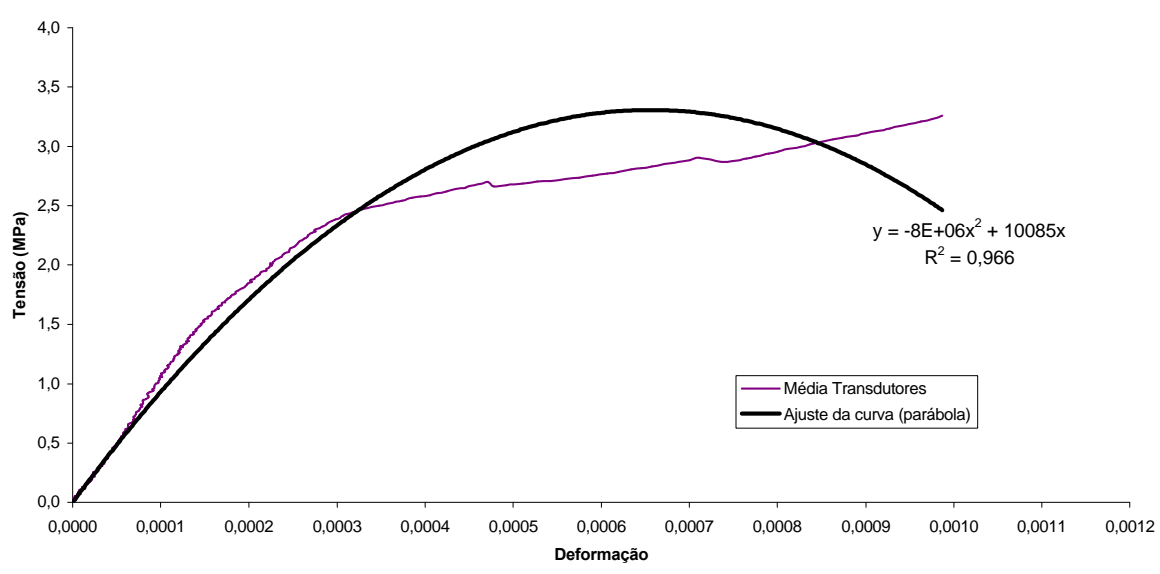

Gráfico Tensão x Deformação PAB2A1E ${ }_{\mathrm{x}} 2$ - Parede $\left(E_{\mathrm{x}}\right)$

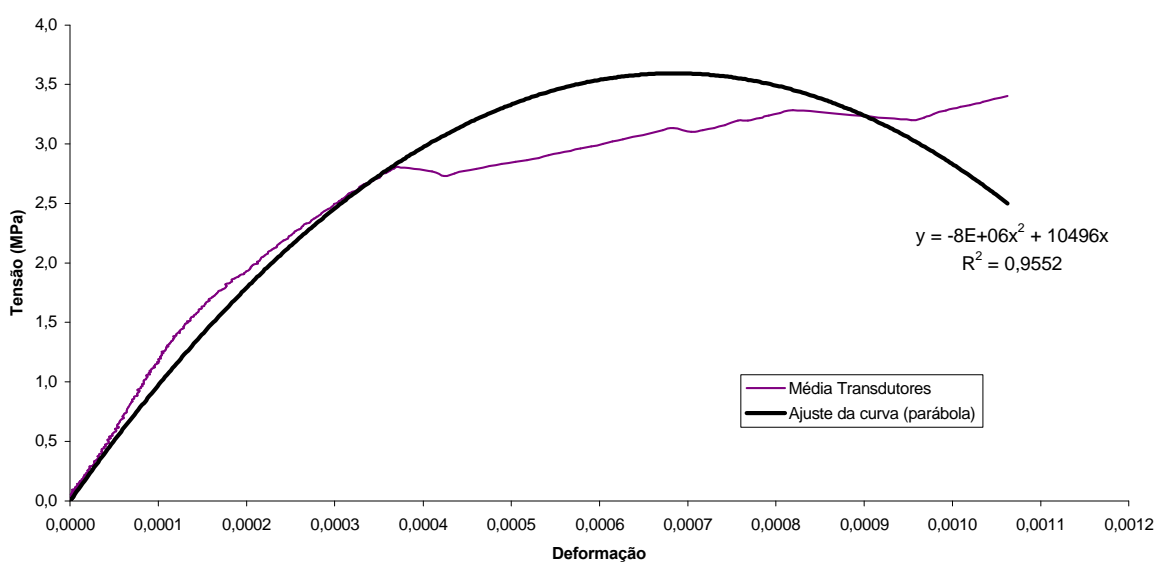

Gráfico Tensão x Deformação PAB2A1E 3 - Parede $\left(E_{x}\right)$

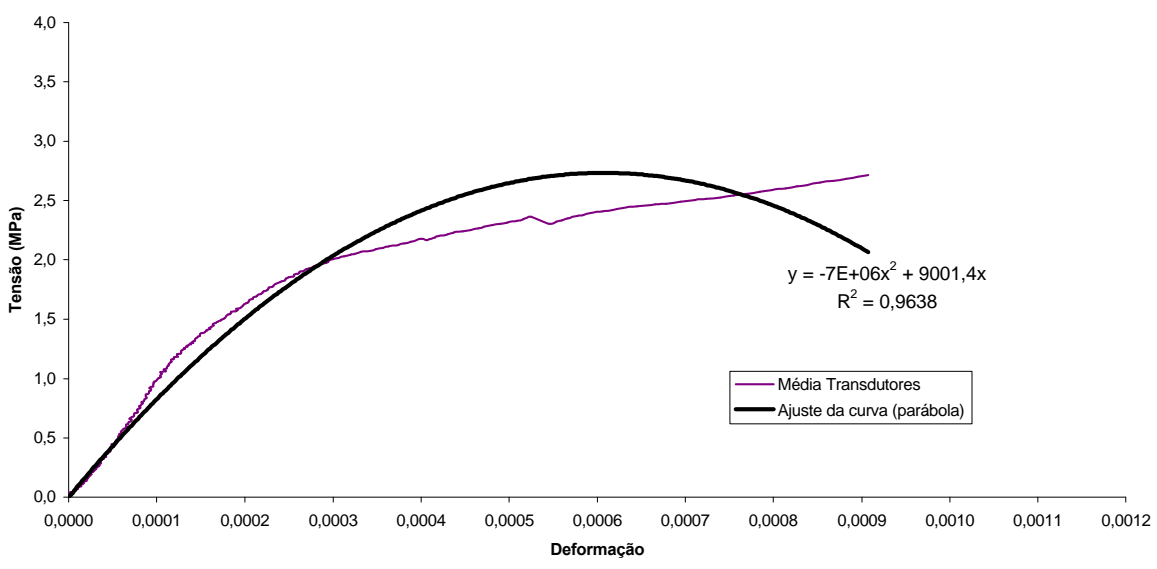


Gráfico Tensão x Deformação PAB2A2E 1 - Parede $\left(E_{x}\right)$

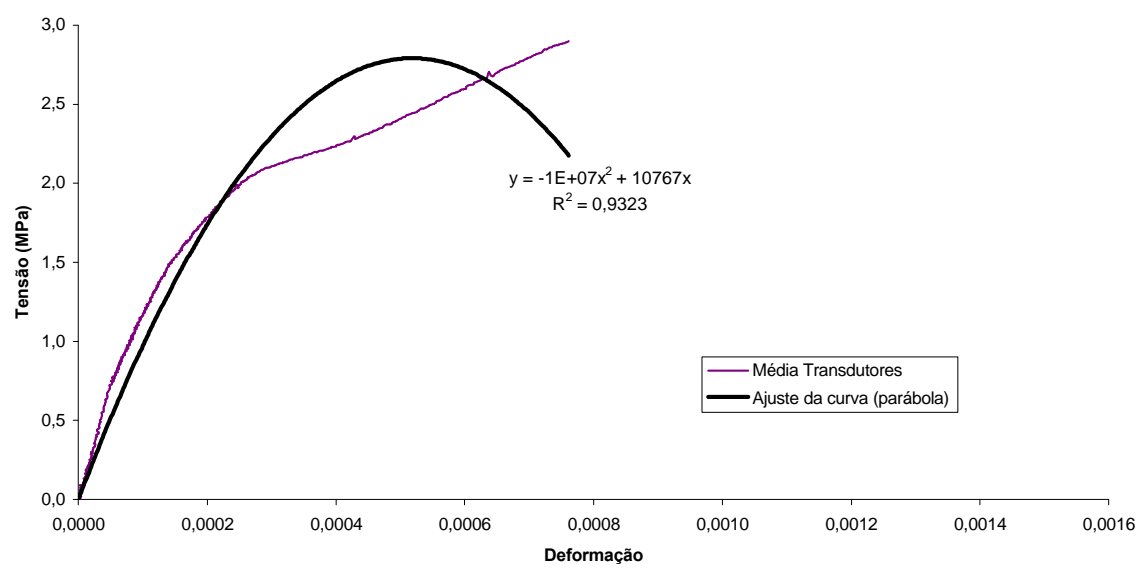

Gráfico Tensão x Deformação PAB2A2E 2 - Parede $\left(E_{x}\right)$

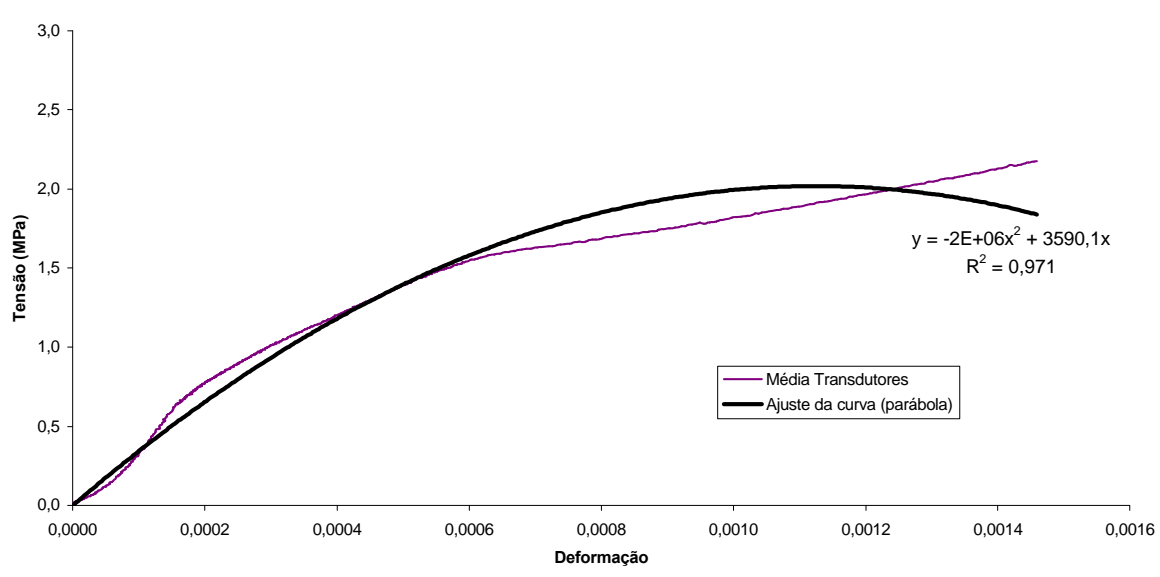

Gráfico Tensão x Deformação PAB2A2E 3 - Parede $\left(E_{x}\right)$

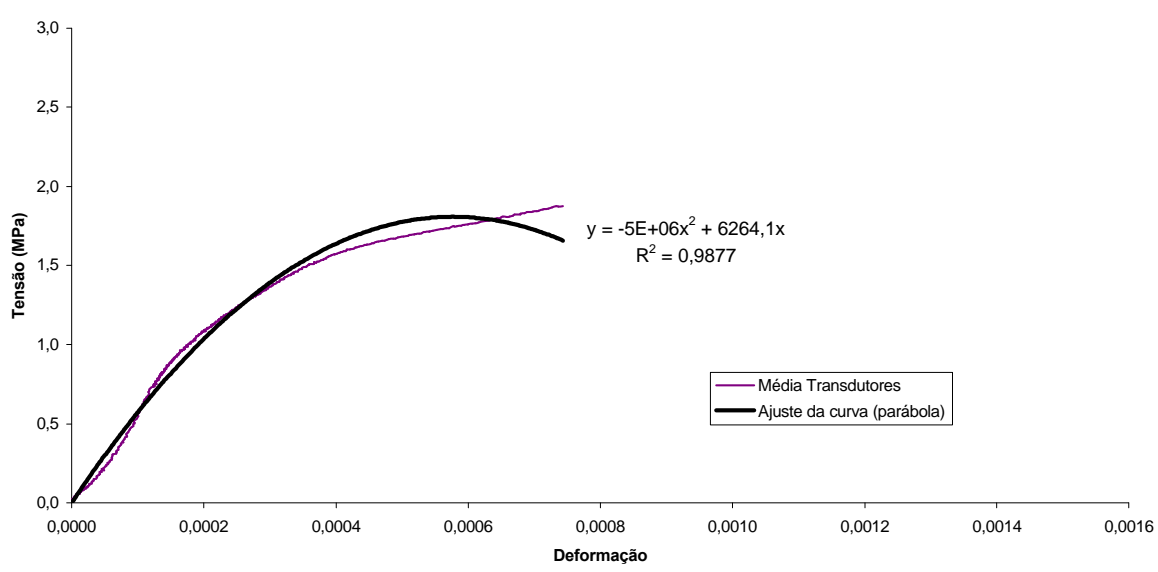




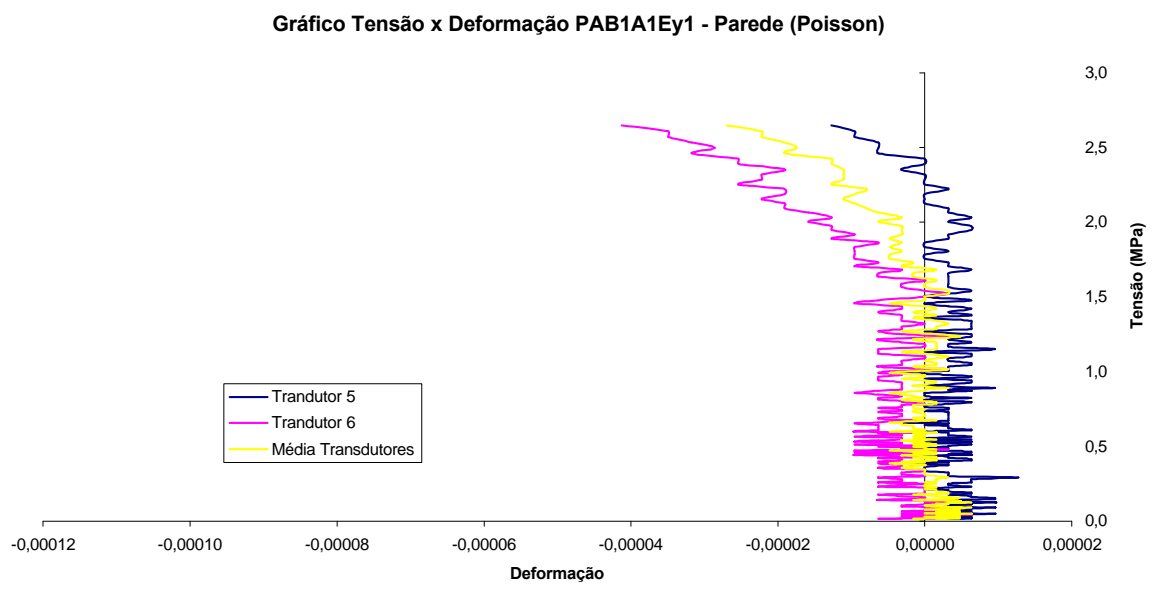

Gráfico Tensão x Deformação PAB1A1Ey2 - Parede (Poisson)

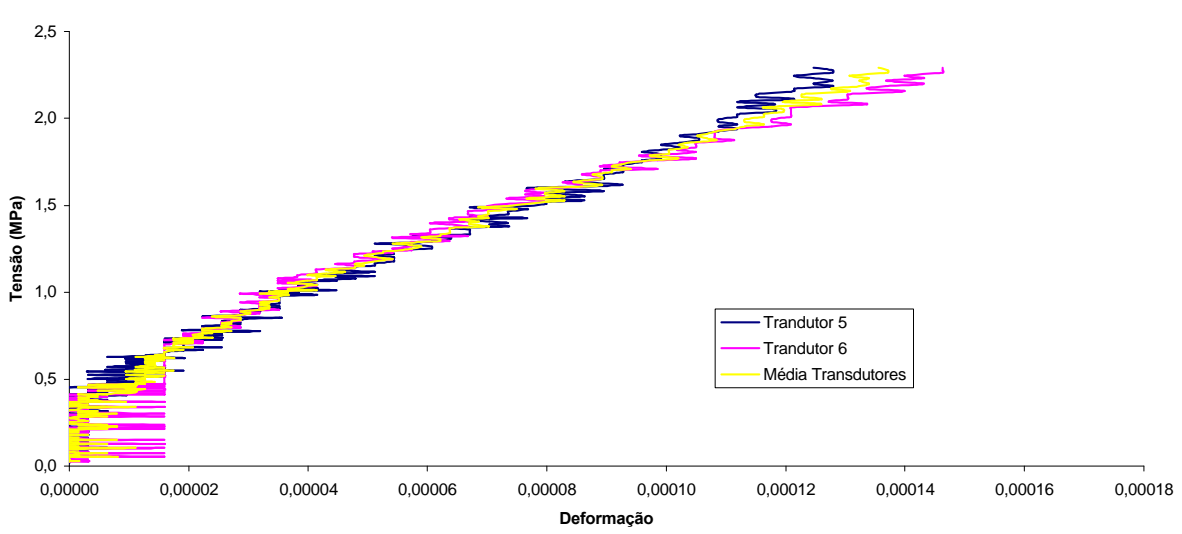

Gráfico Tensão x Deformação PAB1A1Ey3 - Parede (Poisson)

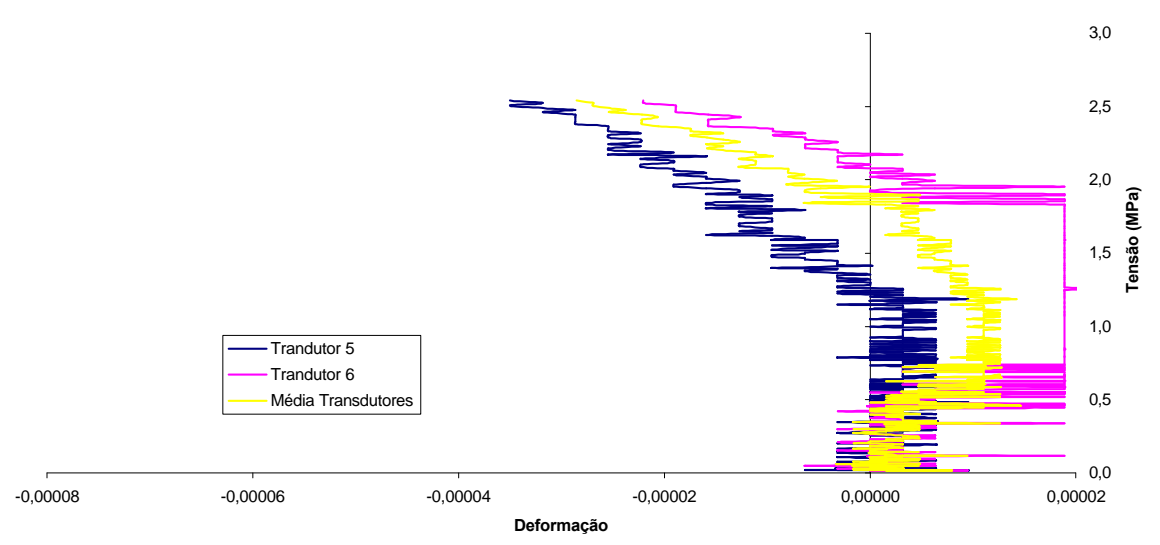




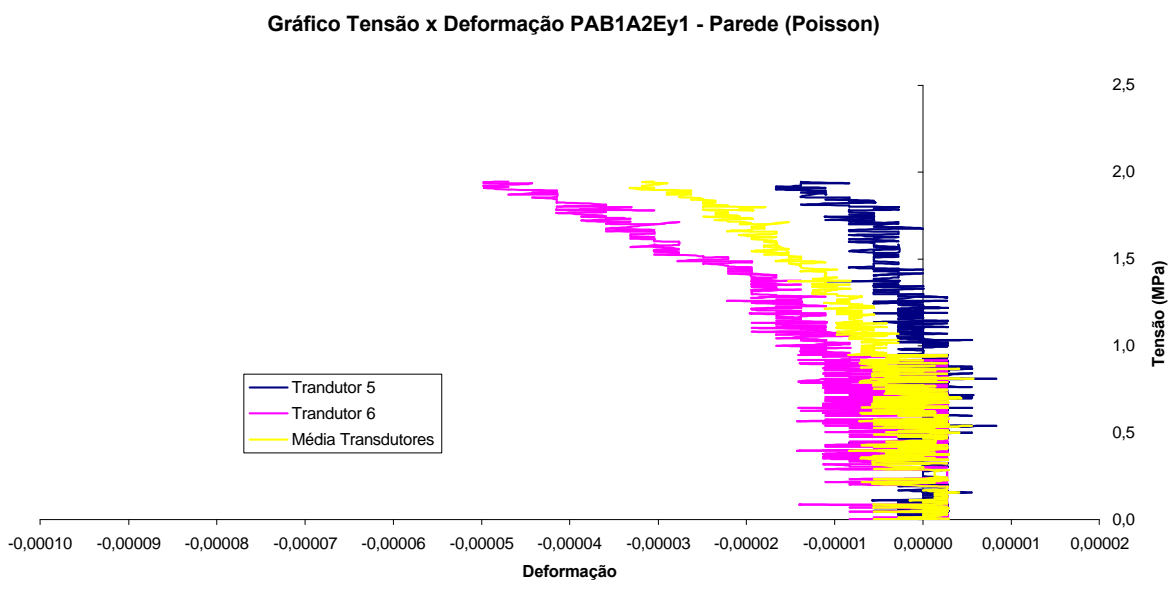

Gráfico Tensão x Deformação PAB1A2Ey2 - Parede (Poisson)
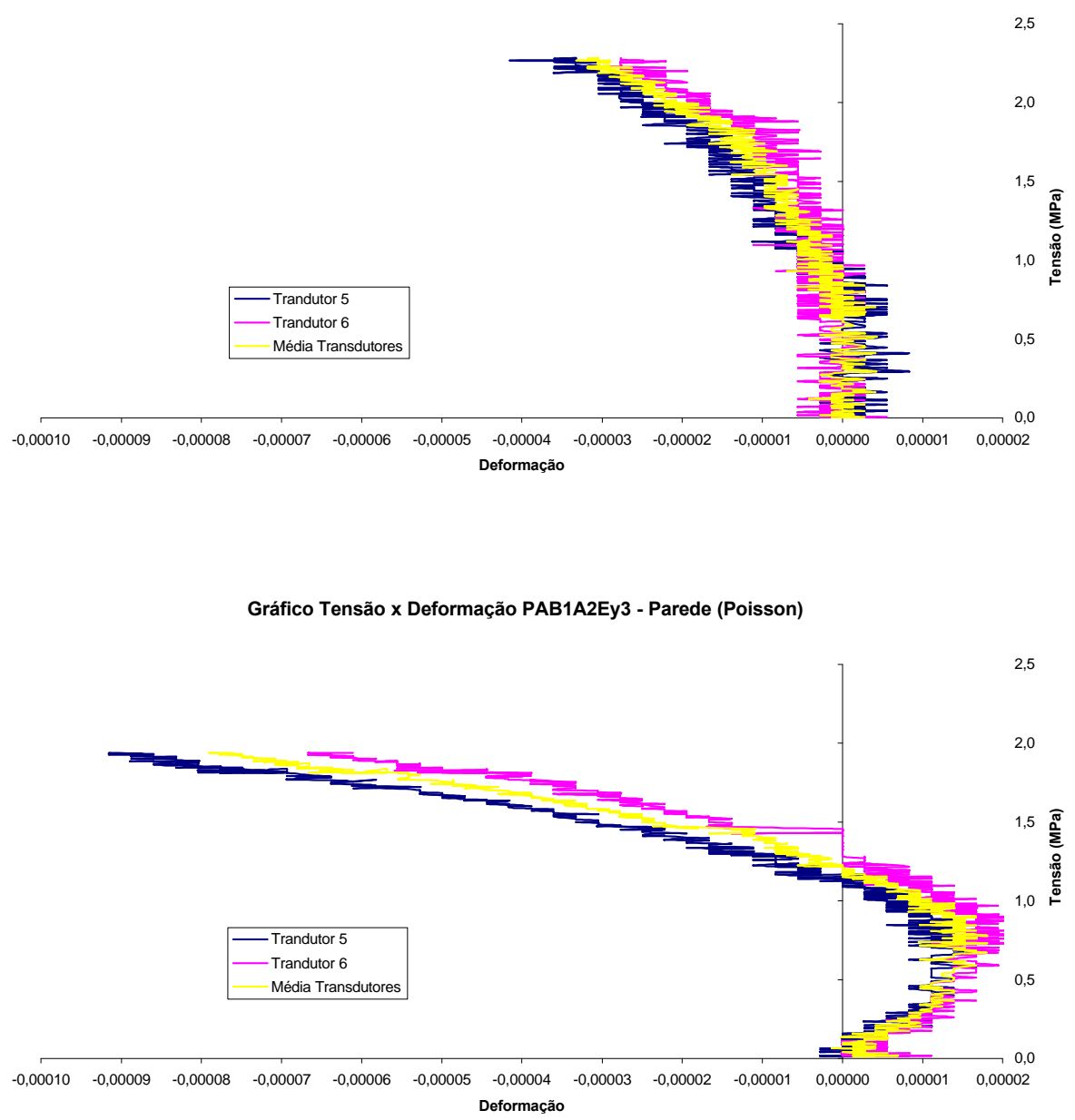

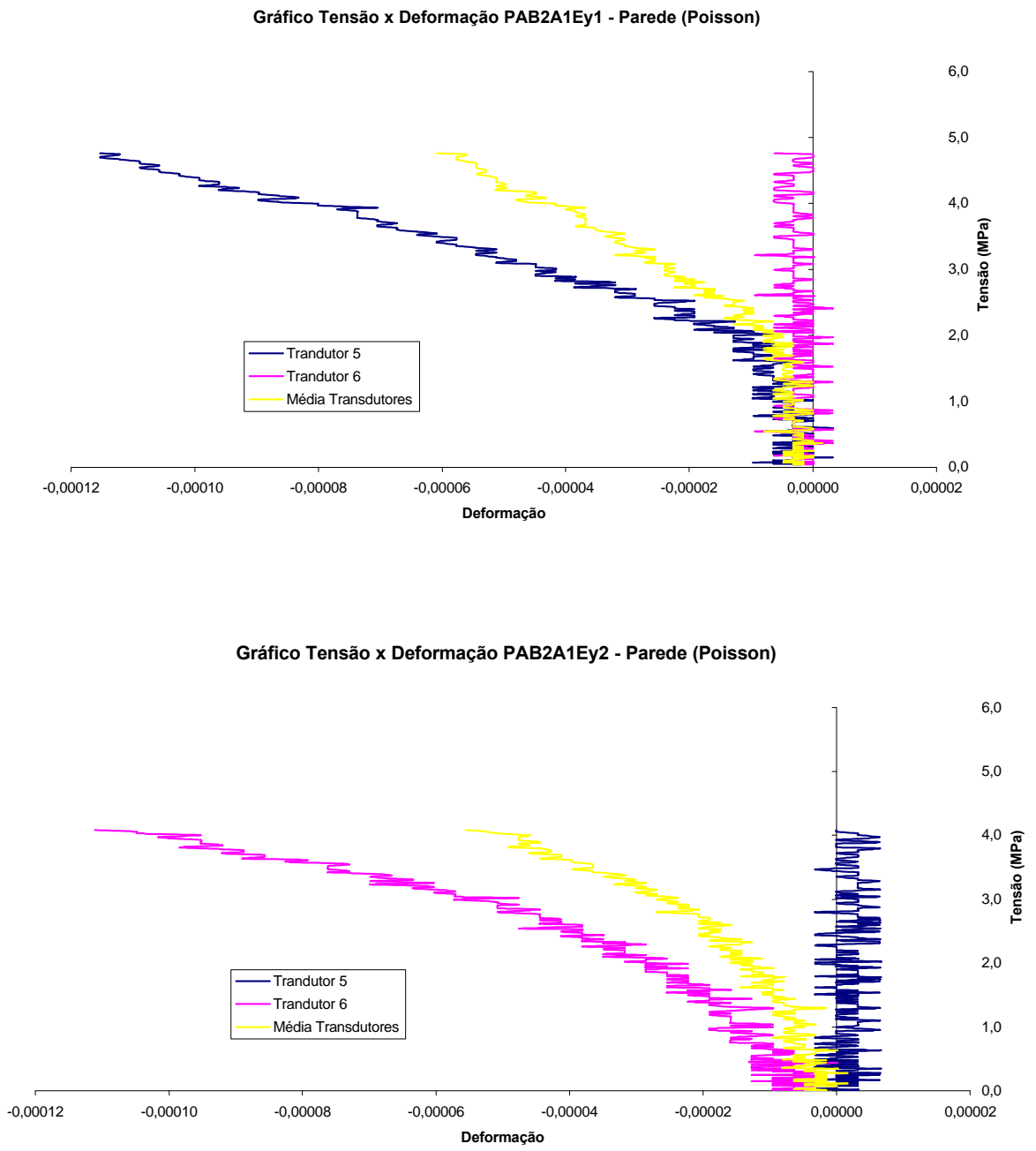

Gráfico Tensão x Deformação PAB2A1Ey3 - Parede (Poisson)

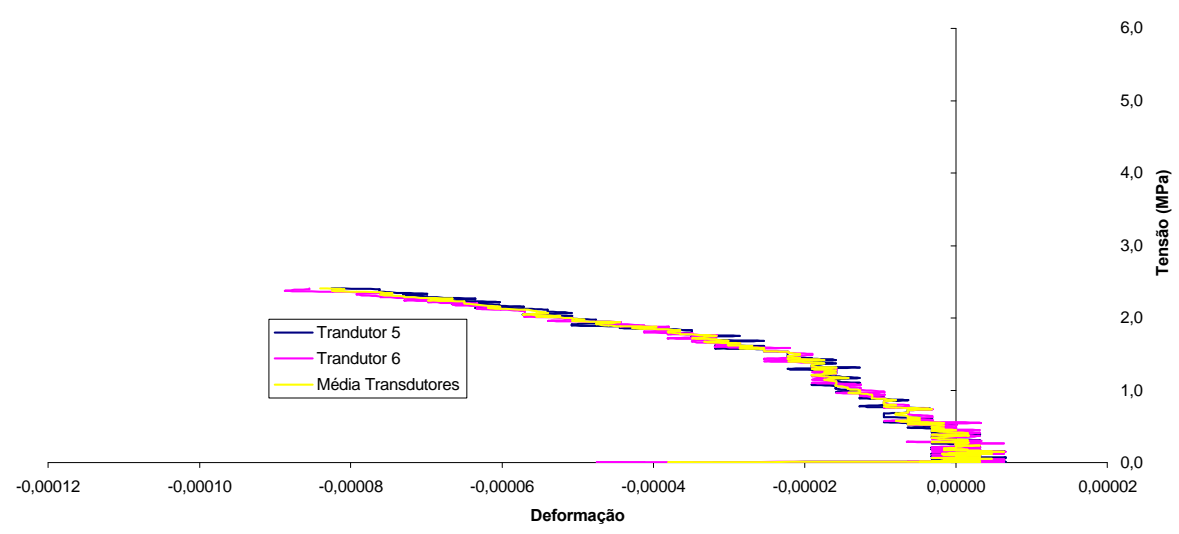




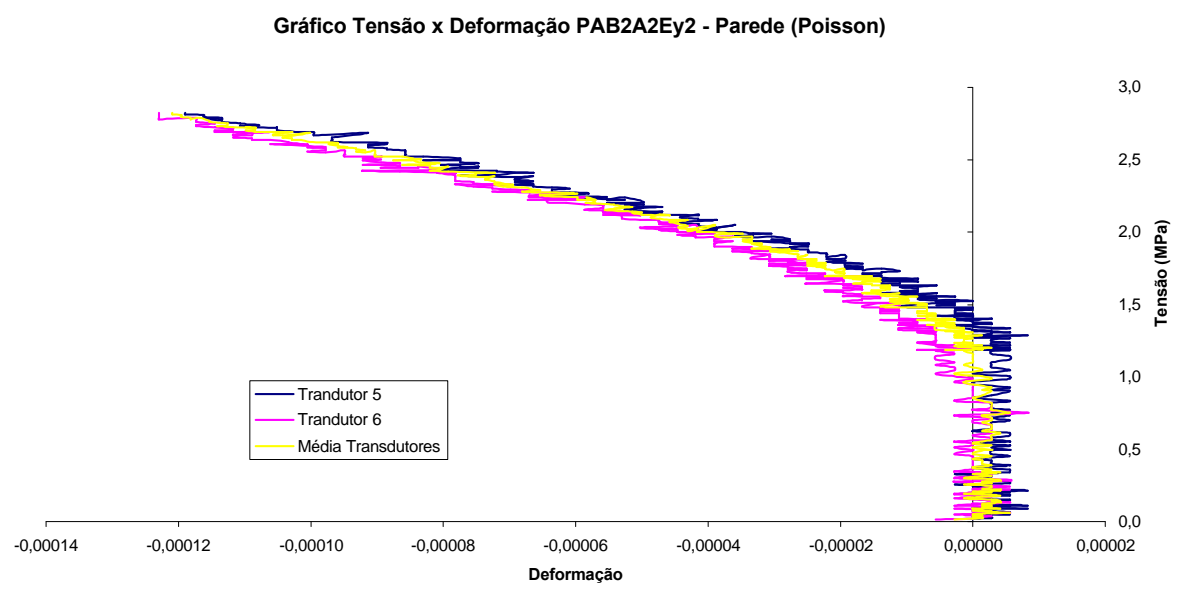




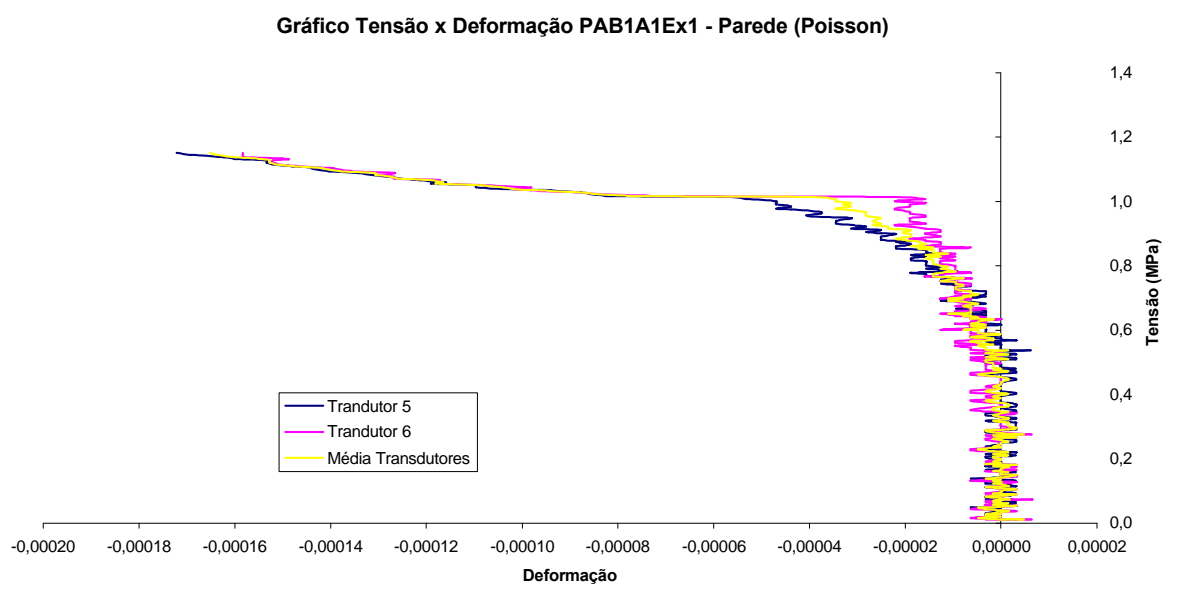

Gráfico Tensão x Deformação PAB1A1Ex2 - Parede (Poisson)

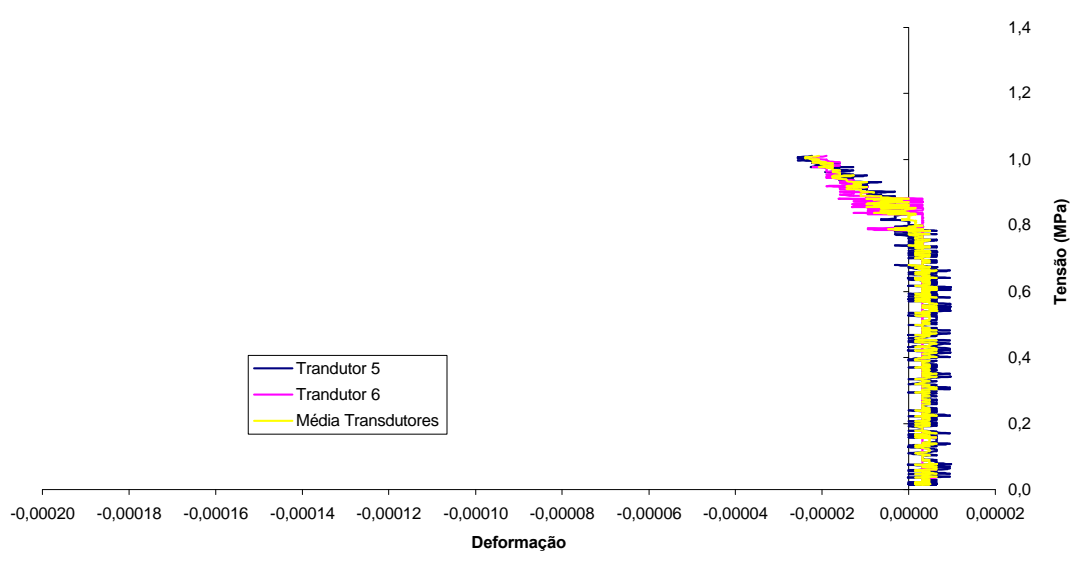

Gráfico Tensão x Deformação PAB1A1Ex3 - Parede (Poisson)

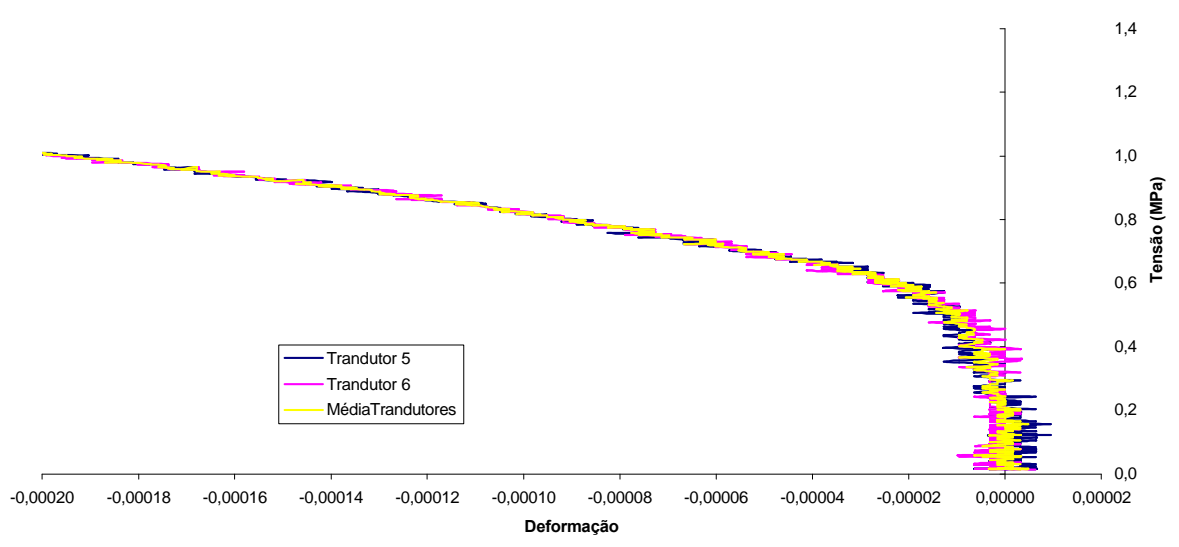



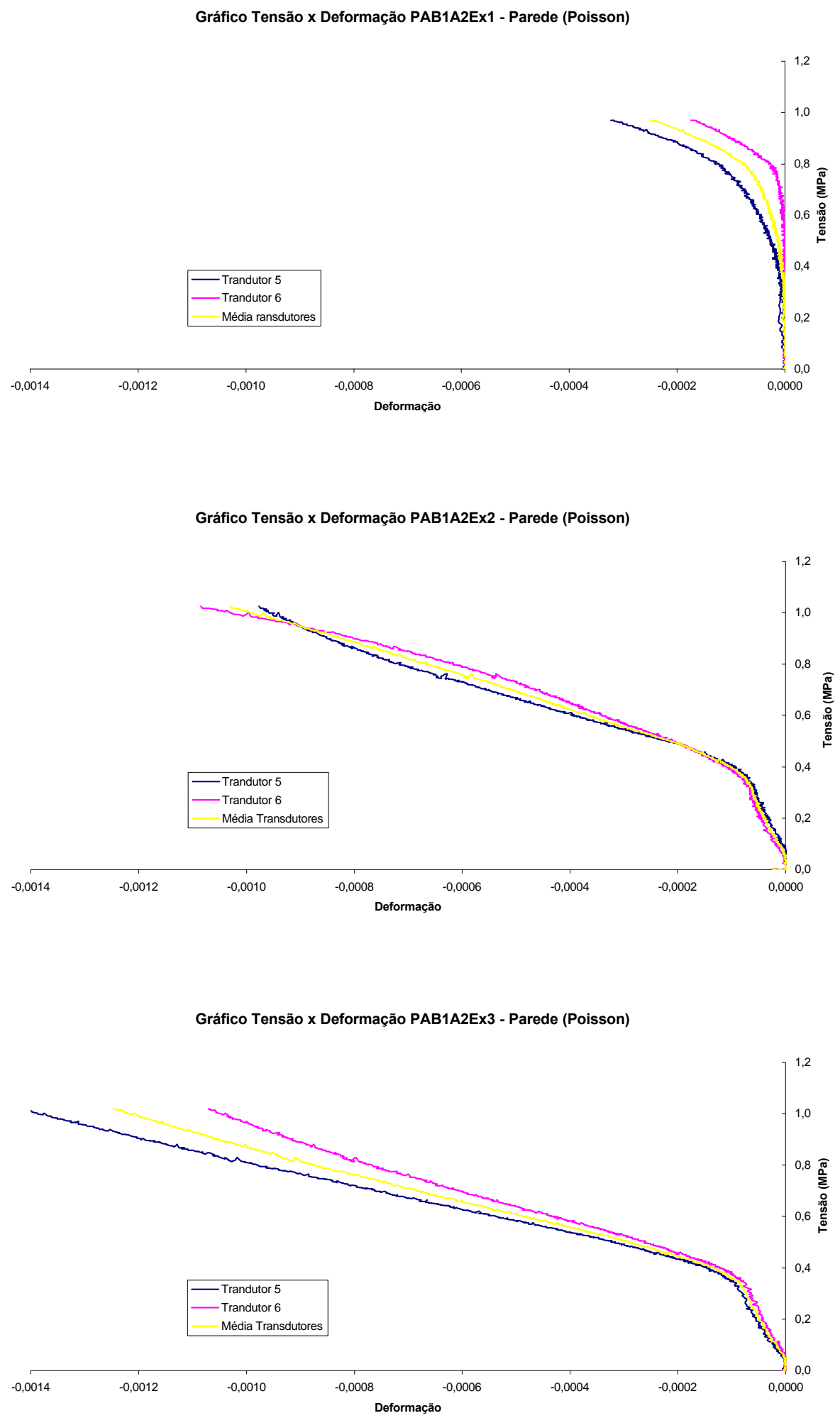

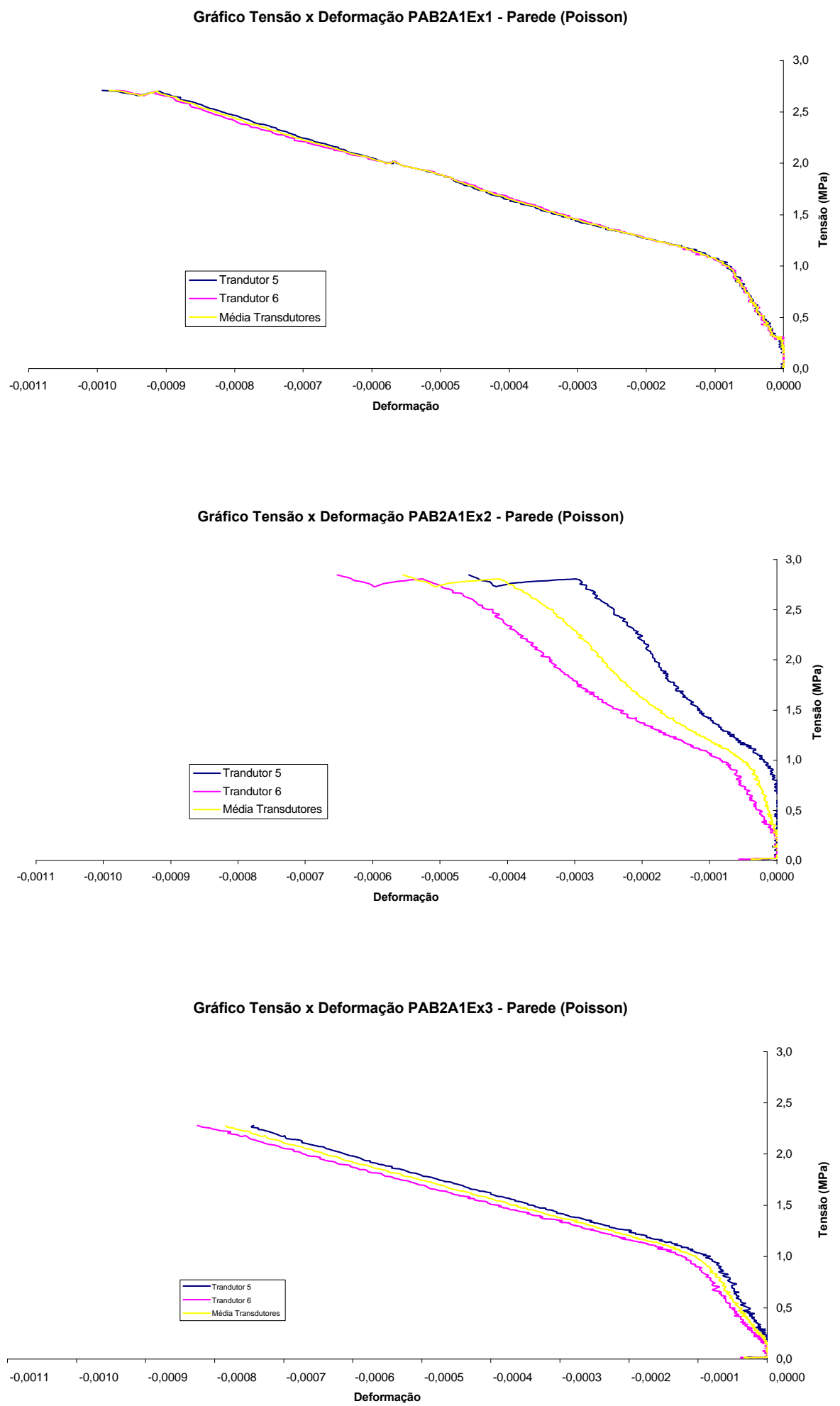


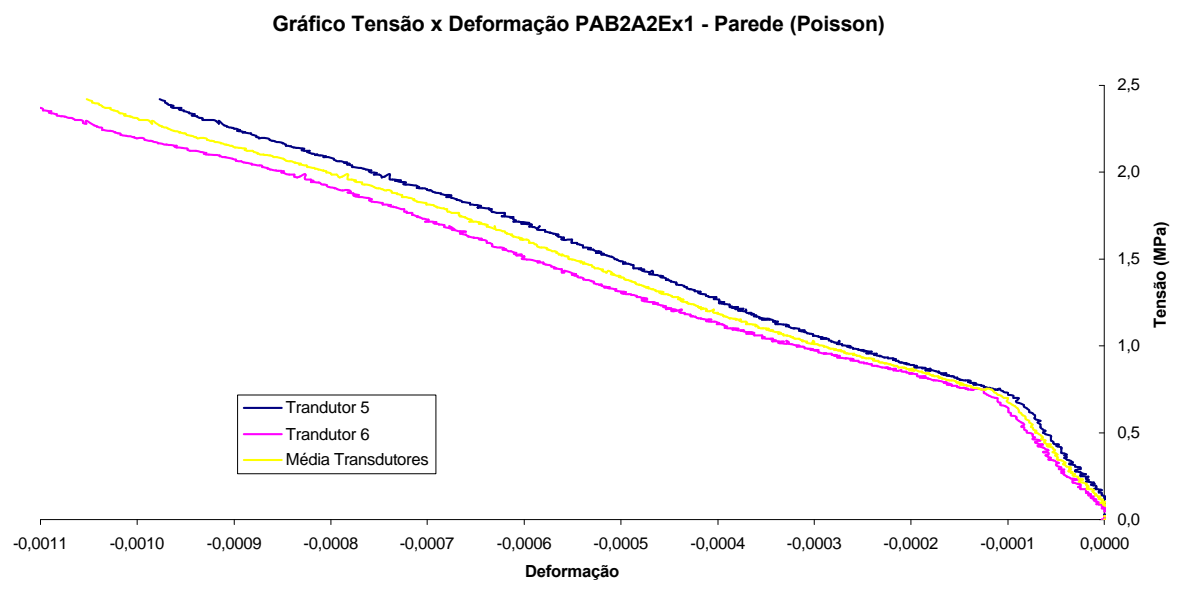

Gráfico Tensão x Deformação PAB2A2Ex2 - Parede (Poisson)

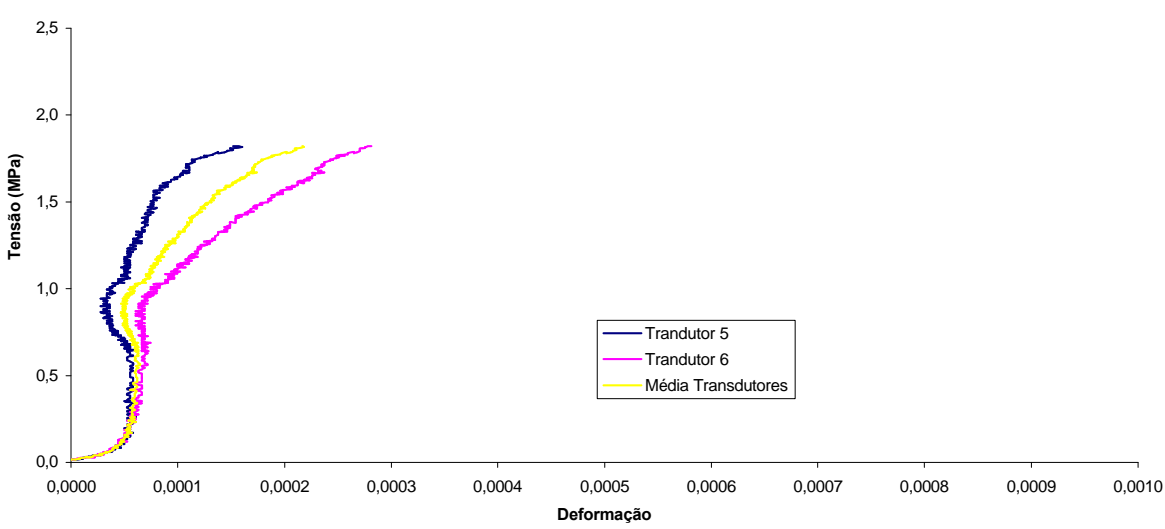

Gráfico Tensão x Deformação PAB2A2Ex3 - Parede (Poisson)

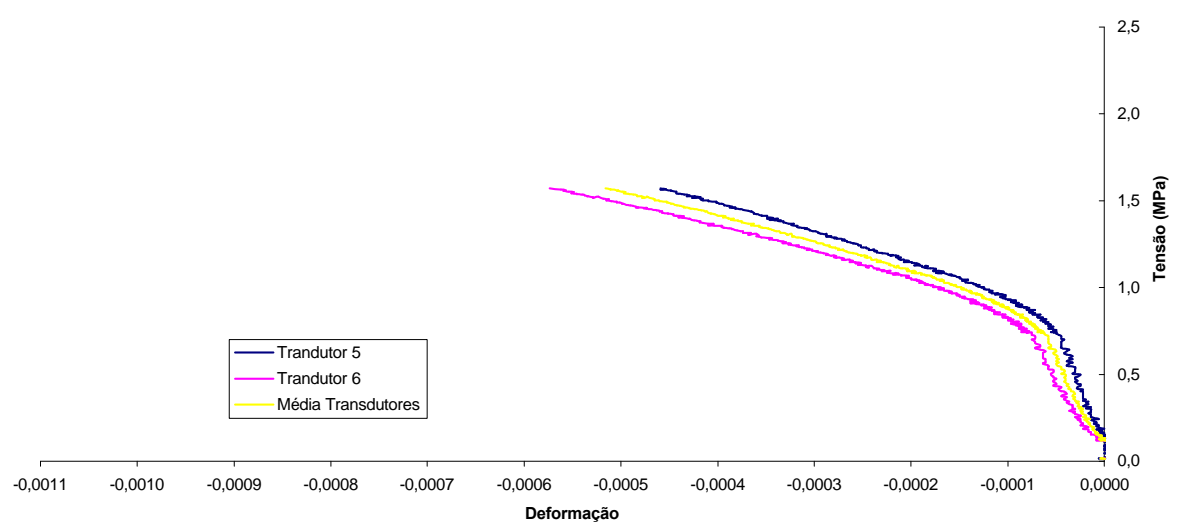




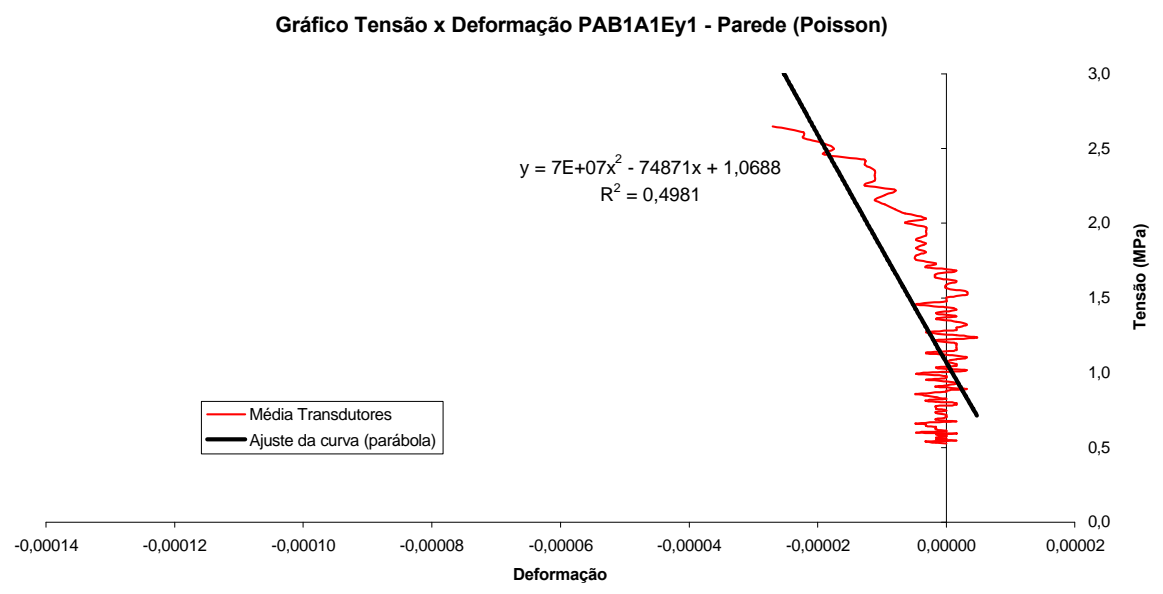

Gráfico Tensão x Deformação PAB1A1Ey2 - Parede (Poisson)

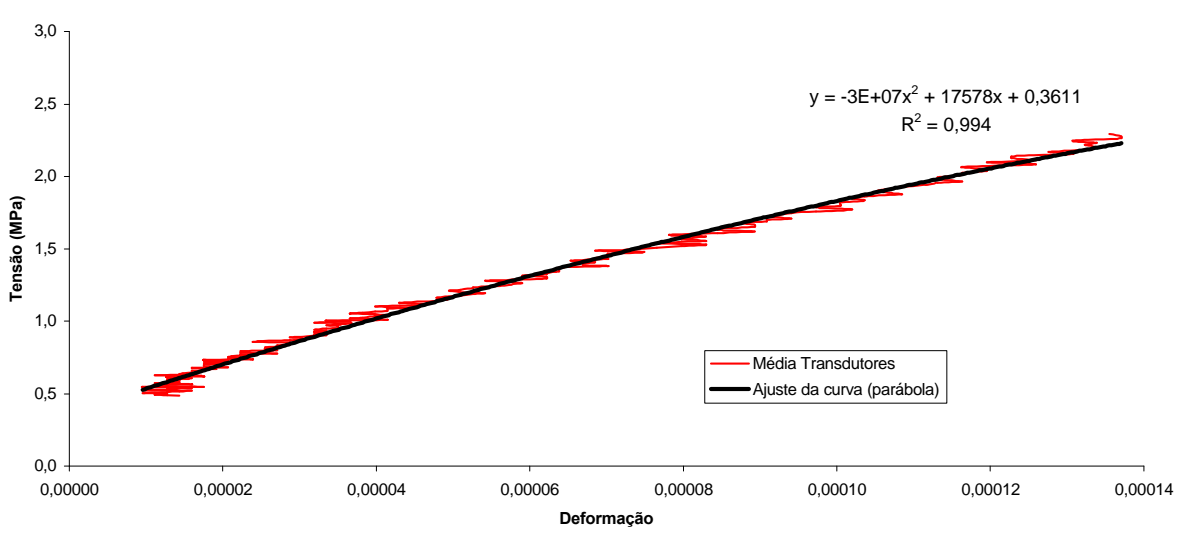

Gráfico Tensão x Deformação PAB1A1Ey3 - Parede (Poisson)

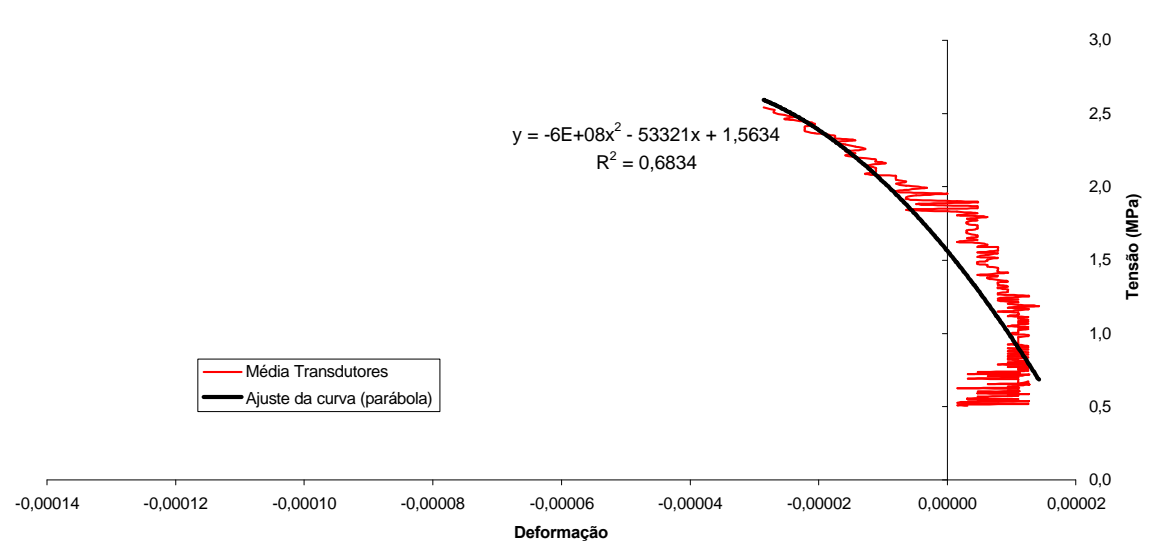




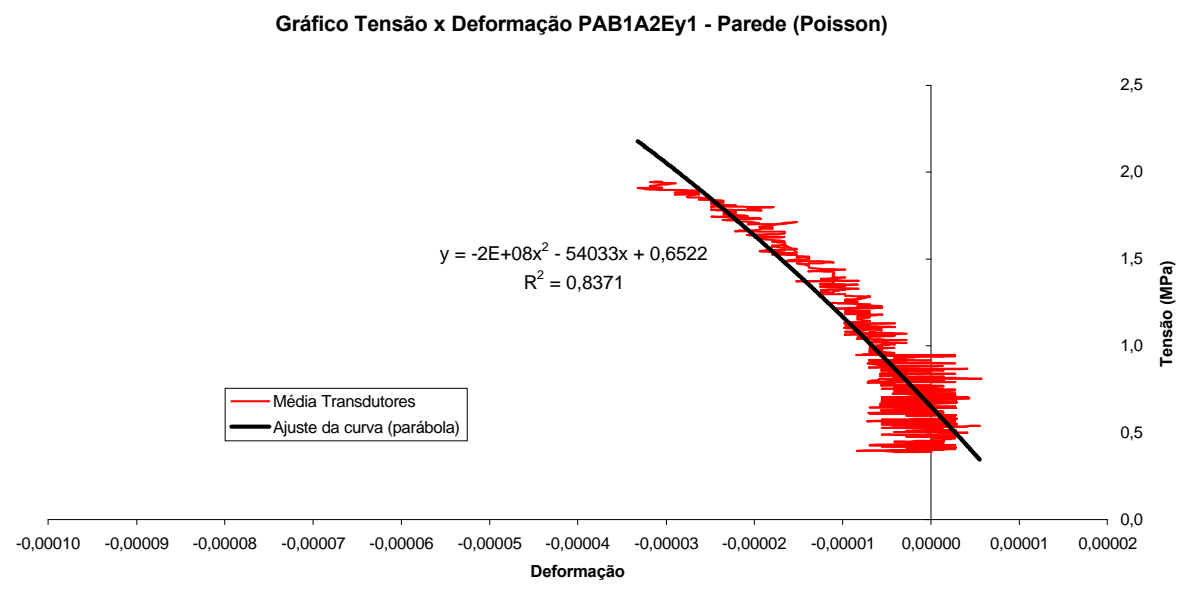

Gráfico Tensão x Deformação PAB1A2Ey2 - Parede (Poisson)
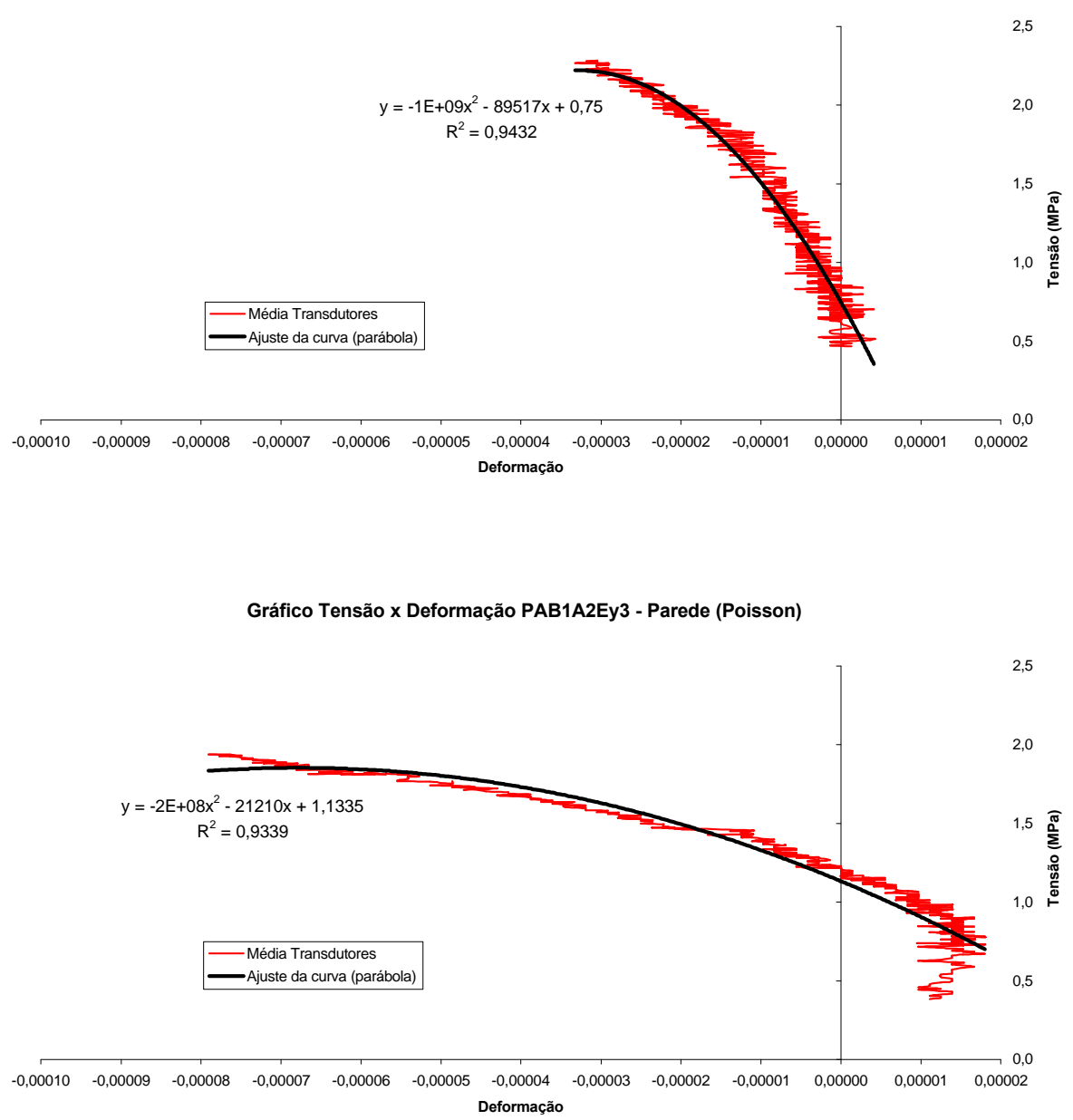


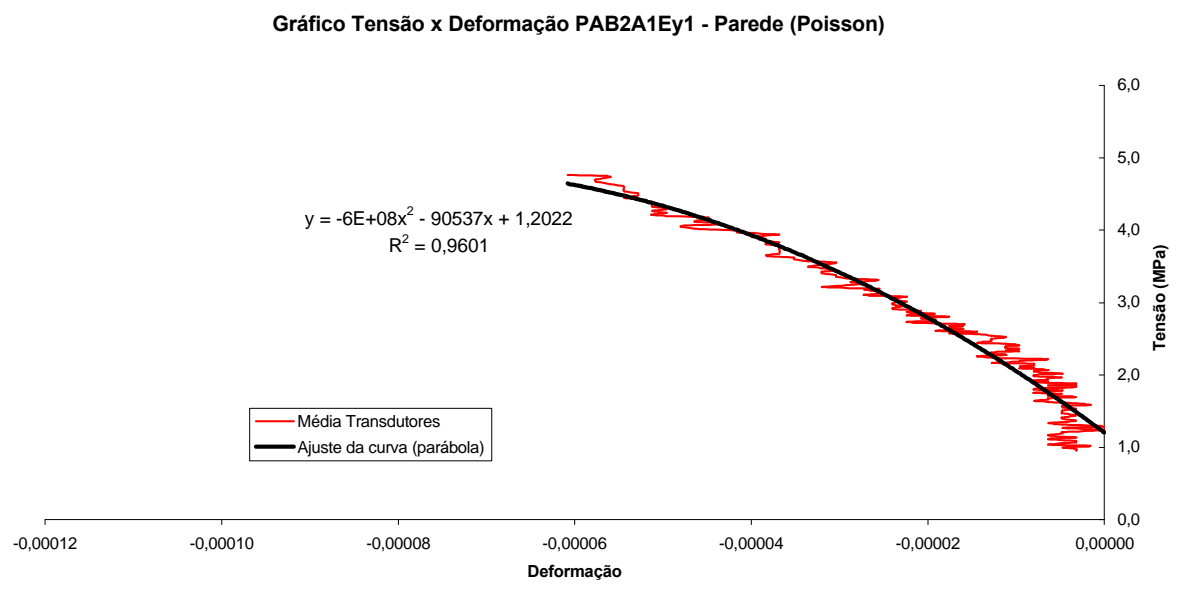

Gráfico Tensão x Deformação PAB2A1Ey2 - Parede (Poisson)

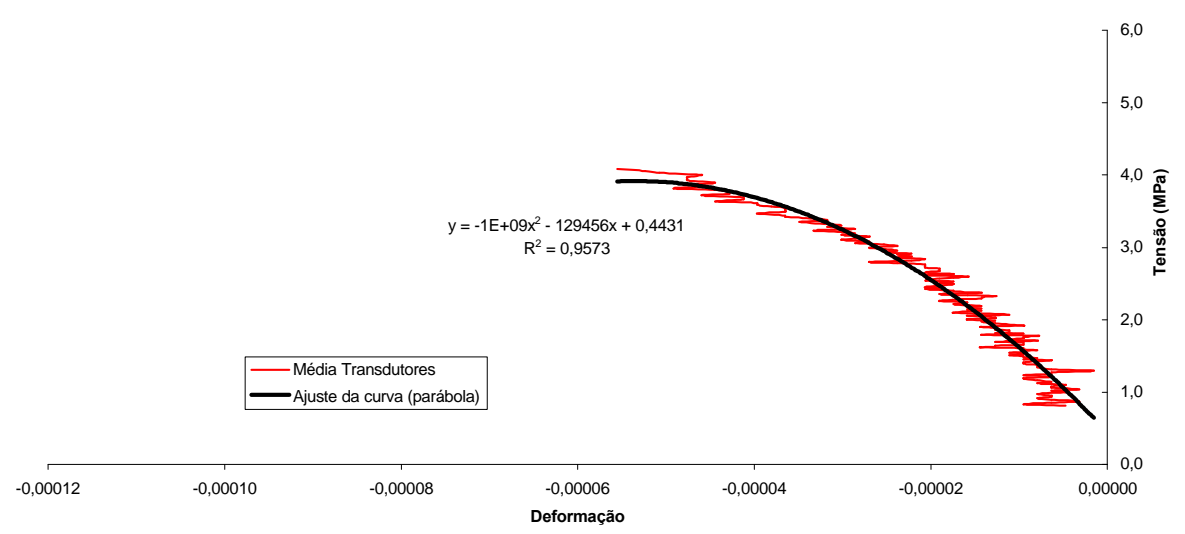

Gráfico Tensão x Deformação PAB2A1Ey3 - Parede (Poisson)

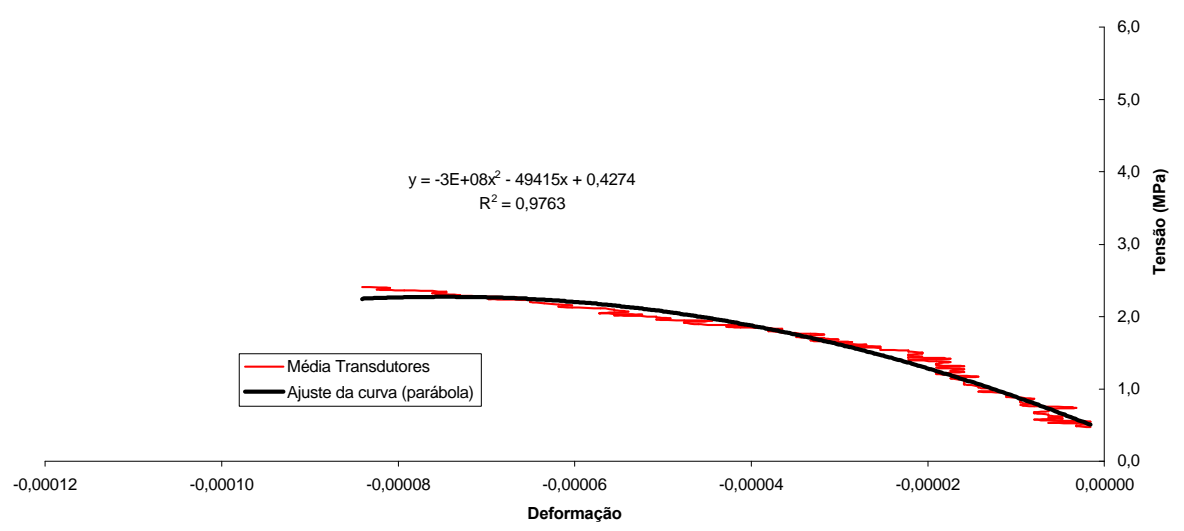




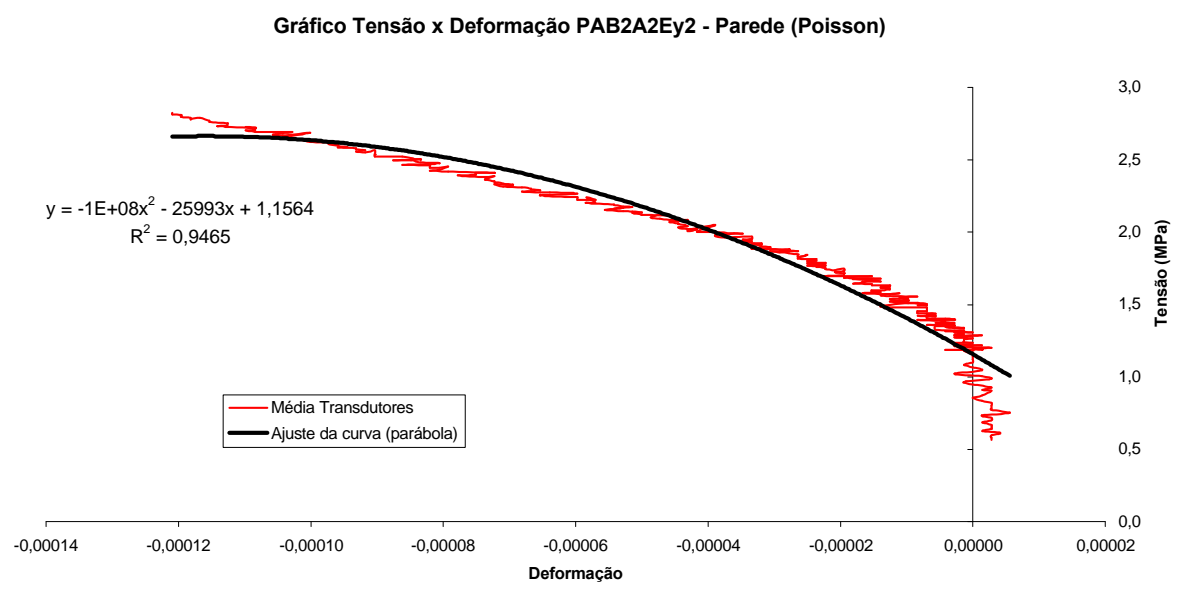




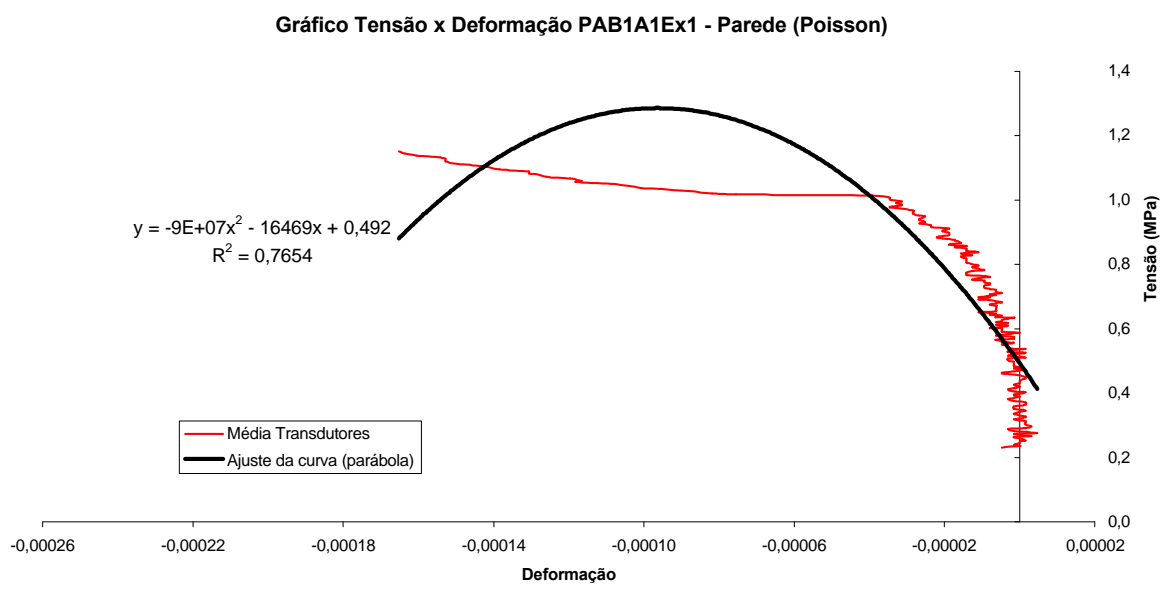

Gráfico Tensão x Deformação PAB1A1Ex2 - Parede (Poisson)

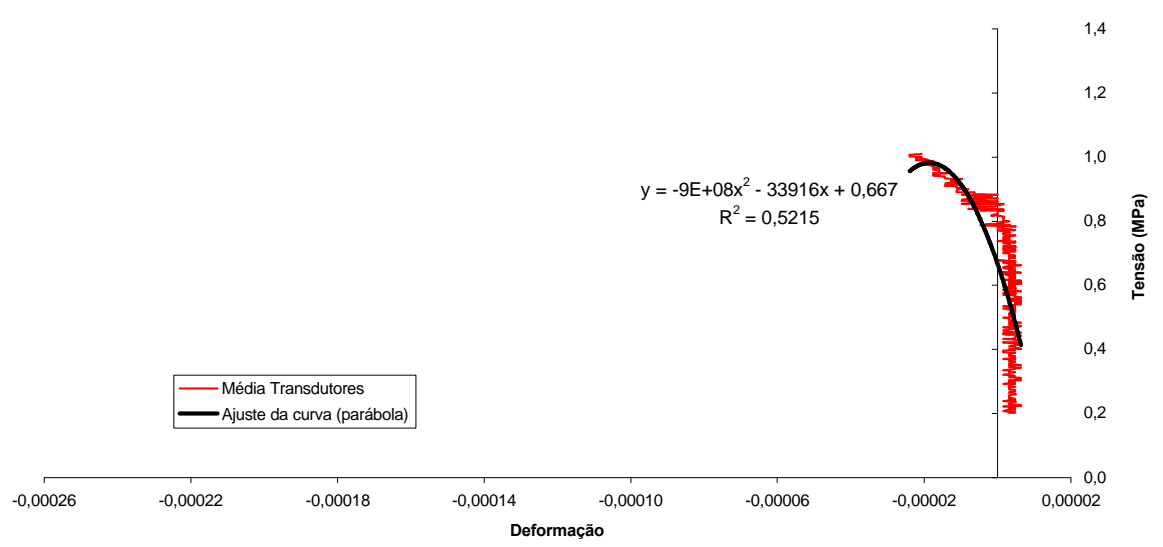

Gráfico Tensão x Deformação PAB1A1Ex3 - Parede (Poisson)

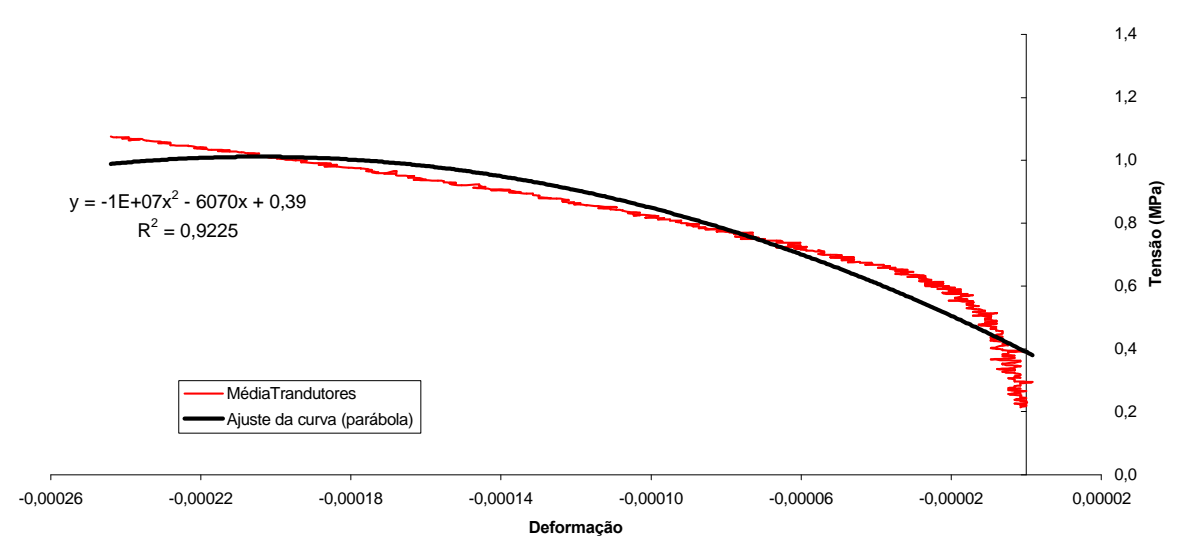




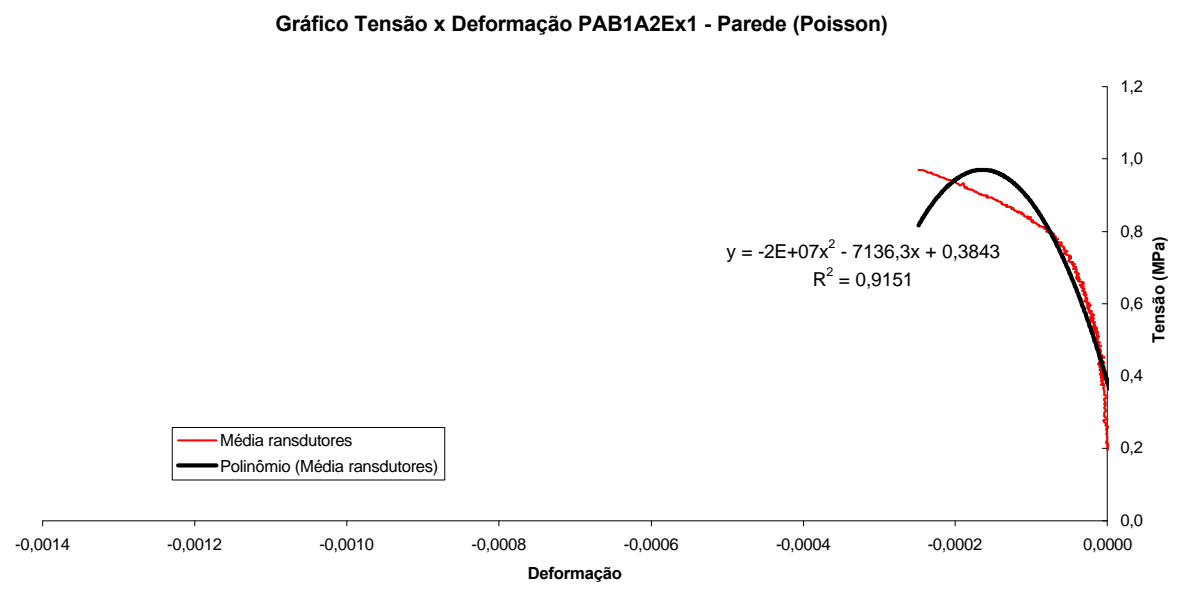

Gráfico Tensão x Deformação PAB1A2Ex2 - Parede (Poisson)

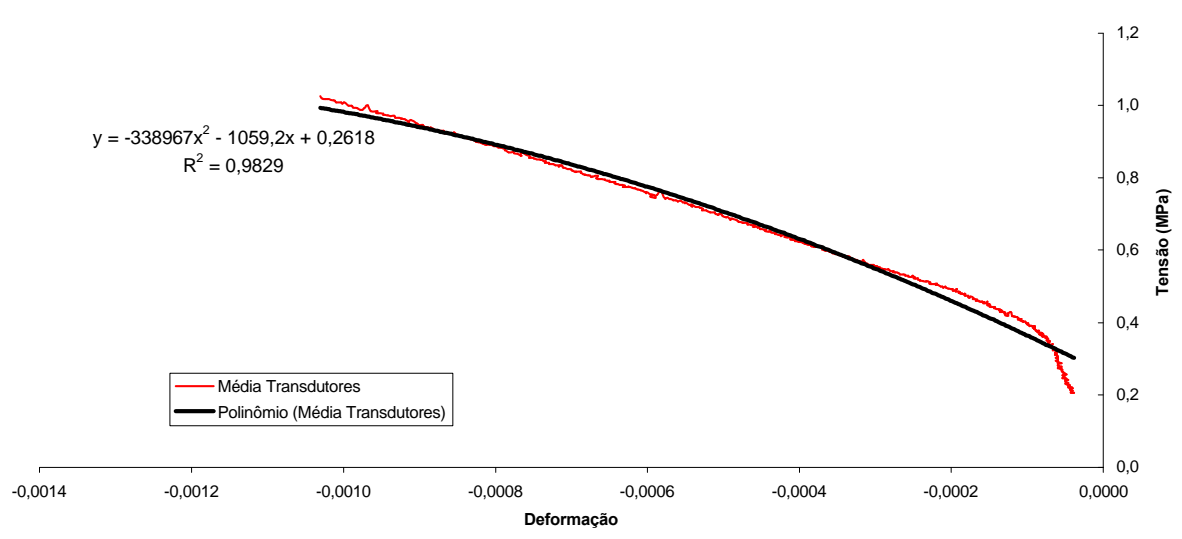

Gráfico Tensão x Deformação PAB1A2Ex3 - Parede (Poisson)

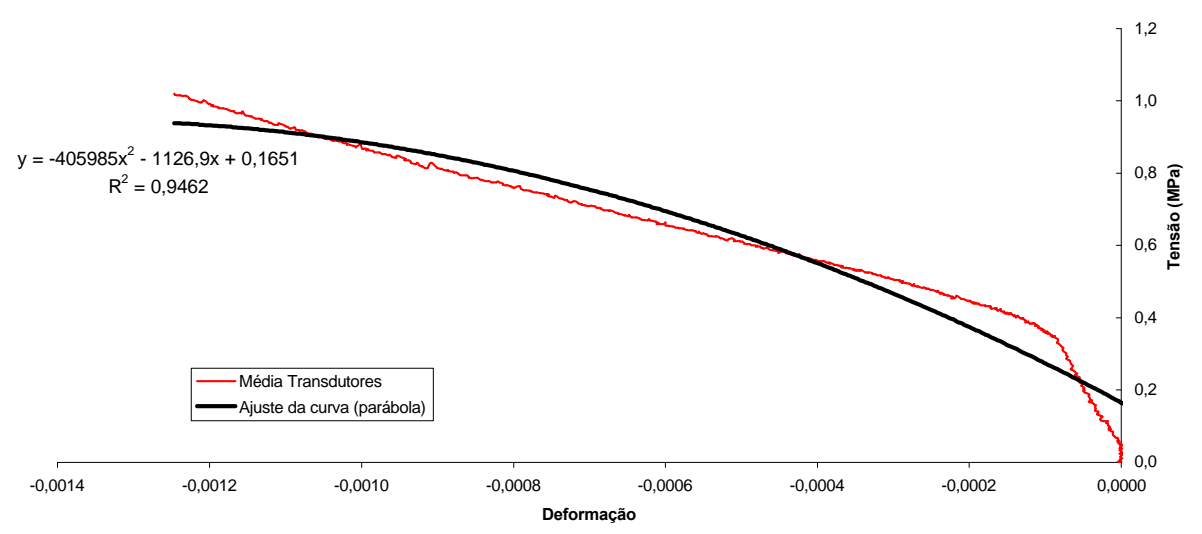


Gráfico Tensão x Deformação PAB2A1Ex1 - Parede (Poisson)

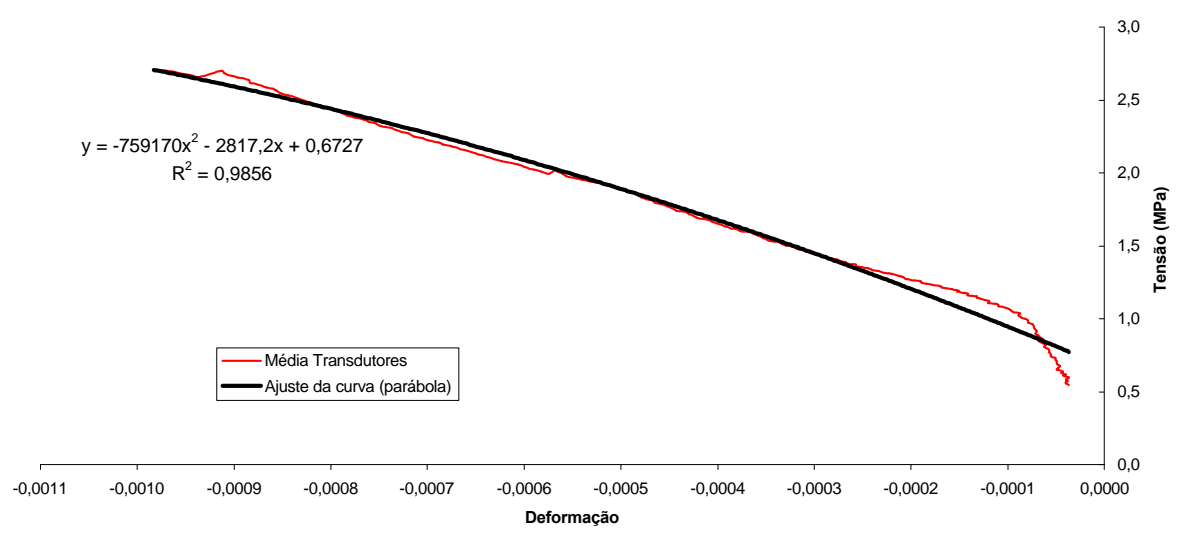

Gráfico Tensão x Deformação PAB2A1Ex2 - Parede (Poisson)

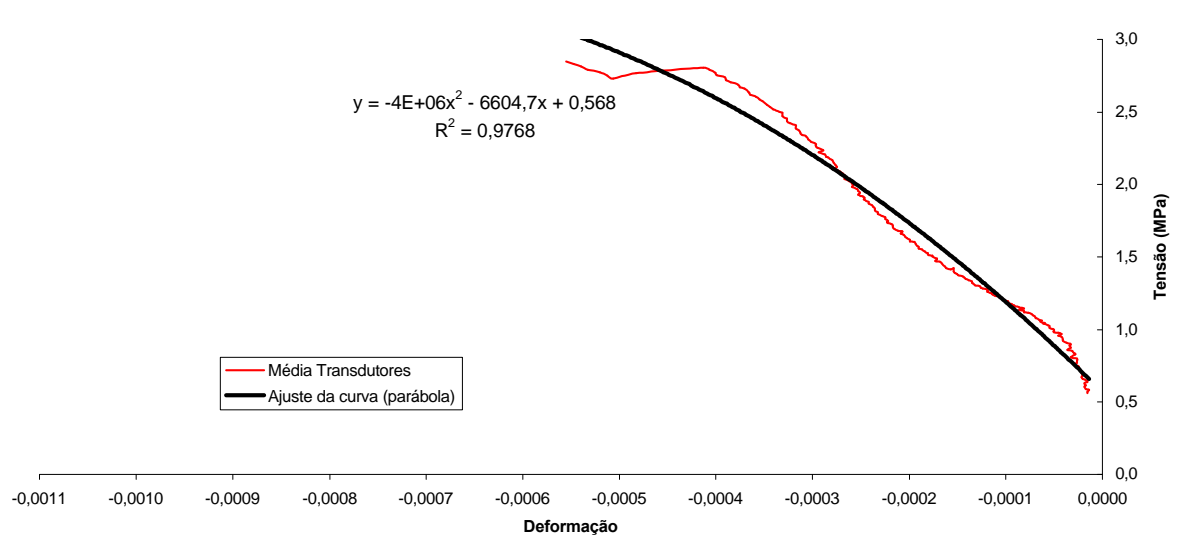

Gráfico Tensão x Deformação PAB2A1Ex3 - Parede (Poisson)

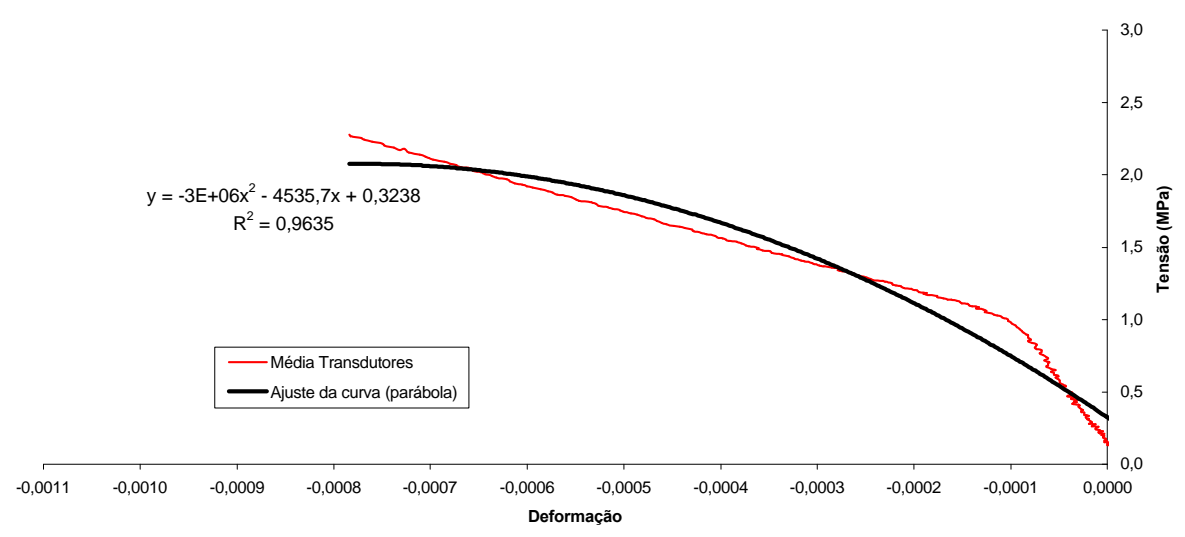




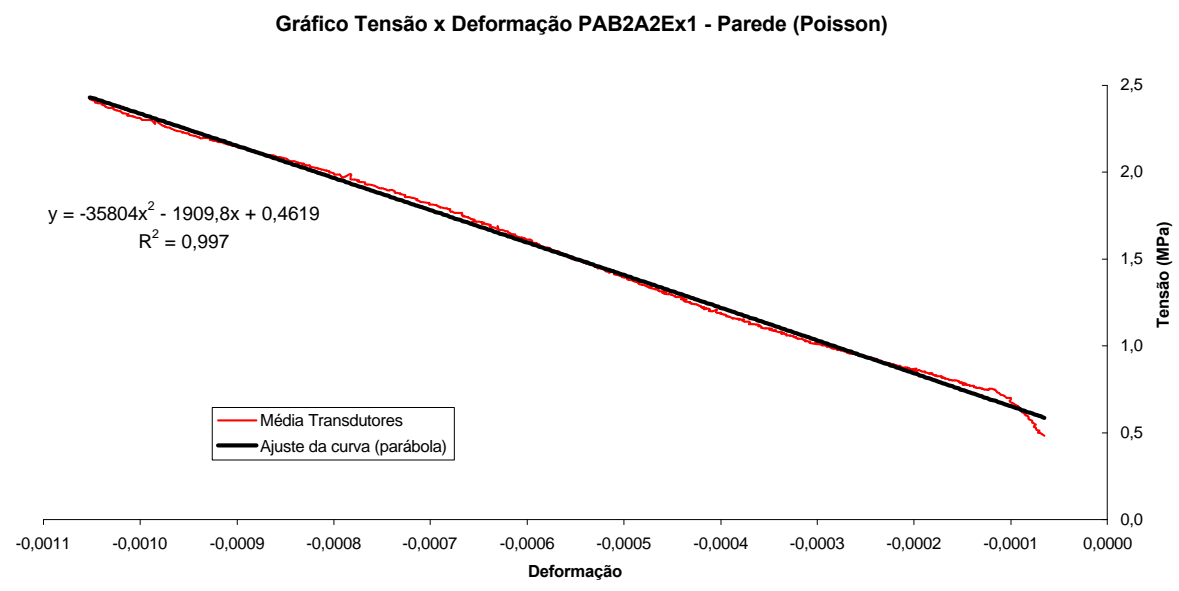

Gráfico Tensão x Deformação PAB2A2Ex2 - Parede (Poisson)

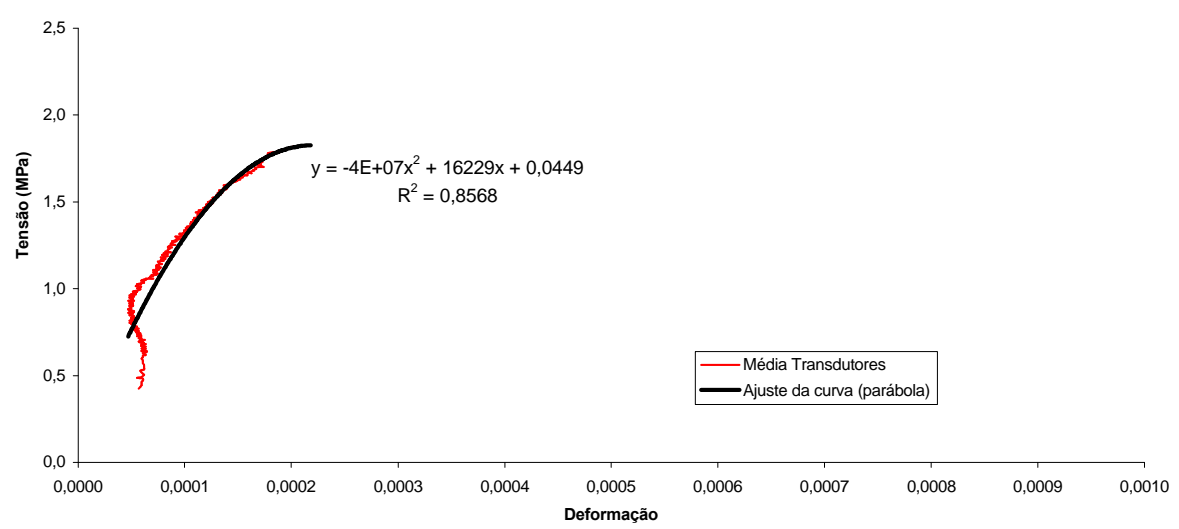

Gráfico Tensão x Deformação PAB2A2Ex3 - Parede (Poisson)

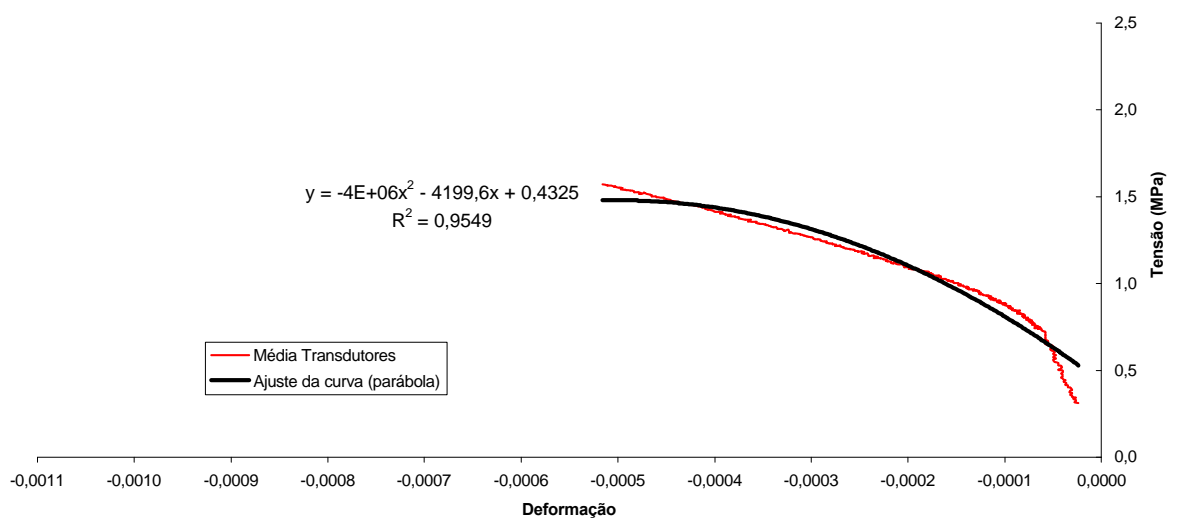



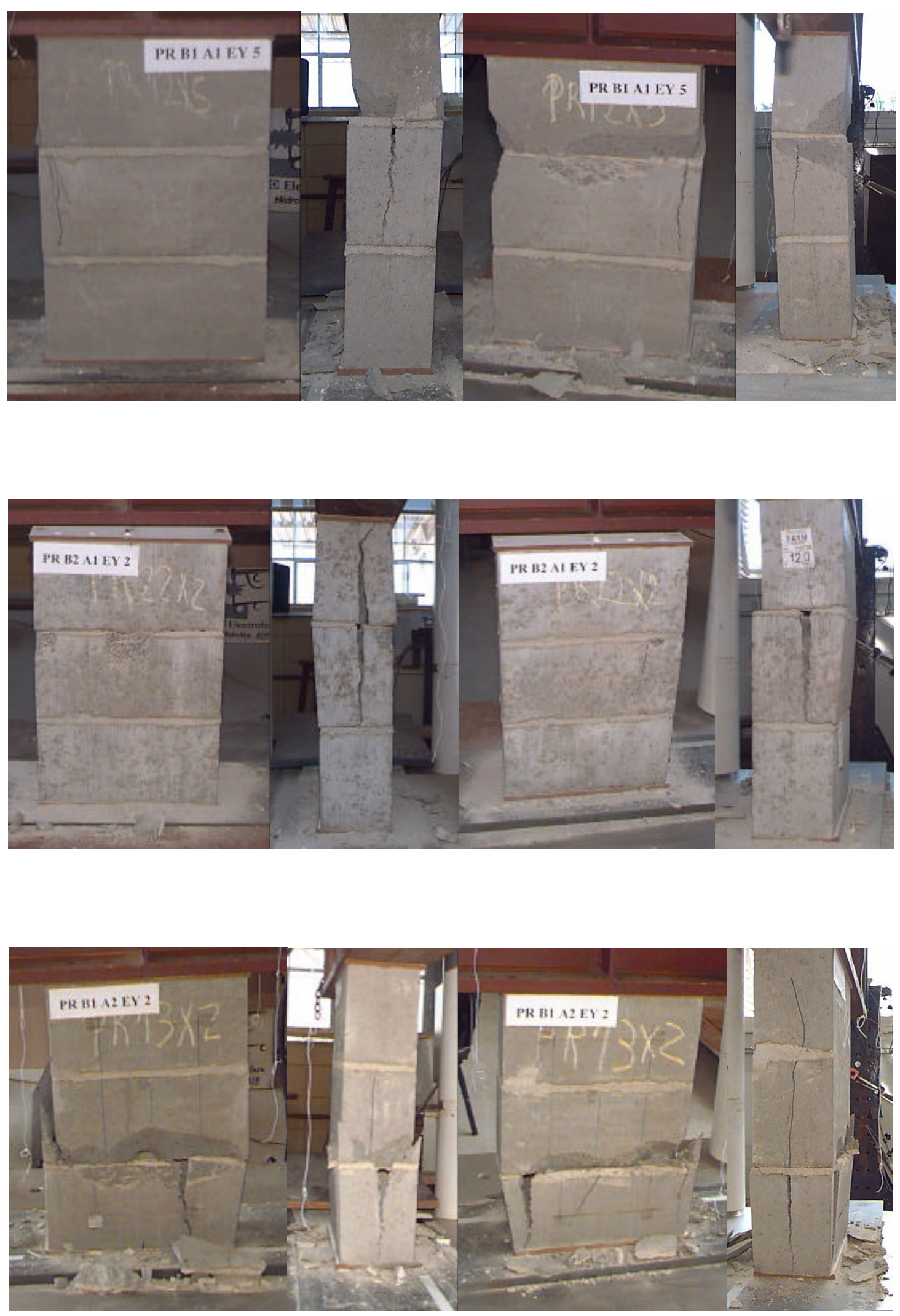

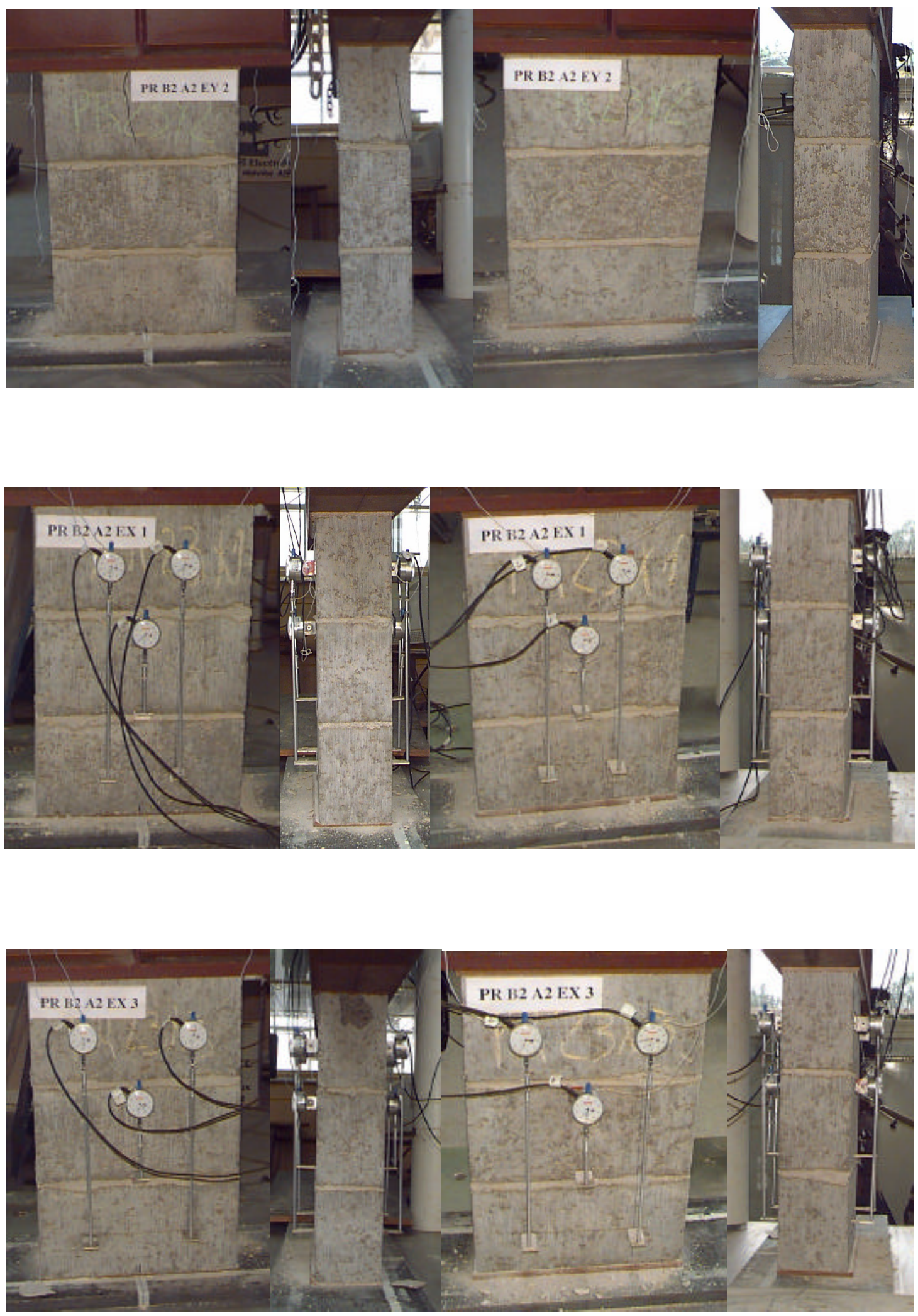

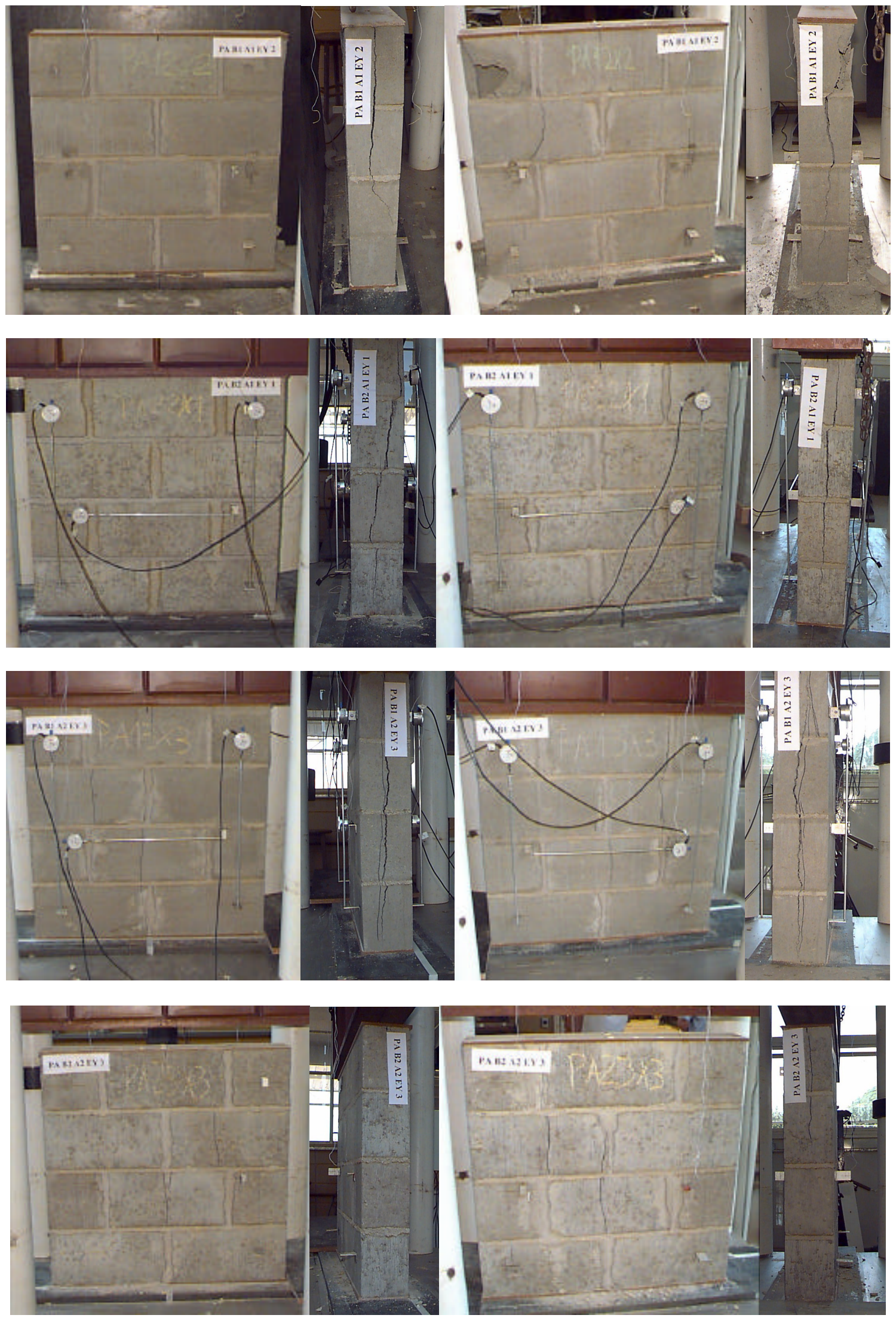

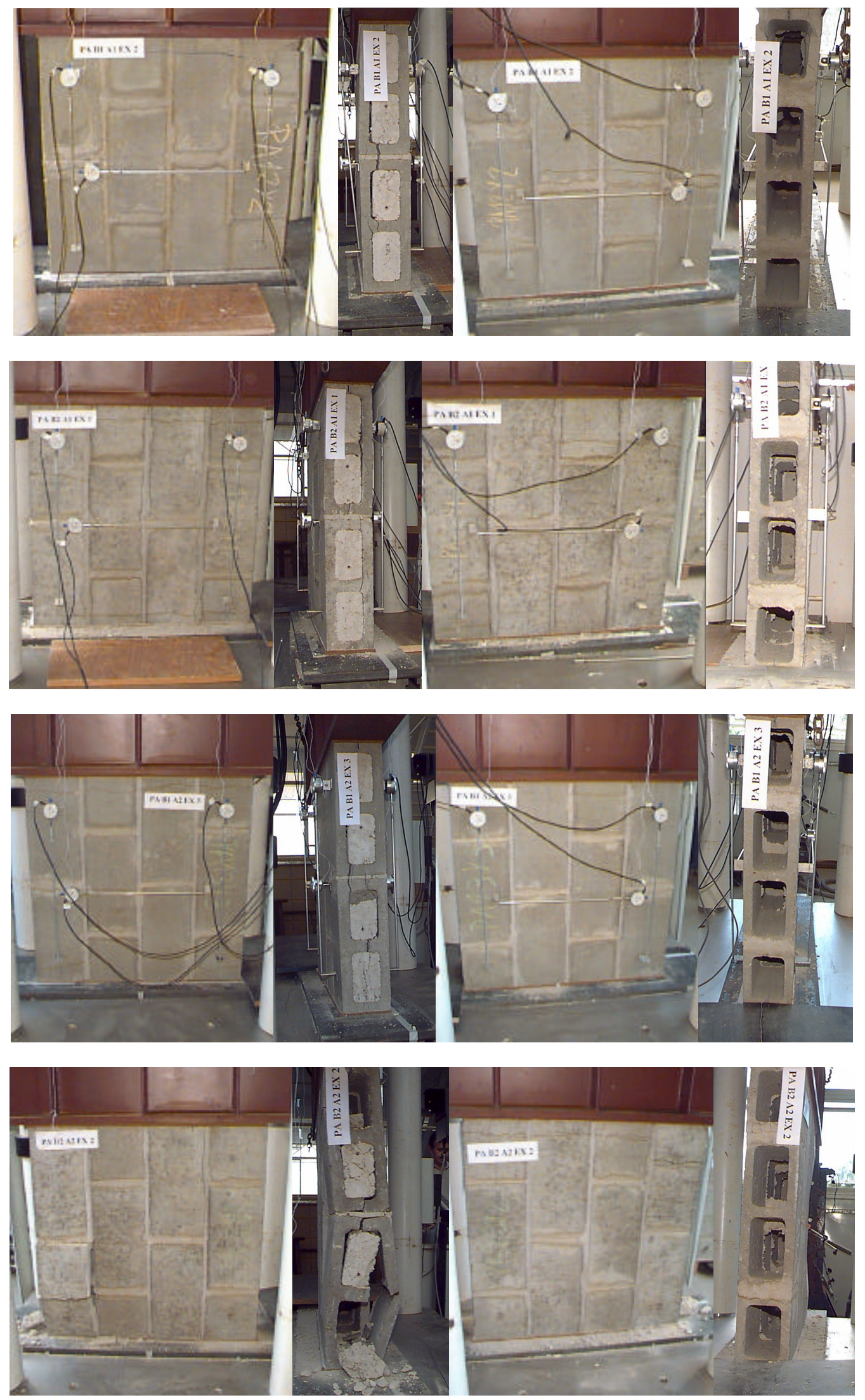


\begin{tabular}{|c|c|c|c|c|}
\hline $\begin{array}{c}\text { Classe de } \\
\text { resistência (MPa) }\end{array}$ & \begin{tabular}{|c|}
$\mathrm{N}^{\circ}$ do \\
$\mathrm{CP}$ \\
\end{tabular} & $\begin{array}{l}\text { idade } \\
\text { (dias) }\end{array}$ & $\begin{array}{c}F_{\text {rup }} \text { do } \\
\text { ensaio }(k N)\end{array}$ & $\begin{array}{c}f_{b}^{*} \\
(M P a)\end{array}$ \\
\hline \multirow{6}{*}{4,5} & 1 & 70 & 559 & 10,23 \\
\hline & 2 & 70 & 572 & 10,48 \\
\hline & 3 & 70 & 514 & 9,41 \\
\hline & 4 & 70 & 656 & 12,81 \\
\hline & 5 & 70 & 596 & 10,91 \\
\hline & 6 & 70 & 600 & 10,98 \\
\hline \multicolumn{3}{|r|}{ Média } & 583 & 10,80 \\
\hline \multicolumn{3}{|r|}{$S_{d}(M P a)$} & 47,47 & 1,14 \\
\hline \multicolumn{3}{|r|}{ CV (\%) } & 8,15 & 10,51 \\
\hline
\end{tabular}

\begin{tabular}{|c|c|c|c|c|}
\hline $\begin{array}{c}\text { Classe de } \\
\text { resistência (MPa) }\end{array}$ & $\begin{array}{c}N^{\circ} \text { do } \\
\text { CP }\end{array}$ & $\begin{array}{l}\text { idade } \\
\text { (dias) }\end{array}$ & $\begin{array}{c}F_{\text {rup }} \text { do } \\
\text { ensaio }(k N)\end{array}$ & $\begin{array}{c}\mathrm{f}_{\mathrm{b}}^{*} \\
(\mathrm{MPa})\end{array}$ \\
\hline \multirow{6}{*}{12,0} & 1 & - & 1392 & 25,49 \\
\hline & 2 & - & 1223 & 22,41 \\
\hline & 3 & - & 1213 & 22,22 \\
\hline & 4 & - & 1383 & 25,33 \\
\hline & 5 & - & 1289 & 23,42 \\
\hline & 6 & - & 1181 & 21,62 \\
\hline \multicolumn{3}{|r|}{ Média } & 1279 & 22,92 \\
\hline \multicolumn{3}{|c|}{$\mathrm{S}_{\mathrm{d}}(\mathrm{MPa})$} & 90,20 & 1,6532 \\
\hline \multicolumn{3}{|r|}{ CV (\%) } & 7,06 & 5,75 \\
\hline
\end{tabular}

* Resistência obtida em função da área bruta. 


\begin{tabular}{||c|c|c|c|c||}
\hline $\begin{array}{c}\text { Série de paredes } \\
\text { correspondente }\end{array}$ & $\begin{array}{c}\mathbf{N}^{\circ} \text { do } \\
\mathbf{C P}\end{array}$ & $\begin{array}{c}\text { idade } \\
\text { (dias) }\end{array}$ & $\begin{array}{c}\mathbf{F}_{\text {rup,a }} \mathbf{d o} \\
\text { Ensaio } \mathbf{( k N )}\end{array}$ & $\begin{array}{c}\mathbf{f}_{\mathbf{a}} \\
\text { (MPa) }\end{array}$ \\
\hline \multirow{3}{*}{ PAB1A1Ex } & 1 & 29 & 184 & 9,39 \\
\cline { 2 - 6 } & 2 & 29 & 219 & 11,17 \\
\cline { 2 - 6 } & 3 & 29 & 197 & 10,02 \\
\cline { 2 - 6 } & 4 & 29 & 192 & 9,78 \\
\hline & Média & 198 & 10,09 \\
\hline & $\mathbf{S}_{\mathbf{d}}$ (MPa) & 14,99 & 0,77 \\
\hline & $\mathbf{C V ~ ( \% )}$ & 7,57 & 7,59 \\
\hline
\end{tabular}

\begin{tabular}{||c|c|c|c|c||}
\hline $\begin{array}{c}\text { Série de paredes } \\
\text { correspondente }\end{array}$ & $\begin{array}{c}\mathbf{N}^{\circ} \text { do } \\
\mathbf{C P}\end{array}$ & $\begin{array}{c}\text { idade } \\
\text { (dias) }\end{array}$ & $\begin{array}{c}\mathbf{F}_{\text {rup,a }} \mathbf{d o} \\
\text { Ensaio } \mathbf{( k N )}\end{array}$ & $\begin{array}{c}\mathbf{f}_{\mathbf{a}} \\
\text { (MPa) }\end{array}$ \\
\hline \multirow{3}{*}{ PAB2A1E } & 1 & 30 & 214 & 10,88 \\
\cline { 2 - 6 } & 2 & 30 & 212 & 10,79 \\
\cline { 2 - 6 } & 3 & 30 & 166 & 8,44 \\
\cline { 2 - 6 } & 4 & 30 & 171 & 8,70 \\
\hline & $\mathbf{M e ́ d i a}$ & 191 & 9,70 \\
\hline & $\mathbf{S}_{\mathbf{d}}$ (MPa) & 2,58 & 1,31 \\
\hline & $\mathbf{C V ~ ( \% )}$ & 1,35 & 13,53 \\
\hline
\end{tabular}

\begin{tabular}{||c|c|c|c|c||}
\hline $\begin{array}{c}\text { Série de paredes } \\
\text { correspondente }\end{array}$ & $\begin{array}{c}\mathbf{N}^{0} \text { do } \\
\mathbf{C P}\end{array}$ & $\begin{array}{c}\text { idade } \\
\text { (dias) }\end{array}$ & $\begin{array}{c}\mathbf{F}_{\text {rup,a }} \text { do } \\
\text { Ensaio (kN) }\end{array}$ & $\begin{array}{c}\mathbf{f}_{\mathbf{a}} \\
\text { (MPa) }\end{array}$ \\
\hline \multirow{3}{*}{ PAB1A1E $_{\mathrm{y}}$} & 1 & 35 & 198 & 10,09 \\
\cline { 2 - 6 } & 2 & 35 & 203 & 10,33 \\
\cline { 2 - 6 } & 3 & 35 & 200 & 10,16 \\
\cline { 2 - 6 } & 4 & 35 & 210 & 10,70 \\
\hline & $\mathbf{M e ́ d i a}$ & 203 & 10,32 \\
\hline & $\mathbf{S}_{\mathbf{d}}$ (MPa) & 5,25 & 0,27 \\
\hline & $\mathbf{C V}(\%)$ & 2,59 & 2,64 \\
\hline
\end{tabular}




\begin{tabular}{||c|c|c|c|c||}
\hline $\begin{array}{c}\text { Série de paredes } \\
\text { correspondente }\end{array}$ & $\begin{array}{c}\mathbf{N}^{\circ} \text { do } \\
\mathbf{C P}\end{array}$ & $\begin{array}{c}\text { idade } \\
\text { (dias) }\end{array}$ & $\begin{array}{c}\mathbf{F}_{\text {rup,a }} \mathbf{d o} \\
\text { Ensaio }(\mathbf{k N})\end{array}$ & $\begin{array}{c}\mathbf{f}_{\mathbf{a}} \\
(\mathbf{M P a})\end{array}$ \\
\hline \multirow{3}{*}{ PAB2A1Ey } & 1 & 29 & 220 & 11,19 \\
\cline { 2 - 6 } & 2 & 29 & 210 & 10,68 \\
\cline { 2 - 6 } & 3 & 29 & 214 & 10,91 \\
\cline { 2 - 6 } & 4 & 29 & 207 & 10,56 \\
\hline & $\mathbf{M e ́ d i a}$ & 213 & 10,84 \\
\hline & $\mathbf{S}_{\mathbf{d}}$ (MPa) & 5,62 & 0,28 \\
\hline & $\mathbf{C V ~ ( \% )}$ & 2,64 & 2,56 \\
\hline
\end{tabular}

\begin{tabular}{||c|c|c|c|c||}
\hline $\begin{array}{c}\text { Série de paredes } \\
\text { correspondente }\end{array}$ & $\begin{array}{c}\mathbf{N}^{\circ} \text { do } \\
\mathbf{C P}\end{array}$ & $\begin{array}{c}\text { idade } \\
\text { (dias) }\end{array}$ & $\begin{array}{c}\mathbf{F}_{\text {rup,a }} \text { do } \\
\text { Ensaio }(\mathbf{k N})\end{array}$ & $\begin{array}{c}\mathbf{f}_{\mathbf{a}} \\
\text { (MPa) }\end{array}$ \\
\hline \multirow{3}{*}{ PAB1A2E $_{\mathrm{x}}$} & 1 & 31 & 110 & 5,62 \\
\cline { 2 - 6 } & 2 & 31 & 103 & 5,24 \\
\cline { 2 - 6 } & 3 & 31 & 110 & 5,63 \\
\cline { 2 - 6 } & 4 & 31 & 101 & 5,15 \\
\hline & $\mathbf{M e ́ d i a}$ & 106 & 5,41 \\
\hline & $\mathbf{S}_{\mathbf{d}}$ (MPa) & 4,69 & 0,25 \\
\hline & $\mathbf{C V ~ ( \% )}$ & 4,42 & 4,59 \\
\hline
\end{tabular}

\begin{tabular}{||c|c|c|c|c||}
\hline $\begin{array}{c}\text { Série de paredes } \\
\text { correspondente }\end{array}$ & $\begin{array}{c}\mathbf{N}^{0} \text { do } \\
\mathbf{C P}\end{array}$ & $\begin{array}{c}\text { idade } \\
\text { (dias) }\end{array}$ & $\begin{array}{c}\mathbf{F}_{\text {rup,a }} \text { do } \\
\text { Ensaio (kN) }\end{array}$ & $\begin{array}{c}\mathbf{f}_{\mathbf{a}} \\
\text { (MPa) }\end{array}$ \\
\hline \multirow{3}{*}{ PAB2A2E $_{x}$} & 1 & 35 & 127 & 6,44 \\
\cline { 2 - 6 } & 2 & 35 & 110 & 5,59 \\
\cline { 2 - 6 } & 3 & 35 & 97 & 4,93 \\
\cline { 2 - 6 } & 4 & 35 & 82 & 4,15 \\
\hline & Média & 104 & 5,28 \\
\hline & $\mathbf{S}_{\mathbf{d}}$ (MPa) & 19,13 & 0,97 \\
\hline & $\mathbf{C V}(\%)$ & 18,40 & 18,43 \\
\hline
\end{tabular}




\begin{tabular}{||c|c|c|c|c||}
\hline $\begin{array}{c}\text { Série de paredes } \\
\text { correspondente }\end{array}$ & $\begin{array}{c}\mathbf{N}^{\circ} \text { do } \\
\mathbf{C P}\end{array}$ & $\begin{array}{c}\text { idade } \\
\text { (dias) }\end{array}$ & $\begin{array}{c}\mathbf{F}_{\text {rup,a }} \text { do } \\
\text { Ensaio } \mathbf{( k N )}\end{array}$ & $\begin{array}{c}\mathbf{f}_{\mathbf{a}} \\
\text { (MPa) }\end{array}$ \\
\hline \multirow{3}{*}{ PAB1A2E $_{y}$} & 1 & 34 & 67 & 3,42 \\
\cline { 2 - 6 } & 2 & 34 & 128 & 6,50 \\
\cline { 2 - 6 } & 3 & 34 & 72 & 3,66 \\
\cline { 2 - 6 } & 4 & 34 & 86 & 4,37 \\
\hline & Média & 88 & 4,49 \\
\hline & $\mathbf{S}_{\mathbf{d}}$ (MPa) & 27,69 & 1,40 \\
\hline & $\mathbf{C V ~ ( \% )}$ & 31,38 & 31,25 \\
\hline
\end{tabular}

\begin{tabular}{||c|c|c|c|c||}
\hline $\begin{array}{c}\text { Série de paredes } \\
\text { correspondente }\end{array}$ & $\begin{array}{c}\mathbf{N}^{\circ} \text { do } \\
\mathbf{C P}\end{array}$ & $\begin{array}{c}\text { idade } \\
\text { (dias) }\end{array}$ & $\begin{array}{c}\mathbf{F}_{\text {rup,a }} \text { do } \\
\text { Ensaio }(\mathbf{k N})\end{array}$ & $\begin{array}{c}\mathbf{f}_{\mathbf{a}} \\
(\mathbf{M P a})\end{array}$ \\
\hline \multirow{3}{*}{ PAB2A2E $_{\mathrm{y}}$} & 1 & 31 & 106 & 5,47 \\
\cline { 2 - 6 } & 2 & 31 & 105 & 5,32 \\
\cline { 2 - 6 } & 3 & 31 & 92 & 4,69 \\
\cline { 2 - 6 } & 4 & 31 & 91 & 4,63 \\
\hline & $\mathbf{M e ́ d i a}$ & 99 & 5,03 \\
\hline & $\mathbf{S}_{\mathbf{d}}$ (MPa) & 8,10 & 0,43 \\
\hline & $\mathbf{C V ~ ( \% )}$ & 8,23 & 8,54 \\
\hline
\end{tabular}




\begin{tabular}{|c|c|c|c|c|c|}
\hline $\begin{array}{c}\text { Parede } \\
\text { correspondente }\end{array}$ & \begin{tabular}{|c|}
$N^{\circ}$ do \\
CP \\
\end{tabular} & $\begin{array}{l}\text { idade } \\
\text { (dias) }\end{array}$ & $\begin{array}{c}F_{\text {rup }} \text { do } \\
\text { ensaio }(k N)\end{array}$ & $\begin{array}{c}\mathbf{f}_{\mathrm{pr}}^{*} \\
(\mathrm{MPa})\end{array}$ & $\begin{array}{c}f_{p r m}{ }^{*} \text { de cada parede } \\
(\mathrm{MPa})\end{array}$ \\
\hline \multirow[t]{2}{*}{$\mathrm{PAB} 1 \mathrm{~A} 1 \mathrm{E}_{Y} 1$} & 1 & 30 & 496 & 9,03 & \multirow[t]{2}{*}{8,45} \\
\hline & 2 & 30 & 429 & 7,87 & \\
\hline \multirow[t]{2}{*}{ PAB1A1EY2 } & 1 & 30 & 386 & 7,19 & \multirow[t]{2}{*}{7,62} \\
\hline & 2 & 30 & 442 & 8,05 & \\
\hline \multirow[t]{2}{*}{ PAB1A1EҮ3 } & 1 & 31 & 418 & 7,34 & \multirow[t]{2}{*}{7,80} \\
\hline & 2 & 31 & 452 & 8,26 & \\
\hline \multicolumn{3}{|r|}{ Média } & 437 & 7,96 & 7,96 \\
\hline \multicolumn{3}{|c|}{$\mathrm{S}_{\mathrm{d}}(\mathrm{MPa})$} & 36,76 & 0,67 & 0,44 \\
\hline \multicolumn{3}{|r|}{ CV (\%) } & 8,41 & 8,39 & 5,49 \\
\hline
\end{tabular}

\begin{tabular}{|c|c|c|c|c|c|}
\hline $\begin{array}{c}\text { Parede } \\
\text { correspondente }\end{array}$ & $\begin{array}{c}\mathrm{N}^{\circ} \text { do } \\
\mathrm{CP}\end{array}$ & $\begin{array}{l}\text { idade } \\
\text { (dias) }\end{array}$ & $\begin{array}{c}F_{\text {rup }} \text { do } \\
\text { Ensaio }(k N)\end{array}$ & $\begin{array}{c}\mathbf{f}_{\mathrm{pr}}{ }^{*} \\
(\mathrm{MPa})\end{array}$ & $\begin{array}{c}f_{\text {prm }}{ }^{*} \text { de cada parede } \\
(\mathrm{Mpa})\end{array}$ \\
\hline \multirow[t]{2}{*}{ PAB1A1E 1} & 1 & 35 & 412 & 7,53 & \multirow[t]{2}{*}{6,67} \\
\hline & 2 & 35 & 318 & 5,80 & \\
\hline \multirow[t]{2}{*}{ PAB1A1E 2} & 1 & 35 & 414 & 7,55 & \multirow[t]{2}{*}{6,90} \\
\hline & 2 & 35 & 338 & 6,20 & \\
\hline \multirow[t]{2}{*}{ PAB1A1E 3} & 1 & 35 & 403 & 7,37 & \multirow[t]{2}{*}{7,37} \\
\hline & 2 & 35 & $* *$ & $* *$ & \\
\hline \multicolumn{3}{|r|}{ Média } & 377 & 6,89 & 6,98 \\
\hline \multicolumn{3}{|c|}{$S_{d}(\mathrm{MPa})$} & 45,63 & 0,83 & 0,36 \\
\hline \multicolumn{3}{|r|}{ CV (\%) } & 12,11 & 12,01 & 5,11 \\
\hline
\end{tabular}

* Resistência obtida em função da área bruta do prisma

** Resultado não obtido por ruptura do prisma durante o transporte 


\begin{tabular}{|c|c|c|c|c|c|}
\hline $\begin{array}{c}\text { Parede } \\
\text { correspondente }\end{array}$ & $\begin{array}{c}\mathrm{N}^{\circ} \text { do } \\
\mathrm{CP}\end{array}$ & $\begin{array}{l}\text { idade } \\
\text { (dias) }\end{array}$ & $\begin{array}{c}F_{\text {rup }} \text { do } \\
\text { ensaio }(k N)\end{array}$ & $\begin{array}{c}\mathbf{f}_{\mathrm{pr}}^{*} \\
(\mathrm{MPa}) \\
\end{array}$ & $\begin{array}{c}f_{\text {prm }}{ }^{*} \text { de cada parede } \\
(\mathrm{MPa})\end{array}$ \\
\hline \multirow[t]{2}{*}{ PAB2A1E 1} & 1 & 31 & 471 & 8,57 & \multirow[t]{2}{*}{8,57} \\
\hline & 2 & 31 & 595 & $10,85^{\star \star *}$ & \\
\hline \multirow[t]{2}{*}{$\mathrm{PAB} 2 \mathrm{~A} 1 \mathrm{E}_{\mathrm{y}} 2$} & 1 & 31 & 452 & 8,21 & \multirow[t]{2}{*}{7,62} \\
\hline & 2 & 31 & 389 & 7,03 & \\
\hline \multirow[t]{2}{*}{ PAB2A1E 3} & 1 & 31 & 388 & 7,08 & \multirow[t]{2}{*}{7,08} \\
\hline & 2 & 31 & ** & ** & \\
\hline \multicolumn{3}{|r|}{ Média } & 459 & 7,75 & 7,76 \\
\hline \multicolumn{3}{|c|}{$\mathrm{S}_{\mathrm{d}}(\mathrm{MPa})$} & 84,79 & 0,78 & 0,75 \\
\hline \multicolumn{3}{|r|}{ CV (\%) } & 18,48 & 10,03 & 9,73 \\
\hline
\end{tabular}

\begin{tabular}{|c|c|c|c|c|c|}
\hline $\begin{array}{c}\text { Parede } \\
\text { correspondente }\end{array}$ & $\begin{array}{c}N^{\circ} \text { do } \\
\text { CP }\end{array}$ & $\begin{array}{l}\text { idade } \\
\text { (dias) }\end{array}$ & $\begin{array}{c}F_{\text {rup }} \text { do } \\
\text { ensaio }(k N)\end{array}$ & $\begin{array}{c}\mathbf{f}_{\mathrm{pr}}{ }^{*} \\
(\mathrm{MPa}) \\
\end{array}$ & $\begin{array}{c}f_{\text {prm }}{ }^{*} \text { de cada parede } \\
(\mathrm{MPa})\end{array}$ \\
\hline \multirow[t]{2}{*}{ PAB2A1E 1} & 1 & 30 & $795^{\star \star \star}$ & $14,43^{\star \star *}$ & \multirow[t]{2}{*}{12,22} \\
\hline & 2 & 30 & 670 & 12,22 & \\
\hline \multirow[t]{2}{*}{ PAB2A1Ex2 } & 1 & 30 & 651 & 11,95 & \multirow[t]{2}{*}{10,60} \\
\hline & 2 & 30 & 508 & 9,25 & \\
\hline \multirow[t]{2}{*}{ PAB2A1E 3} & 1 & 30 & 428 & 7,81 & \multirow[t]{2}{*}{9,49} \\
\hline & 2 & 30 & 614 & 11,16 & \\
\hline \multicolumn{3}{|r|}{ Média } & 574 & 11,48 & 10,77 \\
\hline \multicolumn{3}{|r|}{$\mathrm{S}_{\mathrm{d}}(\mathrm{MPa})$} & 102,98 & 1,89 & 1,37 \\
\hline \multicolumn{3}{|r|}{ CV (\%) } & 17,93 & 18,04 & 12,75 \\
\hline
\end{tabular}

* Resistência obtida em função da área bruta do prisma

** Resultado não obtido por ruptura do prisma durante o transporte

*** Resultado descartado por apresentar um desvio grande em relação aos outros valores. 


\begin{tabular}{|c|c|c|c|c|c|}
\hline $\begin{array}{c}\text { Parede } \\
\text { correspondente }\end{array}$ & $\begin{array}{c}N^{\circ} \text { do } \\
\text { CP }\end{array}$ & $\begin{array}{l}\text { idade } \\
\text { (dias) }\end{array}$ & $\begin{array}{c}F_{\text {rup }, p r} \text { do } \\
\text { Ensaio (kN) }\end{array}$ & $\begin{array}{c}\mathbf{f}_{\mathrm{pr}}{ }^{*} \\
(\mathrm{MPa})\end{array}$ & $\begin{array}{c}f_{p r, m}{ }^{*} \text { de cada parede } \\
\text { (Mpa) }\end{array}$ \\
\hline \multirow[t]{2}{*}{ PAB1A2E 1} & 1 & 31 & 396 & 7,23 & \multirow[t]{2}{*}{7,69} \\
\hline & 2 & 31 & 446 & 8,14 & \\
\hline \multirow[t]{2}{*}{$\mathrm{PAB} 1 \mathrm{~A} 2 \mathrm{E}_{\mathrm{y}} 2$} & 1 & 31 & 522 & 9,57 & \multirow[t]{2}{*}{8,55} \\
\hline & 2 & 31 & 410 & 7,52 & \\
\hline \multirow[t]{2}{*}{$\mathrm{PAB} 1 \mathrm{~A} 2 \mathrm{E}_{\mathrm{y}} 3$} & 1 & 31 & 413 & 7,57 & \multirow[t]{2}{*}{7,57} \\
\hline & 2 & 31 & 413 & 7,57 & \\
\hline \multicolumn{3}{|r|}{ Média } & 433 & 7,93 & 7,94 \\
\hline \multicolumn{3}{|r|}{$\mathrm{S}_{\mathrm{d}}(\mathrm{MPa})$} & 46,45 & 0,85 & 0,53 \\
\hline \multicolumn{3}{|r|}{ CV (\%) } & 10,72 & 10,77 & 6,74 \\
\hline
\end{tabular}

\begin{tabular}{|c|c|c|c|c|c|}
\hline $\begin{array}{c}\text { Parede } \\
\text { correspondente }\end{array}$ & $\begin{array}{c}N^{\circ} \text { do } \\
\text { CP } \\
\end{array}$ & $\begin{array}{l}\text { idade } \\
\text { (dias) } \\
\end{array}$ & $\begin{array}{c}F_{\text {rup }, p r} \text { do } \\
\text { Ensaio }(k N)\end{array}$ & $\begin{array}{c}\mathbf{f}_{\mathrm{pr}}{ }^{*} \\
(\mathrm{MPa}) \\
\end{array}$ & $\begin{array}{c}f_{p r, m}{ }^{*} \text { de cada parede } \\
(\mathrm{MPa})\end{array}$ \\
\hline \multirow[t]{2}{*}{$\mathrm{PAB}_{1} \mathrm{~A}_{2} \mathrm{E}_{\mathrm{x}} 1$} & 1 & 34 & 472 & 8,62 & \multirow[t]{2}{*}{7,90} \\
\hline & 2 & 34 & 393 & 7,17 & \\
\hline \multirow[t]{2}{*}{$\mathrm{PAB} 1 \mathrm{~A} 2 \mathrm{E}_{x} 2$} & 1 & 34 & 342 & 6,22 & \multirow[t]{2}{*}{6,60} \\
\hline & 2 & 34 & 382 & 6,98 & \\
\hline \multirow[t]{2}{*}{$\mathrm{PAB} 1 \mathrm{~A} 2 \mathrm{E}_{\mathrm{x}} 3$} & 1 & 34 & 353 & 6,44 & \multirow[t]{2}{*}{6,72} \\
\hline & 2 & 34 & 386 & 7,00 & \\
\hline \multicolumn{3}{|r|}{ Média } & 388 & 7,07 & 7,07 \\
\hline \multicolumn{3}{|c|}{$S_{d}(\mathrm{MPa})$} & 45,74 & 0,84 & 0,72 \\
\hline \multicolumn{3}{|r|}{ CV (\%) } & 11,79 & 11,91 & 10,16 \\
\hline
\end{tabular}

* Resistência obtida em função da área bruta do prisma 


\begin{tabular}{|c|c|c|c|c|c|}
\hline $\begin{array}{c}\text { Parede } \\
\text { correspondente }\end{array}$ & $\begin{array}{c}N^{\circ} \text { do } \\
\text { CP }\end{array}$ & $\begin{array}{l}\text { idade } \\
\text { (dias) }\end{array}$ & $\begin{array}{c}F_{\text {rup,pr }} \text { do } \\
\text { Ensaio }(k N)\end{array}$ & $\begin{array}{c}\mathbf{f}_{\mathrm{pr}}^{*} \\
(\mathrm{MPa})\end{array}$ & $\begin{array}{c}f_{p r, m}{ }^{*} \text { de cada parede } \\
\text { (Mpa) }\end{array}$ \\
\hline \multirow[t]{2}{*}{ PAB2A2E 1} & 1 & 35 & 552 & 10,05 & \multirow[t]{2}{*}{9,61} \\
\hline & 2 & 35 & 508 & 9,17 & \\
\hline \multirow[t]{2}{*}{ PAB2A2E 2} & 1 & 35 & 538 & 9,80 & \multirow[t]{2}{*}{9,80} \\
\hline & 2 & 35 & $267^{\star *}$ & $4,84^{\star *}$ & \\
\hline \multirow[t]{2}{*}{ PAB2A2E 3} & 1 & 35 & 545 & 9,97 & \multirow[t]{2}{*}{8,54} \\
\hline & 2 & 35 & 393 & 7,10 & \\
\hline \multicolumn{3}{|r|}{ Média } & 507 & 9,22 & 9,32 \\
\hline \multicolumn{3}{|c|}{$\mathrm{S}_{\mathrm{d}}(\mathrm{MPa})$} & 19,36 & 1,23 & 0,68 \\
\hline \multicolumn{3}{|r|}{ CV (\%) } & 3,82 & 13,38 & 7,29 \\
\hline
\end{tabular}

\begin{tabular}{|c|c|c|c|c|c|}
\hline $\begin{array}{c}\text { Parede } \\
\text { correspondente }\end{array}$ & $\begin{array}{c}N^{\circ} \text { do } \\
\text { CP }\end{array}$ & $\begin{array}{l}\text { idade } \\
\text { (dias) } \\
\end{array}$ & $\begin{array}{c}F_{\text {rup }, p r} \text { do } \\
\text { Ensaio (kN) }\end{array}$ & $\begin{array}{c}f_{\mathrm{pr}}{ }^{*} \\
(\mathrm{MPa}) \\
\end{array}$ & $\begin{array}{c}f_{p r, m}{ }^{*} \text { de cada parede } \\
\text { (Mpa) }\end{array}$ \\
\hline \multirow[t]{2}{*}{ PAB2A2E $_{x} 1$} & 1 & 31 & 384,2 & $7,02^{* * *}$ & \multirow[t]{2}{*}{9,29} \\
\hline & 2 & 31 & 508,4 & 9,29 & \\
\hline \multirow[t]{2}{*}{ PAB2A2E 2} & 1 & 31 & 411,9 & 7,50 & \multirow[t]{2}{*}{8,76} \\
\hline & 2 & 31 & 548,9 & 10,02 & \\
\hline \multirow[t]{2}{*}{$\mathrm{PAB} 2 \mathrm{~A} 2 \mathrm{E}_{\mathrm{x}} 3$} & 1 & 31 & 599,3 & 10,94 & \multirow[t]{2}{*}{10,94} \\
\hline & 2 & 31 & $375,5^{\star * *}$ & $6,82^{* * *}$ & \\
\hline \multicolumn{3}{|r|}{ Média } & 491 & 9,44 & 9,66 \\
\hline \multicolumn{3}{|r|}{$S_{d}(M P a)$} & 90,89 & 1,46 & 1,14 \\
\hline \multicolumn{3}{|r|}{ CV (\%) } & 18,53 & 15,44 & 11,77 \\
\hline
\end{tabular}

* Resistência obtida em função da área bruta do prisma

*** Resultado descartado por apresentar um desvio grande em relação aos outros valores. 


\begin{tabular}{||c|c|c|c||}
\hline $\begin{array}{c}\text { Parede } \\
\text { correspondente }\end{array}$ & $\begin{array}{c}\mathbf{f}_{\mathrm{par}}{ }^{*} \\
\mathbf{( M p a )}\end{array}$ & $\begin{array}{c}\mathrm{E}_{\mathrm{par}}{ }^{*} \\
\mathbf{( M P a}\end{array}$ & $\mathrm{E}_{\mathrm{par}}{ }^{*} / \mathbf{f}_{\mathrm{par}}{ }^{*}$ \\
\hline PAB1A1E 1 & 5,27 & 6496 & 1234 \\
\hline PAB1A1E 2 & 4,58 & $3705^{*}$ & $809^{*}$ \\
\hline PAB1A1E 3 & 5,06 & 6269 & 1238 \\
\hline Média (MPa) & 4,97 & 6383 & 1236 \\
\hline $\mathbf{S}_{\mathbf{d}}(\mathbf{M P a})$ & 0,35 & 161 & 3,33 \\
\hline $\mathbf{C V}(\%)$ & 7,12 & 2,52 & 0,27 \\
\hline
\end{tabular}

\begin{tabular}{||c|c|c|c||}
\hline $\begin{array}{c}\text { Parede } \\
\text { correspondente }\end{array}$ & $\begin{array}{c}\mathbf{f}_{\mathrm{par}}{ }^{*} \\
(\mathbf{M p a})\end{array}$ & $\begin{array}{c}\mathrm{E}_{\mathrm{par}}{ }^{*} \\
\mathbf{( M P a})\end{array}$ & $\mathrm{E}_{\mathrm{par}}{ }^{*} / \mathbf{f}_{\mathrm{par}}{ }^{*}$ \\
\hline PAB1A1E 1 & 2,30 & $4234^{* *}$ & 1842 \\
\hline PAB1A1E 2 & 2,02 & 3089 & 1529 \\
\hline PAB1A1E 3 & 2,15 & 3032 & 1409 \\
\hline Média (MPa) & 2,16 & 3060 & 1594 \\
\hline $\mathbf{S}_{\mathrm{d}}$ (MPa) & 0,14 & 841 & 223,12 \\
\hline $\mathbf{C V}(\%)$ & 6,48 & 1,33 & 14,00 \\
\hline
\end{tabular}

\begin{tabular}{|c|c|c|c|}
\hline $\begin{array}{c}\text { Parede } \\
\text { correspondente }\end{array}$ & $\begin{array}{c}\mathbf{f}_{\mathrm{par}}^{*} \\
(\mathrm{Mpa})\end{array}$ & $\begin{array}{c}E_{p a r}^{*} \\
(\mathrm{MPa})\end{array}$ & $\mathrm{E}_{\mathrm{par}} / \mathbf{f}_{\mathrm{par}}$ \\
\hline PAB1A2E 1 & 3,91 & 6335 & 1618 \\
\hline $\mathrm{PAB} 1 \mathrm{~A} 2 \mathrm{E}_{\mathrm{y}} 2$ & 4,57 & 6544 & 1431 \\
\hline PAB1A2E 3 & 3,89 & 4006 & $1031^{* *}$ \\
\hline Média (MPa) & 4,12 & 6440 & 1525 \\
\hline$S_{d}(M P a)$ & 0,39 & 148 & 132,39 \\
\hline CV (\%) & 9,42 & 2,30 & 8,68 \\
\hline
\end{tabular}

* Resistência e módulo de elasticidade calculada em função da área bruta da paredinha;

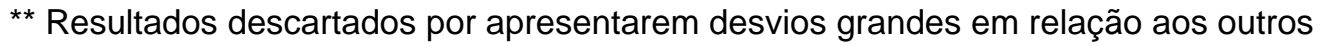
valores; 


\begin{tabular}{|c|c|c|c|}
\hline $\begin{array}{c}\text { Parede } \\
\text { correspondente }\end{array}$ & $\begin{array}{c}f_{\mathrm{par}}^{*} \\
(\mathrm{Mpa})\end{array}$ & $\begin{array}{c}\mathrm{E}_{\mathrm{par}}^{*} \\
(\mathrm{MPa})\end{array}$ & $\mathrm{E}_{\mathrm{par}}{ }^{*} / \mathbf{f}_{\mathrm{par}}$ \\
\hline $\mathrm{PAB}_{1} \mathrm{~A}_{2} \mathrm{E}_{\mathrm{x}} 1$ & 1,94 & 3248 & 1676 \\
\hline PAB1A2E 2 & 2,04 & $1313^{* *}$ & $643^{* *}$ \\
\hline PAB1A2E 3 & 2,04 & 3002 & 1470 \\
\hline Média (MPa) & 2,01 & 3125 & 1573 \\
\hline$S_{d}(M P a)$ & 0,06 & 174 & 145,47 \\
\hline CV (\%) & 2,99 & 5,57 & 9,25 \\
\hline
\end{tabular}

\begin{tabular}{|c|c|c|c|}
\hline $\begin{array}{c}\text { Parede } \\
\text { correspondente }\end{array}$ & $\begin{array}{c}\mathbf{f}_{\mathrm{par}}^{*} \\
\text { (Mpa) }\end{array}$ & $\begin{array}{l}\mathrm{E}_{\mathrm{par}}^{*} \\
(\mathrm{MPa})\end{array}$ & $\mathrm{E}_{\mathrm{par}}{ }^{*} / \mathbf{f}_{\mathrm{par}}$ \\
\hline PAB2A1E 1 & 9,52 & $12652^{* *}$ & 1329 \\
\hline PAB2A1E 2 & 8,16 & 9909 & 1214 \\
\hline PAB2A1E 3 & $4,83^{* *}$ & 8346 & $1729^{*}$ \\
\hline Média (MPa) & 8,84 & 9128 & 1272 \\
\hline $\mathrm{S}_{\mathrm{d}}(\mathrm{MPa})$ & 0,96 & 1105 & 80,92 \\
\hline CV (\%) & 10,86 & 12,11 & 6,36 \\
\hline
\end{tabular}

\begin{tabular}{||c|c|c|c||}
\hline $\begin{array}{c}\text { Parede } \\
\text { correspondente }\end{array}$ & $\begin{array}{c}\mathbf{f}_{\mathrm{par}}{ }^{*} \\
\mathbf{( M p a )}\end{array}$ & $\begin{array}{c}\mathrm{E}_{\mathrm{par}}{ }^{*} \\
\mathbf{( M P a}\end{array}$ & $\mathrm{E}_{\mathrm{par}}{ }^{*} / \mathbf{f}_{\mathrm{par}}{ }^{*}$ \\
\hline PAB2A1E 1 & 5,20 & 8163 & 1511 \\
\hline PAB2A1E 2 & 5,67 & 8572 & 1646 \\
\hline PAB2A1E 3 & 4,53 & 7451 & 1550 \\
\hline Média (MPa) & 5,20 & 8062 & 1569 \\
\hline $\mathbf{S}_{\mathbf{d}}(\mathbf{M P a})$ & 0,60 & 567 & 27,54 \\
\hline $\mathbf{C V}(\%)$ & 11,53 & 7,03 & 1,76 \\
\hline
\end{tabular}

* Resistência e módulo de elasticidade calculada em função da área bruta da paredinha;

${ }^{* *}$ Resultados descartados por apresentarem desvios grandes em relação aos outros valores; 


\begin{tabular}{|c|c|c|c|}
\hline $\begin{array}{c}\text { Parede } \\
\text { correspondente }\end{array}$ & $\begin{array}{c}\mathbf{f}_{\mathrm{par}}^{*} \\
(\mathrm{Mpa})\end{array}$ & $\begin{array}{c}\mathrm{E}_{\mathrm{par}}^{*} \\
(\mathrm{MPa})\end{array}$ & $\mathrm{E}_{\mathrm{par}}^{*} / \mathbf{f}_{\mathrm{par}}$ \\
\hline $\mathrm{PAB}^{2 \mathrm{~A} 2 \mathrm{E}_{\mathrm{\gamma}} 1}$ & $* * *$ & $* * *$ & $* * \star$ \\
\hline $\mathrm{PAB} \mathrm{A}_{2} \mathrm{E}_{\mathrm{y}} 2$ & 5,65 & 8693 & 1539 \\
\hline $\mathrm{PAB} \mathrm{A}_{2} \mathrm{E}_{\mathrm{y}} 2$ & $\star * \star$ & *** & $* * *$ \\
\hline Média (MPa) & - & - & - \\
\hline$S_{d}(M P a)$ & - & - & - \\
\hline CV (\%) & - & - & - \\
\hline
\end{tabular}

\begin{tabular}{|c|c|c|c|}
\hline $\begin{array}{c}\text { Parede } \\
\text { correspondente }\end{array}$ & $\begin{array}{c}f_{\mathrm{par}}{ }^{*} \\
(\mathrm{Mpa})\end{array}$ & $\begin{array}{l}\mathrm{E}_{\mathrm{par}}{ }^{*} \\
(\mathrm{MPa})\end{array}$ & $\mathrm{E}_{\mathrm{par}}{ }^{*} / \mathbf{f}_{\mathrm{par}}$ \\
\hline PAB2A2E $_{x} 1$ & 4,82 & 8770 & 1819 \\
\hline $\mathrm{PAB} \mathrm{A}_{2} \mathrm{E}_{\mathrm{x}} 2$ & 3,63 & $2602^{* *}$ & $718^{\star *}$ \\
\hline PAB2A2E 3 & 3,13 & 5161 & 1651 \\
\hline Média (MPa) & 3,38 & 6966 & 1735 \\
\hline $\mathrm{S}_{\mathrm{d}}(\mathrm{MPa})$ & 0,35 & 2552 & 119,11 \\
\hline CV (\%) & 10,45 & 36,64 & 6,87 \\
\hline
\end{tabular}

* Resistência e módulo de elasticidade calculada em função da área bruta da paredinha;

** Resultados descartados por apresentarem desvios grandes em relação aos outros valores;

*** Corpos de prova rompidos durante o transporte. 


\begin{tabular}{|c|c|c|c|}
\hline $\begin{array}{c}\text { Prisma } \\
\text { correspondente }\end{array}$ & $\begin{array}{c}\mathbf{f}_{\mathrm{pr}}{ }^{*} \\
(\mathrm{MPa})\end{array}$ & $\begin{array}{c}\mathrm{E}_{\mathrm{pr}}{ }^{*} \\
(\mathrm{MPa})\end{array}$ & $E_{p r}^{*} / f_{p r}$ \\
\hline PRB1A2E $_{y} 2$ & 8,16 & 6537 & 801 \\
\hline PRB1A2E $_{y} 4$ & 7,51 & 5829 & 776 \\
\hline PRB1A2E 6 & 7,56 & $3504^{*}$ & $464^{*}$ \\
\hline Média (MPa) & 7,74 & 6183 & 789 \\
\hline$S_{d}(\mathrm{MPa})$ & 0,36 & 501 & 17,88 \\
\hline CV (\%) & 4,66 & 8,10 & 2,27 \\
\hline
\end{tabular}

\begin{tabular}{|c|c|c|c|}
\hline $\begin{array}{c}\text { Prisma } \\
\text { correspondente }\end{array}$ & $\begin{array}{c}f_{p r}^{*} \\
(\mathrm{MPa})\end{array}$ & $\begin{array}{c}\mathrm{E}_{\mathrm{pr}}{ }^{*} \\
(\mathrm{MPa})\end{array}$ & $\mathrm{E}_{\mathrm{pr}}^{*} / \mathrm{f}_{\mathrm{pr}}$ \\
\hline PRB2A2E $_{y} 1$ & 10,11 & 4526 & 448 \\
\hline PRB2A2E $_{y} 2$ & 9,84 & 5215 & 530 \\
\hline PRB2A2E 3 & 9,99 & $8387^{*}$ & $840^{*}$ \\
\hline Média (MPa) & 9,98 & 4870 & 489 \\
\hline $\mathrm{S}_{\mathrm{d}}(\mathrm{MPa})$ & 0,13 & 487 & 57,89 \\
\hline CV (\%) & 1,31 & 10,00 & 11,84 \\
\hline
\end{tabular}

* Resistência e módulo de elasticidade obtidos em função da área bruta do prisma

* Resultado descartado por apresentar um desvio grande em relação aos outros valores. 


\begin{tabular}{||c|c|c|c||}
\hline $\begin{array}{c}\text { Paredinha } \\
\text { correspondente }\end{array}$ & $\begin{array}{c}\mathbf{f}_{\mathbf{p r}}{ }^{*} \\
\mathbf{M P a}\end{array}$ & $\begin{array}{c}\mathbf{E}_{\mathbf{p r}}{ }^{*} \\
\mathbf{( M P a}\end{array}$ & $\mathbf{E}_{\mathbf{p r}}{ }^{*} / \mathbf{f}_{\mathbf{p r}}{ }^{*}$ \\
\hline PAB1A1Ex1 & 2,30 & 4234 & 1842 \\
\hline PAB1A1Ex2 & 2,02 & 3089 & 1529 \\
\hline PAB1A1Ex3 & 2,15 & 3032 & 1409 \\
\hline Média (MPa) & 2,16 & 3060 & 1469 \\
\hline $\mathbf{S}_{\mathbf{d}}$ (MPa) & 0,14 & 40,72 & 84,84 \\
\hline $\mathbf{C V}(\%)$ & 6,48 & 1,33 & 5,77 \\
\hline
\end{tabular}

\begin{tabular}{||c|c|c|c||}
\hline $\begin{array}{c}\text { Paredinha } \\
\text { correspondente }\end{array}$ & $\begin{array}{c}\mathbf{f}_{\mathrm{pr}}{ }^{*} \\
\mathbf{M P a}\end{array}$ & $\begin{array}{c}\mathbf{E}_{\mathbf{p r}}{ }^{*} \\
\mathbf{( M P a}\end{array}$ & $\mathbf{E}_{\mathbf{p r}}{ }^{*} / \mathbf{f}_{\mathrm{pr}}{ }^{*}$ \\
\hline PAB1A1Ey1 & 5,27 & 6496 & 1234 \\
\hline PAB1A1Ey2 & 4,58 & $3705^{* *}$ & $809^{* *}$ \\
\hline PAB1A1Ey3 & 5,06 & 6269 & 1238 \\
\hline Média (MPa) & 4,97 & 6383 & 1236 \\
\hline $\mathbf{S}_{\mathbf{d}}$ (MPa) & 0,35 & 160,62 & 3,33 \\
\hline $\mathbf{C V}(\%)$ & 7,12 & 2,52 & 0,27 \\
\hline
\end{tabular}

* Resistência e módulo de elasticidade obtidos em função da área bruta do prisma.

* Resultado descartado por apresentar um desvio grande em relação aos outros valores. 


\begin{tabular}{||c|c|c|c||}
\hline $\begin{array}{c}\text { Paredinha } \\
\text { correspondente }\end{array}$ & $\begin{array}{c}\mathbf{f}_{\mathrm{pr}}{ }^{*} \\
\mathbf{M P a}\end{array}$ & $\begin{array}{c}\mathbf{E}_{\mathrm{pr}}{ }^{*} \\
\mathbf{( M P a}\end{array}$ & $\mathbf{E}_{\mathrm{pr}}{ }^{*} / \mathbf{f}_{\mathrm{pr}}{ }^{*}$ \\
\hline PAB1A2Ex1 & 1,94 & 3248 & 1676 \\
\hline PAB1A2Ex2 & 2,04 & $1313^{* *}$ & $643^{* *}$ \\
\hline PAB1A2Ex3 & 2,04 & 3002 & 1470 \\
\hline Média (MPa) & 2,01 & 3125 & 1573 \\
\hline $\mathbf{S}_{\mathbf{d}}$ (MPa) & 0,06 & 174 & 145,47 \\
\hline $\mathbf{C V}(\%)$ & 2,99 & 5,57 & 9,25 \\
\hline
\end{tabular}

\begin{tabular}{||c|c|c|c||}
\hline $\begin{array}{c}\text { Paredinha } \\
\text { correspondente }\end{array}$ & $\begin{array}{c}\mathbf{f}_{\mathrm{pr}}{ }^{*} \\
\mathbf{M P a}\end{array}$ & $\begin{array}{c}\mathbf{E}_{\mathrm{pr}}{ }^{*} \\
\mathbf{( M P a}\end{array}$ & $\mathbf{E}_{\mathrm{pr}}{ }^{*} / \mathbf{f}_{\mathrm{pr}}{ }^{*}$ \\
\hline PAB1A2Ey1 & 3,91 & 6335 & 1618 \\
\hline PAB1A2Ey2 & 4,57 & 6544 & 1431 \\
\hline PAB1A2Ey3 & 3,89 & 4006 & $1031^{* *}$ \\
\hline Média (MPa) & 4,12 & 6440 & 1525 \\
\hline $\mathbf{S}_{\mathbf{d}}$ (MPa) & 0,39 & 147,96 & 132,39 \\
\hline $\mathbf{C V}(\%)$ & 9,42 & 2,30 & 8,68 \\
\hline
\end{tabular}

* Resistência e módulo de elasticidade obtidos em função da área bruta do prisma.

* Resultado descartado por apresentar um desvio grande em relação aos outros valores. 


\begin{tabular}{||c|c|c|c||}
\hline $\begin{array}{c}\text { Paredinha } \\
\text { correspondente }\end{array}$ & $\begin{array}{c}\mathbf{f}_{\mathrm{pr}}{ }^{*} \\
\mathbf{( M P a )}\end{array}$ & $\begin{array}{c}\mathbf{E}_{\mathrm{pr}}{ }^{*} \\
\mathbf{( M P a}\end{array}$ & $\mathbf{E}_{\mathrm{pr}}{ }^{*} / \mathbf{f}_{\mathrm{pr}}{ }^{*}$ \\
\hline PAB2A1Ex1 & 5,41 & 8163 & 1511 \\
\hline PAB2A1Ex2 & 5,67 & 8572 & 1646 \\
\hline PAB2A1Ex3 & 4,53 & 7451 & 1550 \\
\hline Média (MPa) & 5,20 & 8062 & 1569 \\
\hline $\mathbf{S}_{\mathbf{d}}$ (MPa) & 0,60 & 567 & 27,54 \\
\hline $\mathbf{C V}(\%)$ & 11,53 & 7,03 & 1,76 \\
\hline
\end{tabular}

\begin{tabular}{||c|c|c|c||}
\hline $\begin{array}{c}\text { Paredinha } \\
\text { correspondente }\end{array}$ & $\begin{array}{c}\mathbf{f}_{\mathrm{pr}}{ }^{*} \\
\mathbf{( M P a )}\end{array}$ & $\begin{array}{c}\mathbf{E}_{\mathbf{p r}}{ }^{*} \\
\mathbf{( M P a}\end{array}$ & $\mathbf{E}_{\mathbf{p r}}{ }^{*} / \mathbf{f}_{\mathrm{pr}}{ }^{*}$ \\
\hline PAB2A1Ey1 & 9,52 & $12652^{* *}$ & 1329 \\
\hline PAB2A1Ey2 & 8,16 & 9909 & 1214 \\
\hline PAB2A1Ey3 & $4,83^{* *}$ & 8346 & 1729 \\
\hline Média (MPa) & 8,84 & 9128 & 1272 \\
\hline $\mathbf{S}_{\mathbf{d}}(\mathbf{M P a})$ & 0,96 & 1105 & 80,92 \\
\hline $\mathbf{C V}(\%)$ & 10,89 & 12,11 & 6,36 \\
\hline
\end{tabular}

* Resistência e módulo de elasticidade obtidos em função da área bruta do prisma.

* Resultado descartado por apresentar um desvio grande em relação aos outros valores. 


\begin{tabular}{||c|c|c|c||}
\hline $\begin{array}{c}\text { Paredinha } \\
\text { correspondente }\end{array}$ & $\begin{array}{c}\mathbf{f}_{\mathrm{pr}}{ }^{*} \\
\mathbf{M P a}\end{array}$ & $\begin{array}{c}\mathbf{E}_{\mathrm{pr}}{ }^{*} \\
\mathbf{( M P a}\end{array}$ & $\mathbf{E}_{\mathrm{pr}}{ }^{*} / \mathbf{f}_{\mathrm{pr}}{ }^{*}$ \\
\hline PAB2A2Ex1 & 4,82 & 8770 & 1819 \\
\hline PAB2A2Ex2 & 3,63 & $2602^{* *}$ & $718^{* *}$ \\
\hline PAB2A2Ex3 & 3,13 & 5161 & 1651 \\
\hline Média (MPa) & 3,38 & 6966 & 1735 \\
\hline $\mathbf{S}_{\mathbf{d}}$ (MPa) & 0,35 & 2552 & 119,11 \\
\hline $\mathbf{C V}(\%)$ & 10,45 & 36,64 & 6,87 \\
\hline
\end{tabular}

\begin{tabular}{||r|c|c|c||}
\hline $\begin{array}{c}\text { Paredinha } \\
\text { correspondente }\end{array}$ & $\begin{array}{c}\mathbf{f}_{\mathrm{pr}}{ }^{*} \\
(\mathrm{MPa})\end{array}$ & $\begin{array}{c}\mathbf{E}_{\mathrm{pr}}{ }^{*} \\
(\mathrm{MPa})\end{array}$ & $\mathbf{E}_{\mathrm{pr}}{ }^{*} / \mathbf{f}_{\mathrm{pr}}{ }^{*}$ \\
\hline PAB2A2Ey1 & $* * *$ & ${ }^{* * *}$ & ${ }^{* * *}$ \\
\hline PAB2A2Ey2 & 5,65 & 8693 & 1539 \\
\hline PAB2A2Ey3 & $* * *$ & ${ }^{* * *}$ & $* * *$ \\
\hline Média (MPa) & - & - & - \\
\hline $\mathbf{S}_{\mathrm{d}}(\mathrm{MPa})$ & - & - & - \\
\hline $\mathbf{C V}(\%)$ & - & - & - \\
\hline
\end{tabular}

* Resistência e módulo de elasticidade obtidos em função da área bruta do prisma.

* Resultado descartado por apresentar um desvio grande em relação aos outros valores;

${ }^{* * *}$ Corpos de prova rompidos durante o transporte. 


\begin{tabular}{|c|c|c|c|c|c|c|c|c|c|}
\hline \multirow{2}{*}{$\begin{array}{l}\text { Nível } \\
\text { tensão }\end{array}$} & \multicolumn{3}{|c|}{ PAB1A1E $x 1$} & \multicolumn{3}{|c|}{ PAB1A1E 2} & \multicolumn{3}{|c|}{ PAB1A1Ex3 } \\
\hline & $\varepsilon_{\mathrm{x}}$ & $\varepsilon_{\mathrm{y}}(-)$ & $-\varepsilon_{\mathrm{y} \mid} \varepsilon_{\mathrm{x}}$ & $\varepsilon_{\mathrm{x}}$ & $\varepsilon_{\mathrm{y}}(-)$ & $-\varepsilon_{\mathrm{y} /} \varepsilon_{\mathrm{x}}$ & $\varepsilon_{\mathrm{x}}$ & $\varepsilon_{\mathrm{y}}(-)$ & $-\varepsilon_{\mathrm{y} /} \varepsilon_{\mathrm{x}}$ \\
\hline $25 \% . f_{c}$ & $1,23 \times 10^{-4}$ & $5,18 \times 10^{-6}$ & $0,042^{*}$ & $1,51 \times 10^{-4}$ & * & * & $1,62 \times 10^{-4}$ & $2,54 \times 10^{-5}$ & 0,157 \\
\hline $35 \% . f_{c}$ & $1,88 \times 10^{-4}$ & $2,15 \times 10^{-5}$ & 0,115 & $2,26 \times 10^{-4}$ & $1,20 \times 10^{-6}$ & 0,005 & $2,46 \times 10^{-4}$ & $6,72 \times 10^{-5}$ & 0,274 \\
\hline \multirow[t]{4}{*}{$45 \% . f_{c}$} & $2,76 \times 10^{-4}$ & $4,31 \times 10^{-5}$ & 0,156 & $3,20 \times 10^{-4}$ & $9,60 \times 10^{-6}$ & 0,030 & $3,53 \times 10^{-4}$ & $1,18 \times 10^{-4}$ & 0,335 \\
\hline & Méc & dia (MPa) & 0,135 & Méc & dia (MPa) & 0,018 & Méc & dia (MPa) & 0,255 \\
\hline & & $\mathrm{S}_{\mathrm{d}}(\mathrm{MPa})$ & 0,030 & & $S_{d}(\mathrm{MPa})$ & 0,017 & & $\mathrm{~S}_{\mathrm{d}}(\mathrm{MPa})$ & 0,091 \\
\hline & & CV (\%) & 21,91 & & CV (\%) & 98,29 & & CV (\%) & 35,54 \\
\hline
\end{tabular}

\begin{tabular}{|c|c|c|c|c|c|c|c|c|c|}
\hline \multirow{2}{*}{$\begin{array}{c}\text { Nível } \\
\text { tensão }\end{array}$} & \multicolumn{3}{|c|}{ PAB1A1E 1} & \multicolumn{3}{|c|}{ PAB1A1E 2} & \multicolumn{3}{|c|}{ PAB1A1E 3} \\
\hline & $\varepsilon_{\mathrm{x}}(-)$ & $\varepsilon_{y}$ & $-\varepsilon_{x} / \varepsilon_{y}$ & $\varepsilon_{\mathrm{x}}(-)$ & $\varepsilon_{y}$ & $-\varepsilon_{x} / \varepsilon_{y}$ & $\varepsilon_{\mathrm{x}}(-)$ & $\varepsilon_{y}$ & $-\varepsilon_{x} / \varepsilon_{y}$ \\
\hline $25 \% . f_{c}$ & $3,30 \times 10^{-6}$ & $1,96 \times 10^{-4}$ & $0,042^{*}$ & * & $3,00 \times 10^{-4}$ & * & * & $1,95 \times 10^{-4}$ & * \\
\hline $35 \% . f_{c}$ & $1,02 \times 10^{-5}$ & $2,82 \times 10^{-4}$ & 0,115 & * & $4,30 \times 10^{-4}$ & * & $4,10 \times 10^{-6}$ & $2,81 \times 10^{-4}$ & 0,015 \\
\hline \multirow[t]{4}{*}{$45 \% . f_{c}$} & $1,71 \times 10^{-5}$ & $3,73 \times 10^{-4}$ & 0,156 & * & $5,67 \times 10^{-4}$ & * & $1,64 \times 10^{-5}$ & $3,72 \times 10^{-4}$ & 0,044 \\
\hline & Méd & dia (MPa) & 0,033 & & dia (MPa) & * & Méc & dia (MPa) & 0,029 \\
\hline & & $\mathrm{S}_{\mathrm{d}}(\mathrm{MPa})$ & 0,015 & & $\mathrm{~S}_{\mathrm{d}}(\mathrm{MPa})$ & * & & $\mathrm{S}_{\mathrm{d}}(\mathrm{MPa})$ & 0,021 \\
\hline & & CV (\%) & 44,89 & & CV (\%) & * & & CV (\%) & 71,26 \\
\hline
\end{tabular}

\begin{tabular}{|c|c|c|c|c|c|c|c|c|c|}
\hline \multirow{2}{*}{$\begin{array}{l}\text { Nível } \\
\text { tensão }\end{array}$} & \multicolumn{3}{|c|}{ PAB1A2E 1} & \multicolumn{3}{|c|}{ PAB1A2E 2} & \multicolumn{3}{|c|}{ PAB1A2E 3} \\
\hline & $\varepsilon_{\mathrm{x}}$ & $\varepsilon_{y}(-)$ & $-\varepsilon_{\mathrm{y} /} \varepsilon_{\mathrm{x}}$ & $\varepsilon_{\mathrm{x}}$ & $\varepsilon_{y}(-)$ & $-\varepsilon_{\mathrm{y} /} \varepsilon_{\mathrm{x}}$ & $\varepsilon_{\mathrm{x}}$ & $\varepsilon_{\mathrm{y}}(-)$ & $-\varepsilon_{\mathrm{y} /} \varepsilon_{\mathrm{x}}$ \\
\hline $25 \% . f_{c}$ & $1,39 \times 10^{-4}$ & $1,47 \times 10^{-5}$ & 0,105 & $3,54 \times 10^{-4}$ & $2,56 \times 10^{-4}$ & 0,722 & $1,56 \times 10^{-4}$ & $3,51 \times 10^{-4}$ & 2,250 \\
\hline $35 \% . f_{c}$ & $2,07 \times 10^{-4}$ & $4,76 \times 10^{-5}$ & 0,230 & $5,39 \times 10^{-4}$ & $5,11 \times 10^{-4}$ & 0,949 & $2,36 \times 10^{-4}$ & $6,32 \times 10^{-4}$ & 2,681 \\
\hline \multirow[t]{4}{*}{$45 \% . f_{c}$} & $2,87 \times 10^{-4}$ & $9,22 \times 10^{-5}$ & 0,322 & $7,82 \times 10^{-4}$ & $8,54 \times 10^{-4}$ & $1,092^{*}$ & $3,36 \times 10^{-4}$ & $9,25 \times 10^{-4}$ & 3,345 \\
\hline & Méc & dia (MPa) & 0,219 & Mé & dia (MPa) & 0,836 & Mé & dia (MPa) & - \\
\hline & & $S_{d}(M P a)$ & 0,109 & & $S_{d}(M P a)$ & 0,160 & & $S_{d}(M P a)$ & - \\
\hline & & CV (\%) & 49,53 & & CV (\%) & 19,19 & & CV (\%) & - \\
\hline
\end{tabular}




\begin{tabular}{|c|c|c|c|c|c|c|c|c|c|}
\hline \multirow{2}{*}{$\begin{array}{l}\text { Nível } \\
\text { tensão }\end{array}$} & \multicolumn{3}{|c|}{ PAB1A2E 1} & \multicolumn{3}{|c|}{$\mathrm{PAB}_{1 A 2 \mathrm{E}_{\mathrm{y}} 2}$} & \multicolumn{3}{|c|}{ PAB1A2E 3} \\
\hline & $\varepsilon_{\mathrm{x}}(-)$ & $\varepsilon_{\mathrm{y}}$ & $-\varepsilon_{\mathrm{x}} / \varepsilon_{\mathrm{y}}$ & $\varepsilon_{\mathrm{x}}(-)$ & $\varepsilon_{\mathrm{y}}$ & $-\varepsilon_{\mathrm{x}} / \varepsilon_{\mathrm{y}}$ & $\varepsilon_{\mathrm{x}}(-)$ & $\varepsilon_{\mathrm{y}}$ & $-\varepsilon_{x} / \varepsilon_{y}$ \\
\hline $25 \% . f_{c}$ & $6,18 \times 10^{-6}$ & $1,47 \times 10^{-4}$ & $0,042^{*}$ & $4,63 \times 10^{-6}$ & $1,65 \times 10^{-4}$ & $0,028^{*}$ & * & $2,35 \times 10^{-4}$ & * \\
\hline $35 \% . f_{c}$ & $1,40 \times 10^{-5}$ & $2,14 \times 10^{-4}$ & 0,065 & $1,08 \times 10^{-5}$ & $2,42 \times 10^{-4}$ & 0,045 & $1,20 \times 10^{-5}$ & $3,38 \times 10^{-4}$ & 0,015 \\
\hline \multirow[t]{4}{*}{$45 \% . f_{c}$} & $2,24 \times 10^{-5}$ & $2,89 \times 10^{-4}$ & 0,077 & $1,84 \times 10^{-5}$ & $3,29 \times 10^{-4}$ & 0,056 & - & $4,46 \times 10^{-4}$ & - \\
\hline & Méd & dia (MPa) & 0,071 & Méc & dia (MPa) & 0,050 & Mé & dia (MPa) & - \\
\hline & & $\mathrm{S}_{\mathrm{d}}(\mathrm{MPa})$ & 0,009 & & $\mathrm{~S}_{\mathrm{d}}(\mathrm{MPa})$ & 0,008 & & $\mathrm{~S}_{\mathrm{d}}(\mathrm{MPa})$ & - \\
\hline & & CV (\%) & 11,93 & & CV (\%) & 15,94 & & CV (\%) & - \\
\hline
\end{tabular}

\begin{tabular}{|c|c|c|c|c|c|c|c|c|c|}
\hline \multirow{2}{*}{$\begin{array}{l}\text { Nível } \\
\text { tensão }\end{array}$} & \multicolumn{3}{|c|}{ PAB2A1Ex1 } & \multicolumn{3}{|c|}{ PAB2A1E 2} & \multicolumn{3}{|c|}{ PAB2A1Ex 3} \\
\hline & $\varepsilon_{\mathrm{x}}$ & $\varepsilon_{\mathrm{y}}(-)$ & $-\varepsilon_{\mathrm{y} /} \varepsilon_{\mathrm{x}}$ & $\varepsilon_{\mathrm{x}}$ & $\varepsilon_{\mathrm{y}}(-)$ & $-\varepsilon_{\mathrm{y} /} \varepsilon_{\mathrm{x}}$ & $\varepsilon_{\mathrm{x}}$ & $\varepsilon_{\mathrm{y}}(-)$ & $-\varepsilon_{\mathrm{y} / \varepsilon_{\mathrm{x}}}$ \\
\hline $25 \% . f_{c}$ & $1,52 \times 10^{-4}$ & $2,59 \times 10^{-4}$ & 1,699 & $1,53 \times 10^{-4}$ & $1,41 \times 10^{-4}$ & 0,922 & $1,41 \times 10^{-4}$ & $2,06 \times 10^{-4}$ & 1,460 \\
\hline $35 \% . f_{c}$ & $2,29 \times 10^{-4}$ & $5,00 \times 10^{-4}$ & 2,182 & $2,29 \times 10^{-4}$ & $2,54 \times 10^{-4}$ & 1,106 & $2,10 \times 10^{-4}$ & $3,67 \times 10^{-4}$ & 1,744 \\
\hline \multirow[t]{4}{*}{$45 \% . f_{C}$} & $3,25 \times 10^{-4}$ & $7,95 \times 10^{-4}$ & 2,447 & $3,23 \times 10^{-4}$ & $3,95 \times 10^{-4}$ & 1,225 & $2,93 \times 10^{-4}$ & $7,38 \times 10^{-4}$ & 2,517 \\
\hline & Méc & dia (MPa) & - & Mé & dia (MPa) & - & Mé & dia (MPa) & - \\
\hline & & $\mathrm{S}_{\mathrm{d}}(\mathrm{MPa})$ & - & & $S_{d}(M P a)$ & - & & $S_{d}(M P a)$ & - \\
\hline & & CV (\%) & - & & CV (\%) & - & & CV (\%) & - \\
\hline
\end{tabular}

\begin{tabular}{|c|c|c|c|c|c|c|c|c|c|}
\hline \multirow{2}{*}{$\begin{array}{l}\text { Nível } \\
\text { tensão }\end{array}$} & \multicolumn{3}{|c|}{ PAB2A1E $_{\mathrm{y}} 1$} & \multicolumn{3}{|c|}{$\mathrm{PAB}^{2 A 1 E_{\mathrm{y}} 2}$} & \multicolumn{3}{|c|}{ PAB2A1E 3} \\
\hline & $\varepsilon_{\mathrm{x}}(-)$ & $\varepsilon_{y}$ & $-\varepsilon_{\mathrm{x}} / \varepsilon_{\mathrm{y}}$ & $\varepsilon_{\mathrm{x}}(-)$ & $\varepsilon_{\mathrm{y}}$ & $-\varepsilon_{\mathrm{x}} / \varepsilon_{\mathrm{y}}$ & $\varepsilon_{\mathrm{x}}(-)$ & $\varepsilon_{\mathrm{y}}$ & $-\varepsilon_{\mathrm{x}} / \varepsilon_{\mathrm{y}}$ \\
\hline $25 \% . f_{c}$ & $1,44 \times 10^{-5}$ & $1,74 \times 10^{-4}$ & $0,083^{*}$ & $1,38 \times 10^{-5}$ & $1,87 \times 10^{-4}$ & 0,074 & $1,77 \times 10^{-5}$ & $1,34 \times 10^{-4}$ & 0,132 \\
\hline $35 \% . f_{c}$ & $2,92 \times 10^{-5}$ & $2,61 \times 10^{-4}$ & 0,112 & $2,26 \times 10^{-5}$ & $2,85 \times 10^{-4}$ & 0,079 & $3,16 \times 10^{-5}$ & $2,00 \times 10^{-4}$ & 0,158 \\
\hline \multirow[t]{4}{*}{$45 \% . f_{c}$} & $5,19 \times 10^{-5}$ & $3,65 \times 10^{-4}$ & 0,142 & $3,37 \times 10^{-5}$ & $4,15 \times 10^{-4}$ & 0,081 & $5,13 \times 10^{-5}$ & $2,82 \times 10^{-4}$ & 0,182 \\
\hline & Méc & dia (MPa) & 0,112 & Mé & dia (MPa) & 0,078 & Mé & dia (MPa) & 0,157 \\
\hline & & $\mathrm{S}_{\mathrm{d}}(\mathrm{MPa})$ & 0,030 & & $\mathrm{~S}_{\mathrm{d}}(\mathrm{MPa})$ & 0,004 & & $S_{d}(M P a)$ & 0,025 \\
\hline & & CV (\%) & 26,63 & & CV (\%) & 4,96 & & CV (\%) & 15,71 \\
\hline
\end{tabular}




\begin{tabular}{|c|c|c|c|c|c|c|c|c|c|}
\hline \multirow{2}{*}{$\begin{array}{l}\text { Nível } \\
\text { tensão }\end{array}$} & \multicolumn{3}{|c|}{ PAB2A2E 1} & \multicolumn{3}{|c|}{ PAB2A2E 2} & \multicolumn{3}{|c|}{ PAB2A2E $x 3$} \\
\hline & $\varepsilon_{\mathrm{x}}$ & $\varepsilon_{\mathrm{y}}(-)$ & $-\varepsilon_{\mathrm{y} \mid} \varepsilon_{\mathrm{x}}$ & $\varepsilon_{\mathrm{x}}$ & $\varepsilon_{\mathrm{y}}(-)$ & $-\varepsilon_{\mathrm{y} / \varepsilon_{\mathrm{x}}}$ & $\varepsilon_{\mathrm{x}}$ & $\varepsilon_{\mathrm{y}}(-)$ & $-\varepsilon_{\mathrm{y} / \mathrm{x}} \varepsilon_{\mathrm{x}}$ \\
\hline $25 \% . f_{c}$ & $1,27 \times 10^{-4}$ & $3,92 \times 10^{-4}$ & 3,090 & $3,04 \times 10^{-4}$ & - & - & $2,06 \times 10^{-4}$ & $1,41 \times 10^{-4}$ & 1,460 \\
\hline $35 \% . f_{c}$ & $1,90 \times 10^{-4}$ & $6,50 \times 10^{-4}$ & 3,412 & $4,84 \times 10^{-4}$ & - & - & $3,67 \times 10^{-4}$ & $2,10 \times 10^{-4}$ & 1,744 \\
\hline \multirow[t]{4}{*}{$45 \% . f_{c}$} & $2,68 \times 10^{-4}$ & $9,10 \times 10^{-4}$ & 3,389 & * & - & - & $7,38 \times 10^{-4}$ & $2,93 \times 10^{-4}$ & 2,517 \\
\hline & Mé & dia (MPa) & - & \multicolumn{2}{|c|}{ Média (MPa) } & - & \multicolumn{2}{|c|}{ Média (MPa) } & - \\
\hline & & $\mathrm{S}_{\mathrm{d}}(\mathrm{MPa})$ & - & \multicolumn{2}{|c|}{$\mathrm{S}_{\mathrm{d}}(\mathrm{MPa})$} & - & \multicolumn{2}{|r|}{$\mathrm{S}_{\mathrm{d}}(\mathrm{MPa})$} & - \\
\hline & & CV (\%) & - & \multicolumn{2}{|r|}{ CV (\%) } & - & \multicolumn{2}{|r|}{ CV (\%) } & - \\
\hline
\end{tabular}

\begin{tabular}{|c|c|c|c|c|c|c|c|c|c|}
\hline \multirow{2}{*}{$\begin{array}{l}\text { Nível } \\
\text { tensão }\end{array}$} & \multicolumn{3}{|c|}{ PAB2A2E 1} & \multicolumn{3}{|c|}{$\mathrm{PAB}^{2 A 2 \mathrm{E}_{\mathrm{y}} 2}$} & \multicolumn{3}{|c|}{ PAB2A2E 3} \\
\hline & $\varepsilon_{\mathrm{x}}(-)$ & $\varepsilon_{y}$ & $-\varepsilon_{x} / \varepsilon_{y}$ & $\varepsilon_{\mathrm{x}}(-)$ & $\varepsilon_{y}$ & $-\varepsilon_{\mathrm{x}} / \varepsilon_{\mathrm{y}}$ & $\varepsilon_{\mathrm{x}}(-)$ & $\varepsilon_{y}$ & $-\varepsilon_{x} / \varepsilon_{y}$ \\
\hline $25 \% . f_{c}$ & - & $1,74 \times 10^{-4}$ & - & $1,02 \times 10^{-5}$ & $1,49 \times 10^{-4}$ & 0,069 & - & - & - \\
\hline $35 \% . f_{c}$ & - & $2,61 \times 10^{-4}$ & - & $3,67 \times 10^{-5}$ & $2,25 \times 10^{-4}$ & 0,163 & - & - & - \\
\hline \multirow[t]{4}{*}{$45 \% . f_{c}$} & - & $3,65 \times 10^{-4}$ & - & $7,48 \times 10^{-5}$ & $3,21 \times 10^{-4}$ & 0,233 & - & - & - \\
\hline & \multicolumn{2}{|c|}{ Média (MPa) } & - & \multicolumn{2}{|c|}{ Média (MPa) } & 0,155 & \multicolumn{2}{|c|}{ Média (MPa) } & - \\
\hline & \multicolumn{2}{|r|}{$\mathrm{S}_{\mathrm{d}}(\mathrm{MPa})$} & - & & $\mathrm{S}_{\mathrm{d}}(\mathrm{MPa})$ & 0,083 & \multicolumn{2}{|c|}{$\mathrm{S}_{\mathrm{d}}(\mathrm{MPa})$} & - \\
\hline & \multicolumn{2}{|r|}{ CV (\%) } & - & & CV (\%) & 53,31 & & CV (\%) & - \\
\hline
\end{tabular}

